\title{
CONCEPCIONES DE LA FUNCIÓN EN LA ARQUITECTURA MODERNA
}





\section{CONCEPCIONES DE LA FUNCIÓN EN LA ARQUITECTURA MODERNA}

Tesis Doctoral

Autor Damián Plouganou, arquitecto

Directores Eduardo Prieto González, Dr. arquitecto Jacobo García-Germán, Dr. arquitecto 

Tribunal nombrado por el Mgfco. Y Excmo. Sr. Rector de la Universidad Politécnica de Madrid, el día

Presidente D

Vocal D.

Vocal D....

Vocal D

Secretario D.

Realizado el acto de defensa y lectura de Tesis el día en la Escuela Técnica Superior de Arquitectura de Madrid

Calificación

EL PRESIDENTE

LOS VOCALES 
Esta tesis fue diseñada por Damián Plouganou entre Agosto y Octubre del 2020. La tipografía utilizada es 'Chivo', diseñada por Gatti \& Omnibus-Type. 
Agradezco especialmente a Eduardo Prieto González y Jacobo García-Germán, mis directores, por su confianza, apoyo y constante interés en los temas que conforman el contenido de esta investigación. Tengo también una deuda con Ana María Rigotti, quien demostró su interés desde la distancia, revisando y comentando el trabajo durante su proceso. Aprovecho para agradecer también a Luis Rojo de Castro, María Teresa Muñoz, Juan Carlos Sancho, Enrique de Teresa, Ángela García de Paredes, Enrique Encabo y Diago García-Setién quienes, en diferentes instancias, alimentaron la tesis con sus revisiones y críticas. Sin 7 todas estas aportaciones mencionadas este trabajo no hubiera sido posible 
1.0.0. Introducción

1.1.0. Problema

1.2.0. Delimitación

1.3.0. Hipótesis

1.4.0. Objetivos

1.5.0. Metodología

1.6.0. Pertinencia

1.7.0. Antecedentes

1.8.0. Estructura

2.0.1. Vitruvio. Evolución y representación

2.0.2. Alberti. De la necesidad a la comodidad

\subsubsection{EFICACIA}

2.1.1. Lodoli. Autenticidad de la función

2.1.2. Durand. La retícula, sistema total

2.1.3. Gínzburg. Método funcional

2.1.4. Meyer. Interrelaciones sociales

2.1.5. Alexander. Forma, contexto y patrón

\subsubsection{ADAPTACIÓN}

2.2.1. Bacon. Uso contra simetría

2.2.2. Ruskin. Función vital y transformación

2.2.3. Greenough. Lo orgánico y lo monumental

2.2.4. Guadet. Composición determinista

2.2.5. Wright. Adecuación al individuo

2.2.6. Häring. Propósito y expresión

2.2.7. Aalto. Diseño de lo particular 

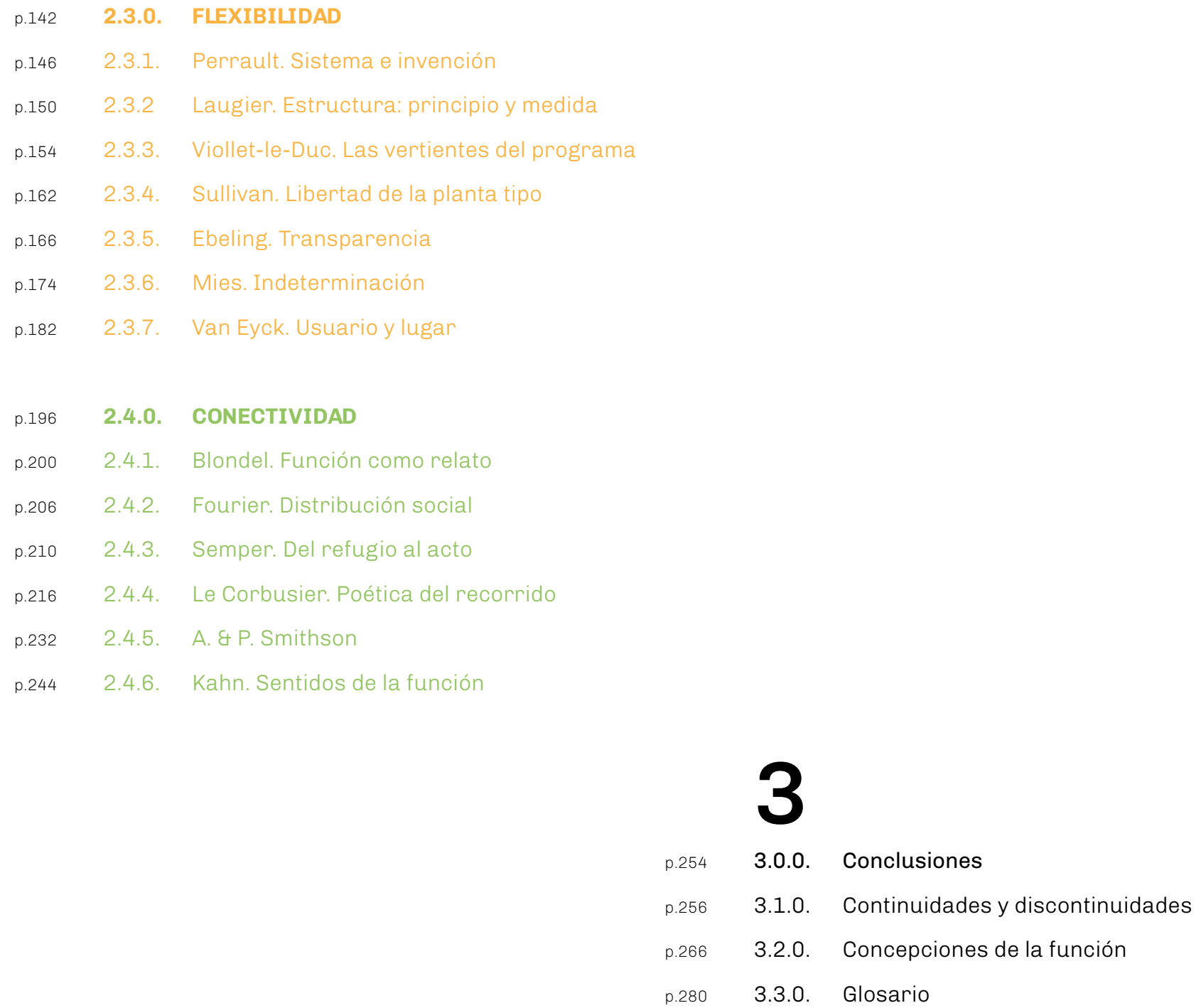
de la arquitectura moderna es la de negar en su discurso las vinculaciones con una tradición. El problema de la 'función' no es la excepción, siendo además uno de los estandartes por los cuales en muchas ocasiones también se ha llegado a identificar a la propia arquitectura de este período como "arquitectura funcionalista" o simplemente "funcionalismo." $Y$ aunque es claro que el recorte comprendido entre la década de 1920 y la Segunda Guerra Mundial resulta especialmente fructífero en cuanto a la atención y a la elaboración que se le otorga al problema de la función, no es menos cierto que gran parte de esos contenidos se encontraban ya presentes, a veces de modo germinal o en otros casos con evidencia rotunda, en la propia tradición disciplinar. Las diferentes ideas que componen este árbol filogenético se encuentran esparcidas en fragmentos de textos; tratados, partes de libros, artículos o discursos que, desde de Los diez libros de arquitectura de Vitruvio son los materiales que, a falta de teorías específicas sobre el problema, ensamblan un corpus conceptual, enriquecido por una miríada de términos y acepciones que configuran un verdadero glosario de la función. El análisis crítico y las relaciones internas de estos materiales permiten visualizar tanto el campo de conocimiento como la propia operatividad de una 'función' entendida ya como problema inherente de la disciplina. Con la intención de avanzar en la profundización y productividad del vínculo entre la función, sus argumentos y el proyecto de arquitectura se entiende que, en sus propuestas más radicales, la arquitectura moderna asume intereses que sobrepasan sus objetivos meramente utilitarios hasta alcanzar propuestas que implican, implícita y/o explícitamente, la extensión de un proyecto de arquitectura a un proyecto de reforma social. En estas operaciones el término 'función' resulta insuficiente, y se expande en un abanico de acepciones las cuales amplían las diferentes concepciones del problema. Estos términos se agrupan en cuatro nociones que engloban los diferentes modos en que la función ha sido interpretada y teorizada: 'eficacia' -racionalismo, cientificismo y economía aplicados a las distribuciones funcionales-, 'adaptación' -consideración de las particularidades de cada necesidad en su contexto específico-, 'flexibilidad' -amplitud de las posibilidades funcionales de un mismo espacio- y 'conectividad' -énfasis en la vinculación, sinergia y relato producidos por la propia configuración de las circulaciones.

palabras clave

función

teoría

terminología

arquitectura moderna 
Abstract A feature of the various experiences that make up the process of modern architecture is that of denying in its discourse the links with a tradition. The problem of 'function' is no exception, being also one of the standards by which on many occasions the architecture of this period has also been identified as "functionalist architecture" or simply "functionalism." Although it is clear that the cut between the 1920s and the Second World War is especially fruitful in terms of the attention and elaboration given to the problem of function, it is no less true that a large part of these issues were already present, sometimes germinally or in other cases with resounding evidence, in the disciplinary tradition. The different ideas that make up this phylogenetic tree are found scattered in fragments of texts; treatises, parts of books, articles or speeches that, from Vitruvius's Ten books of architecture, are the materials that, in the absence of specific theories on the problem, assemble a conceptual corpus, enriched by a myriad of terms and meanings that make up a true glossary of function. The critical analysis and the internal relationships of these materials allow to visualize both the field of knowledge and the very operation of a 'function', already understood as an inherent problem of the discipline. With the intention of advancing in the deepening and productivity of the link between the function, its arguments and the architecture project, it is understood that, in its most radical proposals, modern architecture assumes interests that go beyond its merely utilitarian objectives until reaching proposals that imply, implicitly and/ or explicitly, the extension of an architecture project to a social reform project. In these operations, the term 'function' is insufficient, and it expands into a range of meanings which broaden the different conceptions of the problem. These terms are grouped into four notions that encompass the different ways in which the function has been interpreted and theorized: 'efficacy' -rationalism, scientism and economics applied to functional distributions-, 'adaptation' -consideration of the particularities of each need in its specific context-, 'flexibility' - breadth of the functional possibilities of the same space - and 'connectivity' - emphasis on the link, synergy and narrative produced by the configuration of the circulations itself.

\section{keywords}

function

theory

terminology

modern architecture 
Aunque por su propia naturaleza se entrelacen y hasta se confundan es posible distinguir una noción ecuménica de la función de una noción disciplinar. La primera se monta lentamente, desde experiencias que nacen de la necesidad más inmediata del hombre para subsistir y que, poco a poco, consiguen consolidarse y conformarse como parte de la cultura de una sociedad; la segunda nace de la observación activa de estos hechos, y enseguida alcanza un grado de acción que transforma a la primera y la moviliza hacia un plano más ambicioso; se materializa en (algunos) edificios, pero su esencia se hace presente en la teoría, en los propios textos. Esta distinción posiblemente se asemeja a la que Ute Poerschke plantea entre "uso" y "función»:! mientras que el "uso" atiende a una actividad que necesariamente incluye un objeto la "función" se basa en una relación de causa y efecto que puede tener o no un "propósito" (tercero de los términos que Poerschke compara). . La "función" -término que se adoptará de ahora en adelante para referirse al problema central del presente trabajocuenta por lo mismo con objetivos que sobrepasan la mera necesidad; campo
Poerschke, Ute y Führ, Eduard, "Function, purpose, use in architecture and urbanism," Wolkenkuckucksheim 17, (2012).

II.

La autora coloca el ejemplo de las funciones matemáticas, las cuales pueden tener o no un propósito. A pesar de la cercanía de los tres términos mencionados -en muchas ocasiones utilizados como sinónimos- sus diferencias resultan de enorme importancia para el entendimiento del problema. Ver Ibid. 


\subsubsection{INTRODUCCIÓN}

que se ve ampliado a medida que ciertos autores logran hacer una contribución al estudio del mismo, extendiendo el significado del término o incluyendo alguna otra acepción, dando cuerpo al 'problema de la función'.

Desde la arquitectura del Renacimiento, las acepciones del término 'función' han sido varias, y han encontrado lugar en diferentes ámbitos de la arquitectura, tales como las técnicas constructivas, el rol de la belleza o la organización de los espacios habitables. Quizás sea Viollet-le-Duc el primero que logre distinguir con claridad la cuestión constructiva de la vinculada exclusivamente a la resolución de un 'programa funcional,' operación fundamental que otorgará a la larga una autonomía al problema de la función, y lo desligará de cuestiones técnicas o estéticas.

Aunque el término 'función' no siempre ha sido el más utilizado, sí que a partir de las primeras décadas del siglo XX encuentra su consolidación con el nacimiento de una arquitectura moderna que, a primera vista, parece incorporar las variables funcionales -en su sentido más amplio- como eje principal de sus argumentos, y en donde se termina estableciendo un consenso general para el uso del término. Aún así, la utilización de la palabra 'función' corresponde principalmente a una elección formal, lo cual no significa necesariamente que al mencionarse se haga referencia explícita a la idea moderna de función, la cual, por otra parte, contiene también variados significados, dependiendo del contexto. También es fruto de una serie de traducciones que modifican el término original de cada idioma; un claro ejemplo es el término 'propósito', muy utilizado en los años veinte en Alemania (Zweck), el cual es generalmente traducido al inglés como function.

Dado que el consenso en la utilización del término en el seno de la arquitectura coincide con el desarrollo avanzado de la industrialización, la 'función' no se refiere sólo a la organización de los recintos arquitectónicos, sino que encuentra también cercanía en el propio funcionamiento de los artefactos: 'una función', que debe suplir un problema particular. Cuando en este trabajo se propone la existencia de diversas 'concepciones de la función' se busca expandir ese primer estado lineal de un artefacto sirviendo a un único propósito, entendiendo que el problema de la función alberga una serie de temáticas variadas inherentes a su naturaleza. Las 'concepciones de la función' hacen referencia a las diversas ideas $-y$, por lo mismo, a las teorías- que conjugan el problema, originadas por la necesidad, el confort, la habitabilidad o la representación, no siempre enmarcadas en lo estrictamente arquitectónico. Una vez que la necesidad ha sido cubierta, que la comodidad se ha alcanzado, la función sigue siendo explotada dentro de sus posibilidades de reforma social o de reflexión filosófica; la misma contiene, en su seno teórico, un desarrollo ideológico quizás no siempre explícito, pero que propicia un escenario diferente para un término que, a primera vista parece tener existencia exclusiva en el plano de lo práctico. 
A partir de la modernización, la industrialización y la conformación de la metrópoli el problema de la resolución de las funciones cobra una importancia central en el seno en la arquitectura moderna; de ahí que la higiene y el confort pasen a ser nociones que sostienen la prefiguración de edificios y ciudades cada vez más inmensas. El proceso comienza en el siglo XIX, ${ }^{1}$ pero es en el nuevo mundo del siglo XX, un mundo de lo artificial, de lo construido y no de lo rural o próximo a una supuesta naturaleza natural, donde en la disciplina se asume la misión de reflexionar sobre las condiciones de vida de las personas en entornos esencialmente urbanos. El "cómo vivir" va a ser un tema obligado de la arquitectura de principios del siglo XX, porque el "cómo vivir" es una construcción cotidiana de esa otra gran construcción imparable que es la metrópoli.

La 'función', como problema de la arquitectura moderna, ha estado vinculada principalmente a las interpretaciones y generalizaciones que se han aplicado sobre el término, ${ }^{2}$ quizás antes incluso que al estudio pormenorizado de una casuística que pretenda al menos ordenar, relacionar y categorizar las diversas aportaciones. De esto es que la 'función' no ha tenido siempre la misma interpretación por parte de la historiografía, o incluso por parte de quienes produjeron aportes teóricos sobre el tema. Estas lecturas se han ido transformado a lo largo del siglo XX, fruto del revisionismo, dando como resultado tres situaciones que tienen que ver con: [1.1.1.] la crítica a la idea de un «funcionalismo» -muchas veces tildado de «ingenuo»- propio de la arquitectura moderna; [1.1.2.] la hipótesis de que la función no tiene impacto relevante en el diseño de la mayor parte de los edificios trascendentes en la arquitectura moderna; y [1.1.3.] la generalización de una única idea de 'función' que no se cuestiona las diversas interpretaciones de los autores. Estas tres situaciones, las cuales se detallan a continuación finalizan con [1.1.4.], una síntesis que da cuenta tanto del problema general como de los intereses de la investigación.

El lema construido sobre la 'función' durante la arquitectura moderna de la década del veinte y treinta del siglo XX va a recibir una intensa revisión crítica durante las dos décadas posteriores a la Segunda Guerra Mundial, donde se hace visible la demanda de la re-lectura de un término que en algunos casos parecía haberse comportado como un sinónimo de la propia arquitectura moderna; se trata del "funcionalismo", y su frase asociada, form follows function, descontextualizada y ampliamente difundida proveniente del texto "The tall office building artistically considered", de fines del siglo XIX, en el que Louis Sullivan intentaba dotar al rascacielos de un sentido arquitectónico y estético. La reconstrucción de las ciudades europeas, bombardeadas durante la Segunda Guerra Mundial, y la aparición de conjuntos de vivienda masivos, en la mayoría de los casos diseñados y ejecutados sin cualidades, generaron que la arquitectura y el urbanismo moderno -pretendidamente funcionales- se vieran desenmascarados, no sólo por parte de los usuarios, sino también por las ciencias sociales, especialmente la antropología, la sociología y la filosofía, que visualizaron la escasa posibilidad de construir lugares de apropiación en una arquitectura que se basaba principalmente en la repetición de bloques de vivienda. Varios críticos de este período -entre los que se incluyen aportes
1.1.0.

\section{Problema}

\section{1.}

Al menos este es el recorte historiográfico en el que convergen varios historiadores, como Benevolo, Leonardo, Historia de la arquitectura del Renacimiento (Madrid: Taurus, 1972). (Ed. orig. 1968)., Frampton, Kenneth, Historia crítica de la arquitectura moderna (Barcelona: Gustavo Gili, 2005). (Ed. orig. 1980).

2.

El término 'función', adoptado tanto en el título de este trabajo como en la denominación interna del problema a tratar, no se consolida en el lenguaje disciplinar occidental hasta bien entrado el siglo XIX; anteriormente las diversas ideas sobre la función se materializan en una variedad de términos que hacen referencia a diferentes facetas del problema. La 'función' puede referir tanto a la 'función programática' como a la 'función constructiva', e incluso a la 'función de la belleza' -que podría entenderse posteriormente como la 'función formal'- y efectivamente, en el sistema clásico, no es posible desligar en ningún caso lo funcional de lo constructivo, de lo ornamental o de lo bello. Aunque en las teorizaciones del siglo XIX en torno al neogótico estos parámetros se verán ya alterados y puestos en crisis, el verdadero cambio llegará recién en el siglo XX con la arquitectura moderna donde, al menos en principio, no existe un sistema formal preestablecido al cual adecuarse para poder obtener resultados más o menos satisfactorios. Así, de una variedad de términos que refieren a diferentes problemáticas, se pasa en el siglo XX a un término común -el de 'función'- el cual abarca concepciones diferentes, y que sirve de excusa para dar una denominación que evite confusiones en el marco de este trabajo.

3.

Entre ellos puede mencionarse The death and life of great american cities, de Jane Jacobs (1961), la conferencia "Functionalism today" de Theodor W. Adorno (1965) o Architektur als Ideologie, de Heide Berndt (1968).

\subsection{1.}

\section{Desmantelamiento}

\section{del "funcionalismo"}

4.

Ver Collins, Peter, Los ideales de la Arquitectura Moderna: su evolución. 1750-1950 (Barcelona: Gustavo Gili, 1969). (Ed. orig. 1965).

5.

Esto puede visualizarse en escritos esenciales de la década del cincuenta y sesenta, como "Post-functionalism" de Peter Eisenmann (1976), L'architettura della città de Aldo Rossi (1966) o Complexity and contradiction in architecture de Robert Venturi (1966), pero también en textos posteriores, como "The fiction of function" de Stanford Anderson (1987). Ver Anderson, Stanford, "The fiction of function," Assemblage, 2, (1987). 
fundamentales como "Bauen, Wohnen, Denken" de Martin Heidegger (1951) o "Functionalism Today" de Theodor Adorno (1965)- se encargarán de atacar y desmontar las bases conceptuales de este modelo urbanístico (y en algunos casos también arquitectónico), entendiendo el mismo como exponente claro del "funcionalismo" moderno, ${ }^{3}$ o de desplegar las disparidades individualidades de cada arquitecto. ${ }^{4}$ Pero la existencia de un supuesto "funcionalismo" que engloba el modo de pensamiento del período, producto de una sinécdoque, se mantendrá presente con fuerza. ${ }^{5}$ Los principales ataques a la 'función' moderna serán los de autores como Robert Venturi, Aldo Rossi o Peter Eisenmann quienes, haciendo un intenso uso del término "funcionalismo," desacreditan su rol central y aprovechan las mundialmente difundidas frases form follows function o machine à habiter para exponer un vacío de contenido, el cual les permitirá al mismo tiempo ensamblar nuevas propuestas teóricas basadas principalmente en el lenguaje o en el significado.

1.1.2. Por otro lado existe otra hipótesis, en consonancia con la anterior, que ya había Irrelevancia de la función tenido su comienzo con las primeras lecturas críticas que produjeran Reyner Banham en Inglaterra y Colin Rowe en Estados Unidos, las cuales postulan, en ambos casos aunque con diferentes argumentos, la escasa o nula importancia de la función en la concepción originaria de varios de los proyectos más importantes de la arquitectura moderna. En este caso se afirma que el resguardo positivista en la función fue tan sólo un argumento de la arquitectura moderna para construir su propia estética; un nuevo germen para una forma que ya nada debe a la tradición clásica y que le proporciona además el material esencial de su discurso. En esta idea, sostenida más tarde por Stanford Anderson, ${ }^{6}$ el «funcionalismo" aparece como una ficción en la llamada arquitectura moderna, ya que las preocupaciones formales y estéticas priman sobre las funcionales. Se llegaría de este modo a la conclusión de que la función no ha sido efectivamente un componente de importancia en la producción ni en la vaIoración de la arquitectura moderna ya que ésta última se valió antes de otros recursos, vinculados a la técnica, el significado o la estética. En conclusión, se argumenta que la función supone un problema de necesidad, que funcionó como lema, pero que no fue esencial en los logros de la arquitectura del período; es decir que la 'función' existió como signo erróneo de una producción que escondía otros intereses. Esta interpretación permitió sobre todo desmontar el mito de que la estética maquinista de la arquitectura moderna, expresada a través de sus volúmenes puros, se sostenía sobre una base utilitaria.

1.1.3. Dentro de la propia denominación historiográfica de "arquitectura moderna» Bifurcaciones de la función caben, como es sabido, interpretaciones que se distancian unas de otras con diferencia notable; autores como Kenneth Frampton o Josep Maria Montaner serán quienes intenten esclarecer las diferencias entre los distintos autores y actores dentro de la arquitectura moderna. Esta operación es la que da pie a diferenciar los modos en que la función fue concebida. Así, si bien el higienismo, el urbanismo y la tecnología resultan evidentes demandas socioculturales dentro de un proceso de modernización, la arquitectura moderna super- 
variadas e incluso contradictorias de lo que por acuerdo tácito llaman 'función'. Varias de estas propuestas, que encuentran su construcción tanto en lo teórico como en lo proyectual, resultan radicales y diversas entre sí, permiten a su vez la gestación de un abanico de posibilidades para la función que buscan auto-validarse y que penden únicamente de su propio argumento, no necesariamente confirmado por la experiencia. Esta última actitud supone un cambio de paradigma fundamental para como, en los tratados de arquitectura tradicionales, la función solía ser estudiada y teorizada. En efecto, a diferencia del pasado, para la arquitectura moderna la función será en varios casos también una propuesta de reforma social antes que una mera solución a través de un conocimiento empírico.

A pesar de estar presente, como término, mencionado en la mayoría de escritos tanto de historiadores como de arquitectos de los años veinte, la 'función' no contó en todos los casos con teorías desarrolladas con el mismo rigor e interés. ${ }^{7}$ Es por eso que una idea vaga y a su vez confusa de la misma -y de lo que se entendió como "funcionalismo»- gravita en gran parte de la bibliografía, sin contar siquiera con una definición básica. ${ }^{8}$ Al mismo tiempo, varios de los autores de la arquitectura moderna -con su posición vanguardista-, evitan cualquier vinculación con las teorías de la función existentes en el pasado. Este conjunto de situaciones se contagia a la misma interpretación por parte de la historiografía, y evidencia la imposibilidad de que la unificadora definición de "funcionalismo» cuente con un marco de referencia consistente.

Las tres situaciones comentadas permiten entender que, como se menciona al comienzo, el problema de la función cuenta, desde el inicio, con el propio conflicto que significó su divulgación dentro de la disciplina. La supuesta existencia de una "arquitectura funcionalista» en un período que ronda desde los primeros años veinte hasta la Segunda Guerra Mundial no siempre ha intentado ser desmontada para comprender las verdaderas raíces y matices, sino que ha servido más bien para montar una crítica que abrió espacio a nuevas vías operativas. Tanto en "1.1.1. Desmantelamiento del "funcionalismo" donde se apela a la crítica de un "funcionalismo ingenuo», recurriendo a la frase de Rossi, como en "1.1.2. Irrelevancia de la función," en donde se plantea su improductividad, paradójicamente se sigue recurriendo a la generalización de una arquitectura en la cual la propia noción de función continúa entendiéndose como un bloque teórico indivisible. Por lo mismo la idea de 'función' que divulgaron estas lecturas condujo a la generalización, y por ende a la banalización de un problema que resulta más complejo. Y si bien estas dos hipótesis están incorporadas en buena parte de la historiografía posterior, y se acepta en esta investigación que varias de las obras canónicas de la arquitectura moderna deben su forma a una poética de la máquina antes que a un "funcionalismo» troncal, el rol de la 'función' en estas lecturas suele estar asociado a otorgar un argumento a la forma, o mejor dicho al propio "porqué" de la forma, mientras que la productividad de la tan nombrada 'función' es simplemente desechada.

En efecto, estas dos lecturas anteriores han sido reconsideradas, y resulta claro que, como se menciona en "1.1.3. Bifurcaciones de la función,"
Esta aproximación general es visible tanto en un libro de amplia difusión con vocación teórica como lo es Vers une architeture de Le Corbusier (1923) como en el ámbito historiográfico, tanto en Gli elementi dell'architettura funzionale: sintesi panoramica dell'architettura moderna de Alberto Sartoris (1932) como en Space, Time and Architecture (1941) de Sigfried Giedion.

8.

A esto hay que agregar que los pocos arquitectos que se adentraron en algo cercano a una teoría de la función fueron además escasamente difundidos por la historiografía del período. Es el caso de los alemanes Hugo Häring, Hannes Meyer o el arquitecto y teórico soviético, Moisei Ginzburg; en el caso de Mies van der Rohe, sus primeros proyectos contaron con relativa difusión, pero sus textos tampoco fueron destacados por los historiadores.

\section{1 .4}

La función como problema 
la arquitectura moderna cuenta con una variedad de planteamientos que incluyen, por supuesto, al propio tema de la función. Pero en esta tercera vía interpretativa las revisiones historiográficas no siempre discuten la existencia real de un pensamiento "funcionalista» o verifican la propia productividad de la 'función', o indagan en su tradición teórica, sino que se limitan a perseguir, por medio de estudios monográficos dedicados a cada autor, las particularidades que diferencian cada aportación teórica.

Al margen de los tres problemas anteriormente descritos existe un interrogante central, que tiene que ver conque la mayor parte de los argumentos historiográficos coloca al problema de la función en consonancia con la búsqueda formal, como si la función tuviera siempre a la forma como fin. Pero si la construcción de la forma no es necesariamente el objeto de la función, entonces ¿qué rol significativo tuvo la misma dentro de la disciplina?

En las numerosas críticas hacia el rol de la función en la arquitectura moderna rara vez se plantean preguntas sobre la naturaleza misma de la utilidad, del cómo y por qué de su resolución y finalmente del impacto que ésta tiene en el ámbito social. La importancia efectiva de la función en terrenos extra-disciplinares queda evidenciada en la incisiva recepción crítica de las ciencias sociales y de la cultura en general a partir de la segunda posguerra. Recién en este período consigue entablarse con claridad un diálogo entre la arquitectura y las ciencias sociales, y la función será la herramienta de la arquitectura para poder extender su acción hasta este campo. Los matices que suponen la transformación del límite entre lo público y lo privado, la relación entre las diversas actividades dentro de un edificio, la importancia de lo colectivo y lo íntimo, lo individual y lo masivo, lo accesible e inaccesible, lo útil y lo inútil, la movilidad e interacción, por nombrar algunas dimensiones y perspectivas, serán temas derivados de teorías y operaciones proyectuales sobre la función. Estos matices repercuten directamente en las relaciones que se establecen finalmente entre las personas dentro de un marco físico en el que opera la arquitectura, otorgando a la función una dimensión social fundamental, pero no siempre asumida. Las transgresiones en cuanto a las dimensiones de los espacios, a la vinculación y recorrido de los mismos, a la integración visual y espacial, a la transparencia, a la incorporación de tecnologías y a una renovada relación entre edificios y entorno urbano están presentes en las indagaciones teóricas de la arquitectura moderna.

Al mismo tiempo, como se sugiere al comienzo, más allá de que la función haya estado presente como estandarte de la arquitectura moderna, la gestación teórica de la misma posee una extensa tradición propia que, contrario a lo que la mayor parte de los autores modernos plantearon, posee deudas constantes con el pasado; un pasado que resulta posible remontar hasta Los diez libros de arquitectura de Vitruvio. Esta raíz teórica de la función supone una tradición latente, viva, que no sólo no pierde su fuerza, sino que explica y da sentido a varias de las herramientas asociadas a la función en las décadas del veinte y treinta del siglo XX. Además, en los tratados tradicionales que con 
serie de conceptos enriquecen y explican con mayor profundidad la complejidad de la función en la arquitectura, ya no sólo moderna.

En resumen, los problemas centrales del presente trabajo tienen que ver con los vínculos existentes y no explícitos entre las teorías de la función modernas y tradicionales; los diferentes términos en el campo de las teorías de la función que amplían no sólo el vocabulario sino los conceptos derivados del problema; las relaciones 'internas' entre las propias teorías de la función, sus vinculaciones y diferencias.

Dada la naturaleza del problema, el caso de estudio no resulta en una obra, un autor, ni un acontecimiento particular, sino que son las propias ideas en torno a la función las que construyen ese primer recorte general. Las aproximaciones teóricas elaboradas en el período que se inicia en los primeros años de la década del veinte en el siglo XX y que se extiende hasta fines de la década del cincuenta resultan cruciales para comprender las transformaciones sobre este tema. Una serie de textos y de proyectos producidos la mayoría de ellos en Alemania, la U.R.S.S., Francia, Holanda, Inglaterra y Estados Unidos, plantean por esos años una serie de propuestas que pretenden ser radicales y distantes con respecto a su pasado inmediato. Se trata, por primera vez, de un corte abrupto y de una negación explícita de la tradición de las teorías de la función que hasta el momento habían mantenido un diálogo constante con la historia. Aún así, el foco de la presente investigación en el período de la arquitectura moderna responde a que en ella las distintas propuestas teóricas para la función cobran especial importancia en relación a otras temáticas disciplinares, y se le otorga a su vez a la función un rol imprescindible para mejorar el orden social. Se trata de una visión positivista y humanista que difícilmente pueda encontrarse en planteamientos anteriores a fines del siglo XIX ni a los que siguen a la segunda mitad del siglo XX. Es en este período también donde la disciplina se permite una interpretación significativa del marco social en el que se inscribe el usuario del proyecto; y es también a partir de la revisión crítica de este período desde donde es posible establecer una interpretación productiva del sentido de la función en la primera y segunda generación de arquitectos modernos, y por lo tanto una aproximación más teórica que histórica, que busca profundizar en las herramientas del proyecto.

Como se ha mencionado en "1.1.4. La función como problema," el de la función es un componente inherente a la arquitectura, -suscribiendo a la hipótesis que Renato de Fusco plantea en Storia dell'architecttura contemporanea- ${ }^{9}$ es decir que se encuentra presente desde el Renacimiento en el propio canon disciplinar, por lo que los aportes teóricos a la misma, aunque puntuales, han sido constantes a lo largo de la historia. Por lo mismo resulta preciso definir el rol de la función no entendido como una derivación de la arquitectura moderna, sino como un problema propio de la disciplina. Las propias teorizaciones modernas contienen fuertes diálogos con el pasado que, como se entenderá a lo largo del trabajo, estarán presentes aunque no sea siempre de un modo explícito.
Ver De Fusco, Renato, Historia de la arquitectura contemporánea (Madrid: Celeste Ediciones, 1981), p. 263. (Ed. orig. 1977).

\section{Delimitación}


Al mismo tiempo, el estudio de las concepciones de la función implica en sí mismo una delimitación, en el sentido en que el campo de trabajo se compone principalmente de textos -tratados, libros, artículos y conferencias- que desarrollan una visión de primera mano sobre la función, respaldada también por obras y proyectos de arquitectura en los que se materializan los conceptos.

1.3.0. En las indagaciones más radicales de la modernidad la función asume intereHipótesis ses que sobrepasan sus objetivos meramente utilitarios hasta alcanzar propuestas que implican, implícita y/o explícitamente, la extensión de un proyecto de arquitectura a un proyecto de reforma social. En estas operaciones el término función resulta insuficiente, y se expande en un abanico de acepciones que amplían también las diferentes concepciones del problema. Estos términos se agrupan en cuatro nociones que engloban los diferentes modos en que la función ha sido interpretada y teorizada:

"eficacia" -racionalismo, cientificismo y economía aplicados a las distribuciones funcionales-,

‘adaptación' -consideración de las particularidades de cada necesidad en su contexto específico-,

"flexibilidad" -amplitud de las posibilidades funcionales de un mismo espacio-

“conectividad” -énfasis en la vinculación, sinergia y relato producidos por la propia configuración de las circulaciones.

Estas nociones se componen de teorías elaboradas no sólo en el seno de la arquitectura moderna, sino también en la propia tradición, por lo que se apela a un esquema de árbol filogenético, con el fin de desenterrar las 'ascendencias' de las diversas ramas teóricas de la función, así como sus relaciones y mutaciones. Se trata, en tal caso, de una tradición 'latente', que se mantiene viva y alimenta constantemente las ideas de función.

1.4.0. La intención de este trabajo es la de avanzar en la profundización y productivi-

Objetivos dad del vínculo existente entre la función, sus argumentos y el propio proyecto de arquitectura. Para esto se plantea una revisión crítica de las construcciones teóricas sobre la función con la intención de trazar una genealogía de las aportaciones -y sus relaciones internas- que más fuertemente han incidido. Los objetivos compreden

1. seleccionar los textos que cuenten con aportaciones teóricas sobre la función de relevancia.

2. examinar la terminología de la función, sus diferentes acepciones y connotaciones, y su pervivencia y transformación a lo largo del período estudiado.

3. relacionar las propuestas teóricas sobre la función con el marco de pensamiento en el cual se inscriben.

4. categorizar las concepciones estudiadas con el fin de construir una genealogía que ponga en relación el marco de la arquitectura moderna con el de la tradición.

1.5.0. Los materiales de los que se vale la investigación son principalmente los escriMetodología tos de los mismos arquitectos que, con intenciones programáticas y muchas 
veces en tono de manifiesto, produjeron como aproximaciones conceptuales. Se trata, por lo mismo, de artículos, libros o discursos registrados que suponen un material de primera mano, en los que se buscará al mismo tiempo atender a la terminología empleada en el idioma original en el que fueron producidos, con el fin de poder comprender las complejidades que el mismo problema moderno de 'función' alberga.

Exceptuando contados artículos o fragmentos de libros especialmente dedicados, no existen construcciones teóricas sistemáticas sobre la función; las que aquí se entienden como 'concepciones' se construyen más bien a partir de aportes parciales, no numerosos, volcados la mayoría de las veces en tratados, discursos o artículos publicados en revistas del período que, en algunos casos han sido compiladas y traducidas, pero que en otros requieren de una labor de rastreo y traducción. En efecto, generalmente -y esto es patente tanto en las teorías de la tradición vitruviana como en las modernas- las ideas de función no suelen estar presentadas como un tema diferenciado, sino que se encuentran "escondidas" dentro de un texto que trata principalmente otras temáticas. Si las teorías de la función han sido construidas en la mayor parte de los casos como un tema secundario, la labor de la presente investigación implica principalmente una lectura analítica e interpretativa.

En un segundo paso se ejemplifican las concepciones estudiadas con obras o proyectos significativos del autor en cuestión, con el fin de poder establecer vínculos más fuertes y evidentes con la operatividad de estas ideas, evitando que las mismas puedan ser malinterpretadas por su propia abstracción. En resumen, la metodología se basa en una revisión y análisis de textos que, contrastados con los proyectos de los mismos autores, permitan establecer relaciones productivas dentro de la temática.

Más allá de que el mito del «funcionalismo" haya sido ya desmontado, la importancia de un estudio sobre la función en la actualidad tiene que ver en primer lugar con la continuidad de una visión plana de la 'función', vinculada a una revisión reduccionista de las aportaciones de la arquitectura moderna en cuanto al problema. Pero acaso sea la continuidad histórica de un término tantas veces discutido y tratado desde el Renacimiento hasta comienzos del siglo XX el síntoma más evidente de que la misma definición de 'función' resulta una reducción de un problema que tanto en la historia (utilidad, comodidad, uso, ordenación, disposición, distribución, conveniencia, programa) como en la arquitectura contemporánea, resulta más amplio: el de posicionarse frente a las relaciones sociales que se desprenden de las actividades y del entorno arquitectónico del proyecto. Por lo mismo puede decirse que la relevancia de esta investigación tiene tanto que ver con la consideración histórica de la función, como con lo que de operativo hay en la misma.

Más allá de la necesidad explícita de indagar en un debate teórico sobre las relaciones y categorías de las teorías en torno a la función, el aporte principal de este trabajo se considera ligado estrictamente al proceso de proyecto arquitectónico. Al fin y al cabo, las aproximaciones que los arquitectos ensayaron con respecto a la función tuvieron como único objetivo la reflexión 
en torno al proyecto de arquitectura, más allá de si su material central fue el del texto. Las concepciones de la función, aunque mantengan un mayor o menor grado de abstracción, contienen siempre en sí mismas un fin operativo, cuyo objetivo general es el de poder organizar y/o transformar el modo en que la sociedad habita y se relaciona dentro de un edificio.

Por tratarse de un tema troncal, que acompaña a la disciplina desde su nacimiento, estas indagaciones y sus mismas contaminaciones ideológicas resultan un tema productivo para reflexionar y operar en la actualidad, donde la función vuelve a cobrar importancia en una arquitectura que cada vez se ve más vinculada a problemáticas de medio ambiente, políticas y sociales, en las cuales la función desempeña un rol fundamental. La comprensión de las vertientes conceptuales de la función es un primer paso para dejar de lado las revisiones apasionadas o ideológicas que impiden ver lo que de operativo hubo en ellas.

1.7.0. Es posible afirmar que la primera aproximación real al problema moderno de Antecedentes función se origina con el libro del historiador alemán Adolf Behne, redactado en

1.7.1. 1924 -aunque recién publicado en 1926-, Der moderne Zweckbau, donde abre Primeras lecturas una discusión sin antecedentes en las primeras experiencias de la incipiente arquitectura moderna. Según el autor el hombre primitivo construye por necesidad, pero embellece sus construcciones por la misma naturaleza del juego, el cual resulta también en una necesidad; así convierte a la construcción en juguete e instrumento al mismo tiempo, hasta cierto momento desconocido de la historia en el que el mismo juego supera al instrumento, haciendo a la belleza el valor predominante de la arquitectura en la antigüedad y por ende también en el Renacimiento. Para el autor, la arquitectura moderna busca volver a ese origen en el cual la necesidad prima por sobre las formas impuestas, inspirándose al principio en las construcciones de la ingeniería. Behne categoriza las experiencias contemporáneas en dos lineas: "funcionalistas» y "racionalistas». Los primeros concebirían al edifico como instrumento adaptado al movimiento orgánico del hombre (Häring y Scharoun) y los segundos partirían de la tipificación industrial y de la idea platónica de la forma pura (Le Corbusier). La precocidad del autor para profundizar en el problema de la función y categorizar con firmeza experiencias que se encontraban en pleno proceso de crecimiento resulta en uno de los antecedentes más importantes de este trabajo.

Sin dudas la principal discusión del período tendrá que ver con cómo la función se relaciona con las nuevas formas derivadas de la ingeniería. El libro Bauen in Frankreich, bauen in Eisen, bauen in Eisenbeton de 1928 Siegfried Giedion aborda las construcciones de ingeniería en metal de finales del XIX en Francia, capaces de constituir por sí mismas un nuevo tipo de espacio sin eliminar su "contenido funcional». Se trata de un aporte que la primera historiografía logra sobre la función, donde el autor expresa su deseo de que, ya habiendo conquistado este espacio aéreo devenido de la desmaterialización del hierro, la arquitectura sea capaz de considerar el problema de la función en profundidad por sobre la estética, y con esto poder recién alcanzar «una 
intensa, ya que emergerá conectada a nuestras funciones humanas». Este será el primer paso que lo llevará luego a sentar las bases para "Die Wohnung für das Existenzminimum", (la vivienda mínima) en su libro Befreites Wohnen publicado al año siguiente. Allí el habitar se define como una vinculación entre la vida productiva y la vida doméstica, la cual debería llegar a consolidarse también en un espacio fluido que consiga unificar interior y exterior, como las estructuras de acero presentadas en Bauen in Frankreich...

Siguiendo la vía abierta por Giedion, las lecturas que la historiografía más difundida realiza sobre la función en los años treinta van a estar íntimamente ligadas a la fascinación que tanto los arquitectos más importantes del período como los mismos historiadores de la arquitectura moderna van a tener por las construcciones de la ingeniería del sigo XIX: edificios industriales, estaciones de trenes, puentes, silos, pero también barcos, aviones y automóviles. De la primera selección de construcciones de acero que Hermann Muthesius hiciera en su libro Stilarchitektur und Baukunst de 1902 hasta las múltiples referencias que Le Corbusier utiliza en Vers une architecture de 1923 existe una tensión entre la razón meramente utilitaria de estas construcciones y artefactos y la imagen renovadora que varias de las primeras construcciones historiográficas van a marcar como el camino a seguir en pos de un "estilo moderno». Es probablemente esta tensión la que lleve a la función a ocupar ese lugar ambiguo en la historiografía de la década del treinta. La fuerte difusión de Vers une architecture otorgó una base estilística que dio firmeza al concepto de lo "mínimo necesario", extraído de los interiores de los transatlánticos; así es que en muchos casos la función que supuestamente les daba origen fue definitivamente opacada por esta estética de la máquina. Como menciona Panayotis Tournikiotis en The historiography of modern architecture de 1999 , tanto Nikolaus Pevsner como Emil Kaufmann ${ }^{10}$ consideraban que la función era, junto a la tecnología y a la estética, un componente esencial de la arquitectura moderna, pero en sus primeros libros lo que prima es una presentación de los temas formales de los edificios; la función queda detrás del interés propio de los autores por la estética. Esta posición alcanzaría su cúspide con el catálogo The International Style: Architecture Since 1922 que Philip Johnson y Henry-Russell Hitchcock publican en 1932 con motivo de la misma exposición en el MoMA.

Historiadores de la posguerra como Bruno Zevi o Leonardo Benévolo, ${ }^{11}$ van a incorporar el lema de "funcionalismo" a diferencia de sus predecesores, aunque esto no los llevará en ningún caso a indagar en la vía inicialmente abierta por Behne en cuanto a la marcada diversidad del problema de la función y de los diferentes programas e intereses puestos en juego. Será Edward De Zurko quien se adentre con mayor profundidad a analizar las teorías del llamado "funcionalismo" en toda la historia de la arquitectura, hasta el siglo XIX, con el libro Origins of functionalist theory, publicado en 1957. Este es uno de los antecedentes más relevantes, ya que en él el autor busca demostrar la antigüedad de las ideas "funcionalistas", indagando en su origen, aunque relacionando la función al concepto de belleza, presente desde la filosofía de
Ver respectivamente Pevsner, Nikolaus, Pioneers of the modern movement from William Morris to Walter Gropius (London,: Faber \& Faber, 1936). (Ed. orig. y Kaufmann, Emil, Von Ledoux bis Le Courbusier Ursprung und Entwicklung der autonomen Architektur (Viena: Passer, 1933). (Ed. orig.

11.

Ver respectivamente Zevi, Bruno, Saber ver la arquitectura, Apóstrofe, Poseidón (Barcelona1979). (Ed. orig. 1948). y Benevolo, Leonardo; Galfetti, Mariuccia, y Puigvehí, Anna Pujol, Historia de la arquitectura moderna (Madrid: Taurus, 1963). (Ed. orig. 1960).

12.

Collins, Los ideales de la Arquitectura Moderna: su evolución. 1750-1950, p. 10. 
la antigüedad. De Zurko propone vertientes diversas para el problema de la función, desentrañando una riqueza histórica que hasta entonces no había sido divulgada, aunque al llegar a la arquitectura moderna no se desprende de los tópicos que han caracterizado a la historiografía del período, al continuar considerando la relevancia del problema de la forma por medio del lema form follows function, entendiendo a la función como "valor» de la arquitectura antes que como un problema en sí mismo.

A pesar de no ser específicamente un estudio sobre la función, el libro Changing Ideals in Modern Architecture (1750-1959), publicado en 1965 por Peter Collins resulta un antecedente importante dado que otorga relevancia histórica a los problemas de utilidad y firmeza de Vitruvio, en contraste con la belleza, desestimando con esto los intercambios con el arte. Al mismo tiempo, en un importante movimiento, Collins evita utilizar el término "funcionalismo", por sus connotaciones, desglosando el problema en cuatro "analogías" ("biológica», "mecánica», "gastronómica» y «linguística»). Más allá de que estas "analogías" no resulten una categorización relevante para la presente investigación, el libro de Collins resulta una referencia fundamental por el modo en que el autor enfoca los problemas de la arquitectura moderna, indagando en las propias ideas que subyacen detrás de la producción, antes que en los objetos mismos. Al mismo tiempo plantea una revisión crítica de la historiografía moderna; en la introducción de su libro Collins escribe una sentencia que será una referencia importante para el modo en que se analizarán los materiales en la presente investigación:

Los historiadores de la arquitectura tienen razón al enfocar la importancia de la arquitectura como producto final, considerando el aspecto del edificio, su construcción y la eficiencia con que cumple su propósito. Pero los arquitectos que crearon tales edificios también estaban preocupados por problemas más filosóficos así como por justificar la elección de unas formas materiales en vez de otras. El arquitecto no define su obra solamente por una serie de racionalizaciones como las de un científico, o por presión del "espíritu del tiempo" (Zeitgeist). Tampoco llega a ella por una intuición libre, como el músico o el pintor. Piensa las formas intuitivamente e intenta justificarlas racionalmente. Se produce así un proceso dialéctico regido por lo que podemos llamar la teoría de la arquitectura, que sólo puede ser estudiada en términos éticos o filosóficos.

(...)

El propósito de este libro también es el de ser una historia de los pensamientos sobre la arquitectura más que una historia de la arquitectura en sí. Se interesa más por las ideas que por los edificios...12

1.7.2. En Bauentwurfslehre Ernst Neufert, alumno de la primera generación del BauAportes enciclopédicos haus en Weimar, que posteriormente trabajará en la normalización de la arquitectura industrial alemana junto a Albert Speer, confirma en este difundido manual la primacía de uno de los conceptos centrales por los cuales se va a interpretar la función en la arquitectura: el del aprovechamiento del espacio mínimo. Neufert concibe este proyecto desde 1933, una vez que la Bauhaus ha 
convierte en una herramienta esencial para la proyección arquitectónica sino también en un manifiesto de la primacía de la necesidad básica, esquemática, constatada por un método empirista (la medición manual), que consolida -acaso sin proponérselo- el reduccionismo de la función en la arquitectura moderna.

Posteriormente, el libro de Pevsner, A History of building types, repasa en el año 1978 una veintena de tipos de construcción, entendiendo el 'tipo' por fuera de la discusión del problema de la tipología, propio de esos años, enfocándose más específicamente en un recorrido histórico por la evolución y las variaciones de los programas arquitectónicos. El libro ofrece algunas pistas sobre los cambios sociales y culturales de occidente, desde la edad media hasta el siglo veinte, en relación a la utilización de los edificios, pero el interés del autor recae con más fuerza en el tema del estilo, en clave positivista.

Finalmente, como fruto de la Bienal de Venecia de 2014 curada por Rem Koolhaas, se publica su catálogo, Elements, compuesto por quince libros en los que se estudia tanto la historia, la aplicación, como las ideologías aplicadas a estos componentes esenciales de la construcción -suelo, muro, techo, cubierta, puerta, ventana, fachada, balcón, corredor, chimenea, baño, escalera, escalera mecánica, ascensor y rampa. La importancia de este trabajo radica principalmente en la condición funcional de base que los mismos poseen, pero que a medida que su aplicación se difunde (volviéndose en la mayoría de los casos imprescindible) los propios elementos dotan a la arquitectura de una condición diferencial, a su vez que ellos mismos, los elementos, se impregnan de las ideas arquitectónicas, sociales o políticas. Se trata de una vinculación no lineal entre la construcción y las ideas que se alimenta recíprocamente, dejando al mismo tiempo como resultado una cantidad de información que resulta de relevancia para este estudio.

Como ya se menciona en el "1.1.0. Problema", la arquitectura que centra sus argumentos en la 'función' resulta uno de los blancos más atacados por una buena parte de los historiadores de la segunda posguerra, pero también por varios de los teóricos posteriores. Una de las características comunes de estas operaciones críticas va a ser la de continuar considerando la existencia de un "funcionalismo», como monolito conceptual de la arquitectura moderna. En las conclusiones del libro Theory and Design in the First Age Machine de 1960 Reyner Banham comenta que la palabra "funcionalismo» se usa utiliza por primera vez en el título del libro de Sartoris, Gli Elementi dell' architettura Funzionale, a partir de una sugerencia de Le Corbusier. Según Banham, Sartoris cambia la palabra pero no el concepto del libro, resultando esta operación no una mera anécdota, sino un reflejo del débil compromiso que la mayoría de los arquitectos modernos tuvieron con respecto a la función, es decir, como lema más que como argumento. Banham es uno de los primeros historiadores que afronta la crítica y la desmitificación de la arquitectura moderna, intentando desnudar el puro simbolismo subyacente en el discurso sobre la función. Para el autor un compromiso profundo con las tecnologías de las últimas décadas llevarían a replantear por completo el problema de la función en la arquitectura, como lo hace Fuller en la casa Dymaxion. En el escrito "A home is not a
14.

Gandelsonas, Mario, “Neo-Functionalism," en Oppositions reader: selected readings from a journal for ideas and criticism in architecture, 1973-1984, ed. Hays, K Michael (Nueva Jersey: Princeton Architectural Press, 1998). (Ed. orig. 1976).

\section{Crítica a la función}


house" de 1965 el autor desarrollará aún más la idea de la función biológica, no determinada totalmente por un programa y que se construye a partir de diferentes libertades, guiadas por una percepción humana afectada físicamente a través de la tecnología.

En los años setenta el tema de la función pierde lugar en las discusiones centrales de la disciplina, y por lo tanto los antecedentes provienen de los mismos detractores. Robert Venturi \& Denise Scott Brown escriben "Functionalism yes, but..." en 1974 en el que definen al "funcionalismo" moderno como puro simbolismo, intentando a su vez dirigir el interés hacia otro posible simbolismo, el de la decoración, por medio de una revisión de la tríada vitruviana. Peter Eisenmann publica en 1976 la editorial para la revista Oppositions "Post-functionalism," en la que coloca al "funcionalismo" como la principal herramienta de conexión entre la arquitectura moderna y un humanismo que el autor considera fuera de las preocupaciones de los principales artistas contemporáneos de la época, tales como De Stijl o el Suprematismo en la pintura, como John Cage en la música, más interesados en la exploración de los lenguajes autónomos de sus disciplinas antes que en la impronta social. ${ }^{13}$ Pero este texto de Eisenman iba hermanado a otro, escrito por Mario Gandelsonas para la misma publicación, titulado Neo-Functionalism. A diferencia de Eisenman, Gandelsonas se dedica a explicar un supuesto Neo-rationalism y Neo-realism en las antípodas del "funcionalismo». Según Gandelsonas la postura progresista de los funcionalistas les llevó a encontrar un lenguaje arquitectónico característico, pero esa misma visión se volvió "regresiva" unas décadas más tarde, al ser aplicada en la construcción masiva de la segunda posguerra. ${ }^{14}$

Los antecedentes mencionados resultan fundamentales ya que son los que, en buena parte, clausuran las exploraciones no sólo teóricas, sino también prácticas en cuanto a la función, al menos en lo que respecta al canon. La idea de función queda relacionada directamente a la idea de «funcionalismo ingenuo", acuñado en esos mismos años por Aldo Rossi, en otro libro como L'architettura della Città, que aunque no tiene a la función como foco, plantea una vía alternativa con un interés puesto en lo que de indeterminado tienen las ruinas y las construcciones que se han mantenido a lo largo de los siglos, y cuyo uso original se ha perdido o transformado.

1.7.4. Desde la década del ochenta hasta la actualidad el interés, y por lo tanto las Revisiones aproximaciones teóricas a la función, serán menores. Se destaca una recuperación de las experimentaciones más radicales de los años sesenta en el concepto de event, y las yuxtaposiciones programáticas de Bernard Tschumi y en la interpretación de la metrópolis de Rem Koolhaas que, si bien no forman parte de la investigación, dan cuenta explícita de las relaciones que la arquitectura contemporánea tiene con respecto al los conceptos de función en los períodos a estudiar; tal es el caso de las re-lecturas que Koolhaas hace sobre la «indeterminación programática" en la obra de Mies, o los rascacielos de Chicago presentados en el artículo “Typical Plan," incluido en S.M.L.XL. en 1995.

La génesis y superación del funcionalismo en arquitectura de 1980 , 
problema de la función, partiendo de lo que considera la "crisis del funcionalismo", en instancias de iniciación, florecimiento y superación del mismo desde principios del siglo XIX. A diferencia de las relaciones que De Zurko establecía entre función y belleza, Pérez Gómez argumenta esta crisis a un paulatino alejamiento de la ciencia con respecto a la ética, en una "obsesión por dominar en todos los órdenes del hacer humano". Para el autor el "funcionalismo» en arquitectura es resultado directo de este lugar que la ciencia ocupa y que lleva consigo a la arquitectura a buscar eficiencia en vez de atender a la ética. Desde el principio el autor alerta que la función «...no es simplemente la capacidad de un edificio para adaptarse a su uso»; 15 y considera que el "funcionalismo" en arquitectura obedece a una matematización de la teoría, en el seno del positivismo. Aún así, los temas en los que se centra para su revisión historiográfica tienen que ver sobre todo con las matemáticas y la geometría -las cuales considera el germen del pensamiento «funcionalista»-, sin atender a la propia organización funcional de los edificios; por lo mismo, la idea de 'función' que maneja Pérez Gómez se aleja de la considerada en la presente investigación.

Desde un punto de vista disciplinar, en la misma linea que las críticas posmodernistas, Stanford Anderson plantea en "The fiction of function" de 1987 la hipótesis de que la función nunca jugó un papel de preponderancia en la arquitectura moderna, más allá de servirle como herramienta moral para plantear un nuevo programa estético, argumento que sigue consolidando la generalización de la función como tema, entendiéndola como idea uniforme, y presentándola a su vez como irrelevante en la producción de la arquitectura moderna.

Las cuatro nociones de función planteadas en la hipótesis se traducen directamente a la estructura de la investigación, agregándose un primer capítulo en el que se exploran los orígenes. El orden de los capítulos responde, de algún modo, a cierta jerarquía temática en la cual la función ha sido históricamente considerada, pero que no resulta relevante para el trabajo; dicho de otro modo, el orden de los mismos podría ser subvertido sin que se afectara al contenido de la investigación. A su vez, estos capítulos se dividen internamente por los autores más importantes que han contribuido a enriquecer dicha noción de función, desde la tradición vitruviana hasta la arquitectura moderna, y la aparición de cada uno de ellos sigue, internamente, una estructura cronológica. Los capítulos no son herméticos entre sí, ya que existen evidentemente relaciones cruzadas entre los autores que los componen; esto queda evidenciado en el mismo desarrollo del trabajo, pero se manifiesta más claramente en las conclusiones de la investigación. En “2.0.0. Origen” se recogen las bases del pensamiento de función en la arquitectura, el cual tendrá influencia en toda la historia de la misma; "2.1.0. Eficacia” trata sobre las ideas de función dentro de un marco científico, en referencia a la máquina y al espacio mínimo y necesario para habitar; por otro lado, “2.2.0. Adaptación”, refiere a las teorías que se basan en la función específica para cada actividad o situación, que atiende al individuo y a cada detalle derivado de la vida del mismo; "2.3.0. Flexibilidad" contiene los aportes en relación a las múltiples posibilidades de utilización de

\subsection{0.}

\section{Estructura}


un espacio, y al diseño que permita tales variables; finalmente, "2.4.0. Conectividad" trata de las ideas de función en las cuales el recorrido, el relato y la vinculación entre los distintos espacios son el eje del problema.

Resulta importante volver a remarcar que la investigación se concentra en recoger conceptos y términos originales de cada autor -utilitas, necessitas, distribution, etc.- y que estos no coinciden con las denominaciones de las diferentes categorías (capítulos) que componen el trabajo -'eficacia', ‘adaptación', 'flexibilidad' y 'conectividad'- las cuales responden a un orden general en el cual se enmarcan los diferentes autores, producto de la hipótesis, y que son puestas en relación en "3.0.0. Conclusiones." Asimismo, como se explica en “1.0.0. Introducción”, el término ‘función' se utiliza en este trabajo para referirse de modo general al problema en cuestión y no a una concepción particular del mismo. 



\subsubsection{ORIGEN}

Los orígenes de las teorías de la función coinciden también con lo que por tradición la historiografía considera como los orígenes propios de la arquitectura occidental -entendida la misma como disciplina-, es decir, el Renacimiento, y con este la importancia de un actor, el arquitecto, capaz de posicionarse como autor intelectual de la totalidad de una obra. Más allá de que, desde un punto de vista pragmático, la función formara parte esencial de la concepción arquitectónica, aún cuando este mismo no pudiera plasmarse en escritos, es a partir del Renacimiento en que la misma comienza a ocupar un lugar en el campo de las teorías.

Los diez libros de la arquitectura de Vitruvio no sólo es el tratado más antiguo de la arquitectura conocido, sino que, a partir de su difusión en el Renacimiento supone el punto de referencia al que responderán e intentarán superar todos los demás escritos clásicos. Por esto mismo, hablar de las primeras ideas de función en arquitectura es hablar del concepto de utilitas, componente de la conocida tríada, mencionado, traducido e interpretado en cantidad de ocasiones. Pero la difusión que de este tratado se hace desde el siglo XV -en gran medida gracias al fenómeno de la imprenta- va a colocar al libro de Vitruvio a la par de otro tratado también fundamental: De re aedificatoria, de Alberti supondrá una profundización de las nociones de función existentes en el texto romano e incluirá al mismo tiempo y con un énfasis crítico una discusión que durará siglos: la de la convivencia entre la función y la belleza. La importancia de estos dos escritos -al que se le se sumarán otros como los de Filarete, Di Giorgio, Leonardo, Serlio, Vignola, Cornaro y Palladio- y el lugar que la función ocupa en los mismos los convierten en los claros orígenes del problema, a los cuales, como se ha mencionado, la mayor parte de las teorías, continuarán 
Aunque el mismo Vitruvio se ocupa en la introducción de Los diez libros de la arquitectura de expresar su voluntad en avanzar hacia un conocimiento profundo de la arquitectura que supere las meras descripciones, la historiografía moderna carece de pruebas que den cuenta de la importancia efectiva de los escritos del autor en la Roma antigua, ya que ningún otro texto del período ha sobrevivido. ${ }^{1}$ Aún así, como es sabido, este texto será fundamental en el período que comúnmente se entiende como de consolidación de la disciplina: el Renacimiento; 2 y será también esencial para forjar el género de los tratados como escrito de referencia para el desarrollo de teorías en la arquitectura, incluyendo también el tema de la función. Entre varios, el tratado de Alberti es el siguiente más importante; se propone como una respuesta al de Vitruvio, al utilizar también el formato de los diez libros y la terminología antigua. ${ }^{3}$

Tanto en el tratado de Vitruvio y en el de Alberti, como en la mayoría que continúen de esta tradición, las nociones de función estarán generalmente desprendidas de un conocimiento empírico de primera mano; del enfrentamiento directo con la construcción, el lugar particular, el clima, y en el mejor de los casos, con la observación de edificios existentes, con una intención, en muchos casos, pedagógica. El mismo Vitruvio confiere al «uso» un carácter práctico, y a la "sutileza" un carácter teórico.

La arquitectura es una ciencia adornada de otras muchas disciplinas y conocimientos, por el juicio de la cual pasan las obras de las otras artes. Es práctica y teórica. La práctica es una continua y expedita frecuentación del uso, ejecutada con las manos, sobre la materia correspondiente a lo que se desea formar. La teórica es la que sabe explicar y demostrar con la sutileza y leyes de la proporción, las obras ejecutadas. ${ }^{4}$

En la tradición vitruviana la belleza ocupará sin dudas el lugar central, o más bien el objeto final de las discusiones teóricas, mientras que la función en contadas ocasiones tendrá un desarrollo teórico propio, es decir, no necesariamente atado a la obtención de la belleza. La función como medio, y no como fin es una característica de la mayoría de los tratados hasta el siglo XIX.

Esto se evidencia en la enorme difusión e importancia que la tríada vitruviana (firmitas, utilitas y venustas) ha adquirido; 5 y que resulta sorprendente en comparación al escaso desarrollo que utilitas tiene a lo largo del escrito, ya que a diferencia de firmitas y venustas, sólo aparece mencionada una vez, y exclusivamente en relación a las otras dos sentencias. ${ }^{6}$ La definición de utilitas resulta insuficiente, ("la correcta disposición de las partes de un edificio de modo que no ocasionen ningún obstáculo, junto con una apropiada distribución -según sus propias características- orientadas del modo más conveniente») y por lo mismo es preciso rastrear la noción general que el autor le otorga en el resto del tratado, de manera indirecta. Para empezar, antes de que Vitruvio mencione la tríada en el texto, en el párrafo anterior, indica que la arquitectura está dividida en construcción, gnomótica y mecánica, y que la 'construcción' -la que a su vez se divide en pública y privada- es la que debe cumplir con la triple condición de seguridad, utilidad y belleza, las cuales pasa a explicar inmediatamente. Así es que utilitas cuenta en principio, según la definición
2.0.1.

\section{Vitruvio.}

\section{Evolución y representación} 1.

Se ha trabajado con la traducción al español de Jose Ortiz y Sanz de 1787 contrastada con la edición en español y latín de Oliver Domingo, de la cual se obtienen la mayoría de las citas. La traducción directa del latín de José Ortiz y Sanz de 1787 pretende, según el prólogo de Delfín Rodríguez Ruiz, recuperar el lugar que la obra tuvo en el siglo XVI, luego de las transformaciones que realizara Claude Perrault en el x.XVIII.

Según J. Rivera comenta en el "Prólogo" de Alberti, Leon Battista, De re aedificatoria, vol. 10 (Madrid: Ediciones AKAL, 1991). (Ed. orig.

\subsection{1.a.}

\section{Utilitas}

1452)., al principio circulaba como un manuscrito de mano en mano, y se imprimiría en Roma recién en 1486 .

3

Ver Choay, Françoise, "Alberti et Vitruve," Architectural Design, (1979): p. 26-35.

Vitruvio, Los diez libros de arquitectura, vol. 2 (Madrid: Ediciones Akal, 1992), p. 2. (Ed. orig. 1486)

5

Según Joaquín Arnau, "Con la utilitas vitruviana comienza la historia de la arquitectura funcional". Ver Arnau, Joaquín, 72 voces para un diccionario de arquitectura teórica (Madrid: Celeste, 2000)

"Tales construcciones deben lograr seguridad, utilidad y belleza. Se conseguirá la seguridad cuando los cimientos se hundan sólidamente y cuando se haga una cuidadosa elección de los materiales, sin restringir gas tos. La utilidad se logra mediante la correcta disposición de las partes de un edificio de modo que no ocasionen ningún obstáculo, junto con una apropiada distribución - según sus propias características- orientadas del modo más conveniente. Obtendremos la belleza cuando su aspecto sea agradable y esmerado, cuando una adecuada proporción de sus partes plasme la teoría de la simetría". En Vitruvio, Los diez libros de Arquitectura (Madrid: Alianza Forma, 1995), p. 36. (Ed. orig. 1486).

González, José Luis, El Legado oculto de Vitruvio. Saber constructivo y teoría arquitectónica (Madrid: Alianza Forma, 1993), p. 116.

Vitruvio, Los diez libros de Arquitectura, p. 54. 
antes mencionada, con un cariz claramente técnico. Según esa explicación la arquitectura requiere de una "apropiada distribución" pero la misma no sería esencial para alcanzar la belleza. Como dice J.L. González, «...el concepto de utilidad manejado aquí por Vitruvio sólo afecta a la distribución del edificio, es decir, a la concatenación relativa, dimensionado y orientación de los espacios; la parte material no se ve afectada por esta idea». ${ }^{7}$ Esto lo diferencia claramente de futuros tratados, en especial del de Alberti. Es cierto que, ante la metrópolis que significaba Roma, con una variedad enorme de edificios públicos con diferentes usos, el limitar el campo de utilitas exclusivamente al problema funcional, desligándolo de la belleza, significaba una necesidad primera de difundir un conocimiento requerido para poder satisfacer una serie de problemas técnicos de primera necesidad. Aún así, más allá de estas aproximaciones, la idea de utilitas dentro del texto gravita siempre en la generalidad, y no resulta suficiente más que para posicionarse como una primera denominación del problema de la función.

2.0.1.b. La idea más cercana a una concepción general de la función es posible enconConstrucciones primitivas trarla en la hipótesis que el autor plantea en cuanto al origen de las construcciones en las comunidades primitivas, en el Libro II, Capítulo I:

En un primer momento, levantaron paredes entrelazando pequeñas ramas con barro y con la ayuda de puntales en forma de horquilla colocados en vertical. Otros levantaban las paredes, después de secar terrones de tierra arcillosa, uniéndolos y asegurándolos con maderos atravesados que por la parte superior cubrían con cañas y follaje, con el fin de protegerse de las lluvias y de los fuertes calores. Posteriormente, las techumbres, incapaces de soportar las borrascas de las tempestades invernales, fueron sustituidas por techos de doble pendiente, y así, cubriendo con barro las techumbres inclinadas, consiguieron que se deslizaran las aguas de lluvias. ${ }^{8}$

Para Vitruvio la evolución de la arquitectura tiene que ver con la forma más adecuada de construir según el clima y los recursos disponibles en cada lugar, con un conocimiento acumulativo. Este conocimiento tendría su origen en una analogía, fruto de una primera observación de la naturaleza y de las condiciones climatológicas, como los puntos a partir de los cuales el hombre primitivo entraría en contacto con una serie de soluciones que supondrán un bienestar y un desarrollo paulatino de las condiciones de habitabilidad. Soluciones que se asentarían posteriormente como costumbre, y en su misma continuidad pasarían a transformarse tanto en técnicas constructivas como en modos de apropiarse y habitar las mismas construcciones. Esta concepción evolucionista se mantendrá, aunque con marcadas diferencias, en toda la tradición vitruviana. Es posible entender que los mismos problemas funcionales encuentran un origen en la concepción colectiva que el autor otorga a estas comunidades primeras:

En los primeros tiempos, los humanos pasaban la vida como las fieras salvajes, nacían en bosques, cuevas y selvas y se alimentaban de frutos silvestres. En un momento dado, en un lugar donde espesos bosques eran agitados por 
provocaron el fuego; asustados por sus intensas llamas, los que vivían en sus aledaños, emprendieron la huida. Después, al calmarse la situación, acercándose más y más, constataron que la comodidad y las ventajas eran muchas junto al calor templado del fuego; acarreando más leña y manteniendo el fuego vivo invitaban a otras tribus y, con señas, les hacían ver las ventajas que lograrían con el fuego. ${ }^{9}$

El fuego como foco inicial de un espacio habitable, construido artificialmente; se trata de la primera noción profunda de función, y tiene que ver con un interior necesariamente colectivo. La actividad social como la encarnación genitiva de toda construcción. El fuego como el elemento capaz de 'acercar' socialmente al hombre. A partir de la misma convivencia, se iniciaría el lenguaje oral y la utilización de la primeras herramientas, lo cual permitiría la elaboración de refugios, algunos ensamblados con el follaje de los árboles y otros mediante excavaciones en cuevas, ambos como imitación de los animales.

Mediante una serie de 'herramientas' sería posible, según el autor, acercar la construcción a los tres principios de solidez, utilidad y belleza. Estos son ordenatio, dispositio, eurythmia, symmetria, decor y distributio, de los cuales sólo dispositio, distributio y decor tendrán relación con la función:

La dispositio es la correcta colocación de los elementos de una obra, a través de la "iconografía», "ortografía» y "escenografía» (que Oliver Domingo traduce como la planta, el alzado y la perspectiva), y cada una requiere determinados elementos gráficos para concebirse. Vitruvio, en el texto, relaciona más tarde la dispositio con la colocación según un criterio; no sólo se limita a la disposición de los edificios, que en la mayoría de los casos tienen que ver con la utilidad, sino también con los elementos de la arquitectura y los materiales. Es por esto que dispositio atiende más bien a un concepto de colocación que afecta a todas las fases de la arquitectura. En el Capítulo I del Libro VI Vitruvio trata la dispositio de los edificios según el clima, y en este sentido atiende a la utilidad de los mismos en relación a las orientaciones, comparando entre España, Roma o Egipto; de cómo deben ser techados, o abiertos según la zona. También en el Capítulo V del mismo libro afronta las disposiciones de las construcciones privadas según las categorías sociales. En este sentido Vitruvio define con claridad las estancias sociales de las íntimas en las casas adecuándose a la situación social de las personas. En las notas que acompañan la traducción Jose Ortiz y Sanz relaciona directamente la dispositio con la correcta ubicación y articulación de los diferentes usos de un edificio, que se corresponde con el desarrollo que efectivamente realiza el autor romano a lo largo del tratado. Se trata así de una organización que atiende las reglas tanto de la ordenación como del decoro

La distributio tiene que ver tanto con la correcta utilización de materiales, terreno, economía como con el destino y distribución de los edificios según los requerimientos de los destinatarios. Se trata de una relación entre la edificación y los ocupantes que, según Hanno-Walter Kruft, habría sido más adecuado tratarla en decor. Éste autor interpreta una anticipación de uno de los lemas de la Ilustración, el de la 'arquitectura parlante'. Sin embargo Vitruvio
10.

Kruft, Hanno-Walter, Historia de la teoría de la arquitectura. 1. Desde la Antigüedad hasta el siglo XVIII (Madrid: Alianza Editorial, 1990), p. 31.

11. Vitruvio, Los diez libros de Arquitectura, p. 34 12.

Ver Arnau, 72 voces para un diccionario de arquitectura teórica.

2.0.1.c.

Dispositio, distributio y decor 
no reclama la expresión del edificio según la utilidad de los mismos, sino que «... en general, la disposición de los edificios ha de ser realizada siempre de acuerdo a sus ocupantes». ${ }^{10}$

Será la idea de decor la que cale con mayor profundidad en las cuestiones de la función en todo el texto de Vitruvio, y probablemente la que más haya perdurado como concepto. Decor se compone de tres temas: la "costumbre", la "práctica" y la «naturaleza del lugar». La expresión de la obra según su temática o rito (en griego thematismo) es un derivado de la "costumbre", es decir, de la relación entre la obra y lo que la misma representa. Vitruvio pone el ejemplo de la construcción de templos a Júpiter, al cielo, al sol o la luna, los cuales requieren un techo descubierto; esta vinculación entre espacio y representación es la esencia de la idea de función vitruviana. La idea de 'costumbre' dentro del decor es a su vez fundamental para entender la dimensión representativa de la función, y su trascendencia con respecto a lo útil en sí mismo. A partir de ésta es posible convertir los temas relativos al uso de una edificación en un problema de arquitectura. La "costumbre» es la que guía las correctas decisiones del decor. Por otro lado, la "práctica" tiene que ver con el cuidado de las construcciones según el uso que se les dé, y la armonía entre los diferentes ámbitos de una misma obra, "si las construcciones interiores tuvieran un aspecto cuidado pero sus accesos fueran de baja calidad y despreciables, no tendrían ningún esplendor». ${ }^{11}$ Finalmente, la "naturaleza del lugar», o "decoro natural» hace referencia a la correcta elección del sitio de la construcción, con la disposición de los usos del edificio en relación a las orientaciones más favorables. Exige también una atención al tema de la luz; por ejemplo, la luz oriente en los dormitorios, o a las habitaciones de invierno en el poniente. Es claro que, a partir de la recuperación de Vitruvio en el siglo XV, y de la difusión de la arquitectura renacentista por fuera de Florencia, la mayoría de los tratados de arquitectura incorporará prescripciones relativas al lugar en el que debería asentarse un edificio, con respecto a la situación topográfica, al asoleamiento, al viento, o a los ríos cercanos para considerar la salubridad de sus ocupantes. Vitruvio desarrolla esto ampliamente en el Libro I, Capítulo IV, "La salubridad de los emplazamientos", y Capítulo VII, "Lugares para edificios de uso común" resultando en uno de los problemas con mayor trascendencia respecto a la función. El decor se entiende como parte de la comunicación de una sociedad por medio de las construcciones, ${ }^{12}$ es un lenguaje. En su aproximación Vitruvio compone un nuevo lenguaje a partir de su función social, que no sólo es práctica, sino también simbólica. Es la adecuación de la obra a su propósito; un propósito humano, con usos, costumbres y estilos de vida, que claramente varían según las condiciones culturales. No todo puede resultar "decoroso" en cualquier sitio. Se trata de magnificar, a través de la arquitectura, el propósito inicial de la construcción; cuando es sobrepasado se rompe la ética que sostiene la idea de decor. Pero lo más importante en esta primera noción de función es que, cuando existe el equilibrio, no es posible separar la función de la forma; ambas son necesarias. Ésta separación tendrá que ver en gran parte con la lectura de 
que subraya y complementa la belleza, casi una manera de evidenciarla», ${ }^{13}$ quitándole la correspondencia biunívoca que Vitruvio le confería con respecto a la función. Esto puede comprobarse con claridad en la naturaleza 'mural' de la obra de Alberti. Como también comenta Benévolo, "con Alberti empieza en cambio la interpretación de los órdenes como 'ornamento' de la arquitectura, y la selección de las combinaciones murales según criterios arqueológicos, simbólicos o proporcionales; la imitación, pues, de los organismos antiguos a los que se añaden los detalles decorativos en uso». ${ }^{14} \mathrm{El}$ decor pasará así a ser decoración, o complemento de la forma, pervirtiendo su sentido original.

Sin dudas uno de los desafíos más grandes que el descubrimiento del libro de Vitruvio traerá a los arquitectos del Renacimiento será el de la acomodación de los programas antiguos a las exigencias del presente. ${ }^{15}$ Es cierto que parte de esa traslación ya se había arrastrado en la arquitectura medieval, y el ejemplo más importante es la basílica, originariamente edificio público destinado al foro romano y convertido en base del templo cristiano. ${ }^{16}$ [FG.01] [FG.02] Pero esta traslación resulta únicamente una distribución de un esquema en planta Los arquitectos del Renacimiento buscaban la recuperación del sistema clásico completo, abandonado durante siglos. Como comenta Norberg-Schulz, supondrá también la antropomorfización de los espacios, debido a la ligazón de las proporciones humanas con respecto a los órdenes. ${ }^{17}$ Después de Alberti en Cinque libri d'architettura publicado en 1540, Serlio intentará recuperar el sentido inicial de la idea de decor, bajo un enfoque semántico, en el que se propone que los contenidos romanos originales deben adaptarse a los de la vida cristiana. De esta manera los órdenes clásicos son reinterpretados. Serlio propone, por ejemplo, que el corintio debe reservarse únicamente a la representación de la Virgen María. Así, el sistema clásico se mantiene como forma pero se adapta a la iconografía del presente, transformando o modificando su sentido de decor. Será Palladio uno de los arquitectos que adapte con más claridad la forma y contenido del sistema clásico a las exigencias modernas. En la Loggia del Capitaniato, construida en 1572 en Vincenza, [FG.03] Palladio utiliza un monumental orden corintio en cuatro columnas que soportan toda la fachada sobre la Piaza del Signori, acomodándose a una necesaria escala urbana y cívica; por otro lado reduce notoriamente el impacto de la fachada lateral por medio de un acceso a modo de un arco del triunfo sobre la pequeña calle. Esta acomodación del sistema trata claramente de un código manierista que sobrepasa las nociones del primer Renacimiento, pero que es capaz de otorgar al clásico un sentido de decor que no requiere tanto de iconografías como de relaciones exclusivamente espaciales y proporcionales. ${ }^{18}$

Como uno de los humanistas más destacados de su generación, Leon Battista Alberti posee una mirada general sobre las artes que le permite traspasar las nociones básicas, o de oficio, para avanzar hacia una verdadera teoría de la disciplina arquitectónica. A pesar de que el conocimiento de la construcción de la antigüedad de Alberti proviene de excavaciones que realizó personalmente en ruinas romanas, ${ }^{19}$ De re aedificatoria no está escrito inicialmente para los constructores, sino para los intelectuales del arte que estaban interesados en
13.

Kruft, Historia de la teoría de la arquitectura. 1. Desde la Antigüedad hasta el siglo XVIII, p. 58.

14. Benevolo, Leonardo, Historia de la arquitectura del Renacimiento (Madrid: Taurus, 1972), p. 117. (Ed. orig. 1968)

15.

Para Benévolo "Los tipos de distribución y construcción de los edificios romanos, condicionados por las distintas exigencias del momento a que pertenecen, fueron probablemente estudiados por Brunelleschi -y

\subsection{1.d.}

\section{Interpretación}

más tarde por otras muchas generaciones de artistas-, sin intentar reproducirlos. En cambio, la formas convencionales de los órdenes arquitectónicos y de sus respectivos complementos, que ya los ro- manos habían tomado de la tradición helenística, son nuevamente aceptados como modelos ideales, aptos para transformar el repertorio infinitamente variado de la tradición gótica en un repertorio finito y normalizado". Ibid. p. 70

\section{6.}

Según Zevi la basílica suponía un lugar de encuentro de los hombres en la cultura romana, y es por esto que los cristianos la eligieron para su templo, ya que implicaba la reunión de los fieles frente a Dios; la noción humana de la escala estaba presente. La diferencia estribaba en que la basílica romana se componía de una simetría de dos ejes; es decir que contaba con dos ábsides. Los arquitectos cristianos suprimen uno de ellos, de este modo generaron un acceso para el hombre y un lugar para Dios, un foco final, y un recorrido experiencial para alcanzarlo. Ver Capítulo Cuarto, "La directriz humana del espacio cristiano" en Zevi, Bruno, Saber ver la arquitectura, (Barcelona: Apóstrofe, Poseidón, 1979). (Ed. orig. 1948).

17.

Ver Norberg-Schulz, Christian, Arquitectura occidental (Barcelona: Gustavo Gili, 1999). (Ed. orig. 1974).

18

Resulta importante la observación que realiza Benévolo en cuanto al rol significante que el sistema clásico tiene en el siglo XV y en cuanto a la importancia de la aplicación del mismo más allá de la clase que efectivamente se veía representada en él. "(...) en términos generales, el patrimonio de formas y de símbolos elaborado por la cultura humanista es debido en parte a exigencias de la nueva clase dirigente, pero repercute a su vez de manera decisiva sobre esta clase, puesto que a sus iniciativas se atribuye el prestigio de la tradición antigua y la claridad que deriva de un sistema de formas prefijadas, elocuentes e identificables. En este sentido, la aportación de los literatos y de los artistas, vinculada en parte a las circuns-

\subsection{2.}

\section{Alberti. De la necesidad}

\section{a la comodidad}

tancias políticas contingentes, se proyecta hacia el futuro por encima de las vicisitudes de la clase dirigente renacentista". Benevolo, Historia de la arquitectura del Renacimiento, p. 48. 

tética III: La estética moderna, 1400-1700 (Madrid: Ediciones Akal, 1991), p. 111. (Ed. orig. 1962)

20.

Benevolo, Historia de la arquitectura del Renacimiento, p. 41

21.

"Yo llamaré arquitecto a aquel que sepa con método cierto y perfecto proyectar racionalmente y llevar a cabo obras que, mediante el cambio de pesos y la reunión y conjunción de los cuerpos, se adapten lo mejor posible a las más dignas necesidades del hombre. Para ello, es necesario el conocimiento de las más altas y dignas disciplinas". Ver "Prólogo" en Alberti, De re aedificatoria, 10, p. 29.

22.

Alberti, citado en Kruft, Historia de la teoría de la arquitectura. 1. Desde la Antigüedad hasta el siglo XVIII, p. 53.

23.

«Habíamos observado que el edificio es un cuerpo y, como todos los otros cuerpos, cons-

2.0.2.a. La 'justa medida'

ta de dibujo y materia: el primero de ellos es obra del ingenio, el otro es consecuencia de la naturaleza; uno necesita una mente que razone; el otro plantea un problema del hallazgo y de la elección. Sin embargo, en ambos casos habíamos comprendido que de nada valen sin la intervención de la mano experta del artífice que pueda dar forma a la materia según el dibujo". Alberti, De re aedificatoria, 10, p. 60.

[FG.01]

Apolodoro de Damasco, Basílica de Trajano en Roma. Planta Baja New York: Fletcher, Banister. A History of Architecture on the Comparative Method. Charles Scribner's Sons, acercarse a la arquitectura. En este sentido, como texto fundacional, puede afirmarse que en términos de aportes a la teoría de la función resulta igualmente importante e influyente que el de Vitruvio, y por supuesto supone un paso significativo con respecto a la consideración del rol del arquitecto con respecto a la época medieval, ya que, "Es cierto que a partir de Alberti, todos los artistas importantes sienten el deseo de expresarse, además, por escrito». ${ }^{20}$ De re aedificatoria produce tanto una profundización como un distanciamiento en cuanto a los temas funcionales que planteaban Los diez libros de arquitectura. Alberti, bajo la típica visión humanista, reclama un conocimiento técnico amplio al arquitecto. ${ }^{21}$ Así, según el autor, "un trazado es un dibujo determinado que ha sido concebido en el intelecto, ejecutado mediante líneas y escuadra y realizado con el corazón y el intelecto de un hombre instruido".22 Se trata de herramientas que proporcionan un saber específico, como lo es el dominio de la geometría mediante el dibujo, que permitiría un control completo al arquitecto en todos los ámbitos de la construcción. ${ }^{23}$

El escrito de Alberti, como el de Vitruvio, tampoco resulta sistemático en cuanto a las teorizaciones. En el mismo se superponen nociones técnicas, éticas y estéticas, en diversos ámbitos, con ambigüedades. Pero algo que sí destacará con claridad Alberti, incluso en comparación a escritos posteriores, es su claridad para distinguir lo necesario, lo útil y lo bello; y será este un aporte fundamental para comprender su concepción de la función:

Unas artes las cultivamos por su necesidad; (...) otras son apreciadas porque su conocimiento es muy agradable. no es preciso especificar cuáles son estas artes, porque son conocidas; pero si me preguntas por las más importantes, no encontrarás ninguna que, dejando aparte las otras, no se encamine a sus propios fines. Pero si encuentras alguna de la que de ningún modo puedas prescindir y que una su utilidad con el placer y el decoro, a mi juicio debes incluir allí la arquitectura... ${ }^{24}$

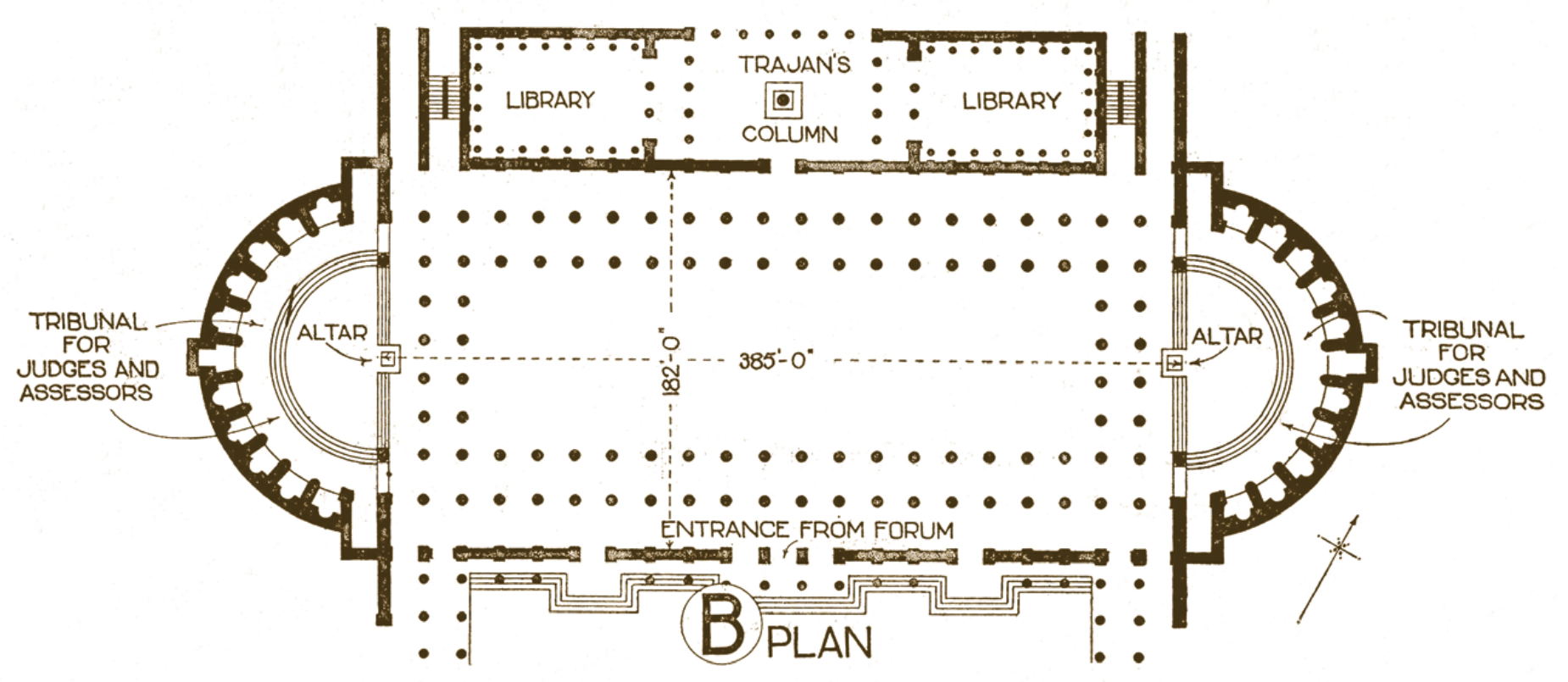


Para Alberti entonces, la arquitectura es la única de las artes capaz de aunar la necesidad, la utilidad y la belleza en armonía. Este es el inicio de la idea de concinnitas; la necesidad y la utilidad serían entendidas por el autor como eslabones necesarios para alcanzar el fin último de belleza, ${ }^{25}$ así los problemas de la arquitectura quedan incluidos en concinnitas como una unidad. ${ }^{26}$ A diferencia de Vitruvio, donde utilitas aparecía como un concepto propio, con sus propias reglas, la concinnitas albertiana no puede ser desligada de la idea general de la arquitectura; la necesidad y la utilidad deben conjugarse para alcanzar la belleza. Según Kruft y Ojeda, concinnitas es un concepto que Al-

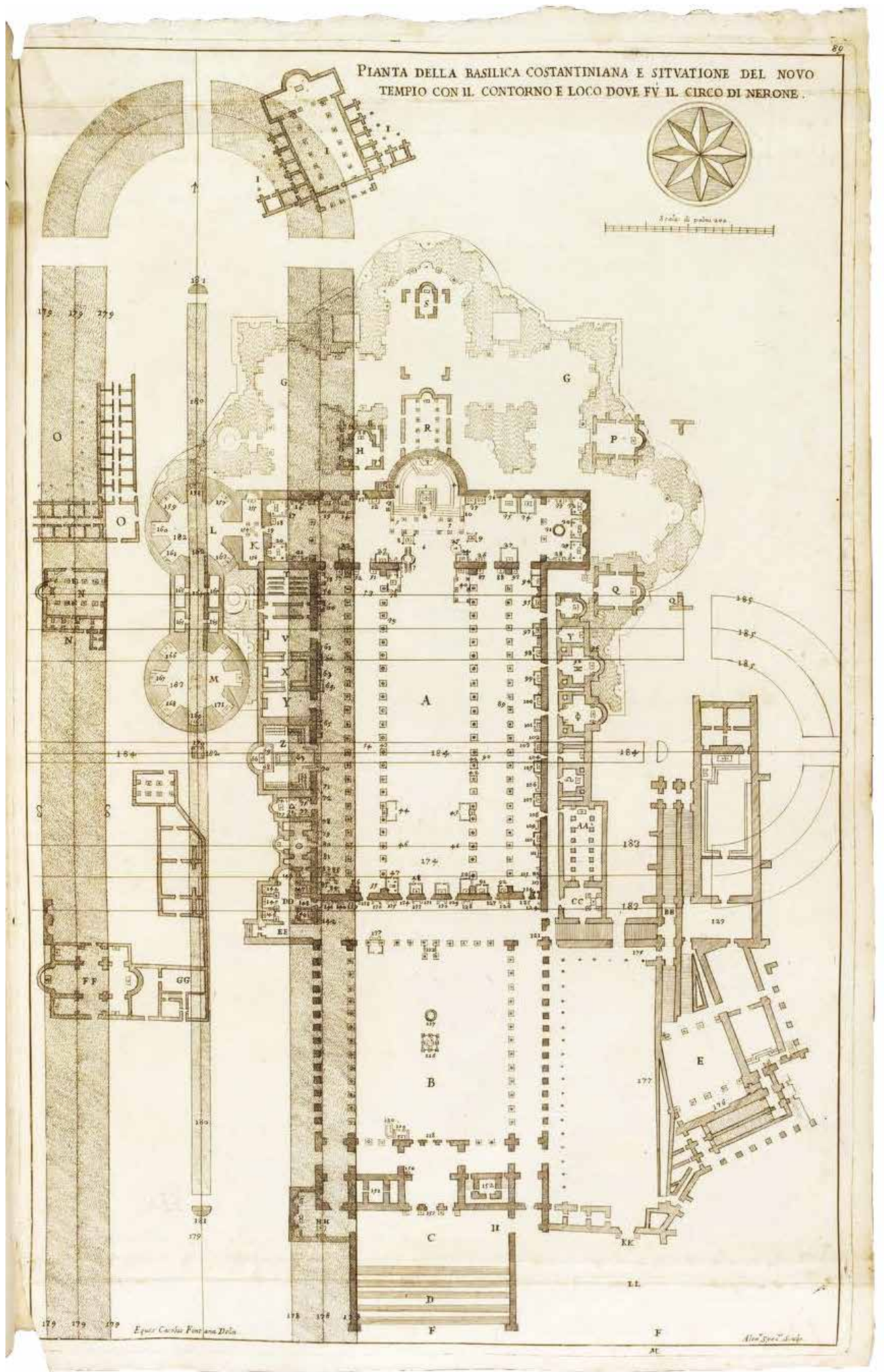

25.

"Ciertamente, si contemplamos el cielo, más nos admiran sus hechos asombrosos, porque vemos su belleza, que nos convencen de su absoluta utilidad". Ibid p. 245.

26.

"Los conceptos artísticos de Alberti eran, por tanto, nuevos, al menos en el sentido de que de su antigua condición de marginales pasaron a ser conceptos principales. Esto concierne en especial a las tesis que establecen que uno de los objetivos fundamentales del arte es la belleza y que el arte es una clase de saber y de ciencia. Y más secundarias aún antes de Alberti había sido la tesis de que el artista dirige su obra mediante el diseño que posee en su mente, y de que la obra de arte pueda superar a la naturaleza. Incluso si estas ideas habían sido enunciadas, lo importante desde el punto de vista histórico es que Alberti las recogiera, y las 'rescatara' y transmitiera a la época moderna, gracias a lo cual prácticamente todos los teóricos posteriores se valieron de ellas". Tatarkiewicz, Historia de la estética III: La estética moderna, 1400-1700, p. 114

27.

Ver Kruft, Historia de la teoría de la arquitectura. 1. Desde la Antigüedad hasta el siglo XVIII.
[FG.02]

Antigua Basílica de San Pedro, con nueva Iglesia de San Pedro y Circo de Nerón superpuestos. Planta Baja

Roma: Carlo Fontana. Il Tempio Vaticano e la sua origine. 1694 , c. 326 
berti construye a partir de la literatura de Cicerón, cuya obra, junto con la de Horacio, el autor genovés admiraba. La base filosófica de Alberti no es la griega (no le interesa la condena del arte que propusiera Platón) sino la romana. En la antigüedad la concinnitas tenía que ver con el refinamiento; Alberti le agrega un sentido de armonía que conjuga el número (numerus), la relación (finito) y la distribución (collocatio) que conforman la «justa medida». ${ }^{27}$ Los números tienen para Alberti una vinculación estrecha con la naturaleza, que repercutirá finalmente en las decisiones funcionales de la arquitectura. Según Alberti “... no habrá ningún animal que se sostenga y se mueva sobre un número impar

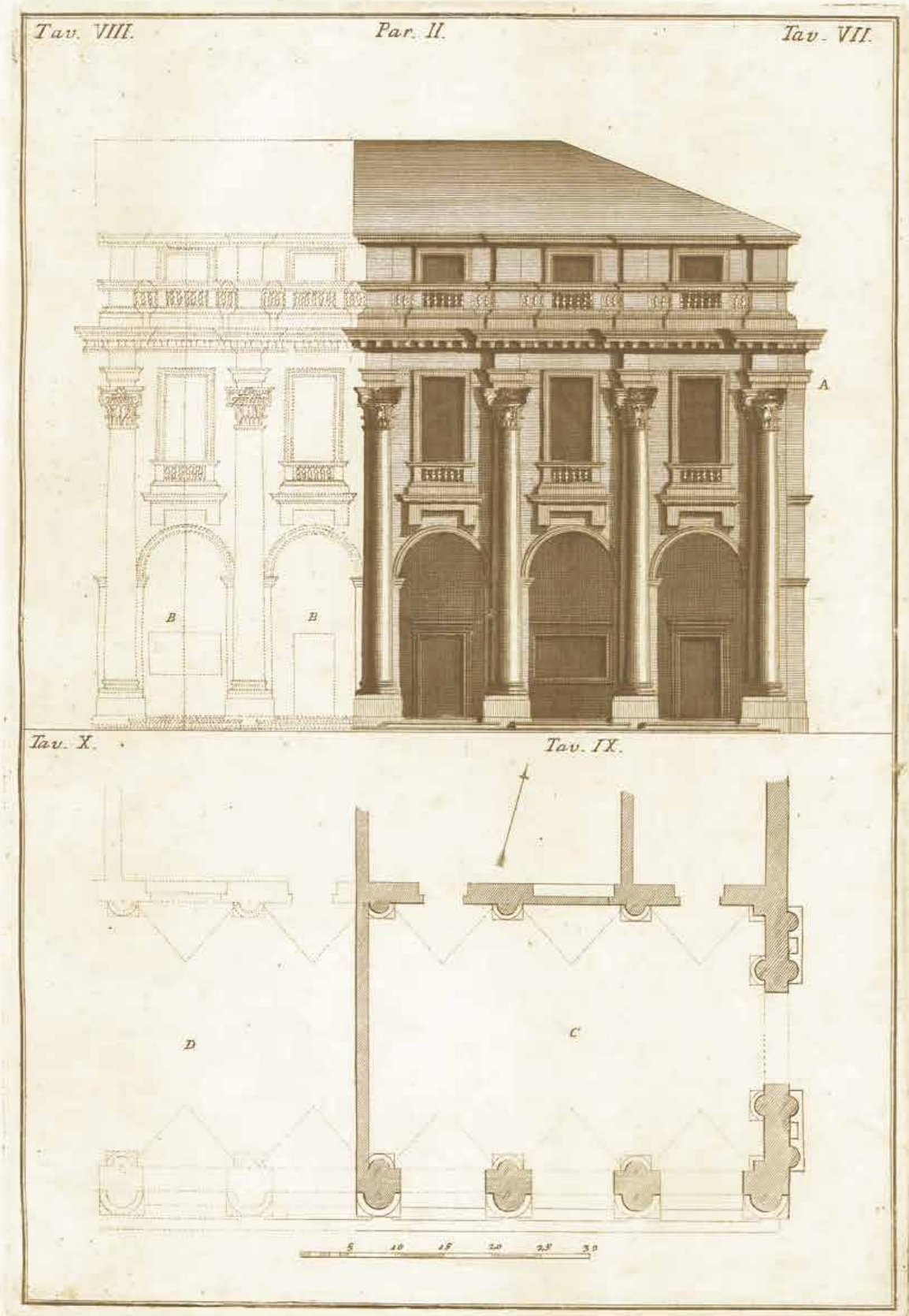




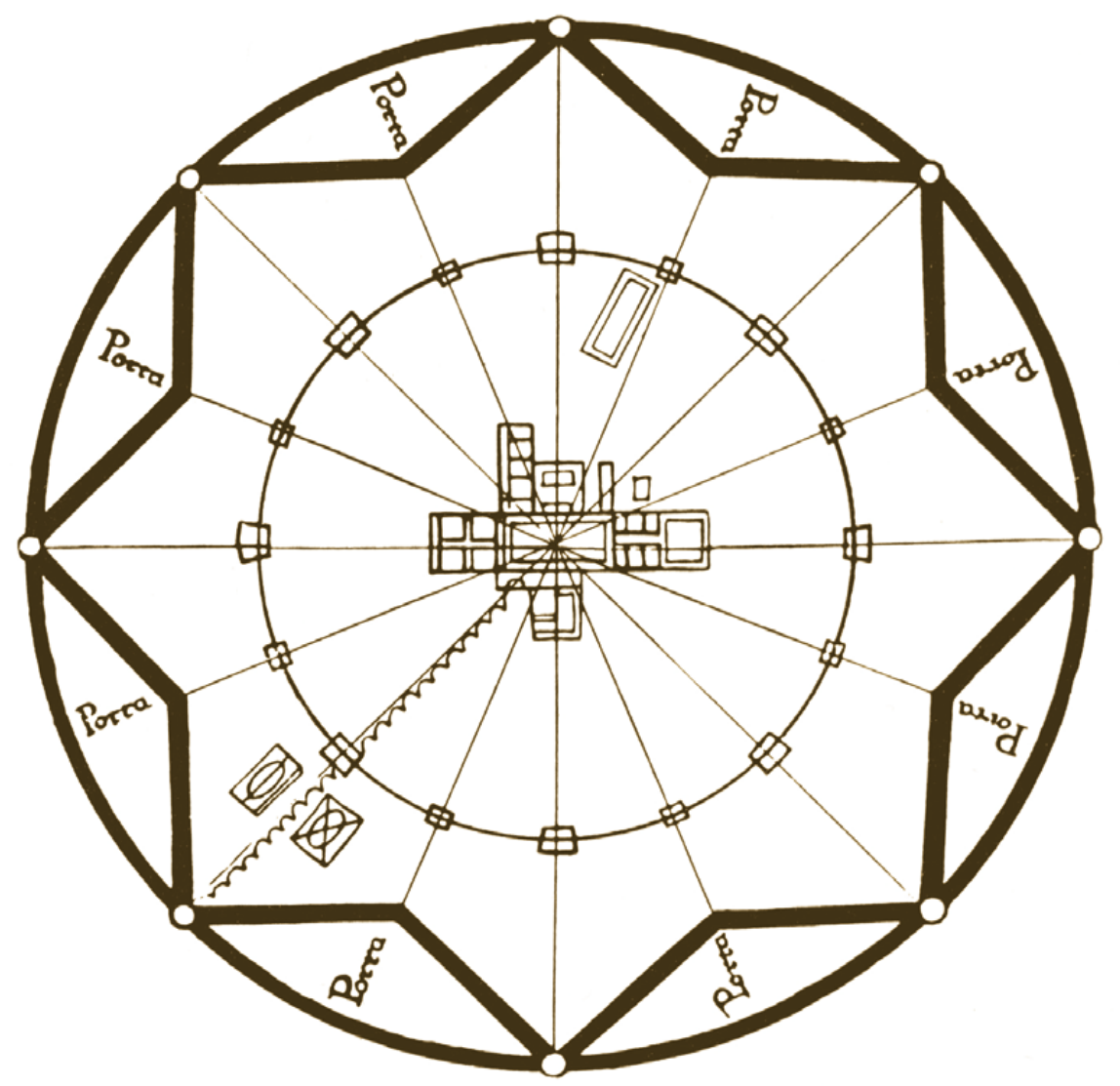

de pies», lo que le hace concluir en que «las aberturas nunca fueron distribuidas en números pares, en lo que obviamente se reconoce que observaban a la naturaleza: si bien ésta dio a los seres vivos un número par de orejas, de ojos y de ventanas nasales, en el centro puso una única y ancha boca». ${ }^{28}$ Concinnitas es entendida normalmente como la idea de belleza albertiana, pero considerando la función resulta más acorde interpretarla como esa 'justa medida,' que funde el proceso mental con el pragmático, el proyecto de arquitectura con la construcción. De este modo el fundamento, la función y la belleza quedan vinculados.

Alberti consigue, mediante las nociones de necessitas y commoditas, separar los requerimientos primarios del hombre, esos que lo vinculan aún con lo salvaje, de una funcionalidad ya ligada a lo estético. Vitruvio ya había expuesto la evolución de las construcciones por el mejor manejo de la técnica (la cabaña y la cueva); pero no había realizado una separación tan importante como la propuesta por Alberti. Necessitas es para Alberti la razón de ser de toda construcción:

Es evidente que los hombres son el motivo de que se hayan instituido los edificios. En efecto, al principio, si es correcta nuestra interpretación, los seres humanos comenzaron a hacer la obra para guarecerse de ellos y proteger sus pertenencias de los elementos climatológicos adversos. A continuación empezaron asimismo a querer no sólo lo que les era necesario para su salud, sino que fue también su deseo que no se pasara por alto lo que pudiera contribuir a
[FG.04]

Filarete,

Sforzinda

Milan: Trattato d'architettura

$1465 . c$
28.

Alberti, De re aedificatoria, 10, p. 387

29.

Ibid. p. 165.

30.

El Trattato, una novela sobre una ciudad imaginaria (Sforzinda, con referencia a Francesco Sforza), gestado entre 1461 y 1464 no contó un una difusión importante más allá de un reducido grupo de artistas de Milán. Su primera edición, en alemán, fue publicada en Viena recién en 1890 , por lo que sólo recientemente el libro ha sido sometido a una análisis más preciso.

\subsection{2.b.}

\section{Necessitas y commoditas}

31.

Esto se explica en Kruft, Historia de la teoría de la arquitectura. 1. Desde la Antigüedad hasta el siglo XVIII, p. 63.

32.

Filarete, citado en Ibid. p. 65. 
Necessitas comenzaría a desaparecer en el momento en que se comenzaran a requerir espacios diferenciados para los diversos usos. Commoditas será ya una primera voluntad de separar al hombre del salvaje; un hombre que no se conforma con las condiciones básicas. Commoditas representaría entonces un segundo estado frente a necessitas; es una satisfacción que proviene no sólo de cubrir una necesidad, sino de encontrar una solución superadora que permita el placer de disfrutar de una actividad realizada en condiciones apropiadas.

Pero las concepciones de necessitas y commoditas tendrían a su vez otras lecturas posteriores que la completarían: en el caso de Filarete, a través de su Trattato d'architettura de 1465, el tema de la función reaparece con una importancia notable. ${ }^{30}$ El origen de la función está para él, como para Alberti, en la necesidad básica, pero retoma a su vez la idea de la cabaña primitiva de Vitruvio, esta vez asociada a la tradición cristiana, colocando a Adán como el primer constructor después de su expulsión del paraíso. ${ }^{31}$ Para Filarete la cabaña primitiva fue concebida con las proporciones humanas y por ende contiene la base de todos los órdenes. Pero eso no implica que el autor considere la cabaña como norma de la arquitectura, como sí ocurrirá en el siglo XVIII con Laugier, sino que la misma contiene en sí misma un sistema de proporciones. De este modo el autor construye una serie de asociaciones antropométricas que tienen que ver con la distribución de la ciudad -Sforzinda- [FG.04] en relación a las partes del cuerpo humano, como si de un organismo se tratara, estableciendo incluso una analogía entre el comer y el habitar. Se trata de un esquema que se anticipa al de Leonardo, quien coloca la figura vitruviana en coincidencia con un cuadrado y un círculo, afirmando que todas las medidas y proporciones de la arquitectura provienen del cuerpo humano. La de Filarete es una concepción de necesidad ligada directamente al desempeño propio de los edificios. Para él la plaza es el ombligo de la ciudad, el sustento; y se basa en las proporciones del hombre, que lleva en sí mismo el orden cósmico y la belleza:

Yo te demostraré que un edificio es como un hombre vivo, así verás que necesita comer para vivir, igual que hace el hombre: así también se enferma y muere, como también muchas veces se recupera de la enfermedad gracias al buen médico. ${ }^{32}$

Asimismo, en Leonardo, la función aparece cuando plantea a partir de 1487 sus bosquejos de ciudades ideales, como posibles soluciones para el problema de la peste que provocó la muerte de un tercio de la población de Milán. En estos bosquejos Leonardo desarrolla un concepto urbanístico sobre la descentralización, la habilitación y la higiene; es decir, problemas de necesidad básica de una ciudad resueltos a través de la observación. Todo el proyecto de Leonardo tiene un carácter exclusivamente funcional a su vez que idealista. En la misma linea que Filarete el Trattato di architettura civile e militare de 1482 escrito por Di Giorgio plantea que todo arte ha de desprenderse de las proporciones del cuerpo humano. Existe una concepción orgánica, en la que se hace referencia al "cuerpo de la ciudad", cuyo centro es la cabeza; aún así no hay, 


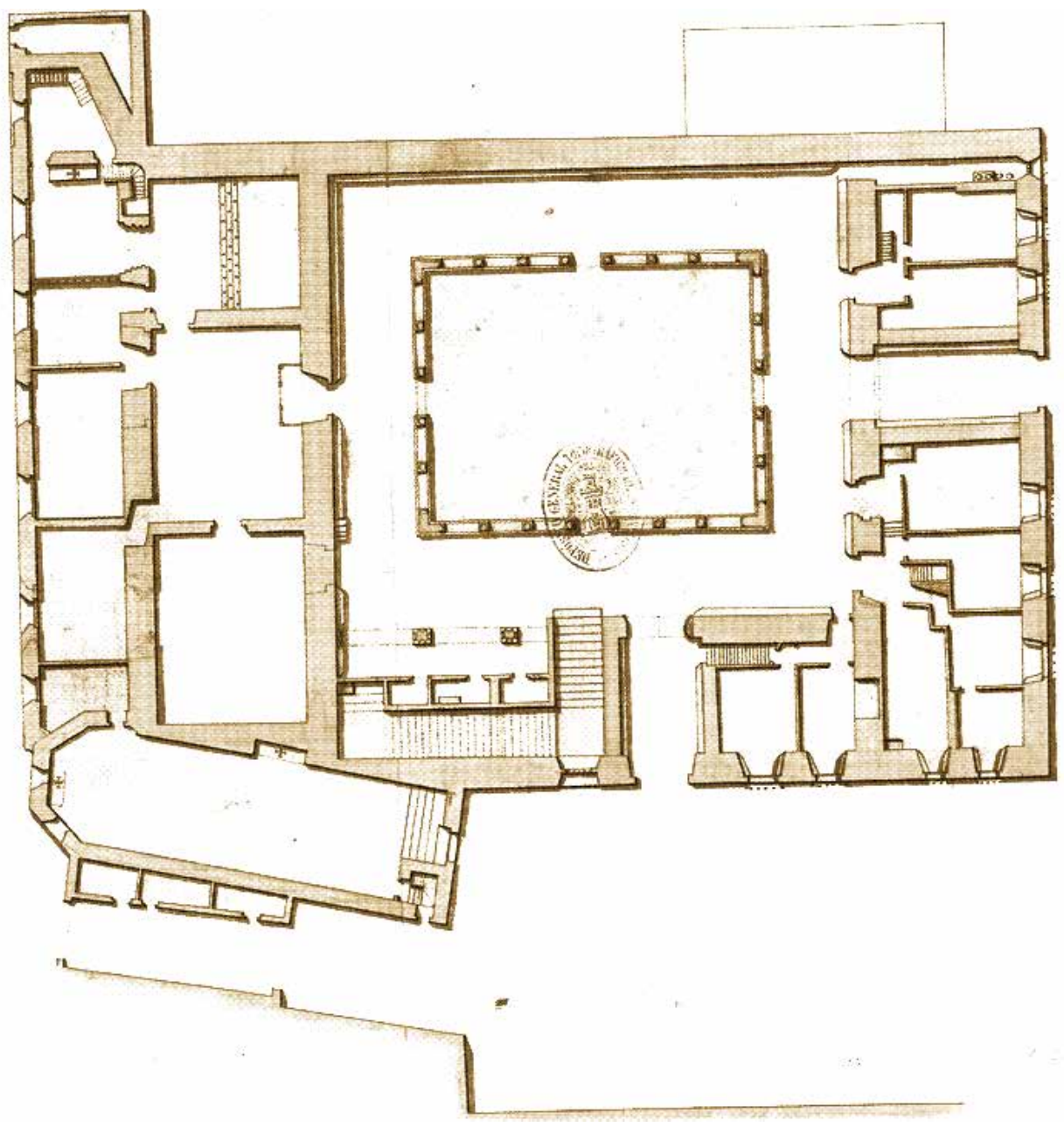

ciudades sin referencia directa al cuerpo humano. Di Giorgio toma, como consecuencia directa de Aristóteles y Platón, la idea del animale sociabile, es decir, de un ser que necesita de los otros para sobrevivir. Por otro lado existe la lectura de Vignola a través de sus grabados comentados de Regola delli cinque ordini d'architettura de 1562, quien adecua las proporciones de los órdenes al encargo arquitectónico, introduciendo lo relativo, y permitiendo que las relaciones entre los mismos puedan mantenerse siempre -utilizando sus fórmulas-, según las necesidades de cada edificio. Podría por ejemplo partirse de una altura dada y mantenerse las proporciones entre órdenes en todo el conjunto sin alterar, en teoría, la armonía. Otra lectura es la que plantea Cornaro en su Trattato dell'architettura de 1575, el primero en mantener una actitud pragmática y distante, llegando a cuestionar que los órdenes sean necesarios para alcanzar la belleza, lo cual lo vincula a la tradición medieval. A Cornaro le interesan exclusivamente las viviendas, y las considera una necesidad básica de la ciudad. Estudia temas exclusivamente utilitarios, como el saneamiento haciendo que, en esta visión, el valor estético sea colocado por primera vez en un lugar subordinado al de la función.

Volviendo a Alberti, esta vinculación entre los requerimientos básicos y el placer permitiría cerrar la operación alcanzando un grado de armonía. Se trata, en definitiva, de cerrar en términos funcionales el círculo de concinnitas. En referencia a los constructores primitivos el autor dirá que:

\section{[FG.05]}

Palacio de la Diputación del Reino de Aragon. Planta Baja

España: Gómez Urdáñez, Carmen. Cartoteca del Instituto de Historia y Cultura Militar. 2011, 1450.
33. Alberti, De re aedificatoria, 10, p. 165.

34.

Según Alberti, "(...) cuando vemos a nuestro alrededor la abundancia y variedad de edificios, comprendemos sin esfuerzo que todos están destinados no sólo a las funciones señaladas y que no están asignados a tal o tal fin exclusivamente, sino que, en función de diversos tipos de seres humanos, sucede que tenemos obras diversas y de múltiples clases". Ibid.

35.

Benevolo, Historia de la arquitectura del Renacimiento, p. 165.

36.

Alberti, De re aedificatoria, 10, p. 76 
[FG.06]

Antonio Sangallo

Palacio Farnesio. Planta baja

New York: Fletcher, Banister. A History of Architecture on the Comparative Method. Charles Scribner's Sons, 1921

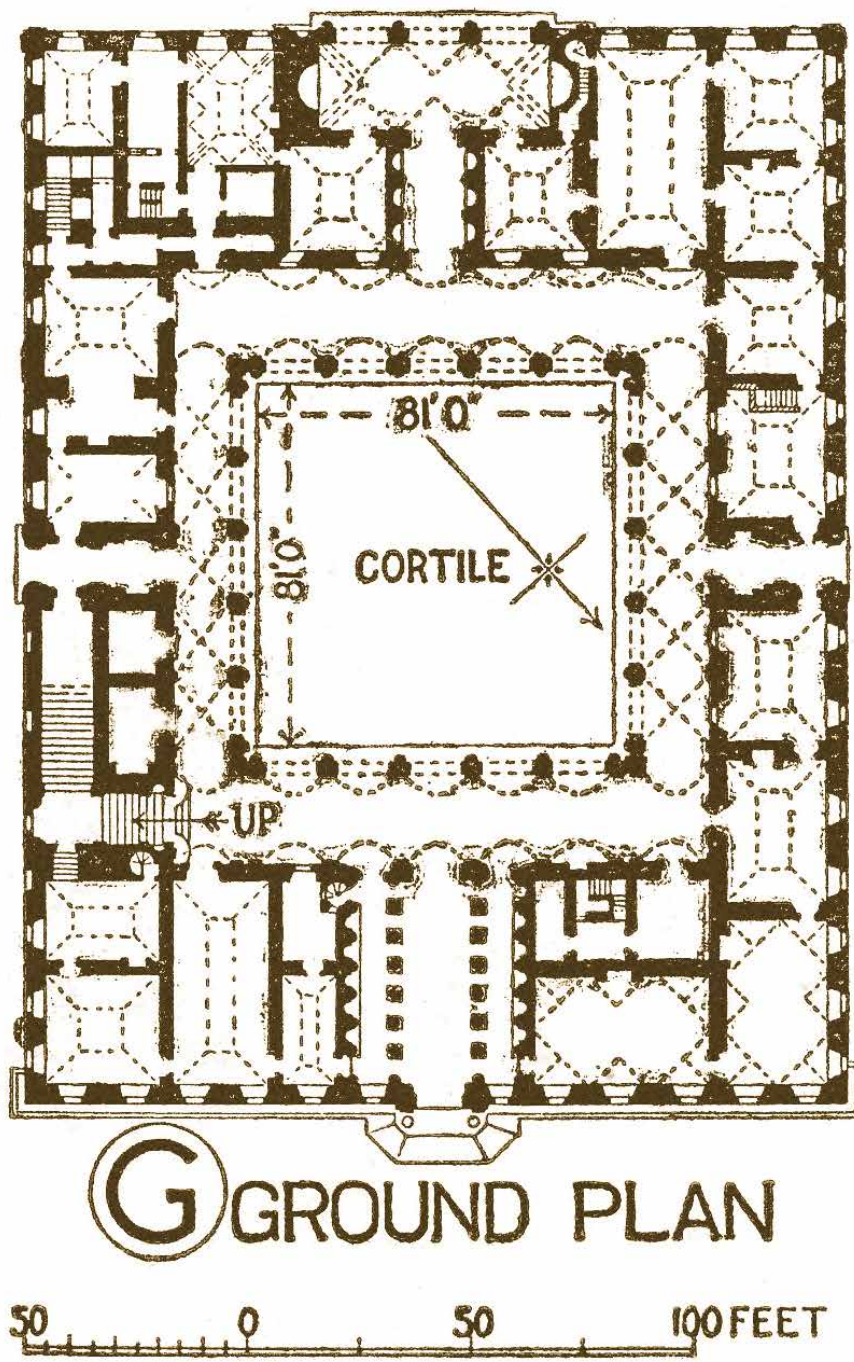

(...) Luego, movidos y seducidos de tal forma por la oportunidad que se les presentaba, llegaron al punto de idear y poner en práctica también aquello que fuera encaminado a satisfacer su placer; de forma que, si uno dijere que hay un tipo de edificios destinados a remediar necesidades vitales, otros destinados a una función concreta, otros diseñados para proporcionar placer puntual, puede que quizás dijera algo sujeto a razón sobre el tema que nos ocupa. $^{33}$

De ahí vendría la separación de usos de los edificios, ${ }^{34}$ que se dividirían según el tipo general; destinados a uso común, a personajes más altos, a condiciones más humildes. Los elementos de que consta cada uno son detallados desde el Libro IV hasta el IX -según Benévolo, el «primer intento» de descripción tipológica realizado, ${ }^{35}$ ya que "como que la finalidad de los edificios es distinta, debimos investigar si un mismo tipo de dibujo se adaptaba a cualquier obra. Por ello, dividimos los edificios en varios tipos". ${ }^{36}$ Como en la mayoría de los tratados, Alberti encuentra sus soluciones en la observación y la experiencia. Aún así, mantiene descripciones de edificios de la antigüedad, ya prácticamente en desuso para ese momento, como termas, anfiteatros o teatros. Siempre que una actividad es detallada hay una referencia directa a lo que "normalmente" se necesita; no existe así una propuesta de transformación de lo existente, sino de considerar los problemas actuales para poder elevarlos al eslabón de con- 
[FG.07]

Machuca, Pedro.

Palacio de Carlos V. Planta Baja

Granada: López Díaz de la Guardia, Fernando.

Recursos de Investigación de la Alhambra,

1952 ,

1527.

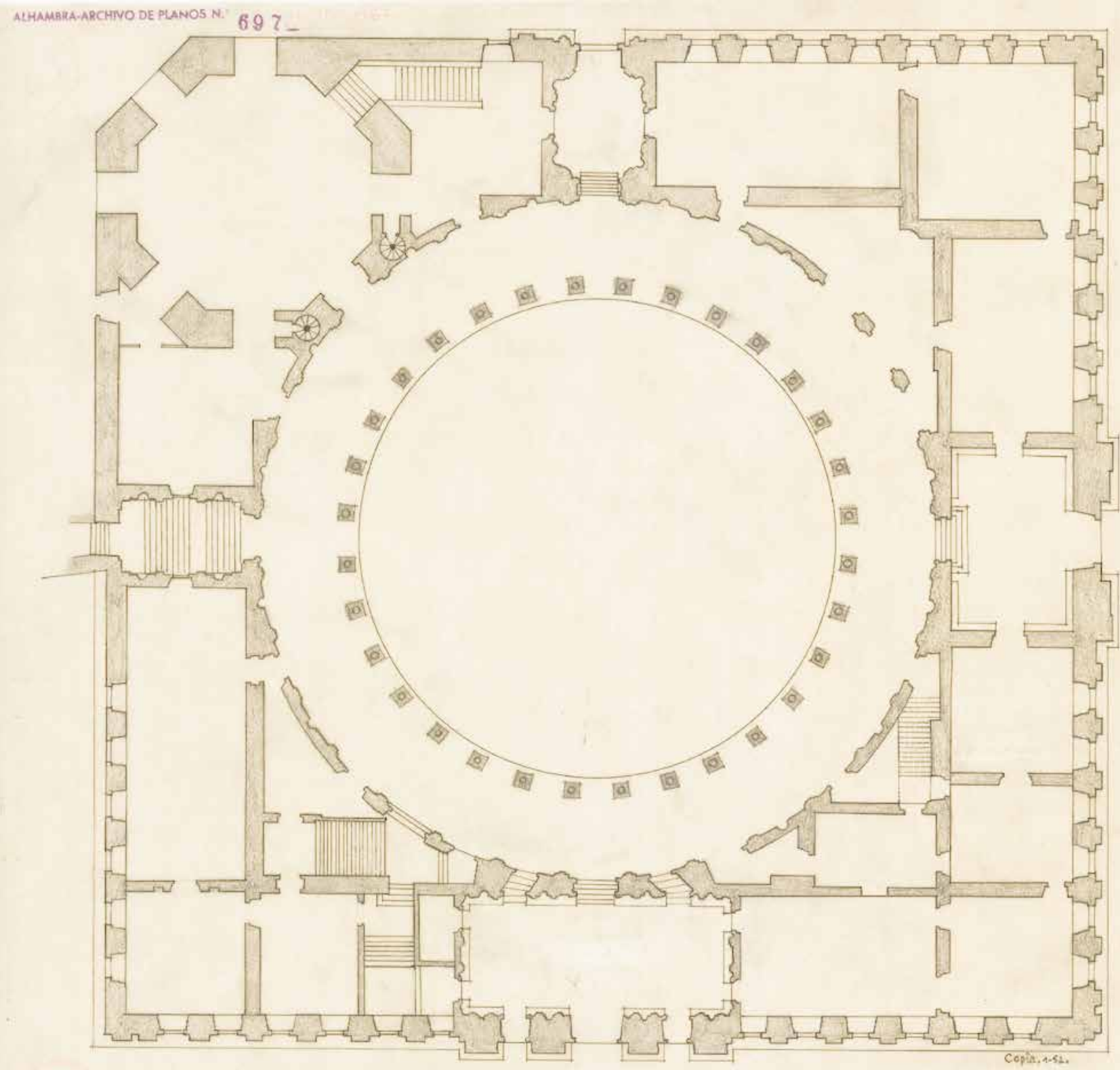

PALACIO DE CARLOS V.PLANTA BAJA - ESCALA, 1:200. 
Zevi propone que esta continuidad entre arquitectura medieval y renacentista se dará en términos espaciales, pero resulta difícil de asimilar una ligazón entre el estilo románico, gótico y renacentista en cuanto a la geometría, y mucho menos a la percepción de sus interiores. La distribución en planta, en cambio, mantiene una similitud mucho evidente. Ver "Capítulo cuarto" en Zevi, Saber ver la arquitectura.

38.

Aunque según Norberg-Schulz los templos de planta central renacentistas presentan una mayor cantidad de variaciones en comparación a los bizantinos. Ver Norberg-Schulz, Arquitectura occidental.

39

Norberg-Schulz también habla de la nueva condición del templo renacentista, que es la de ser un elemento urbano, a diferencia de los palacios o castillos medievales que mantenían su autonomía paisajística. Ver ibid. Rigor geométrico el autor diferenciar entre la cabaña y la cueva como entender el valor de la necesidad y la solución adoptada. En esto yace la separación de lo familiar y lo individual; cada actividad requería, según Alberti, de un ambiente diferenciado, y de este modo se construyeron techos para protegerse de la lluvia y del sol, pero además se escogieron lugares más adecuados para dormir y para morar. En Vitruvio la idea de lo social se explicaba de una forma muy básica. Alberti propone el avance de la función como una práctica casi intelectual. Primero se satisface lo básico, y luego se avanza hacia la búsqueda del placer, en sintonía con la raíz latina de necessitas, la cual refiere a lo 'inevitable' de necesse, a eso que no puede ser obviado. Se trata nuevamente de un proceso evolutivo, pero con dos fases claramente diferenciadas en donde commoditas se acerca a la belleza. La función se desarrolla en De re aedificatoria no como una solución meramente técnica, sino como tema propio de la arquitectura, al introducir la identificación de necesidad como una condición básica e indispensable, por un lado, y de comodidad, como valor, que es devenir del pensamiento arquitectónico, por otro. Es decir que, en un avance significativo con respecto a Vitruvio, Alberti introduce conceptualmente a la función como tema indispensable de la arquitectura.

Aún así, lo que puede considerarse como un aporte fundacional y una primera aproximación teórica cierta con respecto a la función lo será mucho menos en la práctica de la arquitectura del período. Sobre todo en el primer Renacimiento, las distribuciones funcionales no presentan sino una continuidad con sus antecesores del Medievo, ${ }^{37}$ especialmente en el caso de los templos; la planta basilical del paleocristiano seguirá siendo motivo principal, y la planta centralizada mantendrá, desde el bizantino, su distribución. ${ }^{38}$ Será en el acercamiento de estos nuevos arquitectos del Renacimiento a otros programas, como la villa, el palacio, o el anfiteatro, donde se produzca una transformación significativa. El palacio es uno de los ejemplos más ilustrativos de la evolución de necessitas a commoditas. Un esquema de edificio con patio central en el Medievo se componía de una edificación perimetral irregular, como un organismo vivo; una sumatoria de recintos que, por necesidad, iban sucediéndose y acomodándose sin seguir un rigor geométrico, siendo las galerías del claustro los espacios 'conectores' entre recintos interiores, como ocurre en la planta del Palacio de la Diputación del Reino de Aragón, de mediados del siglo XV. [FG.05] Esto se expresaba a la vez en el exterior, con aberturas de diversos tamaños que no buscaban formar parte de una composición general. El palacio renacentista es, al exterior, pura regularidad geométrica, situación que no se mantiene siempre en el interior, por dar preferencia al cuidado por las funciones, lo que claramente redunda en una asimetría en planta, como ocurre en el Palacio Farnesio, [FG.06] además de mantenerse la distribución del claustro se incorpora una vinculación interna a través de puertas. ${ }^{39}$ Es un claro avance en términos de commoditas, sobre todo al considerar la distribución funcional independiente de la expresión exterior y la propia geometría ortogonal definida 
llamara manierismo (terza maniera) que las estructuras organizativas vuelvan a ponerse en discusión. En el proyecto para el Palacio de Carlos V [FG.07] Pedro Machuca traza un patio en una circunferencia inserta dentro de una planta de perímetro cuadrangular, en una operación que, como se ha observado en muchas ocasiones, resulta claramente manierista. Esta idea inicial, geométricamente potente, ocasiona problemas funcionales evidentes en el trazado ortogonal de la distribución de los recintos, resultando en una serie de triángulos en planta difícilmente asimilables a alguna actividad concreta. Dentro del patio se percibe una armonía y orden que no se condicen con la distribución interior. Se trata sin dudas de una confianza en la idea platónica que gobierna al proyecto en términos generales, la cual acarrea consecuencias similares a los de las distribuciones por agregación del Medievo. Un último eslabón lo conforma la arquitectura de Palladio, ya no en el palacio, sino en la villa. La casa como programa había estado ausente de la atención de la arquitectura, y Palladio incorpora un mismo ideal clásico y geométrico a una función tradicional, como es la casa. Paradójicamente, Palladio no utiliza la distribución de la casa romana, con patio central, sino que adopta el esquema del templo. Pero la principal operación en cuanto a la función radica en que el autor no presta atención a las proporciones y dimensiones usuales de una casa tradicional, como puede verse en la planta de la Villa Capra (Rotonda), [FG.08] sino que adapta estas a una nueva geometría. Ambas, necessitas y commoditas, parecen verse satisfechas, sólo que la primera debe adaptarse a unas condiciones que el propio arquitecto imagina y que ya no dependen, como en el tratado de Vitruvio y Alberti, de la observación de las condiciones existentes, sino de la voluntad de un arquitecto, en este caso interpretando y traduciendo las condiciones del clasicismo a cada rincón del edificio. Tampoco será posible saber si la nueva villa palladiana resultara cómoda en su momento, ya que supone la adecuación de los modos de vida a una nueva forma. Se trata, en resumen, de jerarquizar una organización de una regularidad platónica a la cual las funciones deben 'acomodarse'. Esta tensión producto del orden intelectual del arquitecto y la satisfacción de las necesidades en pos de una comodidad será el germen de un tema de discusión sobre la función que se mantendrá por generaciones. 
[FG.08]

Andrea Palladio,

Villa Capra (Rotonda). Planta Baja Venecia: I quattro libri dell'architettura. 1570 ,

1566.

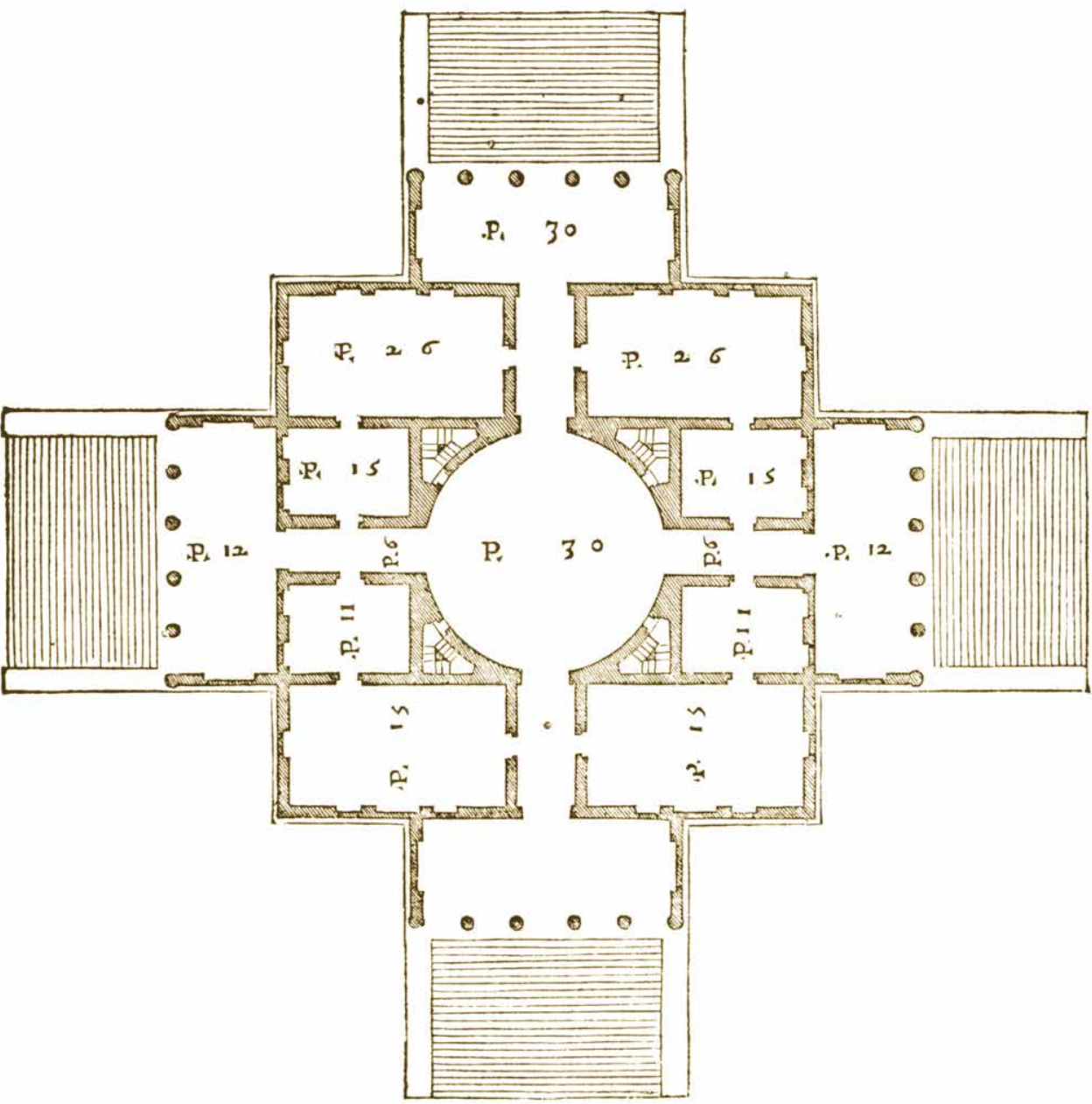


La noción de 'eficacia' refiere a la función dentro de un marco científico; una concepción que no apela al empirismo -el cual empapa al mismo tiempo gran parte de la tratadística tradicional- sino que busca cuantificar, analizar y poder dar respuestas concretas y palpables a la arquitectura, desligándola de la subjetividad y buscando anticiparse a "problemas" concretos. La 'eficacia' no se construye sólo a partir del pensamiento de Descartes como marco filosófico, sino que la misma bebe constantemente de otros ámbitos vinculados a la ciencia y las tecnologías, como el funcionamiento de las industrias o de las máquinas, recurriendo a la estandarización o la economía de medios como nuevos objetivos. Alguna de las prácticas más radicales que la componen suelen perseguir un rigor que permita el establecimiento de reglas; en algunos casos puede incluso posibilitar el cálculo y la solución matemática de un problema funcional.

Los orígenes de la 'eficacia' pueden encontrarse, de un modo menos literal, en las propias definiciones originarias de la función planteadas por Alberti; necessitas es, al fin y al cabo, el diseño aplicado a suplir de la forma más eficiente el problema básico del habitar; el primer eslabón de la arquitectura, antes de adentrarse en commoditas reside, según Alberti, en poder dar cobijo a las necesidades más básicas del ser humano. Una característica notable resulta de que gran parte de los aportes teóricos dentro del marco de la 'eficacia' colocan a la belleza en un segundo plano. En este sentido puede decirse que las apuestas teóricas de Carlo Lodoli en la primera mitad del siglo XVIII son probablemente el primer aporte significativo sobre esta posición. Más allá de que algunos autores franceses como Claude Perrault, Jacques François Blondel o Marc-Antoine Laugier ya habían mostrado interés por recurrir al pensamiento racionalista de raíz en Descartes, la apuesta de Lodoli sorprende por su radicalidad y su notable vigencia en la arquitectura moderna. A pesar de esto, 


\subsubsection{EFICACIA}

las teorías de Lodoli gravitan en un campo abstracto, o al menos mucho más abstracto que el de Jean-Nicolas-Louis Durand, quién conseguirá con Précis des leçons d'architecture dar un salto de importancia en cuanto a lo operativo en la función, considerando el problema del proyecto en torno a la economía y la complejidad de los grandes programas, algo que terminará de sentar las bases para la noción de 'eficacia'. Ya en la arquitectura moderna, uno de los conceptos que con mayor énfasis se trató fue lo que en el período de entreguerras en Alemania se entendió como Existenzminimum; el de superficies de habitar justas, vectores de recorrido mínimo y distribuciones más óptimas desde el punto de vista del aprovechamiento del espacio. Como resultado del taylorismo y el fordismo, matemáticas y diagramas fueron las herramientas principales para conducir un concepto de 'eficacia' que, además, contó con trasfondos ideológicos muy diferentes, desde las primeras indagaciones en la vanguardia arquitectónica de la U.R.S.S. y la Alemania de la República de Weimar hasta la propuesta de un 'lenguaje de patrones' de Christopher Alexander en Inglaterra y Estados Unidos. Por otro lado, en los años veinte, Hannes Meyer y Moiséi Gínzburg se emparentan claramente por un proyecto común, el de una arquitectura que debe ser refundada desde su marco social; ambos comparten el proyecto de una disciplina que debe redefinirse para poder encajar en un planteo socialista, que tiene obviamente a la U.R.S.S. como referente. También en ambos reside la confianza en las nuevas técnicas de construcción, que permitirían una arquitectura 'liviana' capaz de contradecir la permanencia inherente de la arquitectura clásica. Los diagramas -herramienta de la que se valieron ambos de manera sistemática- buscaban dotar a las propuestas de un rigor científico. Al mismo tiempo, la labor de Alexander Klein y Ernst Neufert en el período de entreguerras en Alemania se encuentra más apegada aún a este enfoque; ambas tienen como base la medición y al encaje de situaciones concretas. En este punto es que un autor tan disímil respecto a lo temporal e ideológico como Christopher Alexander plantea una propuesta teórica para la función que se mantiene en diálogo con esta linea de pensamiento, recurriendo a una metodología puramente científica.

Aunque el concepto de 'eficacia' se pueda vincular con facilidad al pensamiento de la arquitectura moderna más racionalista, lo cierto es que el mismo ha estado presente de una u otra manera en gran parte de las concepciones de la función, ya que también se trata de una noción patente en la misma acción de diseño. Es, al fin y al cabo, un modo de entender la función más básica de los objetos; el desarrollo de cierta metodología aplicable que, haciendo nuevamente eco del espíritu de los tratados de arquitectura más tradicionales, permita al diseñador poder resolver problemas funcionales con garantía de éxito. La selección de autores que componen esta categoría se centra, principalmente, en aquellos que la propusieron de manera más enfática y radical, 



\subsubsection{EFICACIA}

Moisei Gínzbur

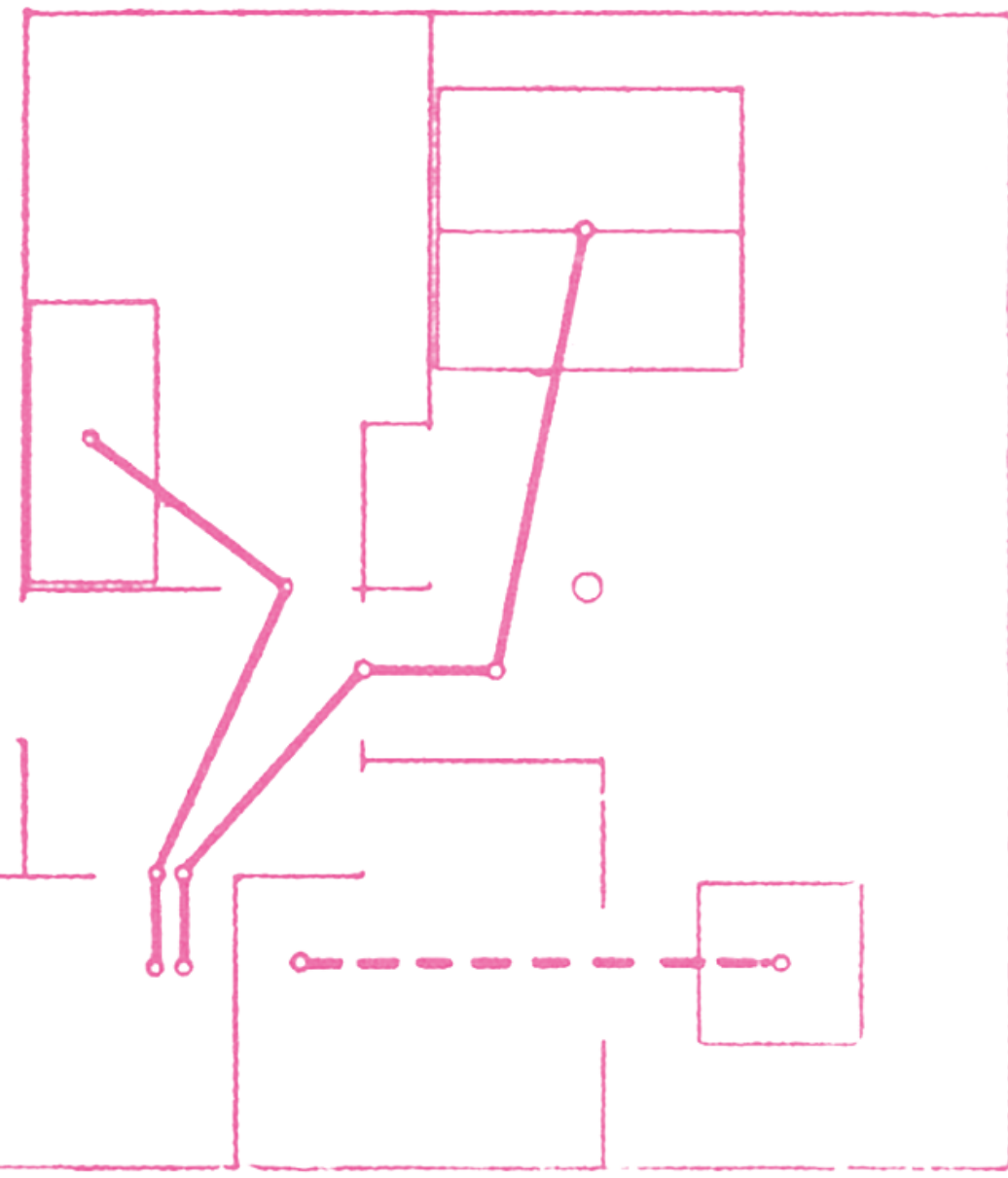


Es sabido que el pensamiento de Carlo Lodoli llega hasta nuestros días gracias a la interpretación que de este hicieran sus discípulos, Francesco Algarotti y Andrea Memmo. También es necesario considerar que la importancia de las ideas de Lodoli en torno a la función recién ha conseguido una valoración significativa en el siglo XX, ya que la radicalidad de sus supuestos teóricos no tuvo alcance efectivo en la arquitectura de Italia, a mediados del siglo XVIII, momento en que la planteara. La propuesta del autor es también descendiente del pensamiento racionalista, en este caso podría afirmarse que llevado a un punto mucho más extremo. Lodoli es el primer autor que discute fuerte y frontalmente con Vitruvio; lo cita irónicamente y se opone a gran parte de sus postulados. Pero en verdad la apuesta del autor italiano no se basa en un rechazo particular a las ideas de Vitruvio, sino que lo toma como referente de un ataque que tiene intereses más profundos, ya que van contra gran parte de los argumentos que sostienen el sistema clásico.

Como afirma González, "Lodoli es uno de los primeros autores que pone en crisis la esencia de las formas clásicas y que a su vez propone métodos para sustituirlas a partir de un mayor conocimiento del comportamiento tectónico de los materiales». ${ }^{1}$ Si ya podía considerarse que Bacon diera un primer paso en discutir algunos de los lineamientos de la arquitectura clásica a favor de ciertas 'necesidades' funcionales, Lodoli se presenta como el primer exponente claro en defender la vinculación entre funzione y rappresentazione, en una tríada que consta de 'formar, adornar y mostrar.' Los elementos del sistema clásico ya no pueden limitarse ocupar el rol de la belleza, sino que deben posicionarse como emisores de la finalidad estricta a la cual deben su sentido. No se trata de negar el ornamento, sino de exigirle su justo lugar en relación a su esencia constructiva. A este respecto las ideas del autor, al menos en términos teóricos, se presentan como netamente modernas.

La metodología de Lodoli es la de una crítica feroz, sin empacho de exigir la condena de edificios que, ya sean antiguos o modernos, irrumpan con algún tipo de falsedad que corrompa los principios anteriormente mencionados. Una de las principales críticas apunta a la honestidad técnica de los edificios: una estructura que aparenta lo que no es en realidad, o un material que busca parecer otro. Las ideas de Lodoli se anticipan a varios de los debates que tendrán lugar en el siglo XIX y XX y que conforman la noción de 'eficacia'. Además de los temas técnicos están también los funcionales, y Lodoli persigue la precisión programática, es decir, edificios adecuados a lo que tienen que servir. Muy lejos de la belleza como objetivo ensimismado, el autor italiano centra su atención en el origen necesario de los edificios, lo cual lo liga inevitablemente con las hipótesis de necessitas de Alberti, y las construcciones primitivas básicas.

Como uno de sus principales divulgadores, Algarotti difunde pero a su vez rebate las posturas de Lodoli en Saggio sopra l'architettura, de 1763, ya que busca recuperar ciertos valores de la antigüedad clásica con vistas a una alternativa de un barroco que ya se encontraba en claro agotamiento. Lo que Algarotti toma de Lodoli es la crítica al regocijo que se basa en el puro ornamento y que se aleja de cualquier regla de construcción:

\section{Lodoli. Autenticidad de la}

\section{función}

$$
1 .
$$

González, José Luis, El Legado oculto de Vitruvio. Saber constructivo y teoría arquitectónica, (Madrid: Alianza Forma, 1993), p. 126.

2.

Algarotti, Francesco, Saggio sopra l'architettura (Venecia: Stamperia Graziosi a S. Apollinare, 1784), p. 19. (Ed. orig. 1753).

3.

Hereu, Pere, Montaner et al., Textos de arquitectura de la modernidad (Barcelona: Nerea, 1994), p. 20. (Ed. orig. 1994).

4.

Aunque es cierto que el edificio construido en su interior poco tiene que ver con el publicado, ya que Palladio tuvo que mantener la construcción gótica preexistente.

\subsection{1.a.}

\section{Crítica al sistema}

5. Textos de arquitectura de la modernidad, p. 20.

\subsection{1.b}

Interior y exterior 
Hemos de creer que el filósofo ni tan siquiera se hubiera decidido jamás a aceptar la más mínima existencia de belleza en donde no se encontrase alguna utilidad (...) No se deberá dar forma, insiste, a nada que no tenga también una auténtica función. Daremos con toda propiedad la denominación de abuso a cuanto se aleje, sin importar en qué medida, de ese principio, verdadero fundamento y piedra angular sobre el que ha de reposar el arte de la arquitectura. ${ }^{2}$ El caso ejemplar para Algarotti es Palladio, de quien dice que "...no colocó nunca en las fachadas de los templos dos órdenes superpuestos, sino que acostumbró siempre a realizarlas de tal modo que, por así decirlo, podía leerse en el frente de un edificio la manera como estaba construido por dentro». ${ }^{3}$ En efecto, no sólo en los templos, sino en gran parte de la obra de Palladio es posible encontrar esta ligazón entre expresión exterior e interior. No en vano utiliza, en I quattro libri dell'architettura, la planta y la elevación, o la sección, en correspondencia, para hacer gala de una continuidad geométrica en todos las partes del edificio. El proyecto de la Basílica Palladiana de Vicenza, en la cual trabaja desde 1549 hasta su muerte, y que publica en I quattro libri... es un ejemplo muy evidente. ${ }^{4}$ [FG.01] El orden toscano de la loggia en la planta baja se corresponde con las aperturas del volumen cerrado que conforma el interior de la basílica. Asimismo, este cuerpo interior queda oculto en los dos primeros niveles por la loggia que lo envuelve, pero emerge en un tercer nivel, haciéndose visible desde la Piazza dei Signori. Esta 'transparencia' entre lo que se ve y lo que el edificio es en realidad promete esa honestidad que reclamaba Lodoli. Por si fuera poco, Palladio recupera el origen funcional de la basílica romana, perdido desde que en la Edad Media pasase a ser la matriz del templo cristiano, con su simetría bi-axial, ya sin foco en el altar, devolviendo su sentido original de centro cívico.

2.1.1.c. A pesar de los ejemplos, Algarotti reniega de esa condición lodoliana puramenRacionalidad sobre te ideal a la que apenas algunos pocos edificios son capaces de responder de naturaleza forma completa. De este modo asume la abstracción de las ideas de su maestro afirmando que función y representación difícilmente puedan mantenerse unidas de principio a fin, sin interrupciones. La oposición de Algarotti se funda sobre todo al inyectar la noción de naturaleza en la matriz del pensamiento cartesiano de Lodoli. Según Algarotti, esta propuesta llevaría al arte a un grado de racionalidad tal que superaría las leyes propias de la naturaleza, ya que esta última contiene elementos que carecen de una estricta función, análogos a los adornos; y, por sobre todo, que la belleza puede encontrarse en un producto que carece por completo de función.

Quizás diga que se pretende ir con excesivas sutilezas y hacer que el arte de construir del hombre sea más exigente que la naturaleza misma en sus obras; pues ésta, aunque jamás actúa en vano y hace todo con medida y razón, sin embargo al haber puesto mamas incluso a los animales machos y haber cubierto con un penacho las cabezas de muchas aves y realizado otras cosas semejantes, carentes de cualquier utilidad, parece como si se hubiera complacido con lo que es mero ornamento y que, a veces, también ella ha condescendido en sus productos con una belleza nada mecánica. ${ }^{5}$ 
En este sentido Algarotti anticipa también un debate moderno que atañe tanto a la noción de 'eficacia' como a la de 'adaptación': el del riesgo de pérdida que supone perseguir el objetivo casi platónico de un objeto que sólo responda a su función en todas sus partes.

2.1.1.d. Se supone que el escrito más cercano a las ideas de Lodoli es Elementi di arRappresentazione chitettura Lodoliana, ossia l'arte di fabbricare con solidità scientifica e con eleganza non capricciosa de Memmo, publicado en Roma en 1786. El autor se centra en este caso en las ideas de funzione y rappresentazione de Lodoli, quien afirmara que "la recta función y la representación son los dos únicos objetivos finales científicos de la arquitectura." ${ }^{6}$ Memmo publica una serie de definiciones de cada uno de los conceptos lodolianos; los cuales serán fundamentales para forjar las bases de la 'eficacia' en la función:

Funzione, remite a solidez, analogía, comodidad y representación, aunque las definiciones resultan vagas, el texto de Memmo se encargará de ampliarlas. $^{7}$

Rappresentazione, es la expresión individual y total que resulta de la materia cuando está dispuesta según las razones geométrico-aritmético-ópticas para conseguir el fin propuesto. ${ }^{8}$

Soliditá, es aquella firmeza individual y total que resulta en los edificios de la teoría estático-físico-química, aplicable a susodicha materia, simple y compuesta. ${ }^{9}$

Analogia es aquella conveniencia regular proporcionada de las partes y del todo, que debe surgir en los edificios de las teorías estereométrico-aritméticas combinadas con normas racionales, aplicables a la forma y medida de los alzados, los elementos, los huecos, y los volúmenes arquitectónicos. ${ }^{10}$

La función en Lodoli está ligada constantemente a la representación y, con su base científica, esta última debe remitir siempre a lo verdadero; lo que es falso nunca merece ser representado. Memmo reafirma finalmente la conocida cita de su maestro de que «todo lo que en arquitectura está en representación debe estarlo también en función", es decir que "el edificio debe concebirse como una representación de su propio fin".

2.1.2. El quiebre social y político que se genera en Francia después de la Revolución

Durand. La retícula, traerá también aparejado una modificación en la enseñanza de la arquitectura, sistema total la cual colocará en un lugar de mayor importancia temas de racionalidad, economía y funcionalidad, que si bien ya estaban presentes en la tradición francesa, se ven acentuados. La École Polytechnique será el nido de conocimiento estandarte de una arquitectura que busca el rigor geométrico y técnico. A su vez mantendrá cierta distancia con respecto a los problemas de forma y belleza, o más bien de individualidad artística, en pos de un enfoque científico ligado a las obras de ingeniería, donde economía y racionalidad ocupan el lugar de mayor importancia. En definitiva, una serie de intereses germinales con respecto a la función y a la 'eficacia,' vinculados a la búsqueda de una normativa con intereses universales que permita hacer frente a las necesidades sociales del momento, lo cual lleva a la ejercitación de proyectos con grandes progra- 
Jean-Nicolas-Louis Durand, profesor de la École Polytechnique desde que la misma se fundara en 1795, busca dar forma en la enseñanza de la arquitectura a las prestaciones para una sociedad revolucionara que Napoleón I exigiera en el poder. Durand persigue una pedagogía del proyecto arquitectónico que esquive la especificidad a la que la disciplina se había mantenido cercana durante tantas décadas. Mediante determinadas herramientas busca hacer frente a cualquier programa arquitectónico que se presente, sin importar su tamaño o complejidad. De algún modo Durand construye el rol de ese proyectista capaz de dar solución a cualquier problema a través de una matriz de pensamiento completamente racionalista. Aunque varios autores vean en Durand el fin de la tradición vitruviana, ${ }^{11}$ lo cierto es que el sistema clásico le servirá de algún modo como pie para aplicar estas normas proyectuales basadas en la economía y la funcionalidad. Boullèe, para quien Durand había trabajado, ya había ampliado las posibilidades del clásico mediante exacerbaciones en la escala y la repetición. Durand, en cambio, buscará la componente racional inherente en el mismo, controlando los exabruptos de la imaginación e interpretando a los órdenes clásicos como una serie de elementos repetitivos con una regla interna construida sobre el pensamiento racionalista.

La noción de économie ya había sido mencionada por Vitruvio y más tarde por Blondel, ambos vinculándola al concepto de distribución (distributio y distribution, respectivamente), pero nunca había sido considerada de un modo tan jerárquico y profundo como en el caso de Durand; para este una de las cuestiones esenciales que el arquitecto debe asumir es la de construir de una manera menos costosa. Este giro supone un cambio drástico en una arquitectura en la que el coste nunca había conformado un 'valor' en sí mismo, es decir, que nunca había sido componente del pensamiento de la arquitectura. Igualmente, la exigencia de Durand no resulta en un racionalismo ciego, ya que es evidente que el arquitecto busca obtener un resultado estético de esta operación: una arquitectura que denote belleza en su austeridad de recursos; pero no sólo estéticos, sino también funcionales. Según Durand, "Se ve por todo lo que precede que en arquitectura la economía, lejos de ser, como se cree generalmente, un obstáculo a la belleza, es por el contrario su fuente más fecunda». ${ }^{12}$ Ya en la "Introducción" de su Précis des leçons d'architecture comienza señalando que la arquitectura es el arte que cuesta más dinero y que los gastos de una obra pueden significar un problema para el Estado, embarcándose en un crítica a edificios como el Palacio de Versalles, Sainte Geneviéve o San Pedro; ejemplos de obras con costos desmesurados que por esto mismo no consiguen, según el autor, magnificencia. Durand, consciente de su pragmático planteo, expresa que «Según la mayor parte de los arquitectos, la arquitectura no es tanto el arte de hacer edificios como el de decorarlos». ${ }^{13}$ El gasto de la decoración la hace de este modo prescindible. Por otro lado, le confiere a la conservación de los edificios un rol también funcional, entendiendo que la preservación de la arquitectura es la que permite también la preservación del mismo hombre:

\subsection{2.a.}

\section{Normas}

\section{1.} Según Moneo alguno de estos autores son serían Kaufmann, Herrmann, Rykwert, Vidler, Tafuri y Hitchcock. Ver el "Prólogo" de Moneo, Rafael en Durand, Jean Nicolas Louis, Compendio de lecciones de arquitectura: parte gráfica de los cursos de arquitectura (Madrid: Pronaos, 1981). (Ed. orig. 1801).

12.

Ibid. p. 15.

13. Ibid. p. 10 .

14.

Ibid. p. 8.

15.

Blondel, Jacques-François y Patte, Pierre, Cours D'Architecture ou Traité De la Décoration, Distribution \& Construction Des Bâtiments: Contenant Les Leçons données en 1750, \& les années suivantes par JF Blondel, Architecte, dans son École des Arts, vol. 6 ( $\mathrm{Pa}$ ris: Desaint, 1777), p. 389. (Ed. orig. 1771).

\subsection{2.b.}

Économie 
conservación; la sociedad su existencia; todas las artes su nacimiento y su desarrollo; sin ella, la especie humana, enfrentada a todos los rigores de la naturaleza, ocupada únicamente en defenderse de la necesidad, los peligros y el dolor, lejos de llegar a disfrutar de todas las ventajas de la sociedad, posiblemente hubiera des- aparecido casi por completo de la superficie del globo. ${ }^{14}$

En este sentido, Durand consigue tender un puente hasta ese momento casi inexistente entre la arquitectura y la ingeniería. La base para la aplicación práctica de esta économie será sin dudas la geometría, expresada con más especificidad en la simetría -ya harto presente en la tradición vitruviana- pero por sobre todo en la retícula como herramienta de proyecto.

2.1.2.c. La noción de composition resulta central en Durand, ya que su aportación perComposition mitirá el avance de este concepto, presente constantemente en el debate francés. Blondel ya había referido vagamente a ella cuando, hablando de la convenance, explicara:

La decencia aparece cuando la disposición externa y las partes principales de su decoración están absolutamente relacionadas con el tema que dio lugar a erigir el edificio, donde la comodidad del espíritu allí preside, como la decencia... ${ }^{15}$

Durand profundiza más en este campo, considerando que los elementos de la arquitectura ligados a la necesidad tienen la misma importancia que los vinculados directamente a los órdenes. Esto lo diferencia notablemente de Vitruvio, y llega a discutir con él la diferencia entre las proporciones del cuerpo y la mínima precisión conque la misma se ha aplicado a los órdenes arquitectónicos. Del mismo modo, y en oposición a Laugier, considera que la cabaña primitiva es un primer ensayo de refugio apenas aceptable, y con nulos resultados artísticos, rechazando también la hipótesis de Laugier en la cual el hombre, apenas después de haber formado sociedad y haber cubierto sus necesidades básicas, buscó belleza en la decoración. Para Durand tampoco es posible continuar la labor de Laugier de discutir y perfeccionar distribuciones de edificios tradicionales, sino que es preciso un replanteo de raíz que los nuevos programas exigen. Así es que serán los elementos del sistema clásico los que le permitirán ahondar en estos modos de composition. Ese "tema", traducido por Durand como el "programa arquitectónico», será entonces el origen.

La composition se vuelve imprescindible en el momento en que, según Durand, no es posible enseñar a diseñar todos los tipos de edificios; se trata de un método más abstracto en el cual se puede obtener un conocimiento general para avanzar frente a los desafíos funcionales. A diferencia del sistema de los clásico -y aunque los órdenes sigan presentes- la composition, se basa en relaciones entre espacios y circulaciones, las cuales se desarrollan a través de una rigurosa geometría en planta. Aquí es donde la cuadrícula característica de Durand hace su aparición como herramienta de diseño y como herramienta base para la 'eficacia' de la función; la misma condensa la racionalidad geométrica con la économie. Así la composition se establece, según el autor, como un lenguaje: 
...se debe dar uno cuenta de cómo el estudio de la arquitectura, reducido a un pequeño número de ideas generales y fecundas, a un número poco considera-

ble de elementos pero que bastan para la composición de todos los edificios; a algunas combinaciones simples y poco numerosas, pero que cuyos resultados son tan ricos y tan variados como los de las combinaciones de los elementos del lenguaje... ${ }^{16}$

En la "Segunda Parte" de Précis des leçons d'architecture... el autor analiza las diferentes "partes" de un edificio como una serie de espacios que -también divididos en "primarios" y "secundarios"- virtualmente contienen un origen funcional, como salas, porches, escaleras o patios. El autor explica en detalle el uso contenido en cada uno de ellos como si de células se tratase. En la "Tercera Parte" se habla del "conjunto", es decir, del edificio como totalidad, que se conforma con la unión de las "partes" mediante el sistema geométrico de ejes y retículas. El mismo Durand aclara que la composition va de lo general a lo particular, pasando por las "partes" hasta llegar al detalle. Similar a la definición de "compuestos" de la Encyclopédie, no basta con conocer las piezas del reloj por separado, ni tampoco el mecanismo completo funcionando, sino que es en la conjunción donde yace la esencia del compuesto. Durand pone a prueba su metodología con una serie de ejemplos publicados dentro de Précis des leçons d'architecture...[FG.02] En los mismos se establecen las dos escalas de trabajo, la del "conjunto" y la de la "parte». En la primera se define la geometría general de las estancias, basadas principalmente en el cuadrado, el rectángulo o el círculo. Las diferentes estancias se ordenan linealmente, centradas en un eje que no sólo corresponde al centro geométrico, sino que también indica el recorrido interior; ya sobre él se disponen las puertas que vinculan los distintos ambientes interiores entre sí. Mientras tanto, en los patios, una circulación exterior techada a modo de claustro se propone como segunda circulación. La solución no resulta novedosa, sino que lo que prima en sí es el rigor geométrico y constructivo aplicado a los diversos proyectos; la posibilidad de, mediante el mismo método, combinar espacios interiores de escalas y cualidades completamente diferentes. Se trata, en efecto, del dominio de un lenguaje mediante una estricta labor geométrica, en la cual la retícula siempre está presente como base. En estos ejemplos la función está suspendida, y lo que se desarrolla es un esquema de organización virgen. Esta organización no es más que una relación abstracta de ambientes a los que, a futuro, se les asignará una actividad; pero los mismos no están relacionados en principio a ninguna actividad concreta, con lo cual la función como tal no se encuentra definida en el edificio. Lo que establece el método es una jerarquía para los ambientes, intentando adelantar un boceto que absorba las complejidades de cualquier programa requerido. Se trata de una vinculación entre las particularidades y las generalidades de las construcciones, o como comenta De Zurko, «Según Durand, la utilidad no provenía de la satisfacción de la mera idiosincrasia, capricho, arbitrariedad o egoísmo personales. Al igual que para Hume, Adam Smith y otros autores del siglo XVIII, para él el concepto de utilidad significó moralmente, ante todo, utilidad pública y el bien para el individuo». ${ }^{17}$
Durand, Compendio de lecciones de arquitectura: parte gráfica de los cursos de arquitectura, p. 21

17.

De Zurko, Edward, La teoría del funcionalismo en la arquitectura (Buenos Aires: Nueva Visión, 1970), p. 162. (Ed. orig. 1957). 


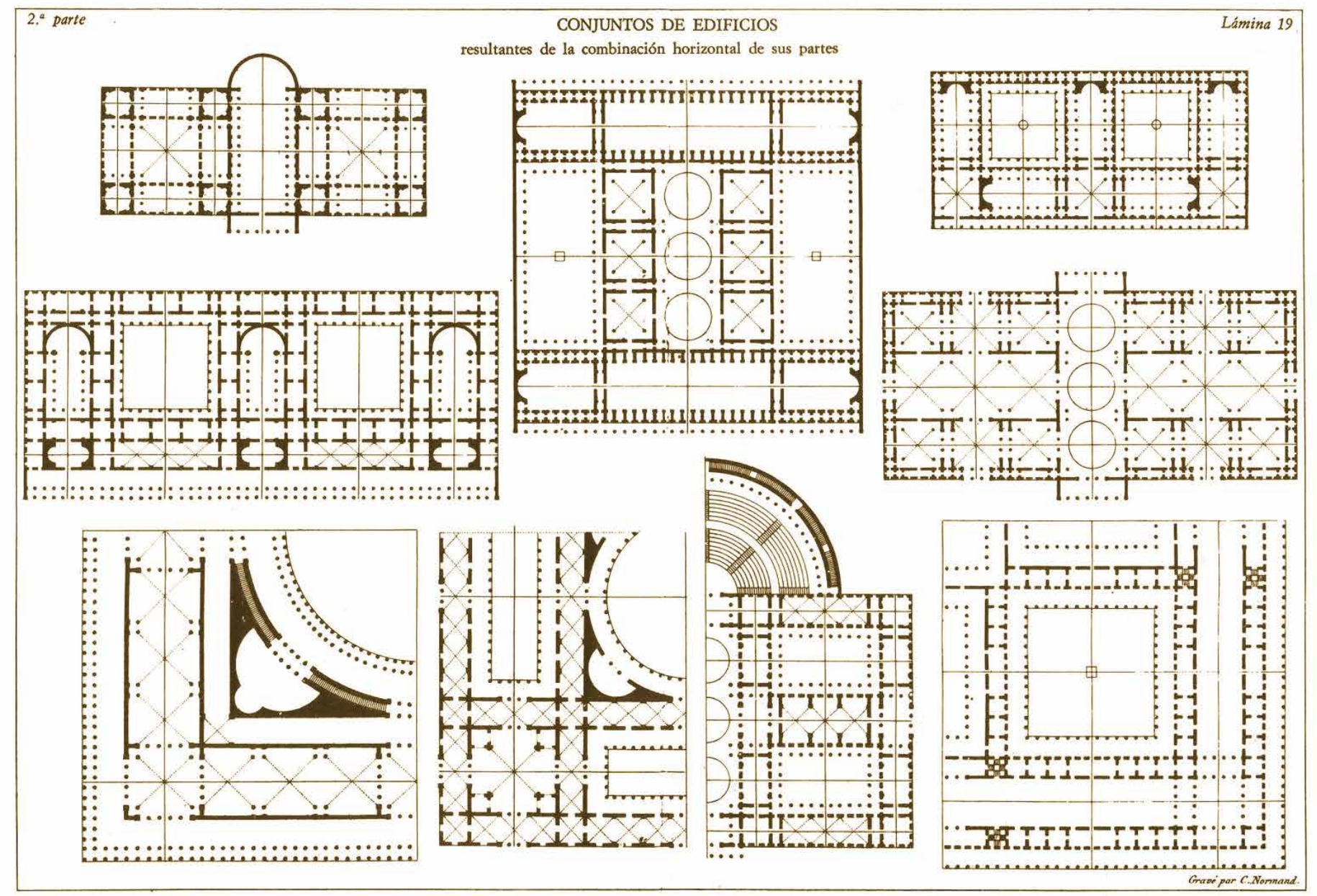


La composition de Durand no es otra cosa que un método proyectual, con una fuerte pretensión didáctica, en el que por primera vez en toda la tradición vitruviana la 'eficacia' de la función aparece por delante de cualquier otro problema arquitectónico. Según Rafael Moneo, "Durand alcanza así su pretensión: un tratado en el que el método, el proceso seguido por el arquitecto en el proyecto fuese lo definitivo, sin consideración alguna para con lo específico». ${ }^{18} \mathrm{Fi}-$ nalmente, la división de tipos de edificios en públicos y privados que establece dentro de la École polytechnique resulta general; el conocimiento particular de cada programa es rechazado por un conocimiento del método. Para Moneo esta neutralidad inicial se supera con el parti, la idea generadora a partir de la cual la composition se vincula con el programa requerido específicamente:

...el acierto del arquitecto radica en identificar el "parti" adecuado al programa sobre el que se trabaja y Durand da pistas de cómo en los "partis", en cuanto que estructuras capaces de asumir más tarde la condición de edificios, cabe establecer diferencias a pesar de su aparente neutralidad. ${ }^{19}$

La síntesis de Durand conlleva a una metodología racionalista que dejará a la función definitivamente atada a un sistema de composición basado en la geometría, la cual terminará más tarde afectando a los órdenes del sistema clásico y a la construcción. Durand logra de algún modo cerrar el círculo de necesidades de su tiempo, llevando al sistema clásico al límite de la racionalidad, pero sin abandonarlo. Muy diferente resultará la idea de composition acuñada posteriormente por la École de Beuaux Arts, donde la relación con la función y la metáfora de la máquina será dejada de lado por la monumentalidad y el formalismo.

En las primeras décadas del siglo XX, con una serie de aportes fundamentales en el marco del socialismo, se completará la construcción teórica de la 'eficacia' como noción estandarte de la arquitectura moderna. Uno de los autores fundamentales es Gínzburg, cuyo acercamiento al tema de la función resulta progresivo, y se centra en los primeros años de su producción teórica, a fines de la década del veinte. En sus primeros dos libros (El ritmo en la arquitectura, de 1923, y Estilo y época. El problema de la arquitectura moderna, de 1924) Gínzburg busca el germen de lo que denomina el "nuevo estilo», aplicando incisivos análisis con respecto a la arquitectura del pasado, y llegando así a sugerir las claves de la arquitectura moderna, de un modo casi científico. En estos textos el tema de la función no será aún profundizado. Será recién en 1926 cuando se acercará por primera vez a lo que denominará como el «método funcional», donde estudia el rol que la forma, los materiales y la estructura podrían tener en la función, en dos artículos publicados en ese mismo año: "Nuevos métodos en el pensamiento arquitectónico" y "Método funcional y forma". Su pensamiento será ampliado y reafirmado sobre todo en su texto "Éxitos de la arquitectura moderna", para consolidarse finalmente, al modo de una metodología, en "El constructivismo como método de trabajo de trabajo, de investigación y enseñanza," ambos publicados en 1927. En estos pocos años Gínzburg consigue como pocos autores detectar el modo en que la función puede ser abordada objetivamente en la arquitectura moderna, atendiendo

\section{Método definitivo}

\section{8.}

Moneo, Rafael "Prólogo" en Durand, Compendio de lecciones de arquitectura: parte gráfica de los cursos de arquitectura, p. XII.

19.

Moneo, Rafael “Prólogo" en ibid.

\section{0.}

En cuanto a la arquitectura, estas dos particularidades esenciales tendrían impacto en el desarrollo acelerado de la técnica, que ha modificado los sistemas constructivos, y el cambio social que afectó especialmente a la U.R.S.S., lo cual modifica los modos de vida habituales.

21. Gínzburg, Moisei, "Éxitos de la arquitectura moderna," en Escritos, 1923-1930, ed. Garrido, Ginés (Madrid: El Croquis, 2007), p. 291. (Ed. orig. 1927).

22.

"Método funcional y forma," en Escritos, 1923-1930, ed. Garrido, Ginés (Madrid: El Croquis, 2007), p. 271. (Ed. orig. 1926).

23. “Éxitos de la arquitectura moderna," p. 306.

\subsection{3.}

Gínzburg. Método funcional 
a los requerimientos de una sociedad en proceso de transformación hacia el socialismo.

2.1.3.a. Las características de gestación de la arquitectura moderna tendrían que ver, Premisas según Gínzburg, con las coyunturas políticas de cada región, con los modos de producción y los modos de vida propios. ${ }^{20}$ El socialismo tendría el rol de construir una nueva base, "Se trata de la reorganización de nuestra economía y de la materialización de un nuevo modo de vida». ${ }^{21}$ Pero aún así, para Gínzburg, en cualquier marco social y productivo, el arquitecto debe poder determinar las 'funciones generales', es decir, los programas sociales; dentro del socialismo de la U.R.S.S. estos serían la fábrica, la vivienda o los clubes. Claramente, los procesos productivos se asocian a las fábricas y los sociales a la vivienda o a los servicios comunitarios. Esto compone lo que Gínzburg denomina «método funcional», el cual buscará servir como base para un pensamiento sólido de la arquitectura moderna internacional, aunque su ejemplo se encuentre siempre en el ámbito del socialismo. Siguiendo la hipótesis de Marx, los cambios dialécticos en la historia no se dan, según él, de un día para otro; por eso es que muchos campesinos mantienen en la nueva U.R.S.S. un modo de vida similar al anterior. Con el «método funcional» Gínzburg pretende, en primer lugar, considerar siempre el ámbito nuevo; que las respuestas se basen en nuevos objetivos. "Así, un método funcional bien entendido exige al arquitecto moderno, en todos los casos sin excepción, unas materializaciones surgidas de las nuevas condiciones de vida". ${ }^{22}$ Repitiendo la apuesta que iniciara Guadet con su concepto de composition desarrollado en Eléments et théorie de l'architecture... Gínzburg afirma que si se aplica este método, la arquitectura resultante debería ser, sin dudas, 'arquitectura moderna', y que si no lo es, significa que el método no se ha seguido correctamente, y que se han aplicado elementos adicionales, no objetivos. En este marco, critica las viviendas para los trabajadores del Soviet de Moscú, en las que no se han tenido en cuenta los nuevos elementos sociales; se ha reducido la superficie de la vivienda y no se ha agregado en ella ninguna "función social», impidiendo a sus habitantes contribuir en nuevos modos de vinculación. Con esto el autor afirma que la arquitectura moderna es una plataforma para la modificación social, y que la arquitectura tiene que servir al nuevo usuario y permitir modos de socialización diferentes.

Para el autor es necesario considerar unas premisas que derivan del objetivo funcional de cada objeto; y asume que, aún habiéndolas planteado correctamente, puede que en la aplicación propia del método no se consideren algunas funciones, lo cual puede traer problemas en el resultado. Pero este proceso no tiene ya más que ver con la labor individual de un arquitecto, como se había hecho hasta el momento en la tradición; Gínzburg plantea un Ilamado global cuando, al referirse al «método funcional» exige que "Esta tarea no puede ser llevada a cabo por un solo arquitecto, ni siquiera por su colectivo, sino que deberá ser todo el activo de las organizaciones sociales soviéticas el encargado de resolverlas. ${ }^{23}$ Una vez estas premisas se hayan identificado con precisión, el resto del proceso del «método funcional» podría, según el autor, ser aplicado. 
Resulta evidente que para Gínzburg la 'arquitectura moderna' aún no se ha consolidado como estilo; está en vías de desarrollo, y por lo tanto es necesario plantear referencias claras en las cuales apoyarse. La más importante que utilizará el autor será la de la máquina, en clara consonancia con la función. A diferencia de la lectura poética e incluso formal que Le Corbusier planteara en Vers une architecture, Gínzburg centra su atención en el estricto funcionamiento de la máquina.

No hay parte ni elemento de la máquina que no tenga un lugar, una posición o un papel particulares en el esquema general, y que no sea fruto de la estricta necesidad. (...) Lo que encontramos en la máquina, esencial y primordialmente, es la más clara expresión del ideal de la creación armoniosa, que hace ya mucho tiempo fue formulado por el teórico italiano, Alberti. ${ }^{24}$

Así, la función y los modos para poder desarrollarla pasan a ocupar un lugar central en la arquitectura, quizás por primera vez en la historia. La diferencia estribaría en esas incógnitas necesarias para abordar lo esencial del problema:

A diferencia de la inspiración abstracta y extremadamente individualista del antiguo arquitecto, el moderno está firmemente convencido de que el problema arquitectónico se resuelve como cualquier otro: mediante el esclarecimiento preciso de las incógnitas y el hallazgo del método correcto de resolución. ${ }^{25}$

Casi en consonancia con Le Corbusier, también afirma que es el ingeniero y no el arquitecto quien muestra hasta el momento el camino al futuro, ya que para cada problema requiere de un cálculo, lo cual va mucho más allá de su capacidad creadora. Pero al mismo tiempo, en lo que quizás hoy pueda leerse como una referencia a la lectura de la máquina que hace Le Corbusier, afirma:

La etapa del ingenuo "simbolismo de la máquina" ya ha finalizado. La arquitectura moderna únicamente debe apropiarse del método creador del ingeniero. (...) ... la búsqueda del arquitecto, en su esencia, es una invención igual que cualquier otra, cuya finalidad es organizar y construir un objeto práctico concreto, dictado por el presente, pero útil también para el mañana. ${ }^{26}$

Para lograr esto último resulta necesario encontrar esas incógnitas, "las incógnitas de nuestro tiempo", que llevarían al arquitecto a actuar en consonancia con el ingeniero, es decir, con un método racional que se aleje de lo subjetivo, y para esto "...hay que descubrir las particularidades relacionadas con la aparición de un nuevo usuario social de la arquitectura: la clase trabajadora...". ${ }^{27}$ Esta labor acerca del usuario y sus particularidades $^{28}$ no será desarrollada con precisión por Gínzburg; un tema central que, en la misma linea, sí indagará Meyer en Alemania. Así, el 'nuevo arquitecto' no tendría que pensar en una serie de encargos particulares, sino imaginar "patrones» de organización urbana, afectando con esto a la misma sociedad. ${ }^{29}$

(...) ante el arquitecto se plantean también otras «incógnitas» que surgen de las particularidades de cada momento concreto de su trabajo, de las particulari- 2.1.3.b.

\section{Incógnitas}

24.

"Estilo y época," en Escritos, 1923-1930, ed. Garrido, Ginés (Madrid: El Croquis, 2007), p. 169.

25.

"Nuevos métodos en el pensamiento arquitectónico," en Escritos, 1923-1930, ed. Garrido, Ginés (Madrid: El Croquis, 2007), p. 245.

26.

Ibid. p. 247.

27.

Ibid.

28.

Gínzburg aclara también que no se trata de entender los gustos de la clase trabajadora, sino exclusivamente sus particularidades, que la elevan al rol de un nuevo usuario histórico.

29.

Afirma que el modelo de la ciudad jardín es el mejor para los poblados soviéticos, y que para aplicarlos resulta necesario luchar contra la mentalidad de políticos que siguen viendo la arquitectura de un modo tradicional.

30.

"Nuevos métodos en el pensamiento arquitectónico," en ibid. p. 250.

31.

Ibid.

32. Ibid. p. 251.

33.

Este tema había sido desarrollado por Gínzburg unos años antes en El ritmo en la arquitectura, y Estilo y época. El problema de la arquitectura moderna.

34.

"Nuevos métodos en el pensamiento arquitectónico," p. 251. 
La resolución de estas «incógnitas» conduce a un método absolutamente nuevo de pensamiento arquitectónico: un método de creación funcional. ${ }^{30}$

Gínzburg describe este método como un análisis de todas las circunstancias funcionales que un proyecto requiere; se dividen en partes según sus funciones, y la solución se organiza según este estudio. La solución espacial sería, al modo de una máquina, organizada como un sistema; cada parte tiene un objetivo particular; un "organismo inteligente» articulado mediante "órganos separados». Esto último lleva naturalmente a la asimetría, a la planta libre y abierta, a la iluminación y ventilación. Gínzburg remata diciendo que "Este método de creación funcional permite no sólo un cálculo preciso de las «incógnitas» del problema sino también de los elementos de su resolución». ${ }^{31}$ Así, tres nuevos conceptos aparecen en torno a las herramientas para la resolución de la 'eficacia' en la función: la «incógnita», el "método» y el "cálculo». El edificio, entendido como un puro producto de la función, sería resuelto casi a modo de una ecuación.

Para el desarrollo del "método funcional» el arquitecto debe ordenar los requerimientos desde lo principal a lo secundario, en cuatro etapas diferenciadas. Habría un primer paso que tendría que ver con «...el establecimiento de la cantidad de las diversas magnitudes espaciales, de sus dimensiones y su conexión mutua.» ${ }^{32}$ El segundo paso sería el de ordenar el espacio interior, con materiales y sistemas constructivos que debe considerar la primera función general. Luego, la tercera etapa sería la de ordenar los volúmenes exteriores, según masas y ritmos. ${ }^{33}$ Cuarto y último, el modo de materializar las superficies de los muros, aberturas, apoyos.

(...) el método de creación funcional conduce a un único proceso creativo, orgánico, donde cada tarea deriva de otra con toda la lógica del desarrollo natural. No hay un solo elemento ni una sola idea del proyecto del arquitecto que sea aleatorio. Todo encuentra para sí una explicación y una justificación funcional dentro de su carácter racional. ${ }^{34}$

La claridad casi matemática con la que Gínzburg expone su propuesta resulta sorprendente al mismo tiempo que novedosa. La función no sólo ocupa el lugar central en la concepción de su arquitectura, sino que la misma puede ser desarrollada a través de un preciso método de trabajo, el cual requeriría también de una serie de herramientas gráficas, las cuales permitirían 'consolidar' el método como forma arquitectónica.

2.1.3.c. Otra de las caras importantes de la apuesta de Gínzburg tiene que ver con la observación interesada del proceso productivo de una empresa. El autor afirma que la fabricación es un proceso dinámico y al mismo tiempo lineal, con diferentes etapas que se dividen con exactitud. Este proceso puede sintetizarse en lo que Gínzburg denomina el "gráfico de movimientos»; se trata de un gráfico dinámico que lo que busca es consolidar un "sistema estático», es decir, un movimiento que, traspasado a un esquema final, daría como resultado una forma concreta. Así, en la fábrica, el "gráfico de movimientos» sigue la linea de la cadena de montaje, pero al mismo tiempo es requerido un "esquema de equi- 
para realizar el proceso, y la distribución del mismo dependería, por supuesto del mencionado "gráfico de movimientos". De esta manera Gínzburg consolida por primera vez la importancia de una herramienta arquitectónica derivada de un método, al confinar la organización espacial a un cálculo científico.

Un desarrollo minucioso del gráfico de movimientos y del esquema de equipamientos, ciertamente aporta carácter científico al proceso productivo. A mayor precisión en los diagramas, mayor acierto en el objetivo. En realidad, el proceso productivo ya está resuelto con los diagramas. ${ }^{35}$

En estos diagramas reside para Gínzburg el espíritu invisible de la función, que es la que da sustento a la arquitectura moderna. Los diagramas son el traspaso objetivo, desde el pensamiento al espacio, de una solución funcional óptima. "...mediante el gráfico se perfila una primera aproximación espacial del objetivo arquitectónico». ${ }^{36}$ Por lo mismo, el gráfico no se corresponde sólo a un diagrama de información, sino que se trata de un diagrama espacial que incluye el germen de la organización del proyecto.

Lo que sigue es 'cubrir' este proceso con un envoltorio arquitectónico acorde. En este paso Gínzburg refiere a una solución espacial, que se adecua exactamente a la función, textualmente, "al modo de un guante", con una definición que, paradójicamente, también utilizará Häring, con resultados claramente opuestos. Esto tiene que ver conque Gínzburg confía al mismo tiempo en una arquitectura producto de la industrialización, y evita la formalización literal del "gráfico de movimientos".

También el proceso productivo central, el de la fabricación, debe incluir otro tipo de proceso secundario, vinculado a las actividades propias de Ios obreros: Ios movimientos, aseos, vestidores, o comedores, lo cual requiere de un gráfico secundario. Así concluye que no se trata sólo de un gráfico productivo, sino también humano, y que la atención debe ser la misma. "Los gráficos complementarios de los procesos cotidianos deben trazarse con la mayor precisión y claridad posibles...»37 Presenta ejemplos de procesos productivos, gráficos de movimientos y edificios para una hilandería, una fábrica de ácido sulfúrico y una central termoeléctrica, [FG.03][FG.04][FG.05] exigiendo al mismo tiempo radicalidad y precisión en la elaboración de esta información:

Podemos afirmar sin temor a equivocarnos que cuanto más radicales y claros sean los gráficos de movimiento y los esquemas de equipamiento, más firme, precisa y brillante será la solución arquitectónica. Un proceso productivo y humano radicalmente nuevo, lógicamente, tendrá como resultado una forma arquitectónica radicalmente nueva. ${ }^{38}$

Si la concepción de este método nace de los procesos de producción, Gínzburg se propone demostrarlo también en la arquitectura. Así, todos los programas, ya sean viviendas, cines, clubes, deberían ser "analizados, fragmentados y materializados" con el mismo método, y con la misma exactitud que un proceso productivo.

Consiste en analizar el objetivo no como un conjunto determinado de espacios con unas superficies específicas, sino como un proceso dinámico que incor-
"El constructivismo como método de trabajo, de investigación y enseñanza," en Escritos, 1923-1930, ed. Garrido, Ginés (Madrid: El Croquis, 2007), p. 340

37. "Éxitos de la arquitectura moderna," 295

38. Ibid p. 297.

39. "El constructivismo como método de trabajo, de investigación y enseñanza," p. 340.

40.

Ver "Éxitos de la arquitectura moderna."

41.

Si bien Gínzburg propone este método, el mis mo será mejor desarrollado por Hannes Meyer en la Bauhaus, haciendo especial énfasis en las relaciones sociales.

42.

En palabras de Ford, «En cualquier hospital las enfermeras se ven obligadas a realizar demasiados movimientos. Pierden más tiempo en sus traslados que en la atención a los enfermos. Este hospital se ha adaptado para ahorrar desplazamientos. Cada habitación es como una unidad completa. Aquí hemos actuado de la misma forma que en nuestra fábrica, tratando de eliminar los movimientos innecesarios". Henry Ford, Mi vida, mis logros, citado en Escritos, 1923-1930, ed. Garrido, Ginés (Madrid: El Croquis, 2007), p. 298. 
realizados y experimentados por el hombre (en las fábricas también por las máquinas), en diferentes momentos del día o la noche y en diferentes períodos productivos, humanos o de cualquier otra clase. ${ }^{39}$

Lo que Gínzburg entiende por una 'correcta resolución funcional' quizás deba encontrarse en la apreciación que él mismo hace de la organización que Henry Ford desarrolla en sus industrias norteamericanas. Gínzburg cita en el mismo artículo a Ford, quien explica que la distribución de las máquinas y el aprovechamiento del espacio responde a un cálculo científico, el cual permite ahorrar tiempo y economizar el máximo espacio dentro de la fábrica. ${ }^{40}$ Así, la lectura del modo de vida del usuario en Gínzburg nace del pragmatismo fordista de entender al usuario como una pieza más de una 'maquinaria social', que se caracteriza, al menos en una primera fase, por el aprovechamiento del espacio y el tiempo. Para él -y en esto yace uno de los puntos claves de la 'eficacia'- las actividades de las personas deben ser economizadas como si se tratara de una fase del proceso productivo. Esa es la lógica que respalda su propuesta. Se debe aprovechar el espacio necesario y reducir el recorrido al máximo posible, lo cual resulta en un planteamiento que dista mucho de la ‘adaptación' de Häring o la ‘flexibilidad' de Mies, en la cual el espacio necesariamente fluye para que esa concepción funcional se pueda poner en práctica.

En el "gráfico de movimientos» Gínzburg supera además la idea de programa arquitectónico establecida sobre todo por la tradición francesa -en especial por Viollet Le-Duc y Guadet- en la cual la premisa se basaba en unas dimensiones genéricas necesarias para cada actividad. El autor se propone estudiar las actividades en sí mismas, en su complejidad, incluyendo sus movimientos, velocidades y características, por fuera de un marco espacial. ${ }^{41}$ Gínzburg reclama que hasta el momento las soluciones funcionales en la arquitectura han sido espontáneas y no se han revisado con detenimiento. Inspirado en Ford y en la explicación que el mismo da sobre el hospital que realizó en Estados Unidos, Gínzburg persigue el análisis exacto de las funciones. ${ }^{42}$

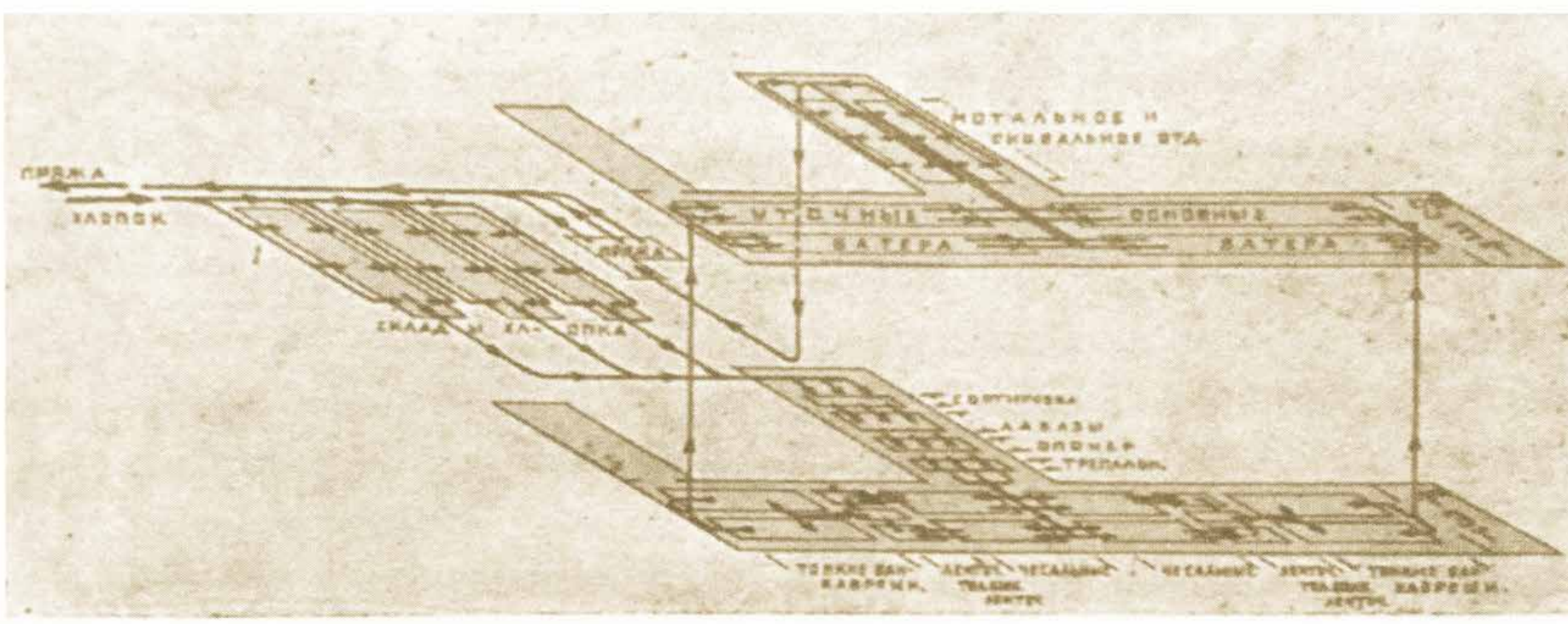




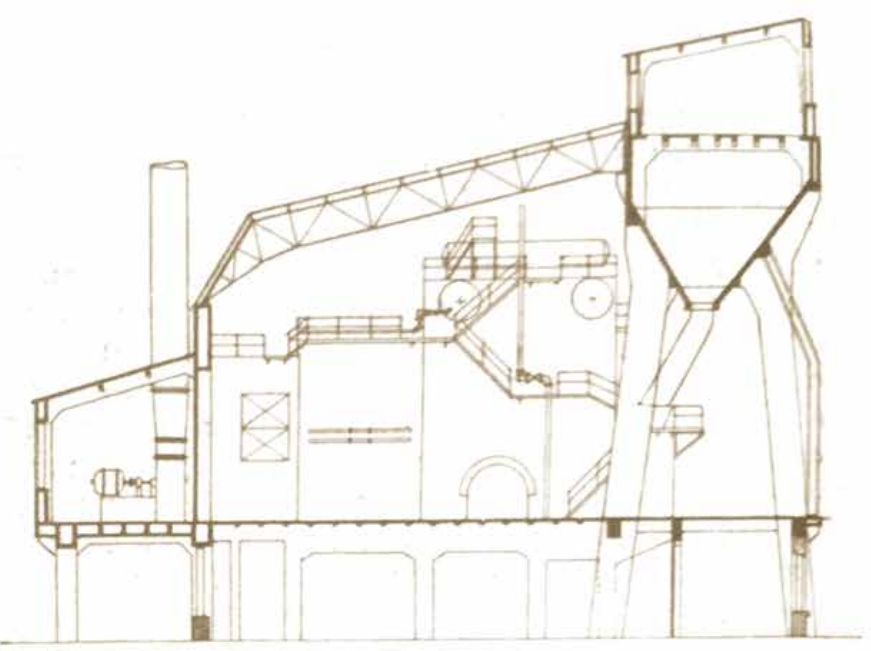

[FG.05]

Moisei Gínzburg

Central termoeléctrica

Moscú: "Éxitos de la arquitectura moderna,"

SA $n^{\circ} 4-5$,

1927

[FG.04]

Moisei Gínzburg

Proceso productivo de una fábrica de acido sulfúrico

Moscú: "Éxitos de la arquitectura moderna,"

SA $n^{\circ}$ 4-5,

1927
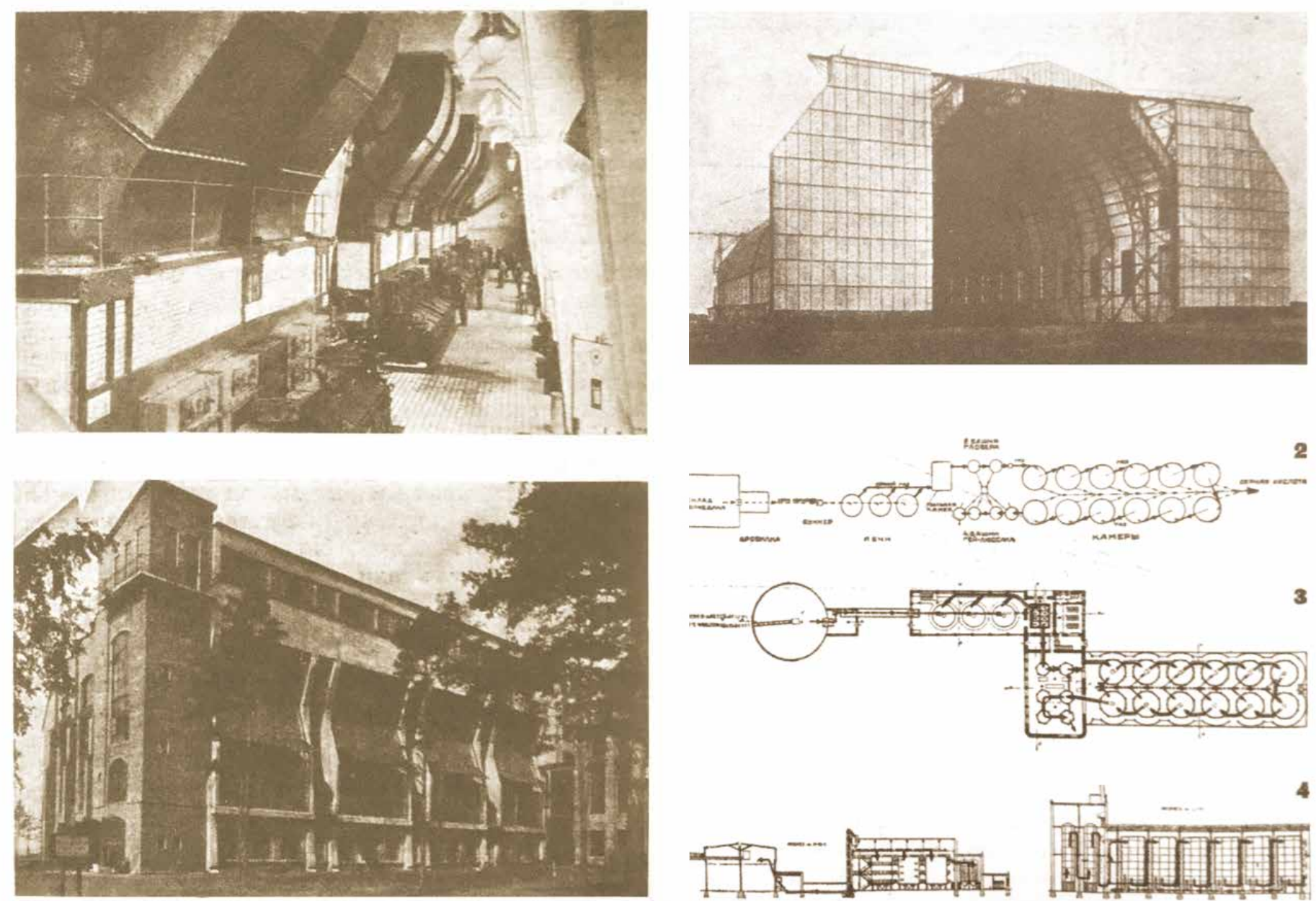
...si queremos crear nuestro nuevo club tendremos que hacer un análisis detallado del objetivo general y considerar todos los movimientos que se vayan a realizar, así como el gasto de energía psíquica humana. También será necesario dividir las numerosas funciones del conjunto, descifrarlas con exactitud y establecer entre ellas una interdependencia. ${ }^{43}$

Para cada programa existiría entonces un "gráfico de movimientos" específico. Así, desarrolla el gráfico para un cine, [FG.06] concluyendo que apenas se diferencia de un proceso industrial, ya que la dirección es sólo una, es lineal, y debe salvarse en el menor tiempo posible. A su vez estudia el «esquema de equipamiento" y enumera actividades específicas del programa, desde la caja de atención, los colgadores hasta los asientos. Estos dos diagramas superpuestos determinarían su forma arquitectónica.

Finalmente Gínzburg enfoca el método funcional a la vivienda. En este caso el "gráfico de movimientos" se concentra en los recorridos internos de una habitación a otra -lo ejemplifica con un esquema de Bruno Taut y con la planta de la residencia en Avery Coonley de Frank Lloyd Wright- y asume que «estos movimientos deben analizarse de igual modo que los de una cadena de montaje. El principio del ahorro sigue aplicándose igual que en una fábrica, pues no es lógico malgastar energías en movimientos y trayectos excesivos. ${ }^{44}$ Aún así, al mismo tiempo reconoce que los movimientos internos en una vivienda nunca tendrán la precisión que los que se producen en una fábrica. El «esquema de equipamiento» correspondería, lógicamente, al mobiliario de la vivienda, buscando nuevamente "el ahorro de la fuerza viva humana". El restaurante en un vagón de tren le sirve como ejemplo radical de esta solución, con notables diferencias de superficie y distribución con respecto a la casa de Wright, pero al mismo tiempo le permite afirmar que no existe una limitación o una excusa para poder aplicar el método, ya sea en un espacio mínimo o en una casa burguesa.

2.1.3.d. Para Gínzburg la arquitectura es un fenómeno derivado de su propio tiempo, Condensador social y entiende que los hechos acaecidos en la revolución rusa son los que sirven para engendrar una nueva arquitectura. Según él, cuando un fenómeno de tal magnitud ocurre, el arquitecto debería prepararse para concebir los «condensadores sociales» de su época. Este "condensador social»-que tendría ciertas vinculaciones a las propuestas del socialismo utópico de Fourier- resulta en una propuesta hasta tal punto abstracta y novedosa que casi podría suplantar al término 'arquitectura', ya que se entiende como una estructura espacial basada estrictamente en la interpretación de un marco social en un momento de cambios profundos. Sería básicamente un espacio identificado directamente a un nuevo modo de vida; pero, en efecto, este modo de vida no es fruto de una lectura de los hábitos -como hasta el momento se había considerado en la tradición de las teorías de la función- sino que es el propio arquitecto quien debe asumir la responsabilidad de proponerlo. Gínzburg reafirma que el «método funcional» es fruto de la revolución social y del avance de la técnica y por esto describe una etapa cambiante, no sólo a nivel técni- 

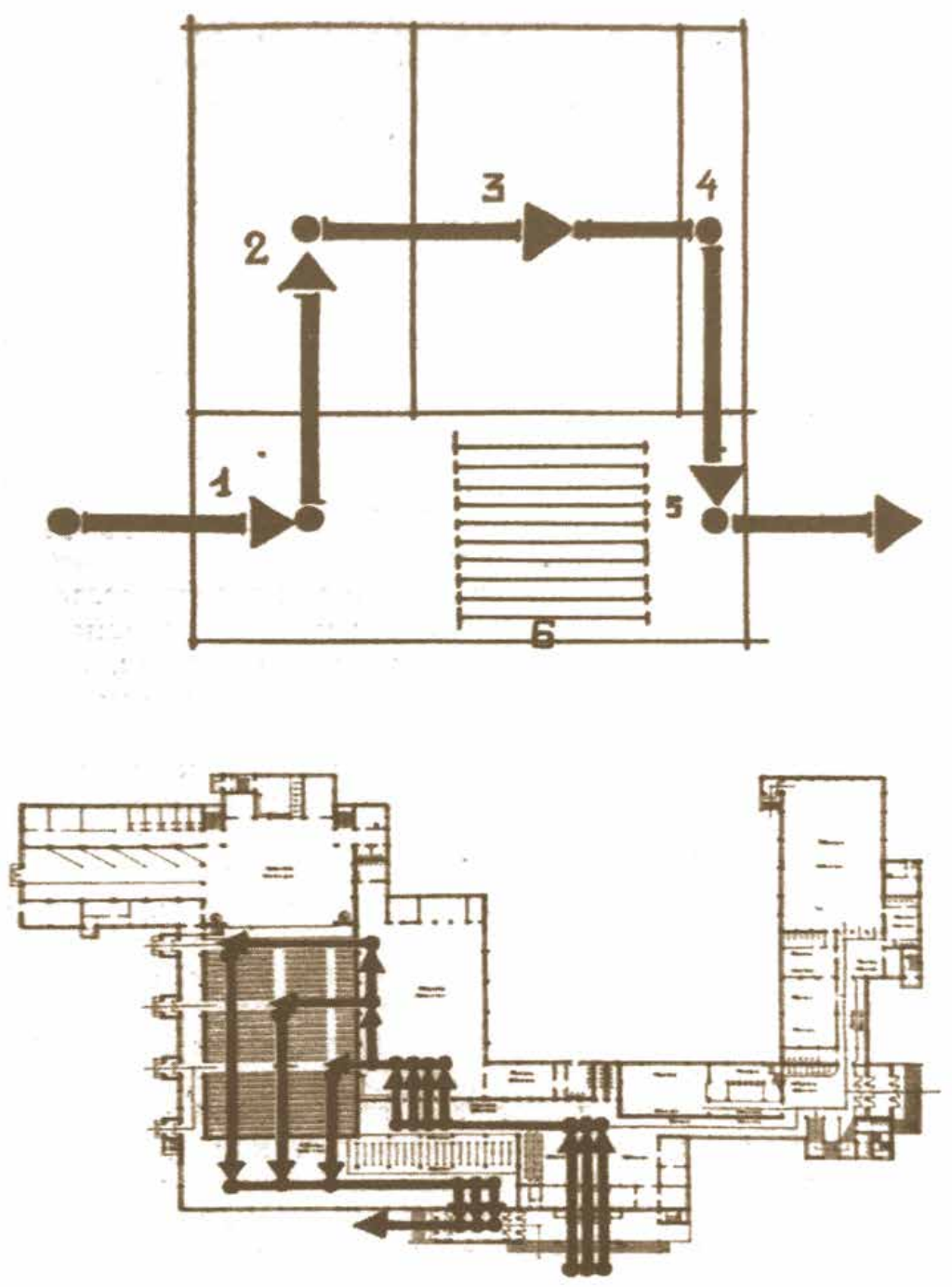

cambios, «la misión de construir la realidad y la organización de las formas de la nueva vida». ${ }^{45}$

Coherente con su empleo de un método, el autor expone que para materializar estos "condensadores sociales" se necesita analizar los objetivos más importantes, los cuales estarían separados en dos grandes temas: por un lado las "Premisas sociales, humanas y productivas» (que incluirían "procesos humanos, laborales; gráficos de movimiento; necesidades de equipamiento; dimensiones de equipamiento; condiciones de higiene y esquema de condensador social») y por otro lado las "Premisas técnicas y constructivas» (que abarcan «materiales; sistemas constructivos y métodos de ejecución»). En esta separación de temas el "método funcional» queda plasmado en su totalidad, al menos en términos teóricos, y probablemente sea su proyecto de 1928 para el Narcomfin de Moscú el que mejor lo exprese en términos prácticos. [FG.07] En este conjunto de viviendas Gínzburg introduce, a través de una compleja sección, espacios colectivos de jerarquía, atravesando las células de vivienda que constaban de tres tipos, los cuales incluían familias tradicionales, parejas o solteros. En un principio el proyecto contaría con una cantidad importante de servicios colectivos que lo harían casi autosuficiente, aunque sólo llegaron a ejecutarse la biblioteca, el jardín en la azotea y el solárium como áreas de ocio; además de la cocina y el comedor comunitario. El proyecto resulta completamente renovador en términos conceptuales y se presenta casi como una semilla de la que

Moscú: "Éxitos de la arquitectura moderna," SA $\mathrm{n}^{\circ}$ 4-5, 1927

45. "El constructivismo como método de trabajo, de investigación y enseñanza," p. 337. 46. "Método funcional y forma," en Escritos, 1923-1930, ed. Garrido, Ginés (Madrid: El Croquis, 2007), p. 274. 


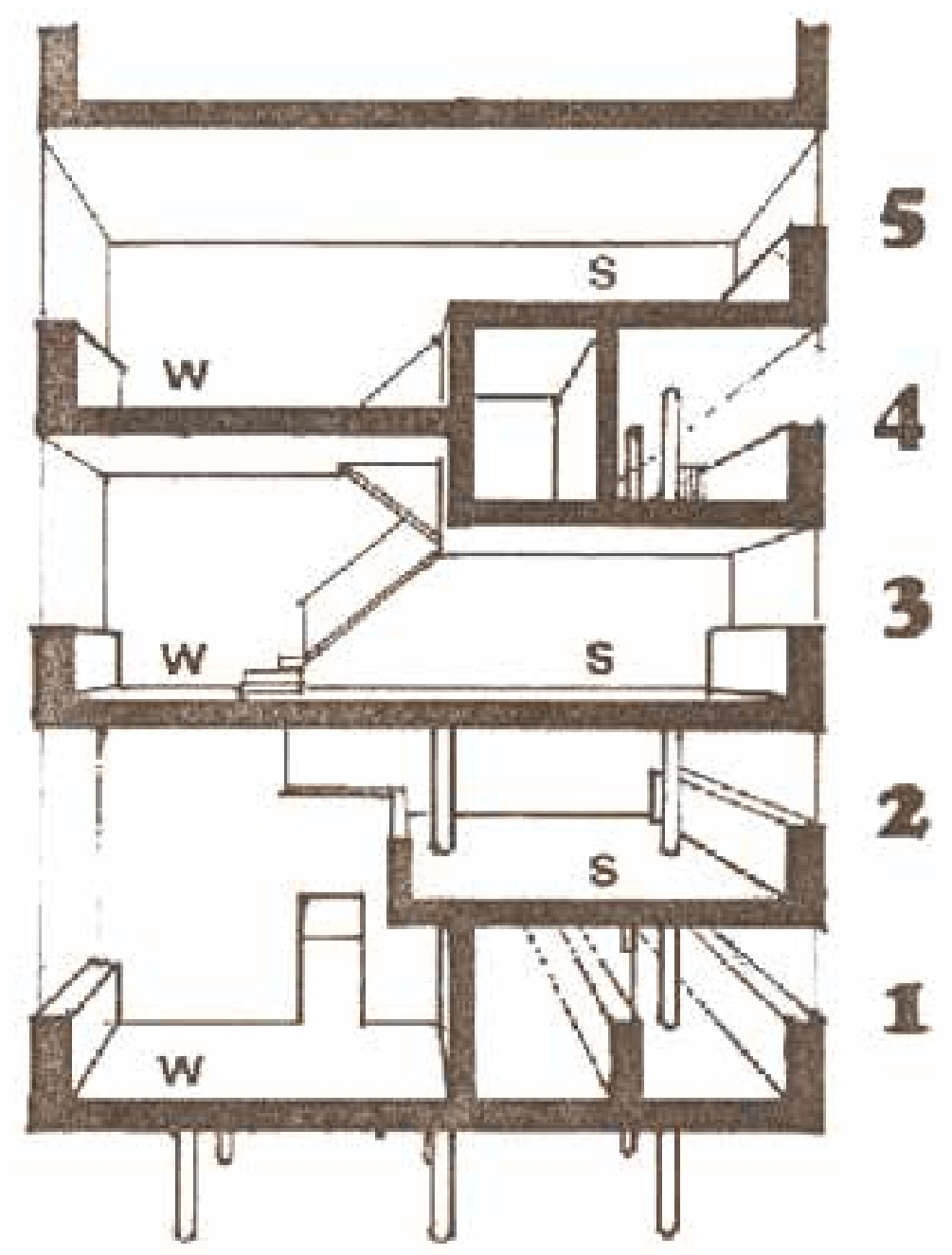

ensayara posteriormente Le Corbusier en sus unité d'habitation.

2.1.3.e. En una diferencia notable con la propuesta de Meyer, Gínzburg niega rotundamente que la máquina pueda reemplazar al arte. Al mismo tiempo se preocupa por la función de la forma, o mejor dicho, por cómo la misma se expresa para que el usuario pueda percibir y comprender la función del objeto. En este sentido Gínzburg supone una continuación de la propuesta de Lodoli (expuesta por Memmo) en la cual el germen de lo representado debe radicar ya en la función misma del objeto. Las palabras de Gínzburg resultan cercanas a las de Memmo, cuando dice que "La forma no sólo debe obedecer a su objetivo principal, sino que además debe hacerlo con la mayor claridad posible, para que nuestro aparato psicofísico la persiga con la mínima pérdida posible de energía perceptiva». ${ }^{46}$ Menciona cómo los colores impactan en nuestra percepción de la higiene de los espacios; que determinados colores favorecen a determinadas funciones; menciona también, como ejemplo, el orden de las ventanas, y si existe cierto desarreglo con respecto al ritmo que nuestra mente pueda percibir como una falla en la función. Es claro que para Gínzburg resulta fundamental entender la expresión de la arquitectura con respecto a la función; y en este caso no se trata de una apuesta puramente objetiva, como es el "método funcional», sino que la forma resulta fundamental para atar la función a nuestro entendimiento. La función sola no alcanzaría, de modo similar a como Ruskin y 
la forma es la que contiene esta 'función'. "...se puede afirmar categóricamente que el método de pensamiento funcional no destruye en ningún caso la importantísima tarea de la formalización arquitectónica, sino que únicamente fija sus leyes. $)^{47}$

Pero si Gínzburg exige eliminar la «interpretación», que antiguamente separaba la forma de la estructura, estas deberían ir ahora juntas, y hacerse una sola en la construcción. Este enfoque funcional exige un pensamiento íntegro y orgánico, que vaya por fuera de lo fragmentario. Así, afirma que los elementos modernos, como la cubierta plana y la ventana estandarizada, son tanto técnicos como formales; de hecho, Gínzburg no le teme a la forma y, de modo similar a la idea de representación de la función que se inició con las teorías de Blondel, confía en el poder de la misma para generar un efecto en el usuario y potenciar lo que de funcional hay en la arquitectura. Un elemento formal puede de este modo ser 'bueno', si considera estas metas.

Por otro lado está también la atención al movimiento que se da en el funcionamiento mismo de la máquina. Pero no en referencia al movimiento de los ocupantes de un edificio, sino al movimiento que el propio edificio contiene en su composición, en su forma; los vectores de fuerza que el propio diseño contiene. Se trata de direcciones, que tienen una relación formal con la máquina. Menciona que los artefactos modernos como el avión o el automóvil utilizan una paleta de materiales sólo producto de su función. Y es una paleta amplia. «... el método de pensamiento funcional correctamente entendido nos lleva a trasladar también el examen de modo especialmente atento a los materiales utilizados y a la elaboración técnica de los elementos de arquitectura...»48 Pero para Gínzburg, el estudio de los materiales no debe conducir a una forma dada, sino que la forma se comporta como una «incógnita x»; es el resultado del proceso.

La materialización de una función determinada, en su posterior desarrollo, plantea inmediatamente al arquitecto una serie de problemas relacionados puramente con su destreza arquitectónica, como son el cálculo de todas esas particularidades y posibilidades del material empleado y de las posibilidades del efecto psíquico y óptico. Dicho de otro modo, el material debe satisfacer no sólo a su objetivo directo, sino también a otras circunstancias complementarias, descubriendo funcionalmente todas sus posibilidades naturales de color, aspecto, fabricación, etc..$^{49}$

Este "problema de la percepción» vinculado a la función, tendría que ver sobre todo con los materiales y modos de construcción con los cuales se materializaría el "condensador social».50 Menciona el estímulo sensitivo (visual, auditivo o táctil) ${ }^{51}$ que permite el conocimiento del objeto y que tiene una relación constante con la "necesidad, la utilidad y el deseo», y que al mismo tiempo reclama su carácter social antes que biológico.

La definición de los fenómenos psico-fisiológicos entra dentro del difícil campo de la higiene de la percepción humana. Ambos son aspectos inseparables del método funcional que junto con un objetivo práctico claramente
50.

Menciona a Kant en Crítica del juicio, como ejemplo de un pensamiento que escindía la percepción estética de la finalidad del objeto, con su concepto de 'desinterés'. Ver "El constructivismo como método de trabajo, de investigación y enseñanza."

51.

Tres temas que también desarrollará de modo práctico Meyer, con sus alumnos en la Bauhaus.

52.

"Éxitos de la arquitectura moderna," p. 307. 
A. हारि口:
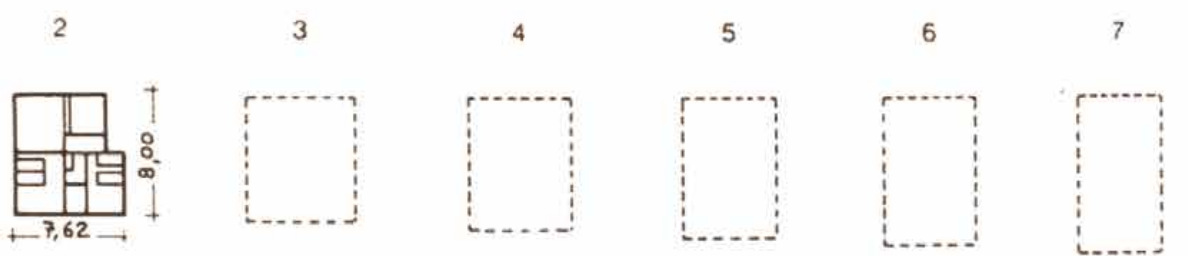

$45,60 \mathrm{~m}^{2}$

B.
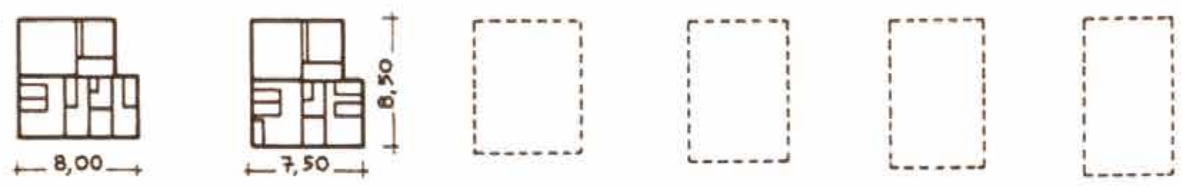

$48,70 \mathrm{~m}^{2}$
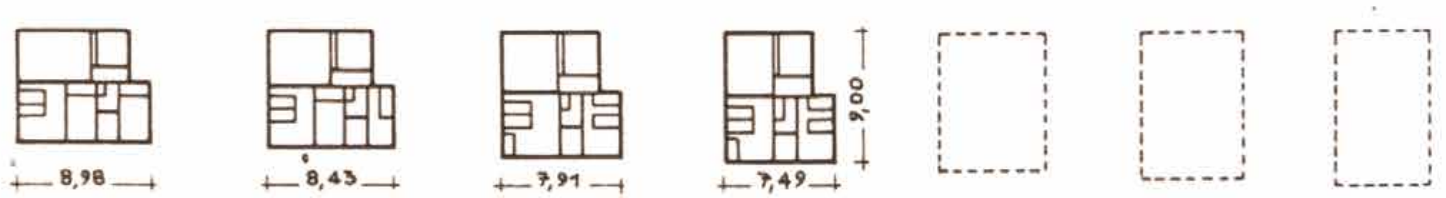

$51,80 \mathrm{~m}^{2}$

․
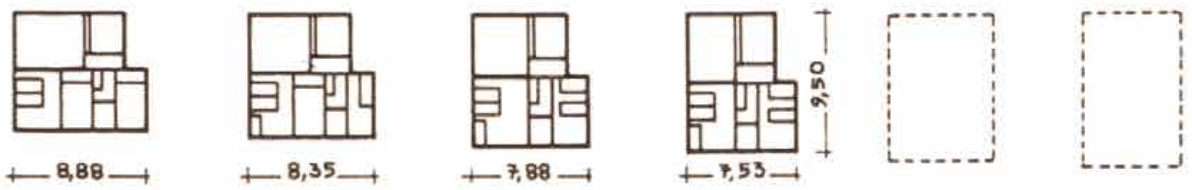

$54,90 \mathrm{~m}^{2}$

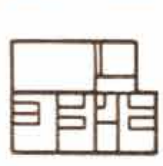

$+8,88 \longrightarrow$

$+8,35 \longrightarrow$
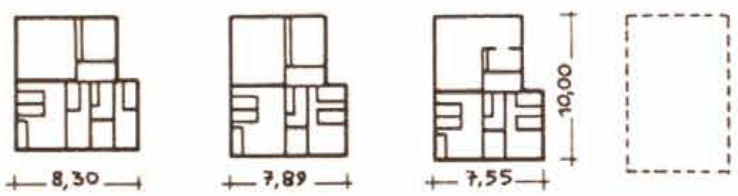

$58,00 \mathrm{~m}^{2}$
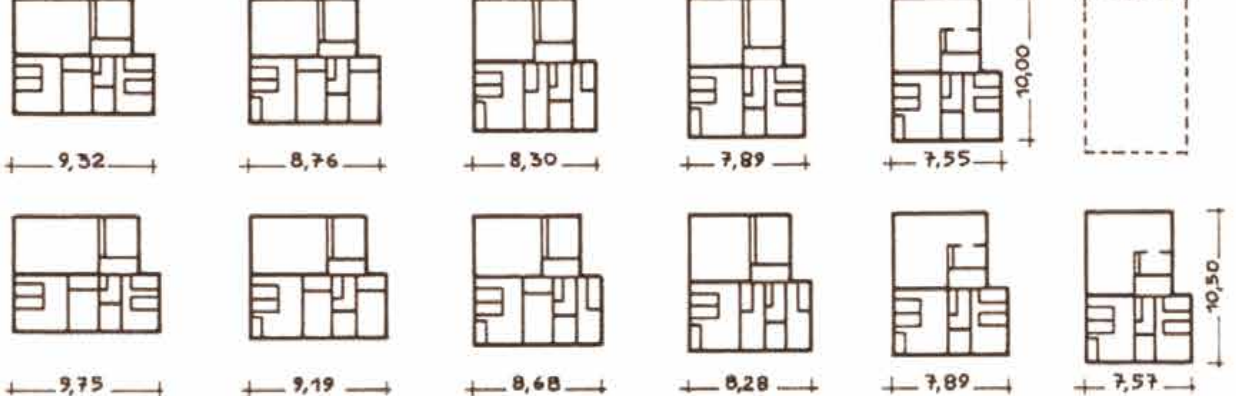

$61,10 \mathrm{~m}^{2}$

$+8,28 \longrightarrow$

$+7,89-$

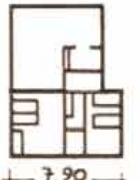

$64,20 \mathrm{~m}^{2}$
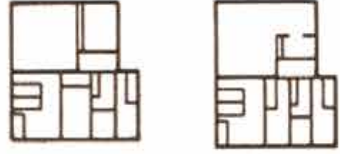

$+10,21 \square$

$+9,59 \longrightarrow$

$+9,07 \longrightarrow$

$+8,65 \longrightarrow$

$+8,26$
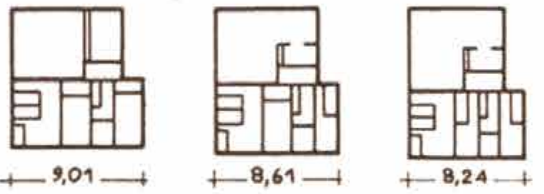

$67,30 \mathrm{~m}^{2}$
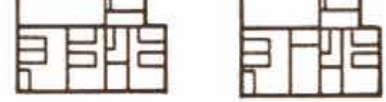

$+9,01 \longrightarrow$
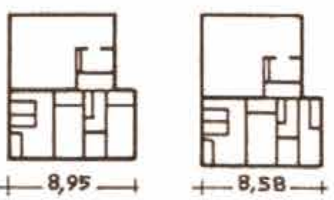

$70,40 \mathrm{~m}^{2}$

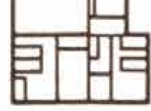

$+9,38 \longrightarrow$

$+8,95 \longrightarrow$
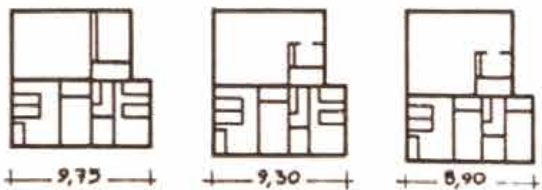

$73,50 \mathrm{~m}^{2}$ 

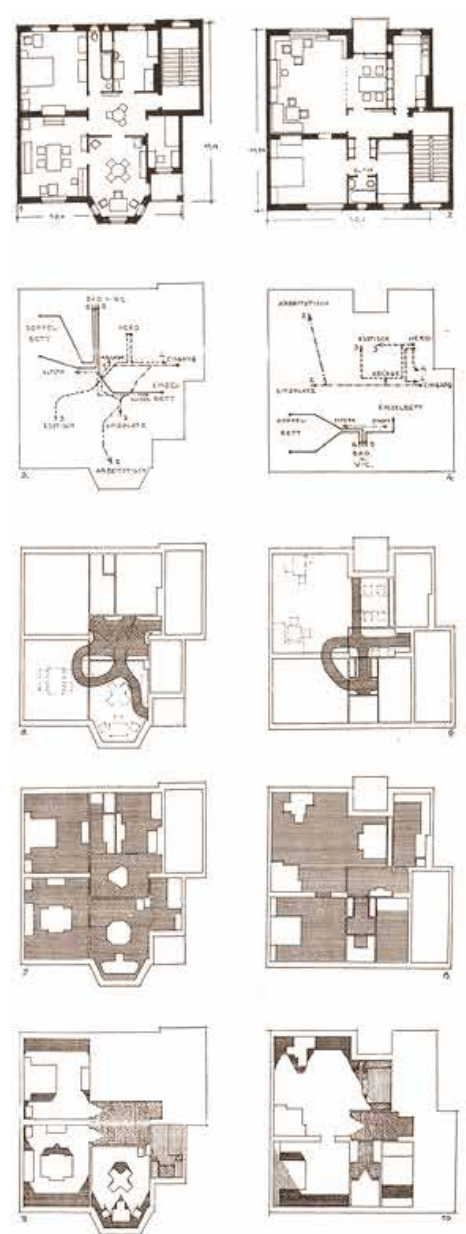

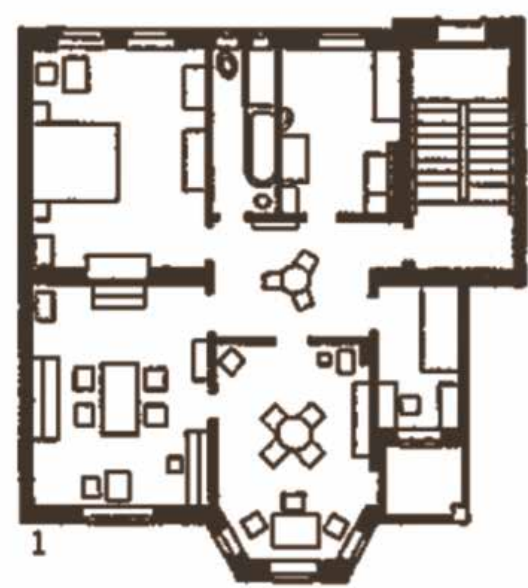

A. Bad Example

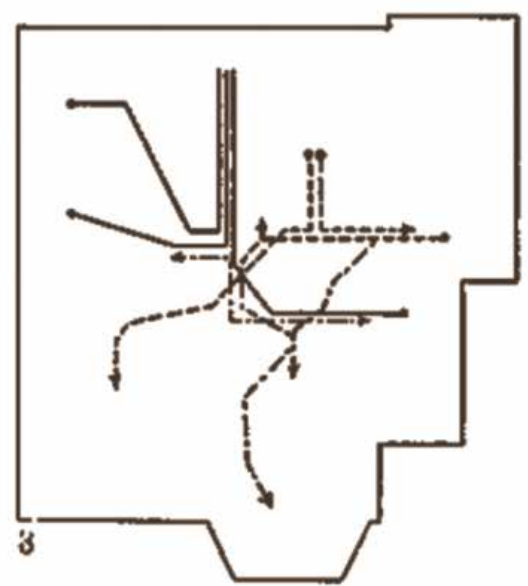

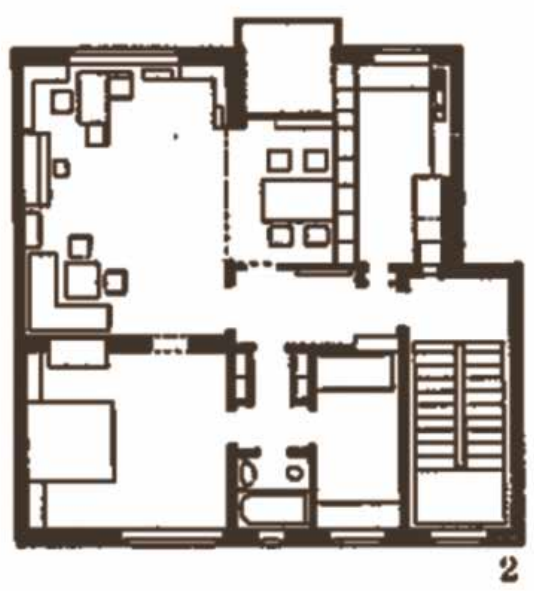

B.' Good Example

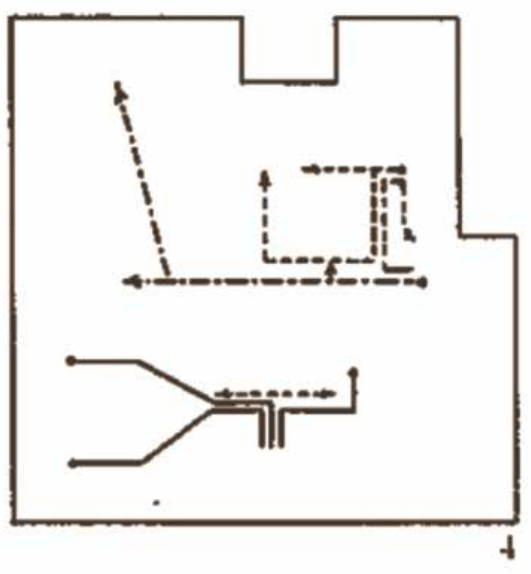

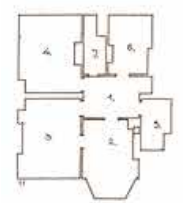
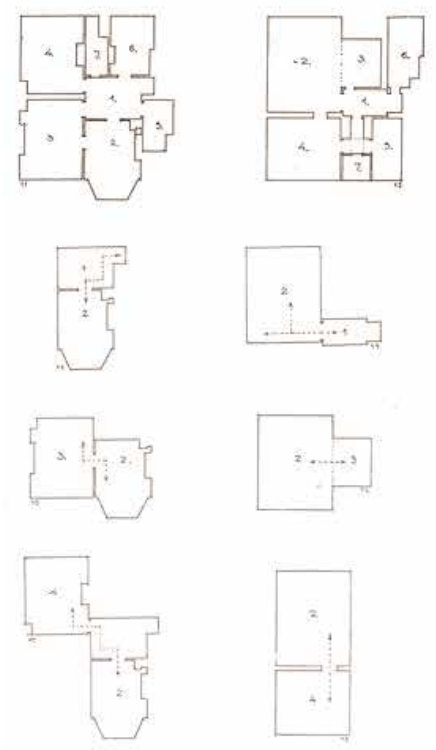

[FG.09]

Alexander Klein

Reichsforschungsgesellschaft

für Wirtshaftlichkeit im Bau-und

Wohnungswesen

Berlin: Die Baugilde 9,

1927.

[FG.10]

Alexander Klein

Reichsforschungsgesellschaft

für Wirtshaftlichkeit im Bau-und

Wohnungswesen

Berlin: Die Baugilde 9,

1927. 
En palabras de Gínzburg, "... es difícil imaginar que un hombre moderno perciba la forma de un automóvil sin tener en cuenta sus funciones como máquina para moverse" "E constructivismo como método de trabajo, de investigación y enseñanza," p. 343.

\section{4}

Ibid.

55

El concepto de Existenzminimum tiene que ver con los debates del CIAM de 1929, que incluyeron el desarrollo de viviendas sociales para Frankfurt, que buscaba establecer un mínimo espacio habitable. Al año siguiente se publicaría en Die Wohnung für das Existenzminimum,

2.1.3.f.

Klein. Auswertungsmethoden

con textos introductorios de Siegfried Giedion y Ernst May. Raumgestaltung von Kleinwohnungen und neue Auswertungsmethoden," Zentralblat der Bauverwaltung 48, 34, (1928).

57.

Ver Bevilacqua, Marco Giorgio, "Alexander Klein and the Existenzminimum: A 'Scientific' Approach to Design Techniques," Nexus Network Journal 13, 2, (2011).

Bernardo Ynzenga ya ha mencionado la diferencia entre la propuesta idealista del discurso de Meyer y obras de orden tradicional es especialmente evidente al comienzo de su carrera. Ver Ynzenga, Bernardo, "Hannes Meyer: hacia, en y después de la Bauhaus," Cuadernos de Proyectos Arquitectónicos, 7

(2017).

Interrelaciones sociales sividad estética del pasado. ${ }^{53}$ Con esta base afirma que «... la percepción es, por tanto, un acto orientado a un objetivo que consiste en dominar con la mayor precisión posible la conciencia del objeto y su significado social, y en aumentar el grado de efecto social de dicho objeto". ${ }^{54} \mathrm{Y}$ de este modo, en un movimiento de síntesis, vincula la arquitectura, entendida como una 'nueva plataforma,' -el "condensador social» derivado de la reforma política de la U.R.S.S.- la 'forma' -recuperada del peso de la tradición, y renovada- y la 'función' -que por primera vez en la historia se coloca como el problema central del proyecto de arquitectura.

Con un enfoque mucho más práctico, pero en una linea similar a la de Gínzburg, en la Alemania de la primera posguerra Alexander Klein -quien también se había formado como arquitecto en Rusia, pero que decidió trasladarse a Alemania en 1920- indagó en la optimización de las distribuciones de planta para la vivienda de trabajadores -lo que Ernst May llamó Existenzminimum ${ }^{55}$ - y que tenía el objetivo principal de reducir la escasez de vivienda en la Alemania del período de entreguerras. Para esto Klein estudió en la vivienda mínima (Kleinwohnungen), un mapa de posibilidades para una misma célula, evitando la fricción indeseada entre situaciones 'íntimas' y 'sociales', aprovechando el máximo de superficie libre, y considerando en lo posible la luz solar, con el objetivo final de reducir a la menor cantidad los prototipos óptimos. Para esto Klein elaboró un 'método gráfico' (Auswertungsmethoden), ${ }^{56}$ una serie de estudios entre una célula que consideraba inapropiada, y una que él mismo proponía; a raíz de esto, elaboró un cuadro de doble entrada con el que poder seleccionar distintas modificaciones funcionales en la distribución de una misma vivienda. [FG.08] Los diagramas de Klein mantienen una cercanía con los de Gínzburg; sobre todo los dos que se vinculan con el recorrido interior de la célula habitable y que buscan producir la menor cantidad de interferencias entre los usuarios en el momento de circular. [FG.09] [FG.10] La economía de recursos y la búsqueda de un tipo definitivo para la vivienda obrera fueron aplicados en dos proyectos de vivienda social en las cercanías de Berlín, Wilmersdorf, de 1927, Zehlendorf de 1928-29 y el de Bad-Dürrenberg en Leipzig, en 1927. ${ }^{57}$

2.1.4. En sus años como director y profesor de la Bauhaus (1928-1930) Hannes MeMeyer. yer, nacido en Suiza y sin una formación específica como arquitecto, elaboró su acercamiento más fructífero sobre el tema de la función. Mientras sus textos abordaban una mirada general sobre el rol de la arquitectura, del mismo arquitecto y de la sociedad, (“Die Neue Welt”, de 1926; "Bauen”, de 1928 y los posteriores en su etapa en México, "Der Architekt im Klassenkampf," de 1931 y la conferencia en México "La formación del arquitecto," de 1938) sus análisis -materializados en diagramas espaciales- y algunos de sus proyectos permitieron comprender con mayor claridad su contribución para la función en la arquitectura. Probablemente la misma no resulta tan radical como su tono, si se la compara con experiencias contemporáneas de la arquitectura moderna. ${ }^{58}$ Aún así, su vocación de análisis y su búsqueda constante de una aproximación 
modo de entender la 'eficaica' vinculado sobre todo en términos ideológicos a la propuesta Gínzburg en la U.R.S.S.

La importancia de Hannes Meyer radica en primer lugar en redefinir el rol del arquitecto en un marco político socialista; una mutación que discute con el mismo 'origen' renacentista de la arquitectura, y que prácticamente no tiene antecedentes en la historia. Para lo mismo, Meyer busca no sólo redefinir las tareas del arquitecto, sino su misma condición dentro de la estructura de clases.

Cuanto más claramente reconocemos los procesos sociales de la lucha de clases, tanto más obligados estamos a juzgar la forma de todas las manifestaciones en el campo arquitectónico, únicamente a la luz de la acción recíproca que se interpone entre la forma y su contenido social. ${ }^{59}$

Así, el propio arquitecto se plantea como un posible luchador revolucionario dentro de la disciplina, ${ }^{60}$ afirmando que el mismo ya no puede verse como individuo creador, sino que "el arquitecto es un organizador de especialistas, pero él mismo no es especialista». ${ }^{61}$ De este modo llega rápidamente a la discusión sobre el acercamiento artístico o técnico de la arquitectura. Meyer plantea cambiar el atelier de arte, con el cual se ha relacionado al arquitecto hasta ese momento, por el laboratorio:

El rechazo del arte en la arquitectura, representado por una parte de los arquitectos capitalistas, lo valoro como uno de los síntomas del derrumbe de la cultura burguesa. Mientras la Revolución Francesa (de la burguesía) transmitió fuertes impulsos desde el fondo de su entusiasmo ideológico, que encontraron su expresión en la época clásicista-romántica de la primera mitad del siglo XIX, podemos decir que no hubo problema. Más tarde el capitalismo floreciente se apoderó de estos recursos estilísticos para transformar los puntales de su poder en templos arcaicos, o para envolver las poblaciones de sus esclavos de fábrica en un encanto paradisíaco. Asqueados por la mentira y la vacuidad de los artificios artísticos, en la práctica arquitectónica capitalista, una porción de arquitectos de vanguardia, habíamos planteado la ausencia del arte en la arquitectura como axioma. Los mejores de ellos se esforzaron por dar forma plástica a los procesos vitales de la sociedad. Este esfuerzo hacia una arquitectura formal era el punto temporal de las relaciones de fuerza aparentemente cambiadas en la lucha de clases de post-guerra. ${ }^{62}$

De esta manera el autor relaciona la tradición estética de la arquitectura con la de la aristocracia; por contraposición le opone un acercamiento técnico, el cual permitiría el contacto con lo social. Menciona temas varios como la aplicación del higienismo, mediante piscinas, sanatorios o por medio de los nuevos artefactos sanitarios, como lavabos, inodoros y bañeras; asimismo, la tecnología también podría entrar en juego, de la mano de la radio, el teléfono, el gramófono o el micrófono. El psicoanálisis, y la masculinidad exterior de la mujer tampoco quedan fuera, ya que considera que las mismas borran las fronteras entre los sexos. Meyer entiende a la arquitectura en un marco político amplio que abandona lo meramente 'artístico' para abrazar una transformación claramente social. 
Al mismo tiempo el autor no entiende que este valor artístico tenga necesariamente que desaparecer de la arquitectura, sino que lo interpreta más bien como una mutación; se preocupa por el tema de la forma en cuanto a contenido social, a contenido vital:

En relación con la arquitectura socialista, consideramos "Arte" la suma de todas las disposiciones que la organización ideológica de una construcción o de la planificación urbana requiere, para que resulte inmediatamente evidente al proletariado. El valor de este arte es determinado por su contenido político. En esta arquitectura proletaria la sublime experiencia de la vida de la masa obrera es la prestación suprema, su heroísmo y su voluntad revolucionaria constituyen las inagotables fuentes de esta arquitectura. $Y$ es precisamente la arquitectura la que conoce el impulso inesperado, gracias a las pretensiones formuladas por la clase obrera, por lo que se refiere a sus viviendas: y todo esto a través de los programas de construcción a gran escala, que deben ser proporcionados a la amplitud numérica de la masa obrera. ${ }^{63}$

Además, tres cosas menciona que hacen que la arquitectura oculte lo que él entiende como estas "verdaderas intenciones". En primer lugar, que la arquitectura se disfrace de templos que den cuenta de la importancia de una institución -lo cual habla del carácter, el gran tema que la arquitectura moderna discutirá. En segundo lugar, que utilicen motivos folklóricos (sobre todo de parte de los especuladores) como atracción para la especulación de la construcción. Tercero, que se construya con materiales que no son de la zona. Asumiendo estos problemas, el arquitecto requeriría , según Meyer, una formación notablemente diferente a la recibida por las escuelas de arquitectura tradicionales. Este cambio podría llevar a un entendimiento del modo de construcción industrial y un acercamiento a los modos de vida de la clase trabajadora.

2.1.4.b. La sociedad igualitaria a la que Meyer refiere tiene, por supuesto, una base Igualdad en el marxismo, pero en su caso se aplica directamente en al menos tres ámbitos. El primero tendría que ver con la destrucción de las fronteras; una idea en la que hace énfasis en varios de sus textos, a través de la cual aboga por el internacionalismo. Meyer no está interesado en las tradiciones culturales, ni mucho menos en la identidad; lo universal es para él casi un sinónimo de igualdad, que debe proyectarse en la cultura y en el arte, así también como en la comunicación, por medio del esperanto. El segundo tiene que ver con la 'igualdad de condiciones de hábitat', que se expresa en la eliminación de todo lo superfluo en la función arquitectónica, para dejar sólo lo esencial. Esto podría entenderse como un ataque al modo de vida burgués y también al individualismo artístico. ${ }^{64}$ Meyer exige una arquitectura que no resalte otra cosa que lo necesario para vivir. Finalmente plantea la 'igualdad de géneros', considerando al hombre y a la mujer con los mismos roles, lo cual lo lleva también a discutir la estructura familiar tradicional.

En su etapa en México, cuando publica "El arquitecto en la lucha de clases", Meyer equipara el núcleo familiar a una concepción burguesa y estática 
originarias, como las de Vitruvio, Alberti o Semper. El hogar se plantea, en este caso, como una representación social del capitalismo, -y el mismo Meyer cita a Marx cuando dice que "La abolición de la economía individualista es inseparable de la abolición de la familia»65- pero más aún de una falta de flexibilidad en la arquitectura:

La "colectivización" técnica de la manera de vivir burguesa es una consecuencia de la concentración capitalista y un síntoma de la incipiente destrucción de la familia como célula de la sociedad burguesa. El "hogar propio" debe ser abandonado. Ya están desarrollando las formas embrionales de la vivienda colectiva del futuro. ${ }^{66}$

La arquitectura que se desprende de la construcción industrializada tiene para Meyer el germen de la liviandad. Este germen afectaría a la misma permanencia de la arquitectura. Meyer ve en la familia un espejismo de orden y permanencia que oculta su propia crisis y desaparición; de ahí el llamado a una arquitectura que ofrezca sus funciones para una sociedad 'en movimiento', que deje de atender lo permanente, y al mismo tiempo conservador, de la sociedad y ponga el foco en modos de vida superadores. Así es que para el autor la representación de la sociedad podría encontrar en la vivienda su propio espejo. La muerte del hogar y la desestructuración de la familia supondría el reto para la arquitectura de imaginar una nueva función que soporte una estructura social alternativa.

Al margen de estas aproximaciones, el autor no se explaya en términos teóricos sobre nuevas propuestas en cuanto a la distribución de la vivienda. De hecho, los textos de Meyer abordan la mayoría de las cuestiones en términos generales y, por momentos, abstractos, siendo finalmente los propios proyectos, o estudios de casos particulares los que mostrarían posibles procedimientos.

Además de la destrucción de la propia familia, Meyer llama la atención sobre un pasado que aún existe y pesa, a pesar de que pueda notarse su desmembramiento. Ejemplos de su pervivencia en la arquitectura serían los teatros y los museos, que aún se sostienen como institución, pero que quedan desiertos; una sociedad artística según él paralizada. En los nuevos tiempos los museos y teatros, tanto en su rol de contenedor como en su propio contenido, darían paso a las ferias, los music-halls, o los aeropuertos. Además, la producción de objetos estandarizados enfatizaría la igualdad. Según Meyer, «Todos estos objetos son productos de función x economía. No son obras de arte. Arte es composición, propósito es función (...) Construir es un proceso técnico, no estético.» ${ }^{67}$

Por otro lado, la construcción no implica para Mayer sólo y simplemente un problema de técnica, sino que es más bien una transformación de unos valores disciplinares, relacionados tradicionalmente -según su entendimiento- con lo estético, en pos de unos nuevos valores que tienen su origen en lo esencial. Habla de "la construcción pura», y ahí reside el sentido funcional. Este pensamiento sobre lo constructivo se manifiesta sobre todo en disciplinas donde no hay tradición, como la publicidad o los procesos fotográficos. Para Meyer, el
Marx, "Ueber historischem Materialismus" Vol. 1, p. 105, Elementarbücher des Kommunismus" en "El arquitecto en la lucha de clases," p. 133.

66.

“La formación del arquitecto,” p. 133.

67.

"El nuevo mundo," p. 55.

68.

Ibid. p. 57.

69.

Ibid

70.

Ibid. p. 58 2.1.4.c.

Construcción pura 
mismo debate de la arquitectura del futuro -y también por supuesto, su función- reside en la construcción. Por lo tanto no sorprende que la noción de una 'sociedad igualitaria' tenga su eco también en ella, lo cual queda en evidencia cuando dice que "La construcción pura es el distintivo del nuevo mundo formal. La forma constructiva no tiene patria, surge entre las naciones, es expresión de una conciencia constructiva internacional. La internacionalidad es una ventaja de nuestra época.» ${ }^{68}$

La función, resaltada por Meyer a través de la «necesidad» debe responder a una igualdad garantizada también por la propia construcción:

Hoy día, las exigencias de vida son fundamentalmente las mismas para todos nosotros. La señal más segura de que exista una verdadera comunidad es que se satisfagan las mismas necesidades con los mismos medios. El resultado de la demanda colectiva es el producto "standard".69

La construcción tiene que ver con los recursos disponibles, y la misma pasará a ser sinónimo de igualdad sólo cuando no haya diferenciaciones, y cuando los "medios" sirvan a toda la sociedad de manera equitativa, sin enfatizar diversidades de clase, ni culturales. Una sociedad cuya estructura es horizontal equivaldría al mismo tiempo a un replanteo de la organización de los edificios, a espacios sin jerarquías, de los cuales Meyer no habla, pero sí quedan evidenciados en sus propios proyectos. Lo vital es, según él, esencial, y por lo mismo es igual para todos. Esta atención a lo más básico supone una apuesta política por la cual dejar atrás una arquitectura que, por tradición ha pertenecido a la institución eclesiástica, los reinados y la aristocracia. Meyer ve un salto cualitativo en la industrialización como herramienta para la construcción de una sociedad homogénea, y refiere explícitamente a modificaciones en ciertos hábitos al comienzo del siglo XX que permiten superar lo conservador de la tradición:

El ayer está muerto. Está muerta la bohemia. Muerto el “ambiente”, el valor, la cumbre, las pinceladas casuales. Está muerta la novela; nos falta fe y tiempo de lectura. (...) Está muerta la obra de arte como "objeto en sí mismo," como "arte por el arte"; nuestra conciencia de comunidad no soporta exageraciones individualistas. $^{70}$

Como ya se ha mencionado el concepto de 'construcción' es fundamental en el autor, y resulta casi evidente que en su concepción Meyer cambie la palabra 'arquitectura' por 'construcción' -Bauen-, ya que busca, en primer lugar, evitar el peso de una tradición que no considera ya pertinente; quiere básicamente -y como la mayoría de los arquitectos modernos- separarse de la historia. La industrialización impacta en la arquitectura, según el autor, de la mano de la prefabricación que, por lo tanto, es obra de especialistas que conocen la industria, la economía y la técnica. Es una obra inevitablemente social, necesaria y por ende no artística. Meyer considera esta postura frente a la construcción como una obra social y una causa común. Se trata, según él, de unir los esfuerzos individuales y colectivos.

En cuanto al construir, Meyer refiere a su experiencia en la U.R.S.S., la 
arquitectura agraria, residencial y de edificios públicos. Meyer valora la aproximación directa de los estudiantes de la U.R.S.S. con la obra, mediante un sistema de brigadas. El estudiante tiene que estar presente en la obra y en contacto constante con el usuario final. Reclama un activismo, una participación y acercamiento de parte del arquitecto a la clase trabajadora, lo cual lo desligaría de su tradicional rol jerárquico. Exige que el arquitecto esté preparado como analizador, capaz de entender la realidad; este "nuevo arquitecto" debe al mismo tiempo poder presentarse como un "inventor creador", que contribuya con una reflexión analítica a los problemas del habitar.

Meyer se posiciona así como un continuador de la concepción racionalista de la arquitectura iniciada por Lodoli y la extiende aproximándose a una noción cientificista, a tono con los debates contemporáneos que merodeaban la arquitectura moderna. En un principio Meyer busca diferenciar la función del arte, -plantea que «El arte se convierte en invención y en realidad controlada. El arte se convierte en realidad. ${ }^{71}$ - considerándola literalmente como una ciencia, aunque es posible ver que esta apuesta no resulta finalmente tan tajante. ${ }^{72}$ Esta inclusión de la función dentro del conocimiento científico define la noción de "eficacia' al mismo tiempo que lo hace desapegarse de cualquier vínculo con la naturaleza.

La obra de arte de hoy, como cualquier producto de nuestro tiempo, está supeditada a las nuevas condiciones de vida y el resultado de nuestro debate especulativo con el mundo sólo podrá ser fijado de forma precisa. La nueva obra de arte es una totalidad, no es un recorte ni una impresión. ${ }^{73}$

Así la organización debe ser social, técnica, económica y psicológica, y el lugar de la función resulta esencial y debe estar sostenido desde lo científico, ya que "toda la vida es función y, por lo tanto, no es artística". Así deshecha el arte y la composición en pos de lo que entiende como 'construcción pura', lo cual no sería otra cosa que una arquitectura despojada de todo lo superfluo:

Pensar en la construcción en términos funcionales y biológicos, dar forma al proceso de la vida, lleva lógicamente a la construcción pura: este tipo de forma constructiva no conoce patria, es la expresión de una tendencia internacional del pensamiento arquitectónico, el internacionalismo es la ventaja de nuestra época. La construcción pura es el sello característico del nuevo mundo de las formas" 74

Meyer menciona que «la arquitectura es, por lo tanto, una manifestación social indisolublemente unida a la estructura social de la sociedad respectiva»75 y si no atiende a estas necesidades resulta en puro snobismo. A su vez entiende que construir es un proceso estrictamente biológico, vinculado a las acciones más básicas del hombre, y dice, para separar la arquitectura del ámbito burgués, que "Ambiente acogedor y prestigio no constituyen los leit-motiv en la construcción de una casa.» ${ }^{76}$ Sí lo constituyen en cambio las necesidades más básicas de la función, las cuales considera como los "únicos factores que hay que tener presentes en la construcción de una vivienda.".

Meyer propone examinar las rutinas de los habitantes de clase trabajadora, lo cual dará una información con cierto grado de precisión sobre las
Dice, "El arquitecto es artista, pues: todo arte es orden. Es decir, realidad traducida en un nuevo orden". "La formación del arquitecto," p. 2.

73.

Ibid. p. 58.

74.

"Contruir," en Textos de arquitectura de la modernidad, ed. Oliveras, Jordi y Montaner, Josep Maria (Donostia: Nerea, 1994), p. 262.

\subsection{4.d.}

\section{Función como ciencia}

(Ed. orig. 1928).

75.

“La formación del arquitecto," p. 1.

76.

“Contruir," p. 261.

77.

Ibid.

78.

Como el mismo autor refiere en su etapa en México, "Arquitectura es un proceso de expresión plástica de la vida social". "La formación del arquitecto," p. 1.

79. Ibid. p. 3.

\subsection{4.e.}

Vida interior 
actividades, permitiendo asumir una función basada en datos confiables, evitando interpretaciones individuales:

1. Vida sexual

2. Costumbres en el dormir

3. Animales domésticos

\section{Jardinería}

5. Higiene personal

6. Protección contra la intemperie

7. Higiene en la casa

8. Manutención del automóvil

9. Cocina

10. Calefacción

11. Asoleo

12. Servicios ${ }^{77}$

También se fija en las interacciones con el exterior, con los servicios, los animales, el jardín, etc. e incluso le da importancia a la incidencia del clima. Hasta este punto Meyer enumera los problemas, y menciona que la función se funda sobre estas exigencias biológicas, artísticas e históricas pero no indica posibles soluciones para esta organización; no hay, en definitiva, una propuesta teórica sobre cómo gestionar estas necesidades a través de la arquitectura.

2.1.4.f. La función aparece en Meyer como un estudio, en su posterior etapa en MéBeziehungen xico, sobre las relaciones en un cuerpo social en el cual el individuo pierde peso y se difumina. Se propone estudiar las actividades humanas (lo que llama Beziehungen) desde un modo científico, esquivando cualquier subjetividad. Se trata de una aproximación sociológica aplicada al espacio y a las relaciones humanas dentro de un marco dado por la arquitectura, y más particularmente, por los proyectos de vivienda colectiva -Siedlungen-en los cuales estaba interesado. Afirma que el arquitecto debe estudiar las necesidades espirituales y materiales y traducirlas en una realidad plástica. ${ }^{78}$ Estas relaciones dentro de un marco arquitectónico y espacial Meyer las denomina Aussenwelt, y las mismas debían poder ser de algún modo cuantificadas para obtener un dato certero que modificara el modo de organizar las actividades. Según él la sociedad define la vida y la arquitectura, en un momento particular, bajo unas condiciones particulares. Las interrelaciones sociales generarían ciertos 'síntomas' naturales a ser considerados en el proyecto para mejorar la convivencia social. Las características de esa misma sociedad son las que busca revisar Meyer para poder obtener soluciones. En sus palabras, "Debemos resolver los problemas arquitectónicos dialécticamente. Es decir, sus nuevas interrelaciones respectivas. Y debemos ejecutarlos diferentemente. Es decir, en su nueva forma funcional respectiva.» ${ }^{79}$ Estas soluciones cobrarán forma a través de diagramas que el autor elabora con sus alumnos en la Bauhaus. Además los diagramas forman parte fundamental de su hacer arquitectónico, en casos como el proyecto para la Petersschule como en su etapa en México, donde le fueron encargados estudios ur-

EFICACIA $\mathbf{7 7}$ banísticos. 
En el proyecto para una Siedlung de una sola planta, se elabora un análisis que titula 'relaciones entre la vecindad' (Beziehungen Zum Nachbar), [FG.11] el cual divide en 1. Relaciones sonoras, 2. Relaciones olfativas, 3. Relaciones visuales y 4. Relaciones sociales. Meyer estaba interesado en distinguir con precisión los componentes que influyeran en las actividades humanas, y avanzar en una arquitectura que fuera receptiva de cada fenómeno que entre los ocupantes se diera, tanto en términos de relaciones positivas como de molestias o interferencias. Esto llevaba a una definición de la 'eficacia' en la función, de modo similar a como lo planteara Gínzburg, a una arquitectura concebida en sí misma como estudio científico del hábitat, centrada en los procesos y, potencialmente, en los resultados, entendidos estos últimos como fase de prueba de una propuesta teórica. La arquitectura moderna era para Meyer antes que nada la posibilidad de liberar a la disciplina del peso de la forma para centrarse exclusivamente en lo que la misma posibilitara a nivel de relaciones sociales.

En el "Estudio para la utilización periódica de los espacios de habitar" (Studie Zur Periodizität Des Lebensraumes) [FG.12] supone 7 habitantes hipotéticos para una vivienda, los cuales compondrían una familia tipo. Se elaboran 3 tablas de actividades, cada una refiere a las estaciones de verano e invierno, agregando también el día domingo. Enumera las 24 horas del día en horizontal y mediante iconos distingue la actividad en que cada habitante podría estar ocupado en ese preciso momento. De este modo obtiene un gráfico no sólo de ocupación de cada habitante, sino una información valiosa para comprender

[FG.11]

Hannes Meyer (profesor). Beziehungen zum Nachbar Dessau: Bauhaus, 1930.

I. BEZIEHUNGEN ZUM NĀCHBAR

- 1. AKKUSTISCHE BEZIEHUNGEN a. row haUS zU HAUS, MUSIK U. 6. WOW GARTEN ZU GARTEN, SPIELRASEN d. VON OER STRAS SE, MOTOR PAD U. ..W. -. HAUSTIERE, HUND, HÜHNER, KATEE E...

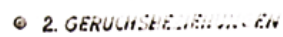
a. RAUCH - SCHORNSTEIN, GARTENFEUER 6. KÜCHENGERUCHE d. WASCHKÜ̈CHE, WRASEN

e. MOTORAO U. S.M.

3. OPTISCHE BEZIEHUNGEN

- von haus zuhaus (Gegenüber) 6. VON GARTEN ZU GARTEN

c. VOM MAUS ZUR STRASSE
d. VON OER STRASSE ZUM HAUS

4. SOZIALE BEZIEHUNGEN

a. (VERSCHIEDENE) GESELLSCHAFTL. STELLUNG

b. PARTEI

c. ORMENSAME BENUTZUNG EINER WASCHKÜCHE<smiles></smiles>

\section{BEZIEHUNGEN ZURAUSSENWELIT}

POSTBOTE - GAS - ELEKTRIZITAT - WAS SER SCHORNSTEWFEGER-HEIZER-KOHLENANFUHR-

REPARATUR-WASCHFRAU-VERWALTER

VER WANOTE - FREUNOE - (HAUSFREUND) - BE SUCHER -

BETTLER-DIEB

KINDER-PASSANT-AUTO- U.S.W.

KRANKHEIT - UNGEZIEFER

REKLAME - RUNOFUNK N..

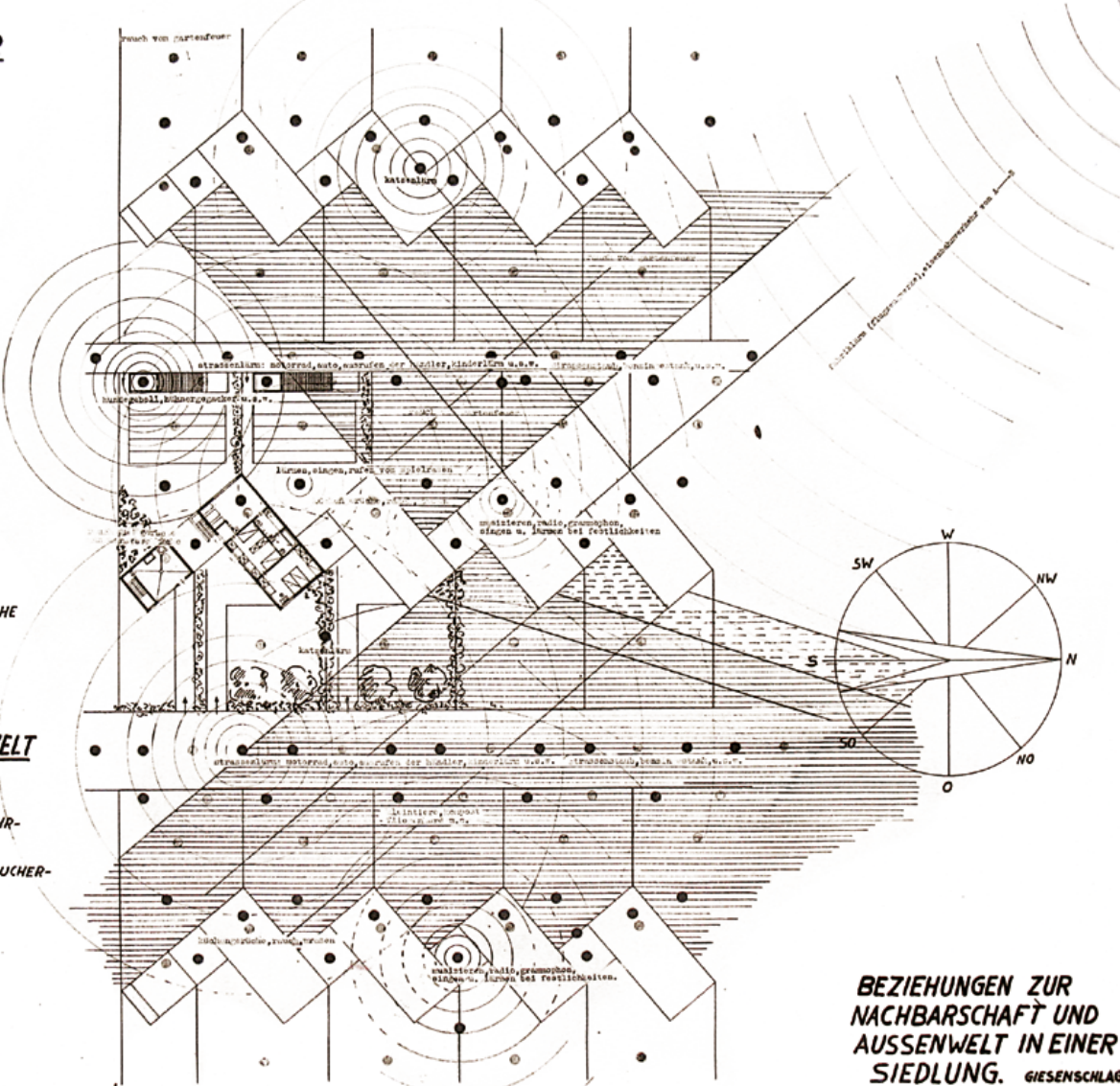


el uso o desuso que tendrá cada uno de las salas de la vivienda. Se plantea una cuarta tabla dividida en los 12 meses del año para cada habitante, con diagramas acerca de las actividades que realizará durante el año, y luego una lista de posibles visitantes a la casa, agregando la distribución de la misma.

Un tercer diagrama se enfoca en un 'ensayo para la vivienda comunitaria' y urbana (Versuch eines Gemeinschaftwohnhauses) [FG.13] para "intentar construir un tipo de vivienda igualitaria para los trabajadores", lo cual se resume en un plan para la vivienda social teniendo en cuenta la jornada laboral, el antes y el después del trabajo. Se plantea un plan a gran escala entre la Siedlung y el puesto de trabajo, considerando una parte proporcional para la naturaleza. La tabla aquí se divide por hora, espacio y ocupantes; a las divisiones de espacio le corresponde información sobre lugar, temperatura, cantidad de luz, particularidad; a la de las personas actividad, alimentación, estado psicológico, estado corporal, indumentaria. Esta tabla se rellena para tener un conocimiento preciso de la vida del trabajador.

Meyer también estudia con sus alumnos del Bauhaus las posibilidades de la forma, calculada a través de factores externos, como el movimiento que se requiere entre una actividad básica y otra, ya sea dormir, hacer ejercicio, trabajar, etc. También ubica los espacios de la casa según la necesidades de

[FG.12]

Hannes Meyer (profesor). Studie zur periodizität des Lebensraumes Dessau: Bauhaus, asoleamiento; las habitaciones de dormir al este, porque el sol de la mañana es requerido al despertarse, y las de estar al oeste para que se utilicen por la tarde. También el estudio de la naturaleza y de los espacios abiertos formaba

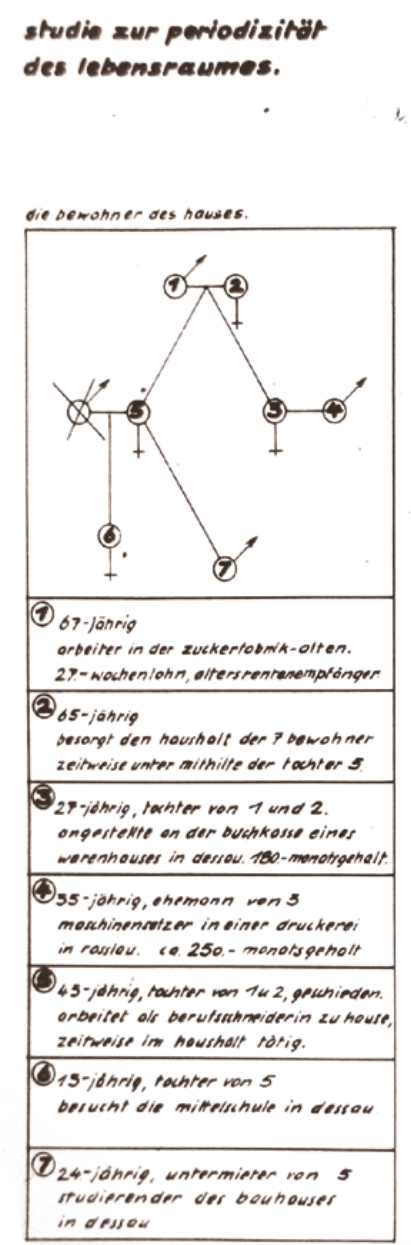

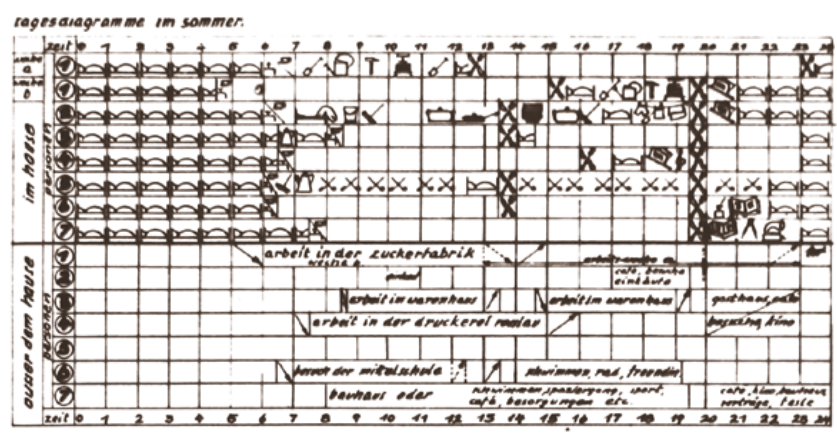
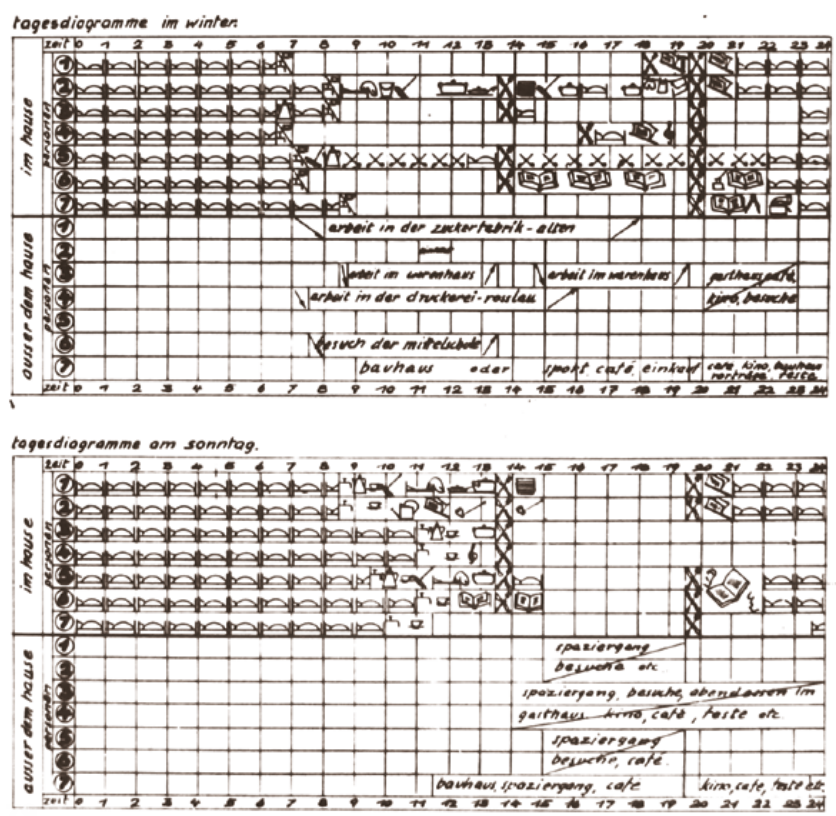

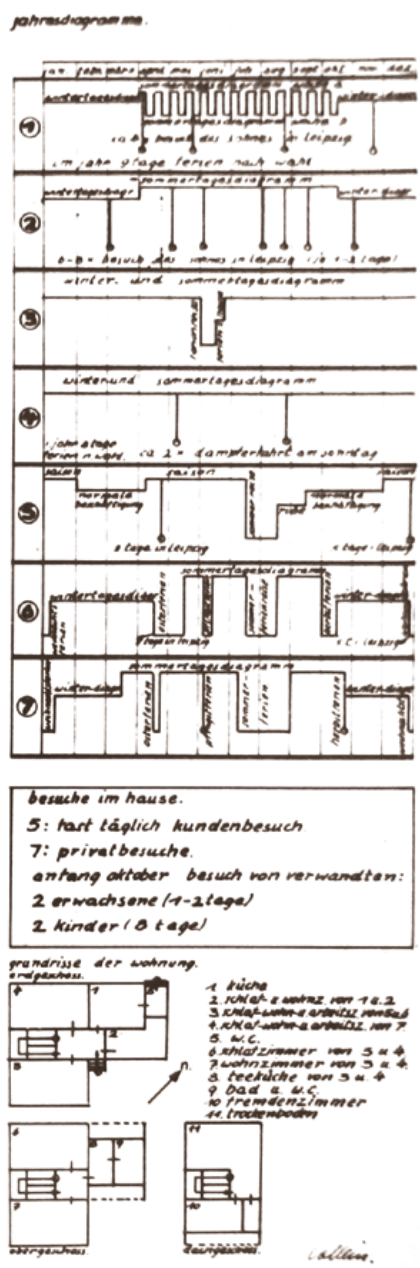




\section{VETSUCh den typ eines gemeinschaftswohnhau- ses zu schaffen, fur die arbeiter einer fabrik des sozialisierten staates mit einheitlicher arbeitszeit.}

da die sozialistische gesellschaftsordnung durch wirtschaftliche taktoren bedingt ist, werden die fabriken die organiantionszentren des staates soin.

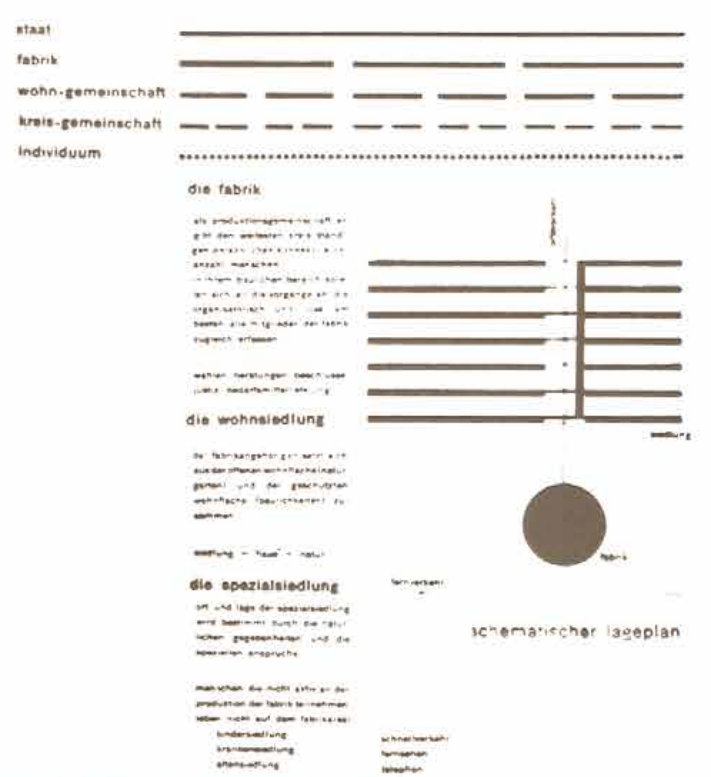

beziehungeh der menschen (individuum, kreis, gemeinschatt) zueinander und zur natur
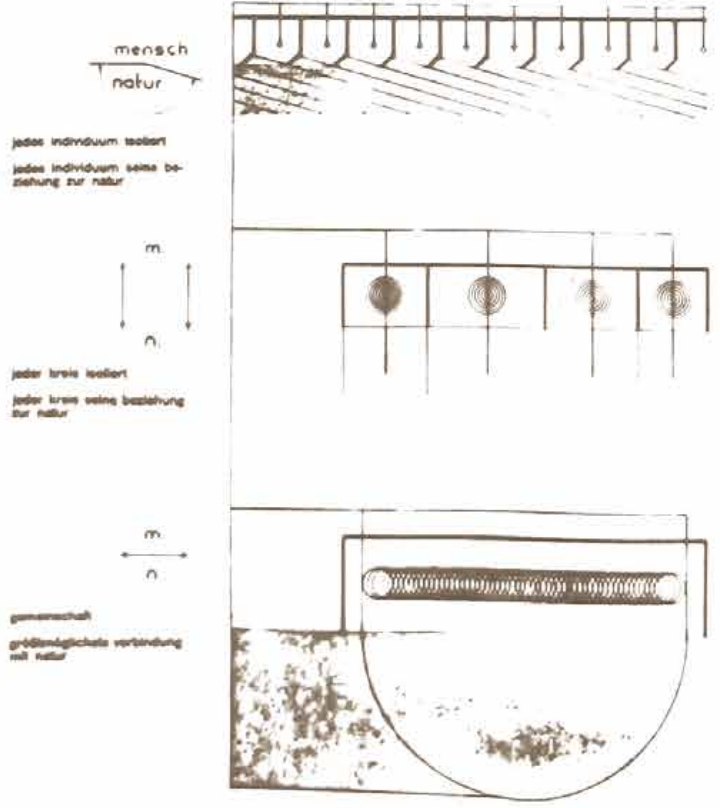

das haus wird konstruiert nach den gegebenheiten des tages. ablaufes und der dadurch bedingten benutzungsbedürtnisse.

(zeitplan)

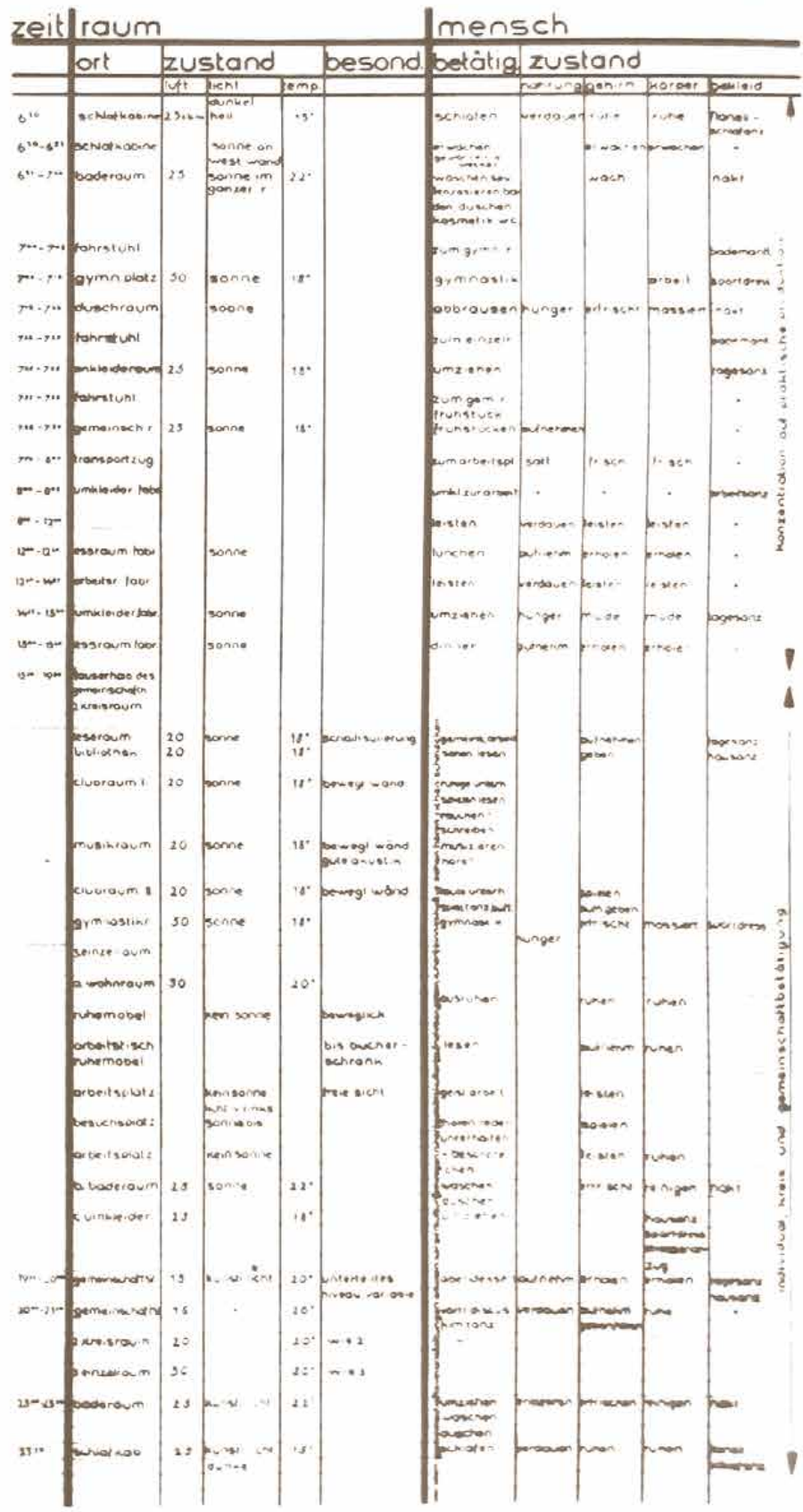


parte del interés de Meyer. En otro diagrama se enfoca en "el jardín como extensión de la vivienda", aunque no concebía al jardín como mero paisajismo, sino como campo productivo.

Meyer entendía que el avance sobre la función tenía que darse por medio de la disposición y contraste de la información; esta información llevaría a una arquitectura que cumpliera con una serie de necesidades que aún no habían sido científicamente revisadas por la arquitectura, y que por lo mismo no se encontraban del todo satisfechas. Aún así, muchos de los problemas que Meyer pone sobre la mesa en cuanto a este estudio científico sobre la función ya habían sido mencionados en casi todos los tratados de arquitectura de la tradición vitruviana. La diferencia principal radica en que Meyer los coloca en un diagrama que puede ser cuantificable.

2.1.4.g. En el momento en que más claramente Meyer se identifica con una sensibilidad Tiempo y velocidad subjetiva tiene que ver con la percepción moderna del tiempo y de la velocidad. En la fotografía, el cine y la publicidad surge una nueva estética de lineas de tensión, de velocidad; las luces, la energía, el tango, el jazz, el formato DIN o la tipificación. Vehículos como autos y aviones eliminan las fronteras de la ciudad y de los estados. Estos son los temas que llaman la atención del autor. La nueva percepción del tiempo y espacio que se amplía; el tiempo que se divide en fragmentos. Con esto, la casa se ha vuelto para el autor más móvil que nunca. Vivienda de alquiler, yates, transatlánticos, roulots, el sentido de patria para Meyer se ha perdido.

El de la circulación quizás sea uno de los aportes más importantes de la propia arquitectura de Meyer con respecto a la función. Esto tiene su germen en ideas anteriormente expuestas sobre la igualdad, la destrucción de la familia y la discusión sobre lo permanente. La modificación de la percepción del tiempo y el espacio por medio de los transportes y la tecnología inspira directamente el movimiento interno de sus proyectos, lo cual lo liga a una tradición comenzada por Blondel, en cuanto al trabajo perceptual de la circulación. Meyer acentúa la importancia de la técnica por medio de sus estructuras, y trabaja el tiempo y la velocidad a través de circulaciones que resultan elementos centrales en sus proyectos. En sus textos de su etapa en la Bauhaus no refiere demasiado a la circulación en sí misma, ya que a Meyer no parece interesarle la economía aplicada a la arquitectura en el sentido de Durand. Ya en sus textos de México destaca la expresión propia de la circulación, con lo cual conecta con temas que van más allá del pragmatismo de la época alemana:

a. Una escalera no sólo debe ser un "medio de elevación," como algunos funcionalistas vulgares quisieran que fuera. Según su "posición social" esta escalera exige un paso solemne o un ascenso rápido.

b. El edificio de una estación ferroviaria no es sólo vivido por el habitante de la ciudad como elemento del aspecto urbano, sino es valorizada por el viajero en tránsito como una de las obras del recorrido, contempladas consecutivamente. c. El recinto teatral puede, por medio de balcones, dar expresión a la clasificación social del público, o bien puede, como anfiteatro, subrayar la igualdad de- 


\section{colaboración del público. ${ }^{80}$}

La aproximación mediante estos ejemplos resulta importante para entender lo relativo de su postura cientificista, enfatizando el valor -que ya queda evidenciado en sus mismos proyectos- de la propia expresión que la función tiene, y que cumple un rol fundamental, más allá de lo meramente técnico. Es muy importante cómo Meyer otorga cualidades por fuera de lo estrictamente funcional, y se acerca a una función social o expresiva. El ejemplo de la escalera es determinante para entender que Meyer también incorpora una sensibilidad a la función. La misma puede visualizarse en dos de sus más importantes proyectos, ambos junto a Hans Wittwer. El proyecto para el concurso de la Petersschule en Basilea (1926) y la ADGB Schule en Bernau (1930).

El proyecto para la ADGB, escuela para la Federación Alemana de Sindicatos que Meyer y Wittwer ganaron por concurso, visibiliza con total claridad el programa funcional, casi al punto de decirse que materializa en contenedores evidentes cada una de sus funciones, de modo didáctico. Se trata de piezas industriales que se repiten según la necesidad, y se yuxtaponen, asumiendo incluso las pendientes notorias del terreno. [FG.14] Utilizan la materialidad y resolución técnica de la fábrica, a la vista, sin recurrir a ningún elemento que pueda considerarse agregado. En este sentido, lo que podría entenderse como 'el lenguaje industrial' -que ya había sido utilizado por Gropius, incluida la Bahuaus de Dessau- es prácticamente puro, hasta el punto de no permitir la implementación de ningún elemento que quede fuera del mismo. La ADGB
[FG.14]

Hannes Meyer y Hans Wittwer ADGB, Bernau. Exterior Essen: Walter Peterhans Estate Museum Folkwang, 1930.

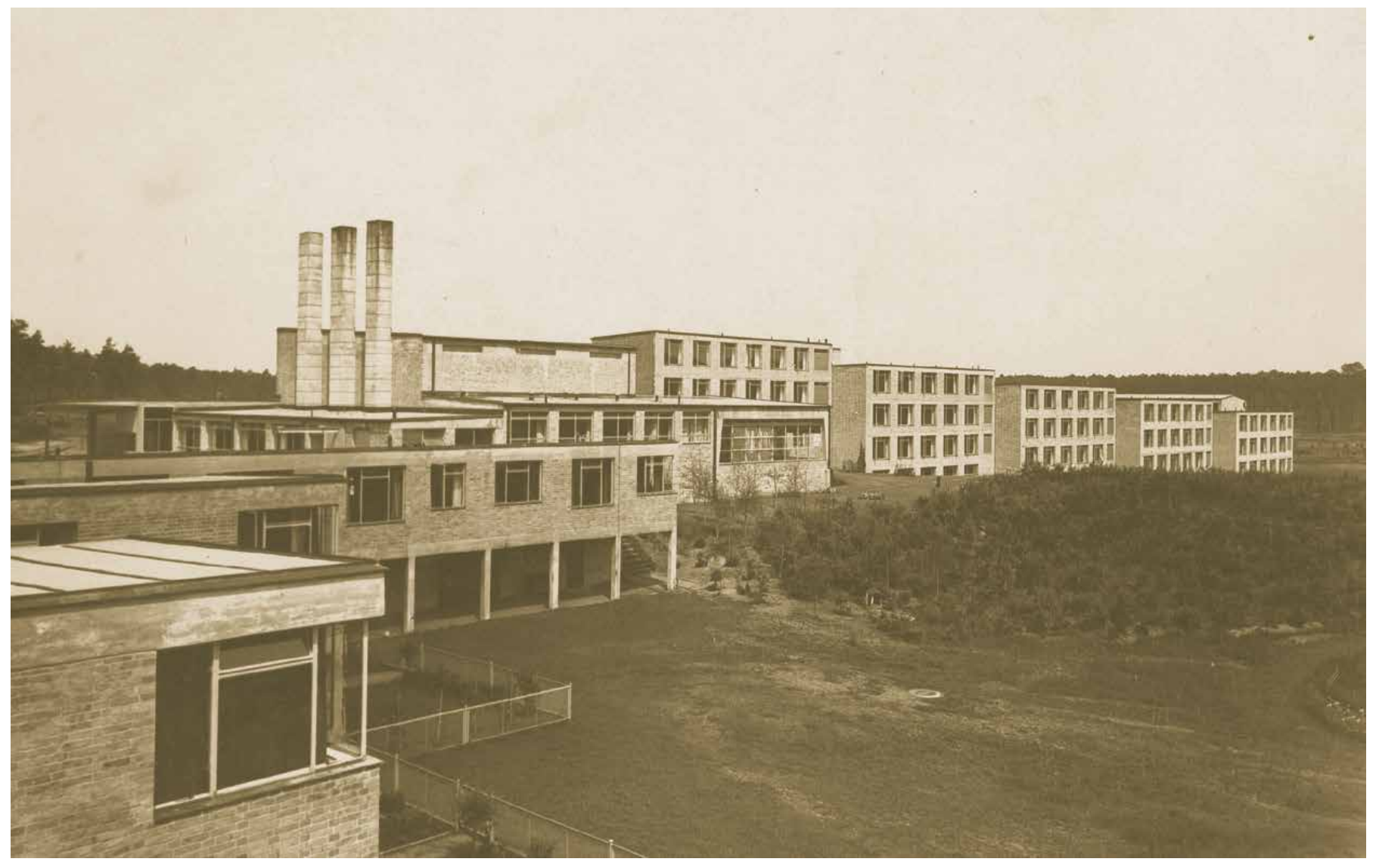


no se diferencia en aspecto de un edificio industrial, y termina de clarificar lo que Meyer y Wittwer habían intentado para la Peterschule unos años antes. Se asemeja a la Bauhaus en el sentido del despliegue en el terreno y la percepción cambiante a medida que se la recorre, pero a eso se le agrega además la acomodación al terreno, y al mismo tiempo la labor sobre el paisaje mediante la selección cuidadosa de las visuales principales y las orientaciones. La construcción en la ADGB Schule está tratada además a modo de un templo. El espacio de intercambio social tiene para Meyer un lugar central, el mismo es destacado mediante la ubicación jerárquica y la amplitud en las dimensiones; la transparencia en los laterales y en el techo, además de una estructura particular que la diferencia del resto de los espacios.

En ambos proyectos la circulación está concebida como un elemento en sí mismo, que se diferencia del cuerpo principal a través de la estructura metálica -esto también sucederá en el proyecto de cinco bloques de viviendas sociales en Törten (Dessau), construido en su etapa como director del Bauhaus. La circulación es exterior e independiente; es decir que no afecta en ningún momento al trazado principal de la planta; es casi como un anexo. La estructura metálica y la transparencia aplicada en la circulación también funcionan como metáforas del movimiento y la liviandad frente al peso del edificio central. [FG.15] Interpretando la intervención de Meyer en el edificio de viviendas, estos

[FG.15]

Hannes Meyer y Hans Wittwer ADGB, Bernau. Interior Essen: Walter Peterhans Estate, Museum Folkwang 1930. conectores también pueden entenderse como elementos transitorios que la misma tecnología puede reemplazar y mejorar. Incluso parece que el mismo edificio sólido y estable pudiera asumir otras variables de circulación. En la ADGB cada una de las salas que componen el cuerpo central tiene su propia

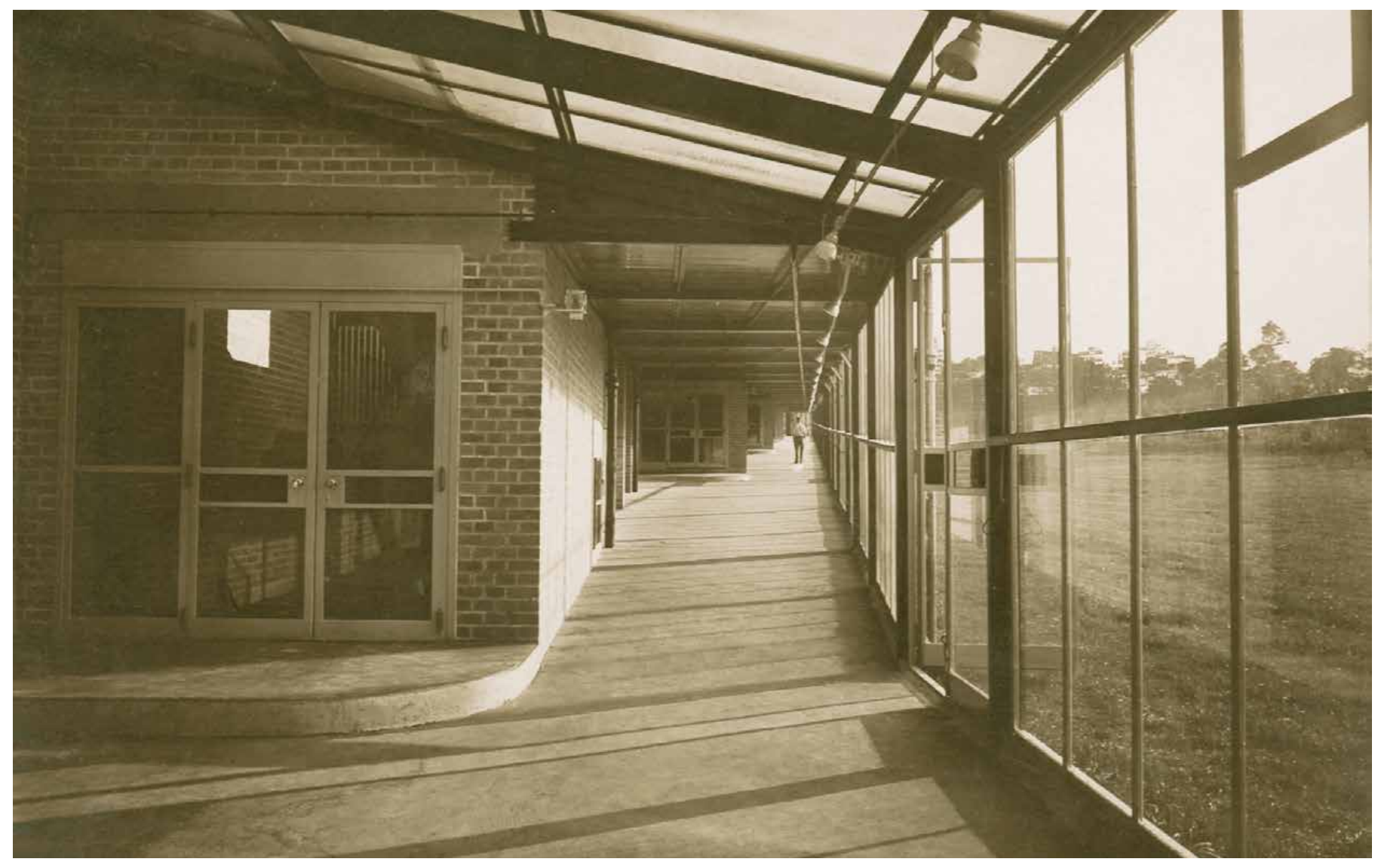


escalera, a la cual se accede por medio de la galería en la planta baja. Se trata nuevamente de una 'eficacia' aplicada a las distribuciones. Aún así Meyer y Witter no renuncian al costado poético que su misma obra puede producir, como metáfora del mundo moderno:

...en el gráfico del presente se ven entre las líneas quebradas de sociedad y economía, las rectas correspondientes a la ciencia y a la mecánica. Constatan la victoria del hombre razonante sobre la naturaleza amorfa. El reconocimiento de estos hechos hace temblar los valores actuales cambiando su morfología; da forma a nuestro nuevo mundo de manera determinante. ${ }^{81}$

Resulta finalmente destacable mencionar ejemplos que el autor recoge, como el viaje al polo norte del Norge, el planetario Zeiss de Jena y el barco rotor de Flettner, entendidos como ejemplos de la mecanización y del avance de la ciencia en el mundo. La ciencia da forma y gana sobre una naturaleza "amorfa". Para Meyer existe también una noción formal en este cambio de paradigma. De modo muy similar a Mies, dice "Cada época demanda sus propias formas. Nuestra misión consiste en conformar el nuevo mundo con los medios de los que hoy disponemos. ${ }^{82}$

Acaso sin proponérselo, Meyer quiso responder a la "incógnita» de Gínzburg, que exigía indagar en las particularidades de ese 'nuevo usuario' que surgía con la sociedad moderna. El estudio riguroso de los hábitos, los horarios y las actividades -tanto pautadas como aleatorias- que el obrero y su familia pudieran tener, son uno de los acercamientos más directos a la problemática de la función que se puedan encontrar en la arquitectura moderna. Es cierto que Meyer, en su corto proceso en la Bauhaus, no consiguió conjugar una teoría sólida sobre cómo abordar este análisis; quizás, a diferencia de Gínzburg, no veía la necesidad de materializar una propuesta teórica, sino que consideraba como suficiente el análisis cuantitativo y la fuerza natural del proyecto de arquitectura para ilustrar posibles soluciones. Al mismo tiempo, por medio de sus diagramas, logra introducir un nuevo modo de comprender la función que, a su vez que se acerca al cálculo del ingeniero, se escapa de la descripción empírica que gobernó toda la tradición de la función. Su énfasis en la circulación como elemento autónomo y dinámico, la materialización concreta de cada espacio como metáfora del programa -estrategia que mantiene viva la noción determinista de Guadet- y el despliegue desprejuiciado de volúmenes buscando condiciones apropiadas para el asoleamiento, las visuales, la acústica y las relaciones sociales son, en resumen, aportes fundamentales para el entendimiento de una función que busca resolver los problemas de sociedad por medio de la 'eficacia'.

Neufert, quien fuera estudiante de una de las primeras generaciones de arquitectos de la Bauhaus, dedicó varios años de esfuerzo a la normalización de las dimensiones de los espacios con un fin funcional, y persiguiendo también la idea de Gropius (con quien colaboraría en su estudio, incluso en el nuevo edificio para la Bauhaus en Dessau) sobre el Existenzminimum. Durante los primeros años de la década del treinta se dedicó a una obsesiva labor de medición intencionada que perseguía unas pautas universales para las

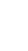


dimensiones de los espacios según su uso específico. Con este material consiguió publicar en 1936 Bauentwurfslehre. Handbuch für den Baufachmann, Bauherren, Lehrenden und Lernenden. -traducido al español como Arte de proyectar en arquitectura-, que con el tiempo se convertiría en un manual moderno de apoyo al proyecto, que además de condensar dimensiones mínimas para dar cabida a cada una de las actividades de la vida moderna proponía soluciones y distribuciones para las situaciones más típicas. [FG.16] En un momento en que las escuelas de arquitectura no habían aún incorporado los preceptos más básicos de la arquitectura moderna, Bauentwurfslehre... adoptaría el camino de los tratados de arquitectura de la tradición, con indicaciones básicas, pero al mismo tiempo necesarias para las 'buenas prácticas' de la profesión.

El libro de Neufert no contiene una propuesta teórica sobre la función, pero el éxito internacional de su divulgación reafirma la importancia de su voluntad pragmática. Bauentwurfslehre... esconde una visión de la arquitectura que bien se emparenta con la búsqueda de una 'eficacia' por medio del estudio antropométrico, tema que no había tenido cabida en las indagaciones de Gínzburg o Meyer. Este aprovechamiento máximo no se limita a la dimensión de las superficies, sino que se extiende al propio diseño, ya que Neufert se concentra en los múltiples modos en que el cuerpo puede moverse, atendiendo a las posibilidades tridimensionales que los espacios, el mobiliario y los artefactos permiten. Al mismo tiempo, apelando a soluciones que tienden constantemente al mínimo posible, muchas de las propuestas de Neufert rozan la incomodidad, o lo mínimo aceptable. No obstante, el objetivo más importante del autor radica en la normalización de estas dimensiones básicas; en 1939 colabora con la estandarización de las normas constructivas de Alemania junto a Albert Speer, y publica BOL, o Bauordnungslehre, que trata justamente de una reglamentación de la construcción, la cual consolida definitivamente el Existenzminimum como parte de la idea de 'eficacia' en la función.

2.1.5. Con una rigurosa formación académica que incluye tanto matemáticas como Alexander. arquitectura, pasando por Cambridge, Harvard, el MIT y Berkeley, Christopher Forma, contexto y patrón Alexander dedicó varios años a elaborar una aproximación al diseño desde el punto de vista matemático. Los objetivos de Alexander quedan plasmados con énfasis en uno de sus primeros escritos, titulado Notes on the Synthesis of Form y publicado en 1966, en el cual las premisas del diseño de la función se basan en las matemáticas, lo que permite concebir los problemas de diseño a través de diagramas, a los que una década más tarde, llamará patterns, en dos libros que, según el mismo autor afirma, forman parte de una misma obra, A Pattern Language, de 1977, y El modo intemporal de construir, de 1979. No obstante, estos libros funcionan casi como un manual de aplicación; la concepción funcional del pensamiento de Alexander ya había quedado formulada en su escrito de 1964.

2.1.5.a. El comienzo de Notes on the Synthesis of Form Alexander deja en claro su postura al hacer un llamado a la racionalidad, a través de una cita de Platón, y titu- 
ESPACIO NECESARIO ENTRE PAREDES

para personas en movimiento, aumentar la anchura $\geqq 10 \%$

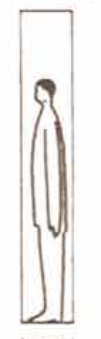

(1)

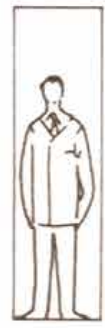

$1-625-1$

(2)

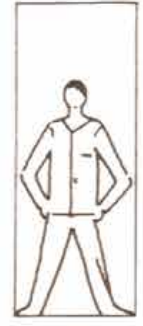

(3)

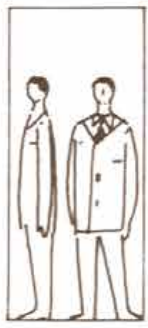

(4)

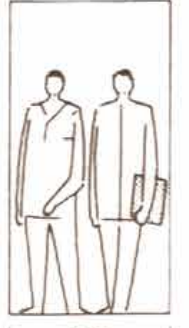

(5) ${ }^{1150}-$

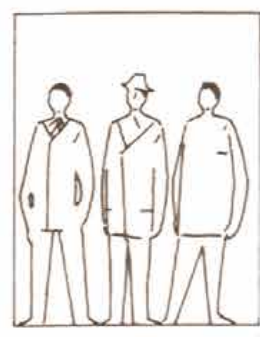

(6)

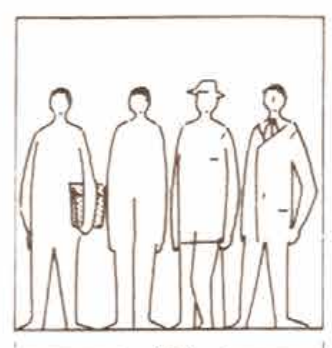

(7)

ESPACIO NECESARIO PARA GRUPOS

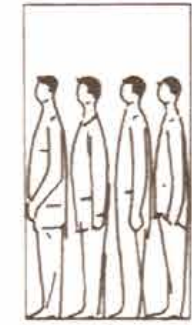

(8) En fila apretade

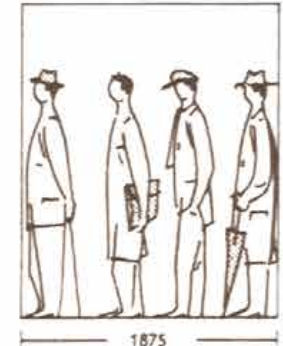

(9) En fila normal

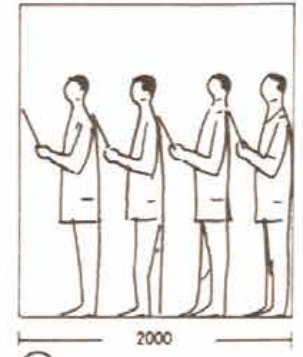

(10) Grupo coral
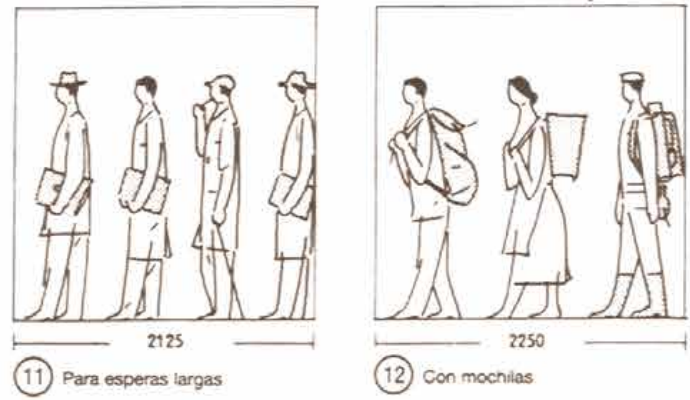

MEDIDAS DE UN PASO

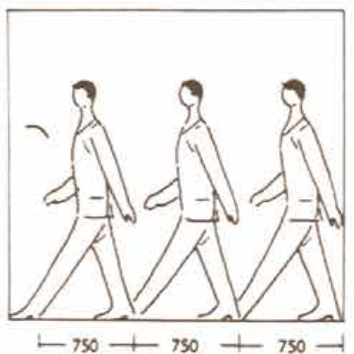

(13) Paso norma

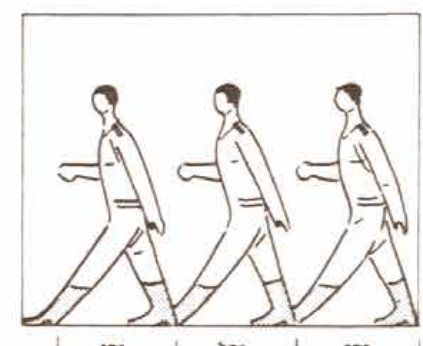

(14) Paso ligero

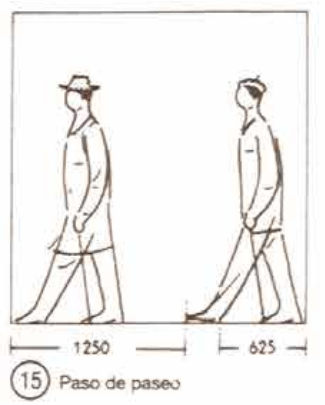

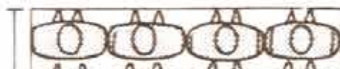

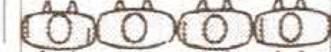

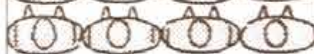

8 ति ती की $\mathrm{A}^{2}$ . मित्रित्र 000000

(16) Maxima densidad por $\mathrm{m}^{2}=$

ESPACIO NECESARIO SEGÚN LA POSICIÓN DEL CUERPO

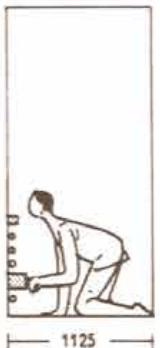

(17)

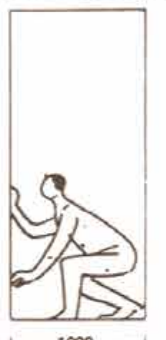

(18)

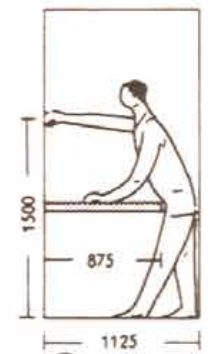

(19)

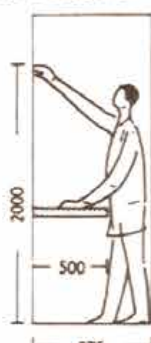

(20)

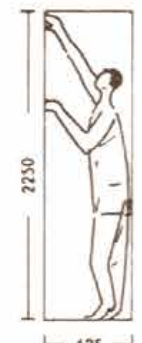

(21)

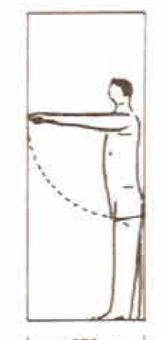

(22)

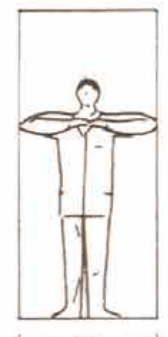

(23)

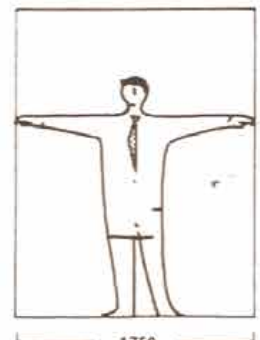

(24)
ESPACIO NECESARIO CON EQUIPAJE DE MANO

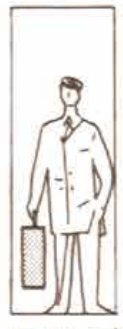

(25)

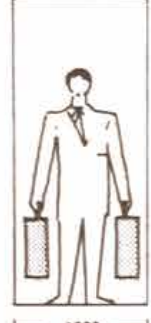

(26)

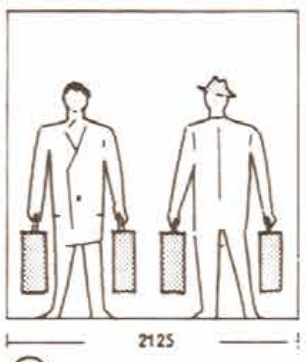

(27)

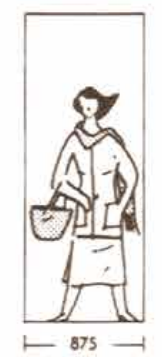

(28)

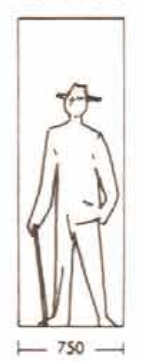

(29)

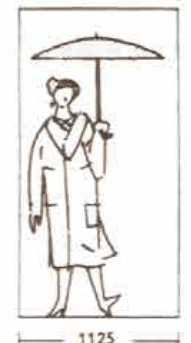

(30)

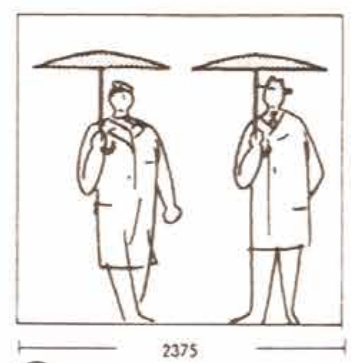

(31) 
resulta de difícil solución ante un panorama complejo como el de la vida moderna, y que frente a una situación tal, en la que lo que más cuesta es conseguir claridad (casi continuando la postura de Lodoli), los diseñadores suelen, en términos generales, evadir el problema funcional central para indagar en exploraciones formales, en un acto de comodidad que, lo que finalmente hace, es alejarse el problema de raíz, dejándolo sin solución. Esta falencia podría, según Alexander, ser solventada por medio de las matemáticas, si se entiende el problema desde una mirada extremadamente racionalista, continuando la linea de Gínzburg y Meyer.

Según su análisis existe una contradicción entre una solución funcional óptima y la complejidad constructiva que este objeto requiere para satisfacerla; en definitivo, una contradicción entre eficacia y construcción -o podría decirse, entre eficacia e industrialización. Así, este problema podría resumirse según él en una tétrada conformada por "eficacia, simplicidad, ensamblado y economía»; todos son requisitos imprescindibles para el diseño, que tienen entre ellos interacciones. Pero ante un problema de diseño complejo que implique, por ejemplo, a todo un conglomerado social, deben considerarse aún muchos más aspectos, lo cual supone fragmentar el problema mayor en subcategorías menores. Este paso hacia la fragmentación del problema en partes menores es una de las primeras propuestas novedosas que Notes on the Synthesis of Form aporta a la noción de 'eficacia'. Alexander apela a dejar a un lado la intuición, la capacidad personal -y hasta cierto punto subjetiva- del arquitecto (o como Alexander prefiere, el 'diseñador') para aceptar los límites de la complejidad, y asumir finalmente que la función sea abordada desde métodos matemáticos que permitan asegurar un resultado óptimo. Como presentación de Notes on the Synthesis of Form dice:

En este ensayo se describe un modo para representar los problemas de diseño que facilita su solución. Se trata de un modo para reducir el vacío entre la pequeña capacidad del diseñador y la gran magnitud de su tarea. ${ }^{83}$

De este modo reafirma el poder de las matemáticas modernas, proponiendo que las mismas pueden servir para afrontar temas de "orden y relación», que son justamente centrales en el diseño. Menciona a Lodoli y a Laugier como ejemplos de autores que desecharon la pura subjetividad poniéndolos en relación con las propuestas de la Bauhaus, afirmando que la arquitectura no logró desarrarse por el camino de la racionalidad que estos autores propusieron, sino que continuó bajo la impresición de la subjetividad.

2.1.5.b. Alexander afirma, citando a D'Arcy Thompson -y de modo similar a como también lo entendiera Gínzburg con su «método funcional»- que la forma es un "diagrama de fuerzas" provocado por los problemas funcionales. Las funciones podrían entenderse como esa "fuerza» que afecta a la «forma»:

...no puede alcanzarse la claridad física en una forma hasta que no haya primeramente cierta claridad programática en la mente y las acciones del diseñador; (...) el diseñador debe remontar primeramente su problema de diseño a sus más tempranos orígenes funcionales y ser capaz de encontrar alguna 


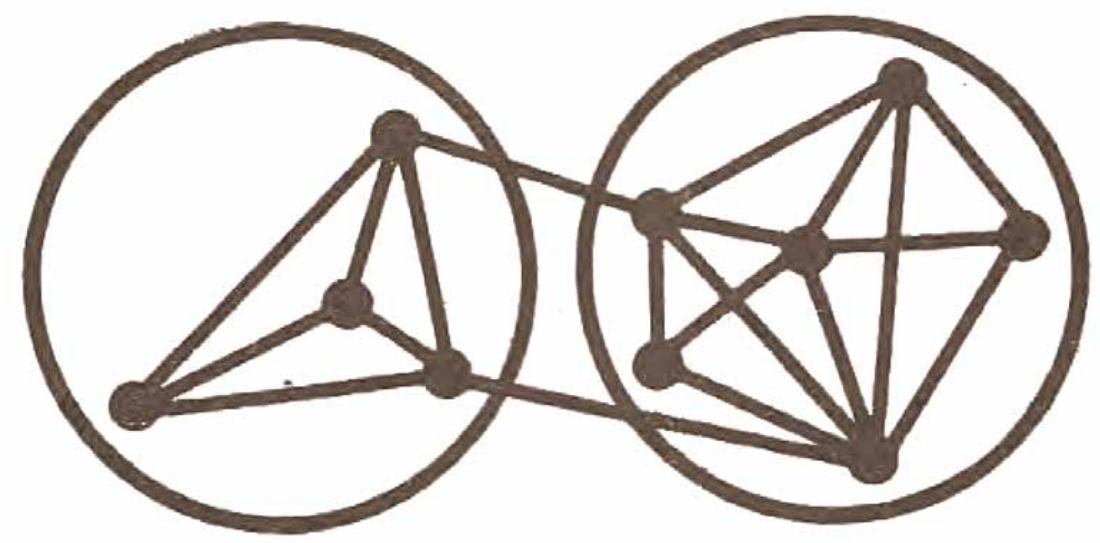

El diseño sería la resolución de un "ajuste", (lo que Alexander entiende por fitness) entre esta "forma" y su "contexto»; la primera es la que el arquitecto domina, y la segunda la que introduce exigencias a la primera. Ya que «... es precisamente la experimentación en el mundo real lo que estamos tratando de reemplazar por un método simbólico", se vuelve preciso encontrar este "diagrama de fuerzas" para un "contexto" complejo, como es el entorno urbano. Dado que la lista de estas exigencias puede ser infinita, el camino, según Alexander, radica en identificar los "desajustes", las incongruencias de la norma que puede haber dentro de un contexto e intentar solventarlos; actuar por el negativo antes que por el positivo, y esta información se traduce de modo binario: valor 1 para el desajuste, y valor 0 para el ajuste; una forma adecuada sería la que contenga todas las variables con valor 0 . Pero cada ajuste de una forma adecuada puede suponer otro desajuste, así «...si en una casa no hay luz suficiente y se agregan más ventanas para remediar este defecto, es posible que el cambio mejore la iluminación pero que deje a los moradores como en vidriera.... ${ }^{85}$ Esto genera un gráfico de puntos por cada variable de desajuste que pueden requerir ser conectados, y a su vez pueden pertenecer a un subsistema. [FG.17]

Alexander diferencia a las culturas que considera conscientes de sí mismas -como sería la cultura moderna occidental-, y a las inconscientes -referidas a las primitivas, que actúan por hábitos que no se someten a discusión. A diferencia de las segundas, las primeras serían capaces de producir modos de pensamiento teórico en cuanto a la arquitectura. Aún así, Alexander sostiene que «...el proceso inconsciente de sí mismo posee una estructura que lo hace homeostático (organizador) y que por lo tanto produce consecuentemente formas bien ajustadas.... ${ }^{86}$, por el otro lado las culturas conscientes de sí mismas tienen más probabilidades de no lograr diseños ajustados a sus contextos. Las culturas inconscientes de sí mismas, sin normas, valiéndose de los recursos disponibles, han ido evolucionando, atendiendo a cada pequeño cambio y necesidad, a la inmediatez, siendo en muchos casos el propietario el mismo constructor; por lo mismo se ha ajustado cada subsistema por separado y se
[FG.17]

Christopher Alexander

Relaciones entre variables

Harvard: Notes on the synthesis of form,

1964

85.

Ibid. p. 46.

86.

Ibid. p. 42.

87. Ibid. p. 85 .

88.

El autor define al diagrama como "...toda pauta que, al ser abstraída de una situación real, comunica la influencia física de determinadas exigencias o fuerzas". Ibid. Al mismo tiempo, "Un diagrama de forma sólo llega a ser útil si sus consecuencias funcionales son previsibles, es decir, si contiene los elementos de un diagrama de requisitos. Un diagrama que expresa sólo los requisitos o sólo la forma no resulta útil..." Ibid. p. 88.

\subsection{5.c.}

Auto-conscientes e inconscientes 
[FG.18]

Christopher Alexander Variables en el diseño de una tetera Harvard: Notes on the synthesis of form, 1964.

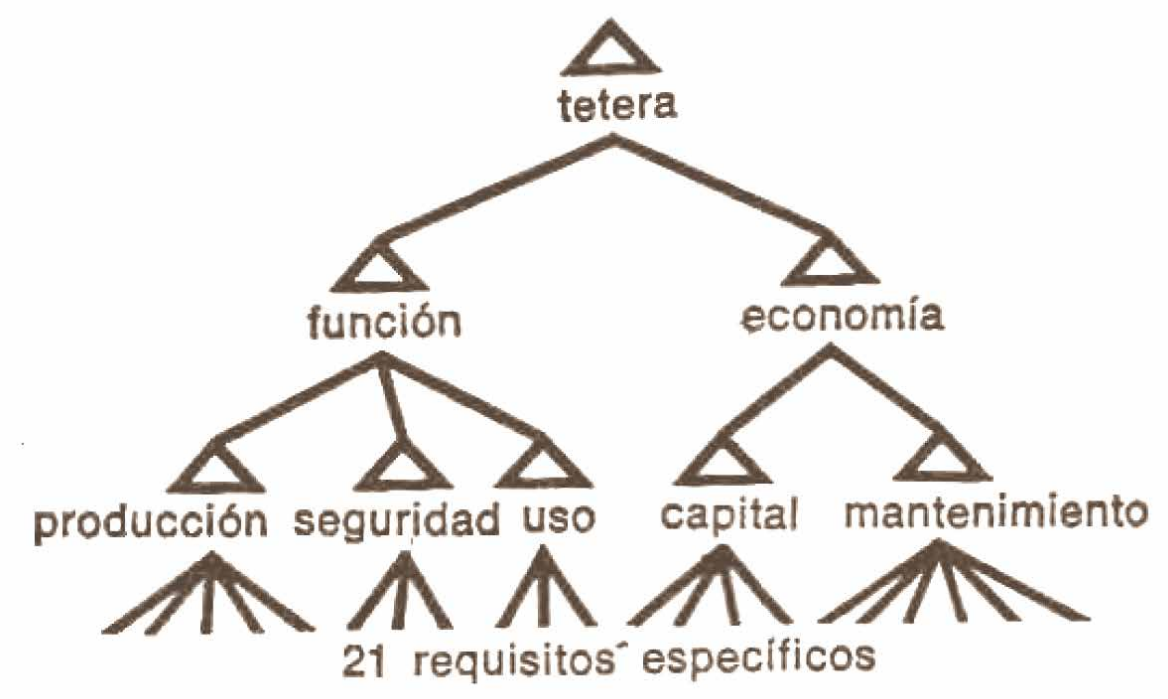

ha conseguido mayor exactitud en cuanto a solventar funciones necesarias. Las culturas auto-conscientes, proponen cambios generales, más veloces, en muchos casos motivados por intereses diferentes, como la especulación, o el mismo enfoque individual del arquitecto autor, hechos que, mediante formas arbitrarias, impiden la atención de los desajustes de lo que Alexander entiende por subsistemas.

Para esto el autor propone esquemas de síntesis de los desajustes, como el que utiliza en el caso del diseño de una tetera, [FG.18] con lo que es posible encarar el problema de raíz con una evidente economía de tiempo. Aún así, no es posible manipular todas las variables al mismo tiempo; resulta necesario fragmentar el problema, y para esto se recurre a la distinción, generando soluciones diversas posibles y expresando todos los criterios de selección. Aplicando este método resulta posible la comparativa, y más tarde la "selección", la cual sería, según el autor, prácticamente un reemplazo del diseño; de algún modo este último tendería a ser prescindible. Para esto Alexander compara, a través de un esquema [FG.19] la relación directa entre el contexto y la forma de una cultura no consciente de sí misma, la relación indirecta (mediante una imagen mental) de la cultura autoconsciente y, finalmente, la propuesta de Alexander de recurrir a una nueva imagen, abstracta, la cual quite la individualidad y se pueda desarrollar de un modo operativo y racional. Esta nueva imagen se construiría a partir de conjuntos matemáticos.

2.1.5.d. Luego de esta fase analítica vendría una fase sintética en la cual se desarroPrograma Ilaría lo que Alexander llama la «realización del programa de diseño». Así, "El punto de partida del análisis es el requisito. El producto final del análisis es un programa, el cual es un árbol de conjuntos de requisito». ${ }^{87}$ Con esto el autor ofrece una definición moderna de la idea de 'programa' la cual deja a este último en poder del propio arquitecto. Es el arquitecto quien debe elaborar el programa en base a los requisitos, y la herramienta es un diagrama, ${ }^{88} 0$ una serie de diagramas que permiten acercamientos a requisitos de mayor complejidad. Estos diagramas sirven para comprender tanto el contexto como la 
Los desajustes podrían escalarse en algunos casos en valores, pero claramente no en todos, ya que existen ciertas variables que no son cuantificables. "El diseñador como hacedor de formas anda en busca de integridad (en el sentido de unicidad) (...). Por la otra parte, el origen de un programa de diseño es analítico y su efecto es el de fragmentar el problema". ${ }^{89}$

En su libro editado años más tarde, A Pattern Language, Alexander presenta, de modo muy diferente a como lo hiciera en Notes on the Synthesis of Form, una serie de 253 patrones que podrían ser aplicados para resolver proyectos urbanos, arquitectónicos y de diseño desde el punto de vista funcional y de un modo completamente práctico; en cada patrón el autor describe un problema a resolver, tratado com si fuera un manual. Cada patrón cuenta, según el mismo Alexander lo describe, con un "trasfondo empírico", que tratan casos donde se evidencia su funcionamiento. Luego se plantea una solución, y se lo conecta con otros patrones que forman parte del mismo problema. De hecho, para el autor la esencia del libro radica, justamente, en esta interconexión entre patrones.

Y así, por ejemplo, usted encontrará que el patrón vegetación accesible (60) está conectado en primer lugar con otros patrones mayores: límite de subculturas (13), vecindad identificable (14), comunidad de trabajo (41) y traseras tranquilas (59). Éstos figuran en su primera página. Pero también está conectado con otros patrones menores: espacio exterior positivo (106), lugares árbol (171) y tapia de jardín (173).

(...)

Ésta es una visión fundamental del mundo. Una visión que nos dice que cuando construimos una cosa no podemos limitarnos a construirla aisladamente, sino que también hemos de intervenir en el mundo que la rodea, y dentro de ella, de modo que ese mundo más amplio se haga más coherente en ese lugar, sea más un todo; y esa cosa que hacemos tiene un lugar en la red de la naturaleza, tal como la hacemos. ${ }^{90}$

Como una aplicación de los principios abstractos de Notes on the Synthesis of Form, Alexander busca finalmente abordar el problema de la función con un manual, o más bien sentar las bases para la construcción de indefinidos manuales, que consideren los requerimientos a solucionar, a modo de una red social, y de algún modo también auto-organizada. El autor asume así la inexactitud del libro, y llama a una continua alimentación de los patrones por medio de la misma práctica de los usuarios, ${ }^{91}$ entendiendo que los mismos patrones tienen una vida y evolución, y que en el libro están formulados a modo de hipótesis.

La propuesta de Alexander se diferencia claramente por concebir a un usuario activo, o a una especie de red social activa que sea capaz de autogestionar su habitar de modo propositivo y reduciendo de algún modo el rol del arquitecto autor. En este sentido podría decirse que la función en el pensamiento de Alexander tiende a una 'eficacia social', no determinada por factores ideológicos individuales, sino por el constante hacer, en este caso ya inevitablemente autoconsciente.

\subsection{5.e.}

\section{Patterns}

91.

Alexander entiende esto "...como primer paso en el proceso social por el que las personas cobrarán conciencia gradualmente de sus propios lenguajes de patrones y trabajarán para mejorarlos." Ibid. p. 12. 

contexto
forma

\section{C1}

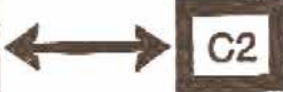
mundo real

contexto

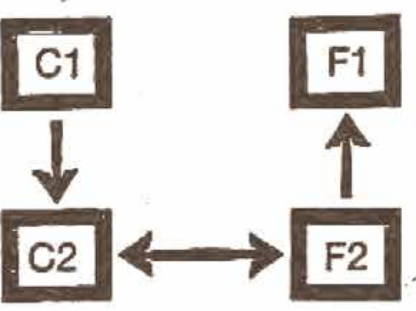

mundo real

imagen mental

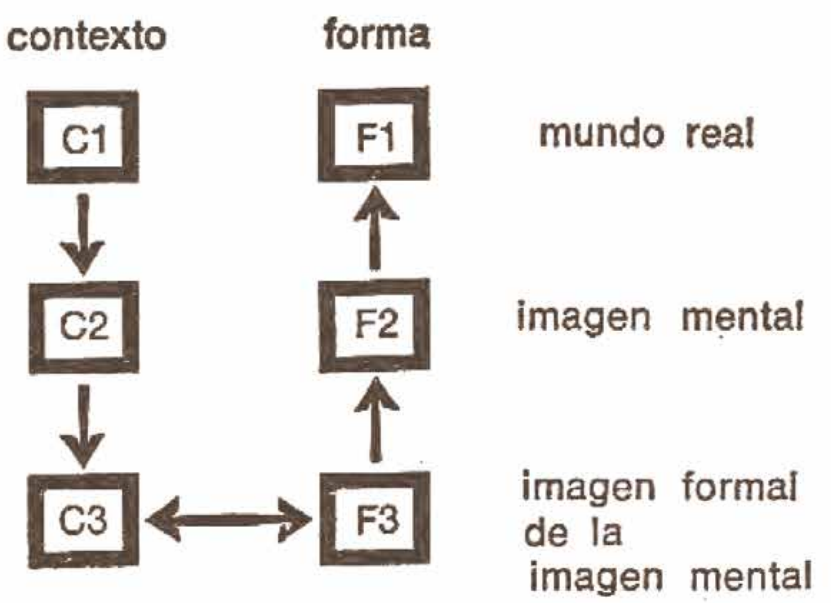

[FG.19]

Christopher Alexander Forma y contexto Harvard: Notes on the synthesis of form, 1964

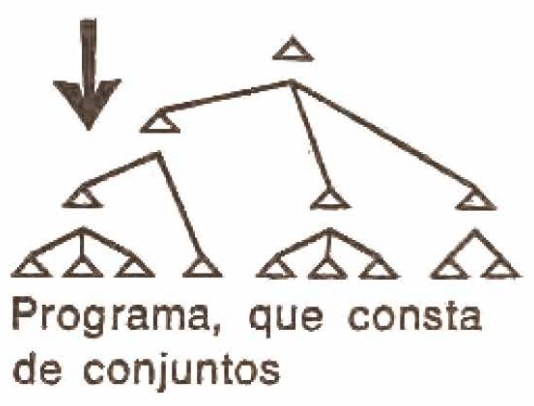

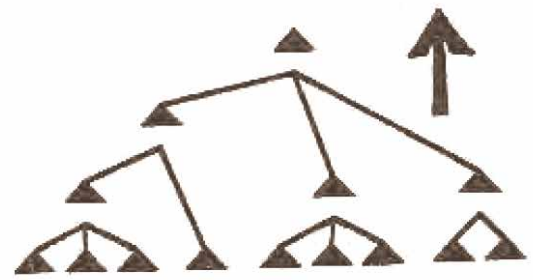

Realización, que consta de diagramas 
La noción de 'adaptación' tiene que ver la acomodación de las distintas funciones y distribuciones internas de un edificio, atendiendo a cada necesidad puntual. Los distintos conceptos que la conforman suelen apoyarse en la observación crítica de los fenómenos cotidianos y naturales, y su traspaso al plano propositivo resulta mucho más arraigado a la experiencia misma; a lo tradicional y a lo empírico antes que a lo normativo. Se trata de una jerarquización de la función entendida en su ámbito físico y geométrico, con un énfasis en el interior por sobre el exterior, implicando un general rechazo a la simetría como constante referencia a la belleza clásica.

Fuertemente ligada al pensamiento organicista, la 'adaptación' encuentra un origen en la linea de pensamiento empirista inglés. Un texto de Francis Bacon de 1625 titulado "Of Building" puede ser considerado como una de las primeras aportaciones. En él Bacon indaga en las distribuciones funcionales de un palacio y se cuestiona la jerarquía de la simetría por sobre la función; con esta operación abre una discusión ante la posibilidad de que la forma propia del edificio dependa de las distribuciones internas del mismo antes que de su composición externa. Esta aproximación será levemente continuada en Inglaterra por Henry Wotton, quien ofrece un planteamiento más pragmático que teórico. Ya en siglo XIX el organicismo se asienta como una estética y un modo de pensamiento, vinculado en parte a la experiencia del romanticismo, con una tradición en autores anglosajones como Augustus Pugin, John Ruskin u Horatio Greenough, quienes asumen que una construcción debe expresar su factura, sus funciones y debe ser capaz de adecuarse a situaciones exigidas por el medio al margen de una idea absoluta de belleza. Por otro lado, en la tradición francesa, donde la noción de 'adaptación' no contará con demasiados seguidores, Julien Guadet, con Eléments et théorie de l'architecture. Cours professé à l'École nationale et spéciale des beaux-arts conseguirá, ya entrando en el siglo XX, dar forma a un pensamiento determinista en cuanto a la configuración de los espacios. La apuesta de Guadet trata, al fin y al cabo, de un énfasis en la correspondencia entre un espacio y su función asignada. Continuando con la linea anglosajona iniciada por Bacon y continada por Pugin, Ruskin y Greenough, se establece una fuerte y amplia influencia en Estados Unidos, la cual se extenderá -a través de los aportes de Louis Sullivan- 


\subsubsection{ADAPTACIÓN}

hasta Frank Lloyd Wright, quien incorpora la importancia de la naturaleza y la vincula directamente al tema del individuo y sus necesidades particulares. A diferencia de Ruskin, Wright acepta la imposibilidad de la artesanía frente a la industrialización, pero al mismo tiempo enfatiza las libertades individuales que conforman la idea de democracia liberal. Sobre estas bases la noción de 'adaptación' encontrará su desarrollo más maduro en la década del veinte en Alemania, en el llamado "funcionalismo organicista", teniendo a Hugo Häring y a Hans Scharoun como principales exponentes. El aporte teórico de Häring, y el empuje por parte de la historiografía por parte de Adolf Behne a través de su libro Der moderne Zweckbau, llevarán a la que sea la expresión más clara de la 'adaptación'. Häring se opone rotundamente al mecanicismo y entiende que la naturaleza se basa en las variaciones de cada particularidad, entendiendo que esta última se sostiene a su vez en las necesidades puntuales de cada ente. Sus proyectos, junto a los de Scharoun, serán los que busquen con mayor empeño esta particularidad que resulta, al fin de cuentas, en una serie de formas arquitectónicas singulares. Esta noción de función, vinculada a la naturaleza, tendrá posteriormente otra interpretación importante mediante la figura de Alvar Aalto -quien hereda gran parte de los intereses teóricos de Häring sobre la naturaleza y la industrialización-, que desde Finlandia consolidará un modo de concebir la función manteniendo una noción de 'adaptación', la cual incorpora como novedad las características regionalistas en cuanto a la construcción y el cuidado por el medio en el que se asienta.

Con una base en la interpretación de la naturaleza, la noción de 'adaptación' no se caracteriza por la generalización de una solución en pos de un ahorro de recursos, sino por un desarrollo exquisito de la peculiaridad de cada necesidad, entendiendo siempre que detrás de esto yace también un principio estético del cual es preciso sacar partido. La 'adaptación' es una noción funcional que tiene que ver con el medio propio en que la arquitectura se asienta, entendido bajo su sentido más literal de territorio, con las características del individuo habitante e incluyendo las técnicas constructivas disponibles. Dentro de esta noción existe un lugar mucho más protagónico para el problema de la forma; no porque necesariamente se espere una resultante formal, sino porque los intereses puestos en juego exigen un diseño capaz de adaptarse al resultado menos previsible para satisfacer los objetivos más específicos. Esto no sólo tiene que ver con las propias funciones humanas, sino también con los modos de construcción propias de cada sitio, lo cual exige considerar constantemente las mencionadas particularidades. Aunque el tema de la forma no suele ser el argumento central de las propuestas incluidas dentro de esta noción, sí que resulta un constante contrapunto conflictivo. Este problema tiene que ver conque en la idea de 'adaptación' resulta mas difícil diferenciar la forma y el contenido, ya que suelen ir en continua sintonía; un conjunto que resulta finalmente la base de la solución arquitectónica. 



\subsubsection{ADAPTACIÓN}

Hans Scharoun Escuela en Darmstadt. Planta Berlin: Hans Scharoun. Bauten,

Entwürfe, Texte, 1951

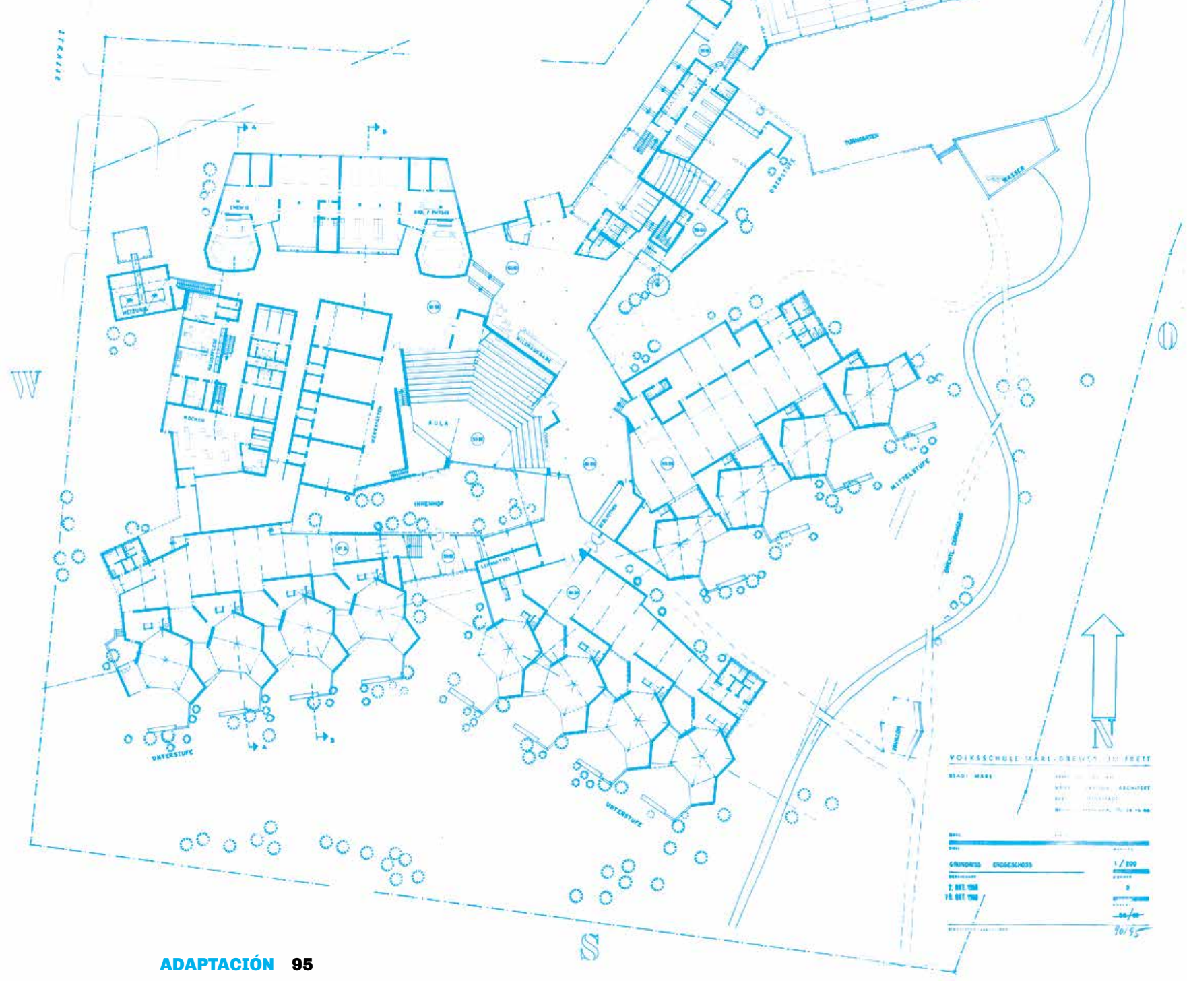


Varias de las teorías arquitectónicas más importantes que surgen después del siglo XVII tendrán como fuente de alimento principal las distintas lineas filosóficas elaboradas en el seno del humanismo. El empirismo, en Inglaterra, tendrá un impacto muy importante en la teorización de la arquitectura. El contexto de la nación en los siglos XVI y XVII estará marcado por una ruptura política, religiosa y cultural con la iglesia católica, -y por ende, con el resto de Europala que colocará a Inglaterra en un lugar de aislamiento cultural que llevará a experiencias arquitectónicas bastante dispares en comparación a los avances culturales de Italia y Francia. No sólo la iglesia no será ya el principal comitente, sino que gran parte de su patrimonio arquitectónico y artístico será destruido. ${ }^{1}$ Dado el ascenso de una clase social alta, el encargo de mansiones y palacios privados implicará la necesidad de manuales técnicos de construcción, pero también de directrices para la corte sobre estas 'nuevas' buenas costumbres. En este contexto, a pesar de que varios de los aportes de la arquitectura del Renacimiento italiano fueran rescatados, ${ }^{2}$ los conceptos que los textos de Vitruvio y Alberti manejaban en cuanto a la función tendrán poco asidero en la Inglaterra de este período. En los tratados ingleses, a diferencia de los italianos, habrá una preponderancia por el pragmatismo, los procedimientos y los modos de hacer.

Es cierto que la filosofía inglesa de corte empirista tendrá su maduración a mediados del XVII y comienzos del siglo XVIII, dela mano de John Locke, Joseph Addison, Francis Hutcheson, David Hume o Edmund Burke. Pero será Francis Bacon uno de los primeros en desarrollar esta forma de conocimiento, siendo además uno de los que sugiera un nuevo entendimiento para la función arquitectónica basado en este pensamiento. El empirismo tiene una presencia constante por tratarse de un modo de conocimiento basado en 'el hacer', a través de la acumulación de experiencias productivas y también por una tendencia hacia la lógica del "sentido común." En la antigüedad clásica el conocimiento a partir de la pura experiencia estaba reservado a las técnicas aplicadas, como la medicina, las artes y la arquitectura, y separado asimismo del 'saber,' es decir, del conocimiento sobre la verdad, la ética o la metafísica. No parece casual que la mayoría de los fundamentos de los tratados de arquitectura sobre el tema de la función tengan que ver con el acercamiento de primera mano al desempeño de los edificios existentes, antes que con la ideación de nuevas configuraciones y distribuciones.

Francis Bacon arremete contra la base idealista que sostiene la arquitectura del Renacimiento, la de un sistema clásico basado no en la experiencia, sino en el apriorismo. El brevísimo ensayo "Of Building," dentro del libro Essayes or Counsels, Civill and Morall, publicado en 1625 -como tercera edición ampliada de un compendio de ensayos que se habían editado por primera vez en 1597-, trata no tanto de la arquitectura sino de la descripción de lo que debería ser un palacio para la nueva aristocracia inglesa. Resulta así fundamental como ejemplo aplicado del empirismo basado en la observación directa de los hechos, pero ofreciendo una alternativa completamente diferente a la abierta por la noción de concinnitas de Alberti. La denominación architecture no es aún
2.2.1.

\section{Bacon. Uso contra simetría}

1. Ver la "Introducción" en Rey, Almudena Herrero et al., Tratados ingleses de arquitectura, 1563-1663: John Shute, John Dee, Francis Bacon, Balthazar Gerbier (Valladolid: Universidad de Valladolid, Secretariado Publicaciones e Intercambio Editorial, 2008). (Ed. orig. 2008).

2.

John Shute, quien escribe The First and Chief Grounds of Architecture, considerado el primer tratado de arquitectura en el Inglaterra, será quien incorpore algunas concepciones del Renacimiento italiano, habiendo estudiado a Alberti. Más tarde Inigo Jones incorporará por primera vez la concepción y denominación de arquitecto (architect) en Inglaterra, y junto a Henry Wotton difundirán fuertemente la obra de Palladio desde Venecia.

3.

Bacon, Francis, The essayes or counsels, civill and morall, vol. 15 (Oxford: Clarendon Press, 1985), p. 18. (Ed. orig. 1625). Traducido por el autor. Ibid. p. 19.

\subsection{1.a.}

Use 
incorporada en su vocabulario, pero sí la de use, articulada probablemente por primera vez en un texto de arquitectura. La primera sentencia del ensayo resulta la más importante en cuanto al tema de la función, ya que la misma dota de total preponderancia al uso de los edificios por sobre la belleza de los mismos:

Las casas se construyen para vivir en ellas y no para la contemplación; por tanto, hagamos que el uso se anteponga a la uniformidad, excepto en aquellos casos en que puedan darse ambos. Dejemos la apariencia para los palacios encantados de los poetas que los construyen con bajo coste. ${ }^{3}$

Esta apuesta resultará de importancia fundamental, no sólo para un contexto inglés distante de las experiencias renacentistas en las que la simetría resulta fundamental para alcanzar el fin máximo de belleza, sino también para complacer las necesidades de los nuevos palacios de la aristocracia, que en verdad se presentaban como desafíos en términos funcionales en los que se requería balancear la simetría (la belleza) con la distribución interna. En la descripción de Bacon hay una inclinación por dejar que las necesidades funcionales encuentren su lugar 'natural' dentro del proyecto, y alcancen, por su misma lógica, la configuración final de palacio. En definitiva, que se acomoden y se ajusten según sus requerimientos intrínsecos.

2.2.1.b. A pesar del poder rupturista de la citada sentencia de Bacon, la misma no suAsimetría pone la destrucción de las bases de la simetría, sino más bien la puesta en primer plano de las necesidades del use y de la correcta organización a través de la experiencias. Bacon afirma que «...para conseguir un palacio perfecto es necesario contar con dos laterales diferentes, uno para los banquetes (...) y otro para el hogar; uno para las fiestas y las celebraciones y el otro para la morada». ${ }^{4}$ Llamativamente, haciendo referencia a dos partes separadas, sigue persiguiendo un equilibrio que considera difícilmente alcanzable aplicando la simetría.

Desde la elección del sitio, pasando por la distribución, la definición de zonas y los detalles intenta en todo momento esclarecer cada uno de los sub-temas que componen el programa del palacio. Sin dejar de lado la uniformidad, se trata de un ejercicio de profundización sobre las nociones vitruvianas, como la de "naturaleza del lugar», o distributio, aplicadas a un proyecto concreto. Diferentes zonas según las actividades, las horas del día, las estaciones del año. El Castillo de Howard -que se trata en verdad de la mansión de la familia del mismo nombre; un tipo de edificio conocido en Inglaterra como country houseconstruido por Sir John Vanbrugh entre 1699 y 1712 es un ejemplo claro de un programa complejo, con numerosas estancias y zonas como las que le preocupan a Bacon.[FG.01] El esquema general, claramente barroco, presenta una batería de habitaciones principales que toman toda la cara este, a las cuales se llega luego de haber pasado por un hall principal; el elemento distribuidor se encuentra a su vez jerarquizado mediante una cúpula. El cuerpo este contiene los servicios ligados a la alimentación (cocinas, almacenes y comedores en el ala este principal y cervecería, panadería y otras dependencias en el ala exte- 
Rey et al., Tratados ingleses de arquitectura,

1563-1663: John Shute, John Dee, Francis

Bacon, Balthazar Gerbier, p. 85.

Agüera Ruiz, Antonio, Los Elementos de la Arquitectura por Sir Henry Wotton. Un texto crítico (Valladolid: Universidad de Vallolid, 1997), p. 78-79. (Ed. orig. 1997)

7.

Wotton, Henry, The elements of architecture (Londres: John Bill, 1624). (Ed. orig. 1624).

Capon, David Smith, Architectural theory (New York: John Wiley, 1999), p. 19-23. (Ed. orig. 1999)

[FG.01]

John Vanbrugh.

Castillo de Howard. Planta Baja

Londres: Vitruvius Britannicus. c. 1720,

1699.

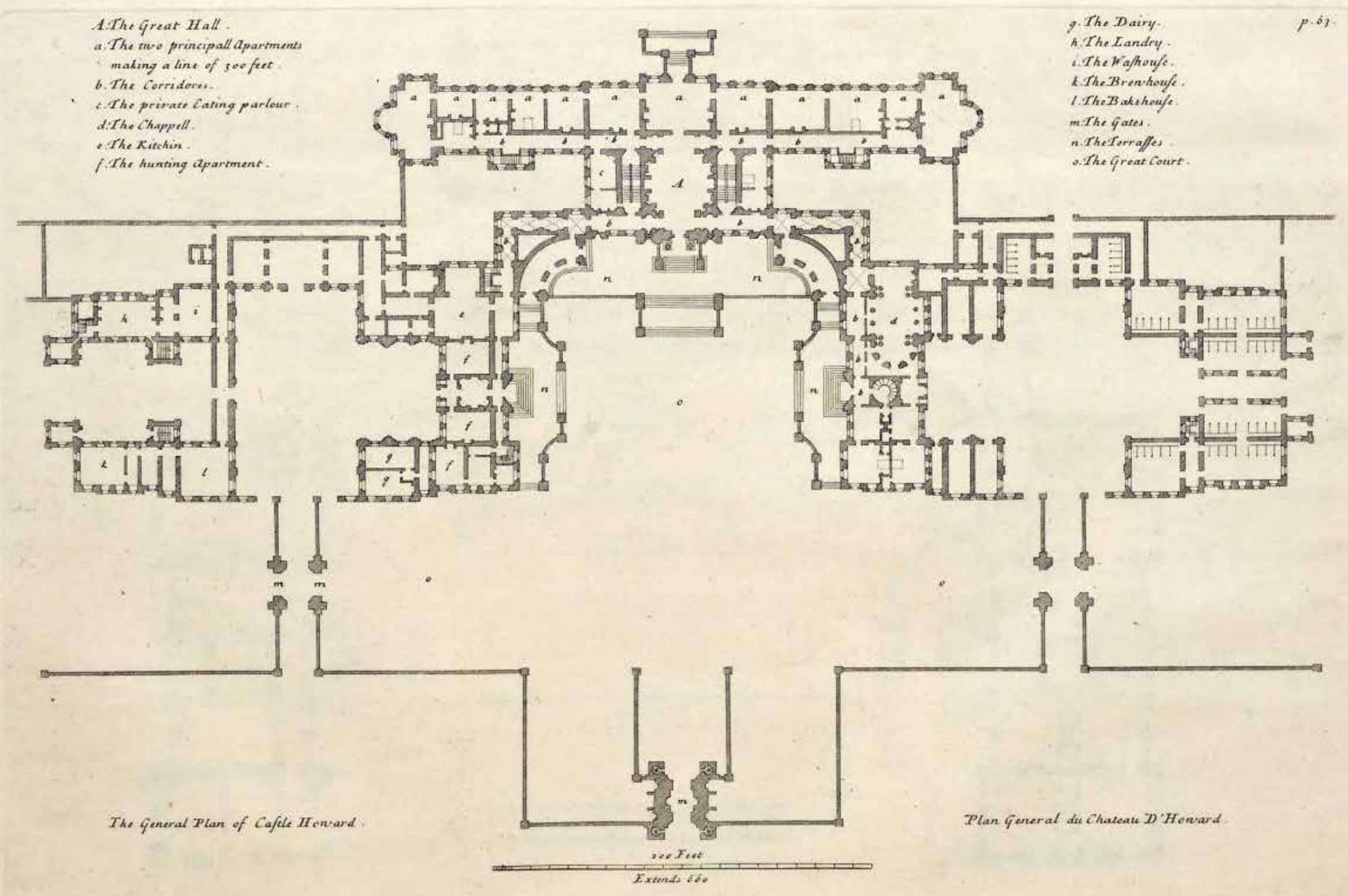


último no construido). Es evidente la concepción asimétrica, no sólo en cuanto a lo funcional, sino también en cuanto a particiones interiores; las que componen estas dos alas este-oeste, paradójicamente, son las que conforman los límites del jardín de acceso al castillo, es decir, puro equilibrio exterior frente a máximo desequilibrio interior, lo cual se logra en gran parte por medio de unas galerías que homogeneizan ambas fachadas. Pero si algo llama la atención es el extenso sistema de distribución (corridors) que permite la articulación de gran cantidad de estancias prescindiendo de galerías exteriores. Este elemento permite la separación de las zonas sociales de las privadas, y se encuentra resuelto con una gran simpleza. Los corredores son también pensados como espacios interiores de importancia, contando con una sucesión continua de ventanas que proporcionan iluminación homogénea y ritmo. En resumen, un programa complejo que acepta la asimetría funcional, pero que aún encuentra la belleza en el equilibrio asimétrico hacia el exterior.

2.2.1.c. La aproximación crítica que plantea Bacon hacia la simetría del sistema clásico

Continuidad de las costumbres no contará con un eco en el período; tal es el caso de Henry Wotton que, como Bacon tampoco tenía formación de arquitecto, y que escribe el tratado The elements of architecture al mismo tiempo que "Of building", mientras ambos pensadores competían por la dirección del Eton College. ${ }^{5}$ Wotton es uno de los arquitectos que, junto a Inigo Jones, introduce la influencia de Palladio en Inglaterra, y lo hace aplicando una precisión científica al estudio de los órdenes, en una linea de pensamiento similar a la que venía desarrollando su competidor. ${ }^{6}$ No obstante, a diferencia de Bacon, Wotton reconoce la importancia de Vitruvio y Alberti. En la Parte I del escrito comienza con una referencia directa al romano, en una traducción al inglés en la que intercambia sorprendentemente el utilitas de Vitruvio por el commoditas de Alberti -commodity, firmness and delight- pero, en el desarrollo del escrito, no establece relaciones entre los tres términos. En este sentido no presenta avances en comparación a las discusiones que Alberti propone frente al texto de Vitruvio; y en relación a la tríada, Wotton afirma que «bajo esta regla, y siempre en relación al uso, cualquier parte debe estar completamente acomodada. ${ }^{7}$ Como ocurría ya en Los diez libros de arquitectura, commodity no va a contar con un desarrollo profundo. Según menciona David Capon, el concepto va a aparecer en el texto en dos ocasiones para referirse al lo opuesto, es decir, a la 'incomodidad,' en referencia a un "acceso incómodo" y a la "incomodidad de las chimeneas de fuegos abiertos en los salones». ${ }^{8}$ Se trata, finalmente, de una concepción llana de lo 'cómodo', que no ofrece nuevas perspectivas frente al concepto de commoditas de Alberti. La palabra use aparece en el libro en varias ocasiones, pero la misma tampoco cuenta con una definición completa.

Por otro lado resulta preciso ligar la noción de ‘adaptación' en Inglaterra con la concepción pragmática de la arquitectura que venía estableciendo sus bases desde el empirismo. El "uso" tiene que ver, en su origen latino, (usus) con el empleo continuo de algo, es decir, con el mismo hábito. En todo el tratado de Wotton, las propuestas que realiza en torno al uso están claramente construidas desde una noción de la costumbre, es decir, de continuidad con 
las costumbres; por lo mismo los textos carecen de la pretensión teórica con la que sí contarán los realizados posteriormente, especialmente en Francia. Pero es justamente este desapego por la aproximación teórica y esta voluntad de pragmatismo la que permite una noción nueva de función bajo el marco de pensamiento de la 'adaptación'. Así será que aparezca por primera vez puesta en duda la relación entre la función de los edificios y la asentada simetría, aunque se limite sólo a una voluntad que aún no acaba de materializarse.

En la región donde la industrialización se desarrolla de manera más intensa y acelerada, la máquina va dejando fuera paulatinamente prácticas que, de un modo u otro, imprimían un carácter personal a las manufacturas. La amenaza de la desaparición del artesano y de su rol como eslabón último de la construcción dio lugar al romanticismo en el arte y la literatura inglesas, y luego a una crítica del materialismo y del utilitarismo de parte de varios poetas y escritores como Charles Dickens o Charlotte Brontë, ${ }^{9}$ o incluso por historiadores como Thomas Carlyle. ${ }^{10}$ En estas lecturas se visualiza una preocupación por la sociedad y las condiciones de vida de la nueva clase trabajadora, al mismo tiempo que una postura reaccionaria ante los efectos que la Revolución Francesa trajera al panorama político europeo del siglo XIX; la crítica a la democracia y la valoración del individuo como posible ‘héroe,' capaz de cargar por sí mismo con todo el peso y la responsabilidad de una sociedad, son síntomas evidentes. ${ }^{11}$

El espíritu crítico que caracterizaba a la Inglaterra del siglo XIX contaba con una fuerte base en la tradición empirista; ${ }^{12}$ esta amalgama envolvía el arte y la estética del período, y bajo este mismo marco de crítica a la industrialización es que se abre la batalla que John Ruskin va a pelear por medio de sus escritos, dando lugar a la arquitectura neogótica en Inglaterra, la cual derivará a su vez en una perspectiva sobre la función fuertemente centrada en lo constructivo. Por otro lado, resultan de importancia los antecedentes de Augustus Pugin, quien reclamara directamente el retorno a un modo de vida medieval y a ciertos valores espirituales. Pugin condenaba la arquitectura clásica, entendiendo que la misma se alejaba de la cultura cristiana, abogando por el gótico como el estilo que mejor representaba lo que él consideraba el «ideal medieval». ${ }^{13}$ Pero además de eso, Pugin recuperaba algunos conceptos de la tradición teórica francesa con respecto a la función -según De Zurko, con una clara deuda a las ideas de adecuación y economía de Durand- ${ }^{14}$ adaptándolos a su interés por el gótico. Ya en el primer párrafo de su libro Contrasts: or, A parallel between the noble edifices of the fourteenth and fifteenth centuries and similar buildings of the present day. Shewing the present decay of taste, escrito en 1836, Pugin exige una belleza sólo posible por la adecuación al uso del edificio. ${ }^{15}$ También al comienzo de The true principles of pointed or Christian architecture: set forth in two lectures delivered at St. Marie's, Oscott publicado cinco años después de Contrasts... Pugin plantea una tríada análoga a la vitruviana -no definida en profundidad- referida a convenience (comodidad), construction (construcción) y propriety (decoro), ${ }^{16}$ afirmando al mismo tiempo que todo ornamento debe enfatizar la construcción esencial de un edificio. ${ }^{17}$ Como también hará Ruskin, Pugin -quien tuvo además una prolífica carrera como arquitecto- emplea la
Ver "Darwin entre las máquinas. Luditas, maquinólatras y organicistas" en Prieto, Eduardo, La ley del reloj. Arquitectura, máquinas y cultura moderna (Madrid: Ediciones Cátedra, 2016).

10. Frampton, Kenneth, Historia crítica de la arquitectura moderna (Barcelona: Gustavo Gili, 2005), p. 42. (Ed. orig. 1980).

\subsection{2}

\section{Ruskin. Función vital}

\section{y transformación}

11.

Esto puede verse en sus conferencias de 1840 , en las cuales destaca el "genio" artísti$\mathrm{co}, \mathrm{y}$ el héroe político de diversos personajes de la historia.

12. Ver Pérez Carreño, Francisca, "La estética empirista" en Bozal, Valeriano y Arnaldo, Javier, Historia de las ideas estéticas y de las teorías artísticas contemporáneas, vol. 1 (Madrid: Visor, 1996).

13.

Ver Pugin, Augustus Welby Northmore, Contrasts: or, A parallel between the noble edifices of the fourteenth and fifteenth centuries and similar buildings of the present day. Shewing

\subsection{2.a}

Pugin. Vida medieval

the present decay of taste. (Leicester: Leicester University Press, 1973). (Ed. orig. 1836).

14. De Zurko, Edward, La teoría del funcionalismo en la arquitectura (Buenos Aires: Nueva Visión, 1970), p. 163. (Ed. orig. 1957).

15.

A pesar de esto Pugin vuelve a hacer énfasis en el concepto de caractère, en el mismo sentido en que lo planteara Blondel en el siglo XVIII. Según Pugin "Se admitirá fácilmente que el gusto por la belleza arquitectónica se basa en la idoneidad del diseño para el propósito para el que el edificio está destinado, y que el estilo de un edificio debe corresponderse con su uso, de tal forma que el espectador pueda percibir de inmediato el propósito por el cual fue erigido". Pugin, Augustus Welby Northmore, Contrasts: or, A parallel between the noble edifices of the fourteenth and fifteenth centuries and similar buildings of the present day. Shewing the present decay of taste. (Londres: A.W. Pugin, 1836), p. 1. (Ed. orig. 1836). Traducido por el autor.

16.

"... la apariencia exterior e interior de un edificio debe ser ilustrativa y estar en concordancia con el propósito para el que está destinado el mismo". The true principles of pointed or Christian architecture: set forth in two lectures delivered at St. Marie's, Oscott (Londres: J. Weale, 1841), p. 42. (Ed. orig. 1841). Traducido por el autor.

17.

Ver Ibid. p. 1.

18.

Ruskin, John, The seven lamps of architecture (New York: John Wiley, 1849), p. 8. (Ed. orig. 1849). Traducido por el autor. 
crítica incisiva para desarrollar sus argumentos teóricos, haciendo siempre énfasis en las técnicas de construcción. Así, en The true principles... el índice se divide según los modos constructivos del gótico. Ruskin hereda de Pugin el impulso crítico sustentado en una ética cristiana; la idea de función es para Pugin también una verdad a la cual el ornamento debe ser fiel.

2.2.2.b. Ruskin intercambia el impulso moderno de transformación por su predilección Juicio estético hacia un arte del pasado cada vez más amenazado por las nuevas técnicas constructivas fruto de la industrialización. Este proceso de modernización es para Ruskin una suerte de amenaza a la cultura artística, la cual busca defender a toda costa. Como Pugin, Ruskin era también un cristiano ferviente -lo cual se evidencia en la ética que funda muchos de sus juicios estéticos-, sosteniendo criterios de justicia, verdad o sacrificio. Estas características explican la imposibilidad de encontrar en Ruskin intenciones de avanzar en la transformación de las ideas asentadas de la función. Esta 'función' -la que refiere a la organización de las actividades dentro de los edificios- se encuentra prácticamente fuera los intereses de este autor, pero por otro lado, sí que resultan fundamentales en su concepción el rol funcional de los elementos propios de la arquitectura, en cuanto a su expresión, sus características estructurales, sus posibilidades y limitaciones constructivas y, por sobre todo, en cuanto a la labor que cada elemento requiere para su concepción constructiva, la cual impacta en la forma y configuración de los edificios, siendo estos dos de los pilares de la 'adaptación'. Como en Pugin, las teorías de Ruskin se apoyan fundamentalmente en la crítica, tanto artística como social; a través de esta construye, paso a paso, un conocimiento sobre la arquitectura que, aunque resulte conceptualmente reaccionario, aparece al mismo tiempo como novedoso. En este proceso es posible visualizar fragmentos que hilvanan problemas funcionales del pasado, o que repercuten de una manera u otra en la constitución de la noción de 'adaptación'.

2.2.2.c. Como explica en la "Introducción" de The seven lamps of architecture, publicado en 1849, el pasado no resulta para Ruskin un valor por sí mismo, sino que es el motivo que le proporciona un material para poder identificar leyes comunes en las artes. Estas leyes serían las "lámparas de la arquitectura», las cuales, según Ruskin, se verían en muchas ocasiones de la historia opacadas o distorsionadas. Reubicar en su lugar de importancia estos valores arquitectónicos es el fin de este libro, y Ruskin apela especialmente a la mencionada ética. En principio distingue la arquitectura de la construcción, explicando que esta última no tiene por qué convertirse en la primera; y que si la arquitectura sólo se diferencia de la construcción por el agregado de "elementos innecesarios», entonces pocos edificios entrarían, por su propia naturaleza, dentro de la categoría 'arquitectura' -templos, monumentos o edificios institucionales. ${ }^{18}$ La atención a esos elementos que, a primera vista, no tienen un rol funcional será también común en la obra del autor, dando lugar a la artesanía como valor cultural, puesta en riesgo por el llamado tajante a la función que la modernidad comienza a imprimir en la arquitectura. Ruskin -casi en respuesta a la postura 
preocupado por la importancia creciente que la relación costo-beneficio tiene en la arquitectura. Para Ruskin construir con más o menos recursos no es un tema de necesidad, ya que en sucesivas ocasiones resulta importante la riqueza. La calidad de la construcción sí es para el autor un tema que puede volverse necesario en la arquitectura. De algún modo entiende que los materiales comprenden una función que no resulta sólo pragmática, sino también sensorial, y por lo mismo su valor propio supera a su valor de cambio. Pero no siempre se trata de los materiales en sí mismos, sino de cómo los mismos son tratados en la construcción; se trata, en definitiva, de construir «lo mejor posible", con los recursos disponibles, pero sin necesidad de recurrir siempre a una économie simplificadora. Según él, más allá del costo, es preferible un material más económico, pero en su mejor estado: "si no se puede piedra, usar ladrillo, pero el mejor ladrillo». ${ }^{19}$

Otro problema relacionado a la économie que Ruskin coloca sobre la mesa, y que ya había señalado con énfasis Pugin, es el de lo visible y lo no visible en un edificio, y el del esfuerzo requerido en la construcción que puede no percibirse, lo cual está directamente relacionado a la función, ya que la existencia de la misma -tanto en la organización del programa como en la función constructiva de un elemento- no siempre resulta evidente. Por lo mismo Ruskin exige un cuidado en los esfuerzos que no reditúan en una expresión evidente (esas partes de un edificio que permanecen ocultas) y resalta la importancia de la distancia de observación. Al mismo tiempo, en el exhaustivo análisis que realiza en torno al gótico, en The stones of Venice, de 1853, enfatiza la relevancia de los órdenes, pero a su vez advierte del peligro que supone el propio sistema, y la valoración exagerada que, según él, se hace de ellos. Aún así, nuevamente, como en las primeras nociones de la tradición vitruviana, tanto la belleza como la función de los elementos encuentran para el autor un nacimiento en la interpretación de la naturaleza, como un aprendizaje directo. Primero naturales, luego humanas; las estrías de la columnas griegas responderían, por ejemplo, a ciertos elementos lineales presentes en la naturaleza; el arco de medio punto estaría tomado de las hojas de algunos árboles. En este entramado Ruskin propone, incluso, una tabla de relaciones entre varios elementos naturales y ornamentales. ${ }^{20}$ De esta manera introduce el conflicto que supone para el hombre lidiar con la linea recta, propia de muchos elementos constructivos, sobre todo en torno a la decoración, dando lugar a una flexibilidad formal que será característica de la ‘adaptación' funcional moderna.

El problema de la ética en la arquitectura, sobre todo ligado a la idea de "verdad” en la función, la cual ya había sido reclamada por Lodoli, reaparece. Aunque Ruskin no traslada la preocupación por la verdad a los temas funcionales en concreto -como sí lo hacía el italiano- sí visualiza los problemas de la función en caso de tener que ser esta atendida de principio a fin. Es decir, si se considera, como lo hacía Lodoli, que la función requiere una atención y honestidad por sobre otras problemáticas del proyecto de arquitectura, ésta reclamará un modo de enfocar el proyecto en el cual los resultados pueden no siempre ser tan previsibles, dado que la función deviene de necesidades que
20.

Ver "La lámapara de la belleza" en Las siete lámparas de la arquitectura (Barcelona: Editorial Alta Fulla, 1987). (Ed. orig. 1849).

21. Ver "La lámpara de la verdad" en Ibid. p. 26.

22. Ruskin considera que las mentiras en la arquitectura pueden aparecer en tres formas diferentes. En: 1. la insinuación de una estructura que no existe. 2. la pintura que insinúa un material o 3. el empleo de ornamentos. Hasta este punto sus teorías se acercan mucho a las de Lodoli. Ruskin considera que el gótico es el estilo con menos mentiras, aunque reconozca que en algún punto también las tenga.

23.

Ver "La lámpara de la verdad" en Ibid. p. 28.

\subsection{2.d}

\section{Expresión}

\section{4.}

Ver Pérez Carreño, Francisca, "La estética empirista" en Bozal y Arnaldo, Historia de las ideas estéticas y de las teorías artísticas contemporáneas, 1.

25.

"En la cúpula del Duomo de Parma, el mismo pintor ha representado la Asunción con tanto poder de engaño que ha hecho que una bóveda de unos nueve metros de diámetro parezca una abertura del séptimo cielo envuelta en nubes, invadida por un impetuoso mar de ángeles. ¿ Es incorrecto? Pues no, el tema enseguida excluye la posibilidad de engaño. Podríamos haber tomado las parras por una verdadera pérgola y a los chiquillos por sus rondadores ragazzi; ahora bien, sabemos que las nubes quietas y los ángeles inmóviles son siempre obra humana; así pues, dejémosle que le ponga toda su intensidad y bienvenido sea, nos podrá encantar, no traicionar". Ruskin, John, "La lámpara de la verdad" en Las siete lámparas de la arquitectura, p. 27.

\subsection{2.c.}

Imaginación 
no se encuentran necesariamente ligadas al lenguaje arquitectónico per se, como sí sucede con la estructura, por ejemplo. Ruskin se anticipa a las limitaciones que una exigencia radical de la verdad puede suponer, incluyendo el tema de la imaginación.

Podría pensarse en un primer momento que todo el reino de la imaginación es también el del fraude. No es así: el acto de la imaginación es un emplazamiento voluntario de los conceptos de las cosas ausentes o imposibles; su placer y su nobleza residen, en parte, en el reconocimiento y la contemplación de aquéllas como tales, es decir, en el reconocimiento de su ausencia o imposibilidad real en el momento de esa presencia o realidad aparente. Cuando la imaginación engaña, se convierte en locura. Es una facultad noble desde el momento en que reconoce su propia idealidad; cuando deja de hacerlo es demencia. Toda la diferencia radica en el acto del reconocimiento, en no ser fraude. Es preciso, en tanto criaturas espirituales, que seamos capaces de inventar y percibir lo que no existe; y en tanto criaturas morales, que sepamos y reconozcamos al mismo tiempo que no existe. ${ }^{21}$

Esta «imaginación» serviría también para explicar los hechos; se trata de una comunicación hacia el exterior en vez de una "mentira»,22 la cual Ruskin entiende de esta manera: "Como ocultaciones engañosas de la estructura se han de clasificar, aunque incluso más vituperables, las presunciones engañosas de ésta -la introducción de miembros que tendrían, o profesan tener, una función, sin tener ninguna». ${ }^{23}$ Pero al mismo tiempo aparece la ya mencionada «imaginación», un concepto central en el empirismo inglés, ${ }^{24}$ que es la que permitiría el juego fundamental en la percepción de la función de los elementos. En esta linea -aunque Ruskin refiere constantemente a la función de los elementos constructivos-, la «imaginación» también tiene proyección en la propia función de los espacios, para los cuales el rango entre lo que se imagina de una actividad y las posibilidades que de la misma derivan resulta amplio. La arquitectura, y la imaginación aplicada a ella, es la que permite proponer una serie de posibilidades que se separan de lo que inicialmente resultaba verdadero para esa actividad original. Ruskin lo ejemplifica a través del fresco de la cúpula del Duomo, ${ }^{25}$ por medio del cual diferencia la idea de "encantamiento" de la de "mentira". Este encantamiento nacido de la imaginación y entendido como obra humana que toma distancia de la naturaleza es uno de los aportes laterales más importantes que Ruskin introduce a las nociones de función. Así comienzan a materializarse en la arquitectura de mediados del siglo XIX en Inglaterra temas que, aunque de modo exclusivamente teórico, había anticipado ya Bacon, en las primeras aproximaciones al empirismo. Esta temprana discusión en torno a los problemas concretos de la simetría tiene proyección directa en Ruskin, quien encuentra el camino en la recuperación de los valores del gótico.

2.2.2.d. La flexibilidad espacial que proporciona la construcción típica del gótico le perLiving architecture mite a Ruskin imaginar una arquitectura que, como organismo vivo, es capaz de mutar en múltiples funciones. Se trata de un sistema abierto plausible de 
27.

Las piedras de Venecia (Madrid: Consejo General de La Arquitectura Técnica de España, 2000), cap. 38. (Ed. orig. 1853).

28.

Este argumento ya había sido utilizado de forma similar por Pugin, quien había afirmado que uno de los principios de la "arquitectura Católica" donde "cada una de las partes posee un destino propio". Pugin, The true principles of pointed or Christian architecture: set forth in two lectures delivered at St. Marie's, Oscott (Londres: J. Weale, 1841), p. 60. (Ed. orig. 1841). Traducido por el autor.

29.

Ver Frampton, Historia crítica de la arquitectura moderna, p. 43.
[FG.02]

Philip Webb

Red House. Planta baja y planta alta

Londres: Heritage Image Partnership, 1859.

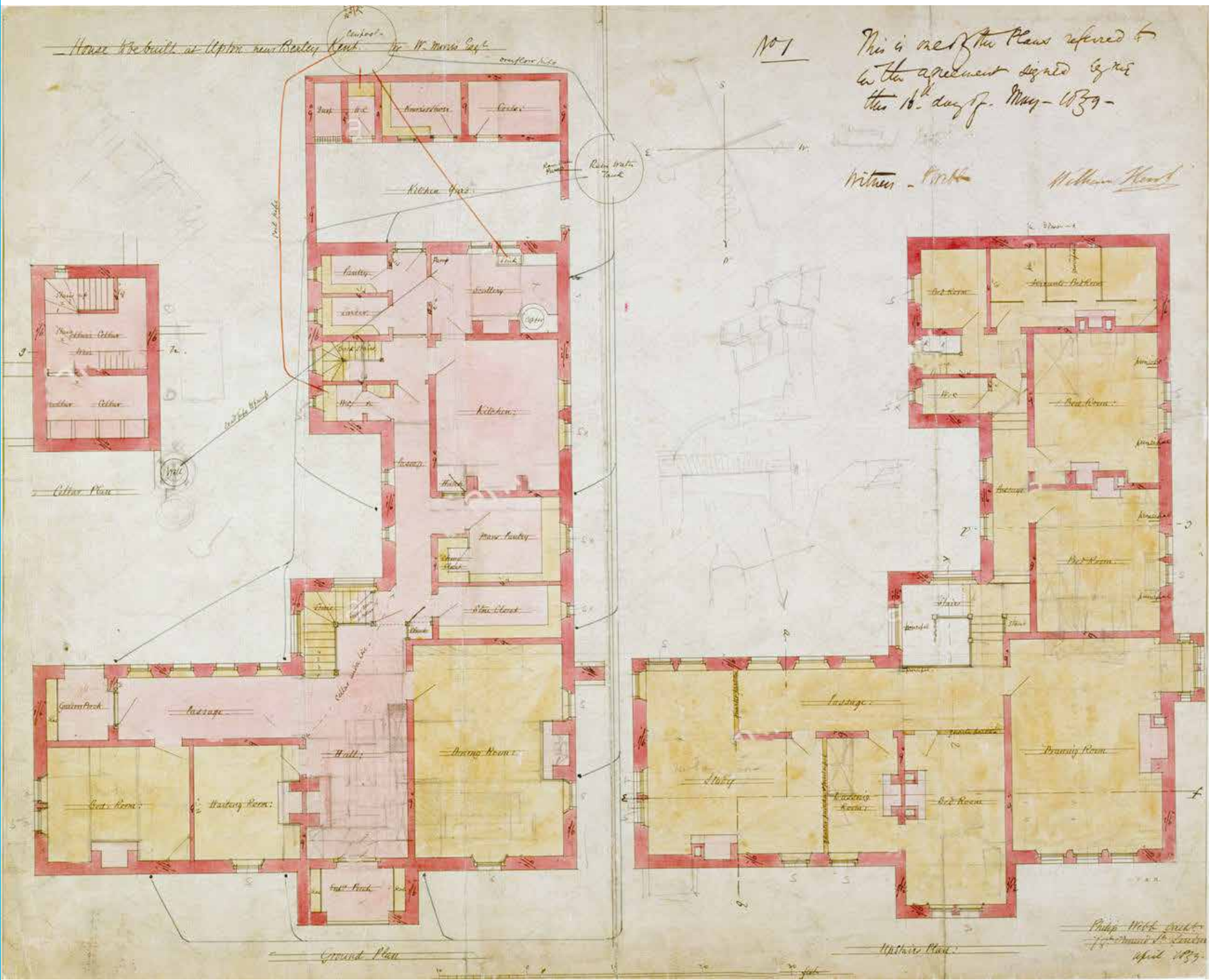


los caprichos casuales que no siempre pueden preconcebirse de modo estrictamente racional. Contrario a la aproximación albertiana de la naturaleza, en la cual se sigue sosteniendo el principio de la simetría, este organismo tiene dentro de sus reglas la capacidad de adaptarse a diferentes fines manteniendo su esencia constructiva, que es lo que al fin y al cabo le interesa al autor. No habría entonces "un tipo de construcción”, sino más bien "un tipo de gótico" para cada programa de necesidades. Ruskin propone que "gran parte de la belleza depende de la energía vital que es propia de lo orgánico», ${ }^{26}$ pero sin perder de vista que está haciendo referencia exclusivamente a la vida que la arquitectura misma genera para sí, es decir, a sus propios elementos, y a la importancia de expresar en la construcción de los mismos esta vitalidad. Llama living architecture a la catedral de Pisa, la cual toma como ejemplo; es decir, a aquella que produce la sensación de acomodación a toda necesidad arquitectónica, con variaciones en los arreglos. Estas variaciones definen una living architecture que no la ve en el uso del edificio propiamente dicho, aunque el mismo produzca -por una novedosa acomodación- un modo de vida diferente, sino en lo maleable de su concepción estructural y constructiva.

En The stones of Venice el autor realiza la que tal vez sea su aproximación más cercana al problema de la ‘adaptación', advirtiendo sobre "la capacidad del gótico de satisfacer cualquier función, sea vulgar o noble». ${ }^{27}$ Ruskin considera que, al tratarse de una arquitectura cuyas proporciones son indeterminadas -en una referencia clara a la arquitectura neoclásica-, se pueden complacer sin inconveniente diferentes usos. ${ }^{28}$ El gótico incluiría una capacidad de "cambio de forma" que le permitiría adaptarse sin perder unidad ni majestuosidad. Satisfaciendo el reclamo de Bacon por una arquitectura que no se viera atada a la simetría, no habría inconveniente para el autor en abrir una ventana, o colocar un arbotante por pura necesidad. La apariencia externa no resulta para Ruskin un condicionante, en el caso del gótico, y la diferencia y el error resultan, incluso, valores. Arquitecturas como las de Philip Webb, William Eden Nesfield o Richard Norman Shaw resultan ejemplares de esta concepción, y resaltan por momentos con mayor vigor que en las teorías del autor inglés la capacidad de adaptabilidad funcional del gótico de esquivar regulaciones devenidas del estilo y adentrarse en las necesidades y diferencias que las distintas actividades de un edificio suponen. Todo esto iba tener lugar en la arquitectura doméstica inglesa, y la Red House de Philip Webb, construida en 1859 en Bexleyheath para William Morris, significó el primer puntapié de una serie de obras que ilustrarían las ideas de revival de la época. ${ }^{29}$ [FG.02] En ella, la 'adaptación' aparece desplegada con una libertad que hasta el momento no había tenido lugar en la arquitectura. La distribución expresa, desde el inicio, la intención de no rendir un homenaje al objeto arquitectónico, sino más bien de recoger la sensibilidad del lugar, o más bien de generar una interpretación del lugar a partir del nuevo edificio; apela a una distribución en 'L', en planta, que se abre hacia un pozo de agua ubicado en el patio, el cual parece desafiar el avance de la tecnología, revalorizando las costumbres medievales y enfatizan- 
su espacio y dimensión necesarios, sin reparar en el riesgo que supone la expresión exterior que, inspirándose en motivos medievales puede, como afirmaba Ruskin, aceptar la aparición de ventanas o salientes donde haga falta. De hecho Webb aprovecha este recurso para ensayar una variedad de aberturas y de modos constructivos con el ladrillo. Aberturas verticales en el prisma de la escalera, ubicado en el encuentro entre los dos volúmenes de la casa; aberturas circulares y cuadradas en la circulación interior la cual va generando diversos modos de iluminación, hasta rematar en una doble ventana con saliente; ventanas notablemente pequeñas en los servicios. Webb no pretende con esta operación retrotraerse hasta al gótico medieval, sino más bien recuperar sus libertades para poder actuar con eficacia frente a las exigencias del siglo XIX. El despliegue de la casa, que por la misma inclinación hacia la satisfacción de las funciones deja ya de lado cualquier equilibrio simétrico -como lo planteara Bacon-, tampoco parece expresar preocupación por alguna otra regla que suponga la búsqueda de la belleza, en un sentido clásico; la expresión de la casa se basa, como afirma Ruskin, en la nobleza de un estilo que resulta conocido y común a la cultura a la cual pertenece. La construcción artesanal de ladrillo y la aparición de múltiples chimeneas que enfatizan la verticalidad del gótico será común, no sólo a la Red House, sino a buena parte de la arquitectura de este período. Si en gran parte de la tradición vitruviana las teorías de la función se construían a través de la observación atenta de las costumbres que iban modificándose, adaptándose o, más bien -y especialmente en el caso de Francia- renovándose, la arquitectura de la Red House supone un paso lateral en el cual se busca incisivamente retrotraer a la sociedad a un modo de vida que, si aún no está caduco, se encuentra en riesgo de desaparecer. Esta operación muestra una afición claramente reaccionaria, pero al mismo tiempo ofrece una muestra de una práctica que será común en el siglo XX, en la cual la función se propone a partir de una interpretación y búsqueda de transformación de la sociedad, con un respaldo que no puede ocultar rasgos ideológicos. Como se ha mencionado, Ruskin cree firmemente en que la utilización de materiales tradicionales - piedra, madera, ladrillo- en desmedro de los materiales industrializados que comienzan a hacer su aparición -como el acero o el cristal- confiere automáticamente a la arquitectura un carácter distintivo. ${ }^{30}$ A su vez discute indirectamente la necesidad de un caractére, en el sentido como lo planteara Blondel, en el cual la finalidad del edificio fuera expresada al modo de un lenguaje social, suponiendo una variedad de caracteres posibles a través de los cuales el arquitecto expusiera su propia interpretación de la función y el sentido social del edificio. Para Ruskin, en cambio, la variedad de caracteres no es necesaria en la arquitectura, sino que busca una sola expresión, noble, honesta o sagrada, más allá del sentido funcional de la misma, la cual queda sintetizada en esos valores medievales, herencia de las visiones de Carlyle. Intercambiando la variedad del caractére por esta expresión única que integra los valores que provienen de la arquitectura medieval, el reconocimiento visible de los múltiples programas de una sociedad en evidentes vías de modernización queda invalidado. Esto tiene su raíz en que Ruskin no considera carácter sagrado, o de alguna acusada y lastimosa fealdad, en la iglesia rural más sencilla o de construcción más desmañada, donde la piedra y la madera se emplean de forma tosca y desnuda, y las ventanas se cierran con vidrio blanco". "La lámpara de la verdad," en Ruskin, Las siete lámparas de la arquitectura, p. 27.

31.

"Así cayó la gran dinastía de la arquitectura medieval. Todo por haber perdido fuerza y desobedecido sus propias leyes - porque su orden, consistencia y organización se habían quebrado por todas partes-, de modo que no pudo oponer resistencia alguna a la acometida de una innovación arrolladora. Todo, fijémonos bien, por haber abandonado una simple verdad. Fue a partir de la renuncia a su integridad, a raíz de empeñarse en asumir la apariencia de lo que no era, que se presentaron las múltiples formas de enfermedad y decrepitud que minaron los pilares de su supremacía". "La lámpara de la verdad," en Ibid. p. 30.

32.

Ruskin considera además que el carácter de un edificio puede venir dado de a inspiración propia en la naturaleza o en del propio poder humano. "La lámpara del poder" en Ibid. p. 59.

33.

Ver Greenough, Horatio, "Aesthetics in Washington," Form and Function: Remarks on Art by Horatio Greenough, (Los Angeles: University of California Press, 1947). (Ed. orig. 1851). Traducido por el autor.

34.

Ibid. p. 37.

\subsection{2.e.}

\section{Carácter medieval}


que el problema de la arquitectura se encuentre en las funciones, ni en la variedad de estas, sino más bien en la construcción de 'una arquitectura' que pueda integrarlas a todas a la vez, al modo de una síntesis. Por lo mismo confía plenamente en la 'adaptación' del gótico; aunque esta pueda también verse en crisis, dados los cada vez más complejos requerimientos programáticos de la Inglaterra del siglo XIX. Pero, como resulta evidente, Ruskin no está interesado en resolver necesidades sociales propias de su tiempo a cambio de poner en juego los valores de la arquitectura medieval. ${ }^{31}$ El suyo es un retorno que implica no sólo la recuperación de los conceptos constructivos y de factura de la obra, sino que incluye también la readaptación a modos de vida que alcancen la emancipación frente a la maquinaria moderna.

Al mismo tiempo, a este único "caractére medieval" -que según el autor sería inherente a la construcción del gótico- le confiere también la capacidad de persistir en el tiempo, ya que «(...) la arquitectura que perdura suele tener dos formas: una caracterizada por una excesiva delicadeza, y la otra por una severa majestad, donde se siente el Poder del Espíritu». ${ }^{32}$ La permanencia es un tema que también tiene relación con el lugar secundario que Ruskin confiere a la función en los edificios. Un objeto que, por su valor propio, siga utilizándose durante siglos y siglos puede significar, o bien que las necesidades de sus usuarios no se modifican significativamente o bien que las necesidades se adaptan a lo que el objeto puede ofrecer. Ambas podrían ser válidas según el discurso expuesto, y en ambas persiste una importancia puesta en el objeto antes que en el sujeto que la utiliza; para Ruskin el valor del sujeto se encuentra en la producción y en la apreciación de la obra de arte; no en su uso explícito.

2.2.3. A través de una serie de ensayos producidos a mediados del siglo XIX, Horatio Greenough. Greenough es capaz de establecer unas sólidas bases para un pensamiento Lo orgánico y lo monumental original en cuanto a la función en los Estados Unidos, abogando por una arquitectura con identidad propia para su nación, al mismo tiempo que divulgando una crítica enfática sobre el neoclasicismo y el neogótico, los cuales contaban con amplio desarrollo en los edificios públicos norteamericanos de su período. Su formación y práctica como escultor no empañan una crítica estrictamente disciplinar y centrada casi obsesivamente en la valoración de la función.

2.2.3.a. Una de las principales batallas de Greenough es la de rechazar lo que consiInner distribution dera como motivos de culturas extranjeras (europeas) aplicados sin un sentido histórico en Estados Unidos. Gran parte de sus críticas irán dirigidas a la obra de Thomas Jefferson, con quien no comparte la adaptación del lenguaje clásico;33 pero a diferencia de Ruskin, tampoco encuentra suelo fértil en la recuperación del gótico. En referencia al Smithsonian College -obra de revival gótico que James Renwick comenzara en 1846- [FG.03] Greenough discute sus aspectos funcionales, diciendo que,

Aún yace cierto misterio en esas torres y en esos campanarios empinados que consigue inquietarme; esta es una cultura práctica. Esas torres deberían estar ahí por algo (...) Propongo, de aquí en más, examinar el edificio en cuando a su 
De modo similar a como lo hiciera Ruskin en Inglaterra, Greenough produce una crítica de la arquitectura que también incluye los rasgos culturales propios y, en menor medida que el autor inglés, una ética. Esta última tendrá que ver principalmente con resaltar los valores pragmáticos propios de la cultura norteamericana. Greenough habla ya de una «arquitectura moderna americana", y para la misma se adelanta a la idea de que el edificio debe expresar su inner distribution (distribución interior), es decir una función basada en los componentes genuinos de la costumbre y las necesidades culturales. La idea de inner distribution, aunque apenas esbozada por Greenough, resultará clave para comprender el desarrollo de la ‘adaptación' en la arquitectura moderna norteamericana y su raíz organicista. Al mismo tiempo que producía esta lectura derivada de una interpretación de la naturaleza y, paradójicamente, al contrario que Ruskin, era también un impulsor de la industrialización y de la renovación que esta pudiera engendrar en la arquitectura estadounidense. Estas dos vertientes contrapuestas son una característica particular de su discurso.

El impulso para un acercamiento más directo entre el arte y la industria está presente constantemente en los escritos del autor, quien es también uno de los primeros en considerar la belleza artística de los artefactos industriales. De forma bastante temprana Greenough no sólo se ve seducido por la estética propia de las máquinas, sino que la misma le sirve también como contrapunto con respecto al tema de la imitación de los motivos clásicos, anticipándose a la apuesta de Le Corbusier en Vers une architecture:

¡Observe un barco en el mar! Vea la forma majestuosa de su casco mientras se apresura a través del agua; observe la curva agraciada de su cuerpo, la transición suave, de redonda a plana, el agarre de su quilla, el salto de sus arcos, la simetría y la rica tracería de sus bastones y jarcias (...) ¿qué imitación de los griegos fue capaz de producir esta maravilla de la construcción? Este es el resultado del estudio profundo del hombre, donde la Naturaleza habla de las leyes de la construcción, no en la pluma ni en la flor, sino en los vientos y las olas; y el hombre se inclinó para escuchar y obedecer. ¿Podríamos llevar a nuestra arquitectura civil las responsabilidades que pesan sobre nuestra construcción naval? Necesitamos mucho tiempo para tener edificios tan superiores al Partenón, según los fines que necesitamos... ${ }^{35}$

Resulta claro que lo que respalda la crítica al neoclásico es la llamada de atención sobre una incorrecta -o incluso nula- interpretación de las necesidades propias de la época; una falta de estudio de los problemas funcionales. Incluso, yendo más allá que Ruskin, supone que nada de lo que está en el pasado puede ser suficiente para conformar la vida contemporánea; y la máquina es el ejemplo más evidente.

Greenough es también uno de los primeros autores en incorporar el concepto de lo orgánico dentro de la arquitectura; ${ }^{36}$ paradójicamente, la definición que dará del mismo será constantemente contrastada con la de monumentalidad. Distingue, en primer lugar, entre la arquitectura puramente monumental -apuntada hacia la simpatía y fe de una comunidad- de aquella que tiene un
"American Architecture," Form and Function: Remarks on Art by Horatio Greenough, en Form and Function: Remarks on Art by Horatio Greenough (Los Angeles: University of California Press, 1947), p. 60. (Ed. orig. 1843).

36.

Como explica Eduardo Prieto, pueden encontrarse rasgos de los orígenes del organicismo -o del antimecanicismo- en diferentes pensadores de la Ilustración de fines del siglo XVIII como Rosseau, o Kant. Un cambio de bases desde lo racional y cuantitativo hacia lo 'vital' y cualitativo. Ver Prieto, Eduardo, "Von Innen nach Aussen. Principios filosóficos del organicismo en la arquitectura," Cuaderno de Notas, 15, (2014).

37.

"American Architecture," p. 54.

38.

Ver "Relative and independent beauty," en

Form and Function: Remarks on Art by Horatio Greenough. (Los Angeles: University of California Press, 1947), p. 74. (Ed. orig. 1853).

39.

“American Architecture," p. 64.

\subsection{3.b.}

Artefactos modernos

40.

“Aesthetics in Washington," p. 20.

\subsection{3.c.}

Organic structure 
valor utilitario, la cual considera como organic structure (estructura orgánica). Para Greenough existe una degeneración en la disciplina, producto de intentar transformar cualquier tipo arquitectónico en un monumento, y de esta manera abandonar el motivo inicial que le dio impulso; incluso abandonar la misma función que le dio sentido inicial:

Si consideramos la arquitectura desde su perfección en los días de Pericles hasta su decadencia manifiesta en el reinado de Constantino, encontraremos que uno de los síntomas más seguros de la decadencia fue la adopción de formas y modelos admirados para fines no contemplados en su invención. El foro se convirtió en un templo; el tribunal se convirtió en un templo; el teatro se convirtió en una iglesia; ¡La columna, ese miembro organizado, esa parte subordinada, establecida por sí misma, usurpó la unidad y fue un monumento! Los grandes principios de la arquitectura fueron abandonados, la corrección dio paso a la novedad, la economía y la vanagloria asociada produjeron mezquindad y pretensión. ${ }^{37}$

Si esta decadencia ya existía en la arquitectura romana, Greenough vuelve a visualizarla, incluso con más énfasis, en el neoclásico aunque, del mismo modo que muchos autores de la tradición vitruviana, Greenough vuelva a entender a la naturaleza como fuente de alimento; lo orgánico como una "armonía multifacética", capaz de responder al llamado de diversas funciones al mismo tiempo. ${ }^{38}$

2.2.3.d. Pero este cambio hacia la armonía no implica un abandono de la monumentalidad -la que el autor considera fundamental-, sino más bien un argumento sólido para la misma. El edificio público será el ejemplo más claro -en evidente sintonía con la construcción del estado norteamericano. Para el autor existen dos temas centrales a los que debe apuntar un edificio público, primero, la organic structure; y segundo, su carácter monumental; ${ }^{39}$ pero será en la primera donde la monumentalidad encuentre su base. Según el autor esto se resume en "plantar un edificio firmemente en el suelo; darle la luz que sea posible, el aire que debe ser necesario; repartir los espacios por conveniencia, decidir su tamaño y modelar sus formas para sus funciones, estos actos organizan un edificio". ${ }^{40}$ Greenough considera que el carácter monumental de un edificio

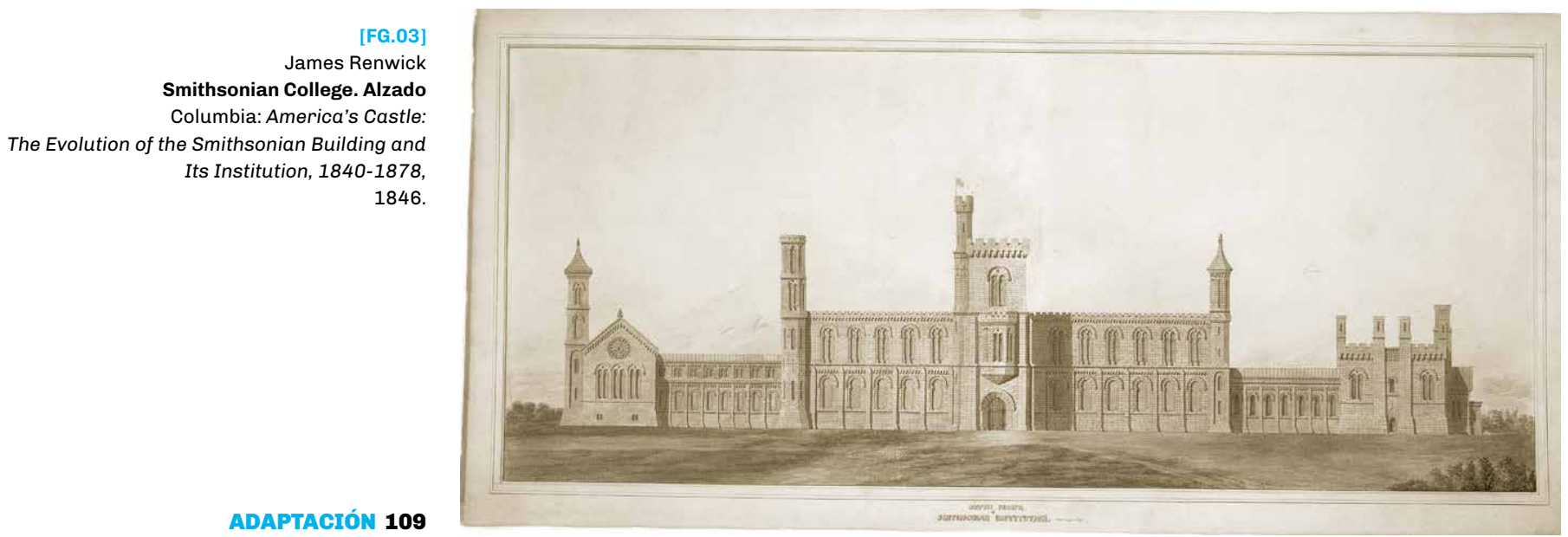


tiene que ver con su adaptación y tamaño al sitio en el que se ubique, pero además depende también de la expresión exterior de su función interior. Con este paso el autor fomenta la búsqueda de una belleza no dependiente de la forma en sí misma, sino de un diálogo con lo interno -esencia de la 'adaptación'- ya que "el carácter monumental de un edificio hace referencia a su sitio; a su adaptación en tamaño y forma a ese sitio. Tiene referencia también a la expresión externa de las funciones internas del edificio». ${ }^{41}$

La organic structure está relacionada, según el autor, con la organización del edificio; por ende lo inorgánico sería también lo no funcional, lo que se introduce como un agregado a lo que ya es esencial. Lo esencial a su vez puede resumirse en la comparación que el autor establece entre el diseño de un tren y la readaptación de una arquitectura del pasado, en una evidente crítica a la arquitectura de Thomas Jefferson. Llama la atención sobre el hecho de que "iLos hombres que han reducido la locomoción a sus elementos más simples, en el carro de trote y el yate América, están más cerca de Atenas en este momento que aquellos que aplicarían el templo griego para cualquier uso!»42

Como en el caso de Ruskin, también existe en Greenough la analogía directa con la naturaleza, en este caso llamando la atención a la capacidad de la misma de adaptarse a los medios, evitando de este modo una centralidad en la forma por sí misma:

\section{(...) observamos los esqueletos y las pieles de los animales a través de todas las} variedades de bestias y pájaros, de peces e insectos, ¿acaso no impresionan tanto su variedad como su belleza? No existe una ley arbitraria de las proporciones, ni un modelo inflexible para la forma . ¡Hay una pequeña parte de la organización animal que no encontramos alargada o acortada, aumentada, disminuida o suprimida ya que, como dictan las necesidades de género o especie, su exposición o su trabajo lo pueden requerir!. ${ }^{43}$

Lo orgánico se entiende de este modo tanto como la adaptabilidad del objeto a su función como al propio medio, lo que en arquitectura podría entenderse como el mismo entorno, el sitio. Según Greenough existiría también una ley de la adaptación, fundamental dentro de la naturaleza, la cual tendría que ver con la modificación del mismo cuerpo dependiendo de las condiciones del sitio particular. ${ }^{44} \mathrm{Al}$ mismo tiempo, el autor estadounidense propone consultar a la naturaleza para comprender los principios constructivos, dado que esta basa su proceso de crecimiento en el principio de adaptación al medio.

Con unas premisas similares a las que manejara Bacon, y a su contemporáneo Bötticher, Greenough brinda un aporte esencial en la noción de ‘adaptación' al proponer que el edificio no debe partir de una forma general, sino de un núcleo interior, hacia afuera. Pero ese núcleo interior es en este caso fruto de unas condiciones propias del sitio, que si se siguen con rigor, dan como resultado lo que podría resumirse en un 'esquema' del diseño del edificio: una primera base que ya contendría ciertas certezas. En una de las premisas fundamentales del organicismo Greenough declara que:

En lugar de forzar las funciones de cualquier tipo de construcción a una forma

\section{1.}

Ibid. p. 21.

42.

Ibid. p. 22.

43.

"American Architecture," p. 57.

44.

Ver Ibid. p. 58.

45.

Ibid. p. 61.

46. Ver Ibid. p. 60

47.

"(...) el banco tendría la fisonomía de un banco, la iglesia sería reconocida como tal, y ni la sala de billar ni la capilla usarían el mismo uniforme de columnas y frontón". Ibid. p. 63.

48.

"Cuando defino la Belleza como la promesa de la Función; Acción como la presencia de la Función; Carácter como el registro de la Función, divido arbitrariamente lo que es esencialmente una sola cosa. Considero las

\subsection{3.e.}

Adaptación al medio

fases a través de las cuales la intención de la organización pasa a ser completa, como si fueran entidades distintas. La belleza, siendo la promesa de la función, debe estar presente principalmente antes de la fase de acción; pero mientras haya una promesa de función hay belleza, proporcionada por su relación con la acción o con el carácter. Hay algo de carácter al final del primer momento de la vida orgánica, ya que hay algo de belleza al comienzo de la última, pero son menos evidentes y se presentan más bien a la razón que a las sensaciones". "Relative and independent beauty," p. 71. Traducido por el autor.

49.

Ibid. p.86.

50.

Como menciona Eduardo Prieto, las analogías de Greenough con respecto a 'lo orgánico' tenían raíces en la literatura británica, a través de Samuel Coleridge y en el romanticismo alemán encarnado en Schelling y Goethe. Ver "Darwin entre las máquinas" en Prieto, La ley del reloj. Arquitectura, máquinas y cultura moderna.

51.

Ver De Zurko, La teoría del funcionalismo en la arquitectura, p. 205.

52. Ibid. 
sin referencia a la distribución interna, comencemos desde el corazón como el núcleo, y trabajemos hacia afuera. El tamaño y la disposición más conveniente de las habitaciones que deben constituir el edificio que se está diseñando, el acceso de la luz que sea posible, la ventilación que se desea conseguir; así tendremos el esqueleto de nuestro edificio. ${ }^{45}$

Una de las paradojas del autor resulta en que, a pesar de posicionarse críticamente frente a la readaptación de la arquitectura clásica a su tiempo, sigue manteniendo conceptos propios del clasicismo, como lo son la monumentalidad y el caractère. A diferencia de la monumentalidad, este último sí que forma parte fundamental del entendimiento de la función en la tradición vitruviana. Para Greenough el carácter tiene que ver con la adaptación de las formas a las funciones. ${ }^{46}$ El autor reafirma el concepto cuando Ilama a cada programa a mantener su expresión, «(...) el banco debería tener la fisonomía de un banco, la iglesia sería reconocida como tal, y ni la sala de billar ni la capilla deberían utilizar el mismo tipo de columnas y frontón».47

2.2.3.f. La función es también para Greenough acción, ya que esta última depende del Instrumento mismo funcionamiento del edificio; de ahí su analogía constante con las maquinarias. La función es movimiento propio; la belleza, en cambio, mantiene su cualidad estática, y si la misma existe es porque engendra dentro un funcionamiento adecuado. Para Greeoungh no hay belleza sin función, y el carácter es la marca de la función, lo que explica qué tipo de funcionamiento se lleva a cabo, en un acercamiento que, en principio, sigue la vía de Blondel. 48

Resulta de importancia el hecho de que Greenough sea uno de los primeros autores en introducir el término «instrumento" en el vocabulario de la función, intentando separar esta última de la arbitrariedad de la pura belleza artística e intentando al mismo tiempo acercarla a la ciencia:

Invoco, por lo tanto, a la ciencia, en todas sus ramas, para detener la marea de embellecimiento sensual y arbitrario, en la medida en que puede hacerlo; no criticando sólo negativamente, sino positivamente, haciendo que el instrumento sea una respuesta multifacética a las multiformes demandas de vida. ${ }^{49}$

Para Greenough, como para muchos autores del período, el problema no yace tanto en la definición precisa de este modo de entender la función en la arquitectura -al fin y al cabo, la formación del autor es artística antes que arquitectónica- sino en afirmar una vez más ${ }^{50}$ que el problema de la belleza tiene su solución en la "esencia interior», esa función que es también origen y que, paradójicamente, es capaz de dar sentido tanto a un organismo vivo como a una máquina. De Zurko remarca al mismo tiempo que las ideas de Greenough contienen al mismo tiempo conceptos mecanicistas, y organicistas, escapando así a las categorías que el mismo historiador propone. ${ }^{51}$ Según De Zurko,

He aquí la médula del funcionalismo de Greenough: Belleza es la promesa de función que un instinto otorgado por Dios torna sensorialmente placentera. La acción es la presencia d la función. El carácter es el registro de la función. La falsa belleza y el afeite son tipos de ineficiencia. El uso de formas y modelos admirados con fines no contemplados en su invención constituye un signo in- 
En 1901 Julien Guadet, quien se formara en el atelier de Labrouste, publicaría su extenso Eléments et théorie de l'architecture. Cours professé à l'École nationale et spéciale des beaux-arts, uno de los libros con mayor difusión en el período, ${ }^{53}$ escrito en base a sus apuntes como profesor en la Ecole des BeauxArts, en un momento en el que la recuperación de la historia de la arquitectura era capaz de incorporar, de modo ecléctico, los diversos estilos del pasado. Para Guadet la historia también resulta imprescindible, pero no busca preferencias dentro de los estilos. La arquitectura griega, romana o medieval es valorada del mismo modo.

Antes que en la elaboración de una teoría general sobre la arquitectura, Guadet está preocupado por la transmisión de un conocimiento sobre el proyecto, retomando nuevamente el concepto de composition, que ya desarrollara Durand. Pera para Guadet la composition se ubica en un lugar más general. Se trata del acto de proyectar per se, y es mucho menos una teoría que una práctica del diseño. De este modo Eléments... está plagado de consejos basados en la experiencia y sentido común del autor, que tienen el fin de encontrar un método proyectual; ${ }^{54}$ esto lo diferencia del resto de aportes en torno a la 'adaptación', pero al mismo tiempo definen cierta metodología, la cual será fundamental para completar esta concepción funcional. Para Guadet la composition tendrá lugar exclusivamente al momento de hacer frente a un proyecto particular; no existen teorías que puedan anticipar una mejor solución, ya que los requerimientos y circunstancias propias de cada encargo particular, según el autor, excederían esta anticipación:
2.2.4.

Guadet.

\section{Composición determinista}

53.

Según José Ramón Alonso, «De amplia influencia en Europa y en América, 'el Guadet' fue el libro de oro beaux-arts en la primera mitad del siglo xx, que predicaba una arquitectura racional y funcional, a la vez que defendía la libertad individual y el primado de la fantasía". Pereira, José Ramón Alonso, Introducción a la historia de la arquitectura: de los orígenes al siglo XXI (Barcelona: Reverté, 2005), p. 191. (Ed. orig. 1995).

\subsection{4.a.}

Proyecto como conocimiento 54.

"En cuanto al método, intentaré siempre ir de lo simple a lo complejo, de lo conocido a lo desconocido, esperando poder demostrar que en arquitectura todo procede por deducción. EI estudiante tiene que volver a hacer el trabajo que durante siglos se ha hecho: entender primero las necesidades primarias, los primeros métodos y el testimonio histórico del arte; más tarde, los elementos complejos y refinados, creados para satisfacer las necesidades mismas, los cuales resultan más complejos:

[FG.04]

Julien Guadet.

Hôtel des Postes du Louvre. Interior

París: Journée d'Étude sur la consultation de la Poste du Louvre

1881.

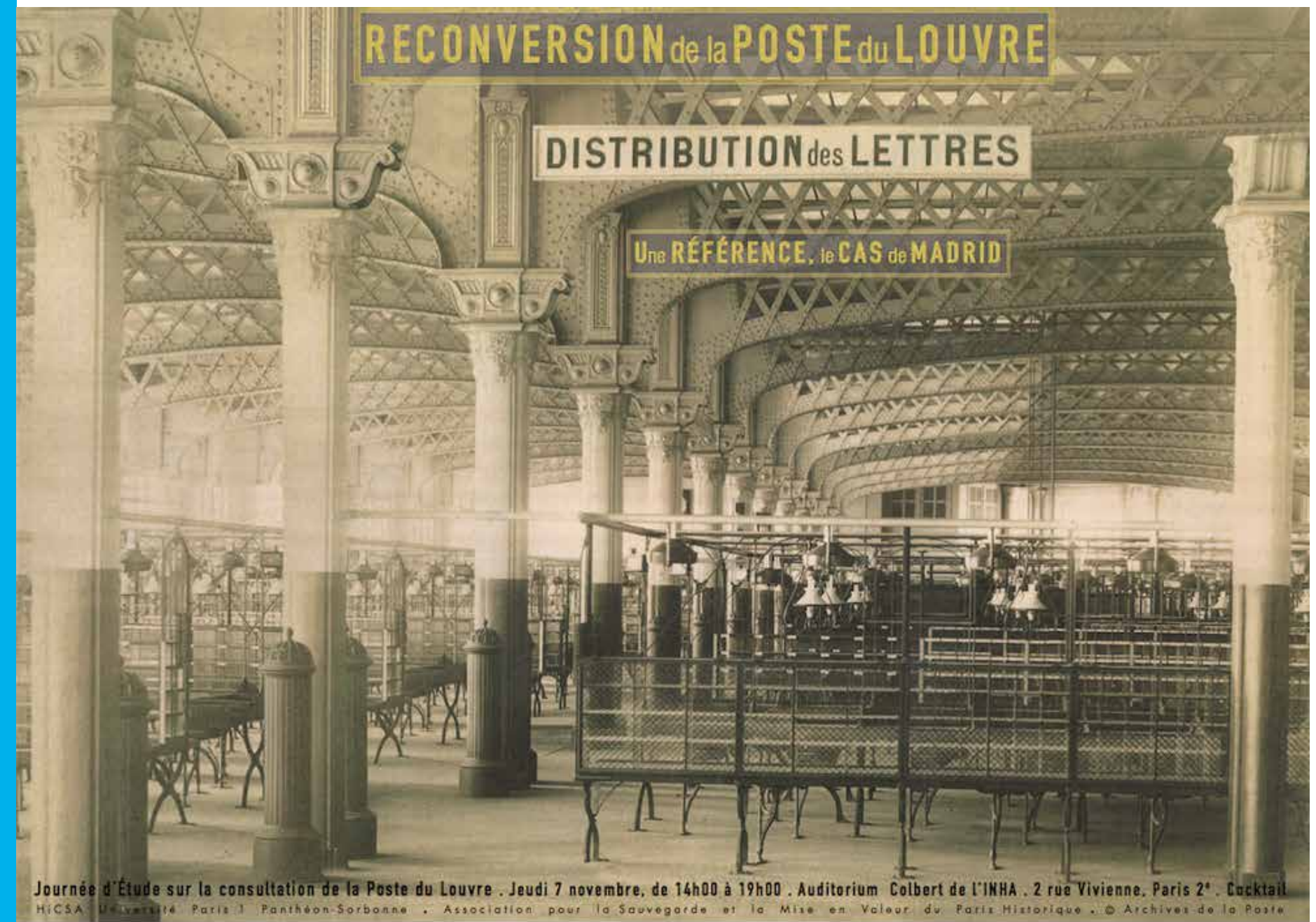


debe poder entender que entre los elementos simples y complejos hay una cadena ininte-

rrumpida, un progreso gradual; verá así el

desarrollo lógico del arte, comprenderá el curso que tuvo durante siglos este trabajo, y que permitió que todas las civilizaciones hayan cooperado; y que sigue obedeciendo hoy la ley eterna del movimiento y de la transformación". Guadet, Julien, The elements and theory of architecture (Berkeley: University of California Press, 1907), p. 15. (Ed. orig. 1894). Traducido por el autor. Ibid. p. 14-15 ducción a la arquitectura contemporánea (Madrid: Nobuko, 2004), p. 45
Supongamos que a un arquitecto se le encarga que diseñe un esquema para un grupo de edificios escolares. El programa es más o menos complicado, la configuración, y muchas veces la insuficiencia de la tierra, los accesos, el vecindario circundante, los requisitos especiales harán que el estudio de su plan sea más o menos laborioso, más o menos perfecto; eso es la composición. Pero habrá asuntos con los que debería estar familiarizado de antemano; por ejemplo, cómo es una sala de clase, un patio de recreo, una cantina, una sala de dibujo, etc. Estos son los elementos de la composición, y esto es lo que podemos, hasta cierto punto, enseñar. ${ }^{55}$

Guadet se refiere entonces a un conocimiento previo que estaría dado por el estudio de situaciones funcionales particulares ya existentes. A través de la composition se conjugan estos diferentes eléments, los cuales entran en relación con mayor o menor éxito. Entonces,

"componer, es hacer uso de lo que uno sabe. La composición tiene sus materiales, como el edificio tiene los suyos, y estos materiales no son más ni menos que los elementos de la arquitectura. Además, la composición escapa a reglas y fórmulas: tiene que ser adquirida, por supuesto, pero difícilmente puede decirse que requiera instrucción teórica». ${ }^{56}$

Guadet anticipa así, al comienzo de su libro, la escasa importancia que la teoría tiene en el proyecto de arquitectura; lo importante es un conocimiento y un método para aplicarlo. lo cual provee una habilidad que se demostrará finalmente en el encargo particular, cualquiera sea.

Resulta igualmente interesante que Guadet considere a los eléments como estas particiones programáticas, que podrían ser estudiadas individualmente, pero que cobran su verdadero sentido al ubicarse en relación a las demás.

¿Qué es componer? Es juntar, unir las partes de un todo. Estas partes son los Elementos de Composición; de la misma manera como se materializan las concepciones con paredes, aberturas, bóvedas, techos -todos ellos Elementos de Arquitectura- se establece la composición con habitaciones, vestíbulos, pasajes, escaleras. Éstos son los Elementos de la Composición. ${ }^{57}$

2.2.4.c. A diferencia de las exploraciones teóricas sobre las posibilidades de la flexibiNoción determinista lidad funcional que Viollet-le-Duc había propuesto en su lectura de la antigüedad, Guadet mantiene firmemente la apuesta por la determinación funcional de cada recinto; el rigor en su organización. Si bien es cierto que existe aún una sintonía con la concepción de "las partes y el todo," ya planteada por Durand, para Guadet componer es sobre todo saber distribuir una planta, pero también implica el momento más personal del arquitecto. Es por eso que se refiere a este proceso como "lo que no se puede enseñar.» Esta libertad individual está cimentada también sobre bases sólidas; de ahí el rigor exigido en el conocimiento sobre cada actividad a realizar en los posibles recinto que conjugan un programa.

Los principios de esta "enseñanza de atelier," que tanta influencia tendrá en el resto de las escuelas del mundo, se basa en la estructuración de la planta bajo la simetría (utilizando los ejes) y la monumentalidad (a través del 


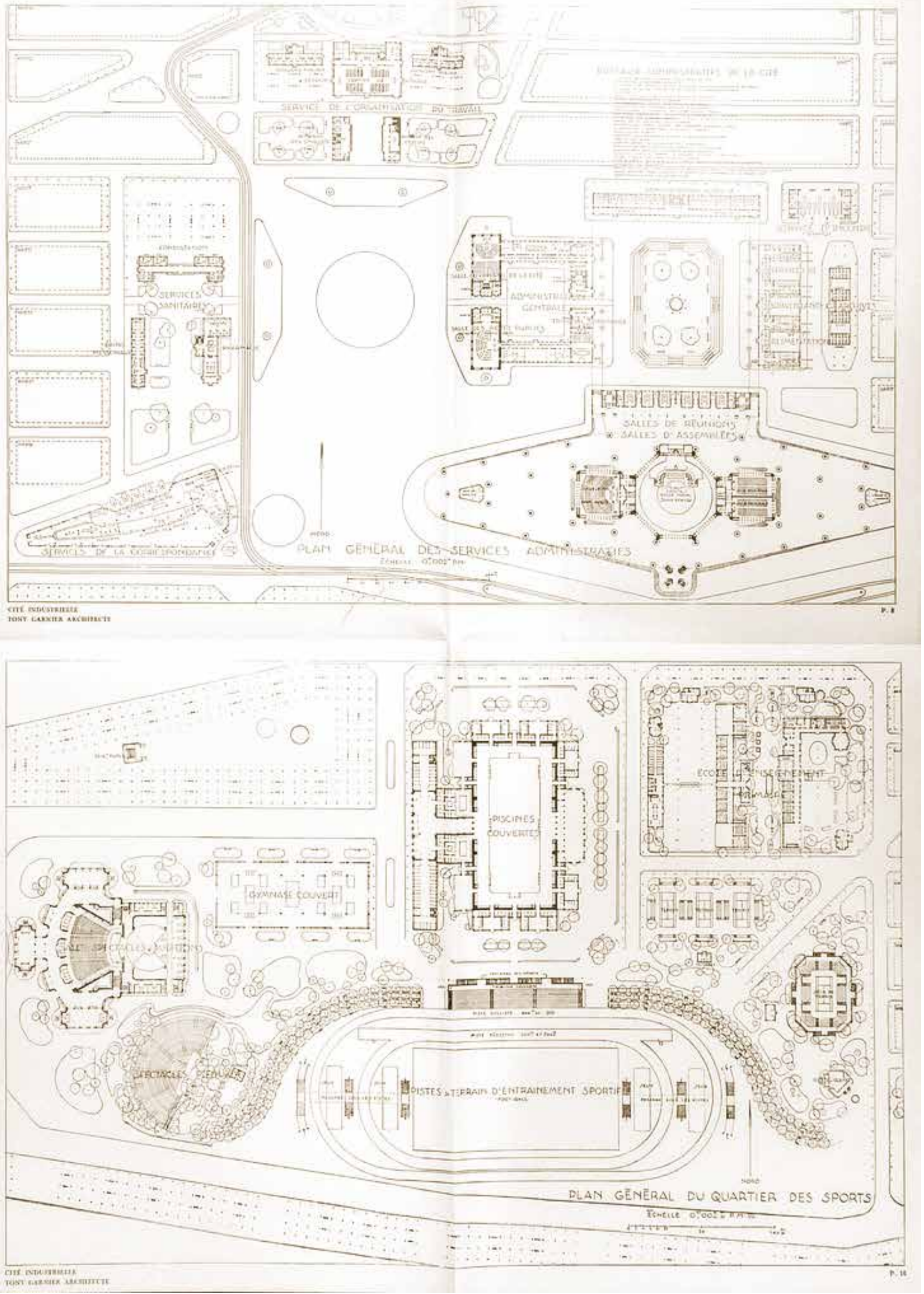




\subsection{4.b.}

\section{Composition}

58.

Como menciona Antón Capitel, en la planta de Guadet radica el rigor de la función, y en los alzados la libertad artística. Ver González Capitel, Antón, La arquitectura compuesta por partes (Barcelona: Gustavo Gili, 2009), p. 111. alzado) ${ }^{58}$ La escala de esta arquitectura será, en la mayoría de los casos, grandilocuente. A pesar de cultivar sus escritos bajo un velo eclecticista, Guadet profesa por sobre todo una actitud liberal frente al proyecto; esta 'libertad' vinculada a la composition lo lleva a proyectar, en 1881 el Hotel des Postes, en la calle del Louvre en París. [FG.04] En este el autor ensaya una fachada con una interpretación muy libre del sistema clásico, siendo esta además una suerte de máscara de la estructura de hierro interior.

Es posible interpretar que la función en la enseñanza de Guadet adquiere un sentido determinista, en el cual el rol de cada recinto mantiene su espíritu originario intacto, con lo que lo exploratorio de la función aparecerá en esos lugares que pongan en relación cada una de estas células, como las circulaciones, los accesos o los distribuidores. A pesar de la simpleza de su planteamiento, la referencia de Guadet resulta fundamental para comprender el cambio de concepción en la función a comienzos del siglo XX, definiendo en parte el espíritu de la 'adaptación'. En Theory and design in the first machine age, Reyner Banham resume que en Guadet puede encontrarse «la búsqueda de un volumen separado y definido para cada función separada y definida, y la composición del edificio de modo que manifiesta esa separación y esa definición». Asimismo, Nancy Dembo afirma que el escrito facilitó la arquitectura de forma pura bajo argumentos utilitarios.

Al mismo tiempo que Guadet utiliza la función como herramienta de sostén de un interés posterior (que es el de la composición volumétrica); la función como problema específico no es desarrollado más allá del estudio de los diferentes componentes espaciales de un programa. Probablemente el proyecto que mejor ilustre esta determinación funcional expresada a través de volúmenes sea el de uno de sus más importantes discípulos, Tony Garnier, quien realizara en 1904 el conocido proyecto no realizado para Une Cité Industrielle, en el cual cada programa se individualiza a través de un edificio particular y reconocible, sentando un precedente fundamental para la 'adaptación' moderna. [FG.05]

2.2.5. En los artículos de la primera década del siglo XX, cuando comienza su carrera Wright. individual después de trabajar junto a Louis Sullivan en Chicago, Frank Lloyd Adecuación al individuo Wright repite la apreciación de Greenough y Ruskin sobre la historia de la arquitectura: rechaza la artificialidad del Renacimiento, el Barroco y el Rococó, resaltando los valores orgánicos del gótico y añadiendo la herencia de otras culturas arquitectónicas, como la egipcia, o la japonesa. A partir de los años treinta hasta los últimos escritos de su carrera concentrará su discurso en una definición de la arquitectura propiamente orgánica, destacándola por sobre la arquitectura moderna europea. Por otro lado, no puede afirmarse que los escritos de Wright tengan la pretensión de contribuir directamente a una teoría de la función, aunque constantemente están dialogando con términos relacionados a ella, como cuando incorporan -de modo sucesivo, y con sentido crítico- la sentencia form follows function, de Sullivan. El aporte teórico de Wright en torno a la función, quizás de modo similar a como ocurre con Mies, 
ese contexto los escritos de Wright en los primeros años del siglo XX alcanzan a condensar exigencias históricas para la función, como las de Bacon, Lodoli, Ruskin y Greenough. Según Collins, "Los historiadores generalmente están de acuerdo en que el mérito de esta nueva interpretación debe otorgarse, en lo que se refiere a teoría arquitectónica, a Louis Sullivan, aunque puede decirse que nunca la expresó o aplicó antes de conocer a Wright.»59 Los textos de Wright se basan siempre en apreciaciones subjetivas, una suerte de ensayos, revisiones históricas, mezclados con vivencias personales, en defensa de su propia obra y con una vocación intensa para fundar lo que él considera una arquitectura moderna norteamericana. Esto último también lo había buscado Greenough, aunque Wright se diferencia de él con un planteo que, ahora sí, puede mantener algún tipo de diálogo directo con la industrialización, a la que considera como "un mal inevitable». La esencia de Norteamérica -tema central en su pensamiento- radica, según Wright, en los valores de libertad individual que provee la democracia, y en este punto es que puede tenderse un hilo sobre su visión de la función y, sobre todo, su aplicación en sus primeras obras.

Como se ha mencionado, una lectura crítica y generalizada de la arquitectura clásica acompaña gran parte de los escritos del autor, de modo análogo a la que realizaran Ruskin y Greenough, pero de modo más superficial. En “In the cause of architecture", quizás el texto más importante de su primera etapa -en el cual busca, en rigor, referir a una "arquitectura de América»- hace una revisión del concepto de "naturaleza" en el Renacimiento. Menciona a Vitruvio y Vignola entendiendo a través de ellos un sentido casi platónico de acercamiento a esta naturaleza, cuya meta, la de imitarla, es claramente inalcanzable. En contraste con esta visión clásica, Wright recurre a lo orgánico, como lo había planteado ya Greenough en el siglo XIX:

El sentido de lo orgánico resulta indispensable para un arquitecto; (...) El conocimiento de las relaciones de forma y función se encuentra en la raíz de su práctica; ¿Dónde más puede encontrar las lecciones de objetos pertinentes que la naturaleza proporciona tan fácilmente? ¿Dónde puede estudiar las diferencias de forma que van a determinar el carácter y cómo puede estudiarlas en los árboles? ¿Dónde puede acelerarse ese sentido de inevitabilidad característico de una obra de arte como puede ser por el intercambio con la naturaleza?60

Como resulta claro en sus palabras, Wright ve en la naturaleza la problemática misma de la función. Por un lado refiere a la «forma y función» en un sentido de relación mutua, tal como lo propusiera Sullivan -continuando, sin ocultarlo, su slogan form follows function-, y vincula esta idea directamente a la de lo 'orgánico'. Básicamente Wright se cuestiona cómo el problema de la forma sumada a la función puede vincularse con la naturaleza, la 'raíz'. Posteriormente en el mismo escrito hace una alegoría a un término japonés específico para explicar el desarrollo natural de las ramas de los árboles; interpreta que la arquitectura occidental carece de este término y por lo mismo está aún lejos de poder hacer una correcta lectura de las lecciones de la naturaleza, ya que el mismo idioma inglés carece de estas herramientas. Para Wright la lógica de la Moderna: su evolución. 1750-1950 (1969), p. 157. (Ed. orig. 1965).

60. Wright, Frank Lloyd, "In the cause of architecture," en On and by Frank Lloyd Wright. A primer of architectural principles, ed. McCarter Robert (Londres: Phaidon, 2005), p. 338. (Ed. orig. 1908). Traducido por el autor.

61. Ibid. p. 341.

62. Wright, Frank Lloyd, "Ausgeführte Bauten und Entwürfe," en Frank Lloyd Wright: primers escrits, ed. Quetglas, Josep (Barcelona: Universitat Politècnica de Catalunya, 1994), p. 68. (Ed. orig. 1911).

63.

Collins, Peter, Los ideales de la Arquitectura Moderna: su evolución. 1750-1950, p. 158.

64.

Wright, Frank Lloyd, "Máquinas, materiales y hombres," en Arquitectura moderna. The Kahn lectures. Princeton 1930 (Barcelona: Paidós, 2010), p. 120. (Ed. orig. 1930).

\subsection{5.a.}

Raíz 
naturaleza yace en que la misma avanza en un perfeccionamiento continuo de sus formas persiguiendo la función pura, permitiendo el desarrollo individual de sus partes. Para Wright esta analogía podía encontrarse en la arquitectura clásica, pero ya no en la renacentista. ${ }^{61}$ En el artículo "Ausgeführte bauten und Entwürfe," publicado en en 1910, -el mismo año que el portfolio Wasmuth en el cual, a través de una serie de litografías, dio a conocer la obra de Wright en el continente europeo- rescata la arquitectura de lo que considera el "otro Renacimiento», que sería el de Mongolia, India, Arabia, Egipto, Grecia y la arquitectura medieval, en la que sí encuentra una relación directa entre forma y función, al modo de la naturaleza. Para Wright esto es posible a través de un estudio de la misma:

...podemos estudiar con provecho estas verdades de forma y estructura, hechos de forma relacionados con la función, rasgos materiales de la línea que determinan el carácter, leyes de estructura inherentes a todo crecimiento natural. Nosotros mismos somos sólo un producto de la ley natural. ${ }^{62}$ Como se confirmará luego, según el autor no existe una división tajante entre la función, la estructura y la forma. En su propia apuesta por lo orgánico todo es uno, y esto incluye tanto la construcción como el carácter de la arquitectura. O como menciona también Collins:

La dificultad está en que, para Wright, significaba demasiadas cosas: formas de plantas, cristales, la posibilidad de crecimiento por suma asimétrica, la relación entre el lugar y el cliente, el uso de materiales locales, la individualidad de toda cosa creada, la necesidad de todo artista de imbuir en su trabajo la integridad de su ser más profundo, etc. etc. Pero, sobre todo, significaba para él la "arquitectura viviente"; una arquitectura en la que las formas inútiles eran desechadas como parte de un proceso del crecimiento de la nación, y en la que toda composición, todo elemento y todo detalle tenía la forma propia del trabajo que debían realizar. ${ }^{63}$

2.2.5.b. Como contrapartida a la naturaleza, Wright pone su ojo en el desarrollo tecnoTecnología por artesanía lógico y la industrialización; en la conferencia de Princeton “Máquinas, materiales, hombres" de 1930 llama la atención sobre el cambio de paradigma entre las anteriores generaciones de arquitectos norteamericanos y las actuales, que Wright simplifica en la sustitución de la artesanía por la tecnología. Las máquinas son, para Wright, las nuevas herramientas, o más bien una «herramienta tristemente necesaria» que, sin embargo, no está del todo escindida de la naturaleza: "Aquí está esto que llamamos máquina, que es lo contrario al principio de crecimiento orgánico, pero que sin embargo lo imita, realizando irresistiblemente la voluntad humana por medio de los hombres.» ${ }^{64}$ Con esta afirmación Wright se separa de las apuestas organicistas de Greenough, y también de las reaccionaras de Ruskin -a quien, a diferencia del primero, suele citar con mayor constancia- para permitir que la máquina ocupe un lugar en su consideración. En "The arts and crafts of the machine," de 1901, Wright comienza entendiendo a la máquina como una evolución del antiguo arts and crafts, y asume que el futuro desarrollo de la misma es inevitable, y que, poco a 
Según Wright, en la Edad Media, la arquitectura condensaba todos los saberes del arte; la arquitectura era la gran contenedora. En el Renacimiento, con la imprenta de Gutenberg, el libro entendido como objeto fue poco a poco destronando a la arquitectura. La imprenta es vista por Wright como la primera gran máquina del hombre, ya que los libros resultan un medio de comunicación y expresión más rápido, barato y eficaz que la arquitectura. Así Wright ve a la misma entrar en una decadencia que queda plasmada en el «pseduoclásico» del Renacimiento. Por eso Wright parece entender a la máquina como una amenaza y al mismo tiempo como un modo de inyectar una energía diferente en la arquitectura. La misma ha permitido al hombre una interpretación clara de la naturaleza -y al mismo de tiempo de la función de la misma. Llama la atención al miedo que gran parte de los arquitectos sienten por el rascacielos, y entiende que este último es un hecho fundamental que, como la máquina, no puede ser negado. Su existencia es más potente y evidente que cualquier negación, y al mismo tiempo encuentra en él un valor, dado sobre todo por la simpleza de su estructura, "...la máquina es un maravilloso simplificador; el emancipador de la mente creativa, y al mismo tiempo el regenerador de la conciencia creativa. ${ }^{65}$

Wright afirma que, ante la aparición de la industrialización y la máquina, lo que se pone en juego son, sobre todo, las formas de la tradición; se vuelve necesario entonces definir unas nuevas formas que dialoguen con ella; estas serían las formas orgánicas y ahí comenzaría su aporte a la ‘adaptación’. Estas formas encuentran -según Wright, y continuando a Ruskin y a Greenough- inicio en el Gótico, por su variedad, incomparable a cualquier otro estilo. El autor recupera a través del gótico la asimetría propia de la búsqueda funcional adecuada a cada situación -al modo de Bacon-, la adaptación al medio natural y la rusticidad y variedad de su factura. Menciona que en Estados Unidos, en la costa este, es donde el neoclásico ha sido sembrado, debido a la consciente falta de una tradición; por otro lado, en el oeste o en el oeste medio -en donde mismo él construye- es donde resulta posible recuperar los valores del gótico para fundar un estilo propio.

En sus comienzos Wright afirma haber intentado traspasar el conocimiento que Adler y Sullivan acumularon sobre los rascacielos a los encargos residenciales que le tocó desarrollar en los suburbios de Chicago. A partir de estas experiencias elabora las bases para "In the cause of architecture" utilizando seis "proposiciones», a modo de principios, relacionadas con lo orgánico en la arquitectura, atendiendo a fundamentos democráticos que encuentran su base en las libertades individuales. En el punto I del artículo Wright hace referencia a la simplicidad y al reposo en el arte. A modo de un tratado clásico, su primera afirmación tiene que ver con no construir más habitaciones de las necesarias en una residencia, y propone una distribución de espacios «sociales» tras la entrada: ventanas, elementos decorativos o mobiliario integrados a la estructura y a la forma -como Ruskin y Greenough exigieran también, basados en las enseñanzas del gótico. "Las viviendas más satisfactorias son aquellas en las que todos o la mayor parte de los muebles están integrados dentro del
Wright, Frank Lloyd, "The art and craft of the machine," en Frank Lloyd Wright: primers escrits, editado por Quetglas, Josep (Barcelona: Universitat Politècnica de Catalunya, 1994), $p$ 20. (Ed. orig. 1901)

66.

"In the cause of architecture," p. 339

67.

También afirmará que "El promedio de la inteligencia humana aumenta de manera constante y, a medida que la unidad individual crece cada vez más, para confiar en nosotros tendremos como nunca antes una arquitectura con una unidad bastante más variada." Ibid. p. 340.

68.

Ibid. p. 339.

69.

"Ausgeführte Bauten und Entwürfe," p. 71.

70.

Ibid

71.

Ibid

\subsection{5.c.}

\section{Democracia}


esquema original, considerando el conjunto como una unidad integral.»66 En el punto II Wright propone que debe haber tantas opciones de casas como de individuos, ${ }^{67}$ asumiendo las variaciones que la misma naturaleza genera en su crecimiento. Esta resulta una de las diferencias más importantes con respecto a la idea de 'eficacia' de la función, dado que en la 'adaptación', la concepción del individuo como ente irrepetible es fundamental; en la 'eficacia' el individuo se entrega a una estructura social superior. De este modo Wright ata la libertad individual inspirada en la democracia norteamericana con el concepto artístico de lo orgánico. Así llega a hablar en el punto III de la adecuación del edificio a su entorno natural, de su armonización con respecto a las particularidades. "Un edificio debería poder crecer fácilmente desde su sitio y tener una forma que armonice con su entorno, si la Naturaleza se manifiesta allí, y si no, hay que intentar hacerlo tan tranquilo, sustancial y orgánico como lo habría sido si ella hubiera tenido la oportunidad». ${ }^{68}$ Los colores y los materiales también requerirían una adecuación a la naturaleza, según comenta en los puntos IV y V; Ios primeros trabajados en su su estado puro, y para los colores hace un Ilamado a los 'tonos calmos, optimistas', tonos pastel, los cuales se materializarían en su propia obra. Finalmente en VI comenta la importancia de un edificio de prevalecer en el tiempo y poder volverse también viejo, como la naturaleza.

Como se ha mencionado, el tema del individuo es central en el pensamiento de Wright. Para él es la cualidad propia del individuo libre la que puede alimentar fehacientemente la totalidad, y volverla armoniosa:

América, más que cualquier otra nación, presenta una nueva propuesta arquitectónica. Su ideal es la democracia y, en su espíritu democrático, las instituciones están concebidas de manera profesional. Esto significa que ella otorga una prima de vida a la individualidad -el mayor desarrollo posible del individuo consistente es convertirse en un todo armonioso- siendo que un aún no se ha beneficiado esa totalidad del sacrificio de la cualidad del individuo, considerando correctamente su propia "individualidad"; siendo que el todo, para ser digno de un todo, debe consistir en unidades individuales, grandes y fuertes en sí mismas, no unidas desde afuera en esclavitud, sino unidas dentro, con el derecho de moverse en unidad, cada una en su propia esfera, pero preservando este derecho al mayor grado de libertad posible para todos. Esto significa una vida individual más grande y más privacidad para la vida... ${ }^{69}$

Siendo además que "En América, cada hombre tiene un derecho peculiar e inalienable de vivir a su manera. ${ }^{70}$ la peculiaridad del individuo descrita anteriormente por el autor debe quedar clara y directamente reflejada en la función del espacio que habita. De hecho, es sobre todo a través de la función que es posible que se consoliden los hábitos y costumbres propias del ocupante. Las funciones revelan, quizás aún más que la forma, las cualidades individuales; pero además la misma función, en su repetición, no sólo presentará una infinitud de variantes, sino, como el mismo Wright espera, será capaz de dar a entender las similitudes que hacen a un modo de vida democrático y que 
Aún así, a pesar del valor propio que Wright otorga a la individualidad, lo mismo no significa que sea el habitante (el cliente) quien pueda decidir directamente sobre su modo de vida y sobre la distribución propia de su espacio habitable; Wright menciona que el cliente debe dar un voto de confianza al arquitecto; el cliente no puede decidir, ya que no está en condiciones de poder hacerlo. El arquitecto tiene como deber, incluso, educar al cliente; volverse su intérprete.

Si bien Wright Ilama constantemente a la cita "form follows function», de Sullivan, él mismo propone una alternativa que dialoga con la misma, sin destruirla. Wright no ve con claridad que la forma sea totalmente dependiente de la función, y que esta última sea la que guíe a la primera. "Si la individualidad de las diversas funciones para las diversas características están altamente desarrolladas, las formas serán completas en sí mismas y, con frecuencia, harán el deber al mismo tiempo desde dentro y desde fuera...» ${ }^{72}$ De este modo, la función para Wright contiene una forma que colabora en el funcionamiento del conjunto, de un modo orgánico que, al mismo tiempo, en el plano teórico, se acerca a la concepción de Ginzburg -no en vano este último había visualizado también esta cualidad en la arquitectura de Wright. Si, como ya se ha comentado, la diferencia con respecto a la concepción de 'eficacia' es explícita en el valor que Wright da a la individualidad, no significa que no comprenda la capacidad ideal de una organización general. ${ }^{73}$

En "The logic of the plan" de 1928 plantea que la planta es el comienzo y el fin del proyecto, porque la planta, en caso de ser buena, es orgánica por naturaleza. La entiende como el "alma" del edificio, ya que el edificio sólo puede vivir gracias a ella, siendo que "...existe una importante ecuación humana en el trabajo, en cada movimiento que se realiza. ${ }^{74}$ En un sentido organicista, Wright entiende que la planta debe alcanzar la idea de fitness, es decir, de una conveniencia profunda entre el hombre y la arquitectura, siendo esta última casi una extensión del primero. Así, "...cada edificio es de la calidad del alma de un hombre, de su sentido de armonía y "aptitud”....»75 En la conferencia "Máquinas, materiales, hombres", plantea una serie de puntos para poder obtener lo que Ilama la "simplicidad orgánica". ${ }^{76}$ Wright busca con esto un modo de simplicidad que no atente contra la arquitectura y que no se acerque de ninguna manera a las expresiones con las cuales la arquitectura moderna de volúmenes blancos y abstractos se estaba caracterizando en su momento.

Si la idea de fitness resulta, en efecto, una continuidad del hombre con respecto a la arquitectura, uno de los elementos a los que Wright recurre para conseguirlo es el propio mobiliario y su diseño; un tema que, hasta el momento, no formaba parte de las preocupaciones de las teorizaciones sobre la función. ${ }^{77}$ En el artículo "In the nature of materials" de 1932, Wright afirma que debe concebirse una nueva forma de «interior», relacionada a la función, en la cual ya no exista una separación con respecto al exterior; ambos se convienen entre sí, y la arquitectura se vuelve integral. El interior es pensado como la semilla de la forma, asentando un concepto que será esencial en la 'adaptación'.

\section{2.} "In the cause of architecture," p. 341.

73.

En este sentido comenta que "...la vida cotidiana aquí encuentra una expresión pertinente a su existencia diaria: una idealización de la necesidad común será seguramente edificante y útil, en el mismo sentido en que el aire puro para respirar es mejor que el aire envenenado con gases nocivos". Ibid.

\subsection{5.d.}

\section{Fitness}

74. Wright, Frank Lloyd, "The logic of the plan," en On and by Frank Lloyd Wright. A primer of architectural principles, editado por McCarter, Robert. (Londres: Phaidon, 2005), p. 347. (Ed. orig. 1928).

\section{5.}

Ibid.

\section{6.}

Según describe el autor, primero, reducir las partes innecesarias de la casa en pos de un espacio fluido; segundo, vincular al edificio con su entorno y su emplazamiento prestando atención al suelo; tercero, eliminar la concepción de habitaciones como cajas cerradas y buscar un espacio libre adecuado a la escala humana; cuarto, construir la casa sobre un sótano; quinto, que las aberturas exteriores tengan una armonía natural y continua; sexto, reducir las combinaciones de materiales diferentes; séptimo, que las instalaciones sean parte del mismo edificio; octavo, incorporar el mobiliario como arquitectura orgánica; noveno, prescindir del decorador.

77.

"...no tardé en darme cuenta de lo difícil que era hacer parte del mobiliario en "abstracto"; es decir, diseñarlo como arquitectura y al mismo tiempo hacer que fuera "humano", esto es, adecuado para el uso humano". "La casa de cartón," en Arquitectura moderna. The Kahn lectures. Princeton 1930 (Barcelona: Paidós, 2010) p. 200. (Ed. orig, 1930)

78.

Ibid. p. 194.

79. Ibid. p. 202

80.

Ibid.

81.

"Así como el esqueleto no es una finalidad de la forma humana ni la gramática es la "forma" de la poesía, así es la función respecto a la

forma arquitectónica. El entrechocar huesos no es arquitectura. Lo menos es más donde lo más no sirve." "El lenguaje de una arquitectura orgánica," en El futuro de la arquitectura (Barcelona: Poseidón, 1978), p. 274. (Ed. orig. 1953).

82.

Ibid.

83.

“La casa de cartón," p. 187 
building por el de natural building. Esto tendría que ver también con esta nueva concepción del interior, remarcada por ciertos "recursos", como la utilización del vidrio, o la continuidad espacial. Por lo mismo, en cuanto al funcionamiento concreto de los espacios, critica que los interiores de las casas tradicionales estaban tan fragmentadas como "celdas penitenciarias", y por eso buscó en sus viviendas tener una planta baja continua, exceptuando la cocina y la sala de servidumbre, eliminando tabiques y puertas innecesarios. "La casa se hizo más libre como "espacio", y también más habitable. Empezaba a surgir la amplitud interior. ${ }^{78}$

En cuanto a la relación de la arquitectura con la máquina, Wright hace un irónico resumen en que todas las cosas de la vida tienen un objetivo primero y esencial, no sólo la arquitectura, con la intención de asemejar esta a cualquier organismo vivo y quitar importancia a la propia metáfora mecanicista. En su artículo "The cardboard house" de 1930, en evidente referencia a la conocida frase de Le Corbusier, dice:

Ahora bien, una silla es una máquina para sentarse.

Una casa es una máquina para vivir.

El cuerpo humano es una máquina que es manejada por la voluntad.

Un árbol es una máquina para dar frutos.

Una planta es una máquina para dar flores y semillas

Y tal como he afirmado antes en algún otro lugar, un corazón es una bomba de succión. ¿esta idea no les estremece ${ }^{79}$

Wright entiende que este principio de "todo es máquina" resulta escaso para la arquitectura, y que una mayor profundidad puede encontrarse en la afirmación de Sullivan de que «la forma sigue a la función», lo cual "es no sólo más profundo, sino también más claro (...) porque esta afirmación contiene lo esencial de toda cuestión. ${ }^{80}$ En su tardío libro The language of organic architecture, publica un breve vocabulario, en el cual incluye el concepto de form follows function, al que le atribuye haber sufrido un abuso de utilización por edificios que no le hacían honor. Lo entiende ya como un "slogan" vacío. ${ }^{81} \mathrm{En}$ parte tiene que ver conque el propio Wright busca proponer su propio slogan, que dialogue con el de Sullivan, adaptándose a su perseguido interés de unidad entre forma y función:

La forma es predicada por la función, pero hasta donde la imaginación poética pueda llegar con ella sin destrucción, la trasciende. "La forma sigue a la función" resulta espiritualmente insignificante: una frase del montón. Sólo cuando decimos o escribimos "la forma y la función son una", adquiere significado la frase. ${ }^{82}$

2.2.5.e. Como es evidente, Wright busca, tanto en sus obras como en sus escritos, esRefugio tablecer una distancia clara con respecto a la arquitectura moderna europea; para él la arquitectura moderna es otro modo de escenografía que intenta emular la máquina desde un punto de vista superficial:

...en la mayoría de las casas de cartón del movimiento "modernista" apenas he encontrado pruebas de que quienes las proyectan dominen la maquinaria o los procesos mecánicos que forjan la casa. En su construcción no encuentro indicios de un método integral. ${ }^{83}$ 
Para Wright un edificio no tendría que parecerse a una máquina. Este no es su cometido, y la máquina no es de ninguna manera arquitectura. Por el contrario, en la conferencia de 1931 que se publicó bajo el nombre de "In the Realm of Ideas," Wright habla de la adecuación del edificio a la tierra, de la posibilidad de generar un refugio cuyo techo se disponga según la escala humana, y que pueda ser aplicada a todos los edificios; extender la vida horizontal del ocupante, ajustando su altura, adecuándola para conseguir «una arquitectura que pueda vivir y dejar vivir.»84 La Casa Robie de 1908 [FG.06] es sin dudas uno de los mejores exponentes de esta idea. La continuidad, una intención que Wright repite en diferentes escritos, tenía también que ver con la eliminación de la columna y la viga, que -en un movimiento que dialoga con lo propuesto por Laugier-se interponen y de algún modo se ensucian los elementos arquitectónicos que realmente definen el espacio y permiten la fluidez. Pero no sólo menciona la estructura, sino que también entran en consideración componentes infraestructurales de la construcción: 85

Toda casa es una imitación del cuerpo humano demasiado complicada, burda, recargada y mecánica. Los cables eléctricos hacen las veces del sistema nervioso, las cañerías representan los intestinos, el sistema de calefacción y las chimeneas son como las arterias y el corazón, y generalmente las ventanas hacen de ojos, nariz y pulmones. ${ }^{86}$

Es claro que el lugar central, el corazón, está atribuido a la chimenea y al sistema de calefacción de la casa. Como ya es sabido, Wright sigue el principio de Semper con respecto al fuego como centro de reunión social o familiar, y las ventanas como las vías de escape de esta guarida. Esta aproximación a una arquitectura que se construye desde un foco central y se expande hacia afuera es también una herencia clara del pensamiento de Greenough. Contrario a gran parte de la arquitectura moderna europea, la transparencia no es una característica que sobresalga en la arquitectura de Wright, sino más bien el contrario, la guarida, el refugio, el interior definido y separado. Esto es incluso más visible en su proyectos para edificios institucionales o empresariales, como Unity Temple, la sede para Larkin Soap Company o incluso el tardío museo Guggenheim, en los cuales los muros se elevan hasta la cubierta y la luz es casi cenital; una "casa" que carece de ojos. Su noción de cercanía con el terreno como continuación de los principios de Semper quedan en evidencia cuando afirma que "Cualquier edificio destinado a propósitos humanos debería ser un rasgo característico elemental a tono con el suelo, complementario de su entorno natural, debería ser un rasgo emparentado con el terreno.»87

Quizás sea la casa construida para Darwin Martin en Buffalo en 1904, la primer obra donde los presupuestos teóricos de Wright en relación a la 'adaptación' encuentran su madurez. En ella se muestra por primera vez el despliegue desenfadado en el terreno, una asimetría segura, que se exagera al máximo a través del despiece de la casa en tres pabellones; uno principal, que alberga los usos básicos, un establo con estacionamiento de carros y una tercera vivienda pequeña. [FG.07] La distancia entre estos elementos se enfatiza por la construcción de una gran pérgola conectora que, a la vez que remarca
Wright, Frank Lloyd, "En el reino de las ideas," en El futuro de la arquitectura (Barcelona: Poseidón, 1978), p. 164. (Ed. orig. 1931)

85. Wright estaba ciertamente interesado en el funcionamiento íntegro del edificio. Muestra de eso es el desarrollo pionero de una calefacción centralizada para el edificio Larkin, construido en Buffalo en 1906.

86. "La casa de cartón," p. 185

87. Ibid. p. 186. 


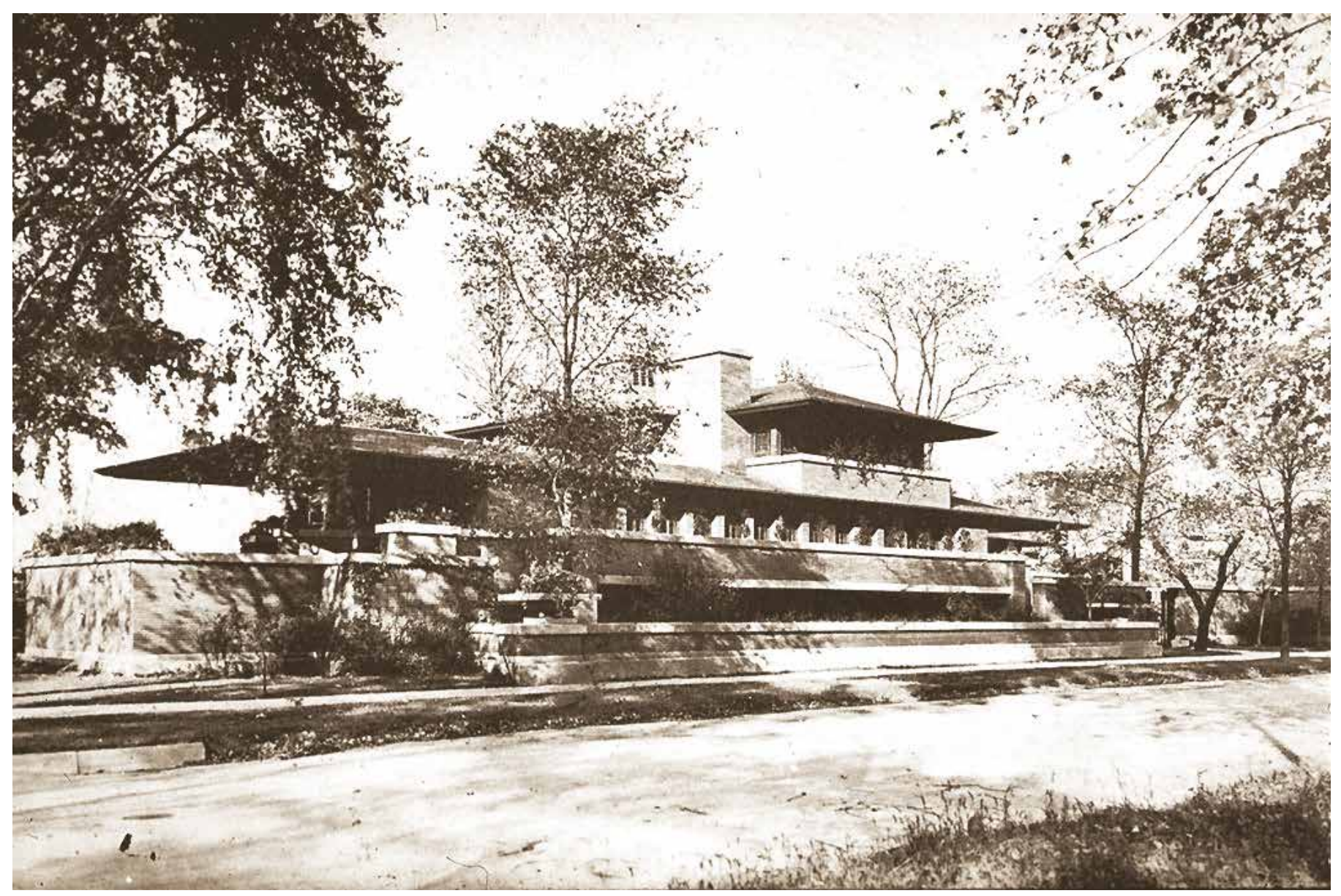




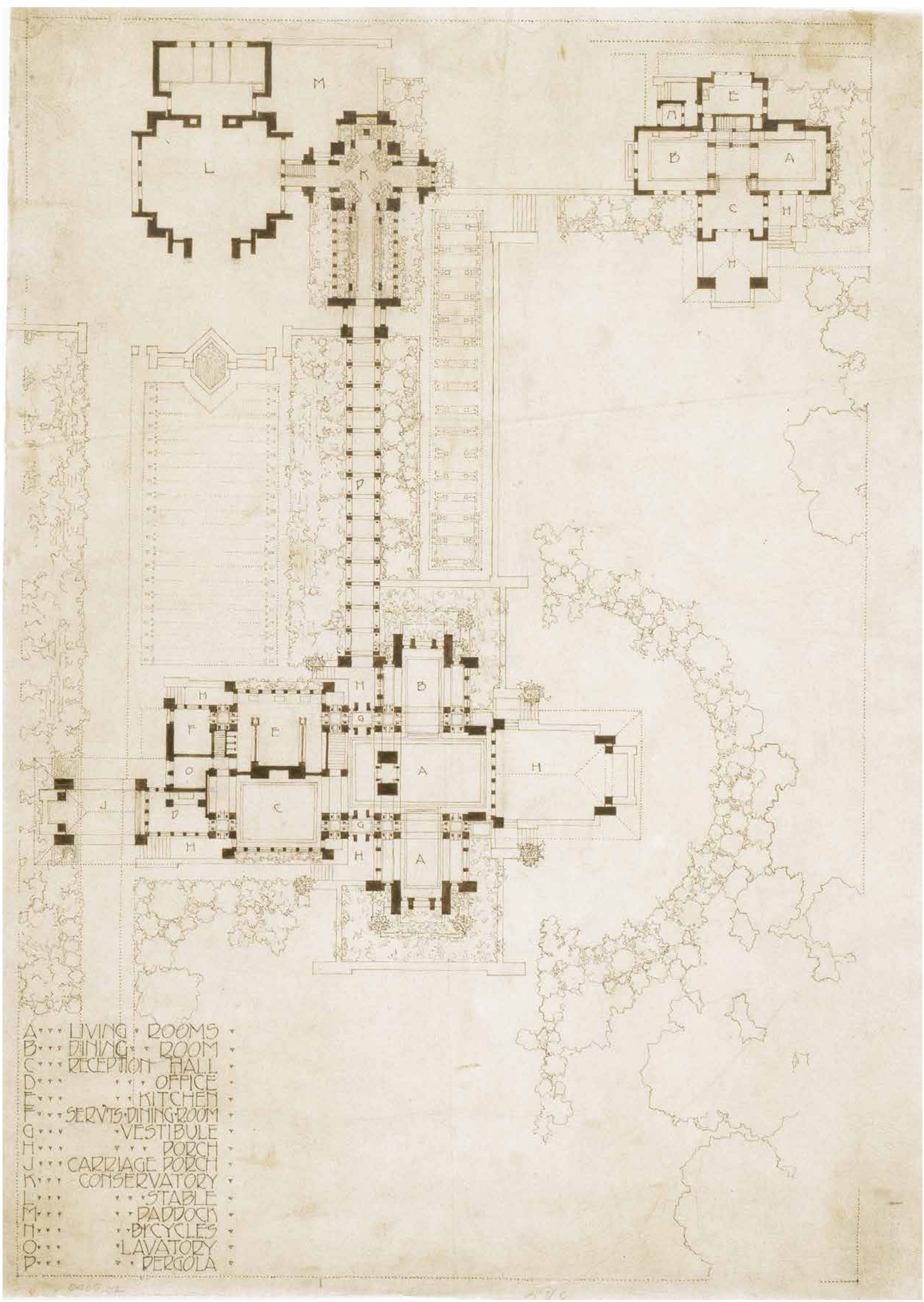


la linea horizontal se apropia del terreno natural y permite recorrerlo y utilizarlo. Wright pone en práctica en esta obra uno de sus recursos característicos que tiene que ver con situar los accesos no por el frente de los volúmenes, sino por sus laterales, evitando la perspectiva central clásica. En el interior, como en la mayor parte de la obra doméstica de Wright, la baja altura de los techos permite una vinculación casi agobiante con la escala humana, y hace que las aperturas al exterior se vuelvan una búsqueda casi necesaria por parte del usuario.

En su explicación del proceso de construcción de sus casas el autor deja entrever también algunas de sus concepciones funcionales, nuevamente muy cercanas a las de Semper. En primer lugar, el sótano que permite separar la casa del suelo y elevarla; los muros perimetrales llegarían hasta el alféizar de las ventanas de la segunda planta, que recorrerían casi todo el perímetro; con esto tendríamos unos muros de cerramiento inferiores y unos muros de cristal en el piso superior. Dadas las cambiantes temperaturas de invierno a verano, un techo que se expande hacia afuera notablemente permite la protección, y se pinta de color claro para que refleje la luz hacia el interior, como una pantalla. "...para mí la casa era sobre todo un espacio interior colocado bajo un buen refugio.»88 Es claro que para Wright la función es resultado de la construcción misma, y están completamente vinculados. Quizás en su idea de refugio se aúnen equilibradamente las ideas sobre la naturaleza y la industrialización. Wright llama a una comunión entre la naturaleza propia del edificio -esa que deriva de la utilización por parte de los usuarios y que permite engendrar una forma- y la propia construcción, que requiere un desarrollo técnico. Lo interesante es que en la visión de Wright estos dos universos no pueden disociarse, y así como la máquina tiene que ser necesariamente una imagen de la naturaleza, la forma (resultante de la función) requiere de una construcción que la sustente, sin perder la unidad. Esta unificación entre función y construcción, naturaleza y máquina resulta en una síntesis de sus significativos aportes.

2.2.6. Hugo Häring, discípulo de Theodor Fischer, al igual que Bruno Taut y Erich Häring. Mendelsohn, ${ }^{89}$ es quizás el autor que con mayor radicalidad evoca este acerPropósito y expresión camiento a la particularidad de la 'adaptación' con una confianza genuina en la forma misma que le da cabida. En sus textos la función siempre será el centro del problema, y el motor de sus propuestas y de su crítica; los artículos que con más énfasis desarrollan este aspecto son los publicados entre 1924 y 1926, al mismo tiempo que compartía estudio con Mies -según Häring, los debates con Mies eran algo natural y constante, a pesar de que cada uno trabajara en proyectos separados ${ }^{90}$ - y fundaba el grupo de vanguardia Der Ring. Pero antes de elaborar estos primeros textos Häring había trabajado en varias propuestas de viviendas unifamiliares en las que había ensayado ya una particular forma de solucionar los problemas funcionales, dando a cada habitáculo interior una particularidad geométrica fruto de la adaptación a la propia actividad a desarrollarse en ella. Estas primeras experiencias, junto con la construcción en 
Behne decidiera darle un lugar de importancia en Der moderne Zweckbau, el libro que en 1923 propone un panorama general de la arquitectura moderna, resaltando las características y diferencias entre las diferentes corrientes. Aquí es donde Häring, junto con Scharoun, ocupan el lugar de lo que Behne entenderá como «funcionalismo».

Del mismo modo que Wright, Häring será uno de los pocos arquitectos contemporáneos a Le Corbusier que exprese enfáticamente su oposición a las concepciones funcionales del arquitecto franco-suizo; y es en esta misma crítica que las propuestas de Häring adquieren también una cualidad y un matiz propio.

En “Wege zur Form”, quizás su artículo más importante, publicado en 1925, Häring Ilama a observar y comprender dos situaciones: por un lado lo que entiende como Zweckerfüllung, el propósito propio del edificio, ${ }^{11}$ y por el otro la expresión del mismo. Se trata de una batalla entre forma y significado. La división y el énfasis puesto en estos dos estados lleva a modos diferentes de entender los objetos. Häring hace referencia un desbalance frente a dos posibilidades: cuando el propósito del objeto se vuelve demasiado importante, la expresión queda disminuida, mientras que cuando el propósito tiene menos lugar, la expresión del objeto puede quedar por delante.

Las formas surgidas del propósito, conformadas por la vida, cuyo carácter primitivo no ha sido modificado por el hombre, son de índole natural y elemental, mientras que aquéllas otras a las que se busca dotar de una expresión, derivan de una norma, de reglas entendidas bajo el conocimiento humano. De manera que las primeras de estas formas, aún sometidas continuamente por circunstancias externas a modificaciones, son desde luego eternas e indestructibles, ya que son formas a las que la vida confiere sin cesar un nuevo renacer. Por el contrario, las formas emanadas de una voluntad de expresión se encuentran sometidas a la caducidad y a las variaciones del conocimiento del hombre. Ello quiere decir que las formas que satisfacen una finalidad práctica surgen asimismo de una manera natural y continúan de algún modo por un sendero anónimo....92

El propósito lleva así no sólo al anonimato, sino también a la búsqueda incesante de una repetición, con el fin de mejorarse a sí misma; por otro lado, la expresión lleva a movimientos erráticos producto de la psiquis del hombre. El caso de las primeras -las que responden a un Zweckerfüllung- incluiría edificios de uso cotidiano, como la viviendas, construcciones de ingeniería, o edificios industriales; mientras que en los templos, edificios religiosos o de culto la "expresión» adquiere mucho mayor lugar. Para Häring resulta lógico no poder encontrar una forma expresiva que al mismo tiempo permita alcanzar un correcto funcionamiento, pero al mismo tiempo es consciente de que, en la naturaleza, las formas elementales son de una naturalidad que nada tiene que ver con la búsqueda de originalidad humana, que sí tienen ese carácter expresivo propio de una realización emocional

...esto significa que las formas derivadas del propósito también surgen de manera natural y, por así decirlo, de forma anónima, mientras que las formas
Es notable que en este artículo Häring no utiliza nunca el término Funktion, sino que hace referencia a Zweckerfüllung, que es el alcance o cumplimiento del propósito.

92.

Häring, Hugo, "Wege zur Form," en Hugo Häring: schriften, entwürfe, bauten, ed. Joedicke, Jurgen; Lauterbach, Heinrich (Stuttgart: Karl Kramer, 1961), p. 13. (Ed. orig. 1925). Traducido por el autor.

93.

Ibid.

94.

Ibid.

\subsection{6.a.}

\section{Zweckerfüllung}


creadas para conseguir una expresión derivan de una constitución psíquica y, por lo tanto, son altamente subjetivas e indeterminables. ${ }^{93}$

Para Häring las formas derivadas del Zweckerfüllung son simplemente eternas, ya que responden a un propósito básico y natural, y las que derivan de la expresión varían con el tiempo, y están sujetas a la condición cultural; son, al fin y al cabo, producto del estilo.

Según el autor, la "expresión» manifiesta cambios importantes en las últimas décadas debido al dominio de la geometría, lo que considera un atentado ante la vida, el movimiento, la naturaleza y sus formas propias. La geometría es para Häring el campo donde más tajantemente se visualiza esta división y se vuelve asimismo irrecuperable. Por lo mismo el llamado de Häring exige básicamente aceptar las formas que derivan directamente del Zweckerfüllung, que no están contaminadas por la expresión, evitando geometrías que considera arbitrarias.

Debemos buscar hacer valer nuestros reclamos de expresión en la dirección de la vida, en la dirección del devenir, en la dirección del cambio de ruta, en la dirección de un diseño natural; desde el diseño hasta cumplimiento del propósito seguimos también la propia ruta del diseño de la naturaleza. ${ }^{94}$

A pesar de estas afirmaciones, resulta poco probable que Häring no considerara una forma particular al momento de enfrentarse a las posibles soluciones arquitectónicas. Esto puede visualizarse en sus primeros proyectos donde, a pesar de que en casos concretos, la forma se adapta para dar cobijo a una actividad particular -el caso más claro es el espacio circular que alberga el comedor, a modo de reunión- los proyectos del autor contienen muchos momentos de geometrías curvilíneas que no necesariamente responden a una función concreta, sino que parecen perseguir una tensión espacial particular. Aunque esta situación estará más depurada en su proyecto para Gut Garkau sus soluciones parecen tener más que ver con las ideas provenientes de Viollet-le-Duc, y de quienes bebieron de ellas, como Guimard y Horta, que de Greenough, o de la propia tradición organicista. Tanto Horta como Guimard buscaban una inspiración en la naturaleza para sus soluciones funcionales aceptando que esta misma abriría un posible camino hacia un estilo. En el caso de Häring, la geometría, más allá de lograr solventar requerimientos funcionales con éxito, consigue expresarse por sí misma y adquirir también una identidad que, a diferencia de Wright, quien aún encuentra referencia en el gótico y en la arquitectura de la antigüedad, poco debe a estilos del pasado.

2.2.6.b. Según Häring existiría un «proceso de definición formal»-Gestaltwerdung-que Gestaltwerdung tendría que ver con la evolución misma de la forma, o más precisamente con el llegar a ser de la forma. Para Häring este proceso tiene que ver con cómo los requerimientos funcionales han afectado los modos de expresión de los objetos. Como también explica en "Wege zur Form”, en particular, en las décadas anteriores a la escritura del artículo, el autor refiere a los objetos de la producción industrial, como los autos, barcos o aviones. Se trata, según Häring, del nacimiento de una espiritualidad nueva, que alcanzaría un nuevo «hallazgo 
Häring entiende que la diferencia principal estriba en que las formas de la naturaleza tienen que ver con el orden de diversas lógicas individuales, que responden a su vez al desarrollo de la vida y al Zweckerfüllung; por lo tanto una búsqueda de la forma por sí misma ${ }^{95}$ sólo nos alejaría más y más hacia una expresión ensimismada y carente de propósito. El camino debe ser, según el autor, el de la naturaleza, y ese camino llevará al verdadero planeamiento, y también a "encontrar" las formas y las geometrías propias, y no a "buscarlas":

Aunque el concepto geométrico de la planta funcionó para promover energía, también fue agotador y mortal. En el curso de estas culturas geométricas, el concepto de planta en sí mismo se alimenta cada vez más, retirándose de las afirmaciones de los vivos, vagando desde el triángulo y el cuadrado al rectángulo y al círculo y, finalmente, a otras descomposiciones y modificaciones. Pero en este momento que experimentamos ahora, en este momento en el que no podemos actuar inicialmente sin conocimiento de la naturaleza, en el que tenemos que actuar según el propósito, no hay otra manera de hacerlo que no sea en el sentido de la naturaleza; saber cómo organizar los elementos de tal manera que su individualidad se desarrolle y, al mismo tiempo, este desarrollo permita la vida del conjunto. Este conjunto es la forma de nuestra vida. ${ }^{96}$

A diferencia de Wright, quien ya había roto el orden formal simétrico, Häring reclama un desarrollo de la naturaleza absoluto, que no atiende necesariamente al sitio donde el objeto se asienta y se relaciona, sino a un principio superior de naturaleza que guía incluso el propio diseño. Sí existe una similitud en cuando a la exigencia de una adaptación necesaria de la sociedad a este modo de vida, lo cual implica, necesariamente, una reforma social que permita la sintonía de una cultura con respecto a su espacio habitable:

...si queremos alcanzar el descubrimiento de las cosas, primero debemos alcanzar el diseño de una nueva vida, una nueva sociedad. Porque no podemos determinar el significado del individuo a menos que sepamos el significado del todo lo que pertenece a este individuo. Por lo tanto, si exigimos que se recurra al camino de la naturaleza para encontrar la forma de los elementos individuales, entonces debemos complementar o, mejor dicho, anticipar que también exigimos la formación de una nueva vida, una nueva sociedad para nuestra encarnación, que continúen también el camino de la naturaleza, y no en contra de ella. ${ }^{97}$

Häring insiste en la necesidad de definir una nueva sociedad, antes que definir sus necesidades de diseño y su Gestaltfindung, aunque no se detiene a desarrollar cuáles serían las particularidades de la misma. Así, entiende que las exigencias expresivas y funcionales deberían finalmente fundirse en un conjunto indivisible; ambos requerimientos solventados al mismo tiempo, evitando la herencia sin sentido de las formas que no responden a ninguna exigencia funcional. Para Häring la forma se construye desde el interior, desde lo que él considera como "la vida»; las particularidades de ese interior deben "desplegarse» hacia afuera y así generar un nuevo resultado exterior. Este resultado no podría considerarse 'forma' en su integridad, básicamente porque no fue concebido desde el exterior. Las formas puras exteriores (y menciona
Häring emplea términos específicos en alemán para esta operación, como Zwangsform, Gestaltfindung o Gestaltgebung.

96. Ibid. 97. Ibid 98. Ibid. 99. Ibid. p. 14. 

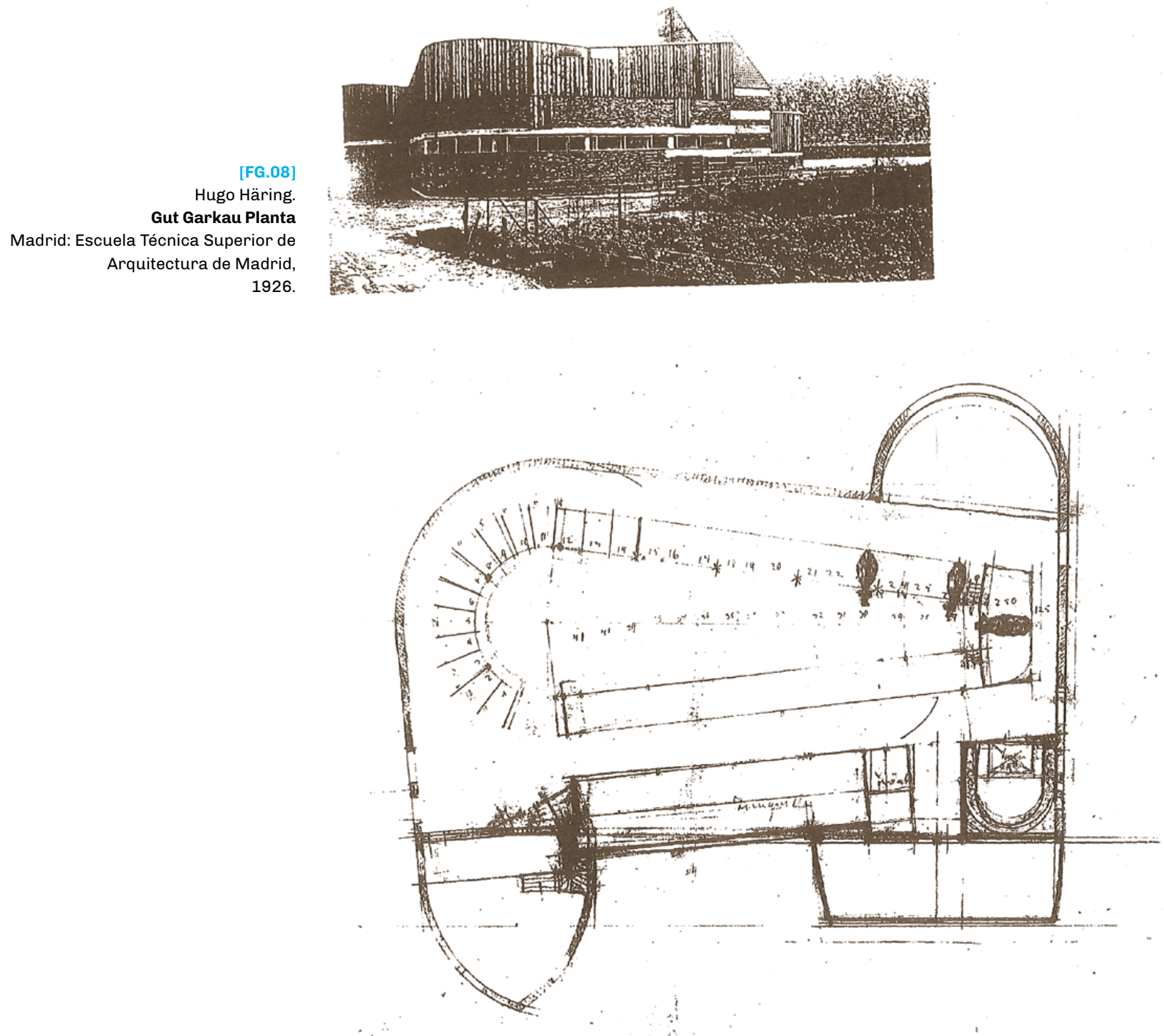

al propio Le Corbusier) las considera una unidad formal, y no una unidad habitable, ya que su origen es puramente geométrico, pero de una geometría que además nada tiene que ver con la naturaleza.

A partir de las leyes de configuración del círculo es imposible obtener que una planta, aunque es probable que encontremos figuras idénticas al círculo en las formas de la naturaleza, en el mismo camino que ésta nos indica. Con ello queremos decir: existe un camino de la forma en el que todos los objetos, tanto los que se conforman a la manera de figuras geométricas como los semejantes a las formas cristalinas, llegan a adquirir su forma definida a partir de la idea encerrada en un concepto individual. Por el contrario, cuando los objetos adquieren su forma a partir de ideas externas, ajenas a su propio interior, el camino hacia la forma discurre por caminos diferentes. ${ }^{98}$

En efecto, la visión de la naturaleza de Häring y Le Corbusier distan mucho, aunque ambos se refieran a ella. A Häring no le es ajena la poesía detrás de la forma pura, y la satisfacción intelectual que produce, pero lo que él persigue es satisfacer la experiencia en sí, no el intelecto. Lo que debe ser mecánico no es la forma, sino su producción; una forma mecánica sólo puede, según Häring, aniquilar la vida. Pero al mismo tiempo avanza, y finaliza "Wege zur Form" diciendo que "No es a nuestra individualidad a lo que debemos dar 
Quizás no sea Gut Garkau el proyecto donde las ideas de Häring quedan mejor ilustradas, pero sin dudas es el que consigue asentar y hacer palpable su pensamiento, por ser la obra más importante que construyó. [FG.08] En su artículo "Funktionelles bauen: Gut Garkau / Das Viehaus" de 1925 lo resume como un establo para 42 vacas, un pajar, una casa y otros pabellones de servicios. La resolución de la planta -con forma de 'pera', según la descripción del mismo autor- considera un radio de giro que permite la circulación natural de los animales sin tener que retroceder; en el extremo se sitúa el toro, en una expresión de jerarquía. Häring habría entrevistado al propietario antes de realizar la obra, consultándole por el modo natural en el que los animales se disponen para comer, al modo de una ronda, para evitar la incomodidad de los mismos. Häring ensaya además modos de ventilación e iluminación natural particulares utilizando la estructura, la separación de los forjados con respecto a los muros o las mismas inclinaciones de la cubierta. En el caso del establo, la iluminación funciona de modo independiente a la ventilación, así esta última puede ser controlada de un modo más eficiente y a la altura de una persona; las aberturas que permiten la iluminación general están ubicadas a lo largo del borde del forjado. La ventilación natural y cruzada en el establo resulta necesaria para evitar el contagio de enfermedades entre los animales. Si Ginzburg intentaba establecer una conexión directa entre la función de la arquitectura y la máquina a través de la lectura de los procesos industriales Gut Garkau es una especie de manifiesto que le permite a Häring, literalmente, vincular la función arquitectónica con la de los sistemas vivos, en este caso, los animales. Aún así, Gut Garkau es también de algún modo una fábrica, es un edificio que alberga un sistema productivo, y su principal diferencia radica especialmente en el valor que Häring otorga a la geometría al momento de elaborar soluciones funcionales. Esta aparente libertad formal está contrarrestada luego por una adaptación a cada pequeña solución que exige una forma particular, la cual tiende normalmente a lo orgánico. El conjunto resulta así una sumatoria de soluciones que, al estar concebidas en el mismo tono, puede leersen como una unidad. No obstante, también hay licencias expresivas, como la cubierta abovedada del techo del pajar, aunque el mismo autor niegue en su texto la referencia a las formas tradicionales de los establos.

Parte de las soluciones que aplicaría en Gut Garkau habían tenido también una expresión teórica en el artículo "Probleme des Bauens" escrito en 1924, al mismo tiempo que realizaba el proyecto. Este artículo está dividido en tres secciones: en la primera Häring describe las tres funciones básicas de una ventana (iluminar, ventilar y permitir vistas) -en este caso sí utiliza el término funktion-; en el punto dos habla de la tipificación, citando a Mies como un ejemplo de este perfeccionamiento, y discutiendo las particularidades de la vivienda mínima; en el tercero refiere a los problemas de la tipificación de la vivienda en masa. Gut Garkau servirá para demostrar las posibilidades expresivas de la adaptación a la función -y con esto el buen desempeño de las mismas, como Ginzburg también lo buscara- pero tomando una distancia con respecto a la repetición de la estética maquinista; al mismo tiempo sino aportará a la

\section{Sistema vivo}

\section{0.}

Häring, Hugo, "Probleme des Bauens," en Hugo Häring: schriften, entwürfe, bauten, editado por Joedicke, Jurgen; Lauterbach, Heinrich (Stuttgart: Karl Kramer, 1961), p. 14. (Ed. orig. 1924), Traducido por el autor.

101.

Häring, Hugo, "Zwei Städte. Eine physiognomische Studie, zur Problema.tik des Stadtebaus," en Hugo Häring: schriften, entwürfe, bauten, editado por Joedicke, Jurgen; Lauterbach, Heinrich. (Stuttgart: Karl Kramer, 1961), p. 18. Traducido por el autor. (Ed. orig. 1926)

102.

Ibid. 
definición moderna de la ventana y sus roles funcionales, mucho más incisivos que los difundidos por Le Corbusier con sus fenêtre en longueur.

2.2.6.d. Ciertamente Häring se encuentra preocupado por la industrialización en la arVida mecanicista quitectura y el alejamiento de una función adecuada a cada célula, que elimina cualquier rasgo de particularidad propia de la naturaleza en la arquitectura. Häring dice que la máquina no es valorada por hacer que todo lo que produce sea igual, sino por ofrecer un acabado perfecto, imposible de alcanzar de otra manera; ahí radica su verdadero valor, y no en la repetición;

...si hay un objetivo de diseño dentro de la tipificación entonces sólo es este: que la máquina haga que la individualidad de la casa sea tan exacta en el sentido de la fabricación, que dentro de la masificación, la objetivación del individuo sea compensada con la pérdida de subjetivación de la totalidad. ${ }^{100}$

A su vez Häring se posiciona contrario la idea de Existenzminimum, barata, producida a través de cálculos matemáticos, y en resumen, a casi todas las instancias que componen la noción de 'eficacia' en la función. En este sentido su posicionamiento tiene una cercanía con Ginzburg con respecto a comprender las funciones de un edificio cabalmente, al modo de un sistema, pero este mismo sistema para Häring no es el industrial sino el natural.

Una de las formas de comprender el particular posicionamiento de Häring con respecto a la función es fijándose en sus opiniones sobre los autores más difundidos de la arquitectura moderna. Häring apunta en "Zwei Städte. Eine physiognomische Studie, zur Problema.tik des Stadtebaus" de 1926 a la sociedad presa de la mecanización que la arquitectura moderna propone, y que derivaría, según el autor, en anulación de las libertades individuales. Empieza mencionando la separación de funciones -habitar, trabajar, descansar, estudiar- que Le Corbusier y Hilberseimer plantean para ordenar las ciudades, sin contratiempos. Aplican así la densidad en altura, evitando los largos desplazamientos, como si de un modo de producción se tratase. Para Häring, se trata en definitiva

de una ciudad resultante de la producción de un orden que se refiere a los valores económicos, a los recorridos y a la circulación de las personas, a los intereses de las empresas y los servicios. Se trata de "fordismo". ${ }^{101}$

En este "Zwei Städte..." Häring intenta sacar a luz el posible funcionamiento de las propuestas de Le Corbusier y Hilberseimer, y el modo de habitar producto de ellas. El orden por sobre el hombre ejerce, según el autor, un sometimiento a un modo de vida mecanicista, y planteamientos que no tienen que ver con el habitar, sino que derivan de un enfoque materialista. Hay en este lugar un punto de contacto claro entre Häring y la valoración del individuo por parte de Wright cuando el alemán dice que

El socialismo que no deja margen al ser aristocrático del alma individual no es socialismo. Toda concepción que cree que la vida social debe encaminarse hacia la uniformidad, la tipificación, lo normativo, está equivocada; su contraria es justamente la adecuada. ${ }^{102}$

En este sentido, Häring puede aceptar, como Wright, que el mundo mo- 
lidiar con esta condición. Lo que no acepta es la mecanización del propio habitar y de la función; la función no puede partir, según Häring, de la mecanización de una sociedad, sino de las libertades del individuo. El autor critica también la distancia y la falta de integración que el paisaje natural tiene en las propuestas de Le Corbusier y Hilberseimer. Entiende que el paisaje es en estas propuestas un tema de pura representación, y no de realidad. También defiende la individualidad y características particulares de cada ciudad ante la homogeneización de las propuestas modernas, algo que ya había mencionado en 1925, en el artículo "Baurat nein -bauherr", en el que profundiza en el problema de la construcción, la política y sobre todo la especulación. Es claro que para Häring el problema de los planteos de Le Corbusier y Hilberseimer radica en la importancia atribuida al planeamiento general por sobre la construcción particular; la masiva propuesta de cientos de departamentos idénticos lleva a la idea de Masse Mensch (hombres masa), a los que se considera también como un tipo repetitivo. Del mismo modo que ataca estas decisiones, juzga a la arquitectura racionalista y repetitiva.

Aunque Häring sea el autor que con mayor claridad se aproximó teóricamente a adecuar la función a situaciones de una obsesiva particularidad, también, al mismo tiempo, Hans Scharoun -colega y amigo de Häring, de quien recibe una notoria influencia- puso en práctica esta aproximación accediendo a una mayor cantidad encargos. Entre ellos se encuentra la especialmente difundida Casa Schminke. [FG.09] Ambos autores contaron además con la difusión del libro de Adolf Behne. Aunque Banham, en Theory and design in the first age machine, afirme que la primera utilización de peso del término "funcionalismo" -de amplio uso a mediado de los años treinta- fue el que acuñó Alberto Sartoris para titular su libro Gli elementi dell'architettura funzionale, fue Behne, en 1923 quien consiguió dotar al término "funcionalismo" de una consistencia pocas veces alcanzada en esas décadas. Behne tuvo una visualización casi prematura de los modos en que la función estaba afectando a la arquitectura moderna; cuando escribe Der moderne Zweckbau Häring se encuentra construyendo Gut Garkau, a la que el mismo Behne refiere, intentando explicar este modo de "funcionalismo» -el mismo Behne le concede el término- que adopta la geometría curvilínea, adelantándose casi a las aproximaciones teóricas que un año más tarde publicará el mismo Häring en "Wege zur Form”:

\section{El espacio rectangular, la línea recta, no son figuras funcionales, sino mecáni- cas. Si procedemos consecuentemente a partir de la función biológica, la pieza rectangular resulta absurda, porque sus cuatro ángulos son espacio muerto, inutilizable. Si circunscribo el espacio de una habitación realmente aprovecha- do, el que llega a ser pisado, obtengo necesariamente una curva. ${ }^{103}$ \\ A pesar de ser el historiador que con mayor énfasis dé cuenta del cam-} bio de paradigma de la función en los años veinte, Behne no busca posicionarse de uno u otro lado, en corrientes que bautiza como "racionalistas" o "utilitaristas". Como historiador es capaz de explicar con lucidez las condiciones contemporáneas de la arquitectura, pero siempre mantiene una clara distancia.
103. Behne, Adolf, La construcción funcional moderna (Barcelona: Ediciones del Serbal, 1994), p. 55. (Ed. orig. 1923).

104.

Peter Blundell Jones explica, refiriéndose a la obra de Häring que «...una comida en la mesa de una casa de granja tradicional significa mucho más que mera nutrición. Reúne a la familia, a intervalos regulares, y por lo mismo regula su día y su trabajo. en ella se definen sus relaciones sociales, y les recuerda constantemente que es responsable de proveer su sustento. en todas estas cosas los edificios sirven como teclas de acceso, como recordatorios del lugar que tienen todas las personas; pero es aún más que eso. Incorporan tanto el indicador del orden social como el marco necesario para la actividad, el marco sin el cual las actividades no podrían suceder, o bien sucederían de otra manera. La disposición de las sillas y la mesa es el requisito principal para que la familia adopte su configuración; pero la ubicación de la mesa dentro un ambiente es también importante en cuanto a la relación con el resto de los ambientes; a la granja como un todo, en relación con el mundo exterior y, también con la cruz colgada en la esquina, en relación con la Deidad." Blunde-

\subsection{6.e}

\section{Funcionalismo}

II Jones, Hugo Häring: the organic versus the geometric, p. 23. Traducido por el autor.

105.

Este es un tema que planteará posteriormente Aldo Rossi, en su crítica a lo que considera el "funcionalismo ingenuo". Ver Rossi, Aldo, La Arquitectura de la ciudad, Editorial Gustavo Gili SA Barcelona (1982). (Ed. orig. 1966). 
traducciones que contribuirían a la reducción de la terminología del problema, publicándose en inglés como The modern functional building, pasando así al español como La construcción funcional moderna. La noción de Zweck (propósito), probablemente mucho más certera en cuanto a las consideraciones que el autor intentaba traer a la luz queda, de este modo, disminuida.

Tanto la arquitectura de Häring como la de Scharoun se nutren de esa atención a los pequeños detalles que componen el día a día de las actividades, en este caso valorados y puestos en primer lugar, para construir un espacio que pueda darles un cobijo acorde. Espacios específicos para cada situación; mobiliario adecuado a la forma que a la vez se adecua a la acción, la atención a las orientaciones -patentes en toda la tradición vitruviana- a la iluminación natural que mejor favorezca a cada actividad. La ‘adaptación' aparece como una oda a la especificidad de la vida humana, un conocimiento profundo y a la vez específico del mundo interior. ${ }^{104} \mathrm{Al}$ mismo tiempo, esta función de adaptación a la célula individual adolece del factor tiempo, del cambio y de lo imprevisible que la misma sociedad alberga a medida que se desarrolla. La permanencia de los hábitos de vida e incluso de las mismas funciones no puede garantizarse, y mucho menos en una sociedad que abraza la industrialización y la aceptación de lo mecánico, lo cambiante. El pensamiento de Häring no repara en tales circunstancias, y su propia obra, junto a la de Scharoun, no hacen sino congelar una serie de particularidades funcionales que ya cuentan con la dificultad de poder satisfacer a usuarios con hábitos de vida diferentes. Cierto es que resulta difícil encontrar concepciones funcionales que hayan considerado a la arquitectura desde el punto de vista de su permanencia; ${ }^{105}$ quizás por el simple hecho de que los cambios no pueden predecirse, y mucho menos en momentos donde estos mismos no se veían modificados de forma tan vertiginosa. El siglo XX plantea otras particularidades, y la 'adaptación' de Häring es una apuesta -incluso comparada con la de Wright- que lleva en sí al menos el riesgo de volverse, paradójicamente, inútil.

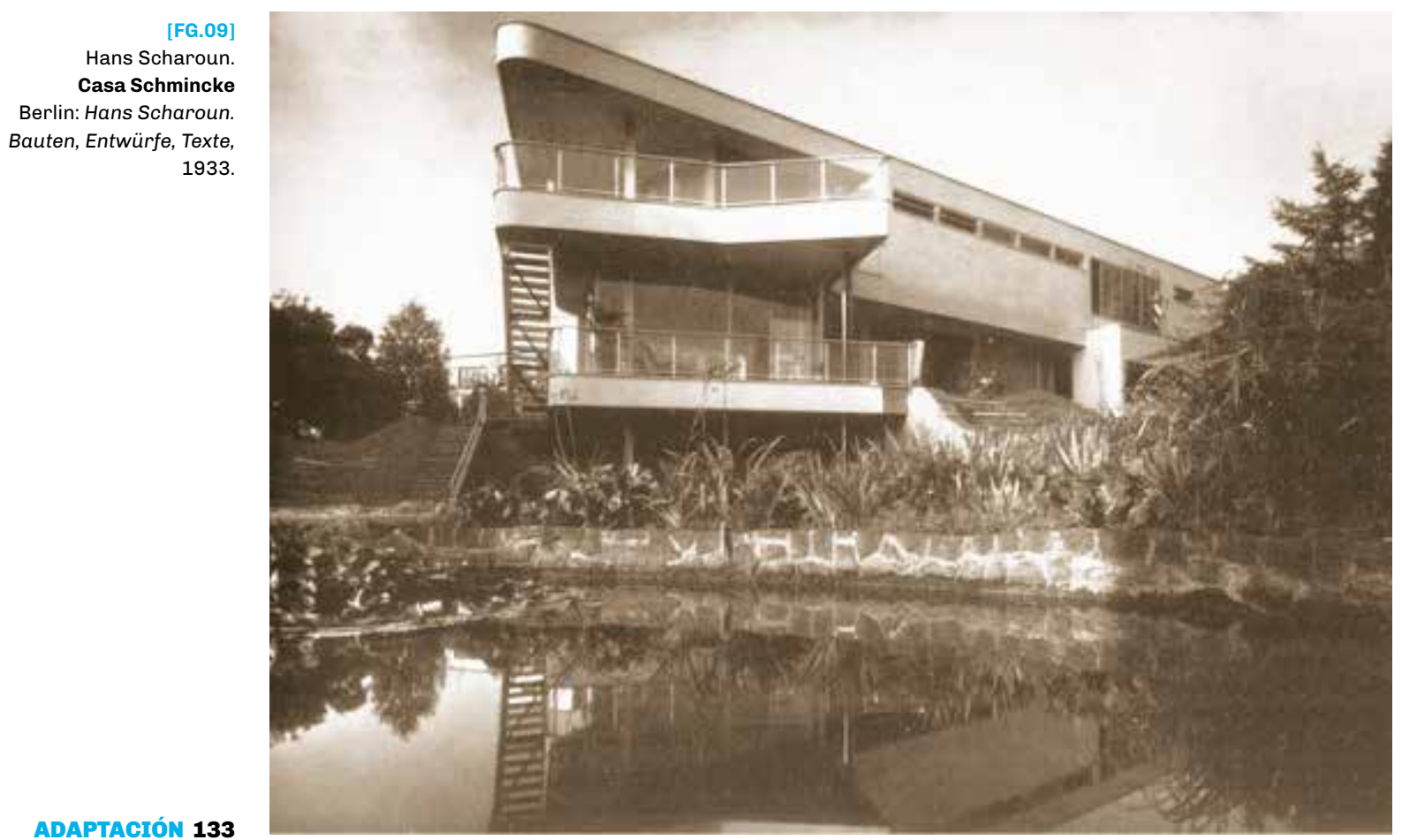


La arquitectura de Aalto significó, cuando las críticas sobre la primer arquitectura moderna se intensificaron, una vía de escape posible, dada su propuesta alternativa que consideraba en primer lugar el entorno natural y material, y abogaba por una "humanización». ${ }^{106}$ Y es justamente esta idea de "humanizar» la arquitectura, la máquina y finalmente la función la que le lleva a recuperar un componente emocional, alejado de lo sistémico, que le conduce a realizar una propuesta de 'adaptación' funcional particular.

Aalto se coloca, tanto a través de sus textos y discursos -sobre todo los que van desde fines de la década del treinta hasta mediados de la década del cincuenta- como de sus proyectos como un heredero directo del pensamiento de Häring, ya que sus soluciones dan cuenta también de un estudio pormenorizado de las actividades humanas más comunes y pequeñas. Al mismo tiempo consigue diferenciarse del autor alemán en el sentido en que lo formal pareciera incluso ocupar un lugar menos importante, es decir que se entiende que cuando Aalto persigue una solución formal no busca congelar un movimiento humano en una morfología particular, al modo de Häring o Scharoun, sino que prefiere cierta síntesis geométrica que acerca al edificio un poco más a sus condiciones de producción antes que a una forma natural ideal. Además Aalto dota a cada programa de una particularidad diferente, o más bien encuentra en cada uno una temática propia que lo hace único. Esto lo lleva a considerar al mismo tiempo el entorno natural y el construido de una manera más cautelosa, y a su vez más vinculada a la función.

En la conferencia que brinda en Viena en 1955 Aalto se concentra en esa batalla contra los problemas formales, los cuales resultarían un velo frente a los verdaderos problemas funcionales, según él mismo entiende, aún más difíciles de resolver. En sus palabras "estamos aquí para humanizar la naturaleza mecánica de los materiales», ${ }^{107}$ o en su afirmación de que "...el hombre no puede crear sin destruir simultáneamente»108 la naturaleza pasa a ser, como en otros autores de la 'adaptación,' un punto de partida, y en este caso además -para ponerla en relación con el tema de la afectación de la arquitectura a su entorno físico- una preocupación primordial en su propia arquitectura. En la conferencia que en 1938 da en Oslo, titulada "La influencia de la construcción y los materiales en la arquitectura moderna", dice:

En la lucha humana contra la naturaleza, somos siempre conscientes del esfuerzo que se realiza para tratar el problema con el que nos enfrentamos, de forma que su importancia y su efecto perjudicial sobre la vida se verá reducido tan pronto como se haya hallado la solución correcta. Si observamos la arquitectura desde este prisma, o sea como un apartado de la lucha entre el hombre y la naturaleza, descubriremos su carácter esencial: una variabilidad sistemática y constante. ${ }^{109}$

Para el autor la relación entre arquitectura y naturaleza resulta en una tensión constante, pero no sólo por el hecho de que la propia construcción modifique un ambiente existente, sino por el modo en que dicha construcción es incapaz de acercarse a esa paradoja que supone la "variabilidad constante". En efecto, Aalto busca tanto en sus proyectos como en sus escritos dar cuenta
2.2.7.

Aalto. Diseño de lo particular

106.

Ver "Alvar Aalto y la tradición nórdica: el romanticismo nacionalista y la sensibilidad doricista, 1895-1957" en Frampton, Historia crítica de la arquitectura moderna.

107.

Aalto, Alvar, "Entre el humanismo y el materialismo," en La humanización de la arquitectura (Barcelona: Tusquets, 1978), p. 47. (Ed. orig. 1955).

\section{8.}

Ibid.

109.

Aalto, Alvar, "La influencia de la construcción y los materiales en la arquitectura moderna," en La humanización de la arquitectura (Barcelona: Tusquets, 1978), p. 10. (Ed. orig. 1938)

110

Ibid. p. 11.

\subsection{7.a}

Variabilidad constante 
de la necesidad de irrumpir en la repetición introduciendo particularidades. Se trata sin dudas de un enfoque novedoso para la función, ya que no presupone la adhesión completa a un paradigma "racionalista» ni a otro "organicista". Aunque Aalto no mencione específicamente el problema de la función, parece casi estar refiriéndose a ella cuando habla de la homogeneidad en el diseño arquitectónico, afectando a lo que él considera como "desarrollo humano":

En la arquitectura existe un enfoque conservador de las formas (...) que apunta a la creación de una homogeneidad formal de los muchos y variados problemas arquitectónicos. La errónea interpretación de la expresión "diseño uniforme”, como aquí se manifiesta, está muy extendida y es uno de los mayores obstáculos que impiden la salida a la luz de las cualidades básicas de la arquitectura. Debería potenciarse la mayor flexibilidad posible en la arquitectura, tanto en su interior como en sus aspectos formales, para afrontar su responsabilidad de ayudar a hallar soluciones a los dilatados problemas humanísticos, sociológicos y psicológicos. Cualquier expresión formal externa (...) impide la participación real y activa de la arquitectura en el desarrollo humano y reduce de ese modo su importancia y su intensidad. ${ }^{110}$

Aalto entiende claramente que el «funcionalismo» -tal como él lo menciona- no tiene que ver con la homogeneidad y ortogonalidad formal de la arquitectura moderna; de algún modo percibe que los problemas formales afectan en primer lugar las posibilidades que la función tiene para aportar a lo que entiende como "desarrollo humano". Este último tendría que ver con problemas en principio extradisciplinares, como la percepción y la psicología, los cuales el autor entiende como primordiales, y a la vez directamente afectados por el entorno arquitectónico. Para Aalto lo «realista» de la arquitectura es esta aproximación que podríamos entender como humanista, y que busca brindar un segundo grado de confort una vez que la organización correcta de los espacios ya había sido conseguida por la primer arquitectura moderna, al desentenderse de la simetría y adoptar la escala humana.

Recuperando la propuesta de Wright pero llevándola a su vez más allá, Aalto no refiere a la naturaleza como una abstracción, de la cual hay que tomar lecciones, sino que más bien considera a la misma como algo concreto, con vida propia, con lo cual hay que lidiar, y a la cual hay que intervenir. De este modo también llama la atención sobre el alejamiento de la sociedad moderna frente a la naturaleza, en un tono casi reaccionario, cuando afirma que las velas resultaban mejores elementos de iluminación que las bombillas, o que la ventilación artificial, por conductos, mata los ozones, los cuales resultan fundamentales para la calidad natural del aire; por lo que el aire en el interior, aunque sirve para vivir, baja las condiciones de vida. En probable concordancia con la situación geográfica finlandesa, Aalto exige la presencia física de la naturaleza en la vida de los hombres, porque entiende que existe allí un bienestar que es incapaz de ser reemplazado por la modernidad.

2.2.7.b. El de la técnica constructiva es un problema esencial en la obra y el pensamiento del autor, y se encuentra directamente vinculada a lo fisiológico, lo so- 
los materiales en consonancia con una concepción de la función, un tema que desarrolla sobre todo en su conferencia en Oslo de 1938. En ella afirma que la influencia directa de los materiales de la construcción en la arquitectura es un tema exclusivo de las construcciones primitivas, donde los materiales no eran sometidos a procesos de tratamiento diferentes. Es decir que los procesos de producción someten a los materiales a un continuo cambio, haciendo de estos algo casi irreconocible. Lo importante entonces en la arquitectura no serían los materiales en sí, sino los procesos de tratamiento de los mismos. Aquí Aalto aprovecha para poder definir con precisión las cualidades de uso de los propios ambientes; problemas como el color, la reflexión de la luz, las condiciones acústicas son trabajados en detalle en sus proyectos y están directamente asociados a los procesos a los que los materiales son sometidos y por los que son afectados. De este modo se explaya en cómo los materiales han influido en la propia distribución de un edificio. Materiales con comportamiento acústico mejorado han permitido obtener recintos de reunión más pequeños sin ocasionar molestias. Asimismo, los sistemas de calefacción centrales han modificado el modo en que tanto los edificios como las ciudades se han planificado, ya que la consideración de estos sistemas resulta primordial antes de que las propias distribuciones se lleven a cabo. En el mismo sentido Aalto refiere al problema del aislamiento, tanto en cuanto a las fuerzas de la naturaleza como al aislamiento de los propios grupos de gente. En el primer caso parece recurrir a nociones cercanas a Semper en cuanto a la cubierta, el muro y el suelo. Menciona a la cubierta como problema central de la arquitectura; con la aplicación de la cubierta plana, sin importar la latitud, y la obtención de plantas bajas diáfanas (en obvia referencia a la arquitectura moderna) la cubierta ha obtenido un rol casi secundario. De este modo rescata con desprejuicio motivos de construcción regionales que nacen de las características del mismo territorio.

Por otro lado está el tema de la estandarización, el cual no considera un logro de la arquitectura moderna, sino que ubica dentro de una herencia histórica de la disciplina. Para él, "uno de los resultados más importantes fue la introducción de programas sistemáticos en la arquitectura». ${ }^{111}$ La estandarización no debe significar, según él, una repetición, sino más bien un número mayor de combinaciones posibles. Esto equivaldría también a una analogía con la naturaleza, la cual se repite por medio de células que generan estructuras diferentes; pero también a una analogía con el pensamiento de Durand, sobre todo en cuanto a su concepción de économie. Aalto avanza aún más en la precisión de esta "economía", en cuanto a su impacto en la función, cuando en la Conferencia en el R.I.B.A. de 1957 Aalto dice:

Si tenemos, por ejemplo, un bloque de cinco pisos, seis pisos, ocho pisos, surge la pregunta: “¿Qué ancho debe tener? ¿Qué largo? ¿Cuál es el método más barato que permita dar a la gente las viviendas que necesitan?". Naturalmente, eso debiera llamarse ciencia. Perno no lo es. La contestación es muy, muy simple: cuanto más ancha la casa, más barata. Esto está claro. Se podría ir más lejos y afirmar que la casa más inhumana es la más barata, que la luz más cara de que disponemos es la luz del día -dejemos eso aparte, y entonces
112

Aalto, Alvar, "Conferencia anual en el R.I.B.A en 1957," en La humanización de la arquitectura (Barcelona: Tusquets, 1978), p. 72-73. (Ed. orig. 1957)

113.

La confusión viene dada por la denominación generalizada de una arquitectura moderna pretendidamente funcionalista, la cual Aalto entiende, casi de modo opuesto, como formalista.

114.

Aalto, Alvar, "La humanización de la arquitectura," en La humanización de la arquitectura (Barcelona: Tusquets, 1978) p. 25. (Ed. orig. 1940).

115 .

Ibid. p. 26.

116.

Ibid. p. 27. 
conseguiremos casas más baratas. Lo más caro es el aire puro, porque no sólo es una cuestión de ventilación, sino también una cuestión de planificación de la ciudad. ${ }^{112}$

2.2.7.c. En el artículo “La humanización de la arquitectura” de 1940, Aalto desarrolla Funcionalismo humano con mayor precisión lo que él entiende por "funcionalismo», o más precisamente por "funcionalismo humano", un concepto construido principalmente en base a ejemplos de sus propias obras. Aalto comienza el artículo afirmando la existencia de una "arquitectura funcionalista" en contraste con otra "formalista", y se propone realizar una interpretación acertada de esta idea de función, ante lo que considera una confusión. ${ }^{113}$ Así, Aalto comienza con una definición abstracta cuando dice:

"La función" es el uso característico, tarea o acción de un objeto. "La función" es también una cosa que depende de otra y varía en función de ella. "El funcionalismo" -según la definición atrevida de los diccionarios- es "la adaptación consciente de la forma al uso" -es a la vez más y menos que ambas cosas, pues debe admitir y contar con ambos significados de la palabra "función". 114

Para Aalto entonces un objeto puede ser funcional en algún campo determinado de la arquitectura y no serlo en otro; puede serlo, como la arquitectura moderna, desde el punto de vista técnico u económico, pero para él «... si la arquitectura abarca todos los campos de la vida humana, el verdadero funcionalismo de la arquitectura debe reflejarse, principalmente, en su funcionalidad bajo el punto de vista humano.»115 Habría entonces un "funcionalismo técnico»-vinculado por supuesto a la arquitectura moderna, el cual se centraría en el aprovechamiento de las técnicas industrializadas y la propia economía de construcción- y un "funcionalismo humano" -que sería el que él mismo encarnaría. El primero sólo tendría sentido para Aalto si el «funcionalismo» en general consiguiera avanzar paulatina y completamente en los diversos campos de la arquitectura hasta poder satisfacerlos a todos; pero esto, según él, resulta impracticable, con lo cual deshecha su posibilidad. El «funcionalismo humano» pertenecería entonces a una segunda fase de la arquitectura moderna. Según Aalto, en un primer período, durante la arquitectura moderna, se exageró la técnica racional, y las funciones humanas no se recalcaron suficientemente; pero el problema no era tanto la racionalización como la insuficiente profundización en la misma. Así se llegaría a esta segunda fase de, donde priman los problemas psicológicos y humanitarios; "...la nueva fase de la arquitectura moderna intenta proyectar los métodos racionales desde el ámbito técnico al terreno psicológico y humano». ${ }^{116}$ Sería un período que no se opondría al racionalista, sino que ampliaría sus métodos (el diseño de sillas metálicas es, según Aalto, un buen ejemplo, ya que técnicamente solventan los problemas, pero humanamente no son del todo apropiadas). Para el autor la arquitectura nunca puede ser una ciencia, por más que algunos métodos le sean cercanos. En cambio, por medio de la consideración de la vida humana, se puede ampliar mucho más el campo científico, incorporando el instinto y el arte. El mismo Aalto pone de ejemplo el caso del centro de tuberculosos Paimio, porque 
(4)

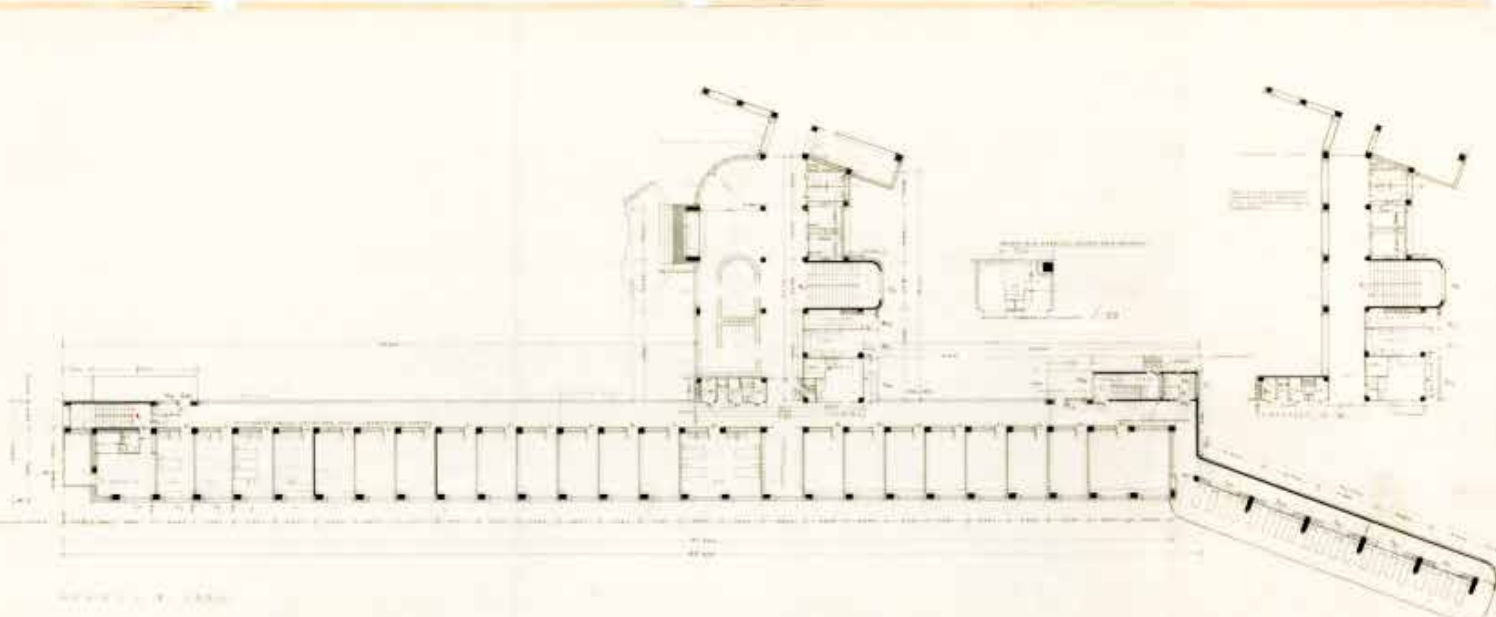



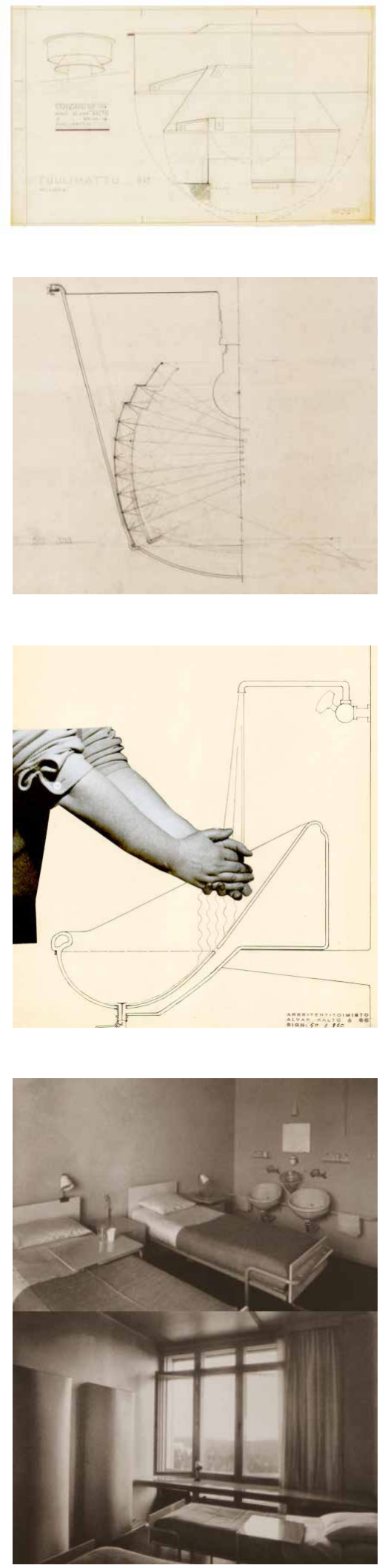

[FG.11]

Alvar Aalto

Sanatorio Paimio. Detalles de lámparas, lavamanos y ventana. Helsinki: Alvar Aalto Foundation, 1933. usuarios con una alta sensibilidad. Aalto menciona haber experimentado dos temas centrales en el proceso de este proyecto: 1. la relación entre el individuo y su habitación y 2. la protección del individuo de grandes grupos de personas y de la colectividad. Así estudió la forma de los habitáculos, los colores, la luz natural y artificial, los sistemas de calefacción y la acústica: [FG.10][FG.11]

Este primer experimento se realizó con una persona en la condición más débil posible, una paciente en cama. Uno de los resultados especiales descubiertos consistió en la necesidad de cambiar los colores de la habitación. En muchos otros sentidos, el experimento demostró que la habitación debía tener una forma diferente a las habitaciones ordinarias. Esta diferencia puede explicarse del siguiente modo: la habitación ordinaria está concebida para una persona de pie; una habitación para enfermos es una habitación para personas en estado horizontal, y los colores, iluminación, calefacción, etc. deben diseñarse teniendo en cuenta este concepto.

Esto significa, prácticamente, que el techo debe ser más oscuro, pintado de un color celeste especial, apto para ser la única visión de un paciente reclinado durante semanas. La luz artificial no puede venir de un aplique ordinario fijado en el techo, sino que el principal centro de luz debe provenir de un lugar situado fuera del ángulo de visión del paciente. (...) Asimismo se consideró la posición del paciente para el emplazamiento de las puertas y ventanas. Para evitar los ruidos, una pared de la habitación era absorbente de sonido, y los lavabos se diseñaron especialmente para que el chorro de agua incidiera en la porcelana en ángulo agudo, evitando el ruido de este modo. ${ }^{117}$

Otro caso que explica con mayor precisión el pensamiento de Aalto en cuanto a este "funcionalismo humano" es el de la Biblioteca Municipal de Viipuri, terminada en 1935, [FG.12] de la que el mismo autor dice:

El problema más importante en relación a una biblioteca es el del ojo humano. (...) El ojo es solamente una parte diminuta del cuerpo humano, pero es la más sensible y quizás la más importante. (...) La luz del día a través de las ventanas ordinarias sólo cubre una parte de una sala grande e incluso si la habitación está suficientemente iluminada, la luz será desigual y variará sobre los distintos puntos del suelo; por esta razón se han usado preferentemente claraboyas en las bibliotecas, museos, etc. Pero la claraboya que cubre el área completa del suelo, produce una luz exagerada, si no se realizan arreglos adicionales. (...) En el edificio de Viipuri, se resolvió el problema con la ayuda de numerosas claraboyas cónicas, construidas de forma que la luz pudiera ser denominada luz diurna indirecta. (...) En Finlandia, el mayor ángulo de incidencia de la luz del sol es casi de cincuenta y dos grados. Los conos de cemento están diseñados de forma que la luz del sol incida siempre indirectamente. Las superficies de los conos expanden la luz en millones de direcciones. Teóricamente, por ejemplo, la luz alcanza a un libro abierto desde todas esas diferentes direcciones evitando de este modo la reflexión al ojo humano de las páginas blancas del libro. ${ }^{118}$

Aalto entiende que cada programa, además de contar con una parti- 
edificio podrían ser menos relevantes. Se trata básicamente de comprender cuál es la temática inherente en cada programa que pueda afectar en mayor medida la utilización correcta del edificio por parte del usuario. Tiene que ver con hacer que estas soluciones quiten barreras arquitectónicas; se trata, al fin y al cabo, de dotar de cierta 'invisibilidad' al edificio. Por otro lado está el tema de la "colectivización", el cual lo lleva a discutir nuevamente con algunos supuestos de la primera arquitectura moderna. En este caso, cuando se refiere a la universidad que construye al norte de Finlandia, plantea el problema del individualismo y la colectividad:

Todos sabemos que la colectividad tiene ventajas positivas, pero que puede también ser nefasta para la gente. Debe hallarse algún punto central entre el absoluto individualismo y la excesiva colectivización (...) En general, los edificios para las clases parecen ser demasiado grandes y el impresionante número de clases significa una colectivización intensa. En lugar de un colegio con muchas clases, intenté construir un agrupamiento de muchos colegios pequeños.. ${ }^{119}$

El mismo argumento puede encontrarse cuando refiere a la organización de capillas para crematorios, las cuales separó para que no hubiera colisiones de ceremonias: "Creo que existen muchas circunstancias en la vida humana en las que la organización se impone demasiado brutalmente. La tarea del arquitecto consiste en proporcionar a la vida una estructura más sensible». ${ }^{120}$ Se trata finalmente, y también como lo propusiera Wright y Häring, de una discusión del valor individual por sobre el colectivo; en el caso de Aalto, su sensibilidad pasa por seguir construyendo lo colectivo sin descuidar los problemas circunstanciales que el mismo puede acarrear, al caer presa de un sistema que tienda a la homogeneidad. Aalto es al mismo tiempo consciente de que el problema de la forma no puede ser desarraigado de la arquitectura -se trata, sin dudas, de una de sus mayores preocupaciones-, ya que lo considera también parte constituyente de esta última. Por lo que él aboga es por la «humanización» de la máquina, y lo mismo no puede concretarse sin atender a la propia forma, la cual entiende como "... un misterio que no conocemos en realidad, pero que proporciona al hombre una sensación totalmente diferente a la de un acto de liberación social como tal».121

La propuesta de Aalto será, en definitiva, crucial para reconducir los valores de la 'adaptación' según las características culturales y geográficas; esto abrirá las puertas, a partir de la década del cincuenta, a los llamados "regionalismos", los cuales volverán a reflexionar y proponer nuevas estrategias funcionales derivadas de cada contexto, ampliando el problema de la función por todo el globo y difuminando su origen eurocéntrico. 
[FG.12]

Alvar Aalto

Biblioteca Municipal de Viipuri Víborg: The Finnish Commitee for the Restoration of Viipuri Library and Petri Neuvonen, 1935.

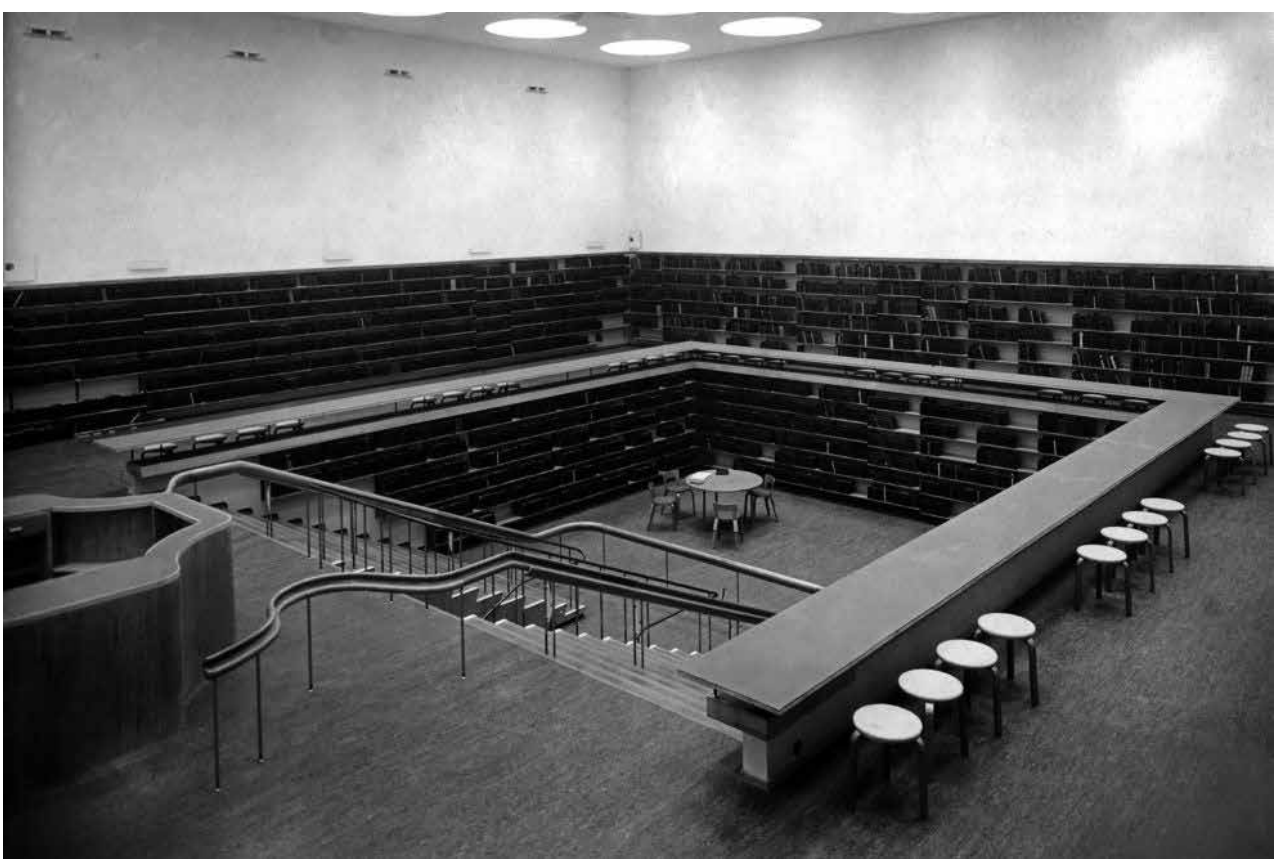


La base del concepto de 'flexibilidad' yace tanto en la amplitud de posibilidades funcionales de un espacio como en las capacidades del diseño para poder comprender y dar cabida a las diferentes actividades a desarrollarse en un mismo sitio. En efecto, se trata de una noción que requiere tanto de un conocimiento profundo de las necesidades como de un compromiso por un diseño que, por su propia naturaleza, tiende a la originalidad o a la exclusividad; por lo mismo la 'flexibilidad' depende, en la mayor parte de los casos, de poder ensamblar un sistema lo suficientemente amplio como para albergar la diversidad.

Aunque las aportaciones en torno a la 'flexibilidad' anteriores al siglo XX resultan menores en comparación a otras nociones, en la tradición francesa el problema ha estado presente, aunque con matices muy diversos, desde el siglo XVII. Claude Perrault es el primer autor que re-elabora la tradición clásica proponiendo un sistema abierto -apelando a la vez al racionalismo y al empirismo- para la interpretación de los órdenes, rechazando la teoría de las proporciones humanas como germen del sistema clásico y argumentando que dichas proporciones son intrínsecas al propio diseño. La misma tradición será retomada luego por Marc-Antoine Laugier quien, valiéndose del estudio de la historia de la arquitectura, será uno de los primeros autores en criticar con profundidad las distribuciones funcionales de algunas de las grandes obras de la historia, proponiendo a la columna como elemento central para propiciar una distribución fluida en los edificios. En su concepción de dégagement la estructura adquiere un rol primordial, no sólo como soporte, sino como elemento funcional que permite o elimina libertades de movimiento; se trata de la distribution y la independencia de la columna como elemento articulador; una base teórica fundamental para el desarrollo de la 'flexibilidad' en la arquitectura moderna. En el siglo XIX Viollet-le-Duc propiciará el terreno para profundizar en la noción de espacio flexible, abierto a diferentes usos, al traer a discusión la idea de programme y describir las amplias posibilidades funcionales de la basílica romana, y de su consolidación como tipo espacial y estructural en el templo. Tanto en la cabaña ideal de Laugier, como en la basílica de Viollet-leDuc lo que prima es el concepto de una estructura permisiva, que se aleja de la fragmentación espacial por medio de muros y salas, y acepta la continuidad e integridad de un único espacio. El posterior aporte de Louis Sullivan a fines del siglo XIX en Estados Unidos tendrá que ver sobre todo con incorporar al rascacielos -cuya distribución funcional resulta en el ejemplo más puro de 'flexibilidad'- dentro del campo de la arquitectura. El rascacielos, un tipo arquitectónico que nace con el objetivo mismo de la libertad funcional hereda, a través de la interpretación que del mismo haga luego Mies van der Rohe, gran parte de 


\subsubsection{FLEXIBILIDAD}

las ideas de Laugier y Viollet-le-Duc sobre la 'flexibilidad.' Los proyectos, escritos y conferencias de Mies -influenciado por el pensamiento de Theo van Doesburg y Siegfried Ebeling- a principios de los años veinte conformarán el corpus principal de noción de 'flexibilidad' moderna, una lucha constante a favor de la no determinación de las actividades y en contra de la obsolescencia del edificio. La noción de 'flexibilidad' adopta, también de la mano de Mies, otros intereses, ligados a lo transparente, lo continuo y lo cambiante, producto -como él mismo lo propone- de un Lebenwiesen moderno y transformador: un espacio para el ser, el cual ya había sido definido por Ebeling, en pos de una desmaterialización de la arquitectura como objeto, liberando su masa y opacidad para asumir la transparencia y libertad del usuario, utilizando la energía. Estas características requieren de unas posibilidades técnicas de construcción que sólo comienzan a ser factibles en este período. Por otro lado, la importancia de De Stijl en la concepción de la 'flexibilidad' resulta fundamental, no sólo por los textos de van Doesburg -quien definiera con mayor énfasis esta condición a través de su idea de "lo informe", de una arquitectura etérea, liberada de los muros de apoyo- sino especialmente por la casa Schroeder de Gerrit Rietveld, obra paradigmática que ilustra con claridad esta noción. El posterior aporte de Aldo van Eyck consigue completar y ampliar la idea de 'flexibilidad', incorporando en esta el tema de la sinergia, la cual sería capaz de superar la mera neutralidad funcional moderna.

Si se acepta por un momento el esquema de que la noción de 'eficacia' se engendra en el plano social y la de 'adaptación' en el individual, la idea de 'flexibilidad' resulta más difícil de ubicar, ya que en ella no se asume a un individuo dado, sino que se forja sobre una apuesta ontológica, la cual exige el descubrimiento del sentido de uso de un espacio. Se trata de una noción que propone un modo de vida no conocido y que depende de la interpretación del propio habitante. En cuanto a las metodologías, la 'flexilidad' se va a destacar especialmente por su representación gráfica, la cual recurre principalmente a la tridimensión; el color y la transparencia patente en las vistas axonométricas de De Stijl, en las que se un espacio aparece al mismo tiempo como diagrama y como planimetría. La 'flexibilidad' trae consigo además un claro lenguaje que no puede sino ser vanguardista, en el que las divisiones espaciales dejan de lado lo estático y pesado de la construcción tradicional para pasar a incorporar las nuevas nociones de lo blando, efímero y translúcido. Se trata de un programa que además de la arquitectura incluye la plástica; y serán especialmente los movimientos de vanguardia rusos y neerlandeses los que pujen por propiciar las condiciones estilísticas para este nuevo entendimiento de la función. Pero además la 'flexibilidad' implica, al mismo tiempo, una modificación tajante del propio habitar; introduciendo una capacidad dinámica, el objeto no sólo permite la diversidad de actividades en un mismo escenario, sino que, 


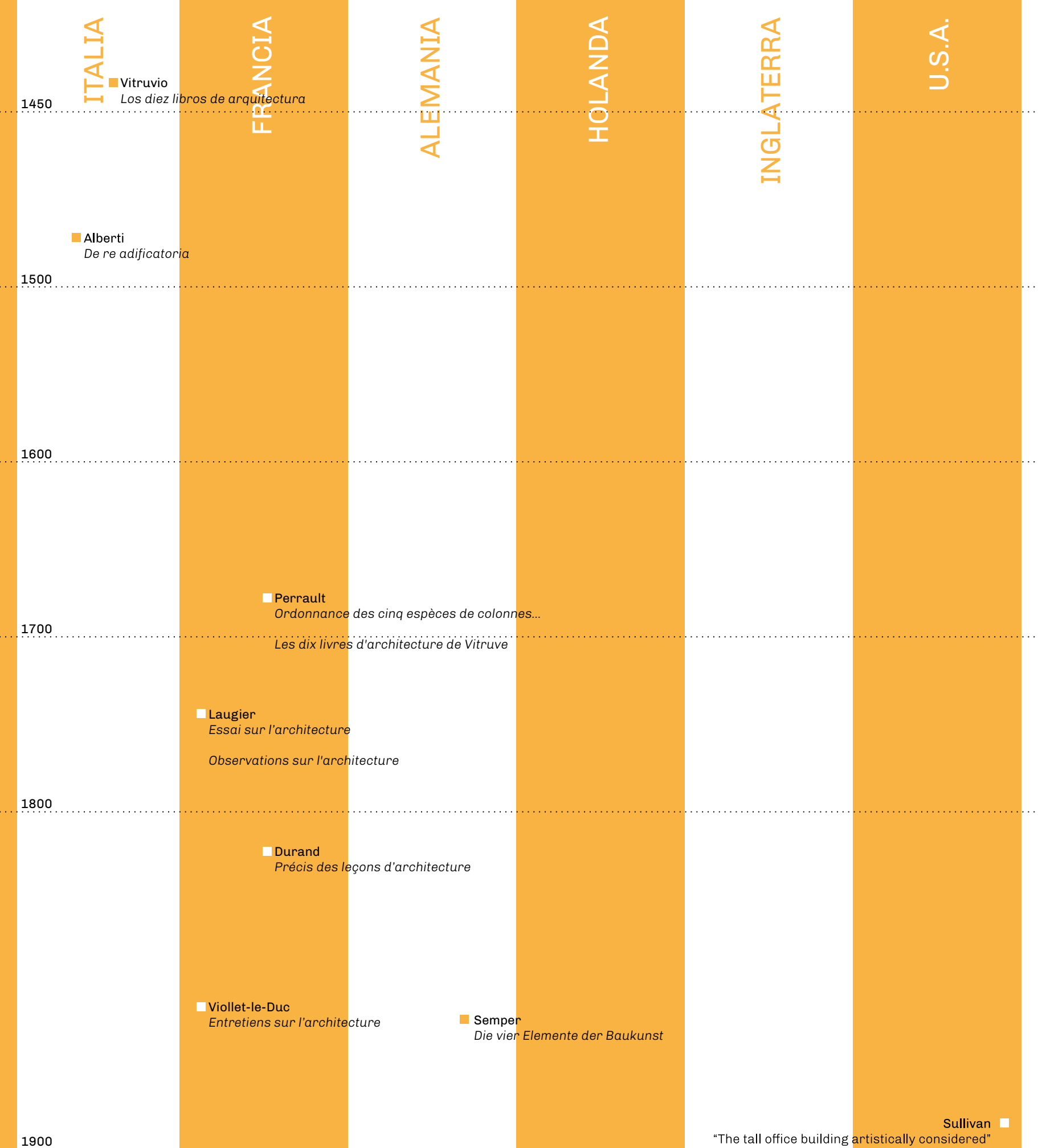

$\begin{array}{ll}\text { Ebeling } \square \text { Mies } & \text { "Bauen" } \\ & \text { "Bürohaus" } \\ & \text { "Conferencia" } \\ \text { "Über die Form in der Architektur" } \\ \text { "Geschäftshaus Adam" }\end{array}$

van Eyck

"Intervention at CIAM 6"

"Child and city"

"On inside and outside space"

"Talk at the Oterloo Congress"

"There is a garden in her face"

"Steps towards a configurative discipline" 


\subsubsection{FLEXIBILIDAD}

Mies van der Rohe

Casas Patio. Planta

Nueva York: MoMA

1938

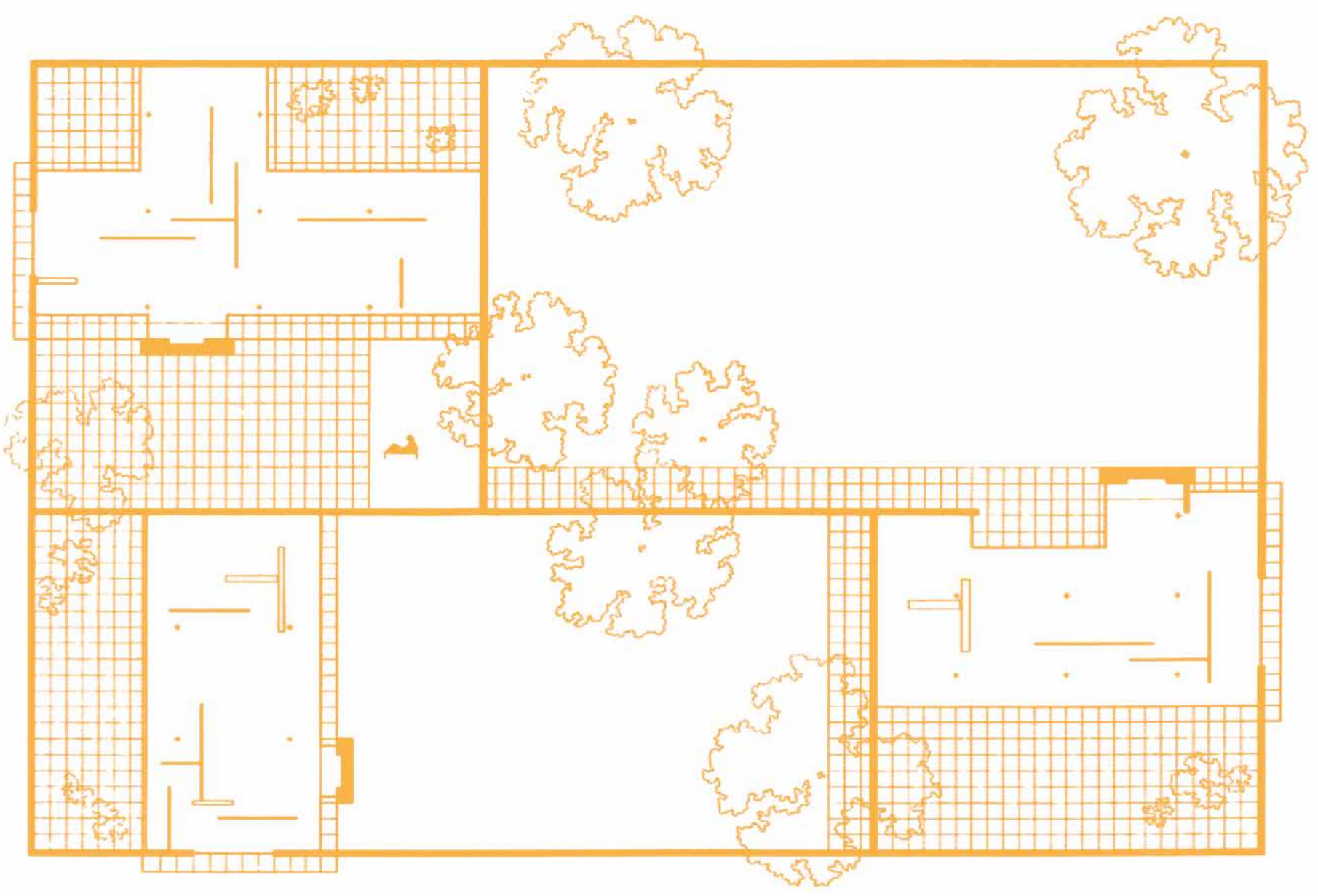


Si algo caracteriza al contexto francés entre los siglos XVII y XIX es una fuerte y autónoma tradición en la enseñanza de la arquitectura. Dentro de las academias francesas se gestarán, durante toda la tradición vitruviana, las aportaciones teóricas más importantes sobre la función, las cuales conformarán, a diferencia del contexto europeo, un propio linaje. A partir de la segunda mitad del siglo XVII harán su aparición una serie de academias de ciencias sociales, ciencias naturales y artes que, en el marco del absolutismo, supondrán un importante giro en la enseñanza. A diferencia de las creadas en Italia en el siglo XVI aquí el poder estatal será el que respalde y controle los contenidos dictados; claro ejemplo de la Ilustración en el contexto de la monarquía. La Académie royal d'architecture, creada por iniciativa de Jean-Baptiste Colbert bajo el reinado de Luis XIV en 1671, será la que albergue el ámbito de discusión más fértil del período, sirviendo a su vez como medio de difusión público para los intereses que la monarquía quería proyectar hacia la arquitectura, que incluirá la famosa querelle des Anciens et des Modernes, en la cual participará también Claude Perrault quien, en su puja por el enfoque científico, llega a batallar contra las explicaciones metafísicas tradicionales.

En este período el sistema de los órdenes será ya parte inherente del hacer arquitectónico y, justamente, las nuevas apuestas en torno al pensamiento de la función tendrán más que ver con una 'función sobre el sistema clásico' que con una función sobre la arquitectura en sí. No obstante sí es de destacar la presencia de algunos programas novedosos, como lo serán los museos, los palacios gubernamentales de gran escala, los palacios privados o los jardines, los cuales supondrán un nuevo desafío. El enfoque de Perrault sobre la función tendrá en parte el objetivo de construir un argumento teórico -basado en una curiosa mixtura del empirismo y el racionalismo- para hacer frente a edificios que no habían formado parte del repertorio arquitectónico, cuya distribución interior pasaba a ser ya un problema de mayor complejidad y, mucho más importante, que debían continuar satisfaciendo también la lógica reglada de los órdenes.

La formación de Perrault es la de fisiólogo, y su herencia más fuerte proviene de John Locke, a quien probablemente conociera personalmente en una de sus estancias en Francia. Habiendo escrito ya varios tratados sobre física, su principal batalla como teórico y profesor de la Académie tiene que ver con la puja por una normativa de la arquitectura que no sólo diera explicación a la importancia de la arquitectura francesa, sino que también garantizara su identidad y preservación bajo el reinado de Luis XIV.

Bajo dirección de Colbert le es encargada la traducción de Los diez libros de arquitectura de Vitruvio, la cual publica en $1673 .{ }^{1}$ En la misma, ampliamente difundida, Perrault aprovecha para traer al frente la discusión en torno a la herencia de la antigüedad, ya que no sólo se trata de una traducción, sino de una interpretación a la vez comentada, con una influencia notable de las ideas racionalistas de Descartes y de Galileo. El objetivo de Perrault es el de introducir el pensamiento cartesiano en el mundo de la teoría de la arquitectura, y para esto pone a prueba el texto clásico sometiéndolo a una crítica

\section{Perrault. Sistema e invención}

1.

La traducción y reinterpretación de Vitruvio en la Francia de Luis XIV se ve necesaria para recurrir a una 'autoridad' teórica mayor en la cual basar las ideas que sustenten una arquitectura para "una Francia más grande". Ver

McEwen, Indra Kagis, "On Claude Perrault: Modernising Vitruvius," Paper palaces: the rise of the Renaissance architectural treatise, (1998).

2.

González, José Luis, El Legado oculto de Vitruvio. Saber constructivo y teoría arquitectónica (Madrid: Alianza Forma, 1993), p. 101.

3.

Perrault, Claude en Vitruvio, Compendio de los Diez Libros de Arquitectura de Vitruvio. Claude Perrault. (Madrid: Imprenta de D. Gabriel Ramírez, 1761), p. 4. (Ed. orig. 1486)

4. Ibid. p. 18.

5. Ibid. p. 7. 2.3.1.a. Vitruvio 
racionalista para obtener una versión más pragmática y moderna, que estuviera a su vez orientada a la enseñanza y a la difusión. El foco está puesto en lo que resulta útil a los arquitectos, modificando incluso el orden de los libros, ya que Perrault interpreta que en los originales "a veces se interrumpen temas para tomar otros". ${ }^{2}$ Perrault se propone, por medio de una traducción, refundar la noción del gusto, otorgándole una base científica y quitándose de encima las explicaciones metafísicas. Para esto busca una norma en la cual evitar la arbitrariedad:

...siendo la Arquitectura un Arte que, por lo que mira a la hermosura de sus obras, casi no tiene otra regla que el buen gusto, consistiendo este en discernir lo bello y lo bueno de lo que carece de esta circunstancia, es de el todo necesario persuadirse que el gusto que se sigue es mejor que otro, para que insinuándose esta persuasión en la mente de los que estudian, formen una idea correcta y reglada, sin la cual quedaría siempre vaga e incierta la elección. ${ }^{3}$

Pero además Perrault incide en el significado del propio texto. Así, cuando Vitruvio escribe que "...la arquitectura es una ciencia que debe ir acompañada de mucha variedad de estudios y conocimientos..." Perrault añade en sus notas "Definición de la arquitectura", virando hacia una interpretación cientificista. ${ }^{4}$ En el "Capítulo Tercero. De la comodidad de los edificios", en su versión, agrega a modo de resumen que los tres puntos en los cuales se basa la comodidad son lo "fértil», lo "accesible» y lo "sano". Perrault da además una breve referencia a la función cuando menciona que Vitruvio trata en su libro tres tipos de arquitectura: primitiva, antigua y moderna, siendo esta última «...la que por acomodarse a nuestras costumbres o por otras razones ha variado algunas cosas en la disposición y proporción que la primitiva y antigua solían observar». ${ }^{5}$ En este sentido otorga una caracterización moderna a las 'costumbres', también como elemento de transformación, en consonancia con la batalla entre antiguos y modernos. Las costumbres serán, como ya lo había sugerido Vitruvio, un argumento para la visión científica de la arquitectura: a partir de la observación de los hechos es posible resolver las necesidades de los edificios actuales.

2.3.1.b. En 1683 Perrault publica Ordonnance des cinq especes de colonnes selon la Necessité methode des anciens, quizás su obra teórica más importante. Entre otros temas introduce la idea de necessité (necesidad), que tiene un lugar de importancia política en la Francia del período, en la que se propone el acercamiento del Estado monárquico a suplir las carencias de la población. Esta necessité trata, al fin y al cabo, de una carencia civil que redunda en una ampliación de los requerimientos básicos a suplir por las construcciones. Para esto se confía en un desarrollo del conocimiento técnico dentro de las academias a partir del cual es posible avanzar hacia el bienestar de la sociedad.

Esta necessité descansaría en la confianza de Perrault en la observación intencionada de los problemas arquitectónicos que, tras un conocimiento preciso, permite avanzar en soluciones concretas. Cierto es que, más allá de mencionarlo, Perrault no alcanza a aplicar este método inductivo al problema 
necesarias para hacerlo, tendiendo al ideal de convertir los problemas de arquitectura en ecuaciones, a pesar de que, como también comenta Pérez-Gómez, el sueño de dominar el objeto a partir de los números llegaría recién en la revolución industrial. ${ }^{6}$

Ordennance... implica de algún modo la continuación de las ideas que Perrault había ya sugerido en su traducción del texto de Vitruvio. En este caso no es el objetivo el de elaborar un tratado general de arquitectura, sino el de estudiar y proponer una serie de reglas que permitan dominar los órdenes del sistema clásico gracias a las matemáticas. Al igual que como ya lo había anunciado en el "Prefacio", de Los diez libros de arquitectura, en Ordennance... Perrault no busca conclusiones cerradas ni herméticas; el suyo sigue siendo, como comenta Pérez-Gómez, un sistema abierto que busca en primer lugar la consolidación del pensamiento científico a partir de un método inductivo basado en la observación de los fenómenos, antes de que las corrientes ilustradas colocaran la verdad por sobre la realidad a fines del siglo XVII. ${ }^{7}$ Aún así, el principal aporte de Perrault al entendimiento de los órdenes no tendrá un impacto directo en los temas de la función, pero nuevamente servirá para allanar el camino a los estudios siguientes, al otorgar jerarquía al edificio en sí mismo antes que al idealismo que protegía las proporciones del sistema clásico. Perrault -en un movimiento que lo separa radicalmente de la concepción de concinnitas de Alberti- rechaza la idea de que las proporciones del sistema provengan del cuerpo humano, y propone que las mismas no se desprenden de las leyes de la naturaleza sino de proporciones intrínsecas a la propia arquitectura. ${ }^{8}$ Es decir que entiende los órdenes como un sistema de auto referencia, que puede mutar y variar según cada situación, cada tipo de construcción o cada programa; esto daría al arquitecto un margen de modificación de las proporciones según cada caso particular. Por lo mismo no existe una norma a la cual recurrir constantemente, sino que la misma se reconstruye según la observación. Este paso supone una base fundamental para el diseño, en el cual se apoyarán gran parte de las aportaciones en torno a la 'flexibilidad.' De aquí establece la diferenciación de lo positivo y lo arbitrario:

Toda la arquitectura tiene como fundamento dos principios, uno es positivo y el otro arbitrario. El fundamento positivo es el uso y la finalidad útil y necesaria para la cual ha sido construido el edificio, tales son la solidez, la salubridad y la comodidad. El fundamento que yo llamo arbitrario es la belleza que depende de la autoridad y de la costumbre; aún cuando la belleza en cierto sentido también se basa en un fundamento positivo, que es la conciencia razonable y la adecuación que cada parte posee en relación con el uso al cual está destinada. ${ }^{9}$

En resumen, la belleza positiva (beauté positive) es para Perrault la científica, mientras que la belleza arbitraria (beauté arbitraire) corresponde al ámbito artístico, que quedaría limitado a la costumbre y la tradición. La base científica de Perrault exige transformar el entendimiento cotidiano de los fenómenos por la sistematización del mismo. Esto dejará sentadas las bases para un continuo estudio de los problemas de la función en Francia, los cuales, al menos hasta el siglo XVIII, se seguirán construyendo sobre bases cartesianas.
Ver la "Introducción," por Pérez-Gómez, Alberto en Perrault, Claude, Ordonnance for the Five Kinds of Columns after the Method of the Ancients (Santa Monica: The Getty Center publication programs, 1993). (Ed. orig. 1683).

\subsection{1.c}

\section{Sistema abierto}

7.

Ver "Introducción" por Pérez-Gómez, Alberto en Ibid.

Esta idea de Ordonnance... no es otra que la expansión del concepto de ordenatio de Vitruvio. Según este último, "La Ordenación consiste en la justa proporción de los elementos de una obra, tomados aisladamente y en conjunto, así como su conformidad respecto a un resultado simétrico. La Ordenación se regula por la cantidad -en griego, Posotes-. La Cantidad se define como la toma de unos módulos a partir de la misma obra, para cada uno de sus elementos y lograr así un resultado apropiado o armónico de la obra en su conjunto". Vitruvio, Los diez libros de arquitectura, vol. 2 (Madrid: Ediciones Akal, 1992), p. 32. (Ed. orig. 1486).

9.

Perrault, Claude, Ordonnance des cinq espèces de colonnes selon la méthode des anciens (Paris: Chez Jean Baptiste Coignard, 1979), p. 175. (Ed. orig. 1683).

10.

Si bien el proyecto del Palacio precede en una década a su libro, Perrault ya había producido un grabado con una fachada muy similar en la publicación del mismo. Aún así, la autoría de este proyecto generó sucesivos debates, ya que, después de la cancelación del proyecto de Bernini, los trazos generales fueron decididos, además de por Perrault, por un comité compuesto por François Le Vau y Charles Le Brun. Ver Allais, Lucía, "Ordenando los órdenes: la 'ordonnance' de Claude Perrault y la columnata este del Louvre," Revista de Arquitectura $8,(2006)$

11.

Aún así la originalidad de Perrault es algo que no puede afirmarse completamente, ya que la columna en pares había sido empleada en 1525 por Giulio Romano, en una de las fachadas del Palacio del té. Aunque también es necesario precisar que en este último caso las dobles columnas tienen sentido como punto de apoyo de los arcos, a diferencia de la cornisa continua que sostiene la fachada del Louvre.

12.

Ver Ranogajec, Paul A., "Claude Perrault, East facade of the Louvre," (2017). 
Perrault no cuenta con una serie de obras que permitan materializar sus postulados teóricos, excepto por el encargo de transformar la fachada oriental en la entrada principal del Palacio del Louvre, en 1667. [FG.01] En él ensaya las ideas que posteriormente se consolidarían en su Ordonnance... ${ }^{10}$ En el proyecto subdivide el cuerpo de la fachada verticalmente en cuatro partes diferenciadas, pero manteniendo aún la expresión de un volumen puro horizontal, lograda en gran parte por la continuidad de un basamento sólido y austero, a partir del cual se elevan los elementos del sistema clásico, manteniendo en todo su largo una altura regular. Esta solución, originaria del barroco francés, tendrá una influencia fundamental en lo que se entiende como la tradición clasicista francesa. Se trata de una interpretación del sistema clásico bajo un estricto rigor geométrico; la solución de columnas en pares, utilizando el orden corintio, fue una apuesta por la invención que ejemplifica las pretensiones teóricas del autor. ${ }^{11}$ Esta interpretación del uso de los órdenes acentúa el ritmo, a la vez que permite la transparencia de la galería, y una mayor iluminación natural en los nichos con las estatuas en el interior, y luego en el interior del edificio, ya que las ventanas construidas posteriormente se disponen entre los amplios intercolumnios (dégagement). La geometría general mantiene un rigor subyacente, ya que en el vacío entre pares de columnas cabría exactamente la columna faltante, por lo mismo la armonía de la fachada se mantiene intacta, y lo que parecen pares de columnas son en verdad ausencias de columnas que corresponden a un vacío controlado. Según Perrault esta disposición sería una invención legítima, entendida como una sexta forma de intercolumnio clásico, frente a los cinco que existían en el texto de Vitruvio. Perrault argumenta esta invención a la necesidad derivada de la costumbre francesa por la intensa iluminación interior, herencia del gótico medieval, ${ }^{12}$ recurriendo, como en sus lecturas, a

[FG.01]

Claude Perrault Palacio del Louvre. Fachada Este Paris: Pierre Jean Mariette. 1738, la contingencia basada en la observación e interpretación de los hechos, filtrados por el rigor geométrico. También tendría que ver con una noción de uso (usage) a la que refiriera su hermano, Charles Perrault:

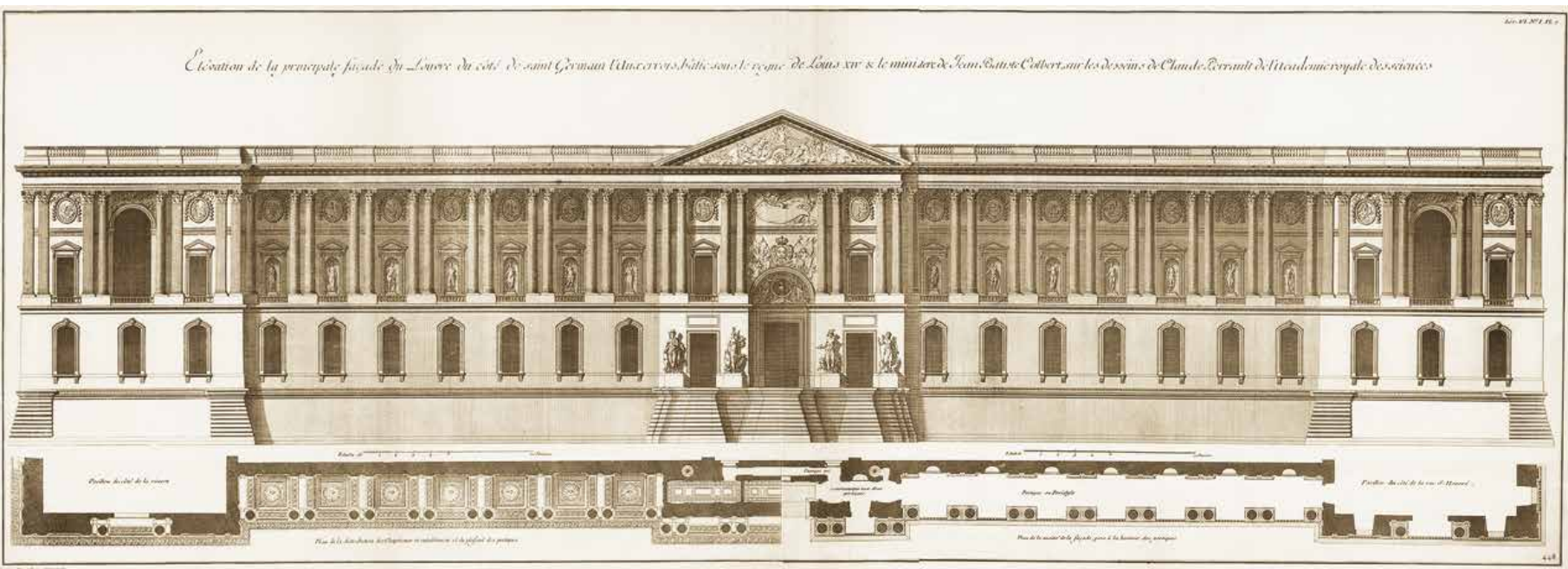


Mientras que en los tiempos antiguos, explica Charles Perrault, las mujeres tenían que dejar de saludarse cuando entraban a los templos, ya que los espacios de entrada eran demasiado estrechos para dos cuerpos, los peristilos modernos mejoran a sus predecesores, acomodándose a su usage. Es por ello que los intervalos estrechos y amplios parecen ser referencias literales al uso antiguo y moderno, respectivamente. Y la columnata del Louvre puede ser entendida como una yuxtaposición en serie de dos tipos de usos: el intervalo corto antiguo, tan estrecho que sólo permite la entrada de un cuerpo; y el moderno dégagement, llevado a cabo lo más amplio posible gracias a la tecnología de estructuras modernas. ${ }^{13}$

Más allá de los posibles argumentos funcionales detrás de la particular solución adoptada en la fachada, lo que prevalece es la idea de explorar las posibilidades de un sistema clásico que no se entiende ya, como podía ser en el Renacimiento, como el ideal al cual acercarse; tampoco como un sistema agotado, sino más bien como una serie de elementos con los cuales es posible seguir innovando y creciendo, ya sea por la intención de conseguir una representación diferenciada como por la necesidad de suplir nuevos problemas funcionales. El aporte de Perrault a la noción de 'flexibilidad' es netamente indirecto; lo que plantea más bien es la duda de que un sistema -el clásico- esté por delante de las necesidades sociales, algo que calará hondo en las experiencias posteriores en Francia.

La carrera de Marc-Antoine Laugier se superpone con la de Blondel, Ledoux y Boullée, ilustrando la diversidad de ideas que era capaz de incluir la tradición teórica de la Francia del siglo XVIII. En Essai sur l'architecture, publicado de modo anónimo en 1752, Laugier hace un esfuerzo por condensar las líneas de pensamiento generales del racionalismo francés y del empirismo británico. De este modo aparece "el primer texto de arquitectura en el que se recogen los cambios cualitativos que definieron la ruptura entre la herencia renacentista y la modernidad iluminista», ${ }^{14}$ que además contó con una notable acogida en el momento. Son evidentes las referencias a Rosseau, en el acercamiento a un clasicismo normativo con orígenes en las construcciones primitivas, pero filtradas por la matriz racionalista. ${ }^{15}$ El tratado continúa por una parte la visión cientificista iniciada un siglo atrás por Perrault, pero lejos de fundirse con el pensamiento racionalista predominante de su época, incorpora cualidades subjetivas a su análisis arquitectónico, como la incidencia de la percepción y la importancia del sujeto. En esta operación el sistema clásico no se vería afectado, ya que por un lado mantendría el respaldo científico en las matemáticas -fundado por Perrault- y por otro incluiría la valoración emocional de corte empirista. Se trata de un intento en el seno de la arquitectura por conciliar dos doctrinas hasta entonces separadas, poco antes de la irrupción del pensamiento de Kant.

La historia de la arquitectura es el material central en la obra de Laugier; la misma es analizada con un agudo sentido crítico con el cual va sentando las bases de su teoría. La arquitectura griega es valorada en primer lugar; la romana como destinada a copiar a la griega hasta la decadencia; la gótica es
Allais, "Ordenando los órdenes: la 'ordonnance' de Claude Perrault y la columnata este del Louvre."

14.

Rubio, Lilia Maure, “Introducción” en Laugier, Marc-Antonie, Ensayo sobre la arquitectura, vol. 14 (Barcelona: Ediciones Akal, 1999). (Ed. orig. 1753).

15.

Ver Kruft, Hanno-Walter, Historia de la teoría de la arquitectura. 1. Desde la Antigüedad hasta el siglo XVIII (Madrid: Alianza Editorial, 1990), p. 197.

16. Laugier, Marc Antoine en Ibid. p. 197-98.

17. Laugier, Ensayo sobre la arquitectura, 14, p. 144.

18. Ibid. p. 45.

19.

Ibid

20.

Ver "Capítulo II" en ibid.

2.3.2.

Laugier. Estructura:

principio y medida 
rescatada, a pesar de la torpeza que el autor aprecia; a su vez, el valor del Renacimiento yace en rescatar el clasicismo. Así, Laugier se propone la elaboración de una teoría que tienda a una valoración genuina de la esencia de la arquitectura clásica la cual, según él, resultó deformada por el barroco en toda Europa. Al mismo tiempo, como es sabido, la propuesta de Laugier tiene una fuerte base en el problema de la estructura; en este sentido presenta también una renovación con respecto a la tradición vitruviana, ya que no centra su interés exclusivamente en el tema de la belleza.

Laugier construye su propuesta retrocediendo hasta los orígenes de la arquitectura, siguiendo, como es natural, el tratado de Vitruvio. Para este último la cabaña primitiva significaba el origen histórico de la arquitectura; en cambio para Laugier implica "el principio y medida de toda la arquitectura", albergando elementos arquitectónicos «naturales, razonables y funcionales». ${ }^{16}$ La idea de la cabaña primitiva como primera construcción, como "el modelo a partir del cual se han imaginado todas las magnificencias de la arquitectura»,17 es para el autor superior a la caverna, ya que la cabaña supone un orden, una geometría y un rigor:

No perdamos de vista nuestra pequeña cabaña rústica. En ella sólo veo columnas, un techo o entablamento, un tejado apuntado cuyos extremos conforman lo que nosotros llamamos un frontón. Hasta aquí ni un rastro de bóveda, menos aún de arco, nada de pedestales ni de ático, incluso ninguna puerta, ninguna ventana. Concluyo, pues, y digo: en todo orden arquitectónico sólo pueden formar parte esencial de su composición la columna, el entablamento y el frontón. Si cada una de estas tres partes se encuentra en la situación y con la forma convenientes, no habrá que añadir nada para que la obra sea perfecta. ${ }^{18}$

2.3.2.b. Blondel ya había otorgado a la columna el rol de origen y símbolo de la arquitectura; de modo análogo Laugier no ve tanto en la cabaña una estructura como una síntesis de la esencia de la arquitectura, la cual debería ser alcanzada también en los demás ámbitos, entendiendo que «acercándonos, en la realización, a la simplicidad de este primer modelo, es como evitamos todos los defectos esenciales». ${ }^{19}$ Esta misma exigencia de simplicidad y racionalidad será la que aplique a la función, al someter al análisis crítico a diversos edificios. De modo similar a como había apuntado Bacon, Laguier no considerará las distribuciones de los tipos arquitectónicos como una herencia intocable de las costumbres, sino que se permitirá discutirlas y transformarlas persiguiendo una commodité contemporánea. Del mismo modo, Laugier no descarta agregar nuevos órdenes a los ya existentes, considerando que los romanos debieron también sumar dos para adaptar el sistema a sus requerimientos. ${ }^{20}$ Para la comodidad de un edificio Laugier vuelve a exigir tres condiciones que conjugan temas presentes en la tradición francesa: situation, distribution y dégagement (holgura). Sobre todo en estos dos últimos se hace presente con fuerza la columna, tanto en la concepción funcional del autor como en su aporte a la noción de 'flexibilidad'. La distribution, a diferencia de la noción de Blondel, quedará directamente ligada al dégagement, dado que para Laugier las columnas, al 


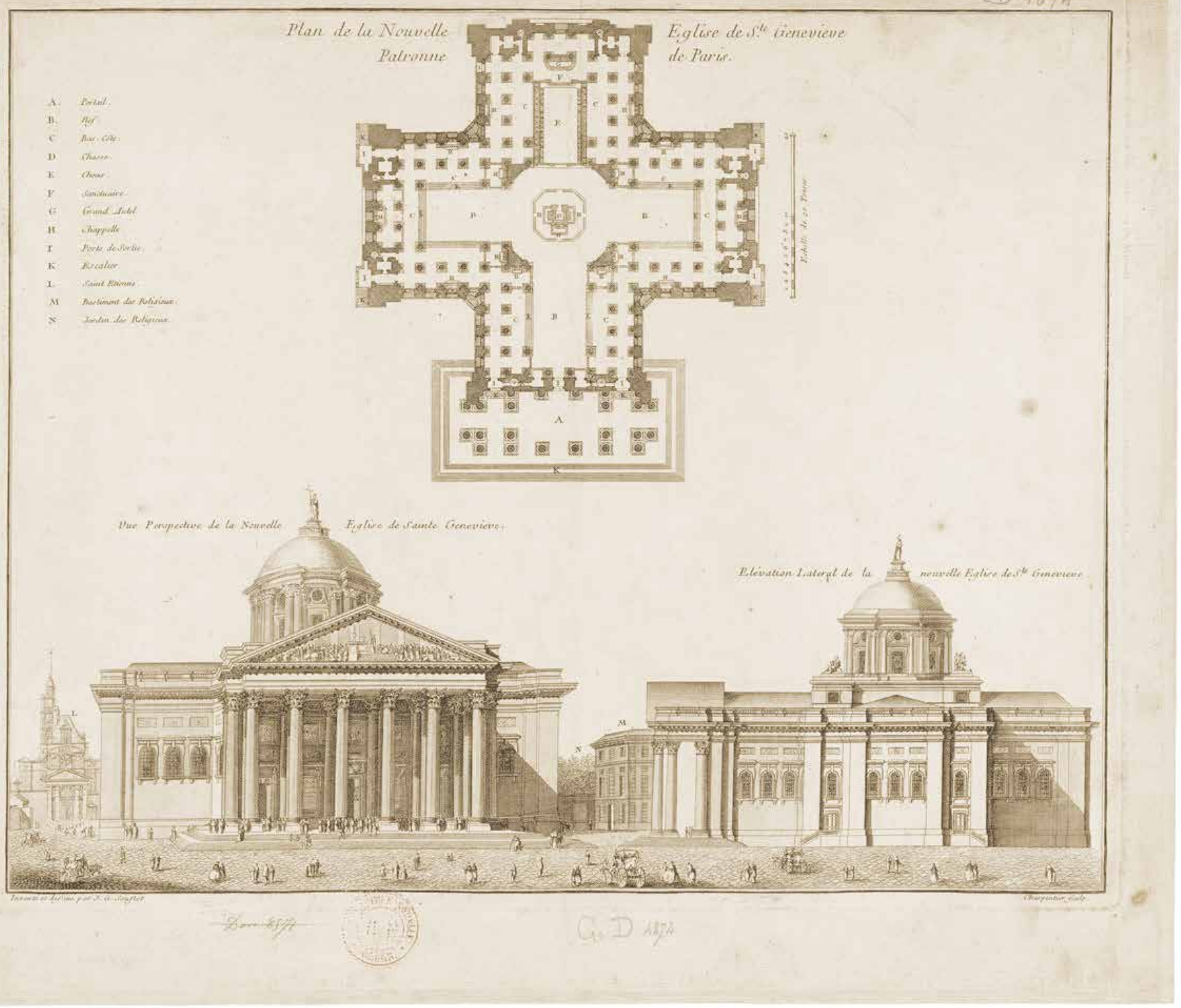


modo da un paso otorgando entidad y validez arquitectónica a un elemento que posee una firme base utilitaria y que, por lo mismo, se asume como moderno. Le atribuye un valor puramente funcional, a diferencia del valor expresivo de la distribution de Blondel, que tendía a proponer situaciones como accesos y entradas a los edificios mucho más regidos por el gusto predominante que por una reflexión propia. Para Laugier en cambio:

...las circulaciones contribuyen mucho a la comodidad del alojamiento (...) Bajo este nombre de circulación se incluyen todas las estancias que sirven para comunicar secretamente el interior de los aposentos al exterior. Estas circulaciones son necesarias para evitar los largos recorridos y para tener al alcance todos los servicios que puedan venir de los offices y de los espacios comunes, para zafarse cuando se desee, para ir y venir sin ser molestado y sin molestar a nadie. ${ }^{21}$

2.3.2.c. La distribution cobra un sentido de economía que comienza a ser entendido Fluidez como indispensable en una sociedad moderna, con programas arquitectónicos cada vez más complejos, desvinculándose de los temas de décoration y constructions, con los que Blondel la había relacionado inicialmente. Alejándose de la idea básica de economía presente en Vitruvio, la distribution de Laugier se entiende más bien como una libertad funcional, que se desprende de la posibilidad de independizar la columna de cualquier otro elemento arquitectónico, para liberarla finalmente en el espacio. En este sentido, Laugier busca una fluidez espacial más cercana al gótico, la cual resulta esencial para fundar el espacio de la 'flexibilidad'. El dégagement que ensayara Perrault en el Louvre era principalmente exterior, una fachada. Laugier piensa en cambio en un dégagement interior que permite liberar el muro para ejecutar las aberturas que sean necesarias según la commodité. La noción funcional-estructural de Laugier resulta sumamente moderna, y la Iglesia de Sainte Geneviéve, [FG.02] construida entre 1758 y 1789 por Soufflot es, como normalmente se considera, el edificio que más claramente condensa estas ideas, por tratarse de una obra que recupera los elementos de la arquitectura griega en clave racionalista, enfatizando la fluidez del espacio gótico. Las columnas adquieren aquí un rol protagónico, realzando su esbeltez bajo un entablamento recto, pero -mucho más importante en cuanto a la función- intercambiando las pilastras por columnas adosadas, para reforzar la independencia de estas últimas e insinuar un espacio de muro ininterrumpido, en el cual unas ingrávidas columnas y una diferencia de nivel de suelo salvada por una decena de escalones, fragmentan el interior según las funciones litúrgicas. La planta en cruz griega con la imponente cúpula central resta protagonismo al altar y confiere al interior un carácter espacial fluido, con diversos puntos de tensión que eliminan la noción de foco. Esta espacialidad particular permite no relacionar directamente esta distribución a la de una iglesia tradicional de planta basilical, la cual supone un recorrido; este es también el motivo -además de estar acabada para los años de la Revolución- por la que se la convirtió en el Panteón laico de Paris, después de 1789. Un espacio que, por su propia lógica interior, responde más 
de que esto no estuviera en los intereses de Soufflot, quien buscara relacionarla a la cruz griega de San Pedro de Roma.

Como se ha mencionado, el aporte de Laugier al problema de la función no puede, entenderse por fuera de las influencias de Perrault y del resto de la tradición francesa. Aunque no es posible comprobarlo, según De Zurko hay una alta posibilidad de que gran parte de las ideas de Laugier en cuanto a las nociones de función, estructura o economía tuvieran deudas directas con otras aportaciones, como las de Lodoli:

...debemos recordar que las ideas expresadas por Laugier no eran tan raras la función, la de la verdad en arquitectura, la relación de la belleza arquitectónica con la natural y la correspondencia entre la arquitectura más evolucionada y el prototipo primitivo, reaparecen una y otra vez con frecuencia suficiente para tornar imposible atribuirlas a una persona en particular. ${ }^{22}$

Quizás el paso más importante con respecto a la construcción de la noción de 'flexibilidad' antes de la arquitectura moderna sea el de Eugène Viollet-le-Duc, continuando con la linea francesa de Perrault, Blondel o Laugier. En Entretiens sur l'architecture de 1863, la obra fundamental de Viollet-le-Duc, en la cual se difunden principalmente sus propuestas sobre la restauración, el problema de la función va a ocupar, al mismo tiempo, un lugar de importancia. El autor busca, de modo similar a como lo hiciera Semper, principios que sirvan como base para poder dar pie a un estilo moderno. En la revisión que emprende sobre toda la historia de la arquitectura, combina el estudio de los griegos, los romanos, la Edad media y el Renacimiento, y construye para cada período diversas hipótesis en torno al problema de la función, que van abriendo su significado hasta proponer, en paralelo, conceptos que resultan incluso antagónicos.

Una construcción lógica e inteligente será lo que el autor reclame constantemente como componentes esenciales para la existencia de un verdadero arte arquitectónico. A Viollet-le-Duc no le interesa indagar en las construcciones primitivas para poder hallar los principios del arte, ya que considera que este primer esfuerzo de refugio no es suficiente. Para él se necesitaría contar con un rigor y una racionalidad que van más allá de las primeras expresiones constructivas del hombre. ${ }^{23}$ En este sentido toma distancia de las explicaciones que suelen aparecer en varios autores de la tradición vitruviana, y que incluso continúan hasta el siglo XIX, como es el caso de Semper. Viollet-le-Duc coloca todo el énfasis en la capacidad racional del hombre, lo cual lo llevaría a encontrar una solución superadora, que incluiría tanto lo funcional, lo constructivo como lo representativo. Este estadio sería incluso superior al de commoditas de Alberti, el cual reclamaba especialmente una función que permitiera alcanzar un placer, cercano a lo estético. En continuidad con esto, resulta interesante su postura de negar que la arquitectura griega tuviera su origen en la construcción en madera. En la "Segunda conversación" de Entretiens sur l'architecture explica con rigor cómo construían los griegos, el nivel de sofisticación y detalle dedicado a cada elemento, con lo cual busca desechar la hipótesis del origen de la construcción en madera, ya que entiende que el mismo está totalmente
De Zurko, Edward, La teoría del funcionalismo en la arquitectura (Buenos Aires: Nueva Visión, 1970), p. 153-54. (Ed. orig. 1957)

23. "Construir una choza con ramas de un árbol no es un arte. Es la satisfacción de una necesidad material. Ahora bien, excavar una morada en un escarpado de toba, dividir los hipogeos en estancias de distintos tamaños en función del número de habitantes o de sus usos, dejar unas pilastras de reserva para sostener el techo; dar mayor anchura a la cabeza de dichas pilastras para conectar sin peligro la roca suspendida y los puntos de apoyo aislados; luego, ir cubriendo poco a poco estos muros y estas pilastras, reservados en la masa, con grabados y signos destinados a mantener el recuerdo de un acontecimiento -el nacimiento de un hijo, la muerte del padre o de la madre, una victoria sobre el enemigo-: esto ya es arte". Viollet-le-Duc, Eugène Emmanuel, Conversaciones sobre arquitectura (Madrid: Consejo General de la Arquitectura Técnica de España, 2007), Tomo I, p. 12-13. (Ed. orig. 1863).

2.3.3.

\section{Viollet-le-Duc.}

Las vertientes del programa

24. Ibid. Tomo I, p. 77.

25. Ibid. Tomo I, p. 77-78.

\subsection{3.a.}

Rigor del diseño 
concebido, tanto desde desde la lógica constructiva como estructural, desde la misma construcción en piedra. La elaboración técnica griega sólo se ve afectada, según el autor, por incorporar posteriormente -primero con los romanos y más tarde en la Edad Media- intereses funcionales relativos al cuerpo humano. ... el orden, o los órdenes griegos que conocemos mantienen sus proporciones relativas con independencia de las dimensiones, y este método, aplicado a los romanos con algunas modificaciones, de las que tendremos ocasión de hablar más adelante, sólo fue rechazado decididamente por los arquitectos de la Edad Media. La arquitectura griega posee un módulo que sólo depende de ella. La arquitectura de la Edad Media posee un módulo que es exterior a ella: las dimensiones del cuerpo humano. La arquitectura romana juega un papel de transición entre ambos métodos, y dicha transición se produce gracias a la preferencia que los romanos otorgan a la satisfacción de las exigencias materiales, a la utilidad, por encima de las formas abstractas e instintivas del arte griego. $^{24}$

Esta apuesta le lleva a inferir que lo que podría entenderse como una 'autonomía de la construcción' que los Griegos habrían descubierto y convertido en el foco principal de su atención habría sido más tarde desmembrada por intereses funcionales. En esta apreciación se advierte la voluntad de Viollet-leDuc de, quizás por primera vez, diferenciar la 'función constructiva' de la 'función organizativa', la cual atendería a esas "dimensiones del cuerpo humano» que el autor menciona.

2.3.3.b. Hasta el momento, incluso en Semper, la noción de función permanecía abierta a problemas tanto técnicos como estéticos, sin ocupar el lugar específico referido a la organización de las actividades humanas. Esto comienza a modificarse con la primera aproximación directa al problema de la función que realiza Viollet-le-Duc, la cual toma como base la comparación entre la arquitectura griega y la romana:

En la arquitectura griega la forma visible, exterior, no es más que el resultado de su construcción. La mejor comparación que puede hacerse con la arquitectura griega es un hombre desprovisto de sus vestidos, de modo que todas las partes exteriores de su cuerpo no son más que una consecuencia de la estructura de sus órganos, de sus necesidades, del ensamblaje de sus huesos, de las funciones de sus músculos. El hombre es tanto más bello cuando todas las partes de su cuerpo están relacionadas con su función, de modo que nada en ellas es excesivo, pero basta con cumplirlas. Por el contrario, la arquitectura romana puede compararse con un hombre vestido. Por un lado está el hombre, por otro lado está el vestido. Dicho vestido puede ser bueno o malo, rico o pobre, puede estar bien o mal cortado, pero en cualquier caso no forma parte del cuerpo. (...) Al encargado de vestir su monumento sólo le piden una cosa: que el vestido esté a la altura del mismo. Por lo demás, no les preocupa demasiado que la ornamentación tenga un sentido, que refleje con exactitud las formas esenciales de la estructura del edificio, que sea el envoltorio exacto y auténtico de sus formas, que sea el reflejo de sus necesidades. Los romanos están por encima -o al lado, si se prefiere- de los racionalistas griegos: no los entienden. ${ }^{25}$ 
La arquitectura griega tiende así a lo esencial, a satisfacer lo necesario sin agregados, pero además con una preocupación por su expresión más genuina ${ }^{26}$-nuevamente aparece la idea de decor, mutada en el concepto francés de caractère. A pesar de que Viollet-le-Duc niegue el origen de esta arquitectura en la cabaña, resulta evidente que en su aproximación esta arquitectura griega mantiene también una continuidad con la idealizada cabaña primitiva de Laugier, quien afirmaba que acercándonos en la realización a la simplicidad de este primer modelo es como se pueden evitar todos los defectos esenciales. Por otro lado, en su apreciación de la arquitectura romana, Viollet-le-Duc disocia la función propia del edificio de su expresión exterior -lo cual pondría en discusión la importancia del decor de Vitruvio- y, aunque en la anterior cita no quede del todo especificado, esto le permitirá plantear al autor, en la "Cuarta conversación" de Entretiens sur l'architecture, el desarrollo extenso de la función que los romanos llevaron a cabo.

De modo similar a como ya lo había anunciado Marie-Joseph Peyre, Viollet-leDuc reconoce en los romanos el haber resuelto problemas funcionales complejos, que sus propios programas de necesidades les exigían, a través de un trabajo riguroso sobre la planta:

La atención de los arquitectos romanos se centraba sobre todo en la composición de las plantas, tal como debe ser un pueblo que debe y quiere imponer unos programas absolutos y ajustados a su estado social y político. En efecto, si echamos un vistazo a los edificios realmente romanos, como las termas, los palacios, las villas o los grandes establecimientos de utilidad pública, lo primero que nos sorprende son sus disposiciones planimétricas totalmente innovadoras. Dichos edificios contienen una aglomeración de salas de modo que cada una de ellas tiene las dimensiones adecuadas. ${ }^{27}$

Será en efecto la planta la que Viollet-le-Duc coloque como herramienta central de diseño de la función en la arquitectura romana. Pero será también la atención a otro concepto que venía cobrando fuerza, especialmente en Francia, desde principios del siglo XVIII, que es el de programme, ${ }^{28}$ lo que puede entenderse como uno de los orígenes más importantes de la noción de 'flexibilidad.' Viollet-le-Duc interpreta en la sociedad romana una serie de necesidades que, con la voluntad propia de un imperio llamado a crecer, se materializan en un programme innovador. Este origen netamente funcional será el que dispare la necesidad de resolver esquemas organizativos cada vez más complejos, característicos de la arquitectura romana. Hasta el momento la idea de programme había contado con un escaso desarrollo teórico. Antoine Quatremère de Quincy se había referido a ella brevemente en su Dictionnaire historique d'architecture, publicado entre 1788 y 1825, en su definición de "malestar» (gêné), afirmando que "Cuando el arquitecto concibe bien y en toda su extensión el programa que debe representar siente una singular facilidad en el orden y la combinación de todas las partes que tiene el arte para someterse a un motivo simple y general». ${ }^{29}$ Pero también, en otros pasajes del Dictionnaire..., se refiere a un "programa moral», o a un "programa ornamental». Por lo mismo, aunque el sentido del término estuviera gestándose, no existía una definición
Esta sería la explicación que un arquitecto griego haría de su edificio, según Viollet-leDuc: "Cuando se confiaba la construcción de un monumento a un arquitecto griego, éste se proponía ante todo cumplir exactamente el programa que se le había encargado. Deseaba que todo el mundo conociera el uso de su edificio, no sólo a través de la disposición general, sino a través de les esculturas que lo ornamentaban. Lo situaba en el lugar observando la orientación más favorable para cada función. Jamás habría ornamentado un edificio destinado a albergar empleados como si fuese el palacio de un gran magistrado o una sala para asambleas". Ibid. Tomo I, p. 85

27.

Ibid. Tomo I, p. 107.

28.

Para los términos en idioma original se ha revisado la edición en francés, Viollet-le-Duc, Eugène-Emmanuel, Entretiens sur l'architecture (Paris: A. Morel et Cie Éditeurs, 1863). Viollet-le-duc se refiere al programme cuando

2.3.3.c.

\section{Programme}

reflexiona sobre la arquitectura, diciendo que "Ha de ser verdadera según el programa, y verdadera según los procedimientos de construcción. Que sea verdadera según el programa significa que cumpla exactamente, escrupulosamente, las condiciones impuestas por una necesidad. Que sea verdadera según los procedimientos de construcción significa que emplee los materiales conforme a sus cualidades y a sus propiedades. (...) las cuestiones puramente artísticas, a saber, la simetría y la forma aparente, no son más que condiciones secundarias en presencia de estos principios dominantes". Viollet-leDuc, Eugène-Emmanuel citado en Frampton, Kenneth, Historia crítica de la arquitectura moderna (Barcelona: Gustavo Gili, 2005), p. 64. (Ed. orig. 1980)

29.

de Quincy, Antoine Quatremère, Dictionnaire historique d'architecture: comprenant dans son plan les notions historiques, descriptives, archaeologiques, biographiques, théoriques, didactiques et pratiques de cet art, vol. 1 ( $\mathrm{Pa}$ ris: Librairie d'Adrien le Clere, 1832), p. 658. (Ed. orig. 1788). Traducido por el autor.

30.

"La apariencia exterior de los monumentos romanos sólo muestra el envoltorio de su contenido, sus plantas no son más que la expresión de sus necesidades, y los romanos jamás sacrifican estos principios a la satisfacción pueril de hacer eso que en nuestra época llamamos arquitectura. En primer lugar buscan la expresión más sencilla y exacta del programa, y luego buscan el modo de revestir las formas dictadas por las necesidades con una apariencia de poder y de riqueza". Violletle-Duc, Conversaciones sobre arquitectura, Tomo I, p. 127

31.

Ibid. Tomo I, p. 282

32.

Ibid. Tomo I, p. 283

33.

Ibid. Tomo I, p. 323.

34.

Ibid. Tomo I, p. 128 
concreta que ligara a programme con el problema de la función, al menos con tanta claridad como lo planteara Viollet-le-Duc.

2.3.3.d. A partir de la necesidad de los romanos de construir edificios más masivos y Forma y apariencia complejos crece-como explica el autor en la "Quinta conversación"- Ia capacidad para resolver plantas ordenadas y efectivas, atendiendo a las necesidades y orientaciones, resaltando sobre todo la resolución simple de las mismas. A esto le suma el desinterés que los romanos muestran por vincular el adorno al contenido del edificio, como si estuvieran disociados, refiriéndose a estos últimos como un "revestimiento." El mismo cuenta con la capacidad de dotar de un caractére al edificio, ${ }^{30}$ y el desarrollo de este caractére, vinculado tanto al origen funcional como a la estructura del edificio, Viollet-le-Duc lo verá en la arquitectura de la Edad Media, en su "Séptima conversación:"

Los arquitectos de la escuela laica de la Edad Media, a pesar de esta tendencia hacia la apariencia que he advertido en todas las épocas, sometieron la forma, en una palabra, la apariencia, a los procedimientos y materiales utilizados. Al salón de un castillo jamás le dieron la forma de una iglesia, a un hospital jamás le dieron el aspecto de un palacio, a un ayuntamiento jamás le dieron el aspecto exterior de una casa de campo. Cada cosa estaba en su lugar y tenía el carácter que le era propio. ${ }^{31}$

Esta interpretación de un caractére maduro de la Edad Media, sobre el que afirma que "es imposible separar la forma de la arquitectura del siglo XIII de su estructura»32 verá su desarrollo en el Tomo II de Entretiens... Luego, en su lectura del Renacimiento, Viollet-le-Duc planteará la decadencia de la arquitectura y su completa disociación con la función. ${ }^{33}$

2.3.3.e. El autor observa en la arquitectura romana la aparición de un estadio de la vague función que no está vinculado en principio a ninguna necesidad particular, pero que sí consta de una necesidad que podría entenderse como genérica, dentro de un marco social:

Si el programa es indeterminado, si las necesidades que expresa dicho programa no están definidas con suficiente exactitud, como ocurre por ejemplo con la basílica, que es un monumento mixto -paseo, mercado, bolsa, tribunal, lugar de discusión, sala de pasos perdidos-, entonces los arquitectos hacen variantes de la planta, interpretan el programa de modos distintos. ${ }^{34}$

La basílica se plantea así como el ejemplo de un tipo de estrategia que permite variantes funcionales, que puede ser utilizado de diversas maneras, y por lo mismo que funciona como semilla de la 'flexibilidad'. La basílica puede interpretarse, siguiendo a Viollet-le-Duc, como la primer noción de indeterminación funcional en la arquitectura -aunque el autor no utilice la palabra indéterminé, sino vague-, y será esta construcción sin acentos, sólo diferenciada mediante las naves que otorgan cierto recogimiento o exposición según cada actividad, la que permita pensar en una arquitectura que no nace para satisfacer un programa particular. La aparición de un tipo arquitectónico que sea capaz de albergar diversas funciones le garantiza también una permanencia, por su propia capacidad de 'flexibilidad'; es justamente esta vaguedad programá- 
defecto. Como lo dijera Laugier, las columnas exentas, con su independencia -especialmente en la planta basilical-, ofrecen la capacidad de generar recorridos en su perímetro, casi como si de fluidos se tratase. Viollet-le-Duc adhiere, agregando que «...puesto que las basílicas son monumentos que albergan distintos usos, y dichos usos pueden variar o tomar una importancia mayor o menor en función de la época y del lugar, los romanos desarrollan infinitas variantes de sus plantas». ${ }^{35}$ Pero una vez reconocida esta innovación el autor vuelve a fijarse en la particularidad de las funciones, afirmando que:

El contenido de los programas suele cambiar poco, puesto que las necesidades de los hombres, en un estado de civilización, son siempre las mismas, con pocas diferencias. Ahora bien, el clima, las tradiciones, las costumbres, los hábitos, los gustos, todo ello hace que dichos programas sean interpretados de un modo específico, en función del tiempo y del lugar. ${ }^{36}$

Ejemplifica esta situación con el teatro griego, el cual, a través de los siglos, ha sufrido cambios drásticos debido a los factores culturales y regionales. Siendo así, «las costumbres de una sociedad no tienen por qué someterse a unas disposiciones arquitectónicas determinadas, sino que dichas disposiciones deben surgir de aquellas costumbres, de unos hábitos que son esencialmente variables. ${ }^{37}$ La basílica contradice esta idea, ya que justamente, su organización inamovible es capaz de recibir diversas actividades sin atender a los matices funcionales de estas. En la basílica las actividades simplemente se practican; se acomodan a la planta existente.

Por otra parte, no resulta de menor importancia la continuidad que el autor establece con Durand. Viollet-le-Duc también se refiere a la composition, entendiendo por ella una estrategia con la cual actuar ante situaciones proyectuales de mayor exigencia, afirmando que "Cuando los programas eran sencillos y no quedaban asfixiados por la multiplicidad de detalles impuestos por unos hábitos diseminados hasta el infinito, era bastante lógico que el arquitecto actuara de forma sencilla». ${ }^{38}$ Para el autor, la composition significa un entendimiento de los problemas de la función, resumidos en el propio programa y en los hábitos. ${ }^{39} \mathrm{El}$ mismo verá su desarrollo, como resulta común en la composition francesa, en la planta, de la cual dirá que "es la traducción literal del programa, y la arquitectura debe someterse a ella».40 Si bien no da una precisión al modo de un método -como sí lo plantara Durand por medio de la pedagogía-Viollet-le-Duc también interpreta la composition como ese entendimiento del todo a través de las partes. En esta noción de composition existe una diferencia importante con respecto a Durand, ya que el primero resalta por sobre todo su distinción entre esta, el programme y los hábitos. Esto implica comprender que el programme requiere unas exigencias generales, y también abstractas, que pueden no estar en concordancia con los modos de vida. El programme sería entonces una herramienta en manos del arquitecto para poder dotar de un primer contenido a esta composition -vacía de contenido, en su primer estado- la cual debería finalmente incorporar la sensibilidad que requieren los hábitos, a través del diseño. El programme resulta un elemento central en la estrategia de organización funcional, pero finalmente este, junto a los hábitos y la propia composition, deben quedar perfectamente articulados.
39.

Para Viollet-le-Duc la composition es el resultado de "1) el programa impuesto; 2) los hábitos de la civilización en que se vive, para componer es esencial disponer de un programa y tener un sentido preciso de dichos hábitos, de las costumbres y de las necesidades". Ibid. Tomo I, p. 328

40.

Ibid. Tomo I, p. 329

41.

Ibid. Tomo I, p. 330

42.

Incluso en la decoración ve una posibilidad funcional, cuando dice que "Aún la línea de follaje que trepa por el capitel, dándole cuerpo, concurren en dar seguridad al observador". Ibid.

43.

"La construcción gótica, a pesar de sus defectos y errores, quizás por ellos, es de útil estudio, es la más segura iniciación a un arte moderno que todavía no existe pero esta peleando por nacer porque establece los principios verdaderos que deben ser válidos aún hoy, porque rompió con la tradición antigua y

\subsection{3.f.}

\section{Composition}

tiene aplicaciones fértiles". Rigotti, Ana María, "Viollet-le-Duc," en Cuaderno del Laboratorio de Historia Urbana (Rosario: Ana María Rigotti, 2009), p. 19

44. Viollet-le-Duc, Conversaciones sobre arquitectura, Tomo I, p. 337-38.

45.

Collins, Peter, Los ideales de la Arquitectura Moderna: su evolución. 1750-1950 (1969), p. 164. (Ed. orig. 1965).

46.

Ver Frampton, Historia crítica de la arquitectura moderna, p. 64.

47.

El cual, según Colquhoun, "fue el primer intento sistemático de reemplazar al sistema clásico de la arquitectura y las artes decorativas, que venía transmitiéndose desde el siglo XVI y que se había consagrado gracias a las enseñanzas de las academias beaux arts" Colquhoun, Alan, La arquitectura moderna: una historia desapasionada (Barcelona: Gustavo Gili, 2005), p. 13. (Ed. orig. 2002). 
ante el resultado que pueda acarrear, tiene relación también con las hipótesis radicales de Lodoli. Viollet-le-Duc busca, por sobre todo, dotar de un sentido funcional a cada fragmento de un elemento arquitectónico; así, la columna no sólo es el sostén, sino que podría plegarse a modo de ménsula para sostener un voladizo, y al mismo tiempo servir de gárgola. ${ }^{42}$ Este conocimiento proviene, como en Ruskin, de la admiración que el autor siente por la arquitectura gótica. ${ }^{43}$

Puesto que cada parte de un edificio o de una construcción debe responder a una motivación, somos sensibles, incluso a nuestro pesar, a cualquier forma que nos indique su finalidad, del mismo modo que somos sensibles ante la visión de un hermoso árbol en el que todas sus partes, desde la base anclada al suelo hasta las ramas más altas, que parecen ir en busca del aire y de la luz, indican con gran claridad las condiciones de vida y de durabilidad de estos enormes vegetales. ${ }^{41}$

Vuelve a aparecer, como en el autor inglés, la valoración de la flexibilidad del gótico como una posibilidad de adecuación de las necesidades funcionales. Atendiendo al viejo reclamo de Bacon, Viollet-le-Duc dice que «Si los arquitectos de la Edad Media admiten la simetría en aquellos monumentos cuyo uso mantiene una unidad perfecta, como por ejemplo las iglesias, no la tienen en cuenta cuando se trata de un castillo, que no es más que una aglomeración de funciones muy diversas". ${ }^{44} \mathrm{Al}$ mismo tiempo Viollet-le-Duc era un admirador de las máquinas (barcos o locomotoras) a las cuales utilizaba como comparación de las construcciones. Como menciona Collins, esta referencia a la forma característica de la máquina- entendiendo que esta cuenta con una función única y exclusiva- en contraste con la necesidad de definición de un estilo en la arquitectura resulta discutible, ya que, por el contrario, la arquitectura incorpora una serie de variables que hacen que no pueda identificarse como un objeto con una única función..$^{45}$ Esta diferencia entre la complejidad funcional de la arquitectura sí fue atendida por algunos de los arquitectos que llevaron a la práctica parte de las ideas del autor francés. La influencia de Viollet-le-Duc llega a ser visible recién en la Europa de fines de siglo,46 con reconocidos exponentes como Antoni Gaudí en Barcelona, Hector Guimard en París, Hendrik Berlage en Holanda, o Victor Horta en Bruselas.

En 1899 Guimard recibe el encargo de diseñar los accesos a las estaciones de metro de París, y como es sabido, las finas estructuras de acero y vidrio que caracterizan su obra suponen un acercamiento a las ideas de VioIlet-le-Duc en cuanto a la 'función del ornamento.' Bajo esta idea, cada pieza se nutre de diferentes roles funcionales; así, una columna puede ser al mismo tiempo un tubo de desagüe pluvial, sostener la cartelería y rematar finalmente en una lámpara superior. Esta suerte de esfuerzo por las múltiples facetas funcionales de los elementos se vería reflejado en una expresión naturalista que conformaría luego la estética propia del Art Noveau. ${ }^{47}$ Pero Guimard estaba igualmente preocupado por las cuestiones funcionales y técnicas que por las estilísticas, algo que continua con su incursión en el diseño de mobiliario. 
En el diseño de los muebles para la casa Beránguer [FG.03] explora las variadas posibilidades funcionales de cada elemento en relación al cuerpo humano y a la naturaleza, en un acercamiento que ya había sido planteado por Ruskin en "La lámpara de la belleza."

También en la obra de Horta se combina la adecuación del programa a una expresión característica heredada del uso intensivo de la estructura de acero y el vidrio -materiales propios del llamado 'racionalismo estructural'. Mediante la utilización de los mismos la particularidad funcional de cada edificio se ve igualada en su expresión y su estructura, con soluciones afines tanto para viviendas burguesas -la Casa Tassel de 1892-, equipamientos sociales -la Maison du peuple de 1900-, como edificios industriales -Á l'Innovation de 1901. La continuidad de una solución constructiva y espacial para distintos programas habla de un primer acercamiento a un carácter 'flexible' en pos de un propio estilo, que aún no alcanza, ni tampoco busca del todo, la indeterminación funcional. Aún así los interiores de Horta tienden más que nunca a una flexibilidad de uso, desprendida de espacios etéreos sostenidos por mínimas columnas de hierro que apenas interrumpen la fluidez. En la Maison du peuple Horta tiene el desafío de enfrentarse a un proyecto mucho más complejo que el de las viviendas unifamiliares de su primera etapa, y demuestra un particular talento para organizar un programa variable en las diversas plantas superpuestas. [FG.04] La singularidad de la solución radica en la distribución del programa -salón de café, tiendas, sala de juegos, salas de reuniones, sala de espectáculos- en niveles con compartimentaciones notablemente diversas. Sorprendentemente, Horta utiliza una estrategia netamente estructural para organizar los programas en altura; así, la densidad y sección de los soportes

[FG.3]

Hector Guimard

Casa Beránger. Mobiliario

New York: Media Center for Art history. Columbia University,

1894.
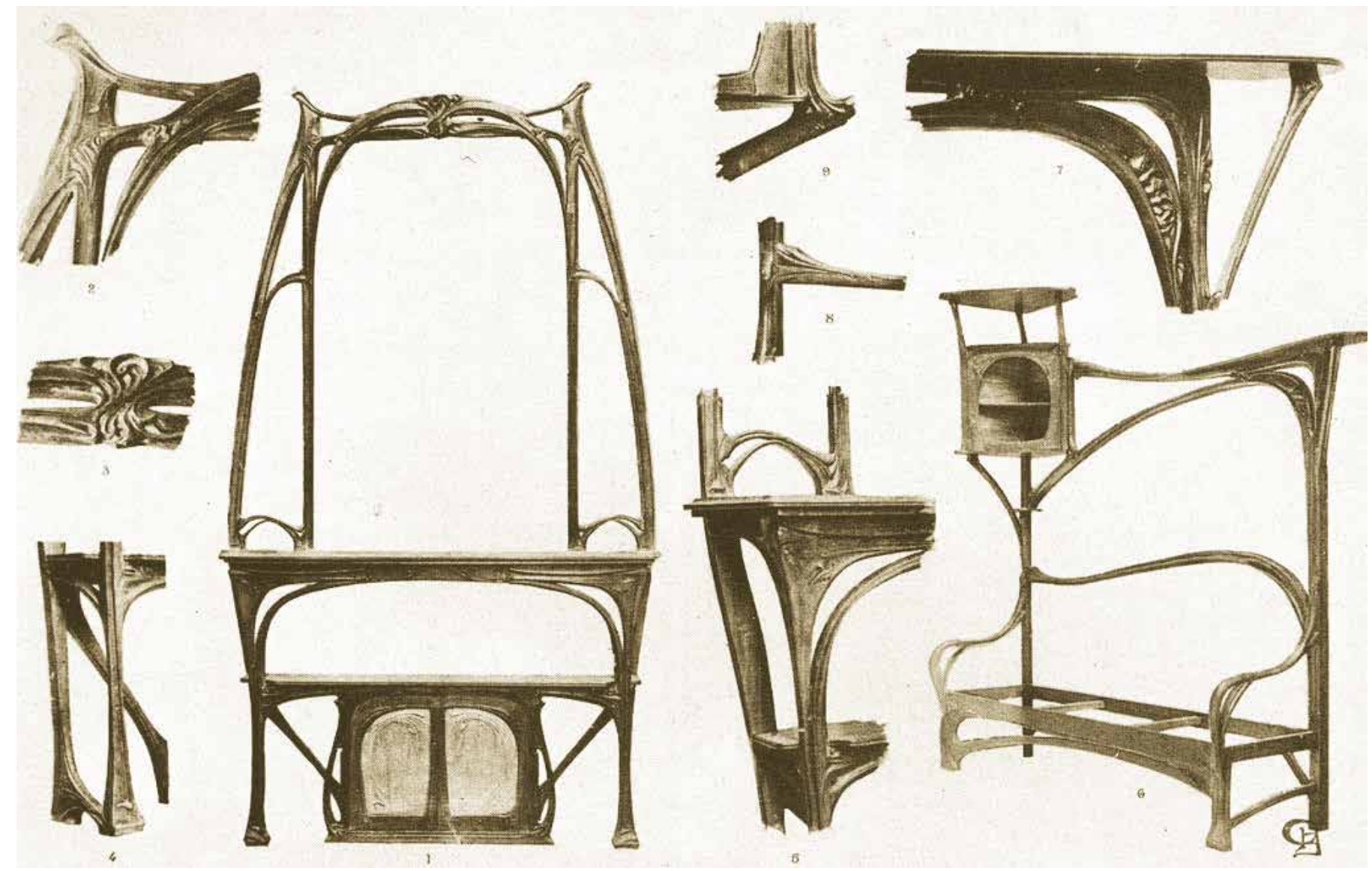

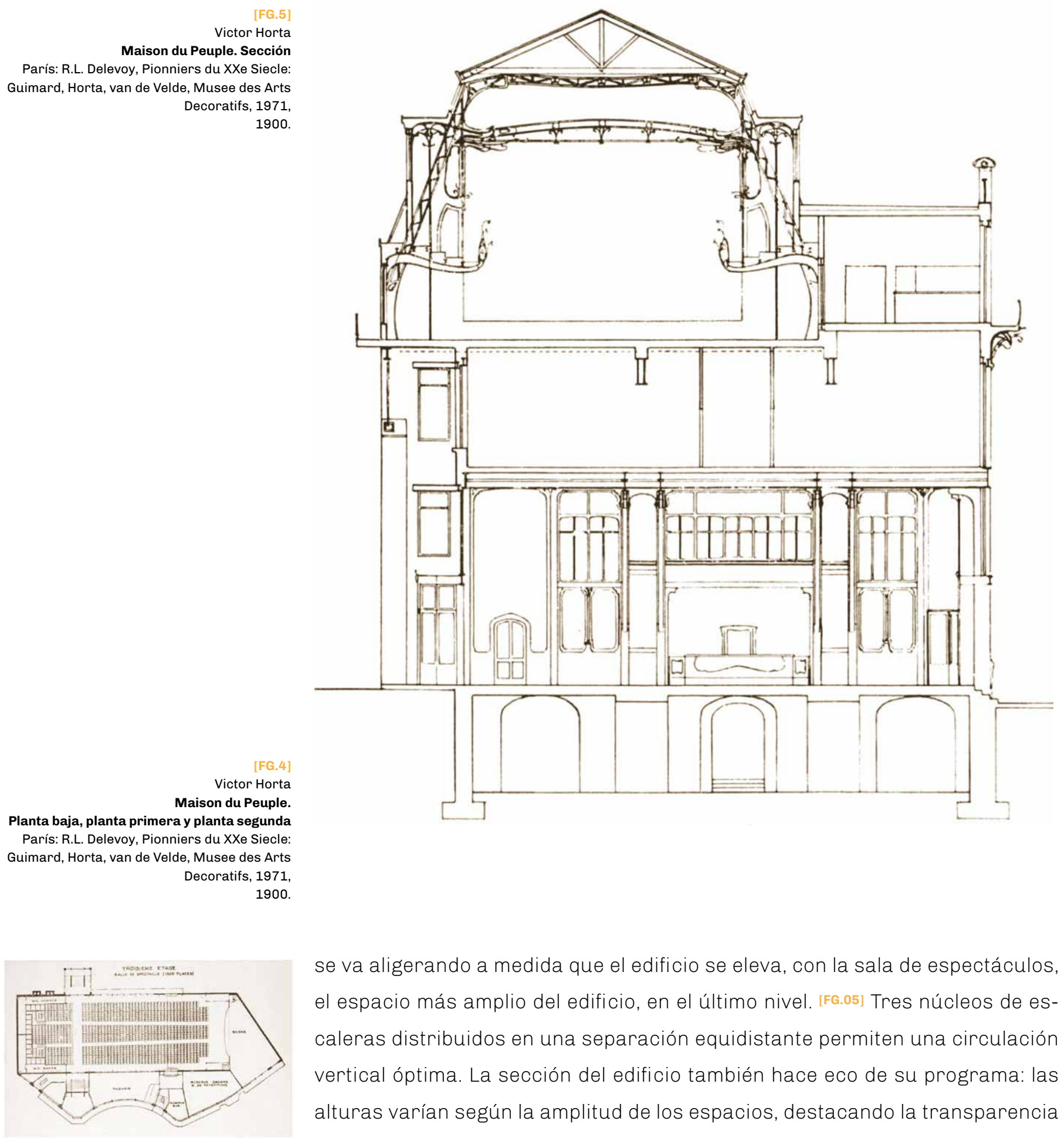

se va aligerando a medida que el edificio se eleva, con la sala de espectáculos, el espacio más amplio del edificio, en el último nivel. [FG.05] Tres núcleos de escaleras distribuidos en una separación equidistante permiten una circulación vertical óptima. La sección del edificio también hace eco de su programa: las alturas varían según la amplitud de los espacios, destacando la transparencia hacia la calle en la planta baja -la cual se desarrolla en una doble altura que
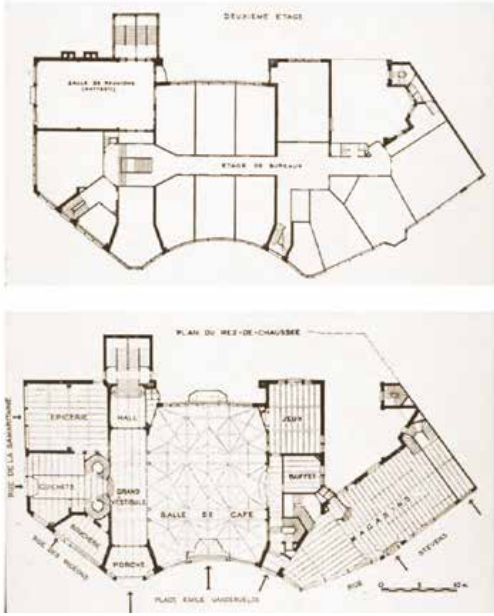
simula dos niveles hacia el exterior-y el remate de la sala de espectáculos, con un sutil ingreso de luz natural a ambos lados del techo. Horta consigue evitar en todo momento que una columna invada un área destinada a una actividad, valiéndose para esto de una estructura de acero de sección mínima acoplada a los muros de mampostería. Al mismo tiempo, casi aplicando las lecciones de Viollet-le-Duc, saca partido expresivo y funcional de cada elemento constructivo; así, la estructura de acero se funde con las barandillas, las lámparas, los desagües pluviales o las carpinterías en una unidad orgánica, y hace eco de esa inspiración que el mismo Viollet-le-Duc encontrara en las estructuras arbóreas; en este caso Horta organiza un programa en el que las mayores y más densas compartimentaciones sirven de base para rematar en un espacio etéreo que se abre a la luz del cielo. Programa y estructura se funden finalmente 
La importancia de la estructura de acero tendría un capítulo especial en el Chicago de fines del siglo XIX. El rascacielos, tipo icónico de la arquitectura del s. $X X$, no resulta tan importante para la función como el propio programa de oficinas, tan requerido en el crecimiento de las grandes urbes estadounidenses. Si bien es cierto que uno depende de otro, y que la planta de oficinas, su espacialidad y su estructura, son justamente resultantes de esa construcción en altura, gran parte de los escritos producidos en torno al tema consideran la potencia inherente en la torre, la altura, la repetición, y los avances tecnológicos que la hicieron posible como el verdadero germen. Al mismo tiempo la necesidad de este programa de oficinas por parte del mercado implica también el nacimiento -no siempre reconocido- de este concepto de "planta libre,» fundamental para las ideas de función modernas, décadas antes de que Le Corbusier propusiera su difundido esquema Dom-Ino.

Como es sabido, los primeros rascacielos comienzan a construirse en la que ya fuera la zona de negocios de Chicago, conocida como el Loop, que había sido destruida por un incendio devastador en el año 1871, debido principalmente a la existencia mayoritaria de construcciones en madera. La reconstrucción de ese centro vacío resultó particular ya que, debido a la suba del precio del valor de suelo, los especuladores de la construcción se plantearon la necesidad de obtener la mayor cantidad de superficie construida posible, para sacar rédito a las inversiones. Al mismo tiempo algunas innovaciones técnicas hicieron posible la acomodación en altura, como el cálculo de la estructura en acero por parte de los ingenieros, la invención del ascensor, y la aplicación de medios de comunicación, como el teléfono y el correo neumático. ${ }^{48}$ Pero más allá de la tecnología que envuelve el nacimiento de este tipo arquitectónico, en lo referido a la función resulta fundamental su consideración como suelo libre; como porción de terreno plausible de ser reproducido idénticamente, tantas veces como sea posible, hacia arriba. Pero por sobre todo resulta fundamental la necesidad de que dicho suelo se mantenga neutral en términos funcionales, ya que cada empresa prefiere distribuir sus recintos de la manera que les parezca más conveniente según sus necesidades, requiriendo directamente la aplicación de una 'flexibilidad' de disposición. De esta presión entre empresarios, ingenieros y especuladores de la construcción es que nace lo que puede entenderse como la 'indeterminación funcional' que, aunque sugerida por Viollet-le-Duc -influencia que también apunta Colquhoun-, ${ }^{49}$ no cuenta hasta mucho más tarde con un desarrollo teórico concreto.

Louis Sullivan es el autor del período que intentó con más énfasis incorporar al rascacielos dentro del marco de la arquitectura, o dicho de otro modo, buscar que el mismo portara un lenguaje arquitectónico, ya que como producto parecía no calzar dentro de las consideraciones disciplinares de fines del siglo XIX El rascacielos comenzó siendo un desafío técnico; una necesidad a ser salvada, antes que un objeto artístico. Por lo mismo, la batalla de Sullivan tiene que ver con lo que de arquitectónico puede ser extraído de este nuevo artefacto urbano. En su artículo "The tall office building artistically considered," publicado en 1896, es donde expresa con mayor claridad su pensamiento. Desde

\section{Sullivan.}

Libertad de la planta tipo

\section{8.}

Una descripción más detallada de los condicionantes que hicieron posible la aparición del rascacielos en Chicago puede verse en Hy-

som, John y Crawford, Peggy, "The evolution of office building research," Journal of Real Estate Literature 5, 2, (1997).

\section{9.}

Según el autor, la importancia de la estructura, originaria de las teorías de Laugier en la tradición francesa, llega hasta la llamada

"Escuela de Chicago" a través de los textos de Viollet-le-Duc. Ver Colquhoun, La arquitectura moderna: una historia desapasionada, p. 35.

50.

En referencia al rascacielos Sullivan dice "Los acepto como un hecho, y digo que el diseño del edificio de oficinas en altura debe ser reco-

nocido y confrontado desde el principio como un problema a resolver, un problema vital que exige una verdadera solución". Sullivan, Louis $\mathrm{H}$, "The tall office building artistically considered," Lippincott's Magazine 57, 3, (1896): p. 10. Traducido por el autor.

51.

Ibid.

\section{2.}

"¿Cuál es la principal característica del alto edificio de oficinas? Responderemos: su altura. Esta altura es tanto para el artista como para la naturaleza su aspecto más emocionante". Ibid. p. 13.

53. Ibid. p. 15.

54.

Que Sullivan revisara la obra de Spencer es una afirmación de Wright. Ver Collins, Los ideales de la Arquitectura Moderna: su evolución. 1750-1950, p. 157.

\subsection{4.a.}

Rascacielos 
el comienzo del escrito Sullivan aclara que no está interesado en las condiciones sociales que hacen posible al rascacielos, ya que entiende que las mismas atañen exclusivamente a "los especuladores, los ingenieros y los constructores», ${ }^{50}$ y pasa directamente a tratar el problema que el mismo acarrea en lo que podría considerarse como su representación arquitectónica. El rascacielos es sobre todo un objeto con unas proporciones no habituales para la tradición arquitectónica, y Sullivan, en un movimiento cercano al de Bötticher, interpreta que su solución estética depende de una forma que es resultado directo de una función natural. Al mismo tiempo propone una discusión disciplinar en la que ataca a los arquitectos que aún buscan la resolución de este nuevo tipo bajo el halo del sistema clásico -base, fuste y capitel- o bajo la analogía ingenua con la naturaleza o la proporción matemática. Sobre esta base Sullivan asumía el origen tecnológico del rascacielos al mismo tiempo que buscaba establecer ciertas premisas en las cuales una 'fachada' arquitectónica podía ser posible entendiendo que "...es la esencia del problema la que contiene o sugiere su propia solución». ${ }^{51}$ Esto le lleva a desmembrar el rascacielos en paquetes funcionales -desde abajo hacia arriba se compondría de un sótano de instalaciones, la planta baja comercial, un entrepiso, una seguidilla de plantas de oficinas exactamente iguales y, finalmente, el ático- que puedan traducirse en una forma que, aún siendo autónoma, no se desliga de su sentido original. Asimismo destaca la importancia histórica que el rascacielos trae con respecto a la altura, interpretada por el autor como la condición distintiva del mismo. ${ }^{52}$

Todas las cosas en la naturaleza tienen una figura, es decir, una forma, una apariencia externa, que nos dice lo que son, que las distingue de nosotros mismos y de los demás.

Indefectiblemente en la naturaleza, estas formas expresan la vida interior, la cualidad nativa, del animal, del árbol, del pájaro y del pez, que se presentan ante nosotros; son tan característicos, tan reconocibles, que simplemente entendemos que es "natural", que son como son. ${ }^{53}$

En estas palabras queda ilustrada la herencia de Bötticher, y asumiendo este linaje podría decirse incluso que el aporte del autor en cuanto al tema de la función resulta secundario si no se incluyera en su artículo una de las frases que será posteriormente estandarte de la arquitectura moderna, en el momento que, siguiendo las ideas anteriormente expuestas, afirma que "la forma siempre sigue a la función».

2.3.4.b. La paradoja de la posteriomente tan utilizada -y descontextualizada-frase detona cuando se considera que su origen es el del edificio de oficinas en altura. Por lo mismo cabría cuestionar cuál es la función a la que Sullivan hace referencia cuando confiere a la misma ser la semilla misma de la forma. Parte de la preocupación por el dilema entre la forma y la función tiene que ver con las lecturas que Sullivan tuvo sobre la obra de Herbert Spencer; aunque, como comenta Collins, no parece claro que Sullivan aplicara esta lógica a sus propios proyectos, ${ }^{54}$ no obstante se trata de un intenso debate intrínseco a la biología, el cual encuentra referencias en las aportaciones alemanas del siglo XIX -Goe- 
Ni siquiera Colin Rowe parece interesado en las mismas cuando escribe "La estructura de Chicago," (1956), en Rowe, Colin, Manierismo $y$ arquitectura moderna y otros escritos, (Barcelona: Gustavo Gili, 1999).

58.

Koolhaas, Rem, "Typical plan," en S, M, L, XL, (Nueva York: Monacelli Press, 1995), p. 344. Traducido por el autor.
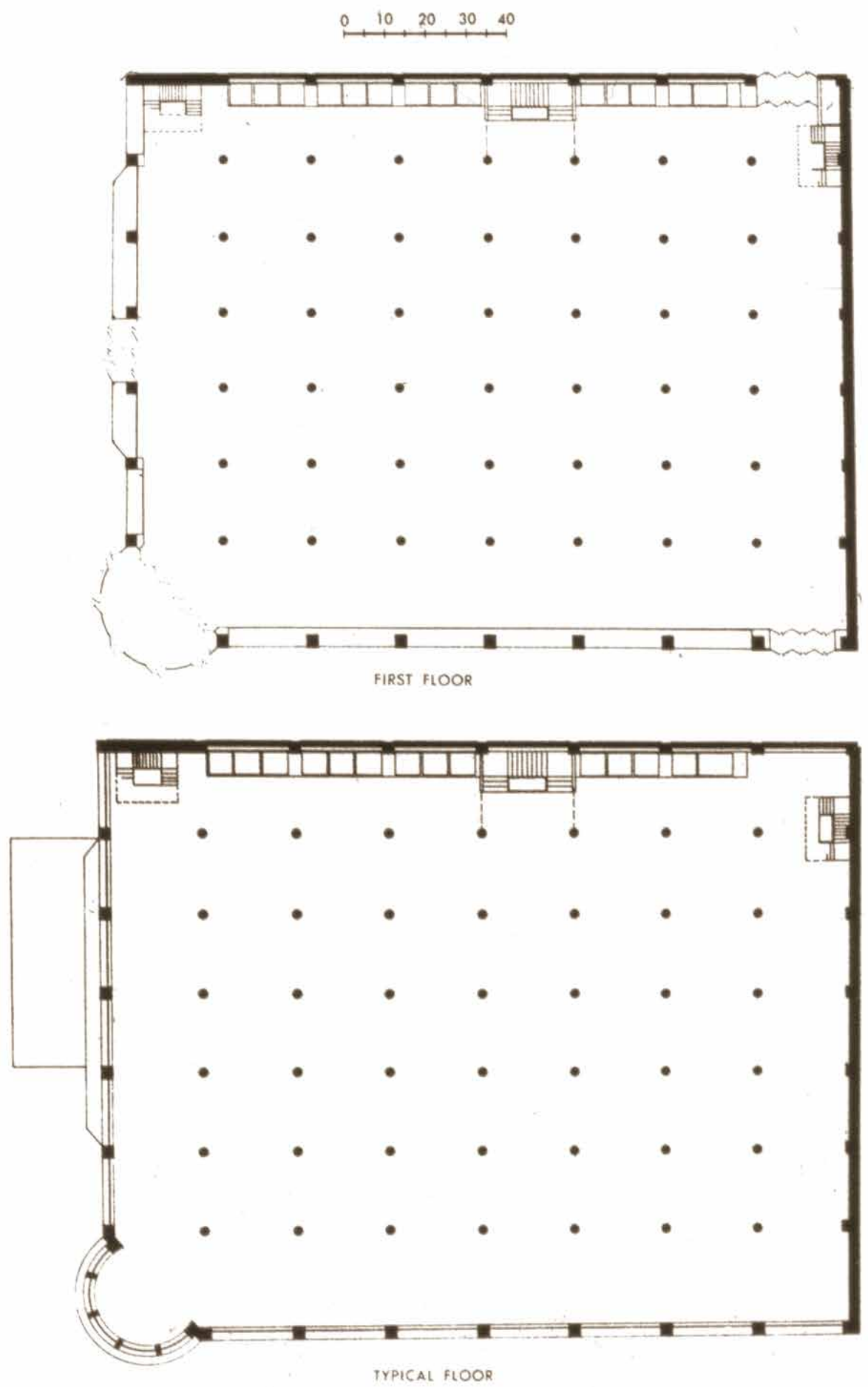
Naturaleza había seleccionado las formas más adecuadas para el ambiente en que estaban situadas»55- como en las británicas -en su teoría de la "Selección Natural" Darwin sostiene que las formas que no tienen una función simplemente no sobreviven. ${ }^{56}$

Sullivan, preocupado específicamente en la resolución formal del rascacielos, entiende que, como en la naturaleza, al hallar la esencia del problema, la forma surgirá naturalmente; en el caso particular del rascacielos, Sullivan encuentra esa esencia en lo que él denomina la "función»; esta se hace visible al analizar el programa mismo del rascacielos -anteriormente descrito-y traspasarlo a la fachada. En efecto, en una de sus obras más reconocidas, el edificio para Carson, Pirie \& Sctott construido en 1899, se verifica la presencia de cada una de estas cinco partes, diferenciadas materialmente mediante la utilización combinada de la ornamentación, en las plantas inferiores, y la austeridad, en la repetición de plantas de oficinas. [FG.06] La propuesta de Sullivan resulta coherente; sin embargo es necesario considerar la posterior utilización -especialmente por parte de la historiografía arquitectónica- de su frase «form follows function", como sinónimo de una función determinista, esa que tiene raíz en Guadet, y que busca asignar a cada necesidad una expresión formal, o mejor dicho, que hace que cada elemento formal devenga de una necesidad particular. Pero la misma aparición de la torre de oficinas supone una innovación en cuanto a la consideración de las funciones dentro de los edificios que escapa al mismo planteo de Sullivan: la posibilidad de una construcción que no requiere de una solución funcional interior, sino más bien de un espacio vacío, plausible de ser llenado, modificado y vuelto a llenar. Sullivan no está interesado en reflexionar sobre esta nueva necesidad funcional, ya que considera esto como un problema técnico que debe ser simplemente resuelto antes que como un tema arquitectónico.

2.3.4.c. La necesaria libertad de la planta que los edificios de oficina requieren lleva a Typical plan construir un suelo liso, constante, sólo interrumpido por los núcleos de servicio y de circulación vertical, y por el ritmo homogéneo de la retícula estructural. Este interior diáfano puede que no haya tenido una importancia a nivel espacial -ya que el mismo será finalmente llenado con divisiones y mobiliario dependiendo de las exigencias de cada empresa-, al menos hasta la obra de Mies. Por otro lado, esta misma condición de vacío lo convierte en una innovación hasta entonces inexistente en términos funcionales, la cual convertirá al programa de oficinas en uno de los modelos de la 'flexibilidad'. Volver a comentar la paradoja de la frase de Sullivan implica contrastar que el nacimiento de la misma se da bajo el programa más indeterminado que se hubiera construido hasta el momento, siendo que "form follows function" se ha vuelto prácticamente un símbolo de la resolución específica, particular, de la función. La lectura en torno a las posibilidades funcionales de la planta de oficinas parecen muy posteriores; ${ }^{57}$ Rem Koolhaas se referirá al mismo, en su breve pero incisivo ensayo "Typical Plan," como una "planta sin cualidades la cual provee múltiples plataformas para la democracia del siglo veinte». ${ }^{58}$ Para Koolhaas la 
parámetros funcionales tradicionales radica en que, estas últimas tienen la vocación de predecir las actividades futuras. Por el contrario, la planta indeterminada del edificio de oficinas evade cualquier anticipación, o más bien como el mismo autor holandés señala, "pospone el futuro, dejándolo abierto para siempre». ${ }^{59}$ Así, la planta del edificio de oficinas supondrá un avance fundamental para una noción de 'flexibilidad' donde la función específica no es considerada.

Puede que el posterior reconocimiento de "Der Raum als Membran", el texto que Siegfried Ebeling publicó en la Bauhaus en 1926, tenga que ver con su confirmada influencia en el pensamiento de Mies, ${ }^{60}$ pero la intensidad y profundidad de sus palabras, al mismo tiempo que su particular modo de expresarse, alcanzan a tocar ciertas temáticas adelantadas a su tiempo y a alimentar otro modo de entender lo 'flexible' de la función. “Der Raum als Membran” es, en primer lugar, un texto polémico e incómodo para su tiempo -escrito en parte como crítica hacia la linea de la Bauhaus de Gropius-, ya que coloca en tela de juicio parte del pensamiento de la arquitectura moderna. Pero - a diferencia de la crítica que establece, por ejemplo, Wright- esta no se funda en la exploración formal de la arquitectura moderna, sino en sus argumentos. Desde el comienzo Ebeling aclara que el ensayo «... va más allá de la simple necesidad»61 refiriéndose claramente a que el mismo pretende extenderse por fuera de los límites del funcionalismo en boga. "Del mismo modo que podemos pasar sin algunas cosas -al fin y al cabo, el poder primordial y cósmico del ritmo del tiempo sigue su curso- también podemos pasar sin arquitectura». ${ }^{62}$

El autor despliega así una suerte de poesía que ejerce fuerza sobre la condición humana y científica en la cual la arquitectura dialoga, se entrecruza, perdiendo y a la vez encontrando su (posible) nuevo lugar. El texto de Ebeling es una oda a la desmaterialización de la arquitectura, a su desaparición y, nuevamente, a su aparición, transformada y transformadora del hábitat humano. No es un texto sobre la función, sino sobre el ser en el espacio-tiempo, ya que para él, «...cualquier organismo naciente es más sagrado, grande y completo que cualquier objeto construido y formado por la mano del intelecto humano. Y rica y próspera es la tierra donde este intelecto no gobierna». ${ }^{63}$

Ebeling sostiene una relación claramente distante con el racionalismo moderno, pero al mismo tampoco acepta el acercamiento empírico hacia la naturaleza, característica de la visión organicista. "Sobre este fondo demoníaco subyace el fundamento de nuestras formalizaciones: ningún argumento, por apasionado que sea, puede mitigar la discrepancia que media entre el pensar y el ser». ${ }^{64}$ O podría decirse también, entre el planeamiento y el acto mismo, individual, de habitar. En su "Advertencia", al inicio del artículo, el autor aclara que en su texto "No se trata de ofrecer soluciones sino de señalar direcciones; no se trata de ofrecer métodos sino de [mostrar] valores». ${ }^{65}$ Pero Ebeling es consciente también de la inevitable necesidad del hombre por avanzar y modificar la tierra como si fuera suya propia, con lo cual entiende que existe una contradicción y que sí resulta preciso establecer al menos las directrices que lleven a posibles soluciones.

\section{Ibid. p. 341.}

60.

Esto es lo que demuestra Neumayer estudiando los apuntes del arquitecto alemán en Neumeyer, Fritz y van der Rohe, Ludwig Mies, Mies van der Rohe: la palabra sin artificio: reflexiones sobre arquitectura, 1922-1968 (EI Croquis, 1995).

\subsection{5.}

\section{Ebeling. Transparencia.}

61. Ebeling, Siegfried, El espacio como membrana (Barcelona: SD Ediciones, 2015), p. 45. (Ed. orig. 1926).

62.

Ibid. p. 47.

63. Ibid.

64.

Ibid.

65. Ibid. p. 48. 
La casa es uno de los temas centrales que el texto aborda, sobre todo porque Fuerzas Ebeling considera que la misma ha tenido una atención mucho menor en comparación a los edificios que representan alguna forma de poder institucional. La descripción con la que Ebeling refiere a "la casa» podría tener una similitud a los elementos esenciales de Semper, pero ciertamente hay en Ebeling un paso más, que tiene que ver con el lugar que el flujo de los habitantes tiene en el espacio. La diferencia resulta aún mayor por el tono poético y a la vez ensayístico que Ebeling utiliza en el lenguaje:

...en un mundo donde las cosas y las experiencias son fantásticamente mutables, la casa permanece relativamente estática, como entidad espacial pluricelular. Su base está, bien fijada de forma rígida, bien simplemente apoyada sobre el terreno a través del cual fluyen múltiples fuerzas. Sus superficies restantes sin embargo, entran en contacto con un medio más fino que es periódicamente penetrado por rayos de luz de calidad variable. La tensión entre esos dos grupos de fuerzas se produce en el espacio hueco interior de la casa, entrando en interacción psicológica y fisiológica con los habitantes según leyes específicas. El grado de equilibrio armónico entre estos tres componentes determina el carácter y calidad de la arquitectura. ${ }^{66}$

Los tres componentes se conforman en base a lo que él denomina como "fuerzas", que serían las propias del terreno, las de las "superficies restantes" (envolvente) y las de los habitantes que llenan el vacío interior. Esta combinación poco tiene que ver con cualquier descripción arquitectónica anterior que tuviera alguna relación con las condiciones propias del hábitat. Ebeling aclara a su vez que no pretende filtrar la historia a través de la búsqueda de estas "fuerzas" o "flujos", sino que se propone indagar en ciertos conceptos que puedan arrojar luz para la arquitectura futura.

Los «flujos» de energía a los que la construcción (a la que Ebeling resume en vivienda) está sometida no resultarían visibles al ojo humano. Para esto se basa en fuentes de energía aún no completamente demostradas por la ciencia; se trata de fluctuaciones ambientales productos de las tormentas eléctricas, del viento o de la nieve que tendrían cierto impacto en la psicología del habitante -y cita las investigaciones del profesor Hellpach de Heidelberg, que sería el que advirtiera del filtro de rayos ultravioletas que ejerce el cristal sobre la luz solar. La piel exterior de un edificio puede, según él, escindirnos de sus efectos físicos, pero no de sus efectos mentales, y el desconocimiento de estos efectos implica para Ebeling la aún primitiva concepción de las viviendas por parte de los hombres.

Pese a que somos capaces de interpretar la naturaleza de un modo progresista, creativo y racional, el concepto que tenemos del espacio arquitectónico actual sigue confiando en la mera tridimensionalidad (...) Cuanto más revelemos las conexiones del material con la naturaleza -incluyendo la del hombre- y cuanto más sintamos la necesidad de hacer de nuestras ciudades verdaderos paisajes urbanos -esto es, naturaleza conformada intelectualmente- más evidente se hará que el carácter de la piel (o membrana) que existe entre el espacio exterior y las dimensiones delimitadas del cuerpo humano está 
fundamentalmente relacionado con el modo en que el espacio está definido y dimensionado a nivel psicofísico -por ejemplo, a través del color. ${ }^{67}$

Ebeling asume que, en principio, esta postura navegaría a contrapelo de la tradición de la belleza, la voluntad de poder, la noción de ciudadanía, es decir, del propio significado de la arquitectura. Entiende que esta nueva noción es más técnica que simbólica, y por lo mismo supone un quiebre. Pero la fuerza de su postura radica en quitar la centralidad de lo llanamente físico para concentrarse en los fenómenos fisiológicos que el mismo espacio puede producir y que afecta directamente el modo de habitar.

Para el autor los sistemas de infraestructuras aplicados a la vivienda, tales como energía eléctrica, calefacción o teléfono se superponen sin ningún miramiento de la arquitectura que lo alberga, y esta situación resulta para Ebeling asombrosa, ya que entiende -como posteriormente también planteará Banham- que la arquitectura asume un lugar estático frente a esta nueva inyección de energías artificiales que envuelven el espacio habitable. Se trata, como él mismo dice, de una "escisión entre arquitectura, tecnología y arte, con la arquitectura situada seguramente en el último lugar de la jerarquía en la mayoría de los casos". ${ }^{68}$ Al entender Ebeling la arquitectura como escenario de "fuerzas" que se yuxtaponen, busca que las mismas, tanto las provenientes de los hombres como de la propia tecnología, tengan una expresión. Por lo mismo, los nuevos sistemas deberían estar, según el autor, incorporados dentro del espacio arquitectónico, integrados más allá de lo escultórico de la arquitectura; la casa como una propia fuente de energía, incluida la de los propios habitantes.

La función aparece en esta lectura como un problema vinculado a estos focos de energía que generan algún tipo de cambio en el comportamiento humano. Pero al mismo tiempo el autor refiere a la «necesidad»; especialmente cuando menciona a naciones subdesarrolladas que viven en climas difíciles, y entiende que el desarrollo intelectual y científico -en este caso el alemán- podría proveerles soluciones para mejorar sus condiciones. En otro momento del texto reconoce -volviendo a Semper-que la chimenea ha sido un elemento que ha transformado las relaciones físicas del espacio interior, en una referencia obvia a la noción funcional de Wright. Por lo mismo confía en que la atención a otros elementos puedan, o deban, generar también modificaciones en la organización interior de la casa. Ebeling menciona algunas posibles soluciones, como la investigación realizada en su momento por un científico japonés en la cual bloques de vidrio se rellenan con una solución salina que absorbe el calor solar, permitiendo transparencia y evitando los efectos de la radiación al interior ${ }^{69}$ En la tercera y última parte de su texto se inclina a plantear algunas hipótesis que pueden entenderse como llamados a la ciencia y a la industria para poder obtener resultados que modifiquen las condiciones de los ocupantes; entre estos Ebeling menciona la energía obtenida de las radiaciones terrestres y aéreas; la posibilidad de captación y conducción de la luz natural hacia espacios que no puedan tener exposición directa al exterior; la necesidad de mezclar luz artificial con luz natural para homogeneizar los interiores
69.

En este punto también refiere a los tratados de Bruno Taut, -con más precisión, a Alpine Architektur, Stadkrone, y Die Frau alas

Schöpferin- a los que considera poco profundos e inconsistentes para tratar las condiciones más esenciales del problema.

70.

Ibid. p. 78.

71.

La cita de Nietzsche proviene del Volumen I de Der Wille Zur Macht, "Dicho brevemente: quizás la evolución completa del Espíritu sea una cuestión del cuerpo; es la historia evolutiva y perceptible de la formación de un cuerpo más avanzado que emerge dentro nuestro. Lo orgánico -como totalidad, y no sólo el individuo orgánico o la especie- está creciendo todavía hacia niveles más elevados. Nuestra avidez por el conocimiento de la naturaleza es una excusa a través de la cual el cuerpo ansía perfeccionarse. 0 dicho de otro modo, cientos de miles de experimentos se llevan a cabo para tratar de modificar la alimentación, el modo de habitar y el modo de vida de los cuerpos: conciencia y evaluación del cuerpo. Toda clase de placeres y rechazos son isignos! de estos cambios y experimentos. En última instancia, ya no será en absoluta una cuestión del hombre: éste debe ser superado." en Ibid. p. 54.

72. Ibid. p. 60-61.

73. Ibid. p. 61 . 
según el momento del día; la potenciación de los reflejos y efectos de color de la luz en las superficies interiores; la expansión del circuito eléctrico a suelos y techos; la utilización del metal como conductor de energía eléctrica; los materiales y proporciones espaciales vinculados directamente a la radiación. En resumen "...debemos entender la casa como un medio conductor, un espacio vacío que canaliza el uso de fuerzas continuo que proviene de la superficie del terreno...", 70 al mismo tiempo que este "espacio conductor» debe vincularse directamente al cuerpo humano. En este último tramo exige también que la arquitectura deje de lado su lugar servicial, el cual sólo confirma las condiciones dadas, y que pase a exigir a la ciencia a partir de un nuevo escenario.

2.3.5.b. En el texto se propone que la referencia deje de ser «la humanidad», para pasar a ser el propio «hombre», una mutación de lo abstracto a lo concreto. Para este «hombre» es que Ebeling imagina un espacio en el cual podría desarrollarse como Fürsichsein ("ser independiente en sí mismo»); dicho espacio contendría el propio espíritu de la forma espacial, ilustrado en su proyecto Kugelhaus de 1926. [FG.07] Ebeling considera esto como un re-descubrimiento del cuerpo, citando un fragmento de Nietzsche ${ }^{71}$ en el cual se profesa la propia superación del hombre como tal. Pero lo que en verdad busca Ebeling es un espíritu autónomo dentro del organismo del cuerpo. Aquí también cabe lo fisiológico y filosófico, volviendo a la idea de que las "fuerzas terrestres" puedan influir en el comportamiento humano, Ebeling ejemplifica diciendo que:

...la diferenciación debe basarse en métodos constructivos que respondan no simplemente al clima y al paisaje sino a un nuevo concepto de naturaleza: implicaría que en un espacio público colocado sobre un plano arenoso y bajo un cielo determinado -factores activadores de determinadas tensiones espacialespodría -y de hecho, debería- ser constituido de modo distinto que otro que se encontrara situado sobre, por ejemplo, un suelo de granito o en el mar, puesto que las fuerzas terrestres son fundamentalmente distintas en un sentido geofísico: en cada caso, las condiciones de radiación atmosférica son diferentes en relación al organismo humano que se expone a ellas a nivel fisiológico. ${ }^{72}$

Al mismo tiempo se pronuncia literalmente en contra de la visión higienista, ya que para Ebeling las soluciones para solventar las condiciones medioambientales -lo que él mismo llama "arquitectura biológica»- no deben resultar tanto técnicas como psicológicas y fisiológicas.

...equiparar el espacio tridimensional -determinado desde un punto de vista estrictamente físico-, a una membrana tridimensional -biológicamente definida- situada entre nuestro cuerpo, [entendido] como débil sustancia plasmática y las minúsculas fuerzas de las esferas [terrestre y atmosférica], que, desde un punto de vista bio-estructural se encuentran en estado latente. ${ }^{73}$

Nuevamente busca cambiar la idea de "humanidad" por la de "hombre", hallándose en este último el ser espiritual, objeto final de su propuesta, de inspiración claramente nietzscheana.

Como se ha mencionado, Ebeling entiende que la arquitectura institucional es la que presenta mayores avances y que la vivienda se encuentra es- 
ha mejorado, en ciertos aspectos, el confort. El autor entiende que las nuevas necesidades espirituales del habitante no tienen lugar en el pensamiento de la vivienda, y en este punto llega al que probablemente sea su aporte más importante al entendimiento de la 'flexibilidad', que tiene que ver con la posibilidad de plantear un habitar basado en la imaginación y en las necesidades no ma-

teriales de la vida, no vinculadas directamente a las nociones tradicionales del hábitat:

...lo que está completamente ausente es una actitud unitaria, intensa y manifiestamente espiritual como fuerza capaz de generar un nuevo estilo. Encontramos por todas partes necesidades interiores aunque se den de forma aislada: por ejemplo, la necesidad de un espacio para el libre y rítmico movimiento de baile; o para el fervor Dionisíaco por la vida; o para la más absoluta concentración; un lugar para las ceremonias místicas; un lugar donde los observadores de las estrellas pudieran estar en comunión con el firmamento en un estado de paz, sin impedimentos visuales o lumínicos. Si sólo una de esas necesidades se diera, servirían al arquitecto de esperado impulso para reagrupar el organismo de la casa de modo espacialmente dinámico en torno a ese estilo de vida y re-evaluar las relaciones constructivas que de él se derivan. ${ }^{74}$

Se plantea con esto una apertura del entendimiento del tema del hábitat que amplía la noción de función hasta prácticamente eliminar la argumentación científica-moderna. Hasta el momento, más allá de la inspiración en la máquina o en la naturaleza, las concepciones modernas de la función se entendían en base a un pragmatismo que satisficiera las comodidades vinculadas a las actividades de algún modo "estandarizadas" de la vida moderna. El planteo de Ebeling tiene que ver, como él mismo lo menciona, con "necesidades espirituales» que se escapan incluso de lo racional. No se encuentra satisfecho con "la expresión de su tiempo»-y aquí puede encontrarse un diferencia fundamental con la apuesta de Mies- ya que entiende que esto hará que el individuo permanezca en un modo estático, casi como receptor de las condiciones políticas y sociales propias, incapaz de imaginar un escenario diferente.

Por eso, el mayor desafío frente a nosotros para el próximo siglo es evidentemente el cultivo de un nuevo tipo de ser humano donde artista y constructor se encuentre, donde todo ser consciente ansíe y radie una nueva evaluación de sí mismo y de sus conexiones con el misterio del universo. ${ }^{75}$

Aún así el autor reconoce la imposibilidad de conocer el origen de este «núcleo espiritual», es decir, el mismo sí proviene de fuerzas individuales o anónimas, pero se encuentra seguro de afirmar que no puede ser fruto de las condiciones funcionales limitadas de la arquitectura moderna, "...toda arquitectura que tome la funcionalidad pura como base y única aspiración intelectual caducará conjuntamente con la forma de vida que parece sustentarla hoy en día». ${ }^{76}$ El espacio concéntrico y flexible de su proyecto para la Casa circular realizado entre 1930 y 1931 parece una respuesta de exploración en cuanto a lo distributivo; [FG.08] escapando de cualquier indicio de juego o definición formal, opta por la superficie continua e infinita de un cilindro de metal y cristal. Y más llamativa aún resulta su flexibilidad interior, con una distribución desde el 


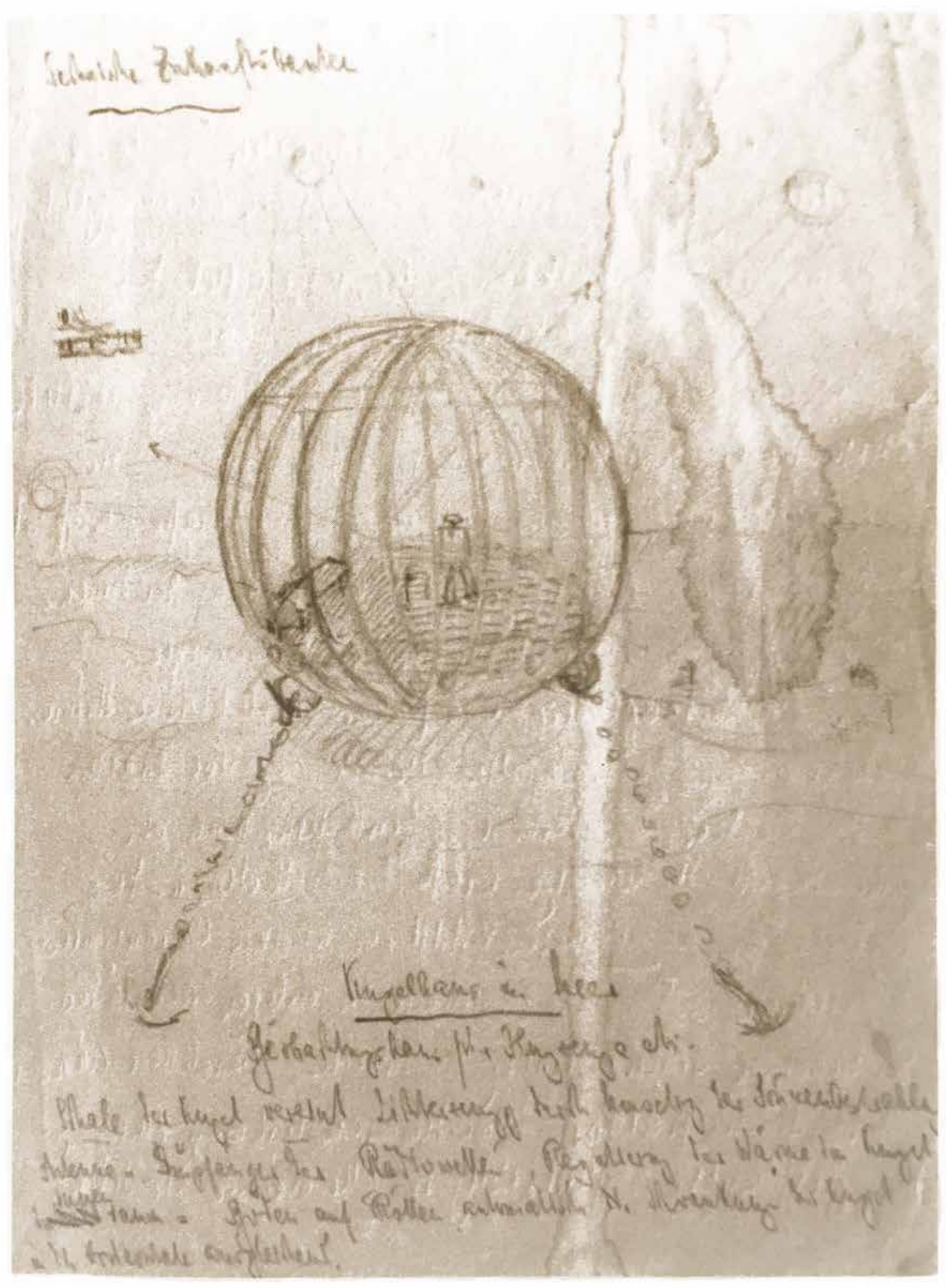


centro -un amplio espacio social indefinido, casi a modo de un patio- y con recintos que bordean el perímetro, los cuales pueden conectarse o desconectarse entre sí. Un esquema que se resumen en un centro al que todos se pueden abrir o cerrar, un diálogo entre lo colectivo y lo individual.

Por otro lado, para Ebeling, el problema yace justamente en que el tema de la función haya sido trasladado a la arquitectura a modo de significado, siguiendo de algún modo esa semilla del decor iniciada por Vitruvio y afianzada posteriomente por la concepción de caractére. Esa "proyección de la vida interior»77 la ve Ebeling en la propia representación de la vivienda o de los distintos modos en los que se presenta el poder (político, religioso, administrativo o burgués); por lo tanto cualquier rasgo de monumentalidad debería quedar deshecho. La «arquitectura biológica», por el contrario, no requeriría de representaciones, sino exclusivamente de apreciaciones sensoriales no simbólicas. Se trata de una percepción que permanece, como él mismo lo menciona, "bajo el umbral de la consciencia», ${ }^{78}$ por lo que el significado busca ser anulado, o al menos intercambiado por un sistema de sensaciones que afecten directamente al cuerpo antes que al lenguaje. Este primer paso se da por medio de las libertades que puede proporcionar la arquitectura mediante la 'flexibilidad'.

La semilla que brinda Ebeling a la noción de lo flexible tiene que ver con la erradicación de una función determinada asignada a un objeto, como en general se ha asentado en la tradición, siendo esta última la que impide la proyección del individuo hacia un modo de vida particular.

Imprimir nuestro estilo de vida a los objetos con eslóganes modernos tales "como voluntad de formalización" o Constructivismo es algo que pertenece al pasado. Todo lo que la arquitectura puede y debe hacer no va más allá del principio de la corteza del árbol o, desde el punto de vista del núcleo de la célula, del principio de la membrana. (...) Para completar e integrar a estas funciones tanto como sea posible, debemos admitir que la funcionalidad y la simplicidad máximas son ambas corolarios de la belleza. ${ }^{79}$

Ebeling no sólo prevé el fin de lo ornamental en la arquitectura, sino también el fin de la arquitectura definida estética o pictóricamente; lo cual implica al mismo tiempo el fin de lo imitativo y el fin del individuo artista. Se trata, de nuevo, de derrumbar cualquier idea de representación. En este punto Ebeling adopta el discurso moderno predominante, y entiende que los materiales industrializados presentan una nueva vertiente que ya no debe ser vinculada a representaciones del pasado; estos materiales presentan el inicio hacia un grado cero de arquitectura, aunque estos no resultarían por sí mismos suficientes.

El desafío más grande es el de concebir las nuevas formas con un nuevo significado, y esto valdría también para la arquitectura moderna predominante, ya que, con un movimiento crítico prematuro, Ebeling observa que los volúmenes puros de la arquitectura moderna resultan deudores directos de lo escultórico, y por lo tanto mantienen una ligazón con lo estético; “...todavía todo es formal, simplificado, si se prefiere, pero nunca sustancial». ${ }^{80}$ Se trata de una mantención del énfasis en la Gestalt (forma), en vez de en el Gehalt (significado).

\section{Nuevo significado}

80.

Ibid. p. 65 . 


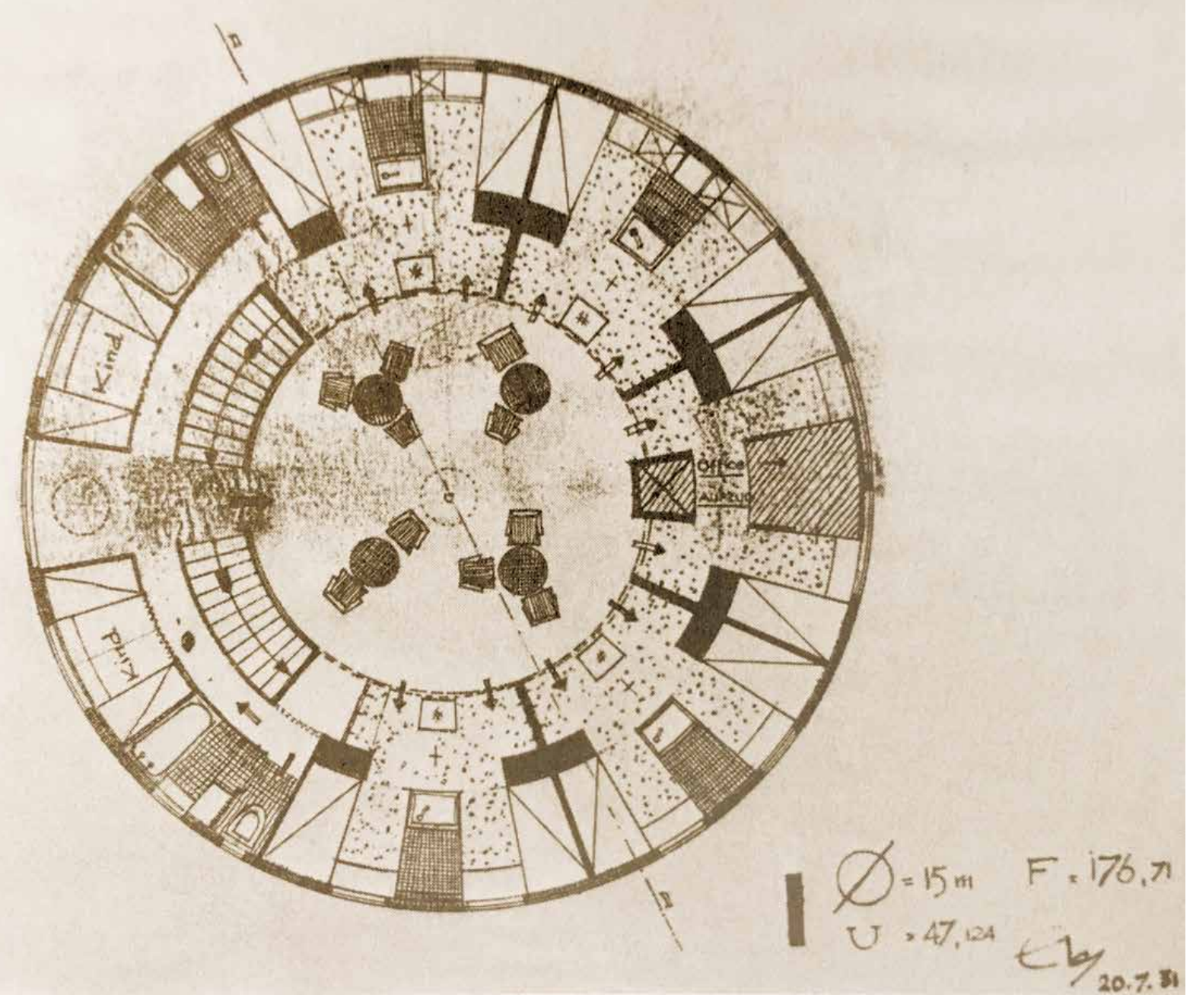


Las obras de ingeniería resultan un modelo casi escultórico para la arquitectura moderna, según Ebeling, y la apropiación conceptual de las mismas es intercambiada por la apropiación estética. Tampoco ve un camino en la estandarización de la vivienda colectiva, la cual entiende como resultado directo de decisiones políticas a raíz de una situación económica, antes que como el diseño del lugar espiritual que la arquitectura necesita. En esta linea critica también la casa estandarizada americana, comercializada como un «todo en uno", en la cual no ve diferencias sustanciales con la vivienda colectiva europea, en la que el arquitecto ha asumido su rol de servicio para una política que tiende al espacio mínimo básico para vivir.

En esta arquitectura Ebeling ve una aproximación al modo cronometrado, de aprovechamiento del rendimiento propio de la máquina, y entiende que este concepto no ha sido incorporado a la arquitectura moderna, en la cual la mayor parte de las traslaciones han sido estéticas. Esta traslación traería, según el autor, una nueva interpretación del espacio desde la máquina, "desde dentro hacia afuera». Aún así, Ebeling no deshecha completamente la estética propia de la máquina, sino que no se conforma con que esta sea el inicio y el fin del proceso de diseño. Según el mismo autor:

\section{...esta crítica no excluye la posibilidad de que esos esfuerzos aporten en algún momento una fuerza plástica que sea capaz de dar una respuesta que se co- rresponda con la estructura psicológica de las diferentes clases sociales. Esta reforma interna del núcleo central de la arquitectura es algo que debemos es- perar que suceda únicamente de forma gradual. ${ }^{81}$ \\ En resumen, el escrito de Ebeling está más centrado en discutir la esen-} cia de la vida en los edificios que en descubrir nuevas estrategias espaciales o formales, probablemente porque, del mismo modo que lo hacía Ginzburg o Häring, entiende que estas últimas se darían naturalmente una vez construidos los presupuestos basados en el entendimiento de un modo de vida particular. La interpretación, y al mismo tiempo la definición de este modo de vida es el cometido del texto, pero al mismo tiempo es la base para resignificar la propia arquitectura y su espacio. El "espacio-membrana" de Ebeling, como comenta Spyros Papapetros ${ }^{82}$ no termina en una envolvente sensible a la luz; ese es sólo el comienzo de una estratificación interior que afecta no sólo a la visual, sino al resto de los sentidos hasta discutir la propia cultura de la vida doméstica.

Los textos más importantes de Mies van der Rohe corresponden a su período en Alemania, y a su vez pueden dividirse entre los de una primera etapa que acompaña a la publicación de sus proyectos para rascacielos y edificios de oficinas, de 1922 y 1923, y los de una segunda etapa que se corresponde con la madurez de su propuesta teórica, entre 1926 a 1928.

Con mucha probabilidad la función en Mies cobra relevancia por la importancia histórica de su obra antes que por sus escritos. O podría decirse que estos últimos resultan importantes dado el aporte fundamental de sus edificios no sólo a la arquitectura moderna, sino también a la definición de una nueva concepción funcional. En tal caso, los textos de Mies resultan breves en cuanto a las referencias a la función, a la que suele tratar de un modo general.
82.

Ver Papapetros, Spyros, "Pieles Futuras," en El espacio como membrana, ed. Avilés, Pep (Barcelona: SD Ediciones, 2015), p. 17. (Ed. orig. 2010).

\section{3.}

Franz Schulze hace hincapié en la especial camaradería que Mies y van Doesburg compartían en los tiempos de trabajo con la revista G. Ver Schulze, Franz, Mies van der Rohe: una biografía crítica (Barcelona: Hermann Blume, 1986). (Ed. orig. 1985).

84.

van Doesburg, Theo, "17 puntos para una arquitectura neoplasticista,” De StijI XII, (1924).
2.3.6.

Mies. Indeterminación 
Al mismo tiempo en los mismos es posible entrever su interés por un tema paralelo, que aunque él nunca vincule directamente al problema de la función, puede entenderse como parte de su argumentación: el de la preocupación por los modos de vida de los usuarios, sus posibilidades individuales y la forma en que la arquitectura los afecta. Asimismo, la noción de 'flexibilidad' en la función miesiana encuentra una cercanía inevitable con los movimientos de vanguardia rusos y neerlandeses, con quienes Mies mantuvo una fuerte relación.

\subsection{6.a. Van Doesburg. Lo informe}

Aunque no quedará plasmado en ninguno de sus textos la influencia de De Stijl en la visión que Mies tendrá sobre la 'flexibilidad' resulta evidente. Su cercanía con Theo van Doesburg, ${ }^{83}$ con quien editará, junto a El Lissitzky y Hans Richter la revista G desde 1923 resultará crucial; el propio Van Doesburg ya había iniciado varios años antes el movimiento De Stijl junto a Piet Mondrian en 1917.

A pesar de que las actuaciones de van Doesburg fueron mucho más efectivas y coherentes en la pintura y en la escritura que en la propia arquitectura, consigue el que será con probabilidad el texto más claro y pragmático en cuanto a la conceptualización de la 'flexibilidad' en arquitectura; se trata de "17 puntos para una arquitectura neoplasticista", publicado en el número XII de la revista De Stijl en 1924 -en el mismo año que pinta 'Construcción espacio-temporal." En esta última pintura se visualiza con claridad lo que en el mismo texto estaba exponiendo acerca del rol de la forma y el espacio, y cómo este podía afectar el propio modo de vivir. Logra definir con precisión la idea más básica de 'flexibilidad' en la arquitectura moderna cuando describe "Lo informe", "La planta” y “la subdivisión." En el punto 5, titulado “Lo informe”, van Doesburgafirma la separación de una arquitectura "definida" formalmente:

La nueva arquitectura es informe, pero al mismo tiempo bien determinada. No reconoce un esquema a priori, un molde en el que volcar los espacios funcionales. Al contrario de todos los estilos del pasado, el nuevo método arquitectónico no conoce tipos fundamentales e inmutables. La división y subdivisión de los espacios interiores y exteriores se determinan rígidamente por medio de planos que no tienen una forma individual. Estos planos pueden extenderse hasta el infinito, por todos los lados y sin interrupción. El resultado es un sistema en cadena en el que los diferentes puntos corresponden a una misma cantidad de puntos en el espacio general; porque existe una relación entre los diferentes planos y el espacio exterior. ${ }^{84}$

En este caso el autor remite a la idea universal original de De Stijl, un espacio infinito sugerido por planos relacionados pero no necesariamente conectados que no encuentran un final, el cual queda claramente plasmado en su obra pictórica. [FG.09] Este espacio etéreo -cercano al descrito por Ebeling y posteriormente materializado por Mies- encuentra su modo de transcripción en la planta de arquitectura. En el punto 8 del mismo texto van Doesburgafirma que

La nueva arquitectura ha destruido la pared en el sentido que suprime el dualismo entre interior y exterior. Las paredes ya no sostienen, se han convertido en puntos de apoyo. De ello resulta una nueva planta, una planta abierta; 
totalmente distinta de la del clasicismo, porque los espacios interiores y exteriores se comunican. ${ }^{85}$

Así es que por medio de la subdivisión de los espacios queda definida la 'flexibilidad' en la planta. A este respecto se posiciona claramente en la descripción que realiza sobre la noción de "subdivisión», en el punto 9,

La nueva arquitectura es abierta en lugar de cerrada. El conjunto consiste en un espacio general, que se subdivide en distintos espacios que se refieren al confort de la vivienda. Esta subdivisión se realiza a través de planos de separación (interior) y de planos de cerramiento (exterior). Los primeros, que separan los espacios funcionales, pueden ser muebles, es decir, pueden ser mamparas móviles (entre las que podemos incluir las puertas). ${ }^{86}$

Al mismo tiempo la eficacia de estas palabras se ven traducidas en la reconocida obra que Gerrit Rietveld construyera también en 1924; la casa Schroeder será un paradigma de la flexibilidad y del movimiento del propio objeto en pos de contener diversas formas de incluir el habitar. Desde su representación axonométrica, [FG.10] tan cercana a la pintura anteriormente mencionada, la obra de Rietveld pone por primera vez al mobiliario en el mismo nivel de jerarquía que la estructura del edificio. El mobiliario, ese objeto que desafía lo estático y que hace referencia directa a la necesidad, es considerado según su capacidad de movimiento para transformar el espacio. Así se encuentran paneles correderos, que permiten una modificación cabal, mutando de un espacio compartimentado a un espacio único, completamente abierto.

Ver van der Rohe, Ludwig Mies, "Edificio de oficinas," en Mies van der Rohe: la palabra sin artificio: reflexiones sobre arquitectura, 1922-1968, ed. Neumeyer, Fritz (Madrid: El Croquis, 1995). (Ed. orig. 1923).

88. Ibid. p. 364 .

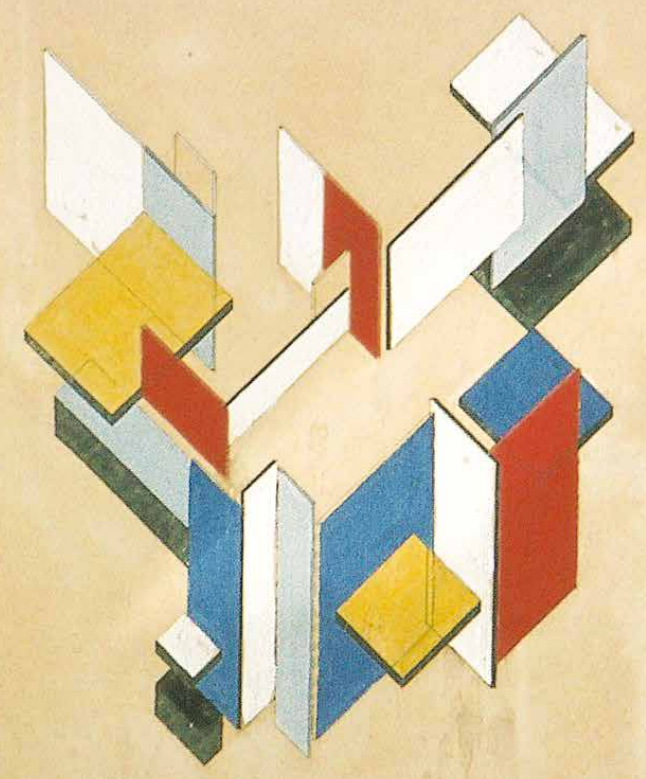


La 'flexibilidad' será interpretada de una manera diferente por Mies, quien no apelará a este tipo de transformaciones físicas, aunque el lenguaje espacial de planos independientes -el cual de alguna manera ya había comenzado con Wright en Estados Unidos- será su marca, y definirá un lenguaje propio para la 'flexibilidad' en los años veinte.

2.3.6.b. El escueto texto de Mies "Bürohaus" publicado en el primer número de la revista G podría entenderse como un segundo paso a partir de "The tall office building artistically considered" de Sullivan. Si el norteamericano había expuesto las condicionantes económicas, técnicas y sociales para el edificio de oficinas, intentando a su vez definir las posibilidades arquitectónicas del objeto, Mies haría una interpretación que podría considerarse casi definitiva en cuanto a la materialidad (hormigón, acero y cristal), espacialidad (grandes espacios diáfanos y abiertos) y, sobre todo, función (interior continuo sin subdivisiones) ${ }^{87}$ del programa de oficinas. Tanto la estructura como la materialidad conforman el corazón de la arquitectura, y refieren a un espacio simple y diáfano, que sienta las bases para el desarrollo de un espacio continuo, flexible y neutral. En una versión revisada del mismo texto que no llegó a ser publicada Mies avanza aún más, afirmando que

La arquitectura moderna hace ya tiempo que ha dejado de limitarse a jugar en nuestra vida un papel decorativo. Los arquitectos creativos no quieren tener nada que ver con las tradiciones estéticas de siglos anteriores. (...) Su actividad ha de servir a la vida. El maestro de los arquitectos sólo puede ser la vida. ${ }^{88}$

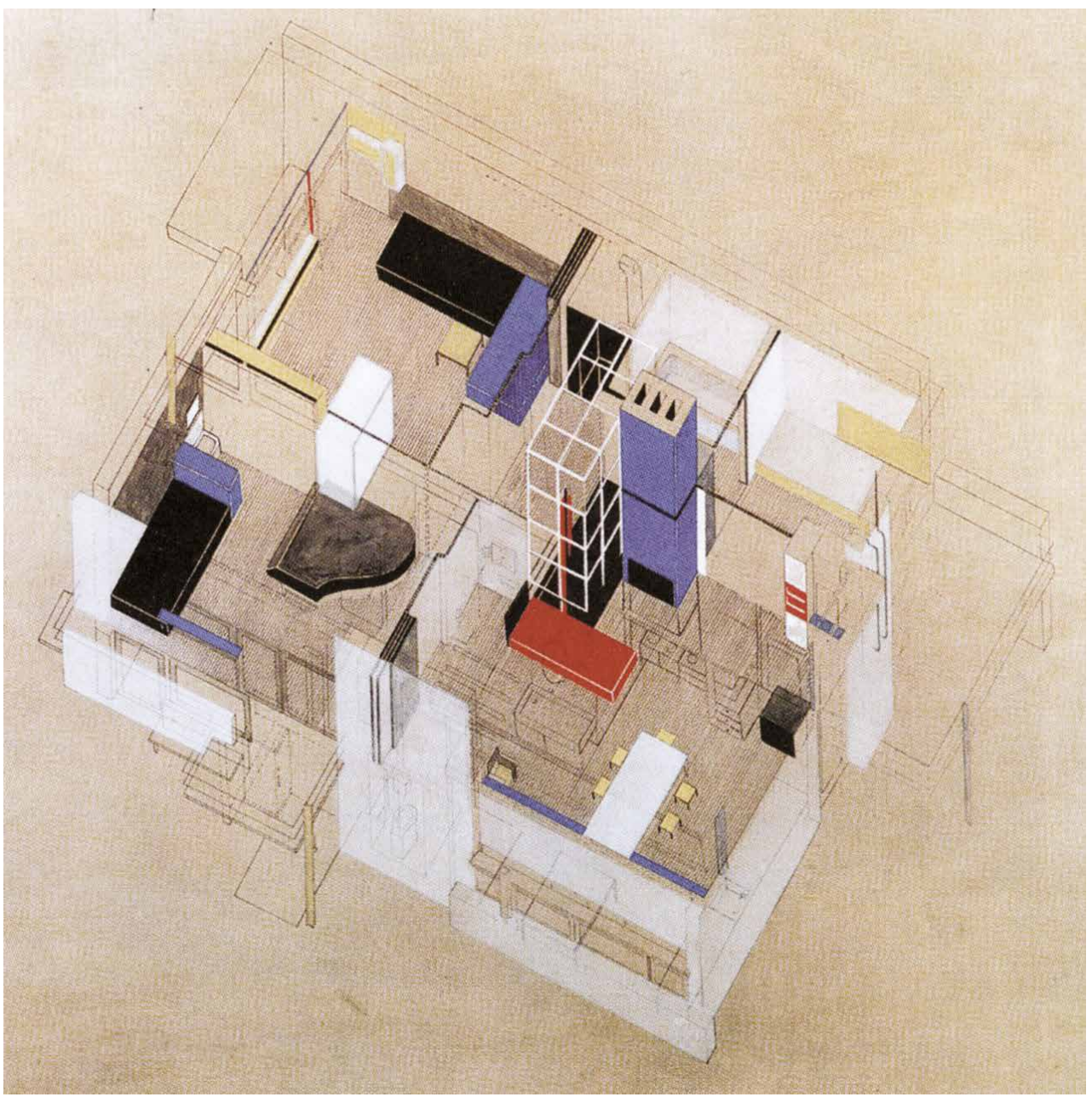


En la misma linea, en una conferencia de 1926 de la que se desconoce su cometido Mies afirma que:

Platón ya reconoció el cambio de formas del estado y de la sociedad y opinaba que la causa de esa transformación se debía a un cambio en la transformación del alma del pueblo, que configura el estado y la sociedad, mientras que el alma a su vez es influido por la forma de vida. ${ }^{89}$

\section{(...)}

Dos grandes campos de la arquitectura se encuentran ante nosotros, al observar la evolución histórica de la arquitectura. El primero apenas abarca la arquitectura para la vida, pero el segundo está estrechamente vinculado a atmósferas espirituales muy determinadas, que percibimos como culturas bien perfiladas.

Las construcciones del primer tipo están vinculadas al suelo sobre el que se levantan, ellas y sólo ellas son realmente autóctonas. Se han formalizado a partir de los materiales del lugar. Sus formas no han sido inventadas, sino que han crecido, (...) a partir de las necesidades de sus habitantes y muestran cómo en ellas subyace el tacto y el carácter del paisaje. Estas características son típicas de todas las casas campesinas, independientemente del lugar geográfico donde se encuentren. Sus diferencias son consecuencias de diferentes características raciales. Pero todas ellas satisfacen mediante vivienda, establo y granero las costumbres de sus habitantes. ${ }^{90}$

El autor espera que el propio tiempo propicie unos nuevos modos de vida (Lebenwiesen) y que naturalmente estos se traspasen a las maneras de habitar y de producir arquitectura. Puede notarse en sus primeros textos una genuina oposición a lo que llama "las viejas formas de vida", las cuales no describe pero se da por hecho que corresponden a lo artificioso de la vida burguesa, propia de fines del siglo XIX. La confianza de Mies radica en que un mundo industrializado hará estallar naturalmente diferentes Lebenwiesen. A diferencia de sus coetáneos modernos alemanes, Häring o Meyer, los escritos de Mies se mantienen en el plano de la generalidad, y nunca se sumergen en el detalle de esos modos de vida heredados a los que repele; cuando llega el momento de comentar cómo los Lebenwiesen se transformarían y adaptarían a las condiciones actuales, paradójicamente vuelve a lo primitivo, a la referencia a la cabaña como refugio básico, y a un habitar despojado. Probablemente en este punto yace la raíz conceptual de la función miesiana, y gran parte del modo de entender la noción de 'flexibilidad' moderna. La tecnología, entendida de un modo simplificado en la arquitectura a través de la aplicación de hormigón, acero y vidrio, permitiría un Lebenwiesen despojado de todo elemento agregado, es decir, la tecnología aplicada exclusivamente a un esqueleto y envolvente mínimos y esenciales permitiría que su negativo, el espacio, se liberara en un continuo vacío. Tan esencial resulta la estructura como la vida misma, y tan agregados resultan los ornamentos como la separación de la vida en ambientes estancos diseñados para cada actividad. La' flexibilidad' en Mies no aparece así por la búsqueda de una optimización funcional, sino por un motivo más general y profundo, vinculado igualmente a los intereses que Ebeling
"Conferencia (1926)," en ibid., p. 383. (Ed. orig. 1926).

90. Ibid. p. 385.

91. "Sobre la forma en arquitectura," en ibid., p. 393. (Ed. orig. 1927)

92.

Mies van der Rohe, Ludwing, "Sobre mi bloque de viviendas," en ibid., p. 396. (Ed. orig. 1927)

93.

Colquhoun, La arquitectura moderna: una historia desapasionada, p. 172 
había expuesto, es decir, el de la construcción de un espacio neutral para el ser, que al mismo tiempo no responda a características particulares, sino que base su calidad en la esencia y en lo básico del ser humano.

Sólo la intensidad vital puede tener intensidad formal.

Todo cómo ha de apoyarse en un qué.

Lo no formalizado no es peor que el exceso de forma.

Lo primero no es nada y lo segundo es apariencia.

La verdadera forma presupone una vida verdadera.

Pero ninguna vida pasada, ni tampoco ninguna vida imaginada. ${ }^{91}$

Mies apela a un habitar que, como él mismo lo expresa, permita el desarrollo del espíritu, que logre conectar con el habitante sin dejar de ser universal. En su traslación al espacio y a la misma función pareciera entender que esta idea etérea requiere de un enfrentamiento con el vacío, con la nada, que conduzca a una auto-realización. Un espacio que por su misma ingravidez evite la reminiscencia a cualquier actividad reconocida, a casi cualquier rastro de cultura, y se mantenga suspendido en una nada, que debe ser poco a poco invadida por las cualidades propias del habitante. En resumen, se trata de liberar al espacio de cualquier connotación y referencia para que el mismo pueda ser llenado con la propia voluntad. La concepción de Mies trasciende la 'flexibilidad' para avanzar hacia una neutralidad funcional.

Uno de los únicos momentos donde Mies refiere directamente -aunque tan solo sea de modo breve- a la noción de 'flexibilidad' es cuando publica su memoria sobre el proyecto para viviendas en Stuttgart:

En la actualidad, los motivos económicos exigen racionalizar y normalizar la construcción de viviendas de alquiler. Pero por otra parte, esta creciente diferenciación de nuestros requisitos de habitabilidad exige mayor libertad en el tipo de uso. En el futuro será necesario hacer justicia a ambos aspectos. La construcción de un esqueleto es el sistema estructural más apropiado para ello. Permite una ejecución racional y deja completa libertad para dividir el espacio interior. Si nos limitamos a configurar sólo el baño y la cocina como espacios constantes, debido a sus instalaciones, y optamos por dividir el resto de la superficie habitable con paredes móviles, creo que se puede satisfacer cualquier requisito de habitabilidad. ${ }^{92}$

Con esta expresión adelanta las estrategias que utilizaría en la mayor parte de sus obras en su etapa de Chicago: en sintonía con la distribución simple de los rascacielos de fines del s.XIX construidos en la ciudad, la conocida definición de un núcleo de servicios que libere el resto del espacio le permitiría desarrollar desde viviendas a museos apelando a la misma estrategia y apuntalando aún más la 'flexibilidad' hasta alcanzar la completa neutralidad. Como menciona Colquhoun sobre Mies, “...las formas neutras podían crear sistemas lo bastante flexibles como para responder a cualquier situación vital imaginable, y así cada edificio podía adoptar una configuración singular aunque estuviese hecho con elementos similares". ${ }^{93}$

A pesar de su particular planteamiento, Mies no desarrolla una acep- 
traducido al inglés como function -la misma traducción que llevaría el libro de Behne-, se remite a explicar que su arquitectura resulta de la atención a un propósito, a pesar de que su entendimiento del problema sea tan dispar al de la mayoría de sus pares contemporáneos, y de que justamente en su caso podría decirse que esquiva cualquier intención de propósito particular. Aún así Mies sí incorpora en muchas de sus memorias la noción de Freiheit (libertad), sobre todo al referirse a las posibilidades constructivas del hierro y el vidrio.

En varias de sus conferencias y textos el hace referencia también a la arquitectura medieval; entiende que en el medievo se propone un nuevo orden sobre el de la arquitectura de la antigüedad. En la Edad Media cambian Ios Lebewiesen y se genera, a partir de este mismo cambio, un sistema arquitectónico acorde. Esta observación le da pie a comparar aquella situación con la del individuo de comienzos del siglo XX, cuando afirma que "Si en la Edad Media el hombre estaba ligado interior y exteriormente a la sociedad, ahora aparece una fuerte emancipación del individuo, que divisa su derecho en la configuración de sus propios proyectos y en el desarrollo de sus fuerzas". ${ }^{94}$ En este mismo texto de 1928 Mies explica que la ciencia moderna se encuentra al servicio de la técnica y no de la vida; en el mundo de la técnica poco a poco todo va pareciendo posible, y todo se subordina a la propia técnica.

Tenemos que dominar las fuerzas desatadas e incorporarlas a un nuevo orden, y precisamente a un orden que deje suficiente espacio libre a la vida para que pueda desarrollarse. Sí, un orden nuevo pero que esté relacionado con los hombres (...) Ha de ser posible resolver la tarea de dominar la naturaleza y al mismo tiempo crear una nueva libertad..$^{95}$

La creencia ciega del autor en la técnica tendría que ver con la esperanza de que ésta última creciera en favor de mejorar las condiciones de vida de las personas, evitando la técnica por la técnica misma. Es en este período que Mies centra su atención en la construcción pura, entendiendo que la misma, por sí sola, puede llevar a un resultado formal satisfactorio y sin tener que ser este último necesariamente buscado; al mismo tiempo una construcción pura otorga también una deseada permanencia en el tiempo de su arquitectura. ${ }^{96}$ El valor de una buena construcción que permita perdurar en el tiempo ofrece la posibilidad -visualizada ya por Ruskin- de que un objeto pueda asumir las necesidades funcionales cambiantes de la sociedad. La introducción al artículo "Bauen" de 1923, escrito con la finalidad de acentuar la construcción por sobre el formalismo, quizás sea el texto de Mies más citado; en él expresa su voluntad de alejarse de cualquier problema formal para centrarse esencialmente en la construcción, "La verdadera plenitud de la forma está condicionada, está entremezclada con la propia tarea, sí es la expresión elemental de su solución»97 Este artículo sirvió también a Mies para difundir su proyecto de Casa de campo en hormigón armado, del mismo año, en el que queda patente la influencia de Wright en la distribución de los espacios. Exceptuando el proyecto para un edificio de oficinas, también de 1923, el espacio continuo y fluido de Mies estaba en estos primeros años más sugerido en sus palabras, por medio de la búsqueda de una construcción simple y honesta, que materializado en
Mies van der Rohe, Ludwig, "Los requisitos de la creatividad arquitectónica," en Mies Van Der Rohe: La Palabra Sin Artificio: Reflexiones Sobre Arquitectura, 1922-1968, ed. Neumeyer, Fritz (Madrid: El Croquis, 1995), p. 455. (Ed. orig. 1928).

95. Ibid. p. 456-57.

\subsection{6.c.}

\section{Construcción pura}

96.

Ver Damián Plouganou, “La nave del tiempo. El edificio de oficinas y la indeterminación funcional," (2019).

97.

Mies van der Rohe, Ludwig, "Construir," en Mies Van Der Rohe: La Palabra Sin Artificio: Reflexiones Sobre Arquitectura, 1922-1968, ed. Neumeyer, Fritz (Madrid: El Croquis, 1995), p. 366. (Ed. orig. 1923)

98.

"Tareas resueltas. Una exigencia a nuestra manera de construcción," en ibid. p. 369. (Ed. orig. 1923)

99.

"iArquitectura y voluntad de época!," en ibid. p. 371. (Ed. orig. 1924)

100.

"Conferencia," en ibid. p. 380. (Ed. orig. 1926)

101.

Ver Mies van der Rohe, Ludwig, "Grandes almacenes Adam," ibid., p. 461. (Ed. orig. 1928).

102.

Mies, dirigiéndose al propio cliente dice "Si se me permite expresar con toda franqueza mis convicciones, creo que un edificio no tiene nada que ver con orientaciones estéticas, sino que únicamente ha de ser el resultado de todas las exigencias que se desprenden de sus fines de utilización". Ibid.

103.

Ver Liernur, Jorge Francisco, "Menos es mísero. Notas sobre la recepción de la arquitectura de Mies van der Rohe en América Latina," Revista de arquitectura, (2003): p. 32. 
un proyecto concreto. Resulta bastante evidente que las intenciones de Mies en cuanto a la construcción estaban claras y que aún no se presentaba un escenario propicio para desarrollarlas. Los artículos de este período, como ya se ha comentado, disparaban intensamente contra la arquitectura de motivos historicistas que aún dominaba la mayor parte del panorama alemán. En una conferencia de 1923, además de exigir que "al proyectar edificios de vivienda se parta exclusivamente de organizar el vivir» ${ }^{98}$ enumera una serie de referencias base, cuyas primeras seis son una vivienda típica nomáda, una cabaña de hojas de un indio, una casa de esquimales, una cabaña en la nieve y una cabaña de verano de un esquimal, es decir, una serie de refugios primitivos.

Por medio de estos textos es posible afirmar que una parte esencial de lo que define el vacío impersonal de la función en la arquitectura de Mies -y con esto la 'flexibilidad' funcional que la identifica- tiene que ver con su constante referencia a la construcción anónima medieval, donde no existía el arquitecto autor, "creaciones de una época entera y no de una persona determinada (...) Estas construcciones son en su esencia completamente impersonales". ${ }^{99}$ Al mismo tiempo de asumir la neutralidad de la construcción primitiva Mies se apoya en referencias modernas, siendo la de Wright la más importante en este primer período en Alemania, en cuanto a su concepción espacial se refiere. Cuando en los bocetos para una conferencia no realizada en 1926 habla de su proyecto para una vivienda de ladrillos [FG.11] dice, "En la planta de esta casa he abandonado el sistema usual de delimitar los espacios interiores, para conseguir una secuencia de efectos espaciales en vez de una serie de espacios singulares. Aquí la pared pierde su carácter de cerramiento y sirve sólo para estructurar el organismo de la vivienda». ${ }^{100}$ Así, la construcción ha perdido su carácter esencial en favor de una espacio continuo y flexible; como se ha mencionado en muchas ocasiones, la referencia al espacio wrightiano resulta evidente.

2.3.6.d. Con el proyecto de 1928 para los almacenes Adams en Berlin Mies reflexiona Neutralidad tempranamente sobre el problema de la 'flexibilidad' al mismo tiempo que hereda la concepción de commodité de Laugier liberando por completo al muro de su función estructural, [FG.12] guiado naturalmente por la condición propia del programa, en donde asume que la variabilidad que el mismo cliente exige es conseguida traspasando la estructura vertical al perímetro del edificio; liberando también el interior, que sólo se ve atravesado por tres núcleos de escaleras. ${ }^{101}$ Aunque el mismo Mies entienda que el edificio atiende únicamente a su cometido, ${ }^{102}$ la frágil piel de vidrio translúcido propuesta resulta en una homogeneidad que responde con una evidente coherencia formal a la neutralidad funcional del mismo. Más allá de que pueda entenderse que la condición de caractére quede eliminada definitivamente en la obra de Mies ${ }^{103}$ al mismo tiempo es posible asumir que existe una búsqueda por expresar la neutralidad, o más bien el caractére de lo neutral. Es decir, al mismo tiempo que se busca un espacio que no remita a una función específica, se busca una forma que no remita a un significado, o al menos que el significado remita, justamente, a la 


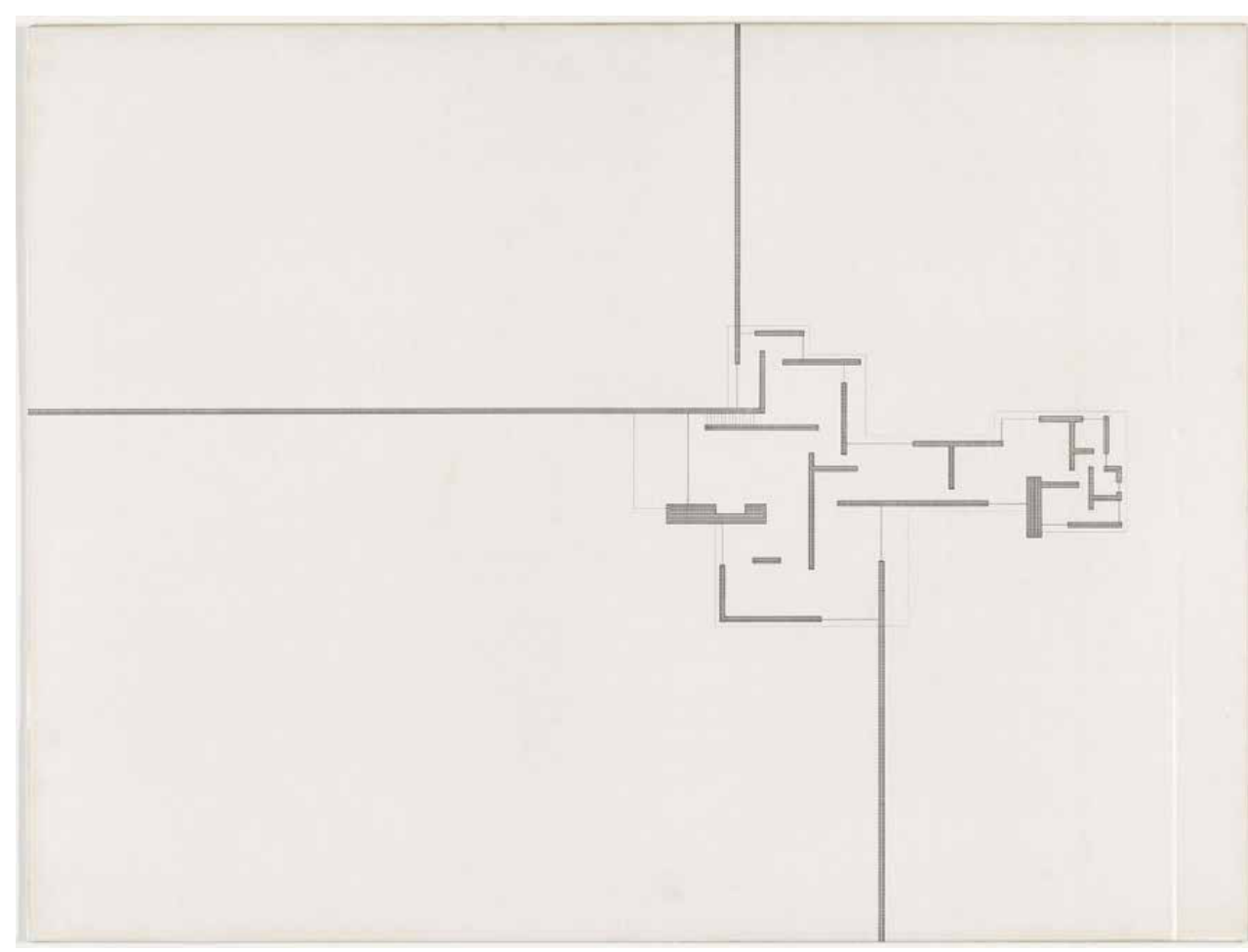

Norberg-Schulz, Christian, "Una conversación con Mies van der Rohe," ibid., p. 514. (Ed. orig. 1958).

[FG.11]

Mies van der Rohe

Casa de Ladrillos. Planta

Nueva York: MoMA,

1923.

más sencillas, tiene su origen en la utilidad, pero, a través de toda la escala de valores, se extiende hasta el campo de la existencia espiritual, el campo de los significados, y la esfera del arte puro.»104 Y en una tardía conversación con Norberg-Schulz en Chicago Mies también resume "Pretendo que mis edificios sean marcos neutros donde los hombres y las obras de arte puedan llevar su propia vida (...) deberíamos esforzarnos por conseguir establecer una mayor armonía entre naturaleza, vivienda y hombre.»105 Este "marco neutro» no resulta ni más ni menos que la negación rotunda del principio clásico de la función propuesto por Alberti, en el cual, para alcanzar la commoditas, resultaría necesario la estricta separación de usos en los edificios.

Si algo diferencia las experiencias renovadoras de los años cincuenta de la arquitectura moderna de los años veinte es que las primeras intercambian el 2.3.7. anhelo vanguardista de transformación a gran escala de las segundas por un nuevo realismo antropológico. Se trata, al fin y al cabo, de repensar al usuario abstracto del Plan Voisin asignándole una identidad, intentando indagar en las complejidades de la vida diaria y de lo que constituye el valor de lo cotidiano. El desafío que se propondrá el Team X tendrá que ver con una última posibilidad de recuperar los valores humanistas de la arquitectura moderna y de demostrar que determinadas estrategias de proyecto pueden mejorar la vida no sólo de los usuarios puntuales, sino de la sociedad en general. Siguiendo la linea de la 'flexibilidad' son propuestas que no están guiadas por una poética del espacio o una búsqueda de composición formal; de algún modo ciertos temas históricos de la arquitectura, como la búsqueda de la belleza, se dejan en un segundo plano para concentrarse en los problemas de índole colectiva o urbana mucho más cercanos a la función efectiva. 
Aldo Van Eyck -quien gozó de una formación multicultural, habiendo nacido en Holanda, crecido en Inglaterra pero estudiado la carrera de arquitecto en la Eidgenössische Technische Hochschule de Zurich- cuenta con una gran variedad de interesas además de la arquitectura. Sus campos de influencia resultan a su vez, en comparación a otros miembros del propio Team X, muy extensos, abordando en sus escritos y producción una gran cantidad de problemas, destacándose sobre todo su participación en la revista holandesa Forum, en la que publicó importantes artículos, especialmente entre 1959 y 1963. Sus intereses, entre los que se cuentan el arte, las matemáticas o las ruinas de los pueblos aborígenes, también se veían reflejados en su práctica arquitectónica; van Eyck estaba preocupado por indagar en un lenguaje arquitectónico con una estética propia, esto queda demostrado también en su admiración por la obra de Gerrit Rietveld, a quien consideraba uno de los arquitectos modernos más importantes. La influencia de De Stijl es notable en el modo en que van Eyck concibe la 'flexibilidad' espacial y el desmembramiento de su arquitectura en planos abstractos es clara deudora de Rietveld, sobre todo en la casa Schroeder. La cercanía de van Eyck con el mundo del arte impregna su obra y pensamiento desde el punto de vista plástico e intelectual; parte de esto tiene que ver conque, aunque oficialmente no formaba parte de él, van Eyck estuvo involucrado también, desde el principio, en las actividades del grupo de artistas neerlandeses Cobra, a fines de la década del cuarenta, relacionados a cierto surrealismo cercano a Klee o Miró.

Por otro lado van Eyck desarrolla desde muy temprano una sensibi-

[FG.12] Mies van der Rohe

Almacenes Adams Nueva York: MoMA, 1928. lidad sobre el modo en que las ciudades, tanto a pequeña y gran escala, son habitadas, y sobre el modo efectivo en que se desarrolla su funcionamiento. De algún modo se contenta con elaborar estrategias funcionales generales, sino

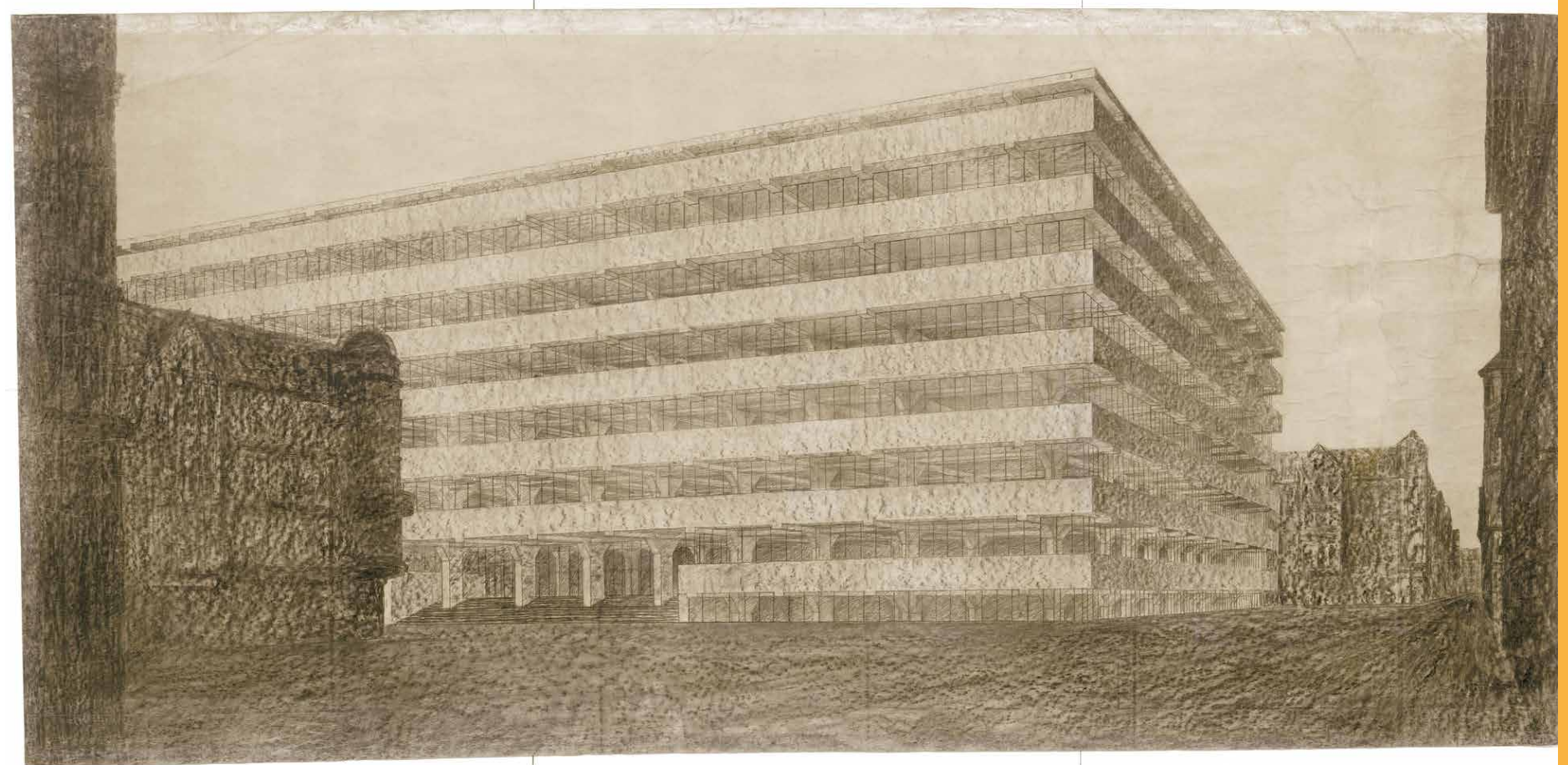


que busca adentrarse en los detalles de los modos de apropiación, tanto del espacio colectivo como del individual. Esto lo conectará directamente con los intereses del Team $X$-algunos de sus miembros ya lo habían puesto en práctica en Inglaterra, a través de las acciones del Independent Group- y le llevará a producir una serie de hipótesis sobre la función, tanto en el plano teórico como práctico, que marcarán una diferencia ya notable con la primer generación de arquitectos modernos.

Una de las primeras acciones importantes de van Eyck tiene que ver con su participación en el sexto CIAM de 1947, en el que hace un llamado a la «imaginación» como herramienta para el descubrimiento de un espíritu nuevo. Según el autor, es la esencia de la propia existencia la que la arquitectura moderna estaba dejando de lado por seguir estancados en solucionar las necesidades materiales, las cuales considera una mera "necesidad primaria». Van Eyck desarrolla este tema en su artículo "We discover style," de 1949, cuando dice que esta «imaginación» es el único remedio sobre una razón que ya ha impregnado la mayor parte de los campos del conocimiento, incluida la arquitectura. Para el autor, el triunfo de la razón se ha interpuesto entre la naturaleza y el hombre de un modo destructivo. ${ }^{106}$ En este sentido identifica las "funciones tangibles" que, como un necessitas, están orientadas de una forma completamente racional a satisfacer las necesidades puntuales:

Las funciones más tangibles son relevantes sólo en la medida en que se ajustan a un entorno con mayor precisión en relación a las tendencias elementales de la humanidad. Lo cual no es más que un requisito previo para el cumplimiento del propósito superior. ${ }^{107}$

Van Eyck se presenta desde el inicio como uno de los arquitectos jóvenes más críticos con el CIAM; reclama a los participantes más importantes -entre quienes se encontraban entre muchos otros Le Corbusier, Sert, Giedion o Gropius- abandonar la concepción "racionalista y mecanicista» por una nueva, que se concentre en mejorar el entorno humano en su modo más esencial. En algún punto existe una cercanía entre este reclamo de van Eyck y el de la «humanización» que a su vez planteaba Aalto -quien también participó en dicho congreso. La puntualización en la «imaginación» iba en contra de las concepciones de 'eficacia' y 'adaptación' funcional a favor de una 'flexibilidad' que no se conformara con lo neutral sino que pudiera resaltar la identidad del usuario. Un acercamiento, no sólo a nivel de escala, sino también a nivel de compromiso con respecto a identificar y dar solución a los problemas concretos del habitar

Si algún hecho le permite a van Eyck avanzar en esta dirección es el particular y temprano encargo de largo término por parte del municipio de Amsterdam para diseñar plazas de juegos para niños (playgrounds) -nada menos que 736 plazas, las cuales diseñó entre 1947 y $1978 .{ }^{108}$ Estos proyectos significaron un importante trampolín para la concepción de la función por parte del autor y para dar a entender cómo esta «imaginación» podía expresarse de un modo productivo sin seguir los patrones modernos que el CIAM planteaba. De un modo análogo a como el sanatorio de Paimio significó un antes y un después
106.

van Eyck, Aldo, "We discover style," en Aldo van Eyck: collected articles and other writings. 1947-1998, ed. Ligtelijn, Vincent; Strauven, Francis (Delft: SUN Publishers, 2008), p. 43. (Ed. orig. 1949).

107.

"Intervention at CIAM 6, Bridgwater 1947," en Aldo van Eyck: collected articles and other writings. 1947-1998, ed. Ligtelijn, Vincent; Strauven, Francis (Delft: SUN Publishers,

\subsection{7.a}

\section{Imaginación}

2008), p. 40. (Ed. orig. 1947).

108.

Ver "Introduction to chapter 4," en ibid., p. 100.

109

"Child and city," en ibid. p. 104. (Ed. orig. 1950) 110.

"On the design of play equipment and the arrangement of playgrounds," en ibid. p. 112 (Ed. orig. 1962) 
en la carrera de Aalto, los playgrounds Ilevaron a van Eyck a una obligada reinterpretación del modo en que se concibe una actividad humana en el marco urbano. [FG.13] Estas reflexiones se volcaron en algunos artículos. El primero fue "Child and city", de 1950, en el que el autor llama a considerar la arquitectura desde el punto de vista del niño y busca integrar esta mirada al resto de la sociedad. Van Eyck afirma, "tengo poca fe en las soluciones que, aunque inicialmente bien intencionadas, intentan adaptar la ciudad al niño aislándolos parcialmente -y a veces casi por completo- en típicos patios cerrados, retirados de la escena urbana». ${ }^{109}$ El autor confía plenamente en que la energía de los niños, canalizada hacia la arquitectura, sería capaz de recuperar la identidad de los lugares, ya que los propios niños son capaces de encontrar interés en los rincones menos esperados, en lo pasajero, a través de la emoción. Esa capacidad de "utilización de lo no utilizable," es lo que diferencia al niño del adulto en cuanto a «imaginación» y permite entender los espacios de un modo lúdico y abierto. Van Eyck transfiere esta visión a los elementos que conforman sus plazas de juegos, utilizando diferentes geometrías que, sin implicar un modo de uso definido, son capaces de sugerir diferentes modos de apropiación. [FG.14] Al mismo tiempo, como el autor describe en "On the design of play equipment and the arrangement of playgrounds" de 1963, esto requiere de un movimiento por parte del arquitecto para acercarse a esa mirada no considerada:

Lo especial de estos playgrounds es que no pertenecen exclusivamente a los niños. (...) muchos arquitectos y planificadores intentan poner todo en orden. Las funciones entran en conflicto entre sí y esto puede significar, por poner un ejemplo, que los niños no pueden dar saltos mortales.

(..)

El playround tiene que ser atractivo como lugar de reunión, para todos, incluidos los adultos, para justificar su existencia. También tiene que ser aceptable para la ciudad, incluso sin contar con el movimiento de los niños. ${ }^{110}$

En este sentido Van Eyck ofrece una nueva visión sobre la 'flexibilidad', al considerar que uno de los problemas de la planificación moderna, que en este caso afecta directamente a los playgrounds, es la constante persecución de un espacio extenso e ilimitado. Esa extensión, a modo de una 'flexibilidad' estéril, conlleva a una sensación de vacío urbano donde se hace más difícil la interacción. Van Eyck puja por espacios que, aunque sean abiertos, puedan ser definidos, y para esto confía en la reducción de la escala y en la definición del carácter de los mismos. Se trata de la construcción de espacios 'flexibles', que sean capaces de albergar un sentido que el usuario pueda interpretar como propio.

2.3.7.b. La coronación de este concepto llega con los diseños para el Orfanato MuniIdentidad cipal de Amsterdam y la Escuela Infantil de Nagele, ambos de 1955, los cuales llevarían al autor a indagar nuevamente en la percepción infantil, intentando establecer lazos de «identidad», esta vez con las complejidades de un edificio. Van Eyck concibe estos proyectos como una suerte de manifiestos de varias de las ideas que habían sido planteadas tanto por él, en su experiencia con los playgrounds, como por el Team X; ambos edificios se plantean como una 


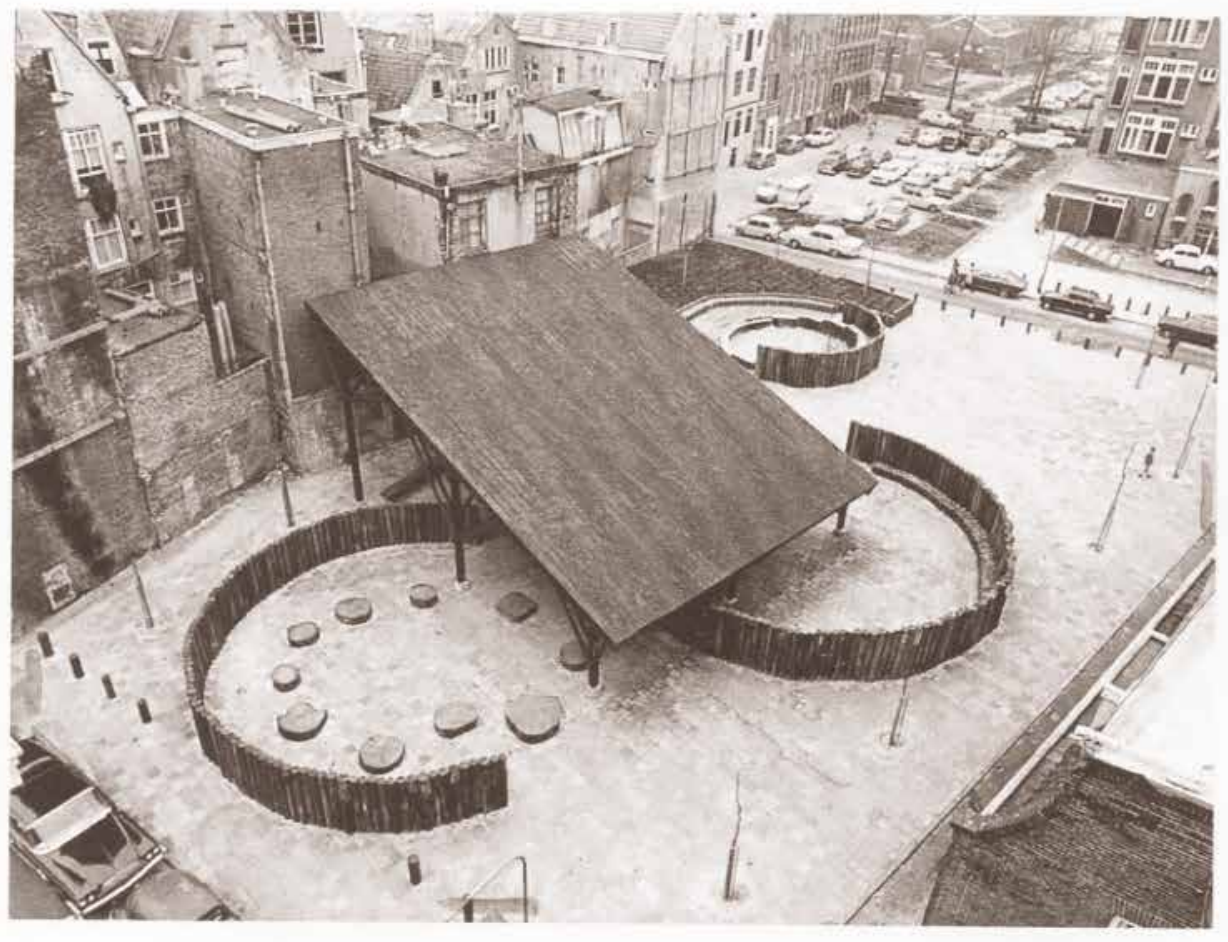


mixtura entre casa y ciudad, exterior e interior, parte y todo. En los dos casos el programa se desmantela a partir de aulas tratadas como células que se presentan en sí mismas como unidades, o casas. [FG.15] Por su posición y apertura estas células permiten una contención a la vez que una fuga visual al espacio colectivo; son capaces de sugerir un lugar de reunión sin ser completamente cerradas. [FG.16] Por medio de la repetición de estas unidades -en ambos proyectos enfatizada por su disposición escalonada- la totalidad de ambos edificios consigue concretar un espacio de mayor escala, y todo el conjunto aparece como un pequeño poblado, en el que la relación entre la unidad y el espacio que la conjuga es vital. [FG.17] En ambos proyectos van Eyck apela a un lenguaje sin herencias modernas que también se extiende a la solución funcional de los edificios, influenciado por su enorme interés en las culturas precolombinas, como las ruinas de Tyuonyi, Pueblo Bonito, Pueblo Arroyo u Ogol, en las cuales también la sumatoria de una cantidad de partes individuales en un medio círculo consiguen amarrar un refugio común de rasgos comunitarios. [FG.18] Tanto en el Orfanato como en la Escuela de Nagele una "calle interior» permitiría la unificación de esta conjunción de escalas domésticas e institucionales, fortaleciendo un espacio ambiguo para el encuentro que articula no sólo las diferentes células, sino el interior con el exterior. Como el mismo autor reclama, "ha llegado el momento de concebir la arquitectura urbanísticamente y el urbanismo arquitectónicamente». ${ }^{111}$ También de estas ruinas van Eyck encontraría inspiración para el lenguaje arquitectónico puntual de sus dos proyectos: las formas que impulsan a la apropiación o a la construcción de un lugar, como los círculos, están constantemente presentes.

[FG.14]

Aldo van Eyck Playground. Elementos Delft: Collected articles and other writings. 1947-1998, 1960 .
La planta del Orfanato y de la Escuela de Nagele se apropian a su vez de ciertas soluciones particulares que el arquitecto había utilizado ya en sus playgrounds para incitar al juego, como cambios de suelo que sugieren distintos

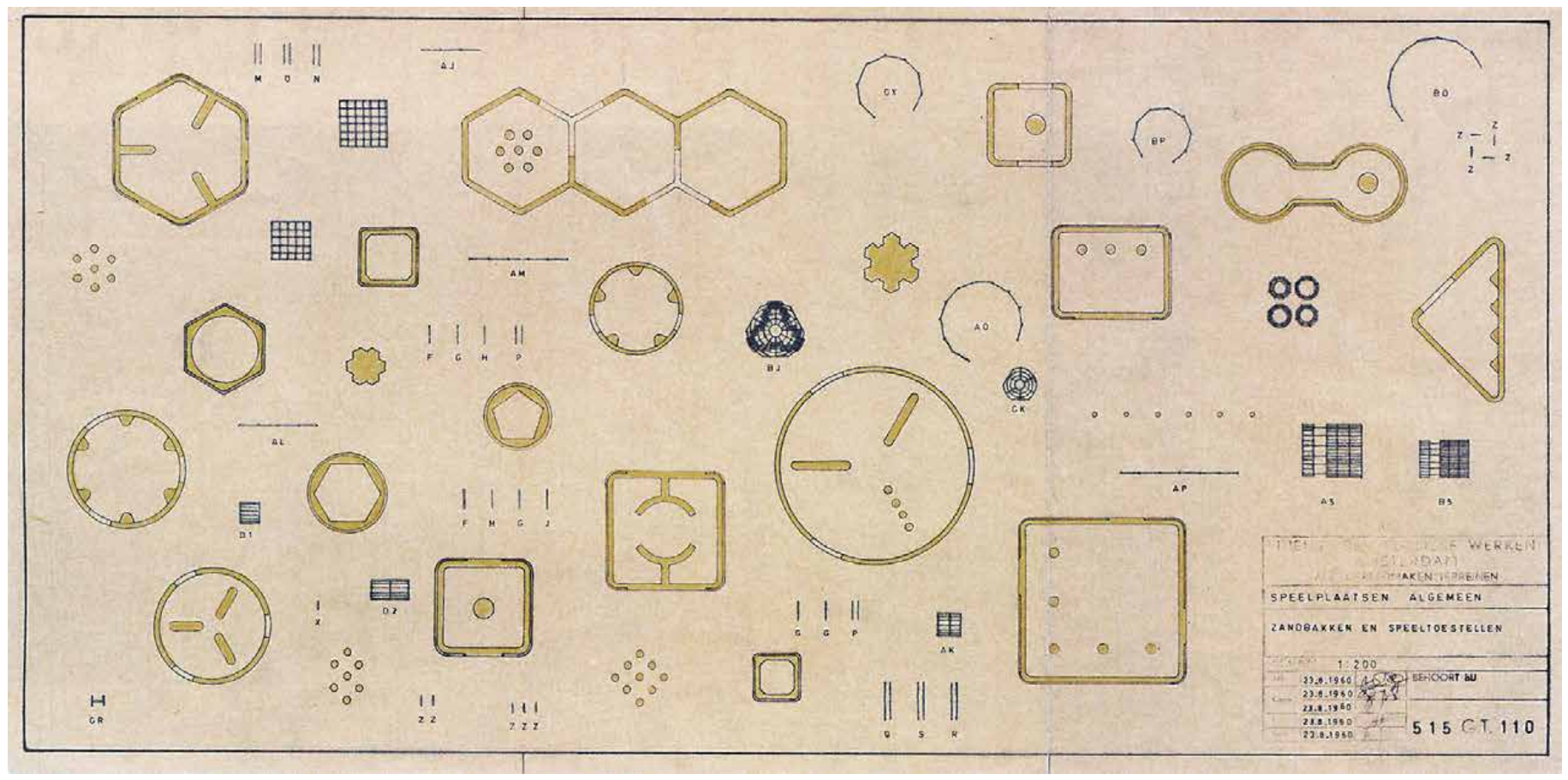




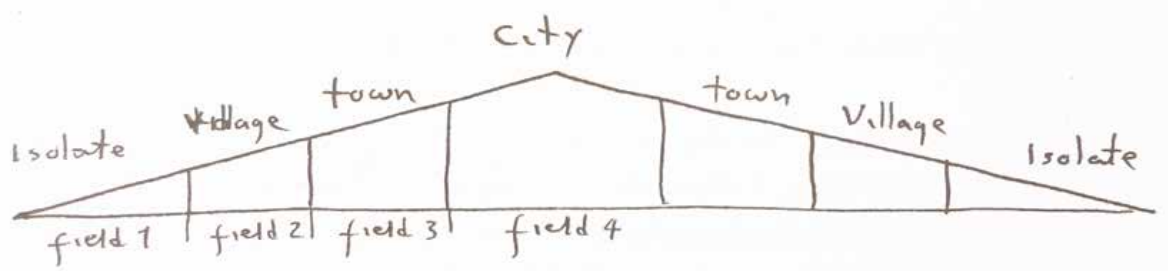

lugares y tipos de uso; amplias zonas techadas en la que los pilares no sólo resuelvan la estructura, sino que expresen también un espíritu lúdico. Cuando el autor presenta el Orfanato en el texto "The medicine of reciprocity tentatively illustrated" hace referencia a una flexibilidad contrastada que supera la neutralidad, diferenciando el pattern estructural, propio de la arquitectura, del pattern de la vida misma:

Dado que el pattern de la casa deriva, abarca y, por lo tanto, también sostiene el pattern de la vida cotidiana dado por sus ocupantes, se entiende que la flexibilidad o adaptabilidad (...) es tal que no es posible cubrir y soportar adecuadamente un modo de vida o una estructura de grupo que se separe del modelo de organización de la casa. Una flexibilidad extrema de estas características habría llevado a una falsa neutralidad, como un guante que no se adapta a una mano particular porque es capaz de adaptarse a cualquier mano. ${ }^{112}$

El entendimiento de esta complejidad inherente a la vida es contrastado con la 'flexibilidad' abierta y neutral. Esta apuesta implicaría un importante paso sobre la 'flexibilidad' de Mies en la que cada situación se resolvía de la manera más abierta posible, más allá de las características del ocupante. Si Mies perseguía la libertad funcional para van Eyck la clave reside en encontrar una diversidad en la repetición con la cual los patrones consiguen cierta complejidad dentro de su principio básico. Se trata, de algún modo, de caracterizar la condición flexible de un espacio. En este sentido es que la «imaginación» es reclamada por parte del autor; imaginación que puede leerse también como compromiso por una «identidad» para el usuario:

La tendencia de desear una gran neutralidad en aras de una mutabilidad extrema es tan peligrosa como la rigidez urbana prevaleciente de la que surge esta tendencia como reacción. Las estructuras arquitectónicas deberían contar con una amplitud suficiente y un significado múltiple sin tener que someterse continuamente a alteraciones. Hay que cuidarse del guante que se adapta a todas las manos y, por lo mismo, no encaja en ninguna mano. Hay que cuidarse de la falsa neutralidad. ${ }^{113}$

Como sus dos proyectos lo demuestran, la «identidad» en van Eyck no tiene necesariamente que ver con lo cultural, sino con identificar el sentido propio de cada elemento arquitectónico para que este trascienda su naturaleza básica y adquiera un carácter que permita diferentes modos de acercamiento. Se trata de dotar de una identidad de uso a los elementos arquitectónicos; sobre todo a aquellos que, en principio, no requieren de una función pero
"Steps towards a configurative discipline," en ibid. p. 341. (Ed. orig. 1962)

[FG.18]

Aldo van Eyck,

Diagrama de asociación

Delft: Collected articles and other writings. 1947-1998, 1954.
[FG.15]

Aldo van Eyck,

Diagrama Unidad

Delft: Collected articles

and other writings. 1947-1998,

1961.

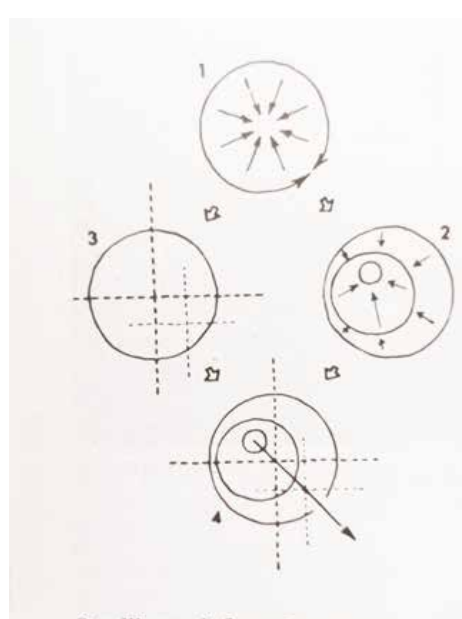

Dwelling unit for 4-6 age group 
Orfanato de Ámsterdam. Planta de aula

Delft: Collected articles and other writings. 1947-1998,

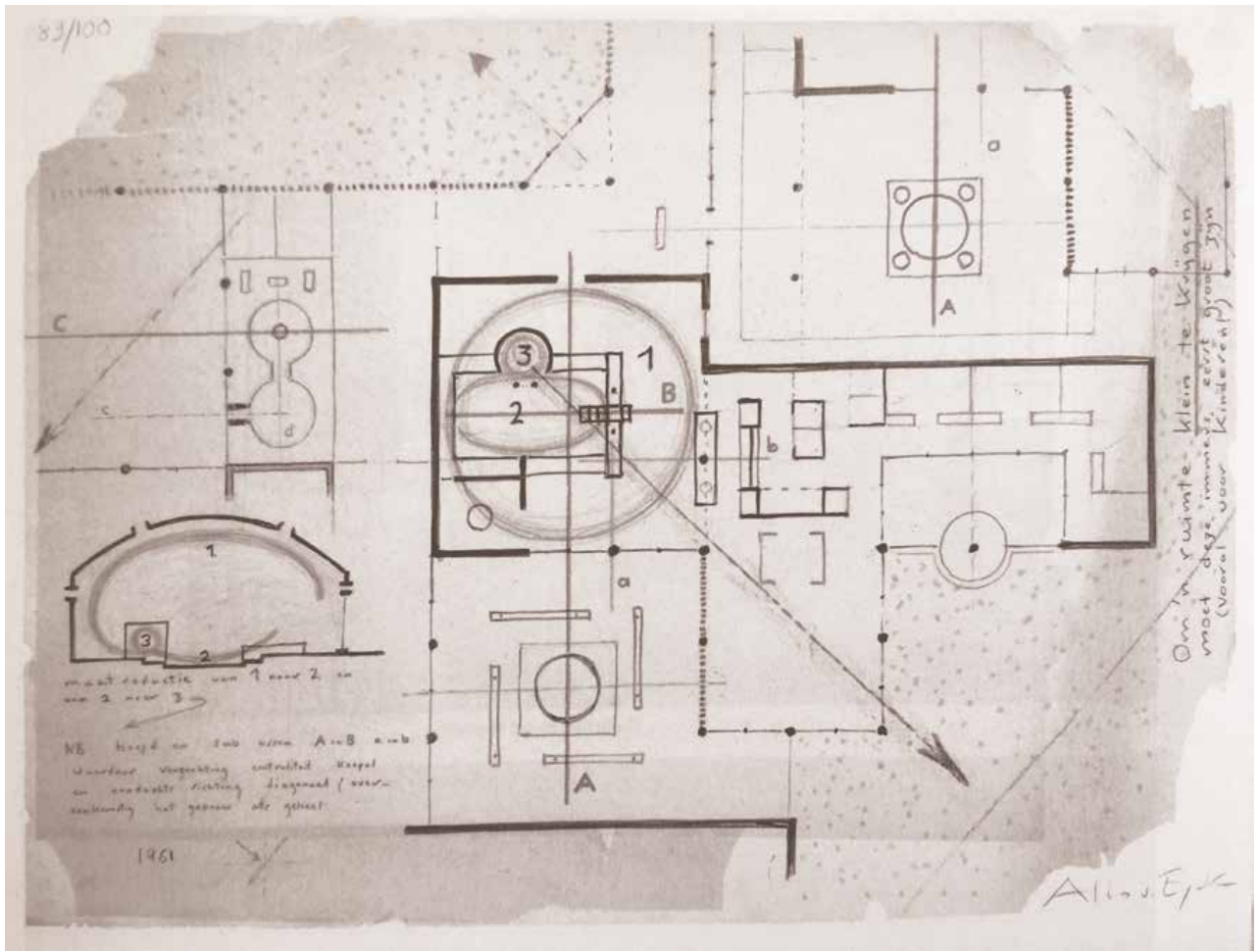

[FG.17]

Escuela en Nagele. Planta

Delft: Collected articles and other writings. 1947-1998,

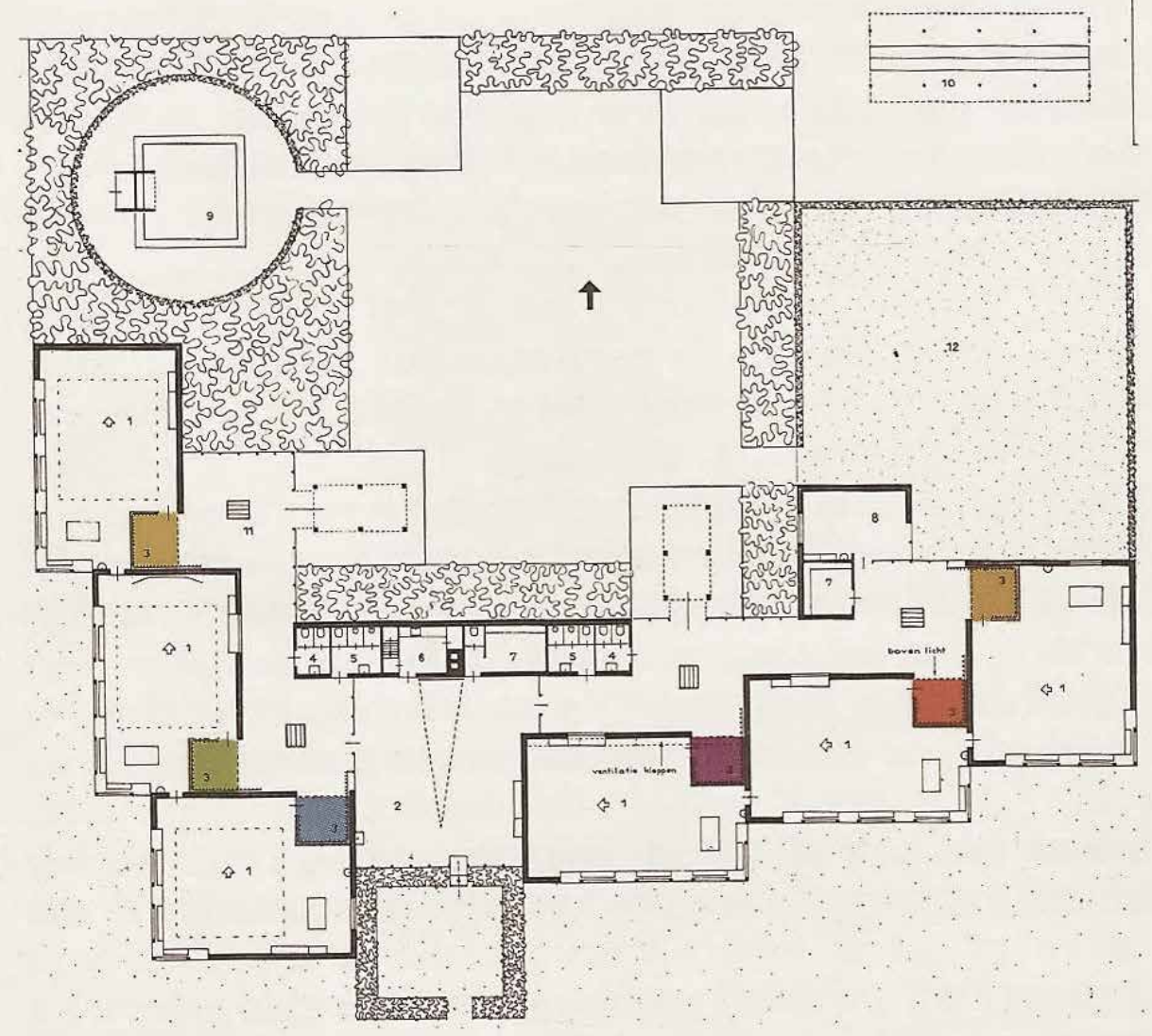


sí de un cierto grado de "emoción" -otro término recurrente en sus escritosque permita una vinculación con el usuario.

Van Eyck refiere en varios ocasiones a una noción de "hábitat» a la cual el arquitecto y urbanista debe responder atendiendo en primera instancia a las necesidades colectivas y humanas antes que a las puramente arquitectónicas; el autor está preocupado por encontrar lo permanente y esencial en el hombre, desechando al mismo tiempo las problemáticas puramente arquitectónicas que no atiendan a estas necesidades. En este sentido la figura de van Eyck supone una renovación importante que representa cierto interés en lo que la arquitectura es capaz de generar en cuanto a interacciones internas por fuera de su marco morfológico. Así, "El hábitat humano debería reflejar y estimular el contacto primario entre el hombre y el hombre, entre el hombre y el objeto...»114 Se trata de la importancia de un espacio de socialización interior y exterior:

No inhalamos exclusivamente, ni exhalamos exclusivamente. Por eso sería tan gratificante si la relación entre el espacio exterior y el espacio interior, entre el espacio individual y el común, dentro y fuera, entre lo abierto y lo cerrado (hacia dentro y hacia fuera), se convirtiera en el espejo construido de la naturaleza humana, para que el hombre pueda reconocerse en su reflejo. ${ }^{115}$

En su participación en el CIAM X junto al Team X, el autor se enfoca en una discusión sobre los cuatro puntos básicos de la Carta de Atenas, sin negar la importancia de estos pero llamando la atención sobre su condición limitada que impide imaginar qué ocurre con las funciones que no pertenecen exclusivamente a alguno de los cuatro ámbitos:

(...) se vuelve evidente que lo que realmente se destina para impulsar vitalidad decae en la celda de las cuatro funciones; mentiras, de hecho, más allá del alcance estrecho del pensamiento analítico. Al relacionar imaginativamente las cuatro funciones entre sí, debería ser posible transmitir lo que hasta ahora ha eludido la "expresión consciente". ${ }^{116}$

La intención de van Eyck, junto a la del resto de miembros del Team $X$ era la de discutir "Por qué el urbanismo concebido según la Carta de Atenas tiende a producir hábitats en los cuales las asociaciones humanas vitales están expresadas de modo inadecuado». ${ }^{117}$ La propuesta del Team X se enfoca en un «diagrama de asociación» en triángulo descendente que busca incluir los diferentes modos de habitar urbanos; en este diagrama la cumbre es ocupada por la ciudad, luego el poblado, la comuna hasta legar al edificio aislado. [FG.19] Este nuevo árbol jerarquías permitía una mayor complejidad sobre los modos de abordar grupos grandes, medianos o pequeños de acumulación, a modo de una red. "Este método de trabajo introducirá un estudio de las asociaciones humanas como principio primero de las cuatro funciones, como aspectos básicos de cada problema en su totalidad». ${ }^{118}$ Esta "human association" es la que van Eyck considera que no ha sido introducida, y es la que permitiría grados de aproximación específicos al problema de la función, buscando las áreas grises que se presentan entre las cuatro funciones de la Carta de Atenas. De algún modo se trata de entender las funciones también en su propio ambiente, evitando las generalizaciones.
114.

2.3.7.C.

Human association

115.

"On inside and outside space," en ibid. p. 126.

(Ed. orig. 1956)

116.

"Orientation," p. 189

117.

Ibid. p. 190.

118.

Ibid. p. 191.

119.

Ibid.

120

"Talk at the Oterloo Congress," en ibid. p. 200 (Ed. orig. 1959)

121.

van Eyck, Aldo y Wogenscky, André, "Report for the comission on the theme of CIAM 9," en ibid., p. 242. (Ed. orig. 1952). 
Al mismo tiempo van Eyck insiste constantemente en modificar los puntos iniciales de la arquitectura moderna -como los utilizados por el CIAM, o por el propio Le Corbusier- por una serie de polaridades:

individual-colectivo

físico-espiritual

interno-externo

parte-todo

permanencia-cambio ${ }^{119}$

En esta búsqueda de una esencia del hábitat van Eyck se muestra interesado por los modos en que la gente realiza sus actividades más cotidianas dependiendo del marco cultural. Se trata de algún modo de avanzar hacia a la esencia de cada actividad, teniendo al «hábitat» como único objetivo.

Lo que he estado haciendo durante años (...) es simplificar (...) la forma en que las personas han vivido y se han comportado en todas las edades y en todo momento, (...) es una cuestión de descubrir, no cómo se hace una cocina en Japón o cómo se hace una cocina en África, sino cómo come un hombre, una mujer y un niño en Japón y cómo come en el Sahara, (...) no el dormitorio, sino el dormir. $Y$ esto aparece si simplemente has entrado en contacto con la realidad; no hacer un dormitorio, no organizar el espacio, sólo hacer un hábitat para que las personas vivan, considerando los problemas de hoy. ${ }^{120}$

Aunque van Eyck se muestra interesado en estudiar y relacionar los modos en que las diferentes culturas realizan sus actividades, se trata de pujar, de un modo similar a como lo intentara Häring, por comprender los mecanismos internos del hábitat humano. Desde el punto de vista de la función implica un claro movimiento desde el interés del objeto -el que demostraba, por ejemplo, Wright cuando refería a las construcciones de las diferentes culturas- al interés antropológico, alimentando esta human association.

En un reporte para el CIAM 9 realizado junto a Wogensky -quien ya había propuesto agregar a las cuatro funciones básicas del CIAM «pensamiento», «actividad" y "salud»- menciona:

Declaramos que el hábitat no puede diseccionarse en partes distintas, ya que se trata de una estructura organizada; la modificación de cada parte modifica el todo.

Declaramos que el hábitat no es estático, sino que se encuentra en movilidad perpetua de acuerdo con la movilidad del hombre y la sociedad. Su organización está sujeta a una renovación continua.

Declaramos que no es estático, sino que existe entre él y el hombre un juego perpetuo de acción y reacción. El hombre reacciona al Hábitat como el Hábitat reacciona al hombre, contribuyendo a condicionarlo y, en consecuencia, a convertirlo en lo que realmente es. ${ }^{121}$

Esta última sentencia resulta esencial para entender el problema del marco cultural de las funciones y de los hábitos. Van Eyck, al mismo tiempo que considera los marcos culturales es consciente de que estos mismos pueden condicionar a las propias actividades humanas. La arquitectura se posiciona así 
and other writings. 1947-1998,

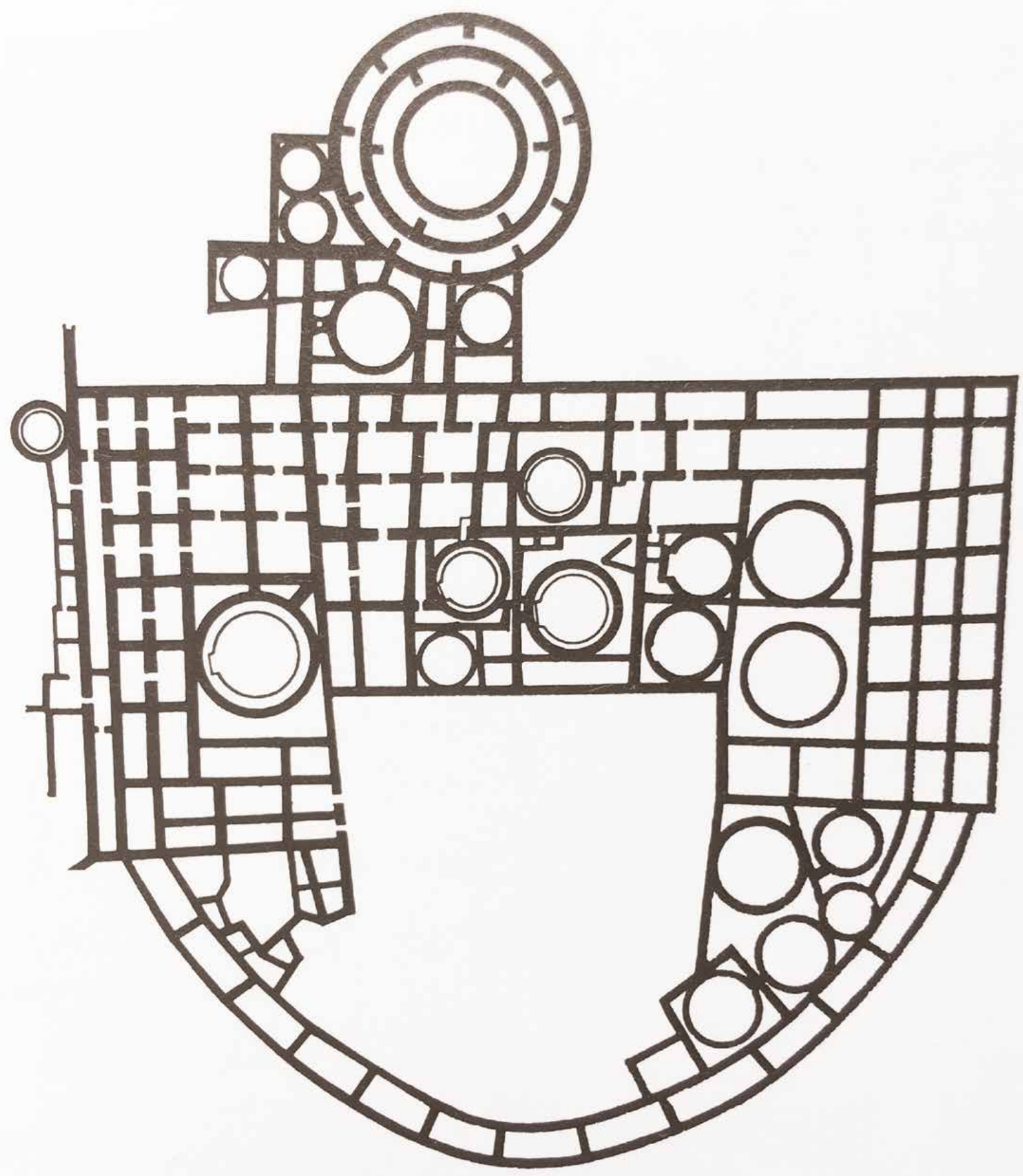


Por otro lado, como se ha comentado, según van Eyck las funciones urbanas no deben anularse la una a la otra, sino potenciarse en su complejidad. El autor entiende que el problema de la separación de las actividades tiene que ver con suprimir esas superposiciones propias de una 'flexibilidad' construida desde lo no determinado -que particularmente tienen un germen en el modo en que los niños se apropian del espacio de un modo irracional. En estas zonas grises van Eyck ubica todas esas otras actividades que no están clasificadas por el arquitecto pero que pertenecen a la realidad urbana. Para el autor las cuatro funciones del CIAM son tan distantes entre sí que conceptualmente no encuentran puntos de contacto; tenían un sentido como propuesta básica de organización frente a las concepciones urbanas del siglo XIX, pero no resultan suficientes para afrontar las complejidades de los modos modernos de habitar.

El autor, de modo similar a como lo plantean A. \& P. Smithson, puja por el desarrollo de una nueva estrategia en la cual la parte y el todo se configuren en una continuidad; en concreto, se trata de un componente urbano que, repetido, puede conformar una red de patrones vinculados entre sí, de modo análogo a como lo propusiera en el Orfanato de Ámsterdam y en la Escuela en Nagele. Cada uno de estos componentes deberían poder garantizar por sí mismos algún lazo de identidad con sus usuarios de modo que, repetidos a larga escala, esta identidad no se viera sustancialmente afectada.

2.3.7.d. Quizás sea en los artículos de la revista Forum donde van Eyck expone más claLugar y ocasión ramente un tono de manifiesto que vuelve a reclamar una visión antropológica en la arquitectura y el urbanismo. Particularmente en el texto "There is a garden in her face" de 1960, en un fragmento planteado como evidente respuesta a Space, time and architecture de Giedion, dice:

Lo que sea que el espacio y el tiempo signifiquen, el lugar y la ocasión significan más.

(...)

Proporciona ese lugar.

¿Es el hombre capaz de penetrar el velo rígido que se interpone entre una persona y otra? entre lo que está aquí y lo que está allí; entre este y el siguiente momento? ¿Es capaz de encontrar el lugar adecuado para la ocasión correcta? No; así que comienza con esto: haz

una bienvenida de cada puerta

una cara de cada ventana. ${ }^{122}$

Con este tono poético propone dotar de identidad funcional a los elementos arquitectónicos. El autor explica que su propuesta de reemplazo del término "espacio» por el de «lugar» tiene que ver conque, para el usuario, el espacio es propiamente el lugar. Se trata, nuevamente, de un cambio desde una concepción puramente arquitectónica a una antropológica; se trata de salir de la abstracción para acercarse a lo concreto. El «lugar» implica, al contrario que el espacio, un marco de "identidad." Se trata de "El espacio donde comes, donde pasas el tiempo (...) es un evento". ${ }^{123}$ Es, en definitiva, un reclamo al arquitecto para transformar a cada espacio en un lugar concreto, con un 
aproximación que, una vez más, vuelve a vincularse con el decor vitruviano. Al mismo tiempo, y no casualmente, da lugar al término event, posteriormente utilizado unas décadas más tarde por Bernard Tschumi para referirse a esas acciones que rompen la barrera de lo cotidiano y que son capaces de expandir la función a nuevas libertades asociadas a la transgresión.

Van Eyck también se refiere a considerar lo colectivo en un primer plano de importancia dentro de la arquitectura: para el autor la arquitectura que podría entenderse como "individual", como la vivienda particular, no supone un desafío mayúsculo como el de conformar, a través de las construcciones, un colectivo social que pueda interactuar y no se vea afectado negativamente por esta nueva condición urbana proyectada. Se trata de ampliar la escala del lugar a lo urbano; y

de concebir una serie de pequeños lugares que puedan articularse en unidad. Según el autor la arquitectura moderna se ha centrado mucho en lo que él considera la "estética de lo individual», elaborando objetos cuidados en el plano del diseño, sin otorgar la misma profundidad a la arquitectura de lo colectivo. El diseño de lo colectivo es para van Eyck también el diseño de este nuevo entendimiento de la función. El tema de la cantidad en este caso resulta fundamental ya que, según van Eyck, la unidad debe contrastarse en esa diversidad.

No tenemos idea de lo que significa un gran número de personas; nuestra sociedad actual se caracteriza por la pluralidad, por la repetición; eso lo sabemos, pero no sabemos exactamente qué y por qué se repite algo, eso es seguro. Uno se enfrenta a diario con el hecho de que es así, pero no conoce los medios para forzar el plural a ordenarse; el orden humano no es el "orden" de la monotonía ni de la reglamentación, sino un orden cuya unidad solo es concebible por medio de la diversidad, y la diversidad solo por medio de la unidad.

(...)

La pregunta es: '¿Se puede pedir a un arquitecto solo, o como parte de un equipo de especialistas, que construya una ciudad para la comunidad, que sea cálida, donde sea bueno estar, donde se pueda vivir, donde no se trate sólo de una cuestión de mantenerse estable a pesar de los problemas, sino en donde realmente se pueda vivir, donde uno realmente tenga la sensación de ser un ser humano adecuado?

No lo sé. ${ }^{124}$

Apelando al escepticismo todo radica en que la identidad del "todo" debe estar presente también en los componentes; es decir que, por inversión, la identidad de cada individuo debe poder expandirse en la totalidad. El autor se pregunta sobre la construcción de una posible "casa» que, con un potencial tal permita, a través de la multiplicación, suplir las necesidades de un gran grupo de personas. Un elemento que, en su repetición incluya en sí mismo el espacio para lo colectivo, pero que este último esté, siguiendo la base del decor, sugerido por su propia morfología: "Cuando debes lidiar con una cantidad de viviendas que puedan necesitar, por ejemplo, una escuela, el proceso de multiplicación de las unidades debería producir por sí mismo un lugar o una forma que sugieran "yo puedo ser una escuela".»125 Se trata de un modo de 'flexibilidad' 
donde la función no está determinada, pero la forma arquitectónica es capaz de sugerirla; una forma que no se cierra tanto para perecer con los cambios de hábitos del tiempo -como en la 'adaptación'-, pero tampoco se abre a una neutralidad que impide alguna forma de «identidad».

La apuesta de van Eyck se asienta definitivamente en el problema de la comunidad pero confiando aún en las soluciones arquitectónicas para poder afrontarlo; el individuo aún está presente, aunque tomando distancia de la concepción wrightiana, en la que la libertad del mismo era, hasta el final, central. Si la arquitectura moderna había considerado lo colectivo en un sentido abstracto, es decir, sin indagar en profundidad en los temas de identidad y apropiación del espacio por parte de la comunidad, Van Eyck demuestra una preocupación humanista que marca el rumbo para nuevos enfoques sobre la función que seguirán creciendo en las décadas siguientes, en los que se asume un compromiso con la particularidad y el sentido de la función antes que con una eficiencia generalizada. 
La 'conectividad' refiere tanto a la vinculación entre los diferentes ambientes dentro de un edificio como a los elementos que la hacen posible, generando en este proceso una interacción entre los usuarios, y provocando, en algunas circunstancias una secuencia de significados. Este "relato" activo, que es parte inherente de su esencia, va a servir también de alimentación para los modos en que la función se expresa y se comunica. Pero además de esto la 'conectividad' incluye la propia separación de actividades del programa, que tienen un inevitable impacto en las relaciones entre los propios usuarios, ya sean estas deseadas o no. Se podría decir que el problema de la 'conectividad' no es sólo intrínseco a la arquitectura, sino también a la sociedad y a la cuestión cultural propia de esta. A través de ella se teje un hilo de conceptos que tratan sobre el modo en que las personas se aproximan a los edificios, los interpretan y los experimentan a través de sus funciones.

En el siglo XVIII Jacques-François Blondel incorpora dos nociones fundamentales que se convertirán en referentes básicos de la 'conectividad': distribution y caractère. Ambas tienen un origen en Vitruvio pero suponen una profundización fundamental tanto para la importancia propia de las circulaciones como para el significado de los edificios -esta última noción será además elaborada con mayor énfasis por Étienne-Louis Boullée y Claude-Nicolas Ledoux a fines del siglo XVIII. Posteriormente será el aporte del 'socialismo utópico' el que acerque de manera radical los temas de la 'conectividad' al plano social. La propuesta de Charles Fourier supone un importante antecedente 


\subsubsection{CONECTIVIDAD}

para la arquitectura moderna en cuanto a la estricta separación de las actividades a través de la configuración espacial y las circulaciones; esto es el phalanstère, un artefacto cuyo diseño permite una intencionada afectación al sistema social y que busca consolidarse como un edificio-ciudad políticamente organizado. Posteriormente, los estudios de Gottfried Semper recuperan la historia para poder consolidar ciertos principios arquitectónicos; en sus escritos el aporte a la noción de 'conectividad' tiene que ver tanto con la idea de un centro -un Herdfeuer que, según el autor, resulta en un necesario punto de significado para los usuarios de cualquier sociedad- como con el desarrollo de determinados elementos arquitectónicos producto del cuidado del mismo: suelos, muros y cubiertas determinan, según Semper, el modo en que los habitantes se relacionen entre sí. Es sabido también que el phalanstère de Fourier supone un antecedente fundamental de las Ilamadas "células urbanas" que varios arquitectos modernos proponen en las primeras décadas del siglo XX. Estos edificios masivos requieren de una serie de elementos que propulsen la 'conectividad', ya sea tanto física como visual, y que pasan a un primer plano, adquiriendo un significado propio: puertas, corredores, escaleras, ascensores o rampas serán objeto de reflexión en las teorías de Le Corbusier, quien a través de Vers une architecture, encuentre potentes referencias en los medios de transporte industrializados, como barcos u aviones, traspasando de algún modo estas lecciones a su propia arquitectura. Fruto de esto deviene el aporte fundamental de la promenade architecturale, la cual permite vincular el problema funcional al espacial en un todo indivisible, dentro del cual la circulación es la base. En la segunda posguerra Alison \& Peter Smithson continuarán indagando en el problema de la conexión y vinculación entre los usuarios de "células urbanas" y aportarán nuevos conceptos, como el de cluster city, o el de mat building. En una linea mucho más ligada a lo sensorial Louis Kahn no sólo enfatizará la idea de 'conectividad' a través del significado de los espacios y de las actividades, sino que alcanzará a proponer un modo diferente de acercarse al problema de la función a través de la subjetividad, en su noción de reprogramming.

Desde la misma experimentación de los espacios de un edificio y sus transiciones hasta la separación social que la misma supone, la noción de 'conectividad' es parte intrínseca de la teoría de la arquitectura, desde que Alberti propusiera su concepto de commoditas. Aún así, las interpretaciones en torno a la misma se mueven en al menos dos planos: uno que podría considerarse como "técnico" -el de raíz higienista, que persigue la separación de los espacios por problemas de exclusiva resolución funcional- y otro ligado a lo sensorial y significativo propio de un espacio -el modo en que una función se expresa y se descubre a través del movimiento. Ambas facetas requieren de un diálogo constante entre lo espacial y lo funcional, entre lo racionalista y lo subjetivo, 


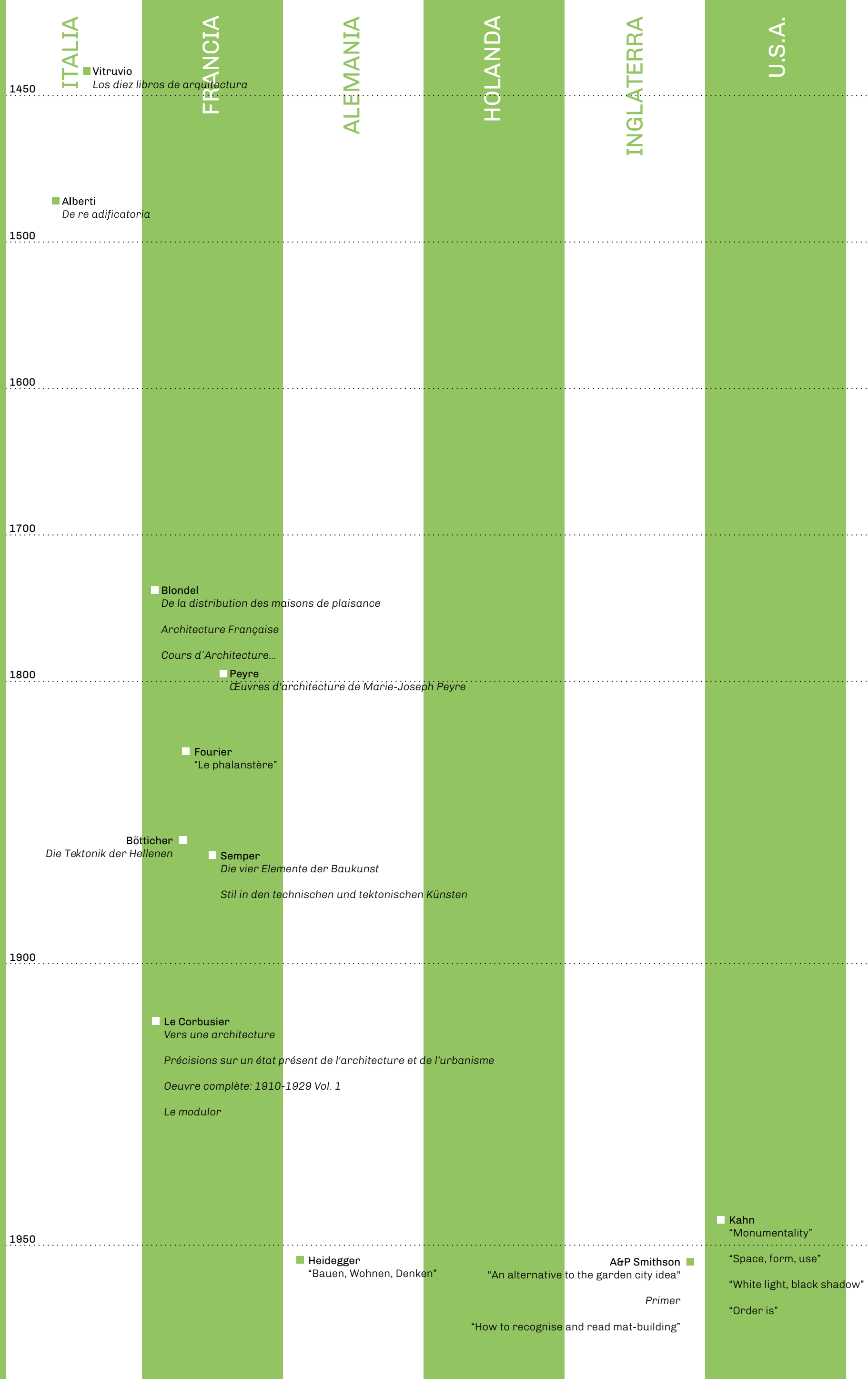


2.4.0. CONECTIVIDAD

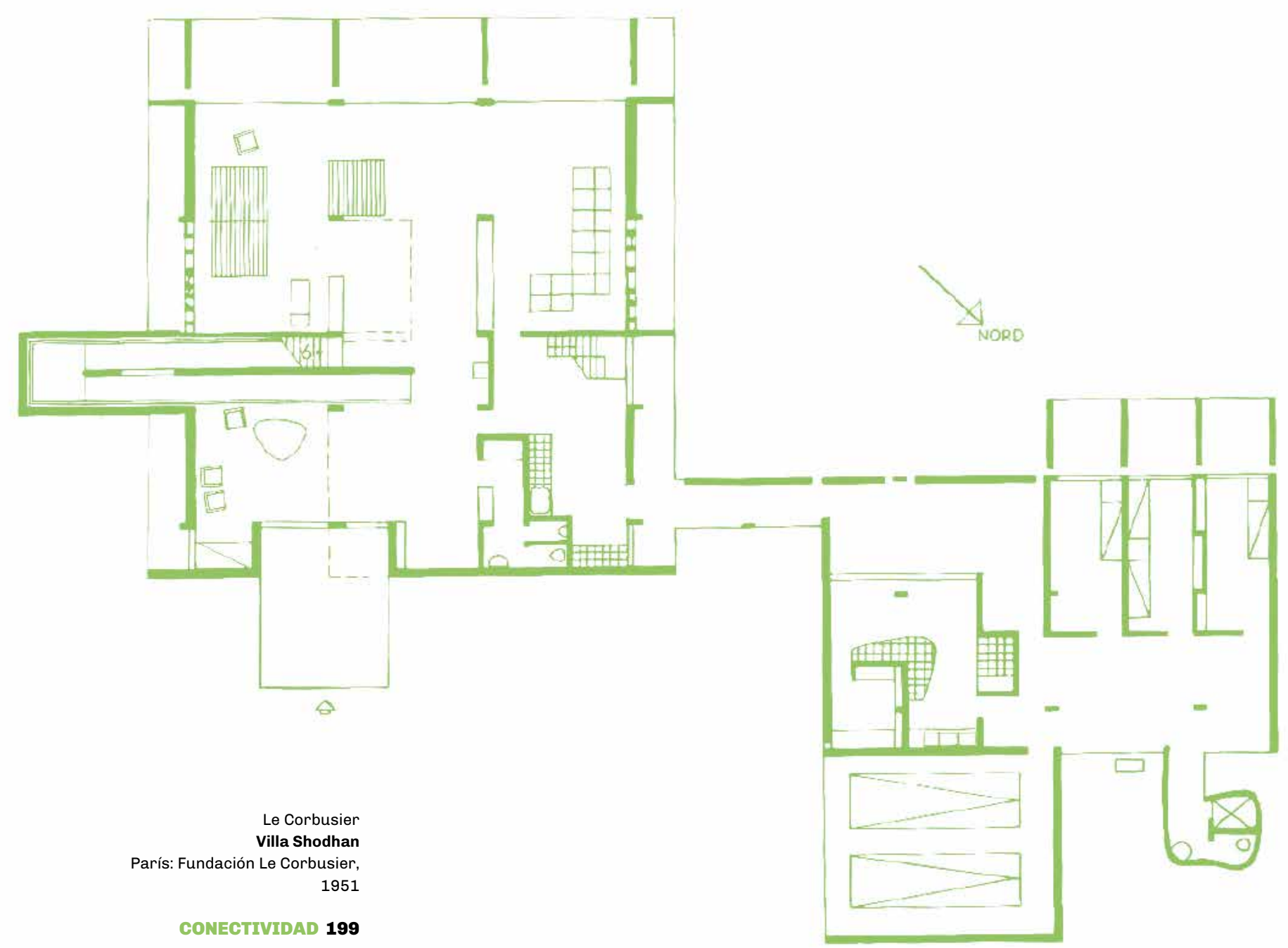


El período de poco más de cincuenta años que abarca desde mediados del siglo XVIII hasta las primeras décadas después de la Revolución será, sólo en Francia, uno de los más productivos en cuanto a los aportes teóricos sobre la función. Este fenómeno responde a dos circunstancias particulares: en primer lugar, las condiciones políticas de la nación, que signan una época que va desde la crisis del absolutismo hasta la Revolución, con impactos sociales que ampliarán inevitablemente el marco de discusión en torno a la función; en segundo lugar, las nuevas escuelas privadas de arte y arquitectura -la Ecole Royale des Ponts et Chausseés, fundada en 1747, y la Ecole des Arts, fundada en 1743, aunque cerrada en 1754 - supondrán un sismo para La Academia, e impulsarán la modernización del conocimiento, manteniendo igualmente la importancia de la innovación disciplinar desde lo pedagógico, como si de un laboratorio se tratase. En este marco el aporte de Jacques-François Blondel será fundamental para hilvanar la tradición teórica francesa, permitiendo a su vez una continuidad a través de varios de sus discípulos.

Con obras como De la distribution des maisons de plaisance (1738), Architecture Française (1756), Cours d'architecture ou traité de la décoration, distribution et constructions des bâtiments (1771-1776), o su contribución con artículos en la Encyclopédie de Diderot, hasta el 1759, sumados a su enseñanza en la Ecole des Arts, la figura de Blondel será de una importancia fundamental en la teoría de la arquitectura francesa antes de la Revolución. ${ }^{1}$ Blondel ordena la tradición teórica francesa e italiana pasando por Alberti, Palladio, de l'Orme, Perrault, Cordemoy y Laugier. La importancia de Blondel radica en que logra condensar varios temas que formaban parte de las discusiones disciplinares anteriores en una serie de herramientas operativas de base racionalista.

En primer lugar Blondel se opone a la noción de beauté arbitraire (belleza arbitraria) que Perrault propone para las proporciones, volviendo a la idea vitruviana de que las mismas derivan directamente de las leyes de la naturaleza. Bajo este precepto Blondel asume dos polos: razón e imaginación, es decir, la racionalidad humana al mismo tiempo que las leyes naturales. ${ }^{2}$ En esta suma existe un lugar para el gusto subjetivo, pero el mismo debe estar contenido bajo un orden que responda a la finalidad del edificio. Para poder establecer las reglas de este orden el autor construye un sistema de normas con vocación absoluta que cuentan además con una intensa proyección didáctica, con el fin de poder ser traspasadas con claridad a las siguientes generaciones. El pensamiento de Blondel en cuanto a lo pedagógico hace especial hincapié en el dibujo como condensador de conocimientos y como medio de control para la imaginación; el dibujo es para Blondel como una balanza que equilibra la razón y la imaginación. Parte de este equilibrio se funda también en su interés simultáneo por las matemáticas y por la historia de la arquitectura.

Cours D'Architecture, uno de los primeros en referirse al tema de la 'conectividad', se divide en tres partes que atienden a décoration, distribution y constructions. Blondel remarca aquí la importancia de la distribution -la cual tiene un primer origen en el concepto de distributio, una de las herramientas de construcción en Los diez libros de la arquitectura de Vitruvio-, no sólo como

\section{Blondel. Función como relato}

1.

Calatrava, Juan A., "Una propuesta de enseñanza de la arquitectura en la Francia de las Luces: Blondel y la Ecole des Arts," Estudios dieciochistas en homenaje al profesor Jose Miguel Caso González, (1995): p. 119.

\section{2.} Ver Ibid. p. 124.

3. Blondel, Jacques-François, Cours D'Architecture ou Traité De la Décoration, Distribution \& Construction Des Bâtiments: Contenant Les Leçons données en 1750 , \& les années suivantes par JF Blondel, Architecte, dans son École des Arts. 2 (Paris: Desaint, 1771), p. 128-29. (Ed. orig. 1675).

4. Ibid. p. 390.

\subsection{1.a.}

Razón e imaginación

2.4.1.b.

Distribution 
un problema del interior, sino también del exterior, es decir, como tema de la expresión formal del edificio. Blondel afirma que la distribution se encuentra en una parte intermedia entre décoration y constructions. Se trata de temas diferentes pero hilvanados en un conjunto. La distribuion, según explica en el capítulo "De la utilidad de la Arquitectura," hace especial mención al tema de la salubridad e higiene de los edificios, problemas a resolver mediante un correcto uso de los conectores, las ventilaciones y articulaciones entre recintos. Blondel no tuvo un desarrollo prolífico como arquitecto, y tal vez su proyecto para un Gran Hotel, publicado en la Encyclopédie de Diderot sea uno de los ejemplos donde mejor se expongan sus ideas sobre la distribución. [FG.01] En efecto, en este proyecto Blondel sigue al pie de la letra sus propias anticipaciones teóricas, y recurre a un despliegue de volúmenes longitudinales en el terreno, con extensas galerías y patios interiores que garantizan una adecuada ventilación a todas las estancias, a su vez que permiten un distanciamiento notable entre los cuerpos para expandir las visuales desde el interior. Asimismo los encuentros entre las lineas de distribución adquieren importancia como 'nodos' de articulación que toman la forma de pequeños salones, salas o vestíbulos, y se destacan por la centralización de su interior; plantas con figuras elípticas, circulares o cuadradas. Para Blondel la distribution es también una parte de la noción de economía que debiera ser aplicada en la arquitectura; una distribution entendida como una aplicación eficiente de las circulaciones, en pos de un ahorro de superficies y recorridos. A pesar de su marcada importancia los elementos que permiten estas circulaciones no son considerados por el autor como un fin en si mismo, sino que esta distribution sigue siendo parte de esa tríada compartida con la décoration y la constructions:

El arquitecto no es decorador, organizador (en francés distributeur) y constructor, pero debe cumplir estas tres ramas a la vez (...) a partir de estos estudios combinados nace la superioridad de la arquitectura. ${ }^{3}$

La influencia que la tríada tendrá en el pensamiento posterior de la arquitectura francesa -en especial en Durand- podría considerarse como la actualización moderna de la tríada vitruviana.

2.4.1.c. Para Blondel la arquitectura de la Francia de su tiempo debe asumir su conCaractère dición histórica en la distribution interior, que además de conseguir comodidad debe expresar la finalidad del edificio al exterior, como «Una arquitectura adecuada, tal como la entendemos, debe aspirar a pintar los ojos externos, en dignidad, valor, fortuna o economía». "Aquí comienza la historia del caractère, otro tema de discusión central de la función, que ya había sido anticipado por Vitruvio, quien había descrito un decor superior (statio) que era el aplicable a los templos de los dioses. La idea vitruviana tenía una validez genérica, que se movía según la calidad del edificio, y que mantenía una común aplicación a sus diversas partes. Del decor de Vitruvio se desprendían las representaciones de los órdenes, como la del dórico, tradicionalmente vinculada a lo masculino. Según Blondel, con el paso de los siglos tales caracteres se desvirtúan y se vuelven irreconocibles por la aparición de nuevos requerimientos funcionales 
asignado a los órdenes, el mismo puede replantearse. A partir del aporte de Blondel el caractère pasará a estar relacionado con el lenguaje de la arquitectura, una lógica de comunicación que permite vincular el origen del edificio, es decir, su función, con su imagen. De ahí el autor refiere a caracteres audaces, femeninos, enigmáticos, severos; se trata de una variedad que puede ser interpretada como una lengua en la cual la función del edificio es la semilla. En este tema será de mucha importancia el aporte posterior de su discípulo, Marie-Josep Peyre, quien agregue que el mismo caractère puede provocar sensaciones como terror, miedo, dulzura, respeto o tranquilidad. Además, Peyre considera que la arquitectura de la antigüedad tiene un valor normativo que debería ser recuperado; en ella ve la belle ordonnance y la distribution (que se supone inventada por los propios franceses) al mismo tiempo. Para Peyre los edificios romanos tenían una distribución óptima, por lo que, en sus proyectos, replica tipos romanos, adaptando su uso al presente.

2.4.1.d. Volviendo a su Cours D'Architecture Blondel remarca ya en la primera sección de la "Introducción" ("De la utilidad de la Arquitectura") la importancia del género de los edificios, lo cual seguirá estando presente a lo largo del texto. Para Blondel la arquitectura naval y la arquitectura de guerra resultan esenciales en la conformación de la «arquitectura civil». El rigor y la racionalidad en necesidades extremas deben ponerse, según el autor, por delante de toda cuestión, y conlleva inevitablemente a avances de importancia. Reconoce un «diseño de la guerra» que, sin ser muy lejano al arquitectónico, permite que una civilización se erija frente a otra. Hasta ahí la racionalidad hace su juego; pero la guerra continúa en su representación, y así aparecen motivos, como el arco del triunfo, que nace de una imaginación también necesaria para dar al suceso histórico una representación social, en este caso, la de transmitir la gloria de una batalla ganada. En este sentido caben con claridad los dos polos antes mencionados (razón e imaginación), ya que la representación no se consigue sólo con el correcto funcionamiento de un artefacto, sino que necesita de un 'relato hacia afuera' que la haga visible. La arquitectura tiene la cualidad de posibilitar, según Blondel, estas dos facetas en paralelo. En esta misma sintonía es que distingue entre la arquitectura "verosímil» y la "verdadera». Para Blondel «Un edificio es, a primera vista, un anuncio de lo que él es», ${ }^{5}$ y la verosimilitud pone por delante la «idea del edificio» antes que la realidad del mismo. La realidad puede a veces no sorprender, ser insuficiente o incluso innecesaria; por lo mismo, atender a la verdad no implica atender a lo verosímil. La verosimilitud puede ser necesaria para establecer una "corrección" que permita entender la idea de verdad. Para Blondel, «Una arquitectura verosímil es el fruto del razonamiento y de la meditación del arquitecto antes que de la aplicación de los preceptos; la verosimilitud es a veces preferible a una verdad que repele más de lo que satisface». ${ }^{6}$

Blondel considera a la arquitectura como un "arte útil», que supone como "el más antiguo de todos y al cual las demás artes se subordinan. Mientras las otras artes se basan en la imitación, la arquitectura más bien crea los objetos que esas otras artes imitan, abre el campo de la imaginación».7 Por lo 
De Zurko, Edward, La teoría del funcionalismo en la arquitectura (Buenos Aires: Nueva Visión, 1970), p. 156. (Ed. orig. 1957).

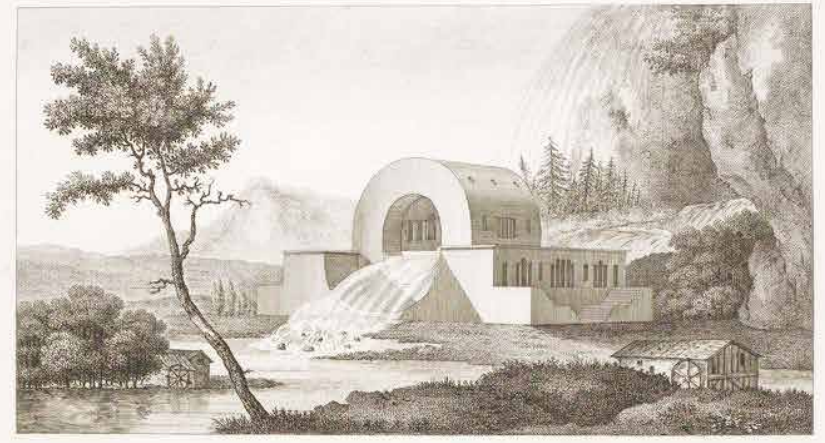

cinest.
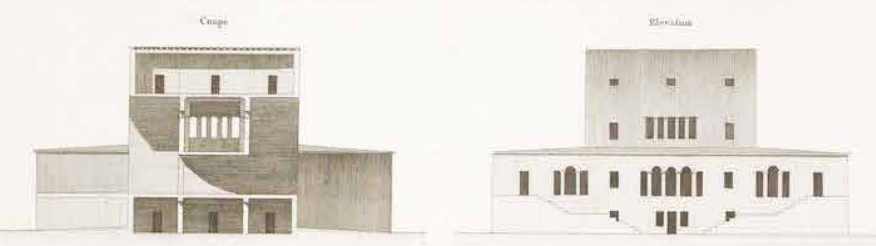

somed tager
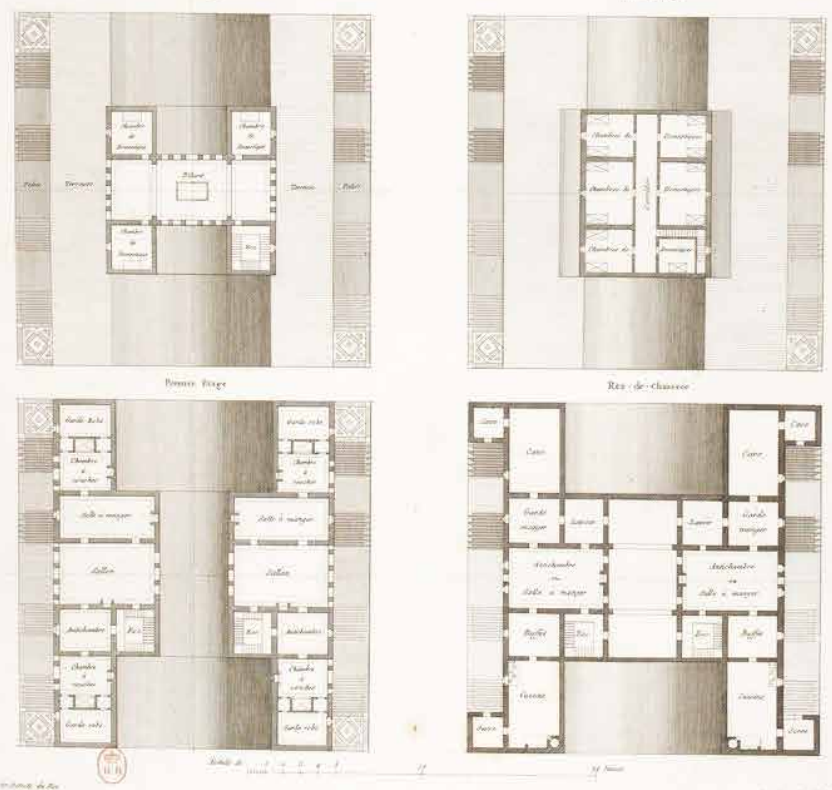

[FG.02]

Claude-Nicolas Ledoux Casa del vigilante del río

París: L'Architecture considérée sous le rapport de l'art, des mœurs et de la législation, 
arquitectura y de su tradición. Interpreta unos orígenes primitivos similares a los de Vitruvio, otorgándole importancia a la columna como elemento originario y constitutivo de la disciplina. Destaca que las primeras columnas fueron invención de los egipcios, autores a su vez del obelisco -elemento esencial que puede entenderse como una síntesis de las ideas del autor-cuya razón estructural confiere su propia forma, la cual además de permitir una audacia estructural la convierte también en símbolo.

2.4.1.e. Parte del pensamiento de Blondel encuentra una continuación y profundización

Boullée y Ledoux. Instrumento educativo a través de dos de sus más notables discípulos: Étienne-Louis Boullée y Claude-Nicolas Ledoux. Ledoux, sobre todo a través de sus diseños, compilados en 1804 en L'architecture considérée sous le rapport de l'art, des moeurs et de la législation, confiere al arquitecto un papel marcadamente diferente al de la tradición; lo coloca como una pieza esencial en la balanza de lo moral, político y cultural. El arquitecto, o mejor dicho, la arquitectura es para Ledoux capaz de «purificar» el sistema social por medio de su mensaje; el arquitecto como educador, y la arquitectura como intermediaria. A pesar de haber vivido el período de la Revolución, Ledoux intentó mantener su discurso al margen de la revuelta social. El autor no persigue un rol efectivo dentro de la transformación que en ese momento vivía Francia, sino que más bien vuelca sus energías a una lucha interna, disciplinar, por el rol general que el arquitecto debiera asumir. Frente a este ambicioso programa Ledoux traspasa el límite meramente expresivo de la idea de caractère de Blondel para alcanzar un rol educativo: el diálogo entre el edificio (su sentido y su fin) y la sociedad. Resulta también una novedad que para Ledoux no existieran edificios de mayor o menor importancia; la cabaña y el palacio tendrán la misma consideración en la llamada "arquitectura parlante»; pero esto no significa una igualdad de condiciones en pos de nuevos criterios sociales, sino una igualdad de oportunidades de comunicación que la arquitectura debe aprovechar para ampliar su marco cultural; la égalité es para Ledoux una igualdad moral dentro de un orden social, y nada tiene que ver con la égalité de la Revolución Francesa. Entre sus muchos proyectos destaca la casa del Vigilante del Río para su proyecto de ciudad ideal de Chaux de 1804, en la que propone, en el volumen principal, una perforación que permite el avance del río; esta operación comunica de forma evidente el sentido primero del edificio, encarnando el rol educacional a través de un mensaje directo. [FG.02] Por otro lado, Ledoux no está tan preocupado por la función concreta del edificio como por su mensaje; su ligazón con la sociedad a través de su imagen. Se trata de una función en todo sentido simbólica. Según De Zurko, la elección de formas puras tiene que ver con el interés de Ledoux por dotar de un significado fácilmente visible a las funciones de los edificios:

Las formas geométricas simples tales como cubos y esferas eran no sólo las más útiles para Ledoux, sino que, siguiendo la tradición pitagórica y platónica, éste vio en ellas un vínculo metafísico con la moral, los ideales sociales y la naturaleza. Asoció, pues, la geometría de la forma arquitectónica con las costumbres e ideales de la gente. Las formas geométricas simples eran de por sí puras y, además, símbolo de virtudes. ${ }^{8}$ 
Por otro lado Boullée, sobre todo a través de su escrito de 1794, Architecture. Essai sur l'art, busca recuperar el caractère como un decoro específico para cada edificio, pero lo entiende no como una comunicación social, al modo de Ledoux, sino como un herramienta que permite indagar en la profundidad del proyecto. Según él,

Imprimir carácter a una obra significa emplear en su justa medida todos los medios más idóneos para no suscitar en nosotros otras sensaciones que aquellas que convienen a su propio asunto (...) El carácter se percibe imaginándolo. Por primera vez en la historia nos enfrentamos a una arquitectura de imagen...9

Finalmente, según Kruft, en referencia a Ledoux y Boullée, "...común a ambos es el desinterés por la función en sentido de utilidad de la arquitectura (...) (ésta) pasa a ser un portador de contenidos, un instrumento educativo, pero no suele ser ni habitable ni utilizable». ${ }^{10} Y$ aunque esta afirmación pueda resultar discutible, cierto es que el aporte de los discípulos de Blondel está más cerca de la representación de la función, de un fantaseo con la misma, que de la indagación en la función concreta de los edificios.

La industrialización trae también consigo el fenómeno de la concentración, exigiendo el acercamiento -y con esto el desplazamiento- de los trabajadores a su puesto de trabajo; la necesidad de urbanizaciones aledañas a las áreas de producción es un fenómeno característico del siglo XIX en el que el asentamiento de una nueva industria comienza a requerir a su vez la aparición de una ciudad contigua, realizada desde cero. Este fenómeno ve aparecer, también como producto de la Revolución Francesa, una serie de propuestas que, bajo parámetros económico-sociales traen dentro de sí una intención de reforma social al mismo tiempo que una arquitectura propia. El Ilamado "socialismo utópico" encarna una de las corrientes que con más énfasis conjuga estas lecturas -generalmente limitadas al plano teórico- con propuestas concretas que incluyen una organización espacial, y una organización rigurosa de las actividades que la componen, en una mixtura entre arquitectura, urbanismo y transformación política. La función del proyecto arquitectónico se entiende, dentro de este marco, como una hipótesis para el correcto funcionamiento de una 'sociedad nueva,' con reglas (e incluso leyes) propias. Por lo mismo, el rol que la 'conectividad' tendrá en estas propuestas requerirá de un rigor que podría asimilarse al de una máquina -adelantándose en un siglo a la célebre frase de Le Corbusier. Pero esta característica no se limita sólo a estos conjuntos habitacionales, sino que es común a otros programas de tamaño considerable que comienzan a ponerse en práctica en el siglo XIX por parte de gobiernos e instituciones, como lo son las cárceles, las escuelas o los hospitales; programas que se planean con el objetivo de garantizar una clara y rigurosa organización, no sólo en términos logísticos, sino también espaciales. Por lo mismo, la función misma del edificio será tensada bajo unas exigencias de particularidad y conocimiento específico de las actividades a realizarse. En la novela de 1516 de Thomas Moro, titulada Utopía se origina este concepto en el cual, por medio de la razón, la política la economía y la organización social
Etienne-Louis citado en Arnau, Joaquín, 72 voces para un diccionario de arquitectura teórica (Madrid: Celeste, 2000), p. 18

10. Kruft, Hanno-Walter citado en González, José Luis, El Legado oculto de Vitruvio. Saber constructivo y teoría arquitectónica (Madrid: Alianza Forma, 1993), p. 119.

11. Cervio, Ana Lucía, "Claves para un habitar apasionado," en Teoría social, cuerpos y emociones, ed. Scribano, Adrián Oscar (Buenos Aires: Estudios Sociológicos Editora, 2013), p. 27.

12.

Fourier, Charles, “El Falansterio," en Teoría de la unidad universal, ed. Cortés, Chantal López y Omar (México: Biblioteca Virtual Antorcha, 2006), p. 26. (Ed. orig. 1822)

2.4 .2

Fourier. Distribución social 
consiguen la perfección. Es un estado que, frente al desequilibrio liberal -que podría verse identificado en la política inglesa- garantiza la igualdad entre las personas. ${ }^{11}$ Cuando la función atraviesa el velo de la necesidad con el objetivo transformador de mejorar la vida recurriendo a un modo de organización que se aparte de las tradiciones, la idea de utopía suele estar relacionada; las propuestas utópicas no sólo plantean un modo de vida ideal, sino que al mismo tiempo funcionan como una crítica a la política de su tiempo. En el "socialismo utópico", como en varios otros casos, las propuestas no provienen necesariamente de una voluntad colectiva, sino más bien del pensamiento individual, de una -en principio- ficción que permitiría finalmente acercarse a la felicidad traspasando el caos existente. Esa es la esencia de Utopía de Moro y es también la esencia del "socialismo utópico»; las experiencias relacionadas a este último representan tanto un programa político como arquitectónico, ya que el mismo edificio es el que condensa el orden que este sistema requiere. Gran parte de las propuestas de Henri de Saint-Simon, Charles Fourier y Robert Owen se nutren de las pésimas condiciones de vida que caracterizan a esta nueva clase trabajadora, producto de los avances de la industrialización del siglo XIX.

2.4.2.b. De entre los teóricos de este «socialismo utópico» probablemente sea Fourier el que más vínculos tenga con la arquitectura, -aunque ya existieran experiencias paralelas, como New Lanark, gestionada por Robert Owen en Escocia durante las primeras dos décadas del siglo XIX- y esto tiene que ver explícitamente con el desarrollo profundo que el mismo autor hace del phalanstère, el edificio que alberga esta nueva organización social. El proyecto del phalanstère, con una disposición exterior simétrica que recuerda a la del palacio barroco, opta por una distribución angosta que va cerrando, en todo su perímetro, una serie de patios interiores. El programa del phalanstère puede asimilarse al de una pequeña ciudad; contiene, además de las viviendas, los lugares de trabajo, los graneros, la escuela, la iglesia y el teatro. En su descripción el mismo Fourier adopta una explicación similar a la de los tratados de arquitectura: recomienda para su ubicación que no se alce muy lejos de una ciudad, que tenga cerca un bosque, que cuente con conexión a un río, que sea un terreno fértil, apto para el cultivo:

El centro del palacio o falansterio, debe dedicarse a las funciones apacibles, comedores, Bolsa, biblioteca, salas de reunión y de estudio, etc. En ese centro estará el templo, la torre del vigía, el telégrafo, las palomas mensajeras, el observatorio, la campana de ceremonias y el patio de invierno, adornado con plantas resinosas y situado al respaldo del patio principal.

Una de las alas debe reunir todos los talleres ruidosos, como carpintería, herrería, etc., y todas las reuniones infantiles que son tan bulliciosas en industria como en música. Se evitará con esta reunión uno de los más molestos inconvenientes de nuestras ciudades civilizadas, donde se encuentran en cada calle obreros de martillo, forjas o aprendices de clarinete, que rompen el tímpano de cincuenta vecinos.

La otra ala debe contener el hospedaje para viajeros, con salas de baile y de reunión de extranjeros a fin de que no asalten el centro del palacio, ni molesten 

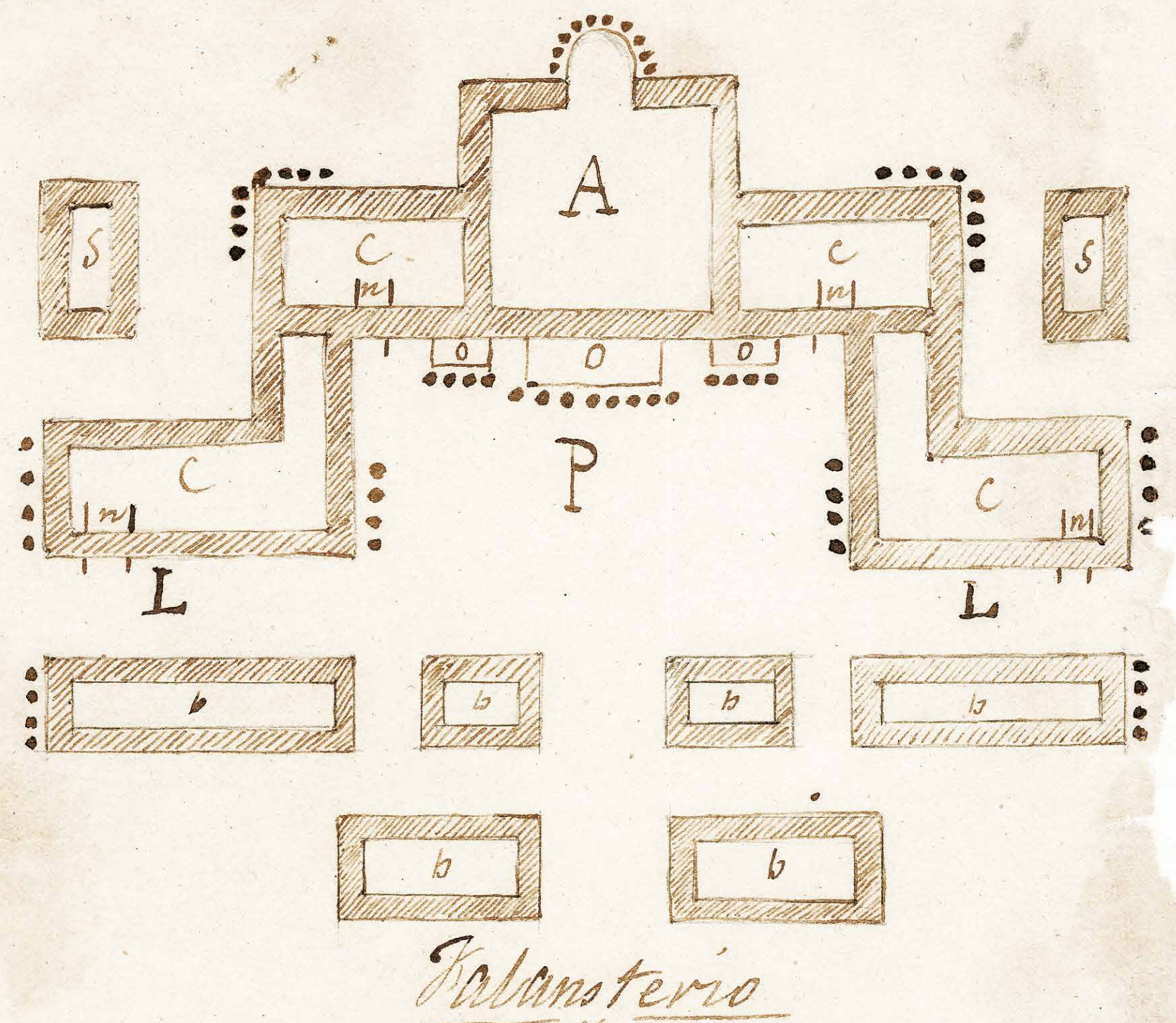

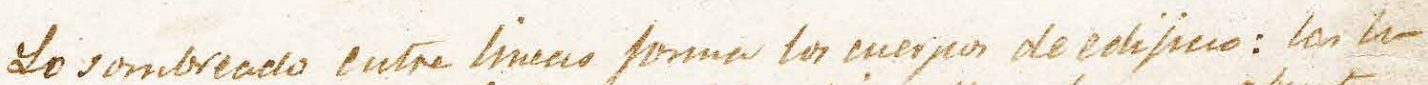

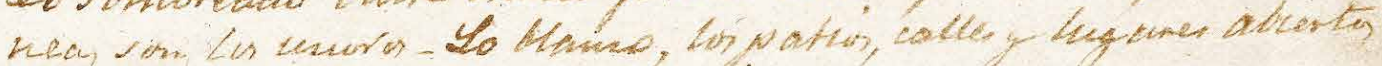

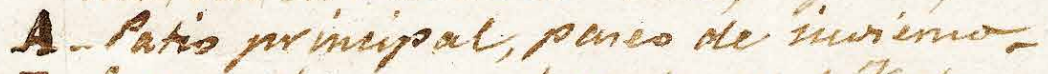

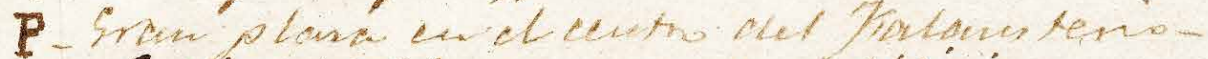

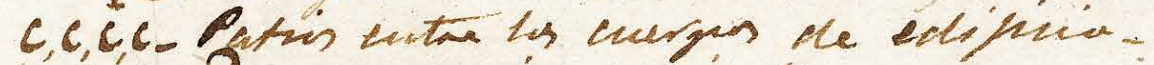

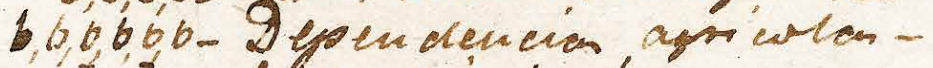

L.L - Conve pons aispl.

S, $s-$ Yylesis, Pearo-

$0,0,0$ - 3es portices para vivizies diversos.

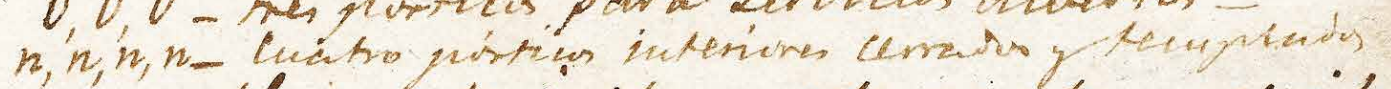

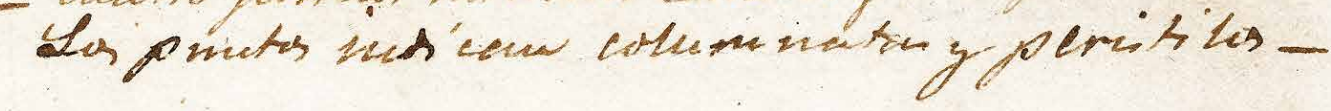



sociales anteriores. Aquí se encuentra uno de los puntos más interesantes de la teoría de Fourier, quien propone que los modos de organización deben ser resultado de un entendimiento de las "pasiones" que caracterizan a cada persona. Para lo mismo elabora un cuadro con doce pasiones, divididas en tres grupos: en el primero, el que denomina "sensitivo", incluye los cinco sentidos; el segundo es el "afectivo", cuyas pasiones serían la ambición, la amistad, el amor y la familia; el tercero es el "distributivo", que incluyen al disidente, alternante o coincidente. [FG.03] Para Fourier estas pasiones, en conjunto con las etapas de la vida, serían los puntos vinculantes dentro de la sociedad, lo cual permitiría ubicar a las personas en un lugar apropiado dentro del phalanstère. Como menciona Ana Lucía Cervio, este nuevo orden tendría que ver con «a) aprovechar y canalizar hacia fines socialmente útiles las discordias naturales entre los hombres, b) rebatir el tedio y la monotonía a que conducen el régimen doméstico e industrial y c) celebrar la reunión corporativa de acuerdo a gustos, instintos, motivaciones y deseos". ${ }^{13}$ Se trata de algún modo de una racionalidad aplicada a la organización social y al trabajo que se basa en características afectivas. El phalanstère se vuelve en este sentido un artefacto inclusivo, que requiere de sus pares opuestos, y las gradaciones entre ellos, tanto en lo afectivo como en lo económico; en el mismo convivirán el rico el pobre, el niño y el anciano, el alegre y el acongojado; esta gradación de desigualdades busca lo que Fourier considera fundamental en una sociedad, que es el "movimiento» según las diferencias, que permitiría a las personas desplazarse de acuerdo a estímulos personales en vez de necesidades u obligaciones. Probablemente, la problematización y consideración de las diferencias entre individuos sea uno de los rasgos más característicos de la 'conectividad' en el phalanstère; los habitantes del mismo no son partículas de una masa uniforme. Aunque no llegue a expresarse completamente desde lo arquitectónico, sí existe en Fourier la particularidad de considerar a los usuarios por sus diferencias, y de distribuir el espacio según las mismas. En este aspecto resulta una propuesta completamente novedosa en el marco de la función, la cual inaugura la incorporación de las variables individuales en un marco social, que cuenta con un vago origen en la idea de necessité de Perrault y el lugar que ocupa el Estado en la regulación de las necesidades.

2.4.2.c. El phalanstère se propone como un nuevo modo de arquitectura y urbanismo liberadores en el marco de la industrialización del siglo XIX, aunque quizás no pueda considerarse un modelo de referencia en cuanto a la 'conectividad' para experiencias posteriores; al fin y al cabo, la distribución del mismo no dista demasiado de la de un palacio real, considerando el séquito necesario para que el mismo funcione con todos sus servicios. Aunque Vitruvio, al desarrollar su concepto de dispositio, ya había atribuido a la arquitectura el problema de organizar los estratos sociales en los edificios, el paradigma representado por el proyecto de Fourier tiene más que ver con la necesidad de que la arquitec- 
elemento imprescindible para su óptimo desarrollo. La importancia radica en que, en la descripción de la distribución del phalanstère realizada por Fourier, se confía en que a través de la 'conectividad' de las funciones de un edificio es posible transformar la propia estructura social. Esta sociedad ideal -imaginada no sólo por Fourier, sino también por Robert Owen en New Harmony, por Guise de Jean-Baptiste Godin en el familistère o por Oliveira de Benoît Jules Mure en el otro phalanstère- tenía entre sus fines regular las actividades humanas, no sólo en cuanto a horarios de trabajo, sino también en cuanto al resto del tiempo; el horario de descanso o de ocio. Por medio de un control riguroso y directo sobre cada detalle de las actividades -encarnado también en las cárceles, escuelas u hospitales- era posible, según esta visión ampliada durante el siglo XIX, alcanzar la felicidad. ${ }^{14}$ Si bien la propuesta de Fourier aparece con un tono liberador en comparación a la noción de "sociedad utilitaria" -cuyo referente más destacado es Jeremy Bentham por su difusión del control social a través del panóptico- en términos funcionales, no presenta soluciones renovadoras, más allá de definir un sector para cada actividad. Su originalidad radica en su concepción de relacionar afectivamente a los grupos sociales, y de requerir para esto de un edificio autosuficiente, que pueda construirse sobre una tabula rasa, y que se comporte desde el minuto cero como una ciudad en miniatura.

El siglo XIX vio aparecer en Prusia a una serie de pensadores de arquitectura de enorme importancia, tanto para dicho periodo como para el siglo posterior. Tanto Gottfried Semper, como Karl Bötticher o August Schmarsow se dedican a revisar en detalle la historia de la arquitectura, recurriendo a veces, como en el caso de Bötticher, a la arqueología, evitando un enfoque puramente historicista, y permitiéndose valorar la conjunción de los diversos estilos sin tener que recurrir, como en el caso de otros pensadores del siglo XIX, a uno en particular. Semper, habiendo estudiado arquitectura en la Ludwig-Maximilians-Universität de Munich, se convierte en uno de los teóricos de mayor importancia, escribiendo fuera de Prusia, la cual se ve obligado a abandonar luego del fracaso de la revolución de 1848, en la cual tomó parte activa. Asentado temporalmente en Londres, escribe en 1851 Die vier Elemente der Baukunst, en los que resalta sobre todo la cuestión técnica de la arquitectura, otorgándole a esta valores estéticos, y entendiéndola a su vez en un sentido evolucionista.

Los escritos de Semper incluyen simultáneamente el interés por los elementos propios de la disciplina -como ser suelos, muros y cubiertas-, y los factores externos que los condicionan -los lugares, las instituciones, la cultura, las formas de vida, y la utilidad en sí misma. El autor intentó indagar en todas estas cuestiones, aunque probablemente sea en las primeras donde lo haya conseguido con mayor profundidad; esto se debe, en parte, a que en la primera publicación de 1863 de Der Stil in den technischen und tektonischen Künsten, su obra más ambiciosa, escrita en sus años como profesor de la Eidgenössische Polytechnische Schule de Zúrich -en la cual trabajó en torno al arte textil, la cerámica, la tectónica y la estereotomía- Semper no llegó a finalizar un tercer tomo, en
Ver Artese, Martín, "Un sujeto disciplinado es un sujeto feliz. Bentham y la noción utilitarista del cuerpo y las emociones," en Teoría social, cuerpos y emociones, editado por Scribano, Adrián Oscar. (Buenos Aires: Estudios Sociológicos Editora, 2013).

15.

Ver Armesto, Antonio, "Prólogo: Der Herd und dessen Schutz: Gottfried Semper o la arquitectura como ciencia" en Semper, Gottfried, Escritos fundamentales de Gottfried Semper. El fuego y su protección. (Barcelona: Arquia, 2014).

16.

Según Ute Poerschke, en el período en que Semper utiliza el término Funktion estaba comenzando a consolidarse casi como una moda, y por lo mismo, tanto él como Karl Bötticher -en Die tektonik der Hellenen- deciden reemplazarla en ediciones posteriores. En el caso de Semper, buscando opciones más originales, como Verrichtung o Dienst. Ver Poerschke, Ute, Architectural Theory of Moder-

nism: Relating Functions and Forms (Londres: Routledge, 2016), p. 83. Sin embargo, como Poerschke asegura, no se trató tanto de un cambio de ideas como de un cambio puramente linguístico. Funktion podía resultar, en una nación en vías de consolidación como estado, una palabra demasiado extranjera.

17.

Ver Armesto, Antonio, "Prólogo: Der Herd und dessen Schutz: Gottfried Semper o la arquitectura como ciencia" en Semper, Escritos

\subsection{3.}

Semper. Del refugio al acto

fundamentales de Gottfried Semper, p.11.

18.

Semper, Gottfried, El estilo en las artes técnicas y tectónicas, o estética práctica y textos complementarios (Azpiazu ediciones, 2013), p. 160. (Ed. orig. 1863).

19.

Ibid.

\subsection{3.a.}

Teoría total 
el cual se expondría un estudio de la estructura social y las condicionantes culturales de la época, ${ }^{15}$ según el autor, "los más poderosos factores del estilo». Con alta probabilidad este trabajo hubiera significado un aporte aún más profundo al problema de la función -o Verrichtung (rendimiento) o Dienst (servicio), como el mismo autor la denomina. ${ }^{16}$ Alguna aproximación a lo que hubiera podido constituirlo queda plasmada en su última obra, el discurso de 1869 , Uber Baustile.

En Der Stijl... Semper busca desentrañar los orígenes y las formas propias de la arquitectura, en dirección a un estilo único capaz de unificar los diversos criterios y conocimientos acumulados en la historia. A pesar de coincidir con Durand en la búsqueda de una teoría general, le critica a este haber mantenido demasiada distancia con respecto a la práctica de la arquitectura, colocando a Rondelet como el ejemplo contrario, es decir, el de una práctica avanzada y un desarrollo teórico escueto. ${ }^{17}$ Esta vocación por una 'teoría total' es común al idealismo característico del siglo XIX -Semper busca reflejarse en Newton o Humboldt-, intentando mantener un equilibrio entre sus propuestas más teóricas y sus observaciones empíricas. Además se ve volcado en esta empresa respaldado por una actitud crítica hacia el eclecticismo imperante en un período en el cual los principios primordiales de la tradición vitruviana se encontraban ya dispersos. Es en este proceso de estudio de los modos de vida primitivos y de las primeras formas de organización en donde Semper va arrojando luz sobre las primeras formas de organización de la arquitectura, sobre sus modos de división y su 'conectividad' interna. Pero, dada la amplitud de los temas que el autor llega a tocar, sus aportes también servirán de base en algunos puntos para las nociones de 'eficacia' o ‘adaptación'.

2.4.3.b. Para Semper resulta fundamental comprender tanto la idea de supervivencia en las tribus primitivas como su constante reminiscencia a formas políticas pasadas que fueron evolucionando, lo cual explicaría la persistencia de diferentes formas de organización, ${ }^{18}$ de modo que

\section{...las formas sociales en apariencia más primitivas manifiestan ser fragmentos arrancados de grandes troncos culturales anteriores por fenómenos natura- les o por catástrofes políticas, como si fueran bloques erráticos; y a la inversa, allí donde dentro del horizonte conocido de la historia cultural aparece el fenó- meno de la conjunción de nuevas formas sociales... ${ }^{19}$ \\ Para construir sus principios fundamentales, Semper vuelve a acer-} carse a la primer hipótesis de Vitruvio, en la cual se concibe el fuego como primer foco de refugio humano, y como catalizador de una comunión social. Este "encuentro" implica, para Semper el Herdfeuer, la primera noción de espacio, un espacio exclusivamente social, en el cual es posible también la existencia de la arquitectura, la cual se hará presente a través de al menos un elemento fundamental que la constituya como refugio: muro, cubierta o suelo. [FG.04] El sentido originario de estos primeros elementos arquitectónicos y su composición no tiene que ver, según Semper, con su rol funcional propio, sino que de lo que se trata es, justamente, de preservar la continuidad de este fuego, que es lo que sostiene la vida en comunidad. 
Antes de erigir tiendas, recintos y cabañas, los hombres se reunían en torno al fuego vivificante, que les calentaba, les secaba y les servía para preparar sus sencillos alimentos. El hogar constituye el núcleo, el embrión de toda organización social. El primer signo de reunión, de permanencia en un lugar, de descanso tras la migración y la fatiga de la casa, lo constituye siempre la erección del hogar y el despertar de la llama crepitante. Muy pronto se le consagró un culto, al que se vinculan las formas y conceptos religiosos más antiguos y permanentes. Constituye un símbolo moral que, desde las épocas más tempranas, une a familias, tribus y pueblos y contribuye con ello a establecer nexos sociales y a satisfacer eficazmente las necesidades más elementales. ${ }^{20}$

La idea del fuego como germen de las comunidades primitivas encuentra, como se ha mencionado, a Vitruvio como primera referencia, quien lo ubica como elemento central de la convivencia humana. Para Semper este Herdfeuer (el hogar, el fuego) implica también el origen de la vivienda, que nace como su protección frente a las inclemencias climáticas o a los ataques de animales salvajes y enemigos. Del cuidado por el Herdfeuer es que se requiere elevar el suelo para evitar crecidas de agua, los muros para evitar el acercamiento de los animales, y la cubierta para protegerse de la lluvia. Estos serían los roles primarios de los tres elementos, que satisfacen la necesidad básica de proteger este foco central. Pero es posible interpretar un segundo estadio funcional de los mismos, ya que cada uno presenta posibilidades que, con la evolución resultarán esenciales en la arquitectura. El 'terraplenado' define, en un sentido muy básico, un espacio artificial y humano para operar frente al suelo y diferenciarse de la naturaleza; resulta, de algún modo, una forma de enmarcar el territorio sin salirse de él; tiende a ser plano, lo cual favorece otras actividades en relación al suelo natural irregular, y es posible que se construya con un material que permita sentarse en él, reunirse. El muro no es sólo protección del viento y de los animales, sino que agrega un elemento fundamental a la arquitectura que es la discontinuidad visual, o podría decirse también, la intimidad; esta cualidad permite en primer lugar separar las actividades una de otra -como ya lo notara Alberti en su idea de commoditas, ofreciendo un primer eslabón para la 'conectividad' Finalmente, la cubierta reemplaza al árbol, que no interrumpe la continuidad con el espacio circundante, pero sí es capaz de definir un lugar propio

En cuanto al origen de las construcciones, la cueva supuso un refugio que, según Semper, debe entenderse como excepcional, ya que no se encontraba en todas partes, por eso es que se debería prescindir de ella al estudiar los tipos constructivos originarios. Para el autor existen entonces dos orígenes: la vivienda recinto, con muro circundante, en cuyo interior se levantan cobertizos abiertos; y la cabaña, la casa exenta en el sentido más estricto. En el primero domina el muro y en el segundo la cubierta. De ahí que la primer vida social existente resulte, para Semper, la vida familiar; de hecho, los primeros estados se organizan, según él, a partir de pactos entre distintas tribus según lazos familiares. "Estas primeras relaciones de asociación que constituyen los estados se transforman en general en un sistema político dominado por un poder
"Teoría comparada de la arquitectura", 1849 en Escritos fundamentales de Gottfried Semper. El fuego y su protección. El fuego y su protección. Vol. 37, (Barcelona: Arquia, 2014) p. 107

21.

"Teoría comparada de la arquitectura" en ibid. p. 111.

22.

"Teoría comparada de la arquitectura" en ibid. p. 107.

23.

"Cuando dos ejércitos consulares romanos operaban al unísono, cada uno de ellos levan-

2.4.3.b.

\section{Elementos originarios}

taba su propio campamento junto al del otro. Este principio de aglutinación constituye la ley de crecimiento de todos los estilos que basan su concepción fundamental en la idea del campamento fortificado, como el de los caldeo-asirios, también el de los persas, chinos e incluso hindúes". Semper, Gottfried, "Sobre los estilos arquitectónicos”, en Ibid. p. 353.

\subsection{3.c}



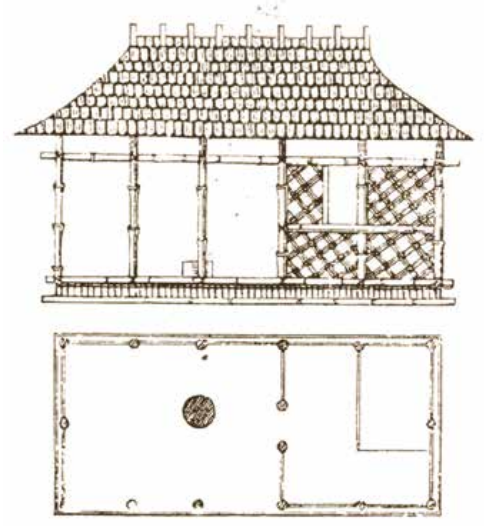

[FG.04]

Gottfried Semper,

Los elementos de la arquitectura Dresden: Die vier Elemente der Baukunst, 1851.

2.4.3.d

Centro

[FG.05]

Gottfried Semper,

Villa Grundriss. Planta Baja

Dresden: Bauen in Dresden im 19. und 20. Jahrhundert

1839

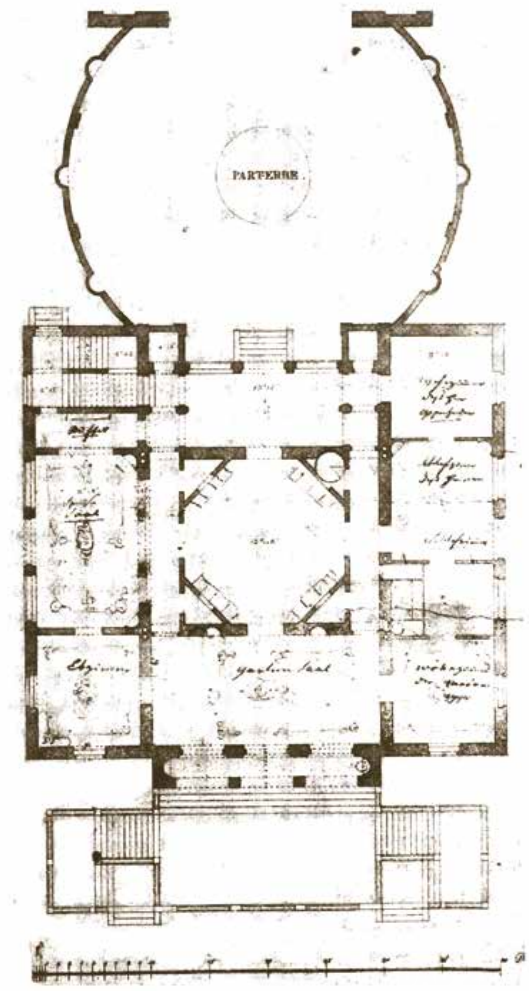

sacerdotal, señorial o principesco, como muestran numerosísimos ejemplos de la Antigüedad... ${ }^{21}$ Cuando analiza los palacios reales de la arquitectura asirio-caldea encuentra un germen de organización que proviene del campamento militar, que se contrapone a la arquitectura egipcia, basada en un elemento central desde el cual se dispone el resto:

(...) una arquitectura surgida del campamento militar (...) No puede desarroIlarse a partir de un núcleo y crecer desde una dimensión pequeña hasta otra mucho mayor, como la egipcia: tiene que nacer con energía, cerrándose en sí misma en torno al elemento central, de manera que sea susceptible de crecer, para formar y añadir un segundo campamento, organizado de modo semejan-

te. Cada pieza perteneciente a ese ejército (la tienda del general, 'el palacio del señor de la guerra') posee una existencia propia ligada a todo el conjunto, hasta llegar sucesivamente a la unidad más pequeña. ${ }^{22}$

Esto constituiría un modo de organización social por partes que requeriría una racionalización previa. A diferencia del modo intuitivo del hogar, correspondiente a la noción albertiana de necessitas, el campamento militar estaría ligado a un esquema de organización sintético, que incluso superaría a commoditas, para acercarse a nociones de la tradición francesa, como la distribution de Blondel, o inlcuso a la composition de Durand, al referirse a la construcción por partes. Semper establece así que con la casa surgen los principios básicos de la arquitectura, pero es en el campamento militar donde se origina lo que podría entenderse como "construcción civilizada". ${ }^{23}$

Además de su labor teórica, Semper también tuvo oportunidad de desarrollarse como arquitecto en algunas importantes obras en las que, sin romper la continuidad con el sistema clásico, se inclinó hacia el eclecticismo. Con influencias palladianas, en la planta de la Villa Grundriss, en Dresden -aunque construida más de una década antes de sus escritos más importantes- es posible verificar la intención de enfatizar este interior casi sagrado, que al autor entiende como el hogar. [FG.05] En efecto, el salón central de la casa busca remarcar un punto central, con su geometría octogonal y su cúpula, que a falta del fuego primitivo, termina rindiendo homenaje a este espacio de sociabilidad, que es el interior burgués. Si en la obra de Palladio este espacio se encontraba atravesado por cuatro aberturas que permitían la fuga visual hacia el paisaje, a la vez que el ingreso de luz natural, en este caso Semper pareciera intentar lo contrario, llevando a este salón a distanciarse más del exterior y encontrar su autonomía en el centro del edificio, quizás ese invisible Herdfeuer. Tanto así que el mismo se diferencia, en el interior de la misma casa, como un volumen de planta cuadrada, cerrado en sí mismo. Además Semper enfatiza en el acceso la idea de terraplenado macizo, al evitar la solución monumental de escalera central, optando por dos escaleras laterales que terminan generando una terraza al frente, que separa considerablemente la casa del suelo. El diseño del parterre posterior podría interpretarse como otro guiño más a su noción de 'protección del fuego;' en él denota, con sus muros cerrándose en círculo, una protección básica hacia lo externo, al mismo tiempo que por la geometría centrípeta se coloca en primer lugar el espacio de reunión central. 
Luego de la consolidación de este primer espacio de sociabilidad que es el hogar, el fuego podrá ser ya reemplazado por un objeto simbólico, al modo de un altar. ${ }^{24}$ Los elementos primordiales de la teoría de Semper tienen en su origen cierta relación con el traspaso de neccesitas hacia commoditas, presentes en la teoría de Alberti, ya que aparecen en principio como formas básicas y necesarias (Grundformen) y más tarde se convierten en símbolos. Este segundo paso, con interés en el significado, tiene que ver con la consolidación del elemento arquitectónico en la cultura, ${ }^{25}$ habiendo atravesado ya el umbral de la necesidad satisfecha, puede pasar a cumplir otros objetivos. Para Alberti, este segundo eslabón iría concentrado en la búsqueda de una comodidad superior a la necesidad. Semper, en cambio, realza la vocación tanto artística como comunicativa de esta primera arquitectura elemental.

El fuego como centro neurálgico se vería reemplazado más tarde por el monumento:

(...) el deseo de realizar cualquier acto solemne, de carácter religioso, un acontecimiento histórico universal, una acción estatal o central, proporcionó siempre la ocasión de perpetuar su memoria acometiendo empresas monumentales (...). El dispositivo festivo adorna y equipa el armazón improvisado con todos los elementos auxiliares y el esplendor que la ocasión del festejo reclama, enalteciendo la fiesta con tapices y cortinas que lo cubren, revistiéndolo con flores y ramajes, adornándolo con festones y coronas, con cintas ondeantes y trofeos. $^{26}$

De esta manera, desde un comienzo, impulsado por la más natural necesidad, como la búsqueda de un refugio, es que se llega al "acto»; ese ritual que, con el tiempo, requiere ser rememorado, y encuentra su perpetuación -haciendo eco de Blondel- en el monumento. El monumento tendría según Semper un importante rol en lo que puede entenderse como función social:

\section{(...) la necesidad que tuvo el hombre de asociar a un objeto exterior sus anhelos} sagrados se tradujo en el culto a los antepasados. Altar y hogar se convirtieron en conceptos hermanos, y la máscara mortuoria del fallecido, en la primera imagen divina. ${ }^{27}$

Esto está vinculado a la naturaleza comunicativa que Blondel visualizaba en la arquitectura por medio del caractère, entendido el mismo como lenguaje, o como una función social que la arquitectura se veía llevada a suplir. En el momento en que una expresión social cobra importancia, la arquitectura aparece como el arte destinado a darle permanencia a través del tiempo. ${ }^{28}$ Como es sabido, el tema de la técnica es central en la teoría de Semper. De modo similar a Ruskin, Semper estaba en contra del uso del hierro en la arquitectura ya que estimaba que este no era capaz de otorgar a la misma la masa y solidez de la piedra, y con estas el carácter monumental que requería. Al mismo tiempo cuestionaba las "cajas de vidrio" -al modo del Crystal Palace, o a algunas obras de Labrouste- ya que no veía que la arquitectura, con sus valores tradicionales, pudiera tener lugar en ellas. Semper presenta una postura clara frente al tema del revestimiento, el cual tendrá su origen en la cobertura textil del refugio primitivo, para aislar y proteger un interior. Así es
24. Ver Armesto, Antonio, "Prólogo. Der Herd und dessen Schutz: Gottfried Semper o la arquitectura como ciencia" en ibid. p. 9.

25.

Ver Armesto, Antonio, "Prólogo. Der Herd und dessen Schutz: Gottfried Semper o la arquitectura como ciencia" en ibid. p. 7 .

26.

Ibid. p. 28.

27.

Semper, Gottfried, "Teoría comparada de la arquitectura" (1849), en Escritos fundamentales de Gottfried Semper. El fuego y su protección. El fuego y su protección. Vol. 37, (Barcelona: Arquia, 2014). p. 108.

28.

"... cada vez que una forma nueva, o modificada en lo esencial, de la sociedad se configuró y encontró arraigo en la conciencia colectiva esa forma encontró a la arquitectura preparada para otorgarle su expresión monumental. Siempre se le reconoció a esta arte su poderosa influencia civilizadora; sus obras portaron conscientemente el sello que elevó a los sistemas religiosos, sociales y políticos dominantes, o en lucha por su predominio, a al categoría de símbolos. Pero ese nuevo impulso, allí donde había llegado el momento, no surgió de los arquitectos sino de los grandes regeneradores de la sociedad". Semper, Gottfried, "Sobre los estilos arquitectónicos" (1869), en ibid. p. 347.

29.

Semper, Gottfried, "Observaciones preliminares sobre la policromía en la arquitectura y la escultura de los antiguos" (1834), en Ibid. p. 77.

30.

Dado que el propósito de todo producto técnico sigue siendo en esencia el mismo en todas las épocas, ya que se basa en necesidades generales del hombre y leyes de la naturaleza, válidas en todo lugar y época, que buscan su expresión formal, y dado que en cambio los materiales empleados para realizar el producto y especialmente las maneras de elaboración de esos materiales cambian substancialmente a lo largo del tiempo y según el lugar y todas las demás circunstancias posibles, es entones apropiado asociar las consideraciones sobre la historia del estilo a las referidas al material. El estilo en las artes técnicas y tectónicas, o estética práctica y textos complementarios, p. 162.

31.

Ibid. p. 178.

\subsection{3. f}

\section{Revestimiento}

32.

Rigotti, Ana María, "Gottfried Semper," en Cuaderno del Laboratorio de Historia Urbana (Rosario: Ana María Rigotti, 2009).

33. Semper explica que los asirios, al revestir el fuste de la columna de madera con metal descubrieron la rigidez de este último, permitiéndoles liberar el interior de madera. 
que el origen del revestimiento tiene, para el autor, cierta coincidencia con el origen de la vestimenta. Estos primeros tejidos evolucionarían más tarde como revestimientos sobre los muros de soporte. [FG.06] Si para Laugier la decoración se inició después de que el hombre consiguiera solventar sus necesidades básicas, para Semper el revestimiento cobra sentido como elemento capaz de enaltecer el ritual que un monumento requiere. Al contrario que Laugier, Semper insiste en el origen funcional del adorno cuando dice que:

Ya desde el desarrollo más temprano del embrión de la necesidad humana, las artes aparecen en una estrecha y creciente relación (...). Las artes nacieron asociadas cuando se empezaron a revestir decorativamente las primeras moradas desnudas, construidas para hacer frente a las inclemencias meteorológicas y a las acechanzas de los enemigos. Esto debió ocurrir muy pronto, pues el juego y el adorno parecen ser inherentes a las primeras necesidades en los albores de la humanidad. ${ }^{29}$

Las artes técnicas cuentan, según el autor, con dos orígenes: en primer lugar con la obra como resultado de la función o el uso al que estará destinada -entendiendo a este como uso concreto o simbólico, en el caso de un monumento-, y en segundo lugar con la obra como resultado del material, las herramientas y procedimientos implementados al producirla. En esta operación, Semper llega a una conclusión fundamental, que en principio podría conectarlo con Ruskin, ya que para él, la función de la arquitectura es estática, es decir que no sufre modificaciones sustanciales en las diferentes épocas, sino que lo que cambia de modo más contrastado es la técnica en la cual la arquitectura se produce. En este sentido Semper visualiza una continuidad de los modos funcionales de la cultura: aunque se requiera, por necesidad, de nuevos programas, los anteriores seguirían siendo válidos. Así, si bien la técnica carga con el peso más grande de la evolución, ${ }^{30}$ no significa que la misma esté exenta, para Semper, de un contenido netamente funcional. De este modo explica que:

La necesidad de protección, de cobertura y de cierre espacial constituyó uno de los primeros acicates para la invención industrial. El hombre aprendió a reconocer la naturaleza y el propósito de las coberturas naturales (la piel afelpada del animal, la corteza protectora del árbol), a utilizarlas para sus propios fines según su función natural correctamente entendida, y finalmente a emularlas por medio del tejido artificial. El uso de estas coberturas es anterior al lenguaje. ${ }^{31}$

En este punto aparece una importante discusión con su contemporáneo Bötticher ${ }^{32}$ que sirve como antecedente de la 'adaptación' funcional. Para Bötticher existe una relación constante entre lo que distingue como la "forma técnica" (Kernform) y la "forma artística" o "simbólica» (Kunstform). Ambas le resultan dependientes una de la otra, siendo que "la forma artística nace del mismo acto en que viene concebido el esquema mecánico de la parte». En cambio, para Semper, no existe tal distinción, dotando incluso al revestimiento de roles técnicos o funcionales. ${ }^{33}$

2.4.3.g. La distinción entre lo natural y lo racional, propio del hacer arquitectónico, es 


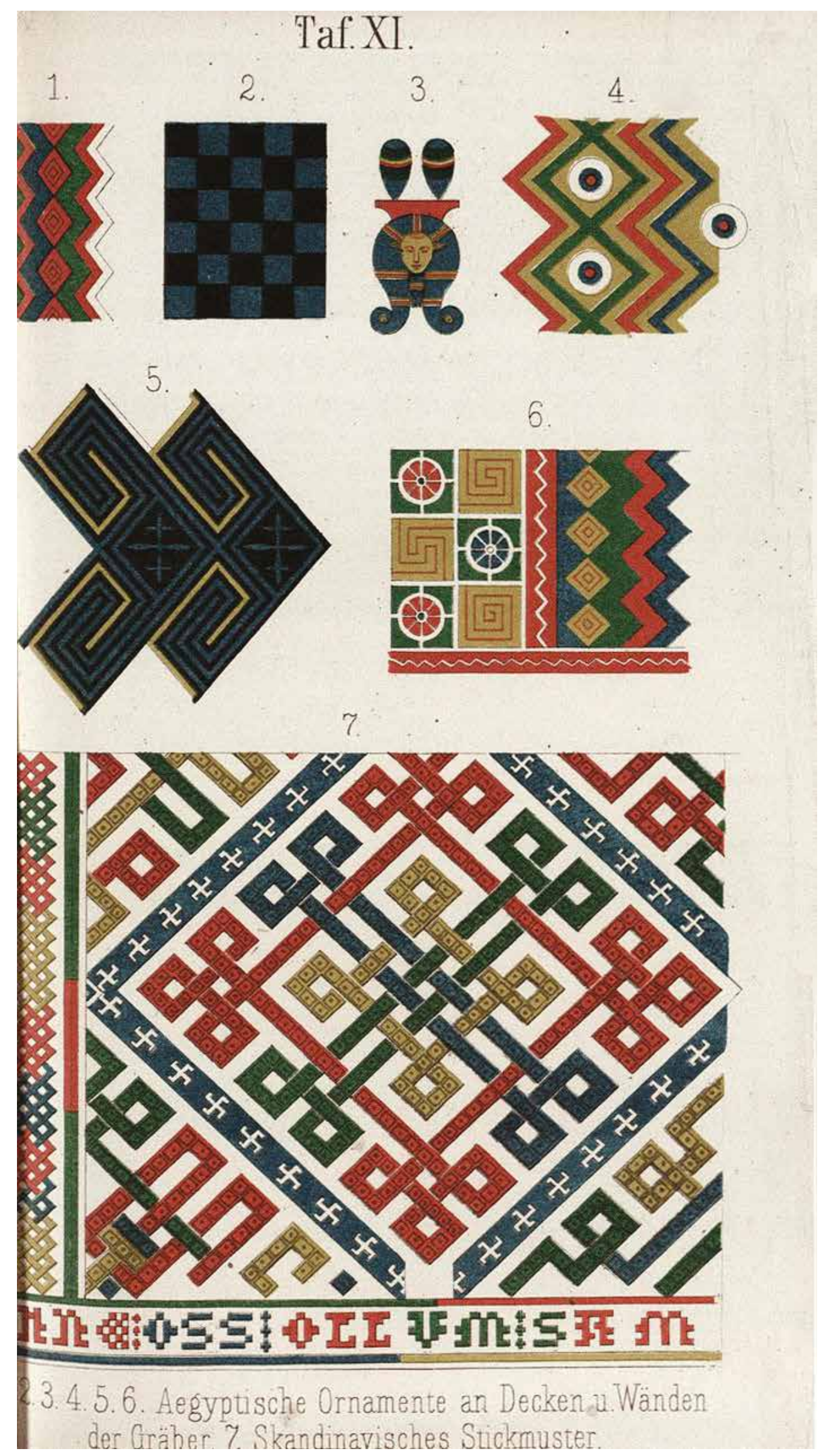

34.
Prieto, Eduardo, La ley del reloj. Arquitectura, máquinas y cultura moderna (Madrid: Ediciones Cátedra, 2016), p. 85-87.

35.

Semper, Gottfried, "Teoría comparada de la arquitectura” (1849), en Semper, Escritos fundamentales de Gottfried Semper. El fuego y su protección. Vol. 37, (Barcelona: Arquia, 2014) p. 104 
un algoritmo morfogenético para poder vincular la forma a su origen. Como explica Eduardo Prieto, Semper llegó a proponer una ecuación matemática en la cual se atendía tanto a la funcionalidad requerida como a la cultura propia en la cual se gestara la obra; una suerte de cálculo para la forma, resultado de la inclusión de diversos factores, culturales, técnicos o funcionales. De este modo se obtendría una forma artística capaz de responder a todo el conjunto de exigencias que decidiera incluirse en la ecuación. Una apuesta científica, la cual sirve como antecedente para la noción funcional de 'eficacia', que no deja de lado la raíz idealista; adelantada a su tiempo y a la vez de difícil puesta en práctica, dada la rigidez de su estructura determinista. ${ }^{34}$

De modo similar a como lo planteara Ruskin, Semper también se ve tentado por identificar una relación entre la función y la naturaleza. Esta, para Semper, la naturaleza aporta ejemplos que podrían ser equiparables al hacer arquitectónico, en cuanto a que dota a todos los elementos de un sentido funcional. Pero al mismo tiempo el autor reclama una posición propia para la arquitectura, la cual tiene sus leyes, que requieren objetividad y regularidad. Por el mismo motivo -y en este caso contradiciendo a Vitruvio- rechaza la cueva como primera morada, ya que entiende que la misma no logra separarse aún de una noción natural e instintiva, y que por esto no llega a pertenecer aún al universo de la arquitectura. La cabaña en cambio requiere de un ingenio y racionalidad en su construcción que, por sí mismos la elevan a lo que Semper entendería como el "hacer arquitectónico", y dentro de esta condición propiamente humana se encontrarían los programas, productos directos de la necesidad. En los fragmentos de su obra inédita, Vergleichende Baulehre, de 1843, Semper refleja cada sección del libro a partir de cada programa: vivienda, edificios religiosos, edificios para la educación, instituciones para la salud, obras públicas, edificios para el gobierno y la administración del estado, edificios judiciales, instituciones militares, monumentos, obras para espectáculos públicos y festivales, y planificación urbana.

La arquitectura produce creaciones originales, no condicionadas por las que existen en la naturaleza. Estas formas se han desarrollado y, en cierto modo, se han definido en el curso del tiempo, de acuerdo con leyes naturales, sí, pero también con el espíritu sistemático del hombre, sin que por ello se hayan impedido ulteriores desarrollos. A estas formas las denominamos orgánicas cuando proceden de una idea básica, adecuadamente concebida, y cuando en el proceso de su formación se evidencian la regularidad y la necesidad intrínsecas, las mismas condiciones que hacen a la naturaleza y a todas sus manifestaciones admirables y perfectas. ${ }^{35}$

Es por esto que los programas, cuando resultan genuinos a la necesidad, sin emular a la naturaleza, resultan para el autor válidos desde el principio. Sin embargo, Semper se pregunta finalmente si el hogar es más importante que los mismos edificios religiosos, ya que si bien el primero es el que da motivo a los principios arquitectónicos -los que constituyen justamente su propia teoría-, el segundo es el que recibe, históricamente, más atención 
significado social. Resulta fundamental entender que, hasta este momento, la casa no había formado parte central de la atención de la arquitectura, y que el propio concepto de "hogar" podía ser trasladado también a otros programas.

El papel protagónico de Le Corbusier en la arquitectura del siglo XX, tanto en su producción literaria como en su obra, obliga a revisar su visión sobre la función aunque, como sucede también con otros autores, su proximidad sobre la misma -constante en sus textos- no implique la elaboración de una teoría profunda sobre el tema. Desde los primeros textos publicados en L'Esprit Nouveau a partir de 1920 -parte de los que compondrán luego Vers une achitecture, en 1923- se visibiliza un acercamiento a la arquitectura desde una condición funcional, desde los problemas de la técnica y la simpleza de la máquina hasta la importancia del plan, como centro neurálgico de la arquitectura. Pero estos mismos materiales resultan esquivos, ya que su aproximación a la función es al mismo tiempo poética y compleja; la función tiene un rol central en los escritos de Le Corbusier, pero a la vez remarca que sus condicionantes no son los que definen la forma arquitectónica, como sí lo es en el caso de Häring. Al mismo tiempo, su inspiración en las máquinas y en el pensamiento del ingeniero tampoco lo llevan a concebir un «método funcional», como lo hiciera Gínzburg. Pero si algo distancia por sobre todo al pensamiento de Le Corbusier de las nociones de 'eficacia' y 'adaptación' es, en primer lugar, la constante insistencia en cuanto a la inclusión de la emoción como ingrediente esencial de la arquitectura y, en segundo lugar, la falta de vocación científica en sus propuestas teóricas. Le Corbusier distingue con claridad la construcción meramente funcional de la arquitectónica, ${ }^{36}$ y no concibe que la función pueda guiar por sí misma a un resultado arquitectónico, a diferencia de la completa vocación funcionalista de Häring, o el enfoque cientificista de Meyer. ${ }^{37}$ Al mismo tiempo sí está en consonancia con ellos cuando afirma que "Todos los hombres tienen el mismo organismo, las mismas funciones. Todos los hombres tienen las mismas necesidades". ${ }^{38}$ Este germen racionalista, que también será visible en su interés por la tipificación, lo conecta con los autores de raíz socialista, al mismo tiempo que su insistencia en la poética y en el recorrido se convierten en ingredientes esenciales de su concepción funcional.

Al inicio de Vers une architecture Le Corbusier afirma que "La arquitectura está más allá de las cosas utilitarias»39, y con esta sentencia da comienzo a una dicotomía inherente a su obra sobre el rol y la jerarquía de la función. No forma parte de este trabajo plantearse qué nivel de importancia tuvo la función en la obra del arquitecto, pero sí intentar desentrañar qué sentido (o sentidos) ocupaba la misma en su modo de pensar y hacer. Como es sabido, los textos de Le Corbusier muchas veces rodean los problemas de modo sintético y con un carácter de manifiesto, lo cual dificulta la profundización y relación entre los diferentes dichos sobre un mismo tema a lo largo de su obra.

Le Corbusier buscó condensar en una serie de esquemas publicados en Oeuvre complète: 1910-1929 Vol. 1, los principales modos de distribuir funcionalmente los edificios. [FG.07] Este croquis resulta ilustrativo las nociones de ‘eficacia' y ‘adaptación', pero paradójicamente, como se menciona al comienzo,
Ver Le Corbusier, Hacia una arquitectura (Barcelona: Apóstrofe, 1998), p. 175. (Ed. orig. 1923).

\section{4 .4}

Le Corbusier.

\section{Poética del recorrido}

37.

Esta diferencia queda claramente expuesta por el debate que presenta Frampton, en el capítulo dedicado a Le Corbusier, en Frampton, Kenneth, Historia crítica de la arquitectura moderna (Barcelona: Gustavo Gili, 2005), p. 161-62. (Ed. orig. 1980).

38. Le Corbusier, Hacia una arquitectura, p. 108. 39. Ibid. p. xxxi. 
ni el pensamiento ni la obra de Le Corsbusier pueden ubicarse completamente en ninguno de ellos, sino que más bien gravitan entre ambos. Este esquema podría entenderse también como una síntesis ilustrada con sus propios proyectos de las ideas de "racionalistas" y "utilitaristas" que Behne había propuesto en 1924; y tiene importancia porque deja en claro que Le Corbusier, en la práctica, no se consideraba ni un "utilitarista»-evitaba la completa definición formal y espacial de su arquitectura teniendo como eje central a las propias funciones- ni un "racionalista»-aunque la tipificación y la industrialización eran parte importante de su discurso, colocaba finalmente la emoción siempre por delante- ni era, por supuesto un convencido de la 'flexibilidad' en la arquitectura -la planta libre tenía más que ver con una estrategia que permitiera libertades espaciales y constructivas antes que con libertades funcionales.

Es entendible que el pensamiento que Le Corbusier tenía sobre la función, al igual que su obra construida, no resulte fácilmente identificable a modo de una categoría; sin embargo sí que puede reconocerse un interés propio por la emoción y el modo en que la arquitectura se percibe y se recorre, los

[FG.07] Le Corbusier,

Esquema París: Oeuvre complète. Vol. 1 cuales conforman gran parte de sus argumentos. Además del tema de la geo-

metría, con sus tracés régulateurs, que conciben la arquitectura como una composición en plano liso con una sorprendente anulación de la profundidad,
2
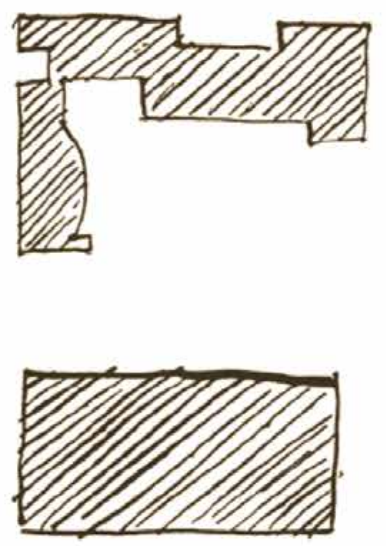

3
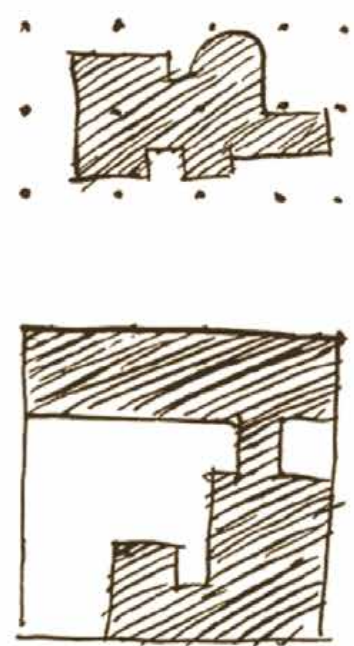
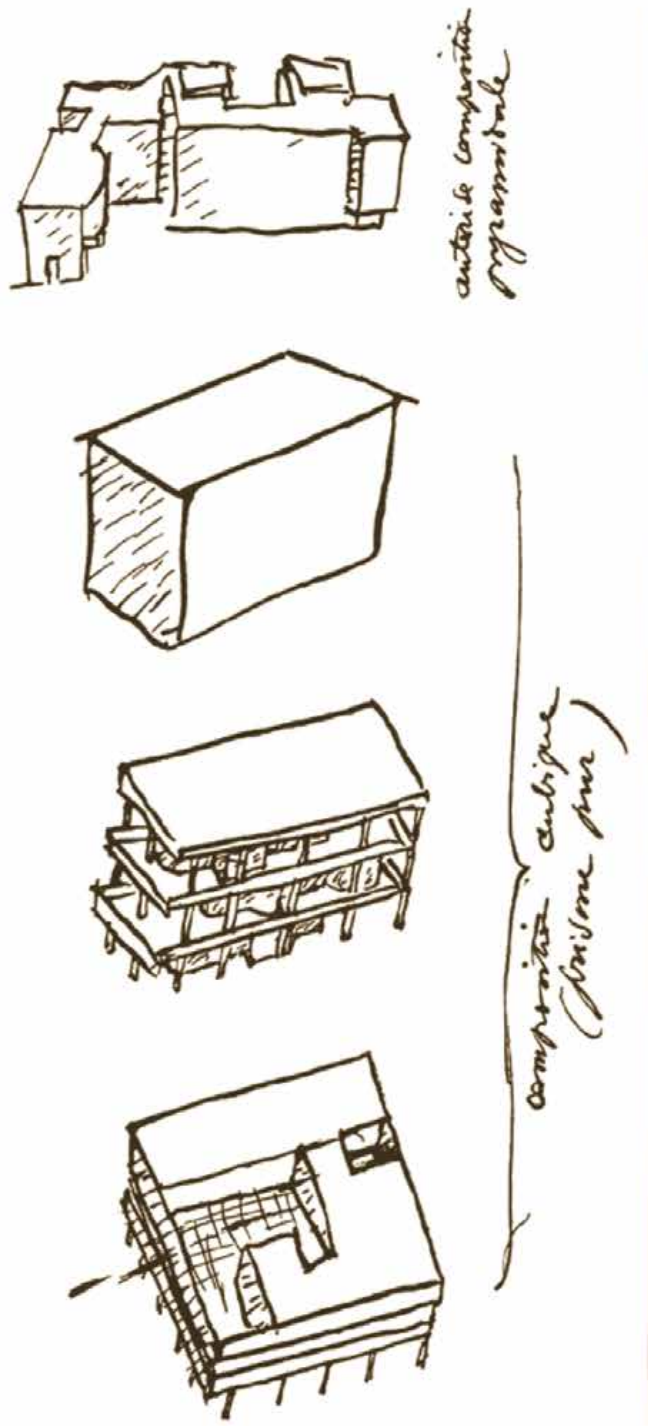
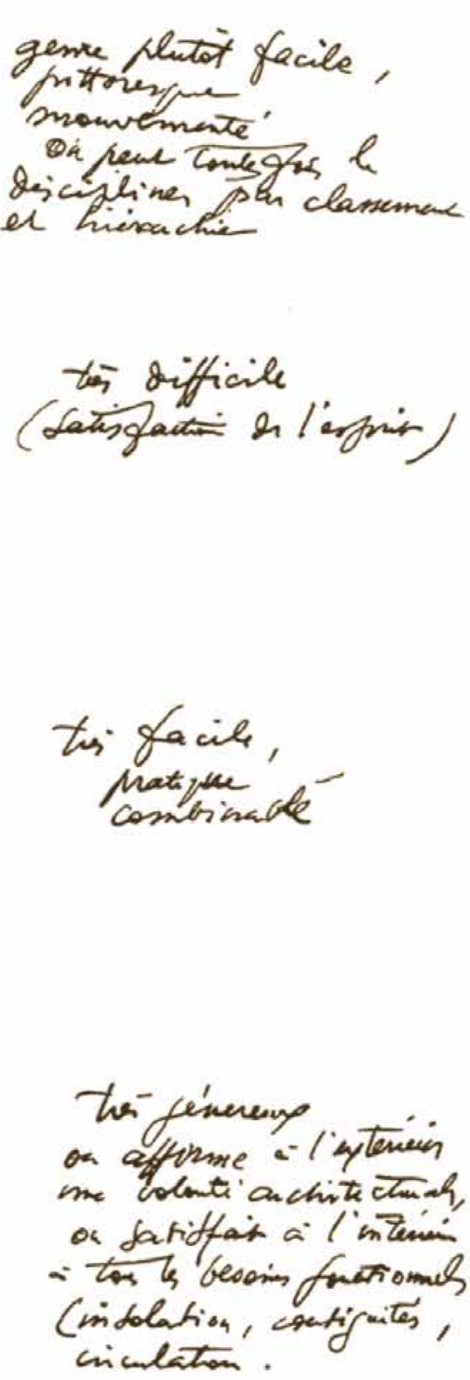
Le Corbusier ostentaba una genuina preocupación por las percepciones y las transiciones dentro de los espacios; una invitación al movimiento y al relato que dan sentido a la noción de 'conectividad'.

El tema de la máquina está sensiblemente ligado a la literatura de la función en la arquitectura desde el mismo Vitruvio. En el caso de Le Corbusier esto se expresa en sus primeros escritos, pero al mismo tiempo que la máquina ocupa un lugar central también lo hacen los mismos ingenieros. En Vers une architecture estos resultan un contraste tan incómodo y conflictivo como provocador y efectivo. Pero Le Corbusier no llama la atención tanto por el lugar de importancia que los ingenieros consiguen frente a los arquitectos a fines del siglo XIX, sino más bien por la capacidad casi inconsciente de los primeros de alcanzar la síntesis formal y funcional, logrando una belleza que, según el autor, es comparable a la de la arquitectura de la antigüedad. Pero no sólo son los ingenieros, sino que también están los productos derivados de la industrialización. A diferencia de Gínzburg Le Corbusier parece extraer más lecciones de las máquinas de transporte -barcos, aviones y automóviles, a los cuales les dedica capítulos exclusivos en su primer libro-que del funcionamiento propio de la fábrica, como lo hacía el arquitecto soviético. Como se comenta al inicio, si la aproximación de Gínzburg resulta mucho más científica, la de Le Corbusier es sin duda poética. En el capítulo "Estética del ingeniero. Arquitectura," en Vers une architecture, evoca la conjunción complementaria de ambas disciplinas:

El ingeniero, inspirado por la ley de la economía, y llevado por el cálculo, nos pone de acuerdo con las leyes del universo. Logra la armonía.

El arquitecto, por el ordenamiento de las formas, obtiene un orden que es pura creación de su espíritu; por las formas, afecta intensamente nuestros sentidos, provocando emociones plásticas: por las relaciones que crea, despierta en nosotros profundas resonancias, nos da la medida de un orden que se siente de acuerdo con el del mundo, determina reacciones diversas de nuestro espíritu y de nuestro corazón; y entonces percibimos la belleza. ${ }^{40}$

En una primera aproximación podría resumirse que para Le Corbusier el ingeniero encarna las soluciones funcionales más limpias, conducido por el pensamiento racionalista; el arquitecto debe incorporar este enfoque, para complementar la "pura creación del espíritu». No obstante, no se trata sólo de metáforas; en efecto Le Corbusier se preocupa por incorporar en su propia práctica las distribuciones lineales y el ajuste entre espacios mínimos y espacios amplios propios de los transatlánticos: unidades mínimas para el habitar individual; salones amplios para los espacios colectivos y, entre estos, conectores de circulación que signifiquen una experiencia en sí mismos. Estos espacios, resueltos por la "ley de la economía», serían también capaces a su vez de conmover. Cuando describe a los aviones en el capítulo con el mismo nombre afirma:

\section{El avión es un producto de alta selección.}

La lección del avión está en la lógica que ha presidido el enunciado del problema y su realización.

\subsection{4.a}

\section{Máquinas e ingenieros}

41. Ibid. p. xxxi.

42.

"Ingenieros anónimos, mecánicos metidos entre la grasa y el hierro de la fragua, han construido esas cosas formidables que son los paquebotes. Nosotros, habitantes de la tierra firme, carecemos de los medios de valoración y sería una suerte que para que aprendiéramos a descubrirnos ante las obras de la "regeneración", se nos brindase la oportunidad de recorrer los kilómetros que representa la visita a un paquebote. Los arquitectos viven en la estrechez académica, en la ignorancia de las nuevas reglas de construcción, y sus conceptos se detienen gustosos en las palomas que se besan. Pero los constructores de los paquebotes, audaces y sabios, crean palacios junto a los cuales las catedrales son muy pequeñas: iy los echan al agua!. La arquitectura se ahoga con las costumbres." Ibid. p. 70-71.

43. Ibid. p. 73.

44. Ibid. p. 89-90.

45.

El modulor (Buenos Aires: Poseidón, 1961), p. 106. (Ed. orig. 1948). 
Los elementos actuales de la arquitectura, ya no responden a nuestras necesidades.

Sin embargo existen las normas de la vivienda.

La mecánica lleva en sí el factor de economía que selecciona.

La casa es una máquina de habitar. ${ }^{41}$

En definitiva, los arquitecturas producidas por el pensamiento del ingenieril, como los aviones o barcos, son también, según el autor, productos de alta selección, que merecen una interpretación arquitectónica; y al mismo tiempo que sugiere la tipificación hace referencia a la economía y a la mecánica, las cuales podrían ser incorporadas por la arquitectura si la disciplina comprendiera la depuración del modo de pensar y actuar del ingeniero. ${ }^{42}$ Esta confrontación que Le Corbusier propone es la que le lleva a mencionar la machine à habiter. Así, "Una casa es una máquina de habitar. Baños, sol, agua caliente, agua fría, temperatura a voluntad, conservación de los alimentos, higiene, belleza mediante la proporción. Un sillón es una máquina de sentarse, etc". ${ }^{33}$ Como el form follows function de Sullivan, esta denominación trascenderá también como uno de los eslóganes de la arquitectura moderna. Pero no será la única vez que Le Corbusier busque demostrar el modo en que los problemas funcionales deben ser estudiados y listados. Unas páginas después que la anterior cita, Le Corbusier plantea una lista de sentidos funcionales para la vivienda que inevitablemente se parece a la que Meyer propusiera unos años más tarde en su artículo "Bauen":

Una casa: un abrigo contra el frío, la lluvia, los ladrones, los indiscretos. Un receptáculo de luz y de sol. Un cierto número de habitaciones dedicadas a la cocina, el trabajo, la vida íntima.

Una habitación: una superficie para circular libremente, un lecho de reposo para tenderse, una silla para estar a gusto y trabajar, una mesa para trabajar, lugares donde poner rápidamente cada cosa en el sitio adecuado.

Cantidad de habitaciones. Una para cocinar y una para comer. Una para trabajar, una para lavarse y una para dormir. ${ }^{44}$

Aún así, en el momento en que aparecen las directrices para dar solución a estos problemas es cuando Le Corbusier se separa del enfoque de la 'eficacia'. Volviendo a la anterior cita, probablemente su inspiración en los barcos sea la que le aporte una fuente más directa con sus propuestas arquitectónicas, en espacial el Aquitania, cuya imagen incluye en Vers une architecture, y resulta una referencia ineludible de sus fenêtre en longueur, presentes en gran parte de sus viviendas, con las cuales, según sus palabras, se garantiza una mejor iluminación, visión panorámica horizontal, y un énfasis en lo linear del recorrido.

En primer lugar, y haciendo eco de Semper, el autor entiende la casa como un abrigo ante la intemperie y los peligros; pero a diferencia del alemán no ofrece ningún principio arquitectónico fruto de estas necesidades. Se trata, más bien, de necesidades básicas de la vida moderna que deben ser suplidas. Como el mismo autor afirma, "Se quiere decir con esto que una casa que cumpla con todos sus deberes puede superar la estricta utilidad de conseguir la 
En el sub-capítulo de Vers une architecture, "El manual de la vivienda," propone una serie de características que tendría que tener la casa moderna a modo de un tratado tradicional de arquitectura; no sólo en cuanto a los requerimientos y al posicionamiento de algunas salas, ${ }^{46}$ sino también en cuanto a la decoración. Pero más allá de estas mínimas propuestas, no se encuentra una base teórica para dar un enfoque a los problemas funcionales que el mismo autor enumera. La machine à habiter resulta una denominación que sin dudas encaja mejor en las propuestas de Gínzburg que en las del propio Le Corbusier.

No ocurre lo mismo cuando concibe sus proyectos de escala urbana, para los cuales, de los problemas pasa a proponer directamente soluciones funcionales. Cuando plantea las ciudades pilotes de su Ville Radieuse para París propone una serie de pasarelas que separan drásticamente la circulación peatonal de la vehicular. Sobre los pilotes la circulación peatonal y, bajo estos, los vehículos y las infraestructuras. Desde este punto de vista, y atendiendo a sus textos, sus propuestas urbanas contienen un germen teórico mucho más claro y contundente que sus propuestas arquitectónicas, tendiendo estas últimas a estar mucho más gobernadas por la particularidad de cada encargo y situación. Siguiendo esta afirmación, para la misma Ville Radieuse propone:

En lugar de trazar las ciudades en rectángulos macizos, con el estrecho laberinto de calles bordeadas por las casas de siete pisos, a pico sobre la calzada y, rodeando patios malsanos, sentinas sin aire y sin sol, se trazarían, ocupando las mismas superficies y con la misma densidad de población, grupos sucesivos de casas de radiantes, que serpenteasen a lo largo de avenidas diagonales. Nada de patios, sino departamentos que abriesen todas sus fachadas al aire y a la luz, y mirasen, no sobre los árboles enclenques de los bulevares actuales, sino sobre praderas, campos de juego y plantaciones abundantes. ${ }^{47}$

En estas palabras puede apreciarse que Le Corbusier ve el problema de la función en un ámbito urbano desde un punto de vista mucho más cercano al de la ingeniería. Dichas propuestas serían capaces de albergar, por su misma economía de medios, una belleza propia. En las mismas palabras del autor, "Los usos llegan a ser modestas o poderosas costumbres; y nadie, en medio de tantas contradicciones agotadoras, adivina que una simple decisión, suprimiendo el obstáculo, pueda abrir paso libre a la vida. A la vida simplemente». ${ }^{48}$ Así, los problemas funcionales en el ámbito urbano quedarán sintetizados en los cuatro usos base para el diseño de las ciudades -habitación, circulación, trabajo y ocio- de La carta de Atenas que el CIAM -en esta etapa liderado por Le Corbusier- publica en 1933. Este conocido documento servirá a la larga para sintetizar -o reducir- el discurso moderno de la función, convirtiéndose en la evidencia de ataque de los principales detractores. Esto no se funda sólo en la división de la función en estos cuatro tópicos, sino también en el tono dogmático, en la abstracción y la distancia que el propio documento emana a través de su vocación universal y poco considerada de las cualidades particulares de cada ciudad o cultura. El CIAM, y con esto Le Corbusier, recupera de esta manera la determinación funcional que había expuesto Guadet en el siglo XIX, en este caso aplicado al urbanismo. que aplicará a sus propios proyectos, por ejemplo, contar siempre con un vestidor en la habitación, concentrar la vida social en una única sala en vez de en fragmentos, o ubicar la cocina arriba para evitar olores.

47. Hacia una arquitectura, p. 47.

48.

El modulor, p. 15.

49.

Hacia una arquitectura, p. xxx. 
2.4.4.b. Aunque para los autores incluidos en la noción de 'adaptación' la planta fuera

Plan el principal eje para la resolución de la función, llamativamente no le dedican a ella la misma atención que Le Corbusier. Casi retomando un tema de la tradición academicista francesa, Le Corbusier pone el plan -en la traducción al español se evita la traslación de plan por 'planta', entendiendo, con razón, que se trata de un concepto que excede el sistema de representación gráfica- como eje de la función y de la forma:

\section{El plan es el generador.}

Sin plan, sólo hay desorden y arbitrariedad.

El plan lleva en sí la esencia de la sensación.

Los grandes problemas del futuro, dictados por las necesidades colectivas, presentan de nuevo la cuestión del plan.

La vida moderna exige, espera, un nuevo plan para la casa y para la ciudad. ${ }^{49}$ En unas palabras que bien podrían encajar en las concepciones de Häring Le Corbusier afirma que «El plan procede de dentro a afuera; el exterior es el resultado del interior». ${ }^{50} \mathrm{Y}$ con esto no parece referirse solamente al tejido de las necesidades interiores, sino también al propio interés por el orden y las circulaciones plausibles de ser configuradas a través del plan; es por lo tanto la partitura donde las diferentes situaciones encuentran relación entre sí, pero no es, como en la composition de Guadet, un fin en sí mismo. El plan es también eso que guía lo que él define como "el volumen" y "la superficie»; y cita a la arquitectura antigua, entendiendo que las grandes obras de estos períodos encontraron lugar bajo el ala de las formas geométricas puras y simples, lo cual para Le Corbusier es garantía de lo sublime, al igual que lo son las obras de los ingenieros. La ordenación de los volúmenes mediante el plan no tendría que ver con un problema de función, sino con un problema estético, el cual Le Corbusier define como "harmonía».

Al mismo tiempo en que le concede al plan una importancia capital, Le Corbusier confía en sus tracés régulateurs -una de las aportaciones más significativas de Vers une architecture- para la resolución de sus fachadas, basado en una regulación a través de relaciones geométricas que, según el autor, existen desde la antigüedad. Esta confianza en el plan (y al mismo tiempo en la función) como generador se ve contradecida por los tracés régulateurs, y es en este punto donde puede entenderse que el problema del proyecto para Le Corbusier es simultáneo y completo; no puede ser simplificado en una sola de sus ramas (en este caso la de la función, que pasa a ser uno de los componentes), y mucho menos para poder alcanzar la belleza, que para él, casi siguiendo a Alberti, confirman el fin último de la arquitectura. En resumen, el plan es la clave de la función, pero no necesariamente de la arquitectura. El problema de la función en Le Corbusier, la cual encuentra su lugar en el desarrollo del plan, no gobierna la obra en su totalidad, como sí lo esperaría Häring; pero al mismo tiempo el plan resulta la herramienta idónea para resolver los recorridos, esa "esencia de la sensación" a la que el autor refiere. La necesidad de un plan que garantice la correcta circulación es parte de la economía, al mismo tiempo que es la experiencia propia del recorrido. 
Desde ese primer croquis apresurado que Le Corbusier traza en su viaje a oriente en la Acrópolis de Atenas (desde los Propileos mirando hacia el Partenón) yace un interés inherente sobre la distancia, la vinculación entre dos puntos, el regalo que supone alcanzar un lugar deseado, el esfuerzo a la vez que la experiencia propia del recorrido. [FG.08] Este interés es patente en la obra de Le Corbusier y gobierna gran parte de sus decisiones de proyecto, hasta tal punto que es capaz de dar un nuevo sentido a la función a partir de esta estrategia.

Parte de sus primeras apreciaciones sobre la circulación las realiza en Précisions sur un état présent de l'architecture et de l'urbanisme, basado en el viaje a América del Sur. El libro es una compilación y ordenación que el propio Le Corbusier hace sobre diez conferencias dadas en Buenos Aires durante 1929, el cual publicaría un año después. En él afirma que

\section{Arquitectura es "poner en orden".}

¿Poner en orden qué?: funciones y objetos. Ocupar el espacio con edificios y caminos. Crear receptáculos para abrigar al hombre y crear comunicaciones útiles para encontrarse. Actuar sobre nuestro espíritu por la habilidad de las soluciones, sobre nuestros sentidos por las formas propuestas a nuestros ojos y las distancias impuestas a nuestra marcha. Emocionar por el juego, de percepciones a las cuales somos sensibles y a las que no podemos sustraernos. Espacios, distancias y formas; espacios interiores y formas interiores; andar por los interiores; formas y espacios exteriores; cantidades, pesos, distancias, atmósferas; es con esto que actuamos. Tales son los hechos en causa. ${ }^{51}$

En el contexto en que Le Corbusier se preocupa por el recorrido existe una disyuntiva, ya que en sus propios textos reclama la lógica de la economía del ingeniero, pero al mismo tiempo entiende que la arquitectura requiere de una emoción. El recorrido, entendido como experiencia, reclama una extensión mayor que la que normalmente se necesita para resolver la conectividad. Es por esto que la 'conectividad' en Le Corbusier se aparta de los intereses de la 'eficacia', ya que no persigue la resolución óptima de las circulaciones, sino que más bien busca una desconexión forzada que haga aparecer esa "distancia" de su inicial croquis en la Acrópolis. Esta aparente disfuncionalidad se ve asimismo compensada por la calidad propia que los espacios separados adquieren, en cuanto a iluminación, ventilación y visuales. Al mismo tiempo, a pesar de su interés por la circulación y el recorrido, Le Corbusier muestra un desprecio evidente por la calle como producto de la ciudad existente, por su falta de orden y belleza. ${ }^{52}$ Por lo mismo, los recorridos que el autor imagina nunca tendrán referencia en experiencias cotidianas u ordinarias, sino en sensaciones renovadoras, espacios de una calidad distintiva.

Para la materialización de estos recorridos, Le Corbusier recurre a algunas herramientas arquitectónicas, como las rampas o escaleras, y otras conceptuales, como el eje. Este es probablemente el primer elemento que Le Corbusier menciona en relación a la circulación. Aclara desde el principio su distanciamiento con respecto a los ejes de composition de la École des Beaux-Arts, y entiende a los mismos como una forma de generar tensiones y de focalizar elementos, la cual se percibe mediante el espacio, encontrando así una limitación del plan:

\section{Promenade architecturale (I)}

50. Ibid. p. xxxii.

51. Precisiones respecto a un estado de la actual de la arquitectura y del urbanismo (Buenos

Aires: Poseidón, 1979), p. 90. (Ed. orig. 1930).

52.

En Précisions... comenta "La calle está llena de gente; hay que vigilar el camino. Desde hace algunos años, está llena de carruajes rápidos: la amenaza de muerte reina entre los dos arcenes de las aceras. Pero ya estamos enseñados para afrontar el aplastamiento." Ibid. p. 220.

53.

Hacia una arquitectura, p. 151. 
El eje es, quizás, la primera manifestación humana; es el medio de todo acto humano. El niño que vacila tiende al eje, el hombre que lucha en medio de la tempestad de la vida se traza un eje. El eje es el que pone orden a la arquitectura. Poner orden, es comenzar una obra. La arquitectura se establece sobre ejes. (...) La ordenación es la jerarquía de los ejes, por lo tanto, la jerarquía de los fines, la clasificación de las intenciones. (...) En consecuencia, el arquitecto asigna fines a sus ejes. Esos fines son el muro (el plano, sensación sensorial) o la luz, el espacio (sensación sensorial). ${ }^{53}$

Pero para Le Corbusier los ejes significan más un elemento al cual atribuir un orden y unas intenciones que una metodología proyectual, como podía serlo para Durand o Guadet. En efecto, según él «el arquitecto asigna fines a sus ejes", y en el caso del recorrido, recordando otra vez la disposición de los propileos en la Acrópolis puede decirse que una serie de ejes trazados en el plan pueden ser capaces de guiar a eventuales experiencias. Para Le Corbusier la circulación conduce a la función, la transforma y la guía; se trata de hilvanar experiencias, pero también de hilar y dar sentido a las actividades según una disposición, una sucesión. El diagrama que el mismo arquitecto elabora para la sucesión de experiencias en el efímero Pavillon des Temps Nouveaux de 1936 resulta ilustrativa; [FG.09] en este se ejercita una entrada y una salida lineales a través de las cuales poder experimentar todas las estancias del pabellón. Aunque el diagrama no refiera a ningún elemento arquitectónico, tampoco resulta completamente abstracto, ya que su trazado se condice que

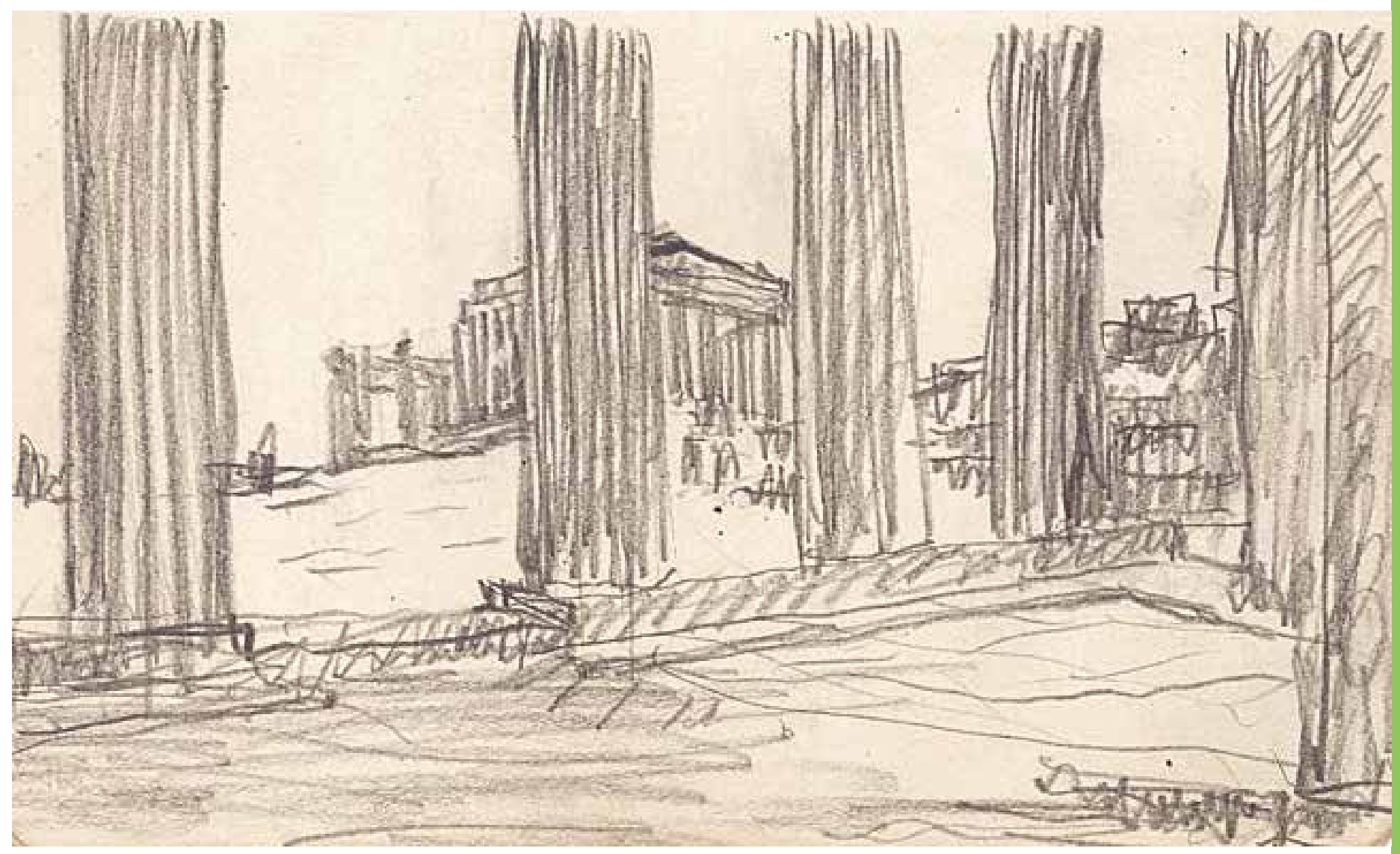


55.

Ver Cohen, Jean-Louis, Le Corbusier and the Mystique of the USSR: Theories and Projects for Moscow, 1928-1936 (Nueva Jersey: Princeton University Press, 1992).

56.

Ver Segura, Alfonso Díaz; de la Maza, Ricardo Merí, y Soriano, Bartolomé Serra, "La construcción del Raumplan," Rita, 1, (2014).

París: Oeuvre complète. Vol. 3

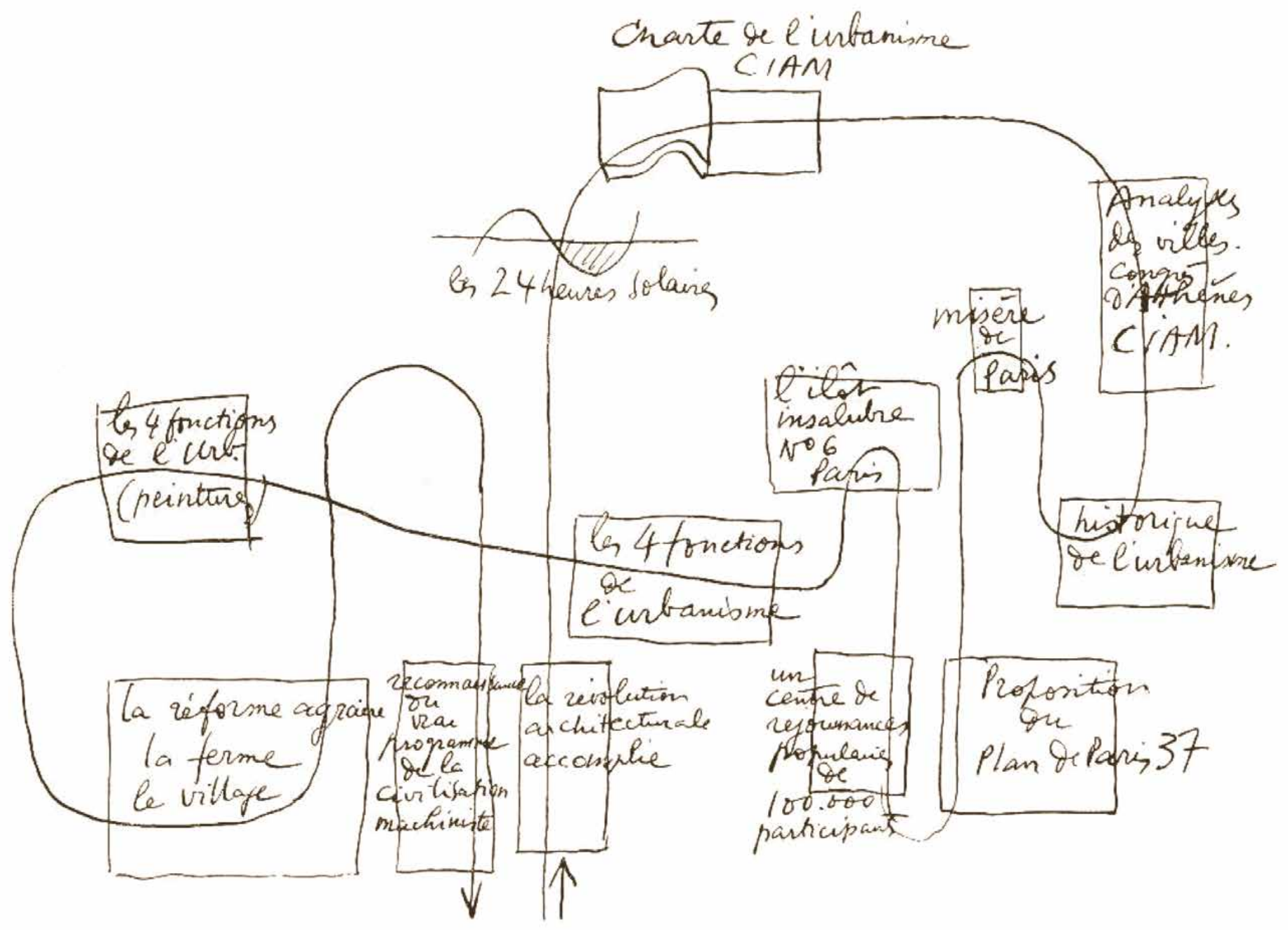


Otra de las veces en que Le Corbusier expresa de manera más evidente su concepción de recorrido es cuando, en Vers une architecture, dice:

Ritmos, distancias, tiempos de la arquitectura, fuera de la casa y dentro de la casa.

Una cuestión de lealtad profesional nos obliga a dedicar nuestra entera solicitud al interior de la casa. Se entra: se recibe un choque, primera sensación. Henos aquí impresionados por aquella magnitud de habitación que sucede a otra, por tal forma de habitación sucediendo a la otra. ¡Ahí está la arquitectura! Y según la manera en que ustedes entren en una habitación, es decir, según sea la situación de la puerta en la pared de la habitación, la conmoción será diferente. ¡Ahí está la arquitectura! ${ }^{54}$

Además del eje, los «ritmos, distancias y tiempos» son los que permiten entender cuán importante resultaba para Le Corbusier el tema del relato y la secuencia espacial; o cierta idea de montaje de experiencias interiores. La promenade ha sido vinculada a su impacto espacial, estético y a su inevitable vinculación con la narrativa -literaria o cinematográfica-, pero la relación de esta con la función resulta tan productiva como compleja. En este punto los elementos arquitectónicos que conforman la circulación adquieren un rol de actores centrales: el corredor, la escalera y la rampa son elementos fundamentales en la obra de Le Corbusier y son tratados normalmente de una manera especial por sus posibilidades de generar una secuencia, un interés entendible, dado que el autor consideraba que la arquitectura y el cine eran las verdaderas artes de su tiempo, ${ }^{55}$ algo que claramente se verificaba en sus esquemas, donde no faltaba una perspectiva desde el punto de vista del visitante, imaginando la secuencia espacial. Este esfuerzo es el que permite entender su constante intención de hacer de la arquitectura un objeto entendible, plausible de ser leído y al mismo tiempo habitado. Esa es quizás su cercanía más clara con la función y no la de la distribución de las actividades, ya que la posición y sentido de estas persigue constantemente el hilo del relato. Para Le Corbusier la función por sí sola es un problema anterior, más básico y fundamental que la necesidad de redefinir ciertas "funciones modernas." Esto se ratifica con la austeridad de algunas de sus últimas obras, como Le Cabanon en Côte d'Azur, en el que la función se reduce al mínimo indispensable. La experiencia visual y espacial no aparece como el único resultado de la proRaumplan menade; esta requiere de una organización funcional que se adapte a su sentido, requiere de una serie de distancias y separaciones que le permitan existir. Desde este punto de vista, la 'conectividad' podría significar para Le Corbusier la razón y el origen mismo del funcionamiento de sus edificios; una función que se desprende de un recorrido. Esta resulta de una deuda con la organización de las funciones y el recorrido que Adolf Loos había ensayado en sus viviendas de las primeras décadas del siglo XX, en especial la Casa Moller, de 1928 [FG.10] o la Casa Müller, de 1930. [FG.11] El conocido concepto de Raumplan -bautizado así no por Loos sino por su biógrafo Heinrich Kulka ${ }^{56}$ - explica el interés del arquitecto por dotar a cada espacio de su justa medida y alturas diferentes, lo 
Mi arquitectura no está concebida en plantas, sino en espacios (cubos). No diseño plantas, fachadas o secciones, diseño espacios. Para mí, no hay planta baja, primer piso, etc. Para mí, solo hay espacios contiguos, continuos, habitaciones, antesalas, terrazas, etc. Las plantas se fusionan y los espacios se relacionan entre sí. Cada espacio requiere una altura diferente: el comedor será probablemente más alto que la despensa, por lo tanto, los techos se establecen en diferentes niveles. Unir estos espacios de tal manera que el ascenso y el descenso no sólo sean inobservables sino también prácticos... ${ }^{57}$

Es cierto que las configuraciones del Raumplan de Loos mantienen la centralidad y la armonía, mientras que la promenade de Le Corbusier desarticula cualquier espacio homogéneo y lo vincula directamente con el exterior, permitiendo otras derivas de recorrido. Pero ciertamente, pocos referentes serían tan importantes para Le Corbusier en su definición del recorrido como Loos. Como comenta Frampton,

(...) la significación de Loos como pionero respondió no sólo a su extraordinaria perspicacia como crítico de la cultura moderna, sino también a su formulación del Raumplan como planteamiento arquitectónico para trascender el contradictorio legado cultural de la sociedad burguesa, la cual, habiéndose privado de la tradición vernácula, no podía reclamar a cambio la cultura del clasicismo. Nadie mejor preparado para recibir esta sensibilidad hiperconsciente que la vanguardia parisiense de posguerra, en particular el círculo que publicaba L'Espirit Nouveau, es decir, el poeta protodadaísta Paul Dermée y los pintores puristas Amédée Ozenfant y Charles-Édouard Jeanneret (Le Corbusier), quienes en 1920 reimprimieron la versión francesa de "Ornamento y delito". 58

La promenade architecturale había sido puesta en práctica por Le Corbusier en los años veinte, en proyectos como la Ville La Roche de 1923 o la Villa Stein de 1927, aún así, quizás sea en el proyecto para la Ville Savoye de 1929 y la misma descripción que el autor utiliza la que ilustre este concepto de manera más acabada. Así describe Le Corbusier en Précisions... el acceso a la casa, donde la promenade architecturale no sólo se materializa como experiencia de recorrido, sino como argumento para hilvanar diferentes situaciones funcionales del proyecto:

Del interior del vestíbulo arranca una rampa suave, que conduce casi sin darse cuenta, al primer piso, en donde transcurre la vida del habitante: la recepción, los dormitorios, etc. Tomando vista y luz del contorno regular de la caja, las diferentes habitaciones van a juntarse, radiando, a un jardín suspendido, que se encuentra allí como si fuese un distribuidor de luz y de sol. Es el jardín suspendido sobre el cual se abren con toda libertad las paredes correderas de cristales del salón y otras de las diferentes habitaciones de la casa: de esta manera el sol penetra por todas partes, llegando hasta el mismo corazón de la casa. $^{59}$

En el mismo texto, continúa luego:

La circulación procura unas impresiones arquitecturales de una diversidad que desconcierta a todo visitante extraño a las libertades arquitectónicas aportadas por las técnicas modernas. Los simples postes de la planta baja,
Loos, Adolf, extracto de una conversación en PIzen (Pilsen), 1930, en Singley, Paulette, How to Read Architecture: An Introduction to Interpreting the Built Environment (Londres: Routledge, 2019). Traducido por el autor.

58.

Frampton, Historia crítica de la arquitectura moderna, p. 96.

59.

Le Corbusier, Precisiones respecto a un estado de la actual de la arquitectura y del urbanismo, p. 158

60.

Ibid

61.

Samuel, Flora, Le Corbusier and the architectural promenade (Basilea: Birkhäuser, 2010), p. 10. Traducido por el autor.

2.4.4.e

Promenade architecturale (II) 
debido a una justa disposición, recortan el paisaje con una regularidad que tiene por efecto suprimir toda noción de "parte anterior" o de "parte posterior" de casa, de "lado" de casa. ${ }^{60}$

Por el tono que utiliza, Le Corbusier indica a un lector y posible visitante los temas centrales que otorgan argumento a sus decisiones, y en esto busca equilibrar la disposición funcional con la apreciación del espacio y la naturaleza circundante. Queda claro que para Le Corbusier el recorrido es el que le permite lograr esta "diversidad". En este texto queda también en evidencia la constante insistencia del autor en conceder importancia a este "visitante extraño" que él mismo menciona antes que al propio usuario común de la obra, lo cual también explica su regocijo en un recorrido que a todas luces se descubre como novedad. Esta vocación de la promenade como primera experiencia se opone sin dudas al recorrido cotidiano, el cual no parece interesarle, al menos no en el mismo grado que otros autores ya mencionados, como Gínzburg. En efecto, las distribuciones funcionales pueden verse sometidas o afectadas por este recorrido experiencial. Pero al mismo tiempo la función alimenta y da sentido a los espacios del recorrido; las características de cada uno de estos espacios ofrecen oportunidades de contrastes y matices para hilvanar el relato de la propia circulación.

Una de las obras donde con mayor claridad puede visualizarse el modo en que el recorrido de la promenade es capaz de tejer y afectar a las funciones del proyecto es la Casa Curutchet, construida en Buenos Aires en 1949. Como también sostiene Flora Samuel, «la promenade sigue una fórmula, ajustada li-

[FG.10]

Adolf Loos, Casa Moller Viena: The Albertina Museum,

1928.

[FG.11]

Adolf Loos,

Casa Müller Viena: The Albertina Museum,

1930 geramente en cada situación para adaptarse a las demandas del sitio y el programa», ${ }^{61}$ y en la Casa Curutchet puede encontrarse justamente una variante que tensa la estrategia de la promenade hacia una situación más incómoda de resolver. En esta casa, que a diferencia de otras de sus más paradigmáticas se encuentra condicionada por un solar estrecho entre medianeras, el autor decide fragmentar drásticamente el programa en dos volúmenes para crear un elemento de conexión intermedio. [FG.12] Este elemento, una extensa
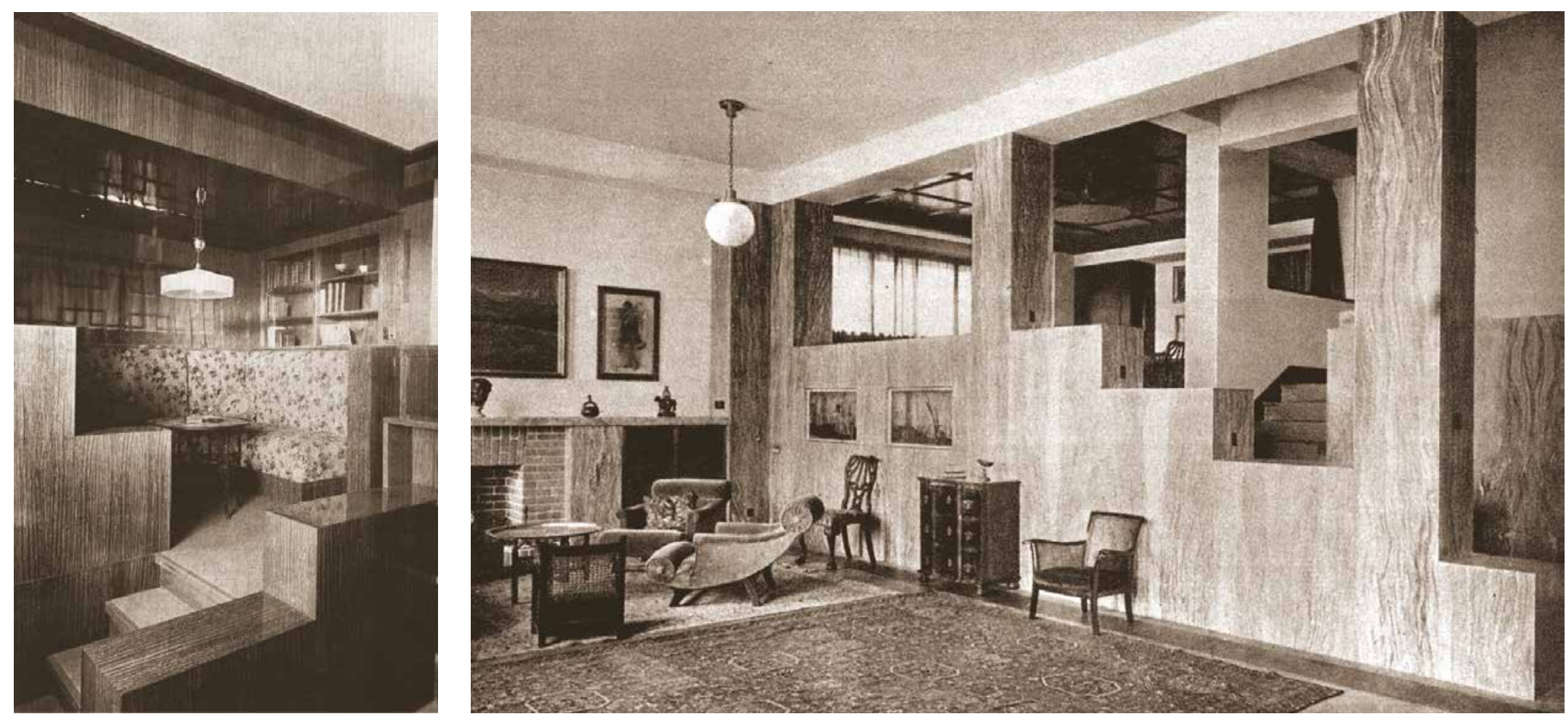

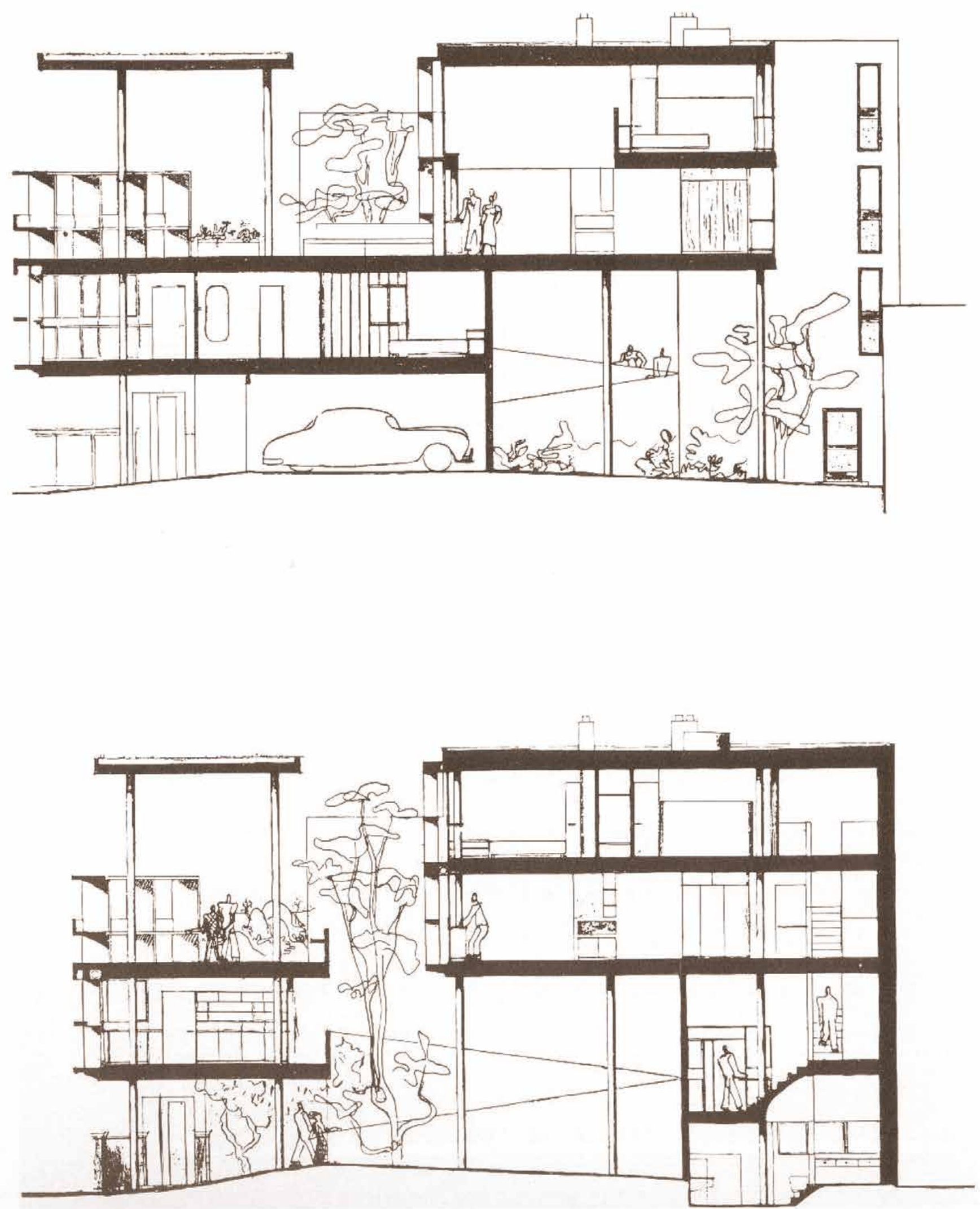
rampa que cruza el patio central en un ida y vuelta, resulta al mismo tiempo necesario (aunque se trate, evidentemente, de una necesidad inventada por la propia configuración del proyecto) y poético. La fragmentación permite que ambos volúmenes obtengan iluminación y ventilación naturales, y que gocen de espacios abiertos -hacia a la calle-y privados -hacia el patio. El remate de este recorrido se da también en una terraza-jardín superior, que en este caso está techada y posee un dominio visual hacia la calle, en altura.

Otro caso paradigmático es el de uno de sus últimos proyectos en Europa, el convento de Sainte-Marie de La Tourette, de 1957. En él Le Corbusier traza una planta en 0 -la cual se compone de la capilla en una de sus caras y el resto del programa cerrándola en un esquema en $U$ - en la que, como en cualquier esquema cercano al claustro, la circulación cobra, desde el inicio, un protagonismo fundamental. Por otro lado, de modo contrario a la típica distribución del claustro, los extensos corredores de la planta de acceso van mutando sorprendentemente de adentro hacia afuera, aprovechando el tiempo del recorrido para ofrecer situaciones cambiantes, visuales al interior del edificio o al paisaje; pero aún más llamativo resulta descubrir que el sistema de circulación en el nivel superior e inferior cambian drásticamente: arriba la circulación toma el perímetro interno mientras que abajo se distribuye desde el centro a modo de una cruz latina. [FG.13] Cada planta se permite una nueva forma de recorrido, ofreciendo además diferentes instancias espaciales y visuales. Uno de los corredores, cercanos al ingreso, presenta una extensa y mínima fenêtre en longueur colocada exactamente a la altura del ojo, la cual atraviesa todo el espacio de lado a lado, permitiendo al caminante ser acompañado (sólo) por la linea de horizonte. [FG.14] A esta se le opone el conocido corredor para el que Iannis Xenakis realizó estudios de armonía en relación a la ventana de lineas verticales, generando un ritmo de sombras y contraluces verticales que se opone drásticamente al anterior. [FG.15] Otro de los corredores se cierra con unas particulares ventanas de hormigón armado que ofrecen una composición que alterna paños transparentes y opacos. [FG.16] Esta diversidad y cuidado por los momentos de circulación resultan ilustrativos de la importancia que Le Corbusier le daba a temas centrales de la 'conectividad', como el movimiento, el tiempo y la sorpresa.

2.4.4.f. En definitiva, si se hace referencia al esquema inicial del propio autor, y comSublime y pintoresco prendiendo la ambigüedad de sus textos y la variedad de sus obras, la concepción de la función para Le Corbusier cabría tanto en la noción de 'eficacia' como en la de ‘adaptación', pero lo que lo diferencia completamente tiene que ver con la constante preocupación por indagar en la conexión entre sus recintos, entre el exterior y el interior, vinculándolo a su vez a Blondel, como si de un relato de las funciones se tratase. En efecto, el modo en que estas actividades se suceden, es el centro problema de la función del autor. Con su insistencia en la promenade rescata un tema inherente a las discusiones tradicionales sobre la función y el modo de poder distribuir razonablemente grandes edificios de plantas extensas. Se trata de un tema tradicional de la arquitectura, sobre 
estática por una nueva que incorpora el movimiento; podría mencionarse la plaza de San Pedro de Bernini de 1656, o la Sala de los Espejos en el Palacio de Versalles de Mansart de 1678, obras incomprensibles sin el movimiento. Pero el origen más claro del concepto de promenade architecturale de Le Corbusier puede atribuirse al pintoresquismo que sirviera de base para el propio jardín inglés, donde nuevas categorías estéticas, como lo "pintoresco" y lo "sublime» se pondrían en juego. Bacon ya había propuesto opciones de distribución interior para edificios de gran tamaño, sin utilizar galerías exteriores. El principal aporte de Le Corbusier radica en dar vuelta el problema: en distancias demasiado largas, donde esta extensión tradicionalmente se entendía como una falencia, Le Corbusier encuentra una semilla poética, no sólo aceptando la extensa separación, sino muchas veces exagerándola lo más posible. Así, los placeres estéticos derivados del empirismo, como la curiosidad o la intriga aparecen en primer plano. ${ }^{62}$ Esta subversión de la función lo lleva a separar volúmenes entre sí, superponerlos y generar extensos elementos de conexión que los vinculen, ya que estos últimos representarán el verdadero lugar de la función. Como se menciona al comienzo, a diferencia del rol que tiene la circulación en los autores incluidos en la noción de 'eficacia', la promenade architecturale de Le Corbusier no es una circulación que busque optimizar la distribución del edificio; al contrario, incita a cierta sobreactuación del hecho mismo de caminar; se trata de estirar al máximo esa acción a través de estrategias propias como la separación de los volúmenes de un edificio, la transición entre interior y exterior y, sobre todo, la utilización de rampas y escaleras que focalicen la mirada y acentúen momentos particulares. Efectivamente a Le Corbusier poco le preocupaban los diagramas de recorridos mínimos que Ginzburg estudiaba como una máquina en cada uno de sus proyectos. Para Le Corbusier estos recorridos debían ser, por el contrario, "máximos"; no sólo en cuanto a distancia, sino también en cuanto a contraste de experiencias.

A pesar de haber sido identificados inicialmente dentro de la corriente inglesa conocida como el "nuevo brutalismo," las primeras apariciones de Alison y Peter Smithson junto al Independent Group mostraron una sensibilidad especial por las condiciones antropológicas de la cultura de posguerra. La exposición Parallel of Life and Art de 1953 mostraba un compendio de imágenes de noticias, fuentes arqueológicas o zoológicas de desconocida procedencia entremezcladas con visiones distorsionadas de figuras humanas; una muestra, quizás, de los restos desensamblados de la guerra en un país que necesitaba a toda cosa iniciar su reconstrucción, no sólo física, sino también existencial. Nigel Henderson, por su parte, retrataba imágenes de niños que lograban encontrar un rastro de vida en las calles arrasadas, apropiándose de las mismas a través del juego. Una visión paralela, a la vez que desesperante, de los intereses que van Eyck encontraba también en lo lúdico de la niñez en la utilización del espacio público. La exposición de 1956 This is tomorrow, también del Independent Group, expone un ligero cobertizo que, como Frampton comenta, ${ }^{63}$ parece reversionar la primitiva cabaña de Laugier después de que el mundo fuera arrasado por una gran guerra: una nueva estructura básica, esta vez no de las ideas estéticas y de las teorías artísticas contemporáneas, vol. 1 (Madrid: Visor, 1996). (Ed. orig. 1996).

63.

Ver "El nuevo brutalismo y la arquitectura del estado del bienestar: Reino Unido, 1949-1959" en Frampton, Historia crítica de la arquitectura moderna, p. 269

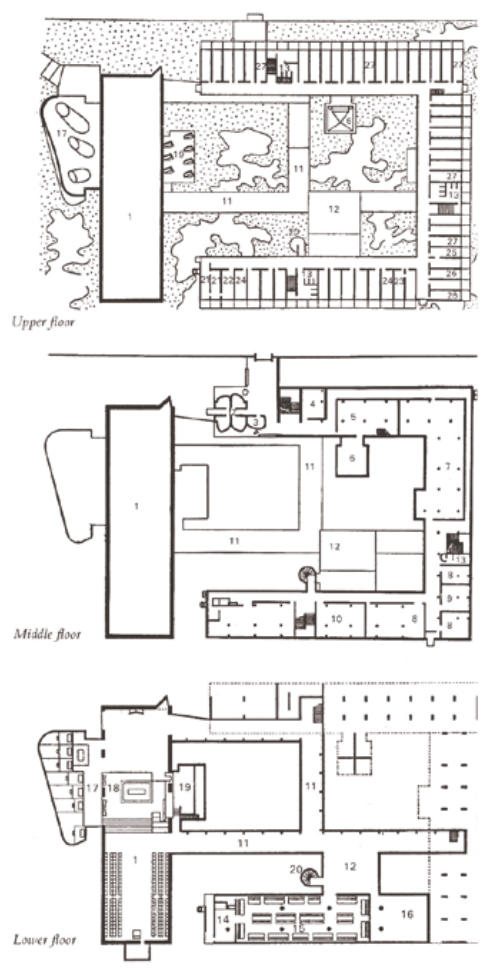

[FG.13]

Le Corbusier,

Convento de Sainte-Marie

de La Tourette. Plantas

París: Le Corbusier Archives, 1957.

2.4.5.

A. \& P. Smithson.

Puentes de sinergia 

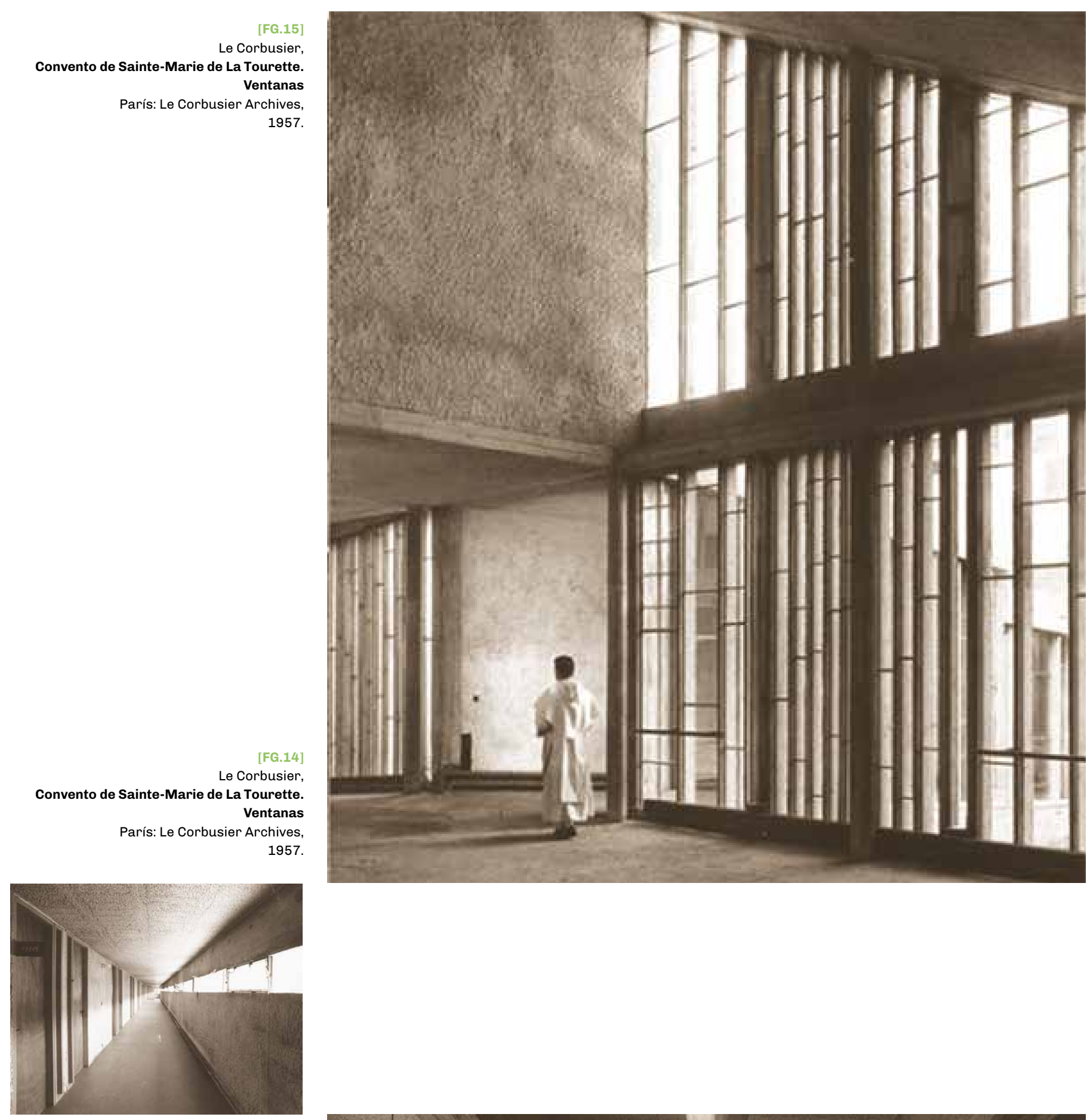

[FG.16]

Le Corbusier

Convento de Sainte-Marie de La Tourette. Ventanas

París: Le Corbusier Archives,
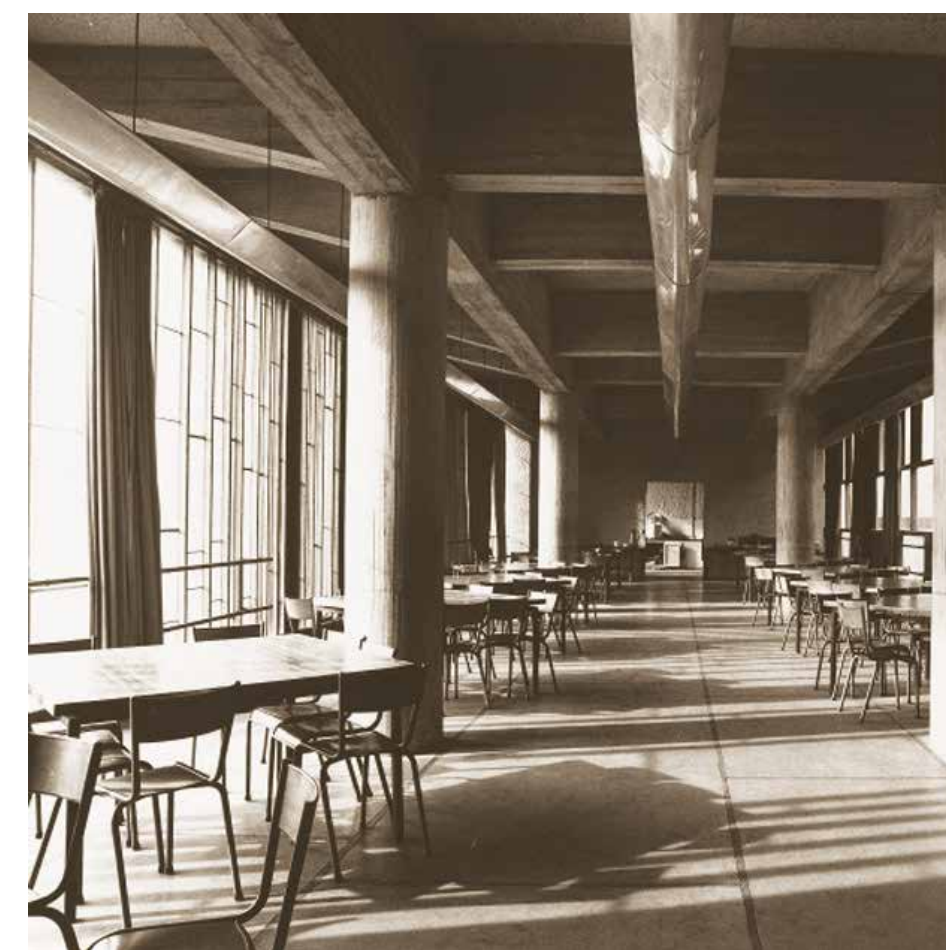

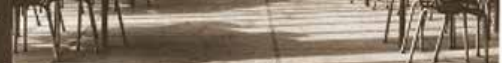

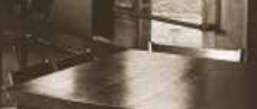

$1>2$
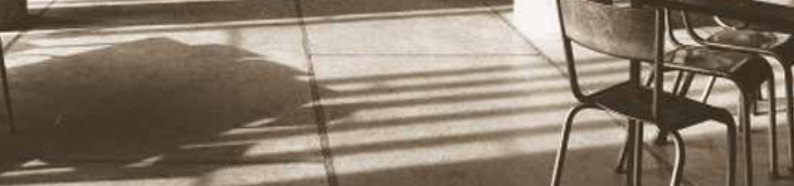

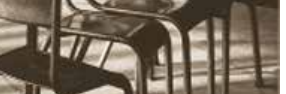


idealizada por un sistema cultural, sino más bien construida con lo que puede encontrarse de lo que queda; una idea que se identificó luego con el concepto de as found, que los Smithson explotaron posteriormente en su obra. Quizás estos dos ingredientes fundamentales, el del interés por lo antropológico ${ }^{64}$ y el de la construcción a través de lo prefabricado -o lo existente- sean los que enmarquen de modo general las nociones de 'conectividad' de estos autores británicos.

El interés por la apropiación de los espacios -convertidos ya en lugarespor parte de la comunidad en una serie de escalas categorizadas y subdivididas y un esqueleto, rígido en su construcción, pero flexible y extensible en cuanto a sus disposiciones, son las bases para ensamblar un proyecto basado en la interacción y la sinergia; una energía colectiva con tintes humanistas que tanto los Smithson como el resto del Team X consideraban olvidada por el CIAM. No obstante, tanto la gestación como la ordenación de los varios conceptos que componen los intereses de los autores por la función no se presentan de modo tan claro como, por ejemplo, en van Eyck. El pensamiento de los Smithson se expone en sus primeros artículos de modo disperso y un tanto abstracto y comienza a sistematizarse a medida que pasan los años y su obra va madurando. Ellos mismos vuelven sobre sus propios textos posteriormente, reescribiéndolos o explicándolos nuevamente, en un esfuerzo por presentarlos con mayor profundidad y claridad.

Casi una década después de la construcción de la Hunstanton Secondary Modern School -primera obra de importancia de A. \& P. Smithson-aparece Primer, el libro del Team X publicado primero como artículo en Architectural Design en 1962 e impreso y editado como libro por Alison Smithson en 1968. En esta publicación el Team $X^{65}$ se presenta como una conjunción de personalidades con inquietudes diferentes, que tienen en común la búsqueda de una "utopía para el presente»; un grupo que no intenta tanto teorizar como construir entendiendo los artefactos, patrones, herramientas y movilidades de su presente. La particularidad de Primer es la de incluir de modo fragmentado las voces de sus diferentes integrantes, entremezcladas sin categorías y con un énfasis en las propias ideas antes que en la autoría. En él se conjugan varios de los aportes centrales de los Smithson en cuanto a la función.

Una apreciación de Peter Smithson sobre la situación contemporánea abre el texto reclamando un acercamiento de los arquitectos a un nuevo marco cultural:

\section{La televisión ha abierto las mentes de la gente y ha hecho que una nueva clase} sea consciente de su existencia como grupo, con necesidad de un estilo de vida propio. Nosotros, como arquitectos, todavía no hemos encontrado un modo de construcción apropiado para este estilo de vida; todavía no hemos construido lugares "donde todo puede suceder".

\section{Nuestra propia casa es rígida y antipática. ${ }^{66}$}

El Independent Group ya se había mostrado interesado por los nuevos íconos de la cultura pop; los Smithson mantuvieron esta fascinación por la tecnología y el confort aplicado a los objetos de uso cotidiano, al automóvil y también a la casa. La cristalización de este interés fue House of the future de
64.

Al mismo tiempo los autores asumen la insuficiencia de los estudios antropológicos para actuar directamente en el diseño, otorgando indirectamente esa responsabilidad al arquitecto: «La antropología social nunca podrá decirte qué hacer. Podrá decir qué patrón en el pasado fue tal o cual, por las motivaciones que una comunidad tenía, etc., pero cuál debe ser el patrón actual me parece más una cuestión de la propia comunidad que de la antropología social". Smithson, Alison y Smithson, Peter en Team X, Primer (Cambridge: The MIT Press, 1968), p. 100. (Ed. orig. 1962).

65.

Como es sabido el Team X, además de A. \& P. Smithson contó con la participación de van Eyck, Bakema, Candilis, Woods, de Carlo, Coderech, Pologni, Soltan y Wewerka quienes también firman diversos aportes en esta publicación.

66. Smithson, Peter en Team X, Primer (Cambridge: The MIT Press, 1968), p. 6. (Ed. orig. 1962).

67. Smithson, Peter en Team X, Primer, p. 8.

\section{8.}

"Hoy en día, nuestro fracaso más evidente es la falta de comprensibilidad e identidad en las grandes ciudades, y la respuesta seguramente yace en un sistema vial claro, a gran escala: la "Autopista Urbana" pasó de ser una función de mejora a una función unificadora. Para

\subsection{5.a.}

\section{Patterns of association}

realizar esta función unificadora todas las carreteras deben estar integradas en un sistema, pero la columna vertebral de este sistema deben ser las autopistas en las propias áreas urbanizadas, donde su misma dimensión en relación con otros desarrollos les permite actuar como elemento visual y simbólico al mismo tiempo, haciendo que todo funcione. Desde nuestro interés por la vida en la calle, nos ha obsesionado el concepto de "movilidad" en todos sus significados y, en particular, las implicaciones del automóvil". En Smithson, Alison y Smithson, Peter en ibid. p. 48.

69.

Simthson, Alison y Smithson, Peter en ibid. p. 52. 
1956, un proyecto para una exposición organizada por el Daily Mail que pedía reflejar la casa y el modo de vida del futuro. Aunque su geometría y tecnología emanaba un dinamismo y modernidad que en apariencia respondía a la demanda anteriormente expuesta por Peter Smithson, a nivel funcional no se apartaba mucho de una concepción de 'adaptación' ejecutada con materiales actuales a su tiempo y con una estética fashion. Los Smithson encontrarían el origen de sus ideas de función en el ámbito urbano, o más propiamente en la calle. Según Peter Smithson:

Podemos reconstruir esa conexión solo a partir de las asociaciones entre personas en lugares que sabemos que ya tienen vida.

Nos movemos alrededor de nuestra casa o grupo humano, transitamos; nos movemos alrededor de nuestro grupo de trabajo, transitamos; compramos; volvemos a transitar.

La principal diferencia con respecto al pattern de generaciones anteriores es que casi nunca caminamos (...) de un distrito a otro, si la distancia es de más de un tercio de milla, por lo que ya no experimentamos la ciudad como algo continuo, más bien como una serie de hechos. ${ }^{67}$

De este modo, la calle, el tránsito, el automóvil68 se vuelven agentes esenciales, en un principio, tal como lo planteara Le Corbusier, sólo que en este caso el ojo de los autores se posa en los propios habitantes y en los lazos de asociación que pueda haber entre ellos. Esta idea, como parte del objetivo principal del Team X, resulta completamente novedosa e incluye otro problema del que también van Eyck se hace eco constantemente: el de la identidad. Las proyectos de conjuntos de vivienda de los Smithson de la década del cincuenta, como el concurso de viviendas para el Golden Lane (1952) o el concurso para Berlín Hauptstadt (1957) -ninguno de ellos construido- dan una muestra clara de un nuevo tejido entre masa, espacio libre y conectividad que busca fomentar el encuentro:

Los estudios de asociación e identidad llevaron al desarrollo de un sistema de complejos edificios vinculados entre sí, destinados a corresponderse de forma más estrecha con la red de relaciones sociales -tal como se dan actualmente- a diferencia de los patrones existentes de espacios restringidos y edificios autónomos. Estos sistemas más libres tienen mayor capacidad de cambio y de modificar su escala e intención a medida que se desarrollan, particularmente en las nuevas comunidades, ${ }^{69}$

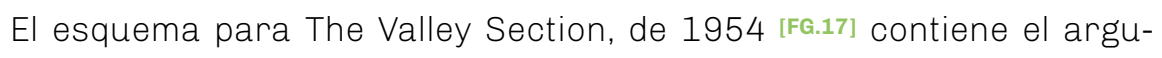
mento principal del Team $X$ para exponer sus nuevas ideas en el CIAM $X$ de Dubrovnik en cuanto a la división y jerarquías de las comunidades (ver el esquema similar desarrollado por van Eyck en 2.3.7.b. Identidad); se trata, básicamente, de una distinción en cuanto a la escala de los grupos sociales. Para los autores resulta esencial encontrar una clara dirección en la división de estos grupos por parte del planificador, y esta división debe considerar, antes que nada, los modos en que los grupos se han relacionado según su condición:

La creación de espacios colectivos no arbitrarios es la función principal del 

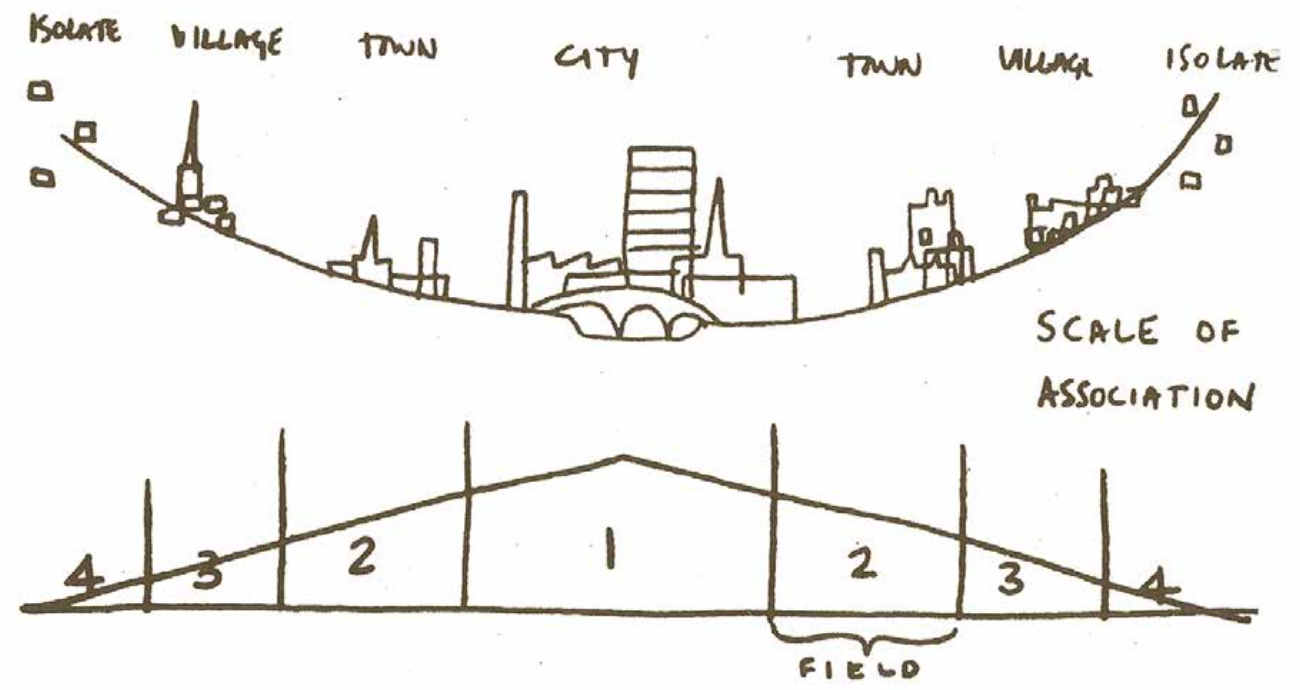

[FG.17]

Alison y Peter Smithson

The Valley Section. Diagrama

Rotterdam: Alison and Peter Smithson: from the house of the future to a house of today, 1954.

El primer grupo básico es, obviamente, el de la familia, tradicionalmente el siguiente grupo social es el de la calle (...) el siguiente el del distrito y finalmente Smithson, Alison y Smithson, Peter en ibid. p. 78. el de la ciudad. Es tarea del planificador hacer aparentes estas agrupaciones como realidades plásticas restringidas.

71. Smithson, Alison y Smithson, Peter en ibid. p. 66.

En los suburbios y barrios marginales sobrevive la relación vital entre la casa y la calle, los niños corren (la calle es relativamente tranquila), la gente se detiene y habla ...

(...)

La calle es una extensión de la casa, en ella los niños aprenden por primera vez del mundo ajeno a la familia, un mundo microcósmico en el que los juegos callejeros cambian con las estaciones y los horarios se reflejan en el ciclo de las actividades. ${ }^{70}$

Considerar que "la calle es una extensión de la casa» implica en primer 72.

"Una ciudad es, por definición, un pattern of association específico, un pattern único para cada pueblo, en cada lugar, en cada momento. Este pattern específico debe desarrollarse a partir de principios que dan consistencia y unidad al organismo en evolución". En ibid. p. 60.

73.

Smithson, Alison y Smithson, Peter en ibid. p. 64.

74.

Smithson, Alison y Smithson, Peter en Vidotto, Marco, Alison + Peter Smithson. Obras y proyectos (Barcelona: Gustavo Gili, 1997), p. 34. lugar que el espacio público, para los autores, debe poder estar vinculado directamente a un colectivo; se trata de un espacio en el cual un grupo de vecinos puede sentirse identificado hasta el punto de concebirlo como lugar, como espacio de uso, es decir, con un carácter que permita construir un vínculo. Esto implicaría un diseño que no cayera simplemente en la repetición de módulos, sino que se permitiera también el establecimiento de unos patrones que, ante similares necesidades, pudieran permitirse particularidades y diferenciaciones según el caso. La arquitectura de los Smithson mantendrá constante ese difícil objetivo de balancearse entre la tipificación y la particularidad, en el cual la función vuelve a adquirir un rol central:

Las necesidades de la nueva sociedad móvil y los sistemas de comunicaciones que la sirven invalidan las técnicas urbanísticas existentes de jerarquías fijas de edificios y espacios anónimos. La configuración de edificios debe dar sentido a la vez que comunicar la función; función en el complejo sentido del papel que desempeñan en las actividades la comunidad en su conjunto. Tal forma de considerar la construcción de ciudades requerirá inevitablemente de la reflexión tanto de los edificios mismos como de los problemas no estáticos, ya sean el flujo, la velocidad, la detención y el arranque, y todas las demás manifestaciones variadas de la ocupación humana. ${ }^{71}$ 
Quizás por primera vez en la teorías de la función se separa claramente entre los problemas netamente "estáticos", que incluirían los edificios en sí mismos, así como sus vacíos y posibilidades espaciales, y por otro lado estarían los temas "no estáticos», que comprenden el material central de la función, esta vez no necesariamente ligado a la definición espacial. Como A. \& P. Smithon mencionan, los mismos se definirían a través de sus velocidades o flujos, es decir a una concepción mucho más intangible y difícil de controlar prematuramente, pero que debe necesariamente considerarse dentro del programa de un proyecto. Este salto será central para identificar la función por fuera del marco espacial y formal de la arquitectura; si bien los estudios de Ginzburg incluían la comprensión del funcionamiento desde un punto de vista abstracto, su materialización quedaba siempre ligada a la definición de un espacio arquitectónico concreto; en este caso la función, entendida como mera acción del cuerpo humano en su marco cultural, tiene un campo de estudio propio que se ubicaría dentro del pattern of association (patrón de asociación). ${ }^{72}$ Si inicialmente se requería una división de comunidades según su tamaño, el pattern of association estaría directamente vinculado a estas divisiones:

El pattern de vida de las personas que habitan un sitio define qué tipo de entorno y qué densidad se necesita. El pattern general de una comunidad incluye grupos con densidades variables, con muchas partes, que pueden llegar a 300 por acre. Dichas concentraciones permitirán la creación de un nuevo sistema de caminos y espacios verdes que compensen el desarrollo de la vida familiar, sin aumentar el área ocupada y sin forzar a las personas a seguir patterns no deseados. ${ }^{73}$

Su conocido proyecto para el conjunto de viviendas para la zona bombardeada de Golden Lane, en Londres, [FG.18] se presenta como uno de los casos en los que estos patterns of association se materializan de forma más clara. En este proyecto los Smithson se enfocan sobre todo en el reemplazo de los puntos básicos de la carta de Atenas por una red de conexiones que de cuenta de la complejidad del habitar a través de lineas de conectividad y encuentro. El proyecto recupera el concepto de la sección de la Unité d'Habitation de Le Corbusier (concluida también en 1952) pero intercambia los corredores centrales por un nivel-terraza -denominados "plataformas" por los autores- completamente abierto al exterior; un espacio de intercambio y encuentro cada tres niveles que atraviesa todo el edificio. [FG.19] Cada una de estas "plataformas» incluiría el acceso a unas 90 viviendas familiares, lo cual garantizaría, por su propio tamaño y 'conectividad', la energía para generar un flujo de intercambio colectivo lo suficientemente rico como para considerar a las "plataformas" como "calles aéreas" que recreen la sinergia del espacio público. [FG.20] Según la propia descripción de los autores, "Dos mujeres con coche de niño pueden detenerse y charlar sin obstaculizar el flujo de paseo y, teniendo en cuenta que los únicos vehículos rodados autorizados para circular son las carretilla del tendero movidas manual o eléctricamente, [estas calles] ofrecen total seguridad a la chiquillería. ${ }^{74}$ Los collages con los que se presenta el proyecto dan 


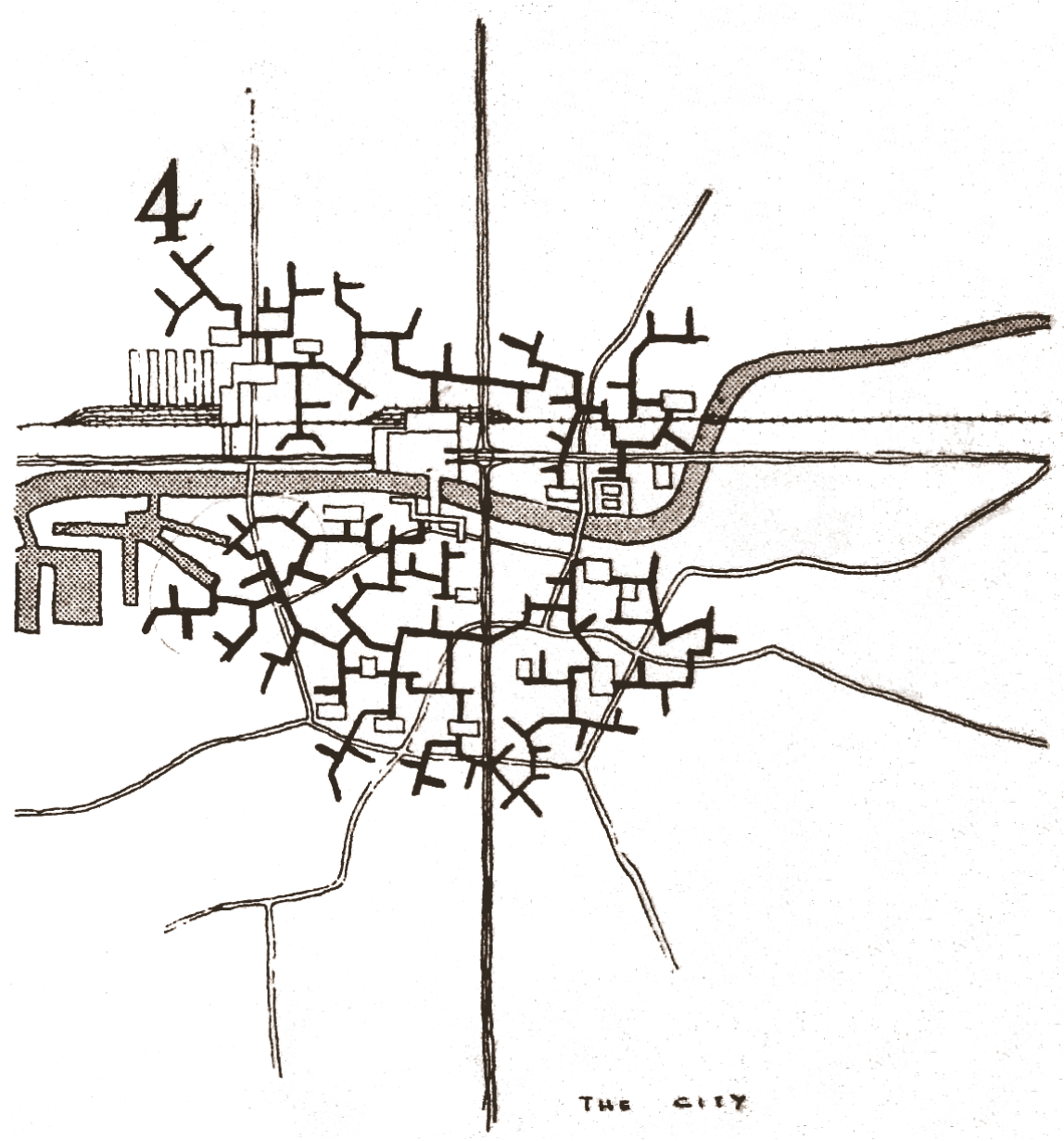

75.

Smithson, Alison y Smithson, Peter en ibid.

76.

Smithson, Alison y Smithson, Peter, "Byelaws for mental health," Architectural Design $\mathrm{n}^{\circ} 9$ Londres, (1960): p. 78.
[FG.18]

Alison y Peter Smithson

Golden Lane. Planta General

Rotterdam: Alison and Peter Smithson : from the house of the future to a house of today, 1952.

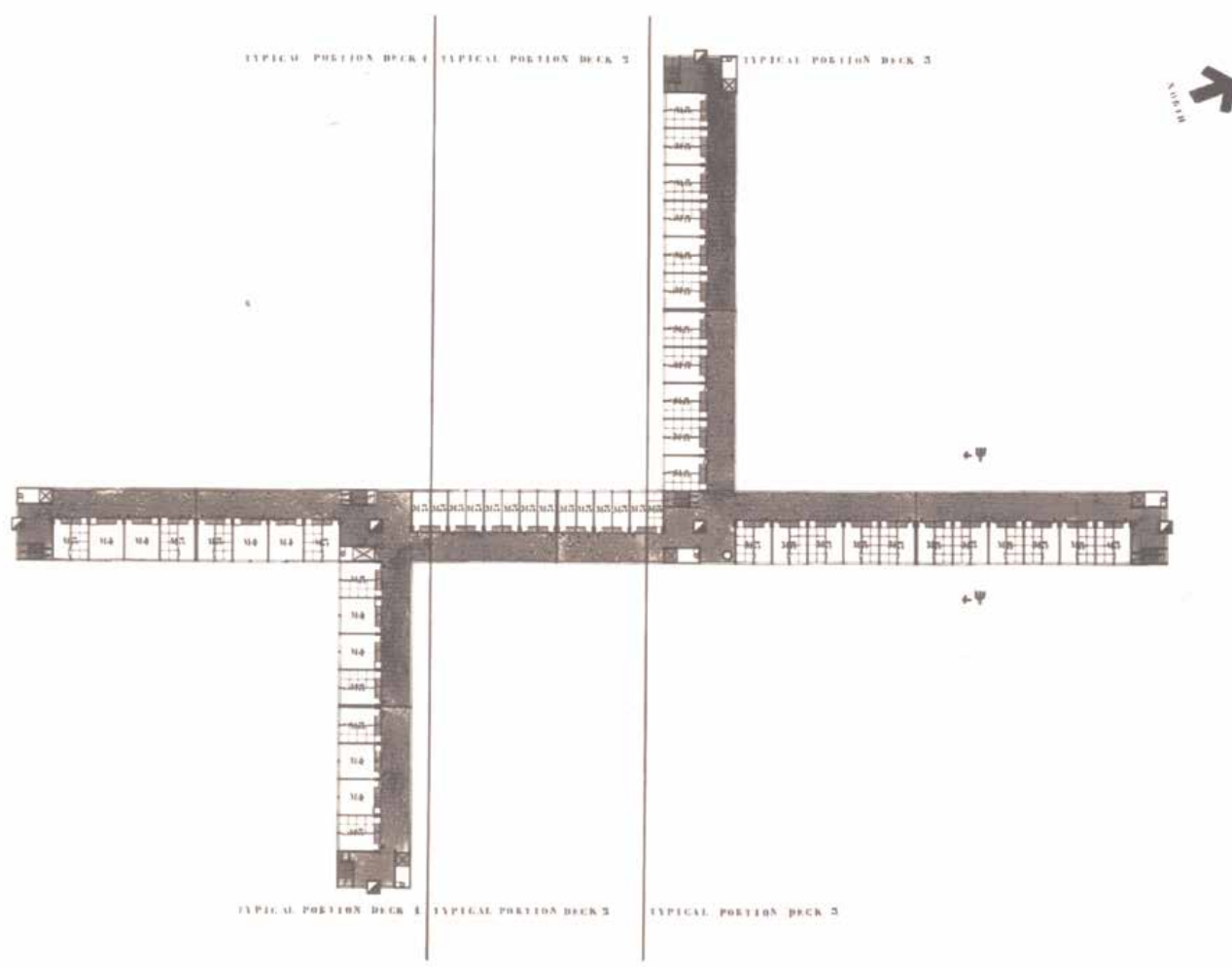

Rotterdam: Alison and Peter Smithson : from the house of the future to a house of today, 
prefabricada se posa. Sin negar el espíritu apocalíptico, sí asume -como en la exposición This is tomorrow- las únicas vías de escape posible: la prefabricación de la construcción y la energía del colectivo humano. Por otro lado, la configuración en planta presenta una unidad -la cual podría expandirse en una ramificación de la densidad de una ciudad-con una espina central y dos brazos perpendiculares; estos cruces implicarían para los autores los puntos de máxima intensidad social "Contrastando con la altura única de estas [las plataformas], las intersecciones tienen una altura triple que invita a quedarse y dejar transcurrir el tiempo". ${ }^{75}$ Como afirmarían posteriormente en su artícuIo "Byelaws for mental health" de 1960:

En la compleja asociación de una comunidad, la cohesión social solo se puede lograr si la facilidad de movimiento es posible; esto proporciona una segunda ley, que la altura de la edificación (la densidad) debe aumentar a medida que aumenta la población total, y viceversa. En el contexto de una gran ciudad de altos edificios, para mantener la facilidad de movimiento, proponemos una ciudad de varios niveles con "calles aéreas" residenciales; estas estarían vinculadas entre sí en un complejo continuo de varios niveles, conectadas donde sea necesario, tanto a los lugares de trabajo como a los elementos de tierra que son requeridos en cada nivel de asociación. Se propone una jerarquía de asociaciones entretejida en un continuo modulado que representa la verdadera complejidad de las asociaciones humanas.

(...)

Opinamos que tal jerarquía de asociaciones humanas debería reemplazar la jerarquía funcional de la "Carta de Atenas". ${ }^{76}$

Golden Lane puede ser visto como un "proyecto-manifiesto" de las primeros conceptos funcionales de los Smithson, al mismo tiempo que como una respuesta concreta a los preceptos urbanos del CIAM; pero al mismo tiempo supone un evidente avance en la profundización del interés por el modo de proyectar frente a la problemática de lo «no estático» que implican las relaciones humanas en un marco arquitectónico; de algún modo, intentar exponerse

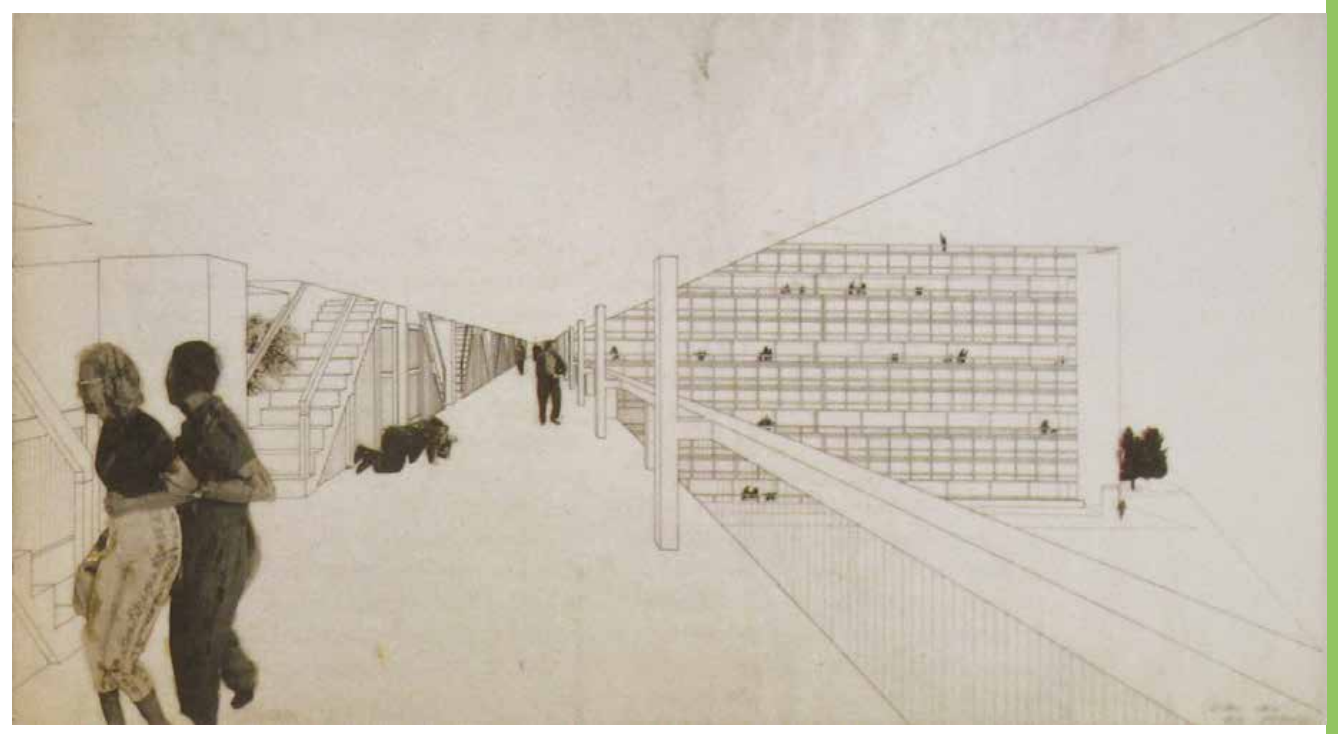


a establecer un orden en eso que, por definición, es imprevisible. Una vez más supone recuperar ese tema que Gínzburg había traído a colación con su idea de "condensador social» y su proyecto para el Narcomfin -del que Golden Lane es sin duda heredero- y que los Smithson consiguen plasmar, al menos teóricamente, en un proyecto concreto, pero también, y por sobre todo, en un discurso que busca a toda costa presentarse como operativo y, hasta cierto punto, metodológico.

"Urban structure" es un importante artículo que, aunque publicado en 1967, recoge las experiencias de los autores desde sus inicios y se presenta a modo de cinco investigaciones ordenadas según el modo en que el propio proyecto se debe ir desarrollando: "asociación», «identidad», "modelos de crecimiento», "cluster»y «movilidad». Esta visión, desde lo antropológico hasta lo urbanístico condensa y da orden a varios de los conceptos que se habían expuesto, de modo framentado, en Primer. Aún así, el concepto de "cluster» es el más importante y el más desarrollado en el texto. Como Alison Smithson remarca, fue utilizado por primera vez en el CIAM X de 1956, junto al Team X.

La idea de "cluster» radica en asumir que a los diferentes modos de "asociación» humana -los cuales se conjugan al momento de establecer una propia «identidad» previendo también sus «modelos de crecimiento»- les debe corresponder una forma específica de hábitat. Es decir, el cluster se presenta como la primera aproximación realmente operativa del planificador, cuyo trabajo pasa por encontrar la mejor estructura y orden para un grupo humano. El "cluster" se mueve entonces entre lo libre y lo estructurado; permite, sobre todo, libertades de crecimiento a futuro, pero asegurando una lógica interna que garantice la «identidad». De algún modo se mueve en un plano abstracto, y tiene el objetivo, por sobre todo, de presentarse como un reemplazo frente a la generalidad de los cinco puntos de la Carta de Atenas. Tanto el "cluster" como los puntos de la Carta de Atenas mantienen a la función como base argumental sólida, sólo que en este caso los Smithson abandonan la postura cientificista para ahondar en un camino más delicado y riesgoso, el de incorporar las lógicas de movimiento, flujo y encuentro de una comunidad de tamaño razonable. Al mismo tiempo entienden que estas lógicas pueden permitir al diseñador concentrarse en nuevos modos de orden para una función que no de la espalda a la complejidad de las situaciones, tal como se plantea en el proyecto para el Golden Lane.

\section{La palabra "cluster", empleada para indicar un modelo específico de asocia-}

ción, fue introducida en sustitución de grupos de conceptos como "casa, calle, distrito, ciudad" (subdivisiones de la comunidad) o «manzana, pueblo, ciudad» (entidades de grupo), demasiado cargadas en la actualidad de implicaciones históricas. Cualquier agrupamiento es un "cluster»: "cluster» es una especie de comodín utilizado durante el período de creación de nuevas tipologías. ${ }^{77}$ Como dan a entender los autores, existe también una preocupación por el problema terminológico. En este período la «función», y algunos de sus derivados, como "circulación", se entendían ya como definiciones asociadas a la arquitectura moderna de los años veinte y treinta; por lo mismo, la
Smithson, Alison y Smithson, Peter, "Estructura Urbana," en Textos de arquitectura de la modernidad, ed. Hereu, Pere; Montaner, Josep María, y Oliveras, Jordi (Barcelona: Nerea, 1967), p. 185.

78.

Smithson, Alison, “Cómo reconocer y leer un mat-building," DPA: Documents de Projectes d'Arquitectura, 27/28, (2011): p. 6.

\subsection{5.b.}

Cluster

79. Ibid. p. 13. 
incorporación de nuevos términos favorecía la postura renovadora que encarnaba el Team X frente al problema de la función.

Según los Smithson, para cada forma de "asociación» correspondería entonces un nuevo "cluster» una configuración diferente de edificio que debe, al mismo tiempo contar con una lógica formal, espacial y constructiva interna que le permita crecer sin destruir -como también lo plantea van Eyck- su «identidad». Como A. \& P. Smithson mencionan, los grupos de asociación se subdividen por su tamaño y complejidad, desde la calle, pasando por el pueblo, hasta la ciudad. Esta división supone una de las consideraciones más importantes del Team X sobre la función, y se materializa con los conocidos esquemas de ramificación de conjuntos residenciales, como si de un árbol se tratara, en el que, en un mismo sistema, coexisten escalas notablemente diferentes, las cuales pueden, aún, garantizar su 'conectividad' física, disipando la disociación social que algunos de los proyectos de conjuntos modernos más reconocidos, como los de Hilberseimer o Le Corbusier, proponían.

2.4.5.c. Si el concepto de "cluster», utilizado por los autores intensamente en la década Mat-building del cincuenta, sirvió también como un modo de evitar -o superar- el término «función»y sus implicancias, el midmo evoluciona más tarde hacia la idea de mat-building, que se presenta como una traslación operativa mucho más directa de un conjunto de ideas que, hasta el momento, permanecían en un plano más abstracto. La primera aproximación al concepto de mat-building aparece en Primer, pero es en el artículo "How to recognise and read mat-building" de 1974 donde Alison Smithson consigue ahondar y disipar las ambigüedades de esta estrategia, la cual, según su descripción, se va materializando a través de proyectos, pero nace necesariamente con una vocación social asociada a la función:

Se puede decir que el mat-building personifica el anónimo colectivo; donde las funciones vienen a enriquecer lo construido y el individuo adquiere nuevas libertades de actuación gracias a un nuevo y cambiante orden, basado en la interconexión, los tupidos patrones de asociación y las posibilidades de crecimiento, disminución y cambio. ${ }^{78}$

La cualidad del mat-building radica en lo que A. Smithson Ilama "asociación colectiva", la cual se vincula a la reducción de la escala en diversas situaciones de un edificio de gran tamaño para volver a acercar a los ocupantes entre sí, intentando cierto sentido de comunidad, o de pequeñas comunidades, en el conjunto. Se trata de una trama que acepta la variabilidad, y que consta de ramificaciones que se interceptan entre sí. En algunos casos se asemeja más a un volumen socavado. El elemento central de esta operación es el vacío, el cual se hace presente perforando la masa construida, permitiendo "controlar" la fuga visual y manteniendo la escala doméstica en lo que A. Smithson llama "dispersión flexible». La percepción espacial producto de esta estrategia reduce sensorialmente el tamaño del edificio y consigue vincular diferentes áreas a modo de células por medio del espacio abierto. "La comprensión debe venir a través de la percepción de las partes, ya que no es posible ver el siste- 
A pesar de que A. y P. Smithson fueron los que pujaron con más énfasis por la consolidación de este concepto y término en el Team $X$, atribuyen al proyecto para la Freie Universität de Berlín, de Candilis, Josic y Woods ser el primer caso construido de un mat-building [FG.21]. Este edificio expone el énfasis puesto en el diseño diferenciado y característico de cada uno de los vacíos, los cuales permitirían generar lazos de "identidad" en los usuarios de las diferentes áreas del edificio; un elemento, el patio -o el vacío- que, por sus particularidades en el diseño, otorgaría cierto caractére a cada área. Cada espacio abierto en conjunto con su zona aledaña incorpora así una distinción por sobre la totalidad. En este sentido se ve la cercanía del concepto de mat-building con la constante búsqueda de van Eyck por alcanzar ese objetivo de construir una «identidad" artificial a través del proyecto. A su vez existía bajo esta estrategia un interés por introducir valores de 'flexibilidad' en las posibilidades de relación que el edificio podía asegurar, a través de un esquema básico para las ampliaciones futuras.

Aceptando que el mat-building se basa en la articulación a través de una sucesión de vacíos, la circulación resulta, después de los patios, el argumento central del proyecto. Los propios autores reconocen el origen de esta idea en proyectos como la Universidad de Venecia, de Le Corbusier o las Casas Patio de Mies. Aún así la circulación en el mat-building ya no se presenta como "elemento", como podía ser en la obra de Le Corbusier, sino que se trata como parte del programa; ya no se limita a vincular un punto con otro a través de una experiencia narrativa, sino que en ella misma se disponen las propias actividades, acentuando el encuentro y la analogía con la calle. "Hacer del edificio una calle" es el objetivo central del mat-building, en el que se apela a una suerte de caos ordenado. Se trata, de algún modo, de una indeterminación que trasciende la 'flexibilidad' funcional para buscar la fricción e interacción que se considera perdida con el corredor -o conector-moderno. Parte de esto tiene que ver también con el interés de A. y P. Smithson por las construcciones árabes, las cuales utilizan como referencia:
[FG.21]

Georges Candilis; Alexis Candilis; Shadrach Woods y Manfred Schiedhelm.

Freie Universität Berlin. Planta Cambridge: Primer, 1963.

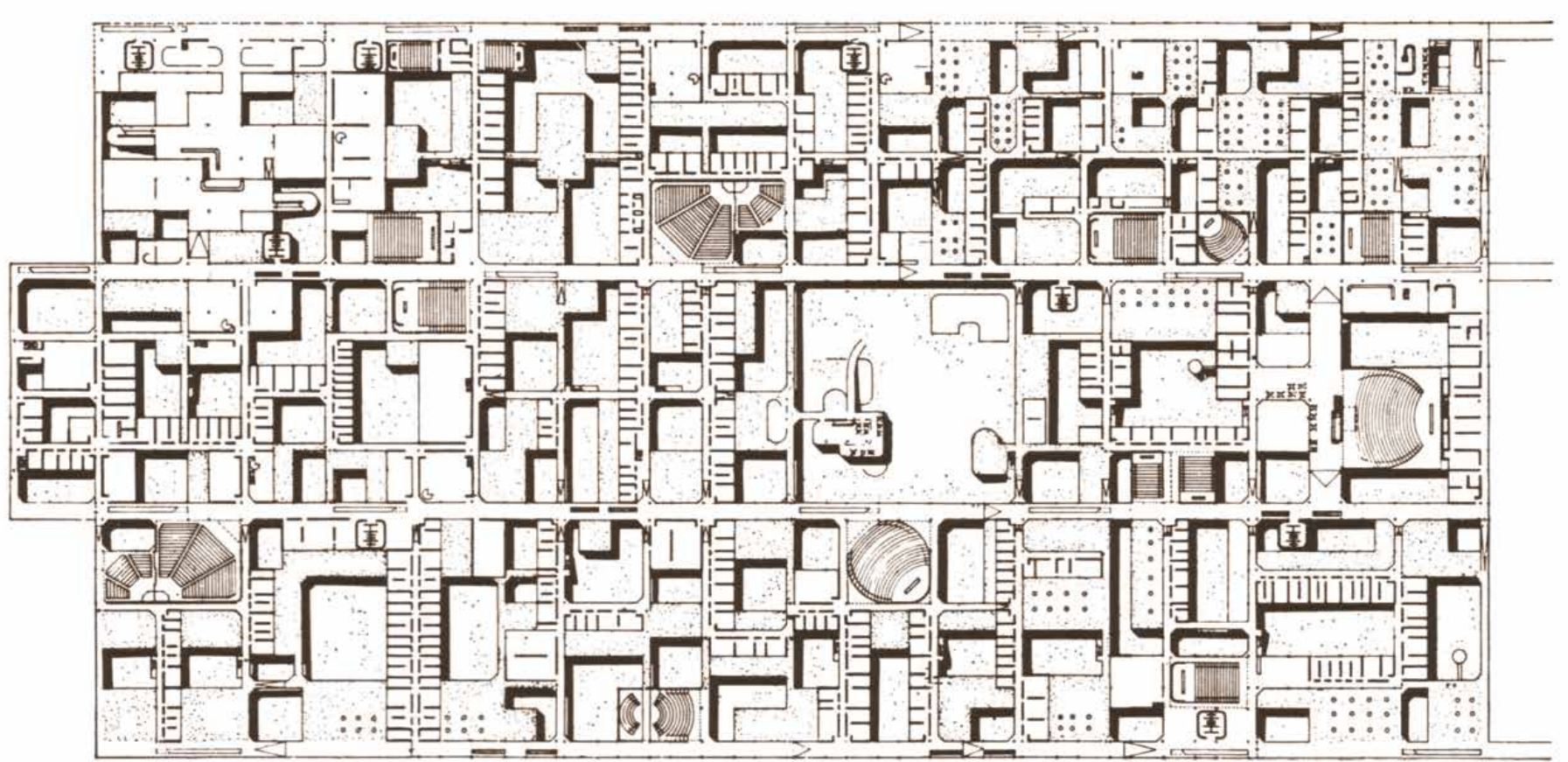


Todavía existe en la ciudad Árabe común una permutabilidad donde el "cubo neutral" contiene una célula elemental susceptible de cambio: de casa a taller, de verdulería a droguería; un callejón de casas con una panadería en medio, se convierte en un zoco con el simple recurso de extender trozos de tela sobre la calle... a medida que crecen las necesidades. Estos cambios todavía suceden en lugares elementales porque la estructura de las células, la organización de los accesos, y el ajetreo gentil a pie y en burro son suficientes para todo lo que se tiene que hacer allí. ${ }^{80}$

Quizás el interés central del mat-building radica en la aceptación de un sistema físico anterior a la función, de modo similar a como ocurría con la Villa Rotonda y la aplicación del esquema formal del palacio clásico a la vivienda, en el caso de Palladio. El mat-building es un sistema que también condiciona conscientemente la disposición y el modo en que se dan las funciones, entendiendo que, más allá de cómo estas se distribuyen, la configuración espacial inicial permitirá obtener unos resultados concretos. Su esencia se basa en la permeabilidad de su estructura y en la posibilidad de incluir en esta funciones mixtas, superposiciones público-privadas e incluso intercambios inesperados. A. Smithson es plenamente consciente de esta transformación:

Teniendo en cuenta la disciplina de una estructura de sistema continuo, las funciones se pueden articular sin los resultados caóticos que se obtienen cuando sólo se persigue la articulación de la función sin establecer primero un orden total. De hecho, es solamente desde esta estructura que puede articularse la función. Las partes de un sistema toman su identidad del propio sistema. Sin orden, no hay identidad, sino sólo el caos de elementos dispares en una competición sin sentido.

Los sistemas tendrán más que las tres dimensiones habituales; incluirán la dimensión del tiempo. Los sistemas serán lo suficientemente flexibles para permitir el crecimiento y la permutabilidad a lo largo de sus vidas. ${ }^{81}$

De este modo el mat-building se presenta como una estrategia renovadora frente a la función, en la cual esta última ya no es el germen, sino que, como un liquido, es capaz de mutar según una estructura preconcebida que, según los autores, es capaz de introducir sinergia en su funcionamiento final. Si los autores comenzaron su carrera analizando los modos de apropiación del espacio por parte de la sociedad, el mat-building puede entenderse como la respuesta, la síntesis de ese aprendizaje.

La última fase del mat-building corresponde a su posible crecimiento abierto en el futuro con la analogía biológica de las ramificaciones, a modo de «tallos» o «redes». El mismo se basa en la construcción de un tronco central, el cual contiene los servicios básicos, al cual las sucesivas ramas pueden añadirse en el futuro. Como se menciona al principio, gran parte de la esencia de la obra de A. \& P. Smithson tiene que ver con su interés en los sistemas constructivos industrializados; estructuras prefabricadas cuyo orden geométrico viene, de algún modo o hasta cierto punto, predefinido; el mat-building es también la explotación de un posible lenguaje basado en la idea del as found, que 
Las ideas de A. \& P. Smithson, como las de van Eyck, intentan esclarecer y poner como objetivo central parte de los intereses humanistas que varios de los autores más importantes de la arquitectura moderna de los años veinte y treinta mencionaban pero no profundizaban; este proceso se complejiza en un escenario de posguerra donde la reconstrucción se presenta como algo inminente y necesario. Ante este panorama los autores se proponen ahondar en el problema acercándolo de una forma mucho más directa e intensa con respecto al propio usuario, entendido este último nunca como individuo, sino como parte de un entramado social que necesita de un cuidado, no sólo de sus funciones básicas, sino también de sus vínculos. Estos últimos son los que, según los autores, pueden garantizar una identidad en conglomerados urbanos que, por su creciente densidad, ponen en riesgo una interacción social casi perdida. Probablemente el interés del aporte de los Smithson a la función radica en la mezcla de esta pretensión de ahondar en las cuestiones antropológicas, al mismo tiempo que proponer soluciones constructivas eficaces y aplicables a corto plazo, lo que los Ileva a elaborar conceptos de clara operatividad, los cuales tendrán una notable influencia posterior, no sólo como estrategia proyectual, sino también como modo de tensionar a las funciones a una 'conectividad' e interacción ya dadas por el propio sistema.

El pensamiento de Louis Kahn en torno a la función supone una de las primeras revisiones realmente críticas a la vocación pragmática y cientificista que empapó gran parte de los argumentos de la arquitectura moderna. Tanto en lo que refiere a sus obras propiamente dichas como a sus teorías -condensadas principalmente en textos con cierta vocación poética y en registros de conferencias-, el aporte de Kahn significa una vuelta hacia las discusiones originarias en torno a la función, tanto así que el mismo autor desprecia el término «función", por las mismas razones que autores posteriores, como Rossi o Venturi lo harán, es decir, por su implantada vinculación con la arquitectura moderna. Kahn está seducido por lo intangible, por la esencia de la arquitectura y la ligazón entre esta y el hombre, y sus argumentos están normalmente atados al problema de la construcción, ya que para Kahn esta última es la simple razón de ser de la arquitectura. Como dice en su texto para la College of Design, Architecture, Art and Planning:

\section{La arquitectura no tiene presencia}

\section{La arquitectura tiene existencia.}

Es un tipo de ambiente en la mente que despierta a cada hombre y eleva en sus sentimientos internos una alegría y una voluntad de expresar en el lenguaje de la arquitectura, lo que revive la maravilla de lo establecido, incluso de lo más pequeño, como un gusano. ${ }^{82}$

El modo de pensar y de escribir de Kahn, de modo análogo a como lo planteara Heidegger, lleva a considerar nuevamente los principios más básicos de la arquitectura, en el momento en que la misma simplemente no existía - o existía a modo de cobijo- reflexionando sobre cada muro, cada abertura o cada columna. "En todo lo que la naturaleza hace, la naturaleza registra cómo Io hizo. La roca registra a la roca. El hombre registra cómo fue hecho». ${ }^{83}$ Esta
82.

Kahn, Louis, What will be has always been: the words of Louis I. Kahn, ed. Wurman, Richard Saul (Nueva York: Access Press y Rizzoli, 1986), p. 73.

83.

"Luz blanca, sombra negra," en Louis I. Kahn: conversaciones con estudiantes, ed. Bell, Michael (Barcelona: Gustavo Gili, 2002), p. 20. (Ed. orig. 1969).

84.

Desde el inicio del discurso Heidegger apunta a un tema que resultará central en el pensamiento de Kahn, "Al habitar llegamos, así parece, solamente por el medio del construir Éste, el construir, tiene a aquel, el habitar, como meta". Heidegger, Martin, Construir, habitar, pensar, ed. Gebhardt, Ana Carlota (Córdoba: Alción, 2002), p. 5. (Ed. orig. 1951).

85.

"Los logros de la ingeniería bélica en hormigón, acero y madera han dado señales de madurez suficiente como para guiar la concepción de estos nuevos edificios. El esqueleto estructural gigantesco ha dejado sentado su derecho ha ser visto. No necesita ya de ningún disfraz para agradar. Nuevas envolventes de materiales transparentes, traslúcidos $u$ opacos, con excitantes texturas y colores pueden suspenderse de sus miembros. Frisos de pintura articularán las circulaciones entre los grandes recintos y esculturas embellecerán su interior". Louis Kahn, "La monumentali-

2.4.6.

Kahn. Sentidos de la función

dad," en Louis I. Kahn: escritos, conferencias y entrevistas, ed. Alessandra Latour y Jorge Sainz (Madrid: El Croquis, 2003), p. 28. (Ed. orig. 1944).

86. Kahn, “Luz blanca, sombra negra,” p. 35-36. 87. "Espacio, forma, uso," en Louis I. Kahn: escritos, conferencias y entrevistas, ed. Latour, Alessandra y Sainz, Jorge (Madrid: El Croquis, 2003), p. 78. (Ed. orig. 1956). 
base tiene, como ya se ha mencionado, al existencialismo como punto de origen, en especial en relación a las ligazones entre arquitectura y pensamiento filosófico que Heidegger expusiera en su discurso de posguerra, "Bauen Wohnen Denken". ${ }^{4}$ Pero Kahn conseguirá dar profundidad y sentido a esta traslación, en especial en torno a la función en la arquitectura.

2.4.6.a. Como es sabido, Kahn está completamente preocupado por la noción de “verdad;" la estructura, la construcción, la función y la misma expresión de dicha función es un conjunto indivisible de suma importancia para el autor. ${ }^{85}$ Esto tiene que ver con su fascinación por la arquitectura de la antigüedad, por lo que su enfoque primero en torno a la función consiste en revisar lo más básico de las necesidades del habitar del hombre, evitando cualquier referencia moderna a nociones como las de 'eficacia' o ‘adaptación', para buscar un equilibrio en la esencia misma de la actividad y el espacio que le corresponde. Nuevamente, no se trata sólo de poder desarrollar la actividad requerida en cada espacio, sino que esta se dé de tal forma que por sí misma genere un significado.

(...) la arquitectura en realidad no existe. Sólo existe la obra de arquitectura. La arquitectura existe en la mente. Un hombre que realiza una obra arquitectónica lo hace como una ofrenda al espíritu de la arquitectura... al espíritu que no conoce estilos, no conoce ni técnicas, ni métodos. Que tan sólo espera aquello que se muestra a sí mismo. Hay arquitectura, y es la materialización de lo inconmensurable. ${ }^{86}$

Esta posición, que evita cualquier signo de "su tiempo" para adentrarse en la monumentalidad clásica y antigua, lo vincula directamente con las nociones de los primeros tratados de arquitectura, con la idea misma de utilitas, o los aportes de Alberti en torno a necessitas y commoditas. Kahn es plenamente consciente de que su diálogo se aparta de las discusiones modernas en cuanto a la función, para adentrarse en el origen mismo del problema y exponer así cada elemento constructivo, con una obsesión que remite claramente a las ideas de Lodoli:

Deberíamos preocuparnos más por diseñar dispositivos estructurales que puedan contener las necesidades mecánicas de las habitaciones y espacios, sin esconderlas. Los cielorrasos suspendidos que ocultan la estructura, tienden a borrar la escala. La sensación que nuestra arquitectura actual necesita ser embellecida deriva, en parte, de nuestra tendencia a ocultar los encuentros y articulaciones, a esconder la forma en que las cosas están ensambladas. Si nos enseñaran a dibujar siguiendo los modos de construcción, desde el basamento para arriba y deteniendo la punta del lápiz en las juntas, el ornamento se desenvolvería desde nuestro amor por la perfección de la construcción y desarrollaríamos nuevos modos de edificación. Resultaría intolerable pegotear y embutir las luminarias y el material acústico, enterrar los conductos y cañerías. Cómo fue hecho y cómo funciona debe infiltrar todo el proceso de construcción. ${ }^{87}$

En esta afirmación resulta fundamental la noción de space construction system ("dispositivo estructural») que el propio autor incorpora a su pen- 
acomodadas en un sentido de orden superior, en el cual la geometría gobernara. En este punto es donde se vinculan sus ideas de función con su interés por la monumentalidad; se trata de una monumentalidad que afecta al orden funcional. Hay una apego por la simetría, tanto de las formas como de las funciones; también en la escala de los espacios y de las funciones. Se trata de una reinterpretación de la forma clásica, incorporando las variables de las necesidades de una "sociedad moderna", aunque el autor no se interesara por este tipo de definiciones. Esta idea es la que en parte conformará el conocido binomio entre espacios "servidores y servidos", concepto que se deja ver en su conversación con John W. Cook y Heinrich Klotz en 1973,88 y que permite entender el modo en que el autor aporta a la idea de 'conectividad'. Si Durand utilizaba la composition para establecer un orden simétrico y jerárquico entre espacios y funciones, la propuesta de Kahn pasa por encontrar antes un sentido a las funciones que derive en un orden espacial, el cual redundará en una unión inseparable entre estructura, construcción, función y espacio. Difícilmente haya un mejor ejemplo de este concepto que la sección del Salk Institute de California de 1959 [FG.22], la cual permite ver una serie de espacios técnicos incorporados al falso techo de un espesor tal que permiten ser accesibles y "servidores" de los laboratorios. El mismo Kahn lo explica cuando dice que:

Este espacio es tan alto como el espacio donde se realizan los experimentos. Estas habitaciones tienen grandes tuberías que alimentan hacia abajo o hacia arriba. Puedes caminar en las áreas de servicio; son tan importantes como los laboratorios biológicos, ya que los controles deben realizarse en áreas muy pequeñas de un laboratorio. ${ }^{89}$

La articulación entre estos "servidores y servidos", tanto los primeros, que refieren no sólo a los espacios técnicos, sino también a las circulaciones verticales o salas secundarias, como a los segundos, los cuales suelen corresponder con las estancias más jerárquicas de un edificio, implican un traspaso esencial de un estado a otro; deben ser, según el autor, denotados en términos espaciales y constructivos haciendo que el mismo edificio, por sus cualidades materiales, sugiera el uso. Se trata, de un modo similar al de Le Corbusier, de una 'conectividad' poética al mismo tiempo que funcional, sólo que en este caso mucho más basada en la esencia de las mismas funciones. En resumen, el edificio debe ser capaz de guiar al usuario y ofrecerle el modo en que el mismo debe ser utilizado, apelando a la espacialidad y a la trascendencia de la misma. La noción de programa había sido principalmente tratada, desde la tradición francesa -especialmente en el caso de Durand, Viollet-le-Duc o Guadet- hasta la arquitectura moderna, como la condensación de los requerimientos funcionales de un edificio por parte de usuarios o instituciones. En algunos casos, como el de Meyer, la misma adquirió una importancia fundamental, al no limitarse simplemente en vincular un espacio a una función, sino comprender el abanico de actividades que componen el programa, por ejemplo, de una vivienda. Kahn continuará esta linea, dando un paso esencial en la concepción del programa arquitectónico al preguntarse antes que nada por el sentido de las funciones: July, 1971" en Cook, John Wesley y Klotz, Heinrich, Conversations with architects (Nueva York: Praeger, 1973).

89. Kahn, What will be has always been: the words of Louis I. Kahn, editado por Wurman, Richard Saul (Nueva York: Access Press y Rizzoli, 1986). p. 130. Traducido por el autor.

90.

"El orden es," en Louis I. Kahn: escritos, conferencias y entrevistas, editado por Latour, Alessandra y Sainz, Jorge, (Madrid: El Croquis, 2003), (Ed. orig. 1955). p. 64.

91. Ibid. p. 65.

92. “Luz blanca, sombra negra," p. 21. 93. What will be has always been: the words of Louis I. Kahn, p. 3. Traducido por el autor.

\subsection{6.b.}

Reprogramming 
Un auditorio

¿es un stradivarius o es una oreja?

Un auditorio

¿es un instrumento afinado para Bach o para Bartok, ejecutado por el director; o es un salón de convenciones?

En la naturaleza del espacio está el espíritu y la voluntad de existir de cierto modo. $^{90}$

(...)

Antes que una estación de trenes sea un edificio,

quiere ser una calle,

crece desde las necesidades de una calle,

desde el orden del movimiento,

un lugar de encuentro

de contornos vidriados. ${ }^{91}$

De este modo el autor plantea un nuevo inicio para el programa, que se funda en la razón de ser del mismo, no sólo en torno a su condición arquitectónica, sino también en cuanto a su lugar en una comunidad. Esta función base, comunitaria y al mismo tiempo significativa, Kahn la condensará en su idea de institution, un término que está presente constantemente en sus textos y conferencias, y que tiene un rol de importancia en cuanto a su concepción de la función:

La inspiración por aprender surge de nuestra manera de vivir.

A través de nuestro ser consciente

sentimos el carácter de la naturaleza que nos formó.

Nuestras instituciones del aprendizaje surgen

de la inspiración por aprender,

que es una intuición sobre cómo fuimos hechos. ${ }^{92}$

Las institutions resultan para Kahn tan fundamentales como fundacionales, ya que en ellas entiende el modo en que la sociedad concibe sus "rituales," es decir sus hábitos ligados a sus construcciones. Institution es el lugar donde las actividades deben cuestionarse, cultivarse, y desarrollarse, y a partir de ahí materializarse en objetos arquitectónicos significativos. Para poder conseguir esto Kahn comienza cuestionándose la razón de ser de los hábitos, trasladando estas reflexiones al diseño. El caso del proyecto para Erdman Hall Dormitories, de 1965, [FG.23] resulta importante ya que, en él, el mismo autor se expresa largamente sobre este proceso:

Es muy interesante entender cómo la mente debe ser estimulada por temas circunstanciales, digamos por el conocimiento, o por el conocimiento específico necesario para comprender la función al construir una residencia como esa. Uno no debe suponer que sabe algo sobre tal edificio cuando comienza a concebir su diseño, sino que debe pensar en cuál es la naturaleza de dicho edificio ¿Cuál es la naturaleza de una residencia para niñas en comparación con un hotel o un edificio de apartamentos o, incluso, por ejemplo, una residencia para hombres? Una residencia para niñas no es lo mismo que una residencia para hombres. En una residencia de mujeres uno debe sentir la presencia de la casa mucho más que en la residencia para hombres. ${ }^{93}$ 
Así, Kahn no piensa tanto en los edificios por su programa sino por lo que significan como establecimientos cívicos para el hombre; esto no incluye sólo las funciones, sino también el lugar que este edificio tiene en el entramado social, y cómo el mismo puede ser incorporado por el hombre de modo más o menos habitual. ${ }^{94}$ "Una de las grandes ausencias de la arquitectura actual es que las instituciones no se definen, que se dan por hechas, tal y como aparecen en los programas se convierten así en edificios». ${ }^{95}$ Para Kahn el problema de la función y de los programas es posterior a otro tema central, que es el de la definición del propio habitar, y este viene dado por las institutions; pero estas deben ser a su vez replanteadas en términos conceptuales por el propio arquitecto antes de tomar cualquier decisión en cuanto al diseño. Se trata de lo que él entiende como reprogramming (re-programar), que constaría de una acción de observación anterior, pero al mismo tiempo definitoria del diseño. Esta aproximación queda expresada con claridad en su conferencia "White light, black shadow" de 1969:

Como trabajo de curso en la universidad, planteé el problema de un monasterio, y yo adopté el papel del eremita que creía en la necesidad de una sociedad de eremitas. ¿Dónde empiezo? ¿Cómo siento esa sociedad de eremitas? No tenía programa, y durante dos densas semanas hablamos de la naturaleza. (La comprensión de la naturaleza es uno de los objetos del eremita). Una chica india fue la primera en decir algo significativo. Dijo, "Creo que en este lugar todo debería surgir de la celda. De la celda surgiría el derecho a existir de la capilla, de la celda surgiría el derecho al retiro, y el de los talleres para vivir. Otro estudiante indio (sus mentes piensan de un modo más trascendente) dijo, "Estoy de acuerdo, pero me gustaría añadir que el refectorio debe ser equivalente a la capilla, y la capilla equivalente a la celda y el retiro igual al refectorio. Ninguno es más importante que los demás". (...) El programa original no contemplaba lo nuevo, no tenía voluntad de vida, y estos estudiantes estaban inspirados. Cada estudiante dio con una solución distinta, pero todos sugirieron una vida nueva, elementos
94.

"Si se toma el programa como algo dado, un ayuntamiento es hoy día un simple edificio de oficinas. Eso sería una pérdida terrible" Kahn, Louis, Conversaciones con estudiantes (Editorial Gustavo Gili, 2002), p. 53.

95.

Kahn, “Luz blanca, sombra negra,” p. 21-22.

96. Ibid. p. 22-24.

97. Kahn, Conversaciones con estudiantes, p. 57 98. Kahn, “Luz blanca, sombra negra," p. 30. 99. Kahn, Conversaciones con estudiantes, p. 45.

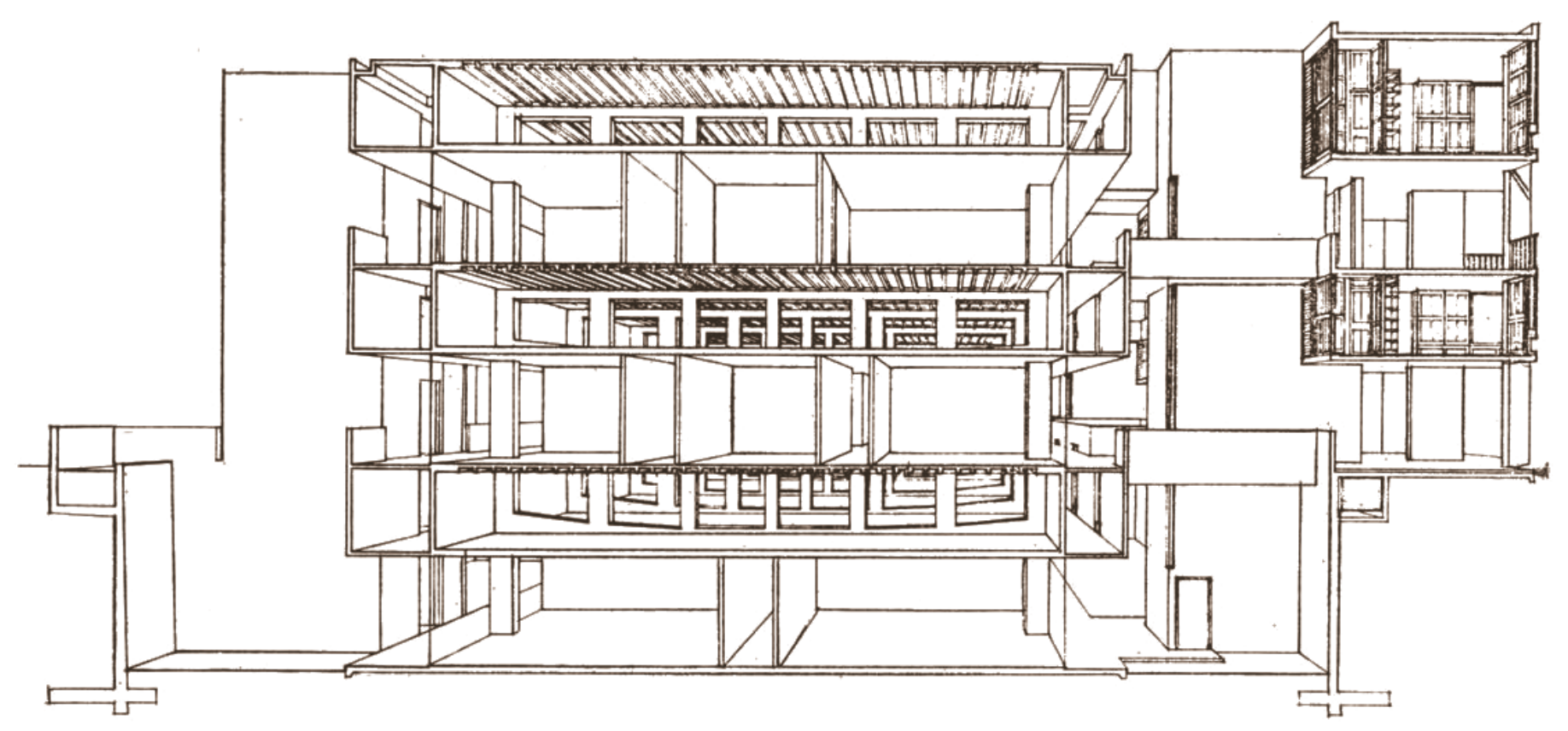


nuevos. No os lo puedo describir todo ahora, pero lo que empezó como una simple reconsideración emergió con el poder de un nuevo comienzo, en el que los nuevos descubrimientos podían llevarse a cabo en un contexto actual. ${ }^{96}$

Como se ha comentado, el principal aporte de Kahn reside en retrotraer a la función a un punto anterior al de su consideración pragmática. Para el autor se trata de hurgar en la naturaleza misma de las instituciones, en la comunión del hombre y su alojamiento. En este sentido es quizás una de las concepciones que, con más fuerza, vuelve a atar el hilo, en parte perdido, de la noción vitruviana de decor, y de la posterior interpretación de Blondel a través del caractère,

(...) diría que existe la obligación de idear programas adecuados. En lo profesional, diría que la posibilidad de encontrar la naturaleza de algo se encuentra precisamente ahí. El arquitecto encuentra en su edificio cierta naturaleza que pertenece a una cierta actividad del hombre. ${ }^{97}$

Pero al mismo tiempo, la posibilidad de idear estos programas y de reformular las instituciones -lo que entiende como reprogramming- está a merced del marco subjetivo del mismo arquitecto.

Todas estas reglas y consideraciones constituyen el programa (si se lo quiere llamar así). Pero programa es una palabra demasiado aburrida. Se trata de comprender la naturaleza de un conjunto de espacios donde es bueno hacer algo en concreto. Ahora bien, decís que algunos espacios deberían ser flexibles. Claro que algunos espacios deberían ser flexibles, pero también los hay que deberían ser completamente inflexibles. Deberían ser pura inspiración... sólo el lugar donde estar, el lugar que no cambia, excepto para la gente que entra y sale de él. ${ }^{98}$

En la acción del reprogramming yace la intención heredada de Heidegger de volver a considerar la etimología de cada palabra, y con lo mismo volver a plantearse el rol funcional de los objetos:

Cuando hago una escuela, intento resolverla a partir de "escuela", y no de "una escuela." En primer lugar está el problema de por qué una "escuela" es distinta de cualquier otra cosa. Nunca leo un programa literalmente. Es algo circunstancial. La cantidad de dinero de que dispongas o dónde debe localizarse, y las cosas que necesitas no tienen nada que ver con la naturaleza de un problema. Así que buscas su naturaleza y después lo confrontas con el programa. Mirad a la naturaleza de algo y después y veréis en el programa lo que queráis... una biblioteca, por ejemplo. Lo primero que se hace es reescribir el programa. Ahora bien, la reescritura debe ir acompañada de algo que la interprete. ${ }^{99}$

Para Kahn la consideración sobre un edificio debe en todo momento comprender la absoluta singularidad del mismo, no sólo como objeto, sino también como institution. En este sentido, el tipo arquitectónico juega un lugar importante, pero lo que justamente Kahn evita es la vinculación entre un tipo arquitectónico y su función. Esta consideración remite claramente a la revisión manierista de la arquitectura clásica -sobre todo a la obra de Palladio-, y la adecuación de tipos arquitectónicos a programas que no necesariamente le corresponden, con la intención de poder de esta manera formular tipos de 

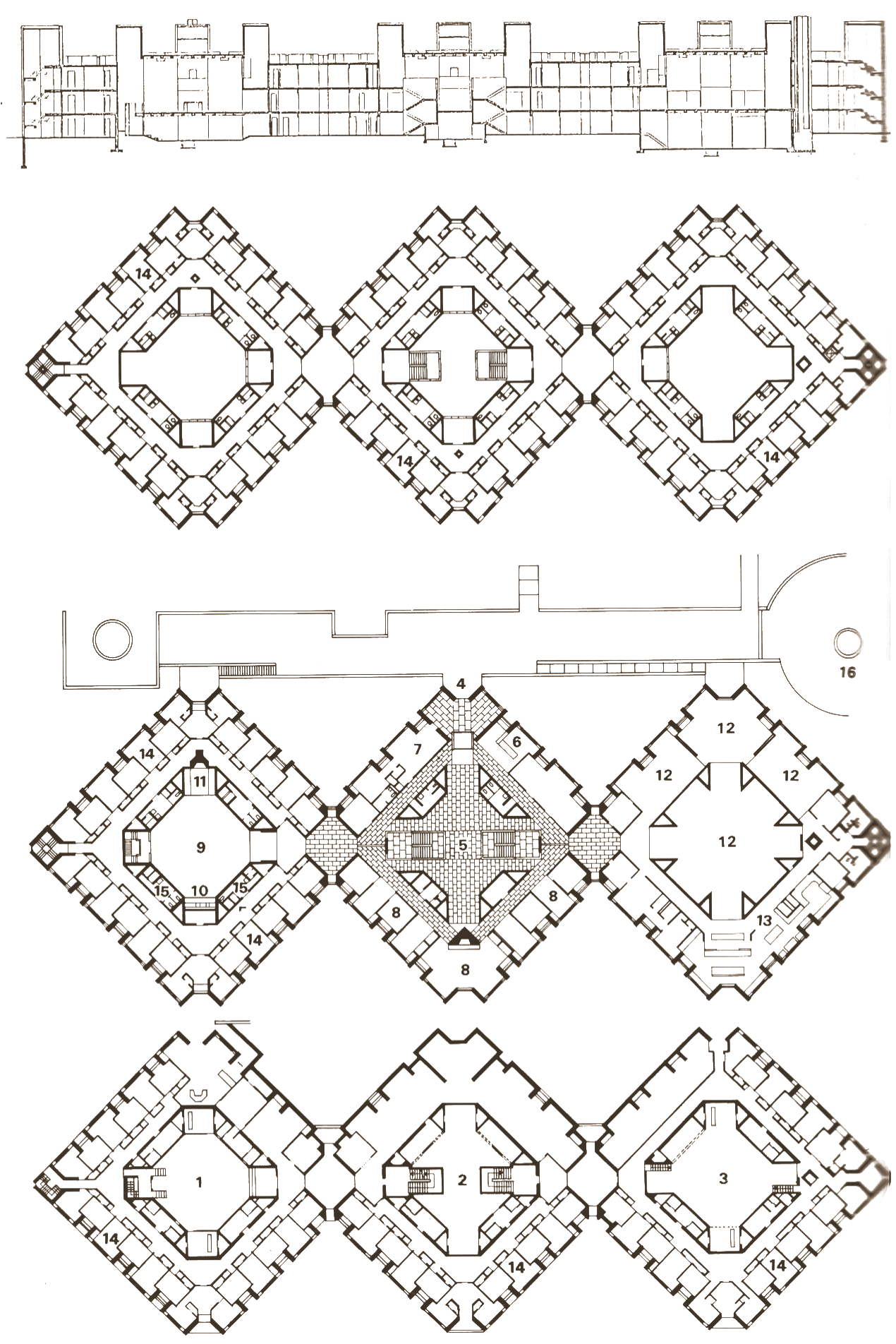
2.4.6.c. Puede decirse que la idea de space types (tipos de espacio) es el último paso Space types en cuanto a la fase de diseño en la obra de Kahn. Estos "tipos" son el resultado de las variantes internas de la solución funcional, al mismo tiempo que de la solución estructural y espacial del proyecto. Se trata del entendimiento de las distintas actividades, de su relación entre ellas, y del modo en que las mismas se materializan en cuanto a posición, tamaño, y condiciones espaciales, tales como dobles alturas, continuidades o transparencias. En definitiva, las características capaces de definir ese significado que permita al usuario, a través de la 'conectividad', experimentar y percibir el sentido del edificio. Una referencia posible se encuentra en su descripción para el centro cultural, en su texto "Monumentality," de 1944:

El conjunto acoge áreas más pequeñas para usos específicos, divididos por paneles de vidrio, yeso o mármol, independientes de la estructura y relacionados sólo con la trama circulatoria. La planta parece continua. El gran lobby es parte del anfiteatro que se hunde en el escenario. La luz viene de arriba a través de una serie ondulada de cúpulas prismáticas de vidrio. ${ }^{100}$

Como se ha mencionado al inicio, Kahn recurre al rigor geométrico y a la simetría para poder resolver las relaciones entre los space types, evitando una relación directa con la escala humana -signo patente de la arquitectura moderna- dando como resultado una arquitectura caracterizada, tanto en su forma como en su percepción interior, por la monumentalidad. Uno de los proyectos que mejor ilustra esta noción es el de la Biblioteca de Washington University en St. Louis, de 1956; al mismo tiempo, pocas descripciones de un proyecto son capaces de verificar una concepción funcional de modo más claro que como lo consigue Kahn en "Space, form and use". Primero, en cuanto a su definición como institution:

Una biblioteca debe ofrecer un sistema de espacio adaptable a las necesidades en el tiempo; los espacios y su consecuente forma como edificio, deben surgir de una interpretación amplia del uso más que de la satisfacción del programa para una sistema específico de funcionamiento. ${ }^{101}$

Como en otros proyectos del autor, la Biblioteca de Washington de 1956 ostenta una imagen que no remite a ningún tipo edificatorio en concreto. [FG.24] La falta de escala de referencia, y la abstracción, tanto en la forma como en la propia configuración de la planta, la convierten en un objeto que difícilmente pueda ser reconocible o asimilable a algún programa. La doble simetría queda al mismo tiempo anulada por la repetición continua de su módulo estructural, que es, al fin y al cabo, la propia expresión del edificio. La planta con forma de cruz griega va reduciéndose nivel tras nivel hasta acabar en un cuadrado, en el último nivel. Kahn puntualiza el modo en que esta forma abstracta permite que los space types cobran sentido a nivel funcional:

El diseño de una biblioteca en torno a las influencias incipientes de los depósitos estandarizados para los volúmenes y con lugares de lectura, puede orientarse hacia una forma con dos tipos de espacios: uno para la gente, otro para los libros. Los libros y el lector no se relacionan de manera estática. Los li- 
instancias de este proyecto nuestro pensamiento se orientó en torno al deseo de encontrar un sistema de construcción espacial en el cual los boxes de lectura fueran inherentes al sistema de soporte que los cobijaba. Leer dentro de un espacio enclaustrado con luz natural en las cercanías de la envolvente parecía bueno. Desde estas unidades espaciales más pequeñas se desplegarían espacios más y más grandes. Este sistema de espacios, si es inherente al sistema constructivo, se aproxima a lo que el arquitecto piensa que el espacio "quiere ser" y a cómo debe ser realizado. ${ }^{102}$

Al mismo tiempo Kahn busca la relación entre estas unidades espaciales y la particular estructura del edificio:

La forma piramidal coloca las mayores áreas próximas al suelo, y un esquema en cruz admite que la luz penetre en el interior del edificio. Los espacios para los libros y para la lectura no se distinguen unos de otros. Hay espacios altos para algunas áreas singulares y espacios bajos para las pequeñas habitaciones o para las áreas tabicadas. Los espacios claustrales no se desarrollan desde la trama de la estructura, sino que están cavados desde un sistema espacial, dividido por muebles de madera abrazando las ventanas. El sistema de columnas y dársenas se mantiene consistente cuando el edificio retrocede para dar una iluminación cenital a los altos espacios interiores y a los niveles intermedios abiertos a ellos. ${ }^{103}$

Gran parte de las ideas que Kahn volcó en el proyecto para la Biblioteca de Washington se vieron reformulados y finalmente concretados en su reconocida obra para la Biblioteca de Phillips Exter de 1965, en la que consigue materializar sus concepciones funcionales y dar a entender con claridad la relación entre tipos de espacios, "servidores y servidos", dentro de una estructura de una escala monumental, que da significado a la institution.

El acercamiento de Kahn a la función no sólo se distancia de las discusiones que se habían dado en el seno de la arquitectura moderna sino que, sobre todo, permite que la misma vuelva a ser interpretada en su marco subjetivo, recuperando el valor, durante mucho tiempo perdido, de la originaria y fundamental noción de decor de Vitruvio. La importancia de la 'conectividad' en Kahn estriba en la acción misma de recorrer y utilizar el edificio, pero al mismo tiempo de "conectar" de un modo original y adecuado con las actividades habituales. A pesar de su declarado distanciamiento de la arquitectura moderna, este posicionamiento lo coloca cerca de Le Corbusier y su concepción de promenade architectural, como puede interpretarse en el siguiente discurso:

Ahora hablaré sobre funcionalismo. Creo que se puede hablar de que las máquinas son funcionales, las bicicletas son funcionales, las fábricas de cerveza son funcionales. Pero no todos los edificios son funcionales. Ahora, deben funcionar, pero funcionan psicológicamente. Hay una función psicológica, que es una función primordial, ya sea una fábrica o no. Sólo para que la gente se sienta involucrada, debe haber un lugar para las personas, incluso en una central atómica se debe considerar que hay personas involucradas en esto. (...) ... traduces el vestíbulo en un lugar de entrada, y se convierte en algo muy diferente.
What will be has always been: the words of Louis I. Kahn, p. 62 Traducido por el autor.

105.

Kahn, Louis et al., Louis I. Kahn: conversaciones con estudiantes (Barcelona: Gustavo Gili, 2002), p. 11. (Ed. orig. 1998). 
por galerías porque conoces su valor, conoces el tremendo valor de asociación, se trata de una galería en vez de un corredor. ${ }^{104}$

La importancia de la función en Kahn estriba finalmente en colocar a la misma dentro del entramado social, recuperando la noción de Blondel de una arquitectura que, por medio de sus funciones, permita la 'conectividad' entre usuarios e institutions. Al mismo tiempo, la obra de Kahn supone un avance cualitativo fundamental en torno a las ideas modernas de función, superando la 'conectividad' más evidente planteada por Le Corbusier y continuada por A. \& P. Smithson, dando paso a nuevas nociones funcionales que tendrán enorme importancia en las décadas posteriores, como la idea de "tipo" de Aldo Rossi. Como comenta Peter Papademetriou, "La "función" dio paso a las ideas de propósito e intención, y los usos de la historia, en cuanto que representación formal, que constituyeron el centro del debate posmoderno de las décadas de los años setenta y ochenta, fueron superados por la obra de Kahn». ${ }^{105}$

[FG.24] Biblioteca de Washington. Planta Chicago: Louis Kahn in the Midwest
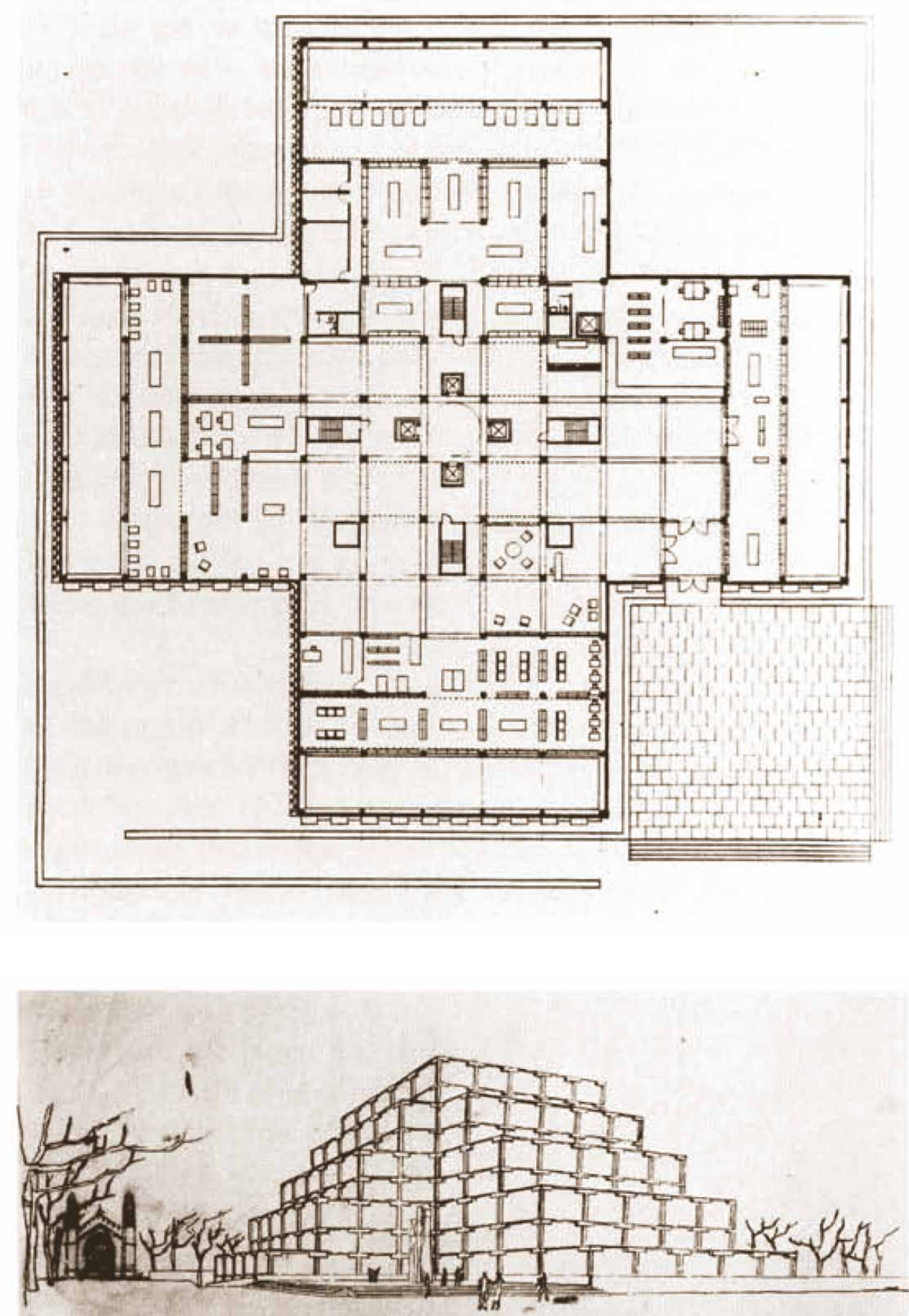

Más allá de discutir la veracidad de la ruptura histórica que supone el proceso de la arquitectura moderna -en la que la mayor parte de los historiadores convergen- la indagación en torno a las teorías de la función da como resultado la recuperación de los lazos entre las discusiones anteriores y posteriores al comienzo de siglo XX. Que la 'función', como tema en sí mismo fuera casi engendrada por la arquitectura moderna, negando aportaciones fundamentales realizadas anteriormente es una hipótesis que ha sido asumida, como ya es sabido, por la primera historiografía moderna, como una apuesta de difusión con tintes vanguardistas. Pero aunque esta propuesta haya sido ya desmantelada, el siguiente cuestionamiento lleva a la reconstrucción de esas ruinas que la ruptura de un supuesto "funcionalismo" radical tuvo con la historia. Esta reconstrucción tiene que ver justamente con el re-ensamblaje de esos trozos separados que pertenecen a una misma familia conceptual. En otras palabras, si la 'función' contenía antes de la arquitectura moderna una cantidad de matices y diferencias que aportaban riqueza al problema, ¿qué temas de la función de la tradición vitruviana y del siglo XIX se transfieren entonces a la arquitectura moderna?, o ¿cuáles son las continuidades o las discontinuidades de dichos problemas?

En un primer paso es posible reconocer temáticas generales que se modificarán sustancialmente en este cambio de período que supone la aparición de la arquitectura moderna. La primera tiene que ver con la misma semántica de la función, lo cual incluye una familia no sólo de términos, sino de conceptos extraviados a lo largo de la historia, que en parte por la convergencia de un problema más amplio condensado en una sola palabra -la de 'función'- deja atrás una serie de conocimientos acumulados. Este proceso trae también aparejado el segundo problema general, que es el de una serie de teorías que no necesariamente se alimentan -ya sea por aceptación o por oposición- de los aportes del pasado, sino que constantemente se presentan como fundadoras o re-fundadoras. Al margen de lo desarrollado en el cuerpo principal de esta investigación, estas conclusiones buscan adentrarse en la síntesis de las continuidades y discontinuidades que alberga el problema de la 
Las principales concepciones en torno a la función elaboradas en el extenso período que abarca desde la publicación de la obra de Vitruvio y la de Alberti hasta fines del siglo XIX ofrecen diversos parámetros. En algunos casos resultan aportaciones más bien circunstanciales; se gestan en un momento preciso, o responden a un interrogante puntual, y resultan más difíciles de vincular a un relato continuo. Pero la mayor parte de ellas conforman una construcción que puede entenderse como histórica; no siempre son lineales, pero sí mantienen vigencia en diferentes períodos; por diferencias y afinidades, pueden categorizarse en grupos, vincularse e incluso diferenciarse rotundamente. Se trata, efectivamente, de un árbol, cuyo tronco es la función, pero sus raíces y ramificaciones presentan interesantes diferencias, que no sólo aparecen en el plano de las ideas, sino que se verifican en una terminología que conforma un propio glosario. ${ }^{1}$ Esta familia de términos, en su mayor parte perdida o no utilizada ya en el siglo XX, mantiene su presencia en las conceptualizaciones que cada autor realiza sobre la función. Es así que el término moderno de 'función', entendido como significante, es capaz de incluir temáticas enriquecidas por un vocabulario que puede considerarse perdido, y al mismo tiempo carece de una definición histórica con vocación centralista a la cual referirse para contrastar su constante transformación en el tiempo. Por lo mismo es posible hablar, en cuanto a lo terminológico, de una discontinuidad, pero más importante aún, es posible afirmar la continuidad conceptual de varias de las aproximaciones teóricas anteriores a la arquitectura moderna. Acaso sea la capacidad de un solo significante de ocultar divergencias conceptuales uno de los hechos más paradigmáticos que trae la función como tema en el siglo XX; ya que detrás de una palabra expresamente ligada a una cultura maquinista se ocultan intereses que sobrepasan ampliamente este marco y que mantienen una evidente deuda con el pasado.

Como se ha mencionado en la Introducción, la 'función', tanto de parte de los arquitectos modernos como de algunos historiadores e ideólogos de la arquitectura moderna, se expone como un componente inherente y muchas veces propio del período. Esto conlleva también a un efecto amnésico de anulación -que ya venía ocurriendo paulatinamente en el siglo XIX-de una familia de términos que explicaban distintos rasgos o sentidos específicos. Resulta notable que las diferentes ideas de función trabajadas en el período estudiado no muestren un desarrollo evolutivo, sino que su presencia en la historia esté más relacionada con la progresión de un tejido, que recurre a reapariciones, transformaciones e incluso repeticiones, antes que a un hilo sucesivo. ${ }^{2}$ Por lo mismo, más allá de las mencionadas 'continuidades' en varias de las ideas de función que se mantendrán en las experiencias del siglo XX, existen también rupturas que son las que, de alguna manera, determinan la diferencia entre una etapa -que se podría denominar como premoderna- y la siguiente, y que resulta preciso considerar. Así es que, para poder profundizar en el diálogo entre las ideas de función premodernas y las modernas y exponer las continuidades y discontinuidades conceptuales resulta necesario centrarse en los temas constantes que comprende la propia naturaleza del problema de la función, los
3.1.0.

\section{Continuidades y}

\section{discontinuidades}

1.

El Glosario de la función en la tradición vitruviana es un trabajo de compilación que antecede a la presente investigación y que recoge las distintas lineas de pensamiento de la función desde Vitruvio hasta fines del siglo XVIII. Ver Plouganou, Damián, Glosario de la función en la tradición vitruviana (Universidad Politécnica de Madrid, 2017).

\section{2.}

Más allá de la importancia del libro de Vitruvio como una referencia constante, y de las aportaciones de los teóricos franceses -que sí se reconocen como una tradición unitaria- los diálogos entre los diferentes autores resultan en la mayor parte de los casos inconexos: no es común hallar referencias entre autores sobre antecedentes en los que ya se ha elaborado un pensamiento similar. Como se sabe, esta situación resultará aún más extrema con el corte producido en las primeras décadas del siglo $X X$.

3.

Y las variantes en sus diferentes idiomas (function, Funktion, funzionale o fonction)

4.

Esto no parece casual ya que, al revisar las acepciones anteriores al siglo XX, resulta notoria la transformación del significado de 'función' en los debates internos de la arquitectura moderna: sigue tratándose de un término que engloba una amplitud y generalidad notorias. Efectivamente, si bien durante el siglo XX el término será prácticamente uno solo, no significa que el mismo conlleve a las mismas argumentaciones. 
cuales tienen que ver con [3.1.1.] la terminología, [3.1.2.] los orígenes, [3.1.3.] el significado, [3.1.4.] la organización social, [3.1.5.] la forma y [3.1.6.] la función en sí misma.

3.1.1. El término moderno de 'función' pasará a condensar las variables terminolóFunción y terminología gicas del pasado, aunque paradójicamente no eliminará necesariamente los conceptos heredados. Por lo mismo, una de las diferencias más grandes que se plantean en las primeras décadas del siglo XX será la de un consenso general en relacionar el término 'función'3 con la organización funcional del programa de un edificio -el término fonction -del francés-, por ejemplo, ya aparece mencionado sucesivas veces en la primera edición de Vers une architecture de Le Corbusier, de 1923 empleando esta acepción-; esto supone, además de un cierto acuerdo en cuanto a lo semántico, una consolidación del problema de la organización funcional como tema autónomo de la arquitectura. La mantención de un único término, el de 'función', para referirse a formas varias de concebir la organización social de los edificios es, en definitiva, una característica propia de al menos la primera mitad del siglo XX, a continuar incluso más allá del período de estudio de este trabajo. ${ }^{4}$ La importancia de este proceso, antes que con lo terminológico, tiene que ver con la conformación definitiva de la 'función' como problema autónomo de la disciplina, por fuera de la discusión técnica o estética. Acaso este cambio suponga una de las discontinuidades más importantes entre el período moderno y el anterior. A partir de la arquitectura moderna la 'función' pasará a entenderse como el problema de la organización funcional de los espacios de los edificios.

3.1.2. La búsqueda de una organización funcional que recupere la noción más pura Función y origen de la vida primitiva, esa que explica a la construcción en su forma más básica y por lo mismo esencial fue el punto de partida de varias de las teorías sobre la función en diversos autores. Si bien en la arquitectura moderna no se hará generalmente referencia a la misma, ciertas propuestas que buscan recuperar lo primitivo de la construcción tenderán lazos de continuidad con nociones del pasado.

Para Vitruvio, el fuego representa un primer refugio para el hombre a través del cual se pasa a la cabaña y a la cueva, como paradigmas de las primeras formas de construcción, en base a la observación de la naturaleza. Para Alberti esta necesidad primaria de refugio se ve reflejada en el concepto de necessitas, casi entendido como un primer eslabón en el que prima la supervivencia por sobre una comodidad-commoditas- que llegará más tarde, como búsqueda de ambientes que satisfagan las necesidades más específicas. En una continuidad, Laugier retoma el problema del "origen" haciendo especial hincapié en la arquitectura griega, como principio de toda construcción; para Laugier la cabaña es medida, construcción y función al mismo tiempo, y consigue condensar, a modo de un modelo, la razón y la experiencia; pero además Laugier postula que la estructura primitiva de la cabaña es la que alberga las 'libertades' funcionales para una arquitectura que se pretende moderna, las cuales resume en su concepto de distribution. Posteriormente será Semper 
tos que servirán de base operativa a la arquitectura moderna. Semper, retomando a Vitruvio, propondrá que el punto de base será el fuego -Herdfeuerque permita el acercamiento de las comunidades primitivas; pero a diferencia de Vitruvio Semper sostiene que ese fuego sigue presente de diferentes modos en las diferentes comunidades, ocupando el lugar de símbolos que requieren protección; a partir de ahí es que se propone el terraplenado, el muro y el techo para garantizar su cobijo.

El concepto de Herdfeuer de Semper -aunque también reinterpretado por Bötticher y Greenough- tendrá un eco tanto metafórico como práctico, gracias también a que el programa de la casa unifamiliar tendrá en la arquitectura moderna una importancia fundamental. El fuego, como interior al cual proteger, estará presente, como es sabido, tanto en las ideas como en la arquitectura de Wright y en su forma de entender la distribución interior de sus viviendas. Wright no sólo encarna la ruptura de la simetría a través de este Herdfeuer -la cercanía con los conceptos de Semper es evidente- sino que también concibe una distribución para la vivienda basada en el espacio de encuentro de la casa: el salón y la chimenea, la cual recrea literalmente este elemento primitivo del cual los espacios se despliegan en una asimetría equilibrada, generando así una nueva matriz de distribución funcional. En 1965 Banham volverá a hacer una apreciación radical del fuego como el elemento capaz de ofrecer libertades máximas a través de su artículo "A home is not a house", en el cual un elemento generador de energía es capaz de ofrecer una libertad máxima interior, además de un regreso a un estadio primitivo, al origen. ${ }^{5}$

La ya mencionada idea albertiana de necessitas, la que hace referencia a la aparentemente simple misión de cubrir las necesidades mínimas -ya sea como metáfora o como realidad- se vuelve también un punto de partida para conseguir una arquitectura esencial, la cual hace presencia tan sólo ante la necesidad más básica; esto encuentra en la arquitectura moderna dos vertientes: por un lado se vuelve a otorgar valor al estudio de las necesidades primarias -los cuales desarrollará Meyer en Alemania-, o bien encontrará lugar en el espacio esencial que sólo se consolida como una construcción mínima -el caso de Mies. En estos casos podría incluso afirmarse que la necesidad básica -necessitas- será puesta como un valor superior a la comodidad-commoditas. $^{6}$

Del lado contrario a la revalorización de necessitas, la idea de commoditas, al menos adoptada en su acepción más general -esa que refiere a la superación de la necesidad en pos de una comodidad 'civilizada'- será quizás una de las bases más claras en las cuales se fundará lo que se entiende como "funcionalismo determinista». Esta concepción, que cuenta con Guadet como gran referente, otorga importancia a la comodidad, en cada actividad y en todos sus detalles, la cual inaugurará, en experiencias como las de Häring o Scharoun, incluso un lenguaje formal propio. Será también la base de ese planteo evolutivo y radical de la arquitectura moderna, que deshecha sistemáticamente las construcciones del pasado y plantea su reemplazo por una arquitectura superadora en cuanto a medios funcionales.
Para ampliar esta noción ver "Banham, Superstudio y el futuro primitivo 1965-1973," HipoTesis Hipo 5, (2017).

6.

Esta aproximación es la que trabajará Witold Rybczynski cuando explique la comodidad en la arquitectura moderna. Ver Rybczynski, Witold, Home: A short history of an idea, vol. 10 (Viking New York, 1986).

7.

Esta idea es ampliamente desarrollada por Banham. Ver Banham, Reyner, Teoría y diseño en la primera era de la máquina (1985). 
3.1.3. Aunque la noción de utilitas prevalecerá con fuerza como uno de los conceptos Función y significado originarios más importantes, su valor radica exclusivamente en ser la primera denominación que se conozca sobre el problema de la función, y en ser también una de las componentes de la conocida tríada. Pero será el de decor el concepto vitruviano que llevará a un entendimiento superior del problema, y que traerá además a colación otra discusión que en la mayoría de los casos -y en especial en el de la arquitectura moderna- resultará incómoda: la de la relación entre función y significado. Aunque la idea original de decor tuviera que ver con la comunicación de la función en tres niveles (el medio físico, las costumbres, y la representación social), en la arquitectura moderna se lo entenderá generalmente como lo 'decorativo,' casi como sinónimo de lo 'agregado,' y por lo mismo innecesario a la función más básica. Esta postura dejará a la concepción de decor, en principio, fuera del interés de la arquitectura moderna. Pero aunque el decor desaparezca del discurso que da lugar a la función, en la arquitectura moderna prevalecerá una ligazón entre una función que requiere, para su expresión, una forma que le sea significativa; esto será, claramente, el lenguaje industrial, o la también llamada 'estética de la máquina', la cual servirá para reforzar la idea de un edificio funcional. ${ }^{7}$ Esto resulta claro tanto en la conceptualización y expresión de los proyectos de Ginzburg como en la idea de una machine à habiter de Le Corbusier y su respaldo teórico en vers une architecture. Esta práctica encuentra una continuidad con esa antigua y desdeñada idea de Vitruvio en cuanto a la necesidad del decor de un edificio. En efecto, para una parte de la arquitectura moderna una forma no resulta igualmente válida que otra. Es decir que se trata de una continuidad que no tendrá que ver ya con la representación de un tipo particular de edificio, como aproximaba la noción original, sino que prevalecerá, sin ser mencionada, a través de una arquitectura que persiga una imagen para representar el buen funcionamiento; es decir, continuará refiriendo a los artefactos creados específicamente para una función que también puedan "verse" más funcionales. La noción de decor, encuentra también continuidad en la propuesta de Kahn, donde se vuelve a reflexionar sobre el sentido primero de las actividades humanas y el vínculo de las mismas con el espacio; es decir, el poder volver a encontrar, a través del diseño, la naturaleza misma de las actividades humanas.

Por otro lado, el caractére -la transformación del decor en un lenguaje que 'comunique' el programa del edificio- será un concepto que, a grandes rasgos, estará eliminado de la arquitectura moderna. La intención de dotar a un edificio de cualidades 'expresivas' según su función será intercambiada en general por un lenguaje abstracto que no diferencia entre programas. Esta discontinuidad encuentra su lógica en la búsqueda de formas y espacios per se, es decir, que puedan concebirse al margen de la especificidad del programa.

3.1.4. Aunque no pueda afirmarse que el tema de la necessité social o cívica -esa Función y organización social necesidad a ser suplida por el Estado- tenga una continuidad directa en el siglo XX, la misma no llega a desvanecerse completamente en un período en el que la arquitectura arriesga planteamientos utópicos. La posibilidad de que la 
del hábitat general es, de hecho, uno de los argumentos que con más evidencia establecen una separación entre las ideas de función modernas con respecto a las del pasado, aunque estas nociones ya tuvieran un inicio en los socialistas utópicos del siglo XIX, como lo menciona Frampton. ${ }^{8}$ La idea de necessité tendrá así una presencia filtrada por la experiencia idealista de Fourier y su concepto de organisation, también social, pero más pragmáticamente ligada a la arquitectura. El concepto de comunidad ideal organizada tendrá, como es sabido, una repercusión fundamental en la arquitectura y el urbanismo moderno en general. La función que supera la búsqueda de una correcta organización para el edificio y asume un rol transformador por sobre la sociedad estaba claramente presente en el proyecto para el phalanstère, y esta idea de un edificio entendido como contenedor de un fragmento de la sociedad -lo que podría entenderse como un edificio-ciudad- es un conocido denominador común de la arquitectura moderna, desde Ginzburg, Meyer hasta Le Corbusier. Aún así no se encuentra en este período un estudio pormenorizado de los objetivos en el plano tanto de lo arquitectónico como de lo social, como es en el caso de Fourier. Exceptuando a autores como Meyer o Ginzburg, es notable una atención puesta en el objeto mismo antes que en su propio funcionamiento, al menos hasta que la preocupación por el habitar concreto de estos contenedores se hace presente, en la segunda posguerra, a través del Team X. La función es, en el caso de las propuestas de Ginzburg, casi una ecuación en la cual el individuo no sólo pierde lugar, sino que la complejidad de las relaciones colectivas no es considerada, ni siquiera como lo hiciera Fourier un siglo antes.

También el de distribution será uno de los términos que, como es sabido, prevalecerá en el siglo XX, reforzando aún más su autonomía, y adquiriendo una importancia aún mayor en la primera mitad del siglo XIX bajo el paradigma del 'higienismo.' Así, la distribution será una estrategia novedosa para el proyecto; la circulación, y el propio elemento 'corredor', albergará la posibilidad de independencia de los ambientes "limpios", al mismo tiempo que se establecerán medios de instalaciones para el agua corriente, y las cloacas. Como es sabido, la distribution, bajo el higienismo también encarna una segregación social, especialmente evidente en la casa burguesa, que hereda las fragmentaciones del palacio. En la arquitectura moderna, y en las experiencias de la misma con la vivienda, estos temas se mantendrán patentes, y la circulación se explotará para segregar la casa bajo las necesidades; pero al mismo tiempo esto se aplicará también a programas de mayor complejidad con gran éxito. La de la distribution es, al fin y al cabo, la estrategia definitiva de la función en la arquitectura moderna; tan importante resulta que se convierte en sí misma en una experiencia, la del 'recorrido,' un relato temporal-espacial -como lo desarrolla Giedion en Space, Time and Architecture: The Growth of a New Tradition- que le permite enmascarar su origen netamente funcional con un nuevo contenido poético. En el mismo tono estaría la idea más simple de économie que reinterpretada, vuelve a reflejarse en la práctica de sacar provecho de las soluciones que impliquen un menor costo, no sólo material sino también en cuanto a la simpleza de las configuraciones de la planta.
Ver "Transformaciones territoriales: los desarrollos urbanos, 1800-1909" en Frampton, Kenneth, Historia crítica de la arquitectura moderna (Barcelona: Gustavo Gili, 2005). (Ed. orig. 1980). 
Finalmente, la organización social es recuperada intensamente en los años de posguerra a través de nuevos conceptos como cluster, acuñado por A. \& P. Smithson, para hacer referencia a nuevas estructuras capaces de contener la densidad de la ciudad, al mismo tiempo que cuidar las jerarquías de los grupos humanos, ya sean familias, barrios o distritos y garantizar una sinergia entre ellos. Por otro lado, el concepto de pattern, utilizado tanto por A. \& P. Smithson como por van Eyck y Alexander, a pesar de sus diferentes acepciones, comparte el poder interpretar de un modo operativo diversas formas de organización social a través de la arquitectura para darles una mejor cabida. Se trata, al fin y al cabo, de un avance y profundización de los distintos modos de organización funcional que se plantearon en la primer arquitectura moderna.

3.1.5. En la tradición vitruviana la función siempre se ha considerado como un eslaFunción y forma bón más en la construcción de la belleza, entendida en la mayor parte de los casos como el motivo definitivo de la arquitectura. Por lo mismo, la importancia de la función se ve contrapesada por intereses paralelos. En la arquitectura moderna se intercambiará la idea de "belleza» por la de "forma», un concepto más abierto y menos conducente que el anterior, pero que no quitará de encima el debate con respecto a esta y la propia función; esto es patente en dos libros fundamentales de comienzos de los años veinte, Vers une architecture, de Le Corbusier, y Estilo y época, de Ginzburg. En el primero Le Corbusier ensaya una base formal con el pasado a través de su tracé régulateur, y Ginzburg estudia el ritmo en la arquitectura, ambos intentando definir un 'estilo moderno' que a la vez no entorpezca el desarrollo de las funciones.

El problema del equilibrio entre forma y función había sido fundado por Bacon, el primero en llamar la atención sobre su patente contradicción cuando se refirió a él en su breve ensayo sobre use en la arquitectura. Una preponderancia en el uso del edificio aproximaba la duda acerca de que una distribución correcta pudiera estar acompañada constantemente de la simetría formal del edificio, la cual se consideraba indispensable para alcanzar la belleza. No obstante, las palabras de Bacon no pasan de un llamado de atención, ya que el en el mismo texto el autor concede finalmente un lugar de preponderancia a la simetría, aceptando que la función tenga que adecuarse. Siendo que la simetría es desmantelada en las últimas décadas del siglo XIX y en las primeras del siglo XX, la asimetría adquiere rápidamente un lugar estable en la arquitectura moderna, valorada como una solución fundamental para actuar frente a la función. Pero si la resolución de la función se veía respaldada por la asimetría, aún quedaba la composición formal, y de ahí la posterior preocupación de Le Corbusier y Ginzburg quienes, junto a otro autores como Giedion -ver Bauen in Frankreich, bauen in Eisen, bauen in Eisenbeton-, encuentran la respuesta en la industria, la ingeniería y la mecanización. La búsqueda de la belleza será reemplazada, a comienzos del siglo XX, por el pragmatismo, y la forma será considerada bajo un halo maquinista o al menos sistematista, como propio de la sociedad de la industrialización.

Será en el siglo XVIII cuando Lodoli, en la misma linea que Bacon, in- 
expanda la relación con respecto a la belleza. Este movimiento será la base teórica fundamental para los planteamientos modernos en torno a la función. La concepción más básica e ideal de que el edificio, su forma, sea la expresión genuina de su funcionamiento interno estaba ya presente en la idea italiana de funzione. Aunque de matriz constructiva y espacial, la funzione de Lodoli remite a una continuidad entre la sección y el alzado, o dicho de otro modo, entre la forma constructiva y la forma representativa de la arquitectura. Lodoli era sobre todo consciente de la necesidad de que este funcionamiento "interior" fuera trasladado al "exterior", del mismo modo que Le Corbusier y Ginzburg se preocuparon por encontrar unos códigos con los cuales forjar esta representación, aunque apelando a la anulación de una idea de fachada, intercambiándola por la de forma. La concepción de funzione, que no se vio reflejada en una práctica concreta en el siglo XVIII, reaparece completamente en la noción general de casi todas las propuestas modernas.

La función, vinculada a una forma específica, tiene a su vez un relato paralelo en el "organicismo", ya que el edificio máquina no necesariamente es el albergue adecuado para cada una de las funciones específicas. El "organicismo", en efecto, basa su expresión formal en los ajustes funcionales requeridos para cada actividad. Esto había sido sugerido por Ruskin en su recuperación del gótico, estilo que destacaba por su adaptabilidad a diversas situaciones y que, por el contrario que el sistema clásico, incorporaba la asimetría, y con esto un lugar claramente diferente para la forma. La idea de lo organic encuentra quizás menos continuidad en la acepción de Ruskin -no solo por la vinculación directa a un estilo, y su posible adaptación a diferentes requerimientos, sino también por el escaso desarrollo que el autor da al problema funcional- que en la de Greenough, ya que la referencia a la naturaleza y al medio en el cual la arquitectura se inserta -las variables regionales- contará con relecturas fructíferas e incluso diversas a partir de sus aportes. Esto ocurre sobre todo en la obra de Wright, en los primeros años del siglo XX, y en la reinterpretación, no sólo de las capacidades del gótico, sino del lugar de la función y de cómo esta afecta a la forma. Lo orgánico es para Greenough lo relativo a la organización propia del edificio, y la fuente es la naturaleza misma.

Ya en la arquitectura moderna se considera un antes y un después lo que puede entenderse como el fin del uso de repertorios del pasado, y con ello muchas de las exigencias que gravitaban conceptualmente en estas tradiciones empiezan a perder lugar, ya que no dependen de un lenguaje pre-establecido. En la arquitectura moderna -además de nuevas posibilidades estructurales, constructivas, formales e incluso semánticas- este campo abierto da impulso a concebir una 'función' desde la tabula rasa, es decir, desde el cuestionamiento inicial sobre el la razón de ser de la función. Tanto en la tradición del vitruvianismo como en las aportaciones del siglo XIX existirán ideas e intenciones destacadas por su radicalidad que no siempre verán su proyección completa en la práctica. Varias de estas ideas serán gestadas dentro del sistema clásico; en muchos casos resultarán conceptualmente tenaces, pero difícilmente aplicables dentro del sistema de los órdenes, limitado tanto por los 
elementos, por sus proporciones internas como por la propia simetría. Aún así, existieron casos como el de Palladio, el de Ledoux o el de Durand, que se permitieron desafiar la organización funcional tradicional, aún trabajando de forma rigurosa con el sistema. Ya en el siglo XIX, el neogótico, por otro lado, no contaba con las mismas 'limitaciones' -si es posible dar cabida a este término-, y la mejor demostración de la conjunción de nuevas concepciones funcionales con una arquitectura capaz de darle lugar es su posterior derivado, el Art Nouveau. Aún así, nada se podrá comparar a las exploraciones transgresoras que en las primeras décadas de la arquitectura moderna se realizaron, y esto se debe justamente a la permisibilidad de concebir la función y de gestar un nuevo lenguaje arquitectónico al mismo tiempo. Esta amalgama resultará fundamental, ya que no habrá deudas que saldar con un sistema formal existente y podrán desarrollarse con plenitud conceptos que en el período anterior sólo gravitaban en el plano de la teoría. El de Ebeling resulta uno de los casos más paradigmáticos, en el que se planteará incluso la desmaterialización de la forma en pos de un espacio pensado exclusivamente para un habitar fluido; idea que, en parte, será continuada por Mies. Pero probablemente la indagación más incisiva de este tema será la que desarrollan, ya en la segunda posguerra, A. \& P. Smithson bajo el concepto de mat-building, el cual propone una estructura espacial a modo de red que pueda permitir, sólo por su configuración física inicial, una mejor interacción entre los usuarios, más allá de la función que se le asigne.

3.1.6. Que la función es un valor en sí mismo en una arquitectura moderna que por Función por función momentos adoptó la denominación de "funcionalista" no resulta una sorpresa. La pregunta debiera apuntar a si esta noción «funcionalista» es genuinamente fundada por la arquitectura de los años veinte, o si efectivamente tiene también una ligazón con su pasado reciente. Por "funcionalista" se entiende un objeto que, en el plano de las ideas, basa su razón de ser, su lógica interna y su materialización en el uso o los usos a los que debe servir. Aunque resulta evidente la imposibilidad de utilizar esta denominación para la mayor parte de las experiencias anteriores al siglo XX, las aportaciones de Francia a fines del siglo XVIII y principios del siglo XIX en la École Polytechnique resultan fundamentales. La función es central en las teorías francesas del mencionado período, y quizás esta aproximación a la función como problema en sí mismo encuentre su lugar en concebir a esta última no como herencia de las costumbres que deben ser solventadas a través de la experiencia -algo que había estado generalmente presente en la tratadística vitruviana- sino en asumir la capacidad innovadora del arquitecto para propiciar escenarios superadores. El inicio de esta linea de pensamiento podría encontrarse en la idea de commodité; primero en Le Muet, quien la desarrollara en 1647; aquí el autor entiende commodité como una reinterpretación de la tríada vitruviana, pero avanzando en unas proporciones que permitirían elaborar configuraciones diferentes para las viviendas, con precisión y, sobre todo, atendiendo a las dimensiones necesarias y justas para la adecuación del mobiliario y su uso. Las proporciones en el caso 
y no buscan, quizás por primera vez, alcanzar la belleza del edificio, sino adecuar a este como espacio de uso. Pero el mismo término encontrará en el siglo XVIII otras acepciones, al vincularla Laugier a una serie de normas para el correcto funcionamiento del edificio. Como es sabido, Laugier practica una combinación entre racionalismo cartesiano y empirismo, el cual se ve en este caso trasladado directamente a la función; a partir de percepciones subjetivas se establecen así ciertos parámetros racionalistas capaces de aplicarse en casos sucesivos. La idea de commodité de Laugier apela en primer lugar a no resolver una función bajo la repetición ciega de la tradición; la innovación del diseño es requerida, y con esto queda establecida la primera piedra para lo que más de un siglo después se entenderá como «funcionalismo». Ideas posteriores anteriormente mencionadas, como la de distribution o économie, son indudablemente sucesoras de esta linea de pensamiento francesa inaugurada ya a mediados del siglo XVII.

Por otro lado está la idea de composition, la cual contó con acepciones diferentes, quedando en buena parte vinculada a la estrategia de diseño eclecticista de la École des Beaux-Arts. No obstante, la noción de Durand hacía referencia a una estrategia de diseño en la cual la función era el foco, dada la inminente necesidad de construir en la Francia de comienzos del siglo XIX edificios de gran tamaño, con necesidades varias, y de una complejidad que no había sido reconocida hasta el momento. Así es que la composición se convierte en una estrategia de lo que podría entenderse como "apropiación funcional" de motivos y formas clásicas. Es, al fin y al cabo, una recuperación del clásico como sistema de ensamblaje de partes capaces de ser yuxtapuestas para resolver diferentes funciones. Bajo un sistema ya dado -el que el neoclásico permitía-, con sus formas ya incluidas, Durand consigue acercarse directamente a la explotando sus posibilidades. Pero lo que sobre todo albergan las teorías de Durand es la jerarquía de la función por sobre otros temas de la arquitectura, y un movimiento que coloca a esta como entelequia de la arquitectura. La composition de Durand será posteriormente reinterpretada, tendrá un eco no asumido en la industrialización, aplicada masivamente a la arquitectura en la segunda posguerra del siglo XX. La posibilidad (y necesidad) de diseñar componentes repetitivos y habitables que, estudiados detenidamente en sus implicancias funcionales, sean capaces de generar un comportamiento superador al integrarse al todo es una continuación de un concepto que el autor francés ya había fundado.

Otro de los términos más importantes en el siglo XX relacionados con la función es el de programme. Se trata de una noción que no había estado presente en la tradición vitruviana de modo explícito, aunque sí existieron en la mayoría de los tratados un orden y conteo de las necesidades de habitabilidad a suplir a través del diseño. El término aparece también en la tradición francesa, ya en el siglo XIX, y es incluido en Entretiens sur l'architecture por Violletle-Duc; en principio refiere a una herramienta que conecta al arquitecto con el destinatario para poder dar orden a una serie de requerimientos vinculados 0 no entre sí. Se trata de un ejercicio que permite un diálogo racional sobre las 
necesidades a suplir y que tiene sentido, del mismo modo que la composition, como reacción propositiva frente a proyectos de gran envergadura. La noción de programme, la cual encuentra lugar exclusivamente en la planta de arquitectura, se consolidará como un término indispensable desde la arquitectura moderna, hasta que adquiera incluso una entidad propia como herramienta de diseño. En la misma linea está la aportación de la experiencia del rascacielos, a fines del siglo XIX. Aunque "The tall office building artistically considered" de Sullivan no tuviera una pretensión teórica sobre la función, y no pasara de ser una detallada descripción técnica, la idea del typical story, para referirse a las 'plantas tipo' del edificio de oficinas, resultan fundamentales para comprender uno de los pensamientos más radicales en torno a las posibilidades liberadoras de la arquitectura en cuanto a la función, más allá de que no siempre mantuviera esta denominación. Typical story es la expresión de una solución funcional novedosa que el edificio de oficinas exige, casi como una nueva necesidad social, frente a un nuevo problema funcional a resolver. Podría considerarse como un avance del planteamiento de programme de Viollet-le-Duc, en el sentido en que se trata de la concepción de un espacio capaz de aceptar o incluir diferentes programas cambiantes. Más allá de que Sullivan inicialmente lo asumiera como un resultado del rascacielos de oficinas, en unas pocas décadas Mies van der Rohe se apropiaría de esta 'solución espacial' para plantear un espacio indefinido funcionalmente, cuyo programme se mantenía completamente abierto.

Por otro lado el impulso de modernización y aplicación de soluciones racionalistas al habitar a comienzos del siglo XX resulta al fin y al cabo ineludible, ya que en la mayor parte de los casos supone dar cabida a la función como eje principal del proyecto de arquitectura. Este proceso fuerza a la aparición de concepciones sobre la función novedosas y, sobre todo, radicales; por lo mismo no existen dudas acerca del punto de inflexión con respecto a su pasado. Producto de esto es la 'indeterminación funcional', expresada en edificios que se comportan como contenedores de diversas y cambiantes actividades, como los grandes almacenes, edificios industriales, edificios para exposiciones y, claramente, los edificios de oficinas, de los cuales Mies se presenta como principal exponente. Al mismo tiempo supone la ruptura radical con la simetría, la búsqueda de cierta fluidez y continuidad espacial, y la adaptación al medio en el cual se inserta; también la importancia fundamental de la circulación, no sólo como elemento de vinculación y economía entre espacios, sino como recorrido y experiencia en sí misma. Finalmente, la transparencia, que desmantela la separación de ambientes y que supone una proyección del interior hacia el ámbito público. Estas modificaciones en los parámetros disciplinares serán las que sienten las bases más importantes para las teorías de la función que aparecerán en los años veinte, y que encontrarán una notable profundización en los años cincuenta, en propuestas como la del reprogramming, de Kahn, en la que se vuelven a revisar los sentidos originarios de las actividades humanas para indagar en qué tipos de espacios pueden tender un lazo más directo y 
Como se ha comentado en la Introducción, cualquier argumento en torno al problema de la función resulta difícil de rastrear en la mayor parte de los textos de arquitectura, tanto en los aquí presentados como en muchos otros que por esa misma carencia se han omitido del estudio, o se han considerado en menor medida. Tanto la 'función' como sus acepciones cercanas de 'utilidad' o 'distribución' son mencionadas por los autores, en muchos casos de manera constante, pero desenterrar las ideas que las fundamentan resulta una tarea mucho más esquiva.

En principio, la 'función' se presenta como un término de común entendimiento, como si se tratara de una convención, por lo que muchos autores no consideran su definición; y es justamente esta omisión la que esconde y no permite visibilizar -al menos en un primer momento- las diferentes interpretaciones. De ahí que la selección de textos que se presentan como el resultado del trabajo ha implicado además un recorte interno dentro de cada texto seleccionado, lo cual requirió, en la mayor parte de los casos, omitir el planteamiento principal del autor con el propósito de poder extraer las ideas de función latentes detrás de escritos muchas veces enfocados en otros temas. Además, en este ejercicio, los proyectos de arquitectura seleccionados han sido fundamentales como ejemplos de las múltiples formas en que la función puede ser interpretada según los diversos pensamientos. Desde este punto de vista, la selección propuesta en el Objetivo 1 se centra, justamente, en estos artículos, capítulos de libros o conferencias que más cercanía tienen con el tema estudiado, los cuales han sido presentados a lo largo del trabajo.

A la terminología variada que impregna la tradición clásica se le opone una primera mitad del siglo XX con una prácticamente unánime utilización del término 'función'. Esto tiene que ver con un proceso de convención que se dio en el seno de la arquitectura moderna y de su historiografía: el de ubicar a la ‘función' -y en muchos casos a su término derivado: "funcionalismo"- como estandarte del proyecto moderno. Aún así, y nuevamente, al resistir la aceptación de que un único término puede ser capaz de aglomerar ideas de índole tan diversa, una parte importante de los resultados del Objetivo 2 tienen que ver con el hallazgo de otros términos que enriquecen el entendimiento de las distintas formas en que la función fue pensada y, sobre todo, permiten comprender los distintos argumentos y objetivos -en muchos casos no estrictamente arquitectónicos- en los que la función se ve implicada. De este modo, términos como Lebenwiessen, Fürsichsein, fitness, Beziehungen, organic, patterns o estrategias, como "método funcional», "gráfico de movimientos", "condensador social», "normalización», o «humanización» completan el entendimiento de la ‘función' en la arquitectura moderna.

Las diversas formas de denominar los temas que derivan, ya no sólo de la función en sí, sino de la propia configuración de las actividades en el espacio que la arquitectura proporciona dan respuesta a lo que se proponía el Objetivo 3. Parte importante de los resultados de la investigación tienen justamente que ver con la recuperación de argumentos que no siempre contaron con difusión suficiente para consolidarse como marco teórico de la disciplina. Aunque 
el presente trabajo acepte e incluso puje por la existencia de una autonomía de la 'función' dentro de la arquitectura, no es menos cierto que el problema presenta constantemente expansiones que tienen que ver con la estética de los objetos, los problemas técnicos o constructivos, o incluso con debates de índole antropológica o filosófica que

A partir de las similitudes que ofrecen las diferentes concepciones de la función se desarrollan, como se enuncia en el Objetivo 4, una serie de categorías. Estas no corresponden a los términos particulares elaborados por los autores de las fuentes primarias, sino que se proponen como una forma general de conformar 'familias' de pensamiento, que al mismo tiempo permitan un estudio y un trazado genealógico. A su vez, 'eficacia', 'adaptación', 'flexibilidad' y 'conectividad' pretenden ocupar un rol operativo más específico, permitiendo dar énfasis a ciertos temas de la función por sobre otros, dejando entrever la matriz ideológica que la misma operación sobre la función puede tener en el proyecto de arquitectura.

Habiendo revisado los diferentes textos que conforman el corpus de los conceptos de la función modernos categorizados según la hipótesis, es posible plantear -como se proponía en el Objetivo General- una genealogía que permite visualizar con mayor claridad las relaciones obtenidas a partir de los resultados de la investigación. Las diversas categorías propuestas en la hipótesis ofrecen complejas relaciones, las cuales se representan en estas mismas conclusiones, en los diagramas incluidos en "3.2.1. Eficacia," "3.2.2. Adaptación," "3.2.3. Flexibilidad," "3.2.4. Conectividad," y "3.2.5. Concepciones de la función." Finalmente se plantea en "3.3.0. Glosario," a modo de síntesis, una compilación que permite verificar, de modo resumido, las variables conceptuales que el problema de la función alberga a través de los propios términos engendrados por los diversos autores. 


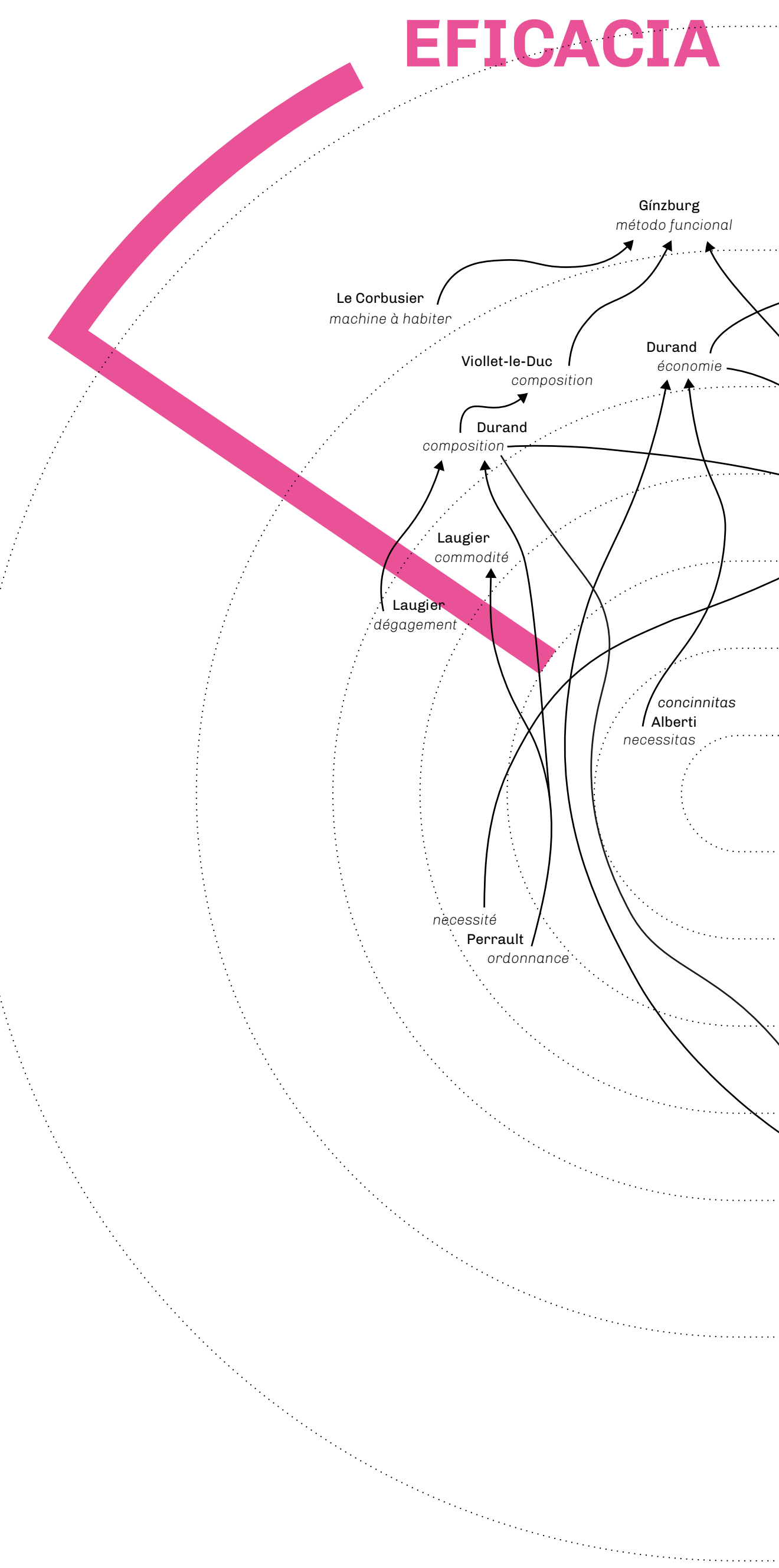


Gínzburg método funcional

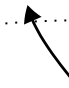

Durand

économie

Durand

composition 


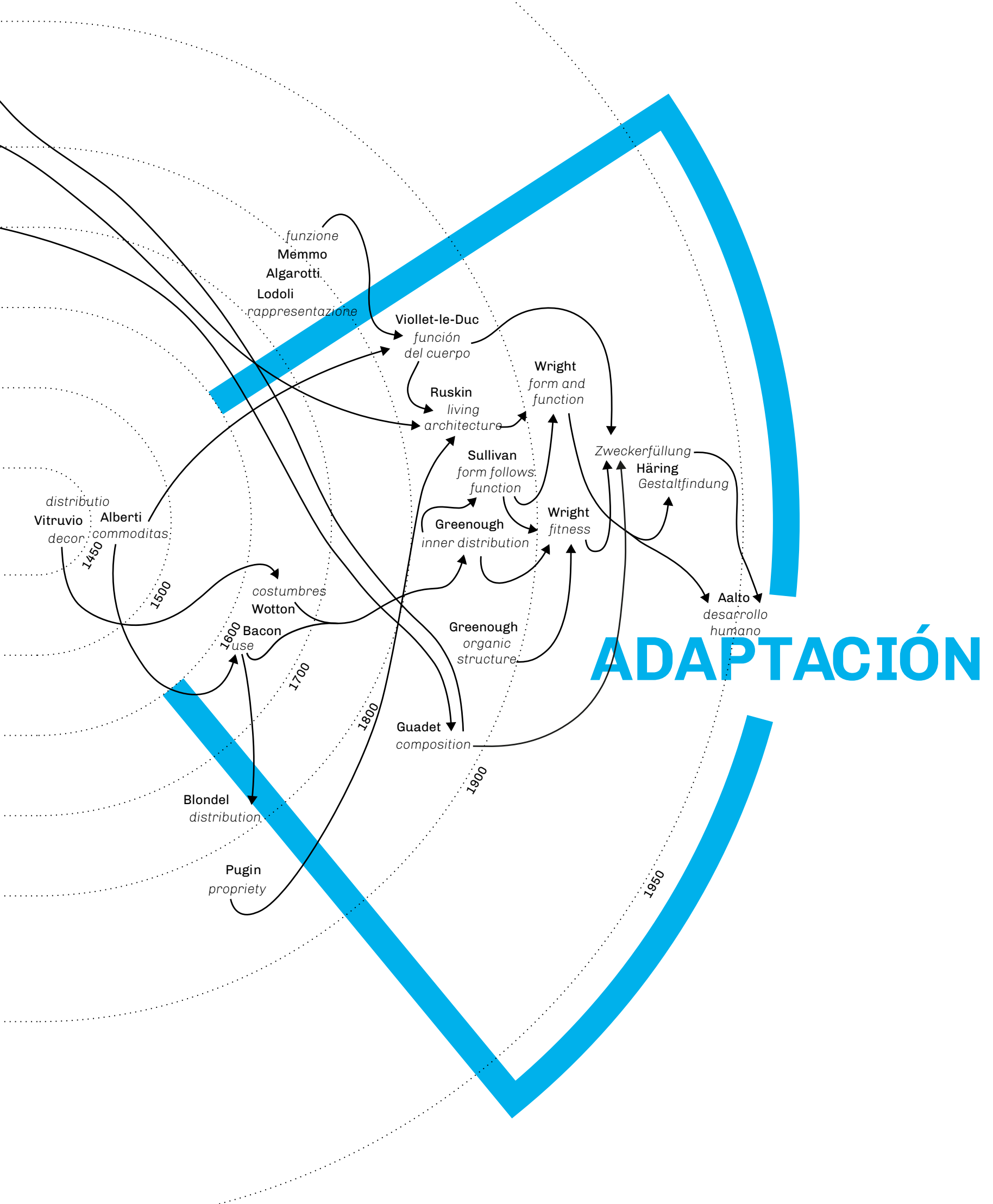




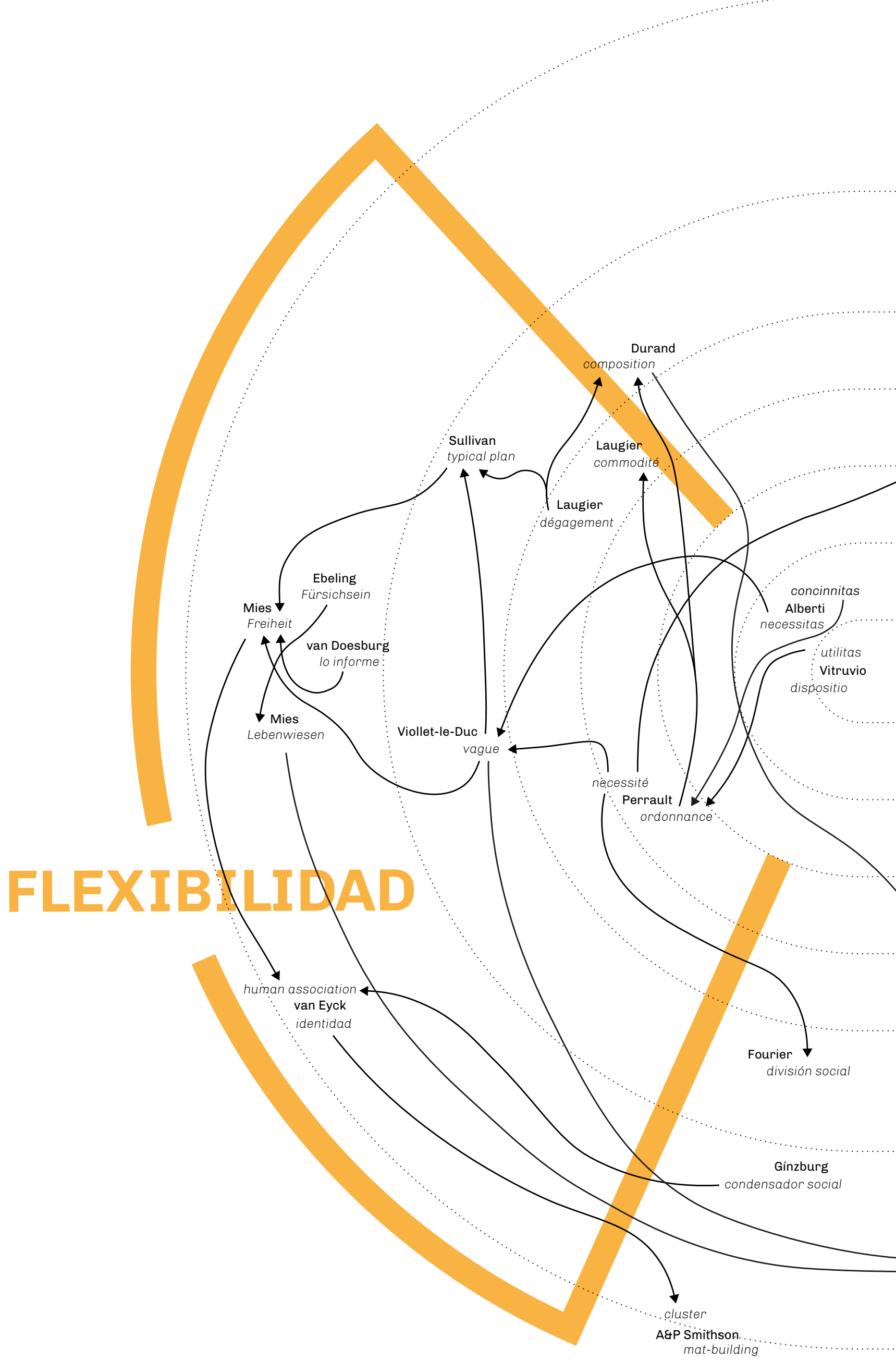




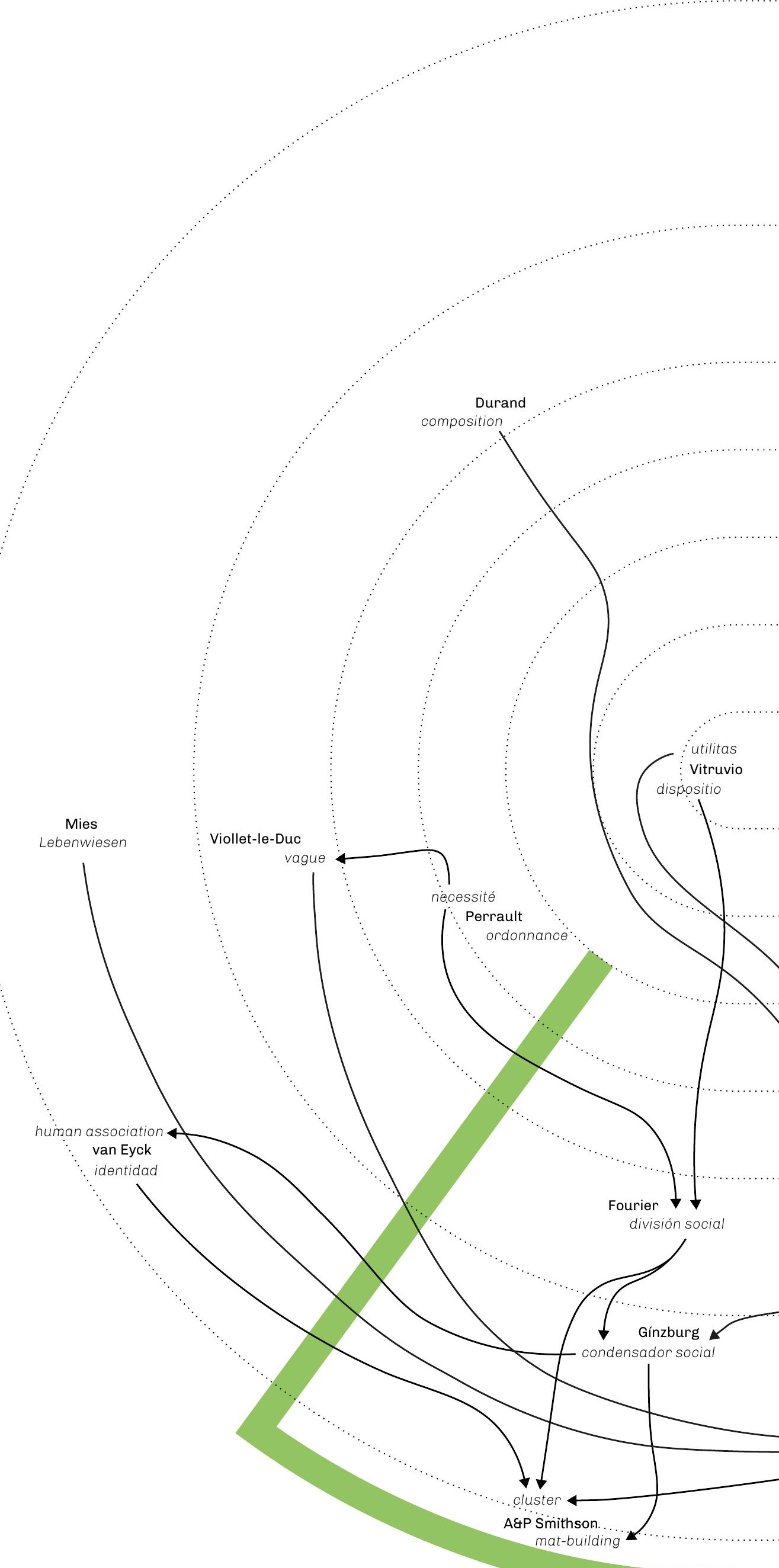




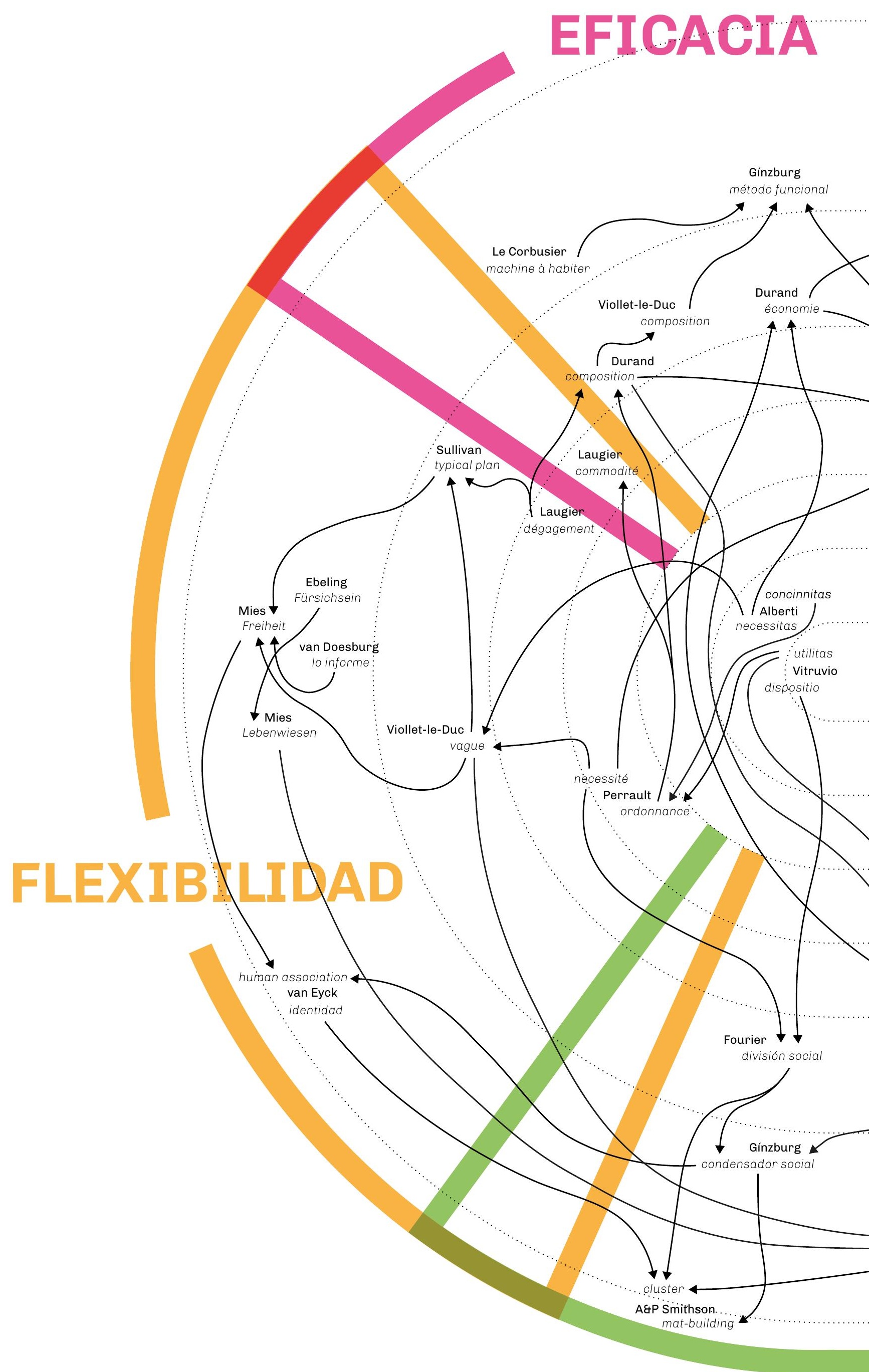




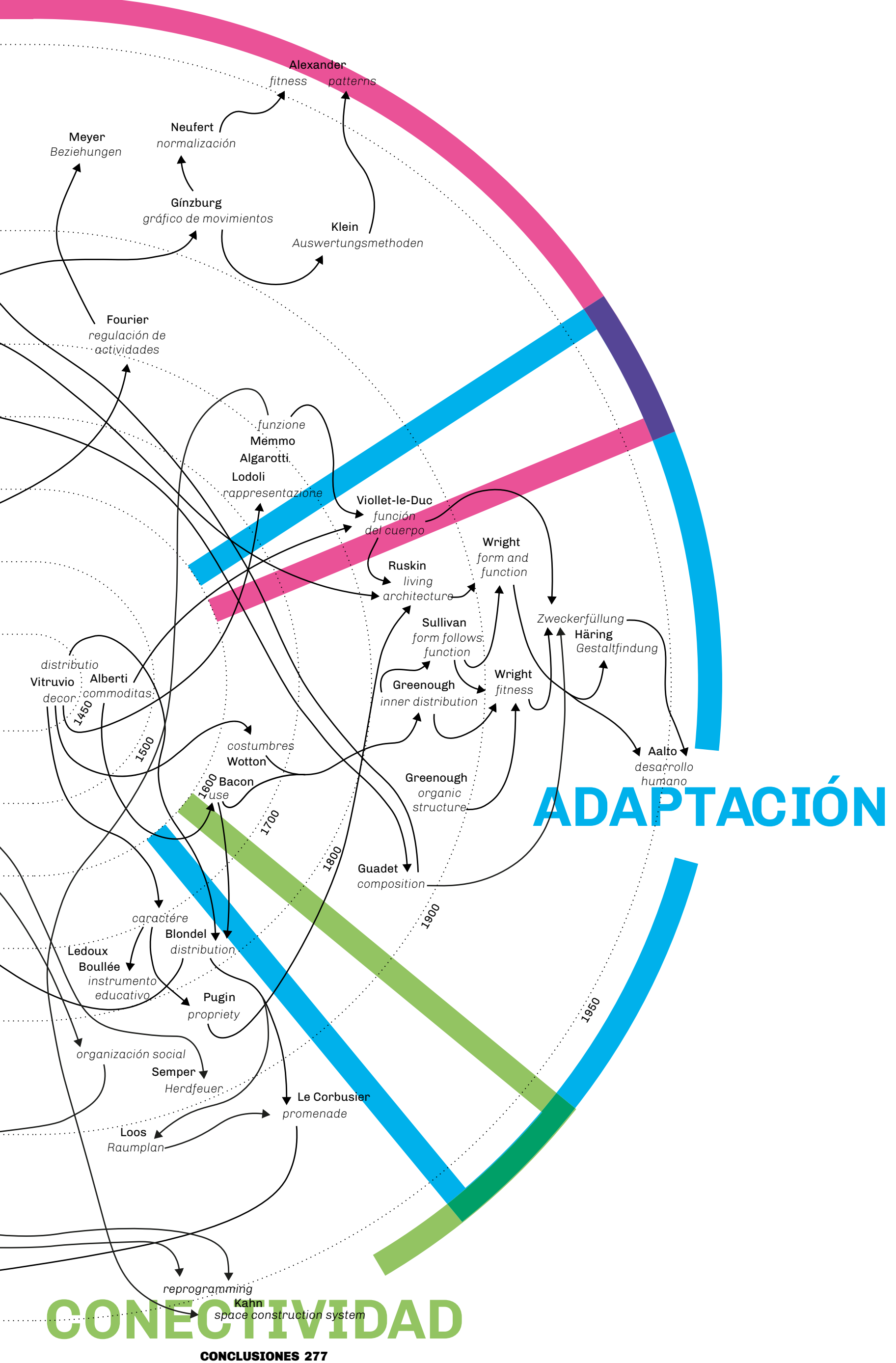


Si los orígenes de la función moderna, como término y como modo de pensamiento resultan borrosos, algo similar puede decirse de su final; principalmente porque el término 'función' continúa utilizándose sistemáticamente en la disciplina hasta nuestros días. Aún así, la 'función' en la arquitectura moderna no se define sólo por la aplicación de un término, sino que se consolida por las múltiples aportaciones teóricas que se hicieron sobre el problema en un corto lapso de tiempo, diferenciándose de períodos anteriores y posteriores. Esta diferencia radica especialmente en esa vocación humanista que se adentrara en la transformación de los modos de habitar, tanto para mejorarlos como para quitarles el lazo de las costumbres y las tradiciones; un proyecto de reforma que, desde una tabula rasa, creciera hasta conseguir mejores condiciones para las personas. Este principio general, en parte idealista, puede visualizarse, a pesar de las diferencias, en gran parte de las propuestas modernas, y comienza a perder espacio en los años de la segunda posguerra europea, cuando comienza a ser cuestionado. Si las propuestas de Aalto, Alexander, van Eyck, A\&P Smithson o Kahn -aunque aún sostengan gran parte de los objetivos de sus predecesores- suponen una primera postura crítica, el advenimiento de nuevas concepciones en la década del sesenta marcan una vía diferente para la función; incorporando la problemática de la tecnología avanzada, la comunidad y la participación, la relación con la ciudad existente o los vínculos con el lenguaje. Hay una separación de ese puro interés que Kant planteaba sobre "lo útil» del objeto artístico hacia una "trans-función," un sistema que se revuelve sobre sí mismo y que, sin haber llegado a conclusiones definitivas, parece volcarse a la satisfacción de otro tipo de libertades, o sugerir nuevas experiencias mitigadas por la modernidad. En estas se pueden incluir las distopías urbanísticas de Archigram, Superstudio o Archizoom; en las que no sólo la función es discutida como herramienta para una acción transformadora, sino que el mismo objeto arquitectónico es puesto en duda ante una sociedad que debe redefinirse a sí misma, y también, por supuesto, definir sus modos de vida y sus necesidades. Es natural afirmar que la problemática de la función sigue siendo fundamental en estas propuestas, pero la misma no se podrá medir ya con los mismos parámetros que la 'función moderna'. En las antípodas de estas propuestas utópicas se publica en 1957 La poétique de l'espace, en el que el pensador francés Gastón Bachelard invita una reflexión subjetiva sobre la ampliación de los límites de lo que significa "habitar»; más tarde, en 1961, aparece The death and life of great american cities, la crítica feroz perpetrada por parte de Jane Jacobs que dejará en evidencia la falta de consideración efectiva del usuario y la comunidad por parte de la arquitectura y el urbanismo modernos y que sembrará el camino para la revalorización de la ciudad existente y la auto-organización colectiva por fuera de las discusiones disciplinares. Por otro lado, como fruto de los movimientos del mayo del 1968, Ios planteamientos de los Situacionistas abren la vía para una arquitectura en donde las acciones no responden ya a la búsqueda de una solución que garantice necesariamente un bienestar social, sino que este último (si existe) se construye a partir de los placeres que, con un origen 
inconsciente o subjetivo, los mismos individuos persiguen; se trata, en definitiva de un alejamiento de la función como proyecto racional y sistemático, donde se emplean recursos cercanos al Surrealismo. La segunda mitad del siglo XX traerá además nuevas apuestas que se propondrán superar completamente la propia idea de 'función moderna', como el concepto de event promulgado sobre todo por Bernard Tschumi, y la recuperación que Rem Koolhaas hará de la idea de programa arquitectónico. Nuevamente, la función sigue existiendo como problemática, pero puede afirmarse que se trata de un nuevo comienzo, o de una transformación sustancial de los argumentos que sustentan las ideas modernas de función, tal como se exponen en los resultados de este trabajo. En este nuevo escenario de la segunda mitad del siglo XX la mención a la función tenderá a referirse de forma simplificada a un modo pragmático de organizar el habitar en los edificios, por lo que con esto, las particularidades intrínsecas en el período de los años veinte a los años cincuenta del siglo XX perderán protagonismo. Esta situación, que ya ha sido mencionada en "1.0.0. Introducción", es la que opaca la miríada de acepciones y de posibilidades operativas que la función alberga como problema histórico de la arquitectura.

En rigor, y como parte del mismo planteamiento inicial, la continuidad del término función en el vocabulario de la arquitectura de la segunda mitad del siglo XX hacia delante supone dos problemas. En primer lugar, la falta de transparencia con respecto a un glosario de la función que, como se expuso a lo largo de la investigación, muestra suficientes variantes como para reconsiderar el sentido de la denominación y su misma profundidad. Pero, en segundo lugar, el propio término 'función' parece mantenerse latente para continuar sosteniendo una idea simplificada de la vocación racionalista y pragmática -en muchos casos vinculada a la visión también simplificada de la arquitectura moderna- con la que puede debatirse la distribución de los edificios. Parte de la vocación del presente trabajo es la de eliminar el velo de los prejuicios revisionistas en pos de una lectura directa de las fuentes y de los actores que dieron origen a distintas formas de pensamiento de un problema. Esta misma vocación es la que no se contenta con buscar posibilidades en las distribuciones arquitectónicas, sino que insinúa el encuentro con otras problemáticas dentro de un marco social y cultural que desde comienzos de la segunda mitad del siglo XX se filtran con naturalidad en diversas facetas de la disciplina. 
Referencias utilizadas

Diccionario DLE

Diccionario de la RAE

Oxford Latin Dictionary

Juan Corominas, Breve Diccionario Etimológico de la Lengua Castellana.

Ernout-Meillet, Dictionnaire étymologique de la langue latine. Histoire des mots (Hors Collection: Langues ) - Cuarta Edición con actualización de Jacques André - 2001. Diccionario Etimológico de Chile Damián Plouganou, Glosario de la función en la tradición vitruviana, Tesis de fin de máster, Escuela de Arquitectura de la Universidad Politécnica de Madrid, 2017.

[Klein] Es el estudio de los recorridos mínimos y máximos de una célula habitacional, basado en el análisis de cada una de las variables de distribución posibles sobre el mismo modelo.

$\mathrm{m} . /$ actividades humanas [Meyer] Consiste en el estudio, cuantificación y listado de las actividades domésticas en detalle. Este estudio tiene la pretensión de aportar un conocimiento de vocación científica específico para las correctas soluciones funcionales.

1. Signo escrito o grabado que se imprime, pinta o esculpe en algo. 2. Rasgo distintivo, particular de manera de ser de una persona o pueblo. 3. Conjunto de cualidades o circunstancias propias de una cosa, que la distingue, por su modo de ser u obrar, de las demás. 4. Condición dada a alguien o a algo por la dignidad que sustenta o la función que desempeña.

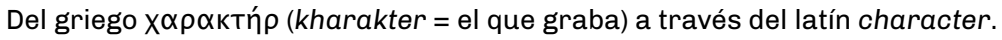

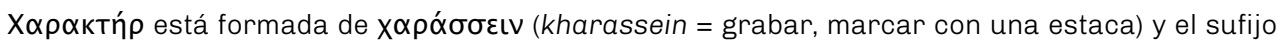

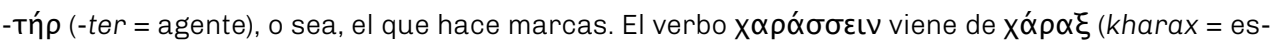
taca) relacionada con la raíz indoeuropea *gher- (rascar, arañar). [Blondel] Funda su base en el lenguaje, en una lógica de comunicación que permite expresar el propósito inicial del edificio en la forma construida. Bajo esta premisa, el caractère se mueve entre las posibilidades de lo subjetivo que permite el lenguaje arquitectónico a través de los órdenes y de un conocimiento de la historia de la arquitectura que permita un argumento fundado. Hace referencia a la "función expresiva" de un edificio a través de caracteres particulares: los templos deben expresar decencia, los edificios públicos grandeza, los paseos públicos elegancia, etc. Resulta también de importancia el papel de la verosimilitud en el caractére, desde donde es posible expresar una idea de verdad que podría no estar presente si no es a través de una leve distorsión que la haga evidente. m./ método gráfico

m./ carácter

\section{Auswertungsmethoden}

\section{Beziehungen}

\section{caractére}

m./ cúmulo o racimo

cluster 
2. Agrupación, conglomerado, agregado, brote.

del inglés medieval

significa "bloque" o "montón" y se aplica a diferentes ámbitos de la ciencia

[A. \& P. Smithson] Responde a una organización basada en unidades con una identidad propia, cuya acumulación o sumatoria alcanzan el grado de un conjunto mayor y pueden adaptarse a diferentes circunstancias. A través del cluster es posible incluir y satisfacer necesidades vitales de las diferentes escalas que componen las poblaciones humanas, garantizando su cercanía y conectividad.

concinnitas f./ armonía

1. Proporción y concordancia perfecta entre las partes de un todo. 2. Juntura, ensamblaje.

del latín concinnitas

del verbo concinnare -ordenar, ordenar adecuadamente- y del adjetivo concinnus - conveniente, elegante, bello.

[Alberti] Se trata de una armonía entre la forma y el uso de un objeto a través de las matemáticas, que se desprende directamente de la observación de la naturaleza y que busca establecerse como una ley en la que nada puede agregarse o quitarse sin empeorarla. La simetría y las proporciones tienen un rol fundamental en esta armonía.

condensador social [Gínzburg] Se entiende como una estructura arquitectónica producto del «método funcional» (ver), es decir que se trata de una interface que vincula una idea de sociedad con su efectiva organización. A su vez este condensador social debe adaptarse a los nuevos modos de vida acaecidos a partir de los cambios sociales.

1. Cosa necesaria para vivir a gusto y con descanso. 2. Ventaja, oportunidad. 3. Buena disposición de las cosas para el uso que se ha de hacer de ellas.

del latín commodus

significa "conveniente", o "cualidad de no tener molestia ni necesitar esfuerzo". Sus componentes léxicos son: el prefijo con- (globalmente, todo, junto), modus (modo, medida), más el sufijo -dad (cualidad)

[Alberti] Se trata de una evolución de la primera necesidad básica -necessitashacia los problemas técnicos y estéticos derivados de las soluciones arquitectónicas; hacia la belleza y la forma de poder conseguirla. Por lo mismo se encuentra en consonancia con la idea de concinnitas, la fusión del proceso mental con el pragmático, el proyecto con la construcción, de modo que la belleza, el fundamento científico y la funcionalidad estén absolutamente vinculados.

commodité f./ comodidad

*ver commoditas

[Le Muet] Tiene que ver con la precisión aplicada a las dimensiones de los re- 
mobiliario. El tamaño de los recintos no tiene tanta importancia como las proporciones entre ancho y largo del mismo, ya que no busca una limitación de dimensiones mínimas en pos de la economía, sino más bien a establecer una armonía en los interiores. [Laugier] La commodité refiere también a una combinación entre el pensamiento racionalista y el empirista. Se trata básicamente del establecimiento de una serie de normas para la distribución y el funcionamiento, las cuales se fundan en observaciones críticas en torno a la resolución funcional de edificios existentes. Estas revisiones no se basan en principios racionalistas, sino más bien en percepciones subjetivas realizadas de primera mano, a partir de las cuales sería posible extraer lecciones aplicables al proyecto. De esta manera se pone en práctica un intento de fundición entre dos lineas de pensamiento casi opuestas. Su principio es el de mantener una distancia crítica con las costumbres, las cuales arrastran problemas funcionales, ya que no permiten una reflexión y una transformación a un estado superior. A través de la commodité se asume también la revisión constante de las proposiciones proyectuales, con lo cual resulta claramente difícil establecer una normativa, ya que el desarrollo histórico y social reclama constantemente la revisión y transformación de las soluciones.

1. Formación de un todo o un conjunto unificado uniendo con cierto orden una serie de elementos.

2. Serie de elementos que forman algo. 3. Arte de agrupar las figuras y combinar los elementos necesarios para conseguir una obra plástica lo más armoniosa y equilibrada posible.

del latín compositio significa "acción y efecto de poner a cada cual lo que le toca". Sus componentes léxicos son: el prefijo con- (junto, todo), positus (puesto), más el sufijo -ción (acción y efecto). [Durand] Se trata de una metodología del proyecto que brinda solución a las necesidades de una nueva sociedad en la que la máquina, como materialización de una idea pura de racionalidad, tiene una importancia fundamental. La composition tiene que ver con el desarrollo de una serie de esquemas de organización genéricos que tienen la capacidad de ser aplicados a diferentes programas. Su construcción se basa en la planta, a través de la cual se establecen dimensiones y proporciones para distintos recintos que luego permitirían absorber las diferentes instancias de un programa complejo. En este lugar, las circulaciones ocupan un lugar de jerarquía, como nexo entre los "compuestos" de un edificio. El conocimiento no recae en las funciones particulares de cada edificio, sino en el entendimiento de las partes y la totalidad, nuevamente, como los "compuestos" de una máquina. Las partes deben ser estudiadas primero, según su jerarquía y sus relaciones, para luego afrontar la composición completa del edificio. [Guadet] La composition también presenta una visión menos abstracta y más enfocada a lo determinista, a partir de la idea de que cada espacio debe ser adecuado específicamente a cada actividad. 
significa "el que es provechoso." Sus componentes léxicos son: el prefijo con -(unión, junto), venire (venir), más el sufijo -nte (agente, el que hace la acción).

[Blondel] Por medio de esta se ponen en relación las partes y el todo -vinculado a la composition-, aunque sin salirse del marco de la representación; es decir del significado original que dio sentido al edificio. [Ledoux] Al mismo tiempo puede considerar el orden social que le dio origen, así como el asentamiento, la ubicación y la economía.

decor m./ decoro

1. Parte de la arquitectura que enseña a dar a los edificios el aspecto y propiedad que les corresponde según sus destinos respectivos. 2. Comportarse con arreglo a la propia condición social. 3. Pureza, honestidad, recato.

del latín decorum

Significa "dignidad, decencia," pero también remite a "lo apropiado" o "lo adecuado." Se asocia con la raíz indoeuropea dek- (tomar, aceptar), presente en el griego $\Delta$ o $\alpha \alpha$ (doxa = opinión, doctrina, alabanza, gloria). Es un principio para designar lo apropiado de la utilización de un estilo o una forma a determinado asunto tratado.

[Vitruvio] Refiere al entendimiento, a la comunicación social a través de las construcciones, y en la cual el fin del edificio, su función, es la base. Se consigue a través de tres niveles: el ínfimo (natural), el medio (habitual) y el superior (ritual). El primero tiene que ver con el medio físico, el segundo con los usos y costumbres y el tercero con la representación social. Existe además un "decoro natural" que proviene de la soluciones del proyecto en relación al entorno en el cual se asienta. Esto se vincula a otras disciplinas afines, además de la aritmética y la geometría, que tendrán relación directa con utilitas (ver), como son la medicina, para conocer las condiciones del clima, el aire y el cielo, y la astrología, para entender las orientaciones y las estaciones del año. Cuando el decor sobrepasa las fronteras de la finalidad del edificio, cuando se vuelve un fin en sí mismo, muta de lo ético a lo exclusivamente estético, y por lo mismo resulta subordinado a la construcción, convirtiéndose en un agregado.

desarrollo humano [Aalto] Es la búsqueda de una flexibilidad formal en pos de la mejor adecuación de las funciones humanas, tanto las fisiológicas como las psicológicas. El énfasis está puesto sobre todo en evitar la imposición externa de las formas que impide que dicho desarrollo sea satisfactorio.

dispositio f./ disposición

*ver compositio

[Vitruvio] Es una idea general que considera aspectos tanto generales como particulares de la arquitectura. Tiene que ver tanto con la ubicación de los edificios considerando las condiciones climáticas dadas por la región, las orienta- 
atiendan a estos temas. También refiere a la distribución interna de cada edificio, dependiendo del grupo social al que se destine la misma.

f./ distribución distributio

1. Reparto de una cosa. 2. Disposición de las diferentes partes y habitaciones de un edificio 3. ubicación de las distintas partes de un lugar. 4. Figura retórica, parecida a una enumeración, en que se afirma o niega algo de cada cosa enumerada. del latín distributio

Significa "acción y efecto de repatir". Sus componentes léxicos son: el prefijo dis- (separación múltiple), tributum (impuesto, contribución), más el sufijo -ción (acción y efecto) [Vitruvio] Hace énfasis en la relación entre la arquitectura y su destino -tanto el dado por el propio edificio como por sus ocupantes- en un sentido cercano al de decor (ver), considerando la ubicación en el terreno, los materiales y la economía de acuerdo a las características del usuario.

f./ distribución distribution

*ver distributio

[Blondel] Se trata de un medio para poder expandir las posibilidades espaciales de los recorridos, a la vez que para tener un control de la eficiencia de los mismos. Implica una primera incorporación del tema de la economía dentro de los problemas funcionales, como fruto de la aparición de programas arquitectónicos de mayor escala y complejidad. De este modo es que la organización de los recorridos comienza a ocupar un lugar de importancia que antes se resolvía mediante la sucesión de habitaciones. La distribution otorga un lugar importante al tema del significado dentro de la función, a través de la representación de elementos como "puertas," o "galerías." [Laugier] Al mismo tiempo la distribution permite la aparición de revisiones críticas sobre la función, como la que se plantea sobre la arquitectura de la antigüedad, la cual tiene la intención de rescatar tipos de organizaciones griegas o romanas que puedan adaptarse a la arquitectura del presente, más allá de que su programa original

fuera diferente.

[Fourier] Separación racional de las actividades humanas atendiendo a las cadivisión social racterísticas y aptitudes propias de cada individuo por fuera de las diferencias de clase. Esta separación se sintetiza en un esquema dividido por grupos a los cuales les corresponde una serie de espacios dentro de un entorno arquitectónico que sustituye, por su escala, a un poblado. 
oĩkos (oikos = casa) se relaciona con la raíz indoeuropea weik- (casa o sede de clan). Esta raíz también está presente en la palabra “villa." El elemento compositivo -nomia (como en ideonomía y taxonomía) está compuesto con la palabra vó $\mu$ os (nómos = ley), de nem- (contar, asignar, tomar o distribuir) y el sufijo $-\iota \alpha(-i a=$ cualidad). Si los griegos llamaron oikos a la casa, con todos sus bienes incluyendo su administración, es lógico pensar que "economía" puede definirse como el conjunto de leyes, normas, costumbres etc. mediante las cuales se administran los bienes de la casa o del Estado.

[Durand] Hace referencia a una organización racionalista que saca partido de las relaciones entre los recintos de la manera más provechosa, pero sin negar las posibilidades estéticas que este procedimiento conlleva. Por lo mismo, no se trata de una concepción absoluta de la economía de los medios para construir, sino más bien del aprovechamiento de los mismos para obtener un rédito arquitectónico, que avale el coste del mismo. Con la économie aparece un puente entre la arquitectura y la ingeniería, que de algún modo facilita la inserción de ésta última, ya que se garantiza una estructura racionalista y una geometría regular que la sustenta. La économie aparece, sobre todo, como método para construir correctamente, pero también para establecer un orden que pueda ser capaz de albergar programas complejos en una matriz racionalista.

\section{fitness f./ conveniencia \\ *ver convenance}

[Wright] Es una idea que se basa en la adecuación de las acciones del hombre y el entorno circundante a la planta de arquitectura. Se trata de un equilibrio entre este movimiento corporal propio de la naturaleza y la arquitectura, como si esta última fuera una extensión de la primera. El resultado sería un espacio fluido, continuo y adaptado al entorno. [Alexander] En otra lectura aparece como un modo de pensamiento profundamente científico en torno a la función, encontrando en las matemáticas su principal base. Hace referencia a una conveniencia entre la forma y el contexto del objeto, entendidos estos como el campo de dominio del arquitecto y las condicionantes del mismo.

\section{Freiheit f./ libertad}

1. Facultad natural que tiene el hombre de obrar de una manera de otra. 2. Falta de sujeción o subordinación. 3. Condición de las personas no obligadas por su estado al cumplimiento de ciertos deberes.

en las lenguas germánicas la raíz proviene de *frij -proviene de la raíz indoeuropea *prai -que se vincula a la idea de lo que es agradable, feliz, querido y que genera afecto.

[Mies] Refiere a las posibilidades de flexibilidad funcional derivadas del diseño de construcciones básicas -aquellas con origen en el mito de la cabaña- que se materializan en sistemas compuestos principalmente por madera, acero y vidrio, con mínimas subdivisiones interiores. 
Significa ‘ejecución, ejercicio de alguna facultad, función, cumplimiento de un deber'. Éste, del verbo fungi, 'cumplir, desempeñar una función, satisfacer, pagar, cumplir, emplear, gozar de'. Está conformada por functus, supino de fungi (cumplir, satisfacer), el cual se relaciona con la raíz indoeuropea *bheug-(disfrutar); y tio, sufijo (-ción) que indica acción y efecto. [Lodoli] [Memmo] Se presenta como una crítica radical a la arquitectura desde la visión de un racionalismo cartesiano. Tal es así que se pone en discusión por primera vez el sistema clásico y su relación con los requerimientos funcionales, y se afirma que el factor fundamental dentro de la arquitectura es la función. Se considera tan importante el origen funcional del edificio, lo que lo hace necesario, a su vez que se vuelve innecesario todo lo que remita a un agregado para embellecerlo.

[Aalto] Es la oposición a una arquitectura que encuentra su origen en la ciencia y en la pureza de las formas. El "funcionalismo humano" se diferencia del «funcionalismo técnico" -el cual se basa en los problemas estructurales y constructivos- por suponer una segunda fase más madura, la cual incluiría componentes psicológicos y sociales en su resolución. Cada programa requeriría la atención particular de ciertos problemas sensibles que pueden afectar a los usuarios a modo de barreras arquitectónicas; el "funcionalismo humano" supondría un equilibrio entre el impacto colectivo e individual de estos proble-

mas.

f./ ser independiente

Fürsichsein

[Ebeling] Es un concepto de matriz filosófica que aboga por un espacio capaz de permitir el desarrollo del ser individual y de sus necesidades espirituales, al margen de una consideración abstracta de "lo colectivo." Este espacio incluiría necesidades "no racionales", permitiendo libertades tanto psicológicas como

fisiológicas más allá de las puramente funcionales.

f./ definición formal

funcionalismo humano

Füsichsein

[Häring] Se trata de un proceso histórico sobre la evolución de la forma a par-

\section{Gestaltwerdung} tir de los requerimientos funcionales de una época; por lo mismo, antes de la definición formal de un objeto se deben definir las necesidades de una socie-

dad, para luego sí encontrar la forma correcta.

[Gínzburg] Consiste en el traspaso de valores dinámicos, como el movimiento y gáfico de movimientos las actividades, a un gráfico, el cual, a su vez pueda ser traducido a una forma o estructura arquitectónica concreta. 
una actividad común, una situación personal o una procedencia.

del latín focus

significa fuego, brasero u hogar. Su origen proviene del principio de la cultura occidental. El culto

al fuego significó uno de los primeros y más importantes de los antepasados griegos, latinos e indoeuropeos. Cada casa contaba con una hogera, una llama viva que implicaba cierta presencia sagrada. Su lugar era el centro o la entrada de la casa como símbolo de protección y de vida. La familia solía congregarse en torno a él para aprovechar la luz y el calor.

[Semper] Elemento central y foco de significado de un edificio; actúa como punto de reunión o de celebración a partir del cual se estructura el resto del interior. Se trata de un espacio distinguido y diferenciado del resto, sin una función específica más que la del significado.

\section{human association f./ asociación humana}

[van Eyck] Se desprende de una función vinculada a las necesidades colectivas antes que a las básicas o primarias. Estas necesidades colectivas tendrían que ver con la apropiación del espacio que pueda alcanzar una comunidad a la vez que con la interacción interna que esta desarrolle en un marco arquitectónico dado. La human association debe ser parte del objetivo de un proyecto que ya no estaría centrado en lo morfológico, sino en intentar establecer, a partir del diseño, diferentes modos de conexiones entre las personas. A su vez estas asociaciones estarían categorizadas según la escala, en grupos de acumulación pequeños, medianos o grandes, los cuales deberían ser abordados de diferentes maneras.

identidad 1. Conjunto de rasgos propios de un individuo o de una colectividad que los caracterizan frente a los demás. 2. Conciencia que una persona o colectividad tiene de ser ella misma y distinta a las demás.

del latín identitas y este de idem, del latín clásico

El término "identidad" contiene la dualidad de, por un lado referir a las cualidades que hacen de una persona única, y por otro hace referencia a las características que poseen las personas que nos hacen percibir que son lo mismo que otras personas. La identidad es lo que hace la diferencia al mismo tiempo que unifica con el resto.

[van Eyck] Se relaciona con las características que deben ser otorgadas a un espacio o a ciertos elementos que lo componen para que los usuarios puedan apropiarse de él y establecer un vínculo especial. La identidad de un espacio o elemento arquitectónico tiene que ver con un compromiso entre el diseñador y los usuarios, entendiendo la naturaleza funcional a la vez que significativa del propio objeto. [A. \& P. Smithson] También se considera como una categoría de estructura urbana desde el punto de vista social, relacionada a la "asociación" y a los "modelos de crecimiento".

inner distribution f./ distribución interior

[Greenough] Es una concepción a través de la cual la función debe expresar por sobre todo los valores culturales "internos" o las costumbres propias de 
[Mies] Es una especulación con respecto a las transformaciones sociales producto de la modernidad, las cuales traerían acarreados nuevos modos de vida que transformarían las costumbres del habitar. La consideración de esta situación da pie a ensayar espacios esenciales en su construcción y en sus delimitaciones, lo cual permitiría la adecuación natural a nuevos modos de vida.

[Ruskin] Un sistema formal flexible que, por su misma naturaleza, permite la inclusión de diferentes funciones en un mismo volumen en diferentes etapas, absorbiendo las variables de escala y requerimientos. Lo que permite que el sistema se sostenga como unidad es la continuidad de una misma concepción constructiva.

[van Doesburg] Se trata de una concepción no determinada por un esquema lo informe racionalista y no condicionada por las necesidades funcionales materializadas en habitaciones; no considera las dimensiones específicas de los espacios, ni tan siquiera los límites entre interior y exterior. La resultante es un espacio en el que predomina la extensión, con una subdivisión geométrica libre, e incluso móvil.

m./ edificio tejido mat-building

[A. \& P. Smithson] Se trata de una estrategia para proyectos de gran escala basada en la definición de un esquema que garantiza una red de conectividad. Este esquema permite definir al edificio como una totalidad formal con posibilidades de crecimiento, pero garantizando dentro una reducción de escala para que las pequeños grupos humanos puedan identificarse. La definición de este esquema es anterior a la asignación de funciones, por lo tanto el mat-building no depende directamente de la estas últimas. La función puede adaptarse a la configuración desarrollada o mutar con el paso del tiempo.

[Gínzburg] Trata de un enfoque general con respecto a las soluciones arquimétodo funcional tectónicas, las cuales deben considerar en primer lugar las condiciones colectivas del socialismo. Tanto los habitantes como todo el conglomerado social deben contribuir a la confección de nuevos modos de vida y socialización y a raíz de esto el arquitecto debe ser capaz de interpretarlos en un orden desde lo principal a lo secundario, considerando una serie de etapas. 
Refiere a lo "inevitable" de necesse, que a su vez deriva del prefijo ne (no) y del verbo cedere (parar), como lo que no puede detenerse. Por lo mismo refleja la falta de algo, lo inevitable, y en este sentido es parte de la naturaleza humana, un requerimiento que no puede ser obviado. Refleja tanto la falta de algo, usualmente indispensable para la vida, como el motivo irresistible de alguna acción. Indica una imposibilidad de un elemento considerado de "alejarse, marcharse o desvincularse" con respecto a aquello que se valora. Encuentra su origen en Ananké, diosa griega de la inevitabilidad, la compulsión y la ineludibilidad, que en la mitología romana fue llamada Necessitas. [Alberti] Se trata de una profundización de la idea general utilitas, ya que se trata de una separación entre la atención primaria del hombre, como es satisfacer la necesidad vital que lo vincula directamente a lo salvaje e imprescindible de la vida -de lo racional y organizado que supone el ser humano. En este primer sentido, necessitas no remite más que a la construcción de un sostén básico para albergar la vida; se identifica con el instinto primario de supervivencia, aquel que poseen tanto los hombres como los animales. De ahí la idea de refugio, que en un primer momento es natural y más tarde construido. En una primera fase la arquitectura no se hace presente, ya que la necesidad es entendida no tanto como una solución arquitectónica, sino como la causante de una serie de fenómenos que tienen que ver con lo comunitario.

\section{necessité f./ necesidad \\ *ver necessitas}

[Perrault] Se trata de un enfoque no tanto disciplinar como político. Tiene que ver con una asistencia a las necesidades básicas de la población, entre las cuales se encuentra la arquitectura. No está relacionada con la concepción primitiva de una carencia destinada a ser suplida por la construcción más inmediata, sino que, por el contrario, se funda en el seno de un Estado que la considera dentro de las necesidades civiles, dentro de los cuales están los propios problemas funcionales. El tema de las costumbres juega un papel importante en la concepción de necessité, sobre todo como material a ser analizado desde el punto de vista científico. Las costumbres, como objeto de observación y análisis, como vía por la cual alcanzar un conocimiento certero de la función, es una concepción idealista que tiende a posibilitar que las matemáticas sean la herramienta de solución de los problemas funcionales.

\section{ordonnance f./ disposición, prescripción}

1. Distribución de todas las partes del edificio. 2. Colocación ordenada o distribución pertinente de los distintos elementos de un composición. 3. Colocación de las cosas en el lugar que les corresponde. 4. Parte de la arquitectura que trata de la capacidad que debe tener cada pieza del edificio, según su destino.

Tiene dos acepciones, por un lado "disposición," del latín compositio

significa "acción y efecto de poner en un lugar adecuado;" sus componentes léxicos son: el prefijo dis- (separación múltiple), positus (puesto), más el sufijo -ción (acción y efecto). 
[Perrault] Se trata de un orden racionalista sobre el sistema clásico que rechaza la teoría de que los órdenes arquitectónicos se basan en las proporciones del cuerpo humano. Se argumenta que la geometría que regula el sistema es autónoma, es decir, que tiene una base puramente arquitectónica y, por lo mismo, tanto funcional como estética. La ordonnance se materializa en una serie de reglas geométricas aplicadas al sistema clásico a través de las cuales es posible el orden riguroso de los edificios. No se trata en sí de una definición de los problemas funcionales, pero los mismos también se encuentran implicados, dado que el sistema de los órdenes da también lugar a proporciones espaciales que definen la función de los edificios; las modificaciones en la concepción de las proporciones repercuten en las mismas proporciones de los ambientes.

[Greenough] Tiene que ver con una postura general ante el problema de la función antes que con una solución particular. Se trata de una observación teniendo como referencia los ejemplos de la naturaleza, los cuales Ilevarían a entender la arquitectura considerando primordialmente las soluciones formales derivadas de los requerimientos funcionales.

[Semper] Organización racional del espacio que permite la interacción de una organización social comunidad; tiene como origen la vida familiar y por su misma repetición llega hasta la vida comunitaria. Este crecimiento, realizado en torno a un punto central de significado -Herdeuer- es el que permite los aparición de un sistema político y su expresión a través de un espacio ordenado que lo represente. El resultado puede ser resumido en un esquema sintético para la 'construcción civilizada'.

m./patrones

[Alexander] Se trata de un conjunto amplio de problemas en el campo del diseño para el cual se aplican soluciones basadas en un respaldo empírico. Las soluciones recurren a una lógica elemental y buscan conformar una serie de combinaciones que, como conjunto, permitan la solución de un problema amplio. La escala de cada uno de los problemas varía, desde la más grande (urbana) a la más pequeña (objetos), y el conocimiento y agregación de cada problema puede ser hecho por el mismo usuario, con el fin de ampliar el conjunto. [van Eyck] Existen también patterns físicos, que podrían definirse como las estructuras espaciales, y patterns relativos a la vida misma, dado por la cotidianidad y el modo de habitar de los usuarios. [A. \& P. Smithson] Encuentran también vínculo con los modos de asociación humana y las formas en que los mismos pueden ser categorizados y operados desde la arquitectura. Estos patterns of association se definen a partir de cómo la sociedad se ha dividido según su tamaño y características en diferentes instancias espaciales: la familia, la calle, el distrito o la ciudad. 
1. Previa declaración de lo que se piensa hacer en alguna materia u ocasión. 2. Sistema y distribución de contenidos. 3. Proyecto ordenado de actividades. 4. Serie ordenada de operaciones necesarias para llevar a cabo en un proyecto. 5. Cada una de las operaciones que, en un orden determinado, ejecutan ciertas máquinas.

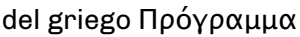

significa "escrito con anterioridad." Los antiguos griegos utilizaban el término para referirse a la orden del día, o sea, las actividades planeadas y prescritas que serían como guía durante funciones organizadas.

[Viollet-le-Duc] La organización de la información que contiene los requerimientos funcionales que un proyecto debe satisfacer-sobre todo al tratarse de edificios de tamaño considerable o funciones complejas- y que suele tener su expresión en la planta.

promenade architecturale rappresentazione

Raumplan

reprogramming

m./ recorrido arquitectónico

[Le Corbusier] Itinerario arquitectónico extenso definido por elementos como corredores o rampas que atraviesa diferentes instancias funcionales de un mismo edificio. El recorrido hilvana el exterior con el interior o los diferentes niveles de una forma continua, ofreciendo una sucesión de condiciones espaciales y visuales diversas dentro de un mismo objeto arquitectónico.

f./ representación

[Lodoli] [Memmo] Responde a una expresión genuina de la función, que a su vez es capaz de expresarse formalmente. La traslación de la función del edificio al exterior debe darse a modo de una "transparencia", que podría entenderse mediante la visualización de una continuidad entre la sección y el alzado de un proyecto, en el sentido en que éste último podría construirse en base al primero, sin ninguna interferencia. Existe así una vinculación directa y biunívoca entre rappresentazione y función, por lo que se reafirma que todo lo que en arquitectura está en representación debe también estarlo en función, es decir, que el edificio debe ser en sí la representación de su función.

m./ plano espacial

[Loos] Sistema basado en la importancia distintiva de cada una de las células espaciales, expresada a través de sus dimensiones y variables de altura de techo y ubicación espacial con respecto a las habitaciones contiguas. El Raumplan incluye también el itinerario que hilvana, a través de escaleras que salvan alturas medias, los diferentes espacios de un interior.

m./ re-programación

[Kahn] Reflexión en torno a la naturaleza de las actividades humanas y de los requerimientos de un edificio. Esta noción busca replantearse de modo subjetivo el sentido primero de las actividades más básicas y de las propias instituciones con el fin de fundar un nuevo programa para un edificio. 
[Kahn] Construcción basada en la "verdad" de los materiales y la lógica estructural con signos de monumentalidad que, por su misma honestidad inspira un modo de habitar básico, casi primitivo, separado de cualquier signo de su tiempo. Este sistema requiere al mismo tiempo una geometría básica que se exprese en la construcción y que por su misma rigidez defina el orden funcional.

f./ planta tipo typical plan

[Sullivan] Es un tipo constructivo normalmente asociado al programa de oficinas que refleja de manera literal la no determinación funcional. Se trata de una planta sin subdivisiones interiores, sólo atravesada por pilares y elementos de circulación vertical, con un perímetro transparente, la cual puede ser subdividida según la necesidad del usuario.

*ver usus

[Perrault] Combina, desde un punto de vista pragmático, las necesidades funcionales con las estéticas. Se basa en la existencia de un "buen gusto", regulado por una norma basada en el estudio, la cual se construye a partir de la visión científica, es decir, la observación de las experiencias que conforman las costumbres, con el objetivo de encontrar una serie de reglas generales que eviten las arbitrariedades. Las costumbres ocupan un lugar de importancia en el concepto de usage, ya que desde estas se proponen dos principios: el "principio positivo", vinculado al uso, y el "principio arbitrario", de una belleza que, aunque dependa también de la costumbre, se basa en una concepción de «belleza positiva" con raíz racionalista. [Cordemoy] Posteriormente se llegará a dudar de la posibilidad de combinar la "belleza positiva" con la idea de usage, ya que se cuestiona que tal ligazón sea factible mediante la simetría del sistema clásico.

m./ uso

1. Costumbre o hábito. 2. Uso específico y práctico a que se destina algo. 3. Capacidad o posibilidad de usar algo. 4. Usual y común en un tiempo. 5. Conforme a la costumbre. del latín usus significa "emplear, aprovechar una cosa" [Bacon] Remite a la configuración de los ambientes de un edificio, a su mejor distribución, basada en la experiencia y la costumbre. Se desarrolla mediante la descripción detallada de una serie de soluciones proyectuales para un edificio particular. Se trata también de un acercamiento pragmático que busca poner en duda la primacía de la belleza de la forma por sobre la funcionalidad propia del edificio. 
más el sufijo -dad (cualidad). El verbo latino uti, antiguamente era oeti, el cual derivó en ouit, en francés, y de ahí utillaje y útil en sentido de utensilio.

[Vitruvio] Hace referencia a la resolución general de los problemas de organización funcional antes que a una definición de un concepto particular. Tiene que ver con un desempeño adecuado en cuanto a la distribución y dimensionamiento de los distintos ambientes que componen un edificio. Su inicio se basa en una interpretación de la evolución de las comunidades primitivas cuyo primer refugio se estima en el descubrimiento del fuego, el lugar de reunión que permite no sólo hacer frente al frío inhabitable, sino también albergar relaciones sociales, que devendrían en las primeras comunidades. El primer acercamiento a la construcción trae como consecuencia la primera forma arquitectónica, la cabaña, que surgiría por una necesidad satisfecha de las condicionantes del propio entorno natural. Estas construcciones, que tendrían su origen en una analogía -fruto de una primera observación de la naturaleza y de las condiciones climatológicas- son la base a partir de la cual el hombre primitivo entraría en contacto con soluciones que supondrán un bienestar y un desarrollo paulatino de las condiciones de habitabilidad, asentándose posteriormente como costumbre.

vague $\mathrm{m} . /$ indeterminado

1. Que carece características precisas o de límites definidos. 2.

del griego örıєıov (asperión)

significa "sin límites", "sin definición» de $\alpha$ - «no" y пвĩ $\alpha \rho$ "límite». Significa lo que no puede limitarse, que carece de una forma definida. Lo indefinido o indeterminado.

[Viollet-le-Duc] Un sistema neutral que permite suficientes variables como para que un mismo edificio pueda satisfacer y acomodarse a diferentes requerimientos funcionales.

Zweck m./propósito

1. Objetivo que se pretende conseguir. 2. Adecuado u oportuno para lo que se desea o para el fin a que se destina.

del latín propositum

significa algo "puesto a la vista, como un proyecto futuro." Compuesto del prefijo pro -(hacia adelante) y postium, participio de ponere (poner).

[Behne] Trata del cumplimiento de las necesidades materiales de un edificio, así como de su propósito orgánico, es decir, su destino.

\section{Zweckerfüllung m./ cumplimiento del propósito}

[Häring] Trata de una discusión entre la satisfacción del propósito de un edificio y la expresión de este último, diferenciando ambos, pero entendiendo el equilibrio entre ellos como un balance que se debe considerar constantemente. No todos los programas arquitectónicos pueden alcanzar este balance, y es posible encontrar edificios más volcados hacia el propósito -Zweckerfüllung-y otros más volcados hacia la expresión. Los primeros tendrían un origen natural y los segundos uno subjetivo. 
Bibliografía

"La influencia de la construcción y los materiales en la arquitectura moderna." En La humanización de la arquitectura Barcelona: Tusquets, 1978. (Ed. orig. 1938)

"La humanización de la arquitectura." En La humanización de la arquitectura. Barcelona: Tusquets, 1978. (Ed. orig. 1940) "Entre el humanismo y el materialismo." En La humanización de la arquitectura. Barcelona: Tusquets, 1978. (Ed. orig. 1955)

"Conferencia anual en el R.I.B.A. en 1957." En La humanización de la arquitectura. Barcelona: Tusquets, 1978. (Ed. orig. 1957)

Los Elementos de la Arquitectura por Sir Henry Wotton. Un texto crítico. Valladolid: Universidad de Vallolid, 1997. (Ed. orig 1997)

De re aedificatoria. Vol. 10, Madrid: Ediciones AKAL, 1991. (Ed. orig. 1452).

Ensayo sobre la síntesis de la forma. Buenos Aires: Infinito, 1976. (Ed. orig. 1964).

Un lenguaje de patrones. Barcelona: Gustavo Gili, 1980. (Ed. orig. 1977).

Saggio sopra l'architettura. Venecia: Stamperia Graziosi a S. Apollinare, 1784. (Ed. orig. 1753).

"Ordenando los órdenes: la 'ordonnance' de Claude Perrault y la columnata este del Louvre." Revista de Arquitectura

"Un sujeto disciplinado es un sujeto feliz. Bentham y la noción utilitarista del cuerpo y las emociones." En Teoría social cuerpos y emociones, editado por Scribano, Adrián Oscar. Buenos Aires: Estudios Sociológicos Editora, 2013.

La poética del espacio. México D.F.: Fondo de Cultura Económica, 2012. (Ed. orig. 1957)

The essayes or counsels, civill and morall. Oxford: Clarendon Press, 1985. (Ed. orig. 1625).

"A home is not a house." Art in America (1965).

Teoría y diseño en la primera era de la máquina. 1985. (Ed. 1960)

Los Angeles: the architecture of four ecologies. California: University of California Press, 2009. (Ed. orig. 1971).

La construcción funcional moderna. Barcelona: Ediciones del Serbal, 1994. (Ed. orig. 1923).

Historia de la arquitectura del Renacimiento. Madrid: Taurus, 1972. (Ed. orig. 1968).

Historia de la arquitectura moderna. Madrid: Taurus, 1963. (Ed. orig. 1960).

"Alexander Klein and the Existenzminimum: A 'Scientific' Approach to Design Techniques." Nexus Network Journal 13, no.

Cours D'Architecture ou Traité De la Décoration, Distribution \& Construction Des Bâtiments: Contenant Les Leçons données en 1750, \& les années suivantes par JF Blondel. Architecte, dans son École des Arts. 2. Paris: Desaint, 1771. (Ed. orig. 1675)

Hugo Häring: the organic versus the geometric. Stuttgart: Ed. Menges, 1999

Historia de las ideas estéticas y de las teorías artísticas contemporáneas. Vol. 1, Madrid: Visor, 1996

"Una propuesta de enseñanza de la arquitectura en la Francia de las Luces: Blondel y la Ecole des Arts." en Estudios dieciochistas en homenaje al profesor Jose Miguel Caso González, Vol. 1. Universidad de Oviedo: Instituto Feijoo de estudios del siglo XVIII, 1995 
Choay, Françoise

Cohen, Jean-Louis

Collins, Peter

Colquhoun, Alan

Cook, John Wesley, y Klotz, Heinrich

Le Corbusier

De Fusco, Renato

de Quincy, Antoine Quatremère

De Zurko, Edward

Dembo, Nancy

Durand, Jean Nicolas Louis

Ebeling, Siegfried

Eisenman, Peter

Evers, Bernd

Filatere

Forty, Adrian

Fourier, Charles

Frampton, Kenneth

Gandelsonas, Mario

Giedion, Sigfried
"Claves para un habitar apasionado." En Teoría social, cuerpos y emociones, editado por Scribano, Adrián Oscar. Buenos Aires: Estudios Sociológicos Editora, 2013.

"Alberti et Vitruve." Architectural Design (1979): 26-35

Le Corbusier and the Mystique of the USSR: Theories and Projects for Moscow, 1928-1936. Traducido por Hylton, Kenneth. Nueva Jersey: Princeton University Press, 1992.

Los ideales de la Arquitectura Moderna: su evolución. 1750-1950. 1969. (Ed. orig. 1965)

La arquitectura moderna: una historia desapasionada. Barcelona: Gustavo Gili, 2005. (Ed. orig. 2002).

Conversations with architects. Nueva York: Praeger, 1973

Cuando las catedrales eran blancas. Un viaje al país de los tímidos. Buenos Aires: Poseidón, 1958. (Ed. orig. 1937).

El modulor. Buenos Aires: Poseidón, 1961. (Ed. orig. 1948)

Vers une architecture. Vol. 1, Paris: Arthaud Poitiers, 1977. (Ed. orig. 1923).

Ouvre Complete. Vol. 1. Zurich: Les Éditions d’architecture, 1977. (Ed. orig. 1929-1970).

Precisiones respecto a un estado de la actual de la arquitectura y del urbanismo. Buenos Aires: Poseidón. 1979. (Ed. orig. 1930)

Hacia una arquitectura. Barcelona: Apóstrofe, 1998. (Ed. orig. 1923).

Historia de la arquitectura contemporánea. Madrid: Celeste Ediciones, 1981. (Ed. orig. 1977).

Dictionnaire historique d'architecture: comprenant dans son plan les notions historiques, descriptives, archaeologiques, biographiques, théoriques, didactiques et pratiques de cet art. Vol. 1, Paris: Librairie d'Adrien le Clere, 1832. (Ed. orig. 1788)

La teoría del funcionalismo en la arquitectura. Buenos Aires: Nueva Visión, 1970. (Ed. orig. 1957)

La relación forma-función en el lenguaje estructural del siglo XX. Caracas: Consejo de desarrollo científico y humanístico, 2003.

Précis des leçons d'architecture données à l'École Royale Polytechnique. Vol. 1, París: I'Ecole Royale Polytechnique, 1805 (Ed. orig. 1805)

Compendio de lecciones de arquitectura: parte gráfica de los cursos de arquitectura. Madrid: Pronaos, 1981. (Ed. orig. 1805)

El espacio como membrana. Barcelona: SD Ediciones, 2015. (Ed. orig. 1926).

"Post-functionalism." Oppositions 6 (1976): 1963-88.

Teoría de la arquitectura: del Renacimiento a la actualidad, 89 artículos sobre 117 tratados. Londres: Taschen, 2006.

Sforzinda, Florencia: Trattato d'architettura, 1465

Words and buildings: A vocabulary of modern architecture. Vol. 268, Londres: Thames \& Hudson, 2000.

"El Falansterio" en Teoría de la unidad universal, editado por Cortés, Chantal López y Omar. México: Biblioteca Virtual Antorcha, 2006. (Ed. orig. 1822).

Historia crítica de la arquitectura moderna. Barcelona: Gustavo Gili, 2005. (Ed. orig. 1980).

"Neo-Functionalism" en Oppositions reader: selected readings from a journal for ideas and criticism in architecture, 1973-1984, editado por Hays, K. Michael. Nueva Jersey: Princeton Architectural Press, 1998. (Ed. orig. 1976)

Bauen in Frankreich, Eisen, Eisenbeton. Munich: Klinkhardt \& Biermann, 1928

Befreites Wohnen. Frankfurt: Syndikat, 1985. (Ed. orig. 1929) 
"Nuevos métodos en el pensamiento arquitectónico" en Escritos, 1923-1930. Madrid: El Croquis, 2007. (Ed. orig. 1926).

"Método funcional y forma" en Escritos, 1923-1930, editado por Garrido, Ginés. Madrid: El Croquis, 2007. (Ed. orig. 1926)

"Éxitos de la arquitectura moderna" en Escritos, 1923-1930, editado por Garrido, Ginés. Madrid: El Croquis, 2007. (Ed. orig. 1927)

"El constructivismo como método de trabajo, de investigación y enseñanza" en Escritos, 1923-1930, editado por Garrido, Ginés. Madrid: El Croquis, 2007. (Ed. orig. 1927).

La arquitectura compuesta por partes. Barcelona: Gustavo Gili, 2009.

González Capitel, Antón

El Legado oculto de Vitruvio. Saber constructivo y teoría arquitectónica. Madrid: Alianza Forma, 1993.

González, José Luis

"Aesthetics in Washington" en Form and Function: Remarks on Art by Horatio Greenough, Los Angeles: University of California Press, 1947. (Ed orig. 1851).

Greenough, Horatio

"American Architecture" en Form and Function: Remarks on Art by Horatio Greenough, Los Angeles: University of California Press, 1947. (Ed. orig. 1843).

"Relative and independent beauty" en Form and Function: Remarks on Art by Horatio Greenough, Los Angeles: University of California Press, 1947. (Ed. orig. 1853).

The elements and theory of architecture. Los Angeles: University of California Press, 1907. (Ed. orig. 1894).

Guadet, Julien

"Wege zur Form" en Hugo Häring: schriften, entwürfe, bauten, editado por Joedicke, Jurgen; Lauterbach, Heinrich Stuttgart: Karl Kramer, 1961. (Ed. orig. 1925)

Probleme des Bauens" en Hugo Häring: schriften, entwürfe, bauten, editado por Joedicke, Jurgen; Lauterbach, Heinrich Stuttgart: Karl Kramer, 1961. (Ed. orig. 1924)

Baurat, nein -Bauherr" en Hugo Häring: schriften, entwürfe, bauten, editado por Joedicke, Jurgen; Lauterbach, Heinrich Stuttgart: Karl Kramer, 1961. (Ed. orig. 1925)

"Zwei Städte. Eine physiognomische Studie, zur Problema.tik des Stadtebaus" en Hugo Häring: schriften, entwürfe bauten, editado por Joedicke, Jurgen; Lauterbach, Heinrich. Stuttgart: Karl Kramer, 1961. (Ed. orig. 1926).

Construir, habitar, pensar. Editado por Gebhardt, Ana Carlota Córdoba: Alción, 2002. (Ed. orig. 1951).

Textos de arquitectura de la modernidad. Barcelona: Nerea, 1994.

"The evolution of office building research" en Journal of Real Estate Literature 5, no. 2, 1997.

Muerte y vida de las grandes ciudades. Madrid: Península, 1973. (Ed. orig. 1961).

What will be has always been: the words of Louis I. Kahn. Editado por Wurman, Richard Saul Nueva York: Access Press y Rizzoli, 1986

"Luz blanca, sombra negra" en Louis I. Kahn: conversaciones con estudiantes, editado por Bell, Michael. Barcelona: Gustavo Gili, 2002. (Ed. orig. 1969).

"Espacio, forma, uso" en Louis I. Kahn: escritos, conferencias y entrevistas, editado por Latour, Alessandra y Sainz, Jorge Madrid: El Croquis, 2003. (Ed. orig. 1956).

"La monumentalidad" en Louis I. Kahn: escritos, conferencias y entrevistas, editado por Latour, Alessandra y Sainz, Jorge. Madrid: El Croquis, 2003. (Ed. orig. 1944)

"El orden es" en Louis I. Kahn: escritos, conferencias y entrevistas, editado por Latour, Alessandra y Sainz, Jorge. Madrid El Croquis, 2003. (Ed. orig. 1955).

Louis I. Kahn: conversaciones con estudiantes. Barcelona: Gustavo Gili, 2002. (Ed. orig. 1998).

Von Ledoux bis Le Courbusier Ursprung und Entwicklung der autonomen Architektur [en ger]. Viena: Passer, 1933.

"Grundrissibildung und Raumgestaltung von Kleinwohnungen und neue Auswertungsmethoden" en Zentralblatt der Bauverwaltung 48, no. 34, 1928 

orig. 1990)

History of architectural theory. New York: Princeton Architectural Press, 1994.

Latour, Alessandra Sainz

Laugier, Marc-Antoine

\section{Lauterbach, Heinrich, y Häring, Hugo}

Ledoux, Claude Nicolas

Liernur, Jorge Francisco

Madia, Luis J.

McEwen, Indra Kagis

Memmo, A., y Lodoli

Meyer, Hannes

Mies van der Rohe, Ludwig por Neumeyer, Fritz. Madrid: El Croquis, 1995. (Ed. orig. 1923).

"Construir" en Mies van der Rohe: la palabra sin artificio: reflexiones sobre arquitectura, 1922-1968, editado por Neumeyer, Fritz. Madrid: El Croquis, 1995. (Ed. orig. 1923)

"Tareas resueltas. Una exigencia a nuestra manera de construcción" en Mies van der Rohe: la palabra sin artificio: reflexiones sobre arquitectura, 1922-1968, editado por Neumeyer, Fritz. Madrid: El Croquis, 1995. (Ed. orig. 1923)

"iArquitectura y voluntad de época!" en Mies van der Rohe: la palabra sin artificio: reflexiones sobre arquitectura, 19221968, editado por Neumeyer, Fritz. Madrid: El Croquis, 1995. (Ed. orig. 1924).

"Conferencia (1924)" en Mies van der Rohe: la palabra sin artificio: reflexiones sobre arquitectura, 1922-1968, editado por Neumeyer, Fritz. Madrid: El Croquis, 1995. (Ed. orig. 1924).

"Conferencia (1926)" en Mies van der Rohe: la palabra sin artificio: reflexiones sobre arquitectura, 1922-1968, editado por Neumeyer, Fritz. Madrid: El Croquis, 1995. (Ed. orig. 1926).

"Sobre la forma en arquitectura" en Mies van der Rohe: la palabra sin artificio: reflexiones sobre arquitectura, 19221968, editado por Neumeyer, Fritz. Madrid: El Croquis, 1995. (Ed. orig. 1927).

"Sobre mi bloque de viviendas" en Mies van der Rohe: la palabra sin artificio: reflexiones sobre arquitectura, 1922-1968. editado por Neumeyer, Fritz. Madrid: El Croquis, 1995. (Ed. orig. 1927).

"Los requisitos de la creatividad arquitectónica" en Mies van der Rohe: la palabra sin artificio: reflexiones sobre arquitectura, 1922-1968, editado por Neumeyer, Fritz. Madrid: El Croquis, 1995. (Ed. orig. 1928).

"Grandes almacenes Adam" en Mies van der Rohe: la palabra sin artificio: reflexiones sobre arquitectura, 1922-1968, editado por Neumeyer, Fritz. Madrid: El Croquis, 1995. (Ed. orig. 1928).

"Discurso de ingreso como director del Departamento de Arquitectura del Armour Institute of Technology" en Mies van der Rohe: la palabra sin artificio: reflexiones sobre arquitectura, 1922-1968, editado por Neumeyer, Fritz. Madrid: El Croquis, 1995. (Ed orig. 1938).
Neufert, Ernst
"Una conversación con Mies van der Rohe" en Mies van der Rohe: la palabra sin artificio reflexiones sobre arquitectura, 1922-1968, editado por Neumeyer, Fritz. Madrid: El Croquis, 1995. (Ed. orig. 1958). 
"Pieles Futuras" en El espacio como membrana, editado por Avilés, Pep. Barcelona: SD Ediciones, 2015. (Ed. orig. 2010)

Introducción a la historia de la arquitectura: de los orígenes al siglo XXI. Barcelona: Reverté, 2005. (Ed. orig. 1995).

La génesis y superación del funcionalismo en arquitectura. México: Ed. Limusa, 1980

Ordonnance des cinq espèces de colonnes selon la méthode des anciens. Paris: Chez Jean Baptiste Coignard, 1979. (Ed. orig. 1683)

Ordonnance for the Five Kinds of Columns after the Method of the Ancients. Santa Monica: The Getty Center publication programs, 1993. (Ed. orig. 1683).

Pioneers of the modern movement from William Morris to Walter Gropius. London: Faber \& Faber, 1936.

Historia de las tipologías arquitectónicas. Editorial Gustavo Gili, 1979

“Banham, Superstudio y el futuro primitivo 1965-1973." HipoTesis Hipo 5 (2017).

"Glosario de la función en la tradición vitruviana." Universidad Politécnica de Madrid, 2017.

Architectural Theory of Modernism: Relating Functions and Forms. Londres: Routledge, 2016. (Ed. orig. 2016).

"Function, purpose, use in architecture and urbanism." Wolkenkuckucksheim 17 (2012)

"On safety pins and other magnificent designs." Pegasus, London, Mobil Oil company, UK, Spring (1972).

"Von Innen nach Aussen. Principios filosóficos del organicismo en la arquitectura." Cuaderno de Notas, no. 15 (2014):

La ley del reloj. Arquitectura, máquinas y cultura moderna. Madrid: Ediciones Cátedra, 2016. (Ed. orig. 2016).

Contrasts: or, A parallel between the noble edifices of the fourteenth and fifteenth centuries and similar buildings of the present day. Shewing the present decay of taste. Londres: A.W. Pugin, 1836. (Ed. orig. 1836)

The true principles of pointed or Christian architecture: set forth in two lectures delivered at St. Marie's, Oscott. Londres: J. Weale, 1841. (Ed. orig. 1841)

Contrasts. Leicester: Leicester University Press, 1973. (Ed. orig. 1836)

"Claude Perrault, East facade of the Louvre." (2017).

Tratados ingleses de arquitectura, 1563-1663: John Shute, John Dee, Francis Bacon, Balthazar Gerbier. Valladolid: Universidad de Valladolid, Secretariado Publicaciones e Intercambio Editorial, 2008. (Ed. orig. 2008).

"Gottfried Semper" en Cuaderno del Laboratorio de Historia Urbana Rosario: Ana María Rigotti, 2009. (Ed. orig. 2009).

"Viollet-le-Duc" en Cuaderno del Laboratorio de Historia Urbana. Rosario: Ana María Rigotti, 2009. (Ed. orig. 2009).

Raumplan versus plan libre. Nueva York: Rizzoli, 1987

L'architettura della cittáa. 1. ed. Milano: Clup, 1978. (Ed. orig. 1966). La Arquitectura de la ciudad. Editorial Gustavo Gili SA Barcelona. 1982. (Ed. orig. 1966).

Manierismo y arquitectura moderna y otros escritos. Barcelona: Gustavo Gili. Vol. 137,1999.

The seven lamps of architecture. New York: John Wiley, 1849

Las siete lámparas de la arquitectura. Barcelona: Editorial Alta Fulla, 1987. (Ed. orig. 1849).

Las piedras de Venecia. Madrid: Consejo General de La Arquitectura Técnica de España, 2000. (Ed. orig. 1853).

Home: A short history of an idea. Vol. 10, New York: Viking, 1986
Papapetros, Spyros

Pereira, José Ramón Alonso

Pérez Gómez, Alberto

Perrault, Claude

Pevsner, Nikolaus

Pevsner, Nikolaus; i Ramió, Joaquim Romaguera; Saurí, Esteban Riambau; i Guardiola, Oriol Bohigas, y Puigvehí, Anna Pujol.

Plouganou, Damián

Poerschke, Ute

Poerschke, Ute, y Führ, Eduard

\section{Price, Cedric}

Prieto, Eduardo

Pugin, Augustus Welby Northmore

Ranogajec, Paul A.

Rey, Almudena Herrero; Dee, John; Shute, John; Bacon, Francis, y Gerbier, Balthazar.

\section{Rigotti, Ana María}

Risselada, Max

Rossi, Aldo

Rowe, Colin

Ruskin, John 
Schnaidt, Claude, y Meyer, Hannes

Schulze, Franz

Segura, Alfonso Díaz; de la Maza, Ricardo Merí, y Soriano, Bartolomé Serra

Semper, Gottfried

Smithson, Alison

Smithson, Alison, y Smithson, Peter

Smithson, Peter

Sullivan, Louis $\mathrm{H}$.

Summerson, John

Tatarkiewicz, Wladyslaw

Team X

Tournikiotis, Panayotis

van Doesburg, Theo

van Eyck, Aldo

Hannes Meyer: buildings, projects and writings. Salenstein: Niggli, 1965.

Mies van der Rohe: una biografía crítica. Barcelona: Hermann Blume, 1986. (Ed. orig. 1985).

"La construcción del Raumplan." Rita, no. 1 (2014): 60-69.

El estilo en las artes técnicas y tectónicas, o estética práctica y textos complementarios. Buenos Aires: Azpiazu ediciones, 2013. (Ed. orig. 1863)

"Escritos fundamentales de Gottfried Semper." El fuego y su protección. Arquia / Temas 37 (2014)

How to Read Architecture: An Introduction to Interpreting the Built Environment. Londres: Routledge, 2019.

"The Future of furniture." Interior Design Supplement, Architectural Design 28 (1958): 175-78.

"Byelaws for mental health." Architectural Design n9, Londres (1960): 356-57.

"Cómo reconocer y leer un mat-building." DPA: Documents de Projectes d'Arquitectura, no. 27/28 (2011): 6-23. (Ed. orig. 1974).

"The Built World: Urban Re-Identification." Architectural Design. N6 (1955): 185-88.

"An alternative to the garden city idea." Architectural Design, №7 (1956).

"Estructura Urbana." En Textos de arquitectura de la modernidad, editado por Hereu, Pere; Montaner, Josep María y Oliveras, Jordi, 185-88. Barcelona: Nerea, 1967. (Ed. orig. 1967).

"Dubrovnic 1956" en Aldo van Eyck: collected articles and other writings. 1947-1998, editado por Ligtelijn, Vincent; Strauven, Francis. Delft: SUN Publishers, 2008. (Ed. orig. 1956).

"Social Foci and Social Space." Architectural Design n¹2, Londres (1960): 488-89.

"The tall office building artistically considered." Lippincott's Magazine 57, no. 3 (1896): 406.

El lenguaje clásico de la arquitectura: de L.B. Alberti a Le Corbusier. Barcelona: Gustavo Gili, 1984. (Ed. orig. 1963).

Historia de la estética III: La estética moderna, 1400-1700. Madrid: Ediciones Akal, 1991. (Ed. orig. 1962).

Primer. Cambridge: The MIT Press, 1968. (Ed. orig. 1962).

La historiografía de la arquitectura moderna. Vol. 5. Barcelona: Reverté, 2001.

“17 puntos para una arquitectura neoplasticista." De Stijl XII (1924).

"Architecture of the Dogon. Paper presented at the Forum (September 1961)," 1961.

"Labyrinthian Clarity." World Architecture 3 (1967): 121-2.

"Intervention at CIAM 6, Bridgwater 1947" en Aldo van Eyck: collected articles and other writings. 1947-1998, editado por Ligtelijn, Vincent; Strauven, Francis. Delft: SUN Publishers, 2008. (Ed. orig. 1947).

"We discover style" en Aldo van Eyck: collected articles and other writings. 1947-1998, editado por Ligtelijn, Vincent; Strauven, Francis. Delft: SUN Publishers, 2008. (Ed. orig. 1949).

"Child and city" en Aldo van Eyck: collected articles and other writings. 1947-1998, editado por Ligtelijn, Vincent; Strauven, Francis. Delft: SUN Publishers, 2008. (Ed. orig. 1950)

"On the design of play equipment and the arrangement of playgrounds" en Aldo van Eyck: collected articles and other writings. 1947-1998, editado por Ligtelijn, Vincent; Strauven, Francis. Delft: SUN Publishers, 2008. (Ed. orig. 1962).

"On inside and outside space" en Aldo van Eyck: collected articles and other writings. 1947-1998, editado por Ligtelijn, Vincent; Strauven, Francis. Delft: SUN Publishers, 2008. (Ed. orig. 1956).

"Orientation" en Aldo van Eyck: collected articles and other writings. 1947-1998, editado por Ligtelijn, Vincent; Strauven, Francis. Delft: SUN Publishers, 2008. (Ed. orig. 1954)

"Talk at the Oterloo Congress" en Aldo van Eyck: collected articles and other writings. 1947-1998, editado por Ligtelijn, Vincent; Strauven, Francis. Delft: SUN Publishers, 2008. (Ed. orig. 1959).

"There is a garden in her face" en Aldo van Eyck: collected articles and other writings. 1947-1998, editado por Ligtelijn, 
"The medicine of reciprocity tentatively illustrated" en Aldo van Eyck: collected articles and other writings. 1947-1998, editado por Ligtelijn, Vincent; Strauven, Francis. Delft: SUN Publishers, 2008. (Ed. orig. 1961)

"Steps towards a configurative discipline" en Aldo van Eyck: collected articles and other writings. 1947-1998, editado por Ligtelijn, Vincent; Strauven, Francis. Delft: SUN Publishers, 2008. (Ed. orig. 1962).

"What we are after is a new and as yet unknown configurative discipline" en Aldo van Eyck: collected articles and other writings. 1947-1998, editado por Ligtelijn, Vincent; Strauven, Francis. Delft: SUN Publishers, 2008. (Ed. orig. 1966).

"Report for the comission on the theme of CIAM 9." En Aldo van Eyck: collected articles and other writings. 1947-1998, editado por Ligtelijn, Vincent; Strauven, Francis. Delft: SUN Publishers, 2008. (Ed. orig. 1952)

Complejidad y contradicción en la arquitectura. Editorial Gustavo Gili, 1995. (Ed. orig. 1966).

Venturi, Robert

"Functionalism, yes, but." Arquitecturas bis: información gráfica de actualidad, no. 5 (1975): 1-2. (Ed. orig. 1974).

El espacio de la Ilustración. La teoría arquitectónica en Francia a finales del siglo XVIII. Madrid: Alianza, 1997. (Ed. orig.

Alison + Peter Smithson. Obras y proyectos. Barcelona: Gustavo Gili, 1997

Vidotto, Marco

Conversaciones sobre arquitectura. Madrid: Consejo General de la Arquitectura Técnica de España, 2007. (Ed. orig. 1863)

Entretiens sur l'architecture. Paris: A. Morel et Cie Éditeurs, 1863

Los diez libros de arquitectura. Vol. 2, Madrid: Ediciones Akal, 1992. (Ed. orig. 1486).

Vitruvio

Los diez libros de Arquitectura. Traducido por Domingo, Oliver. Madrid: Alianza Forma, 1995. (Ed. orig. 1486)

Compendio de los Diez Libros de Arquitectura de Vitruvio. Editado por Claude y Tardieu. Madrid: Imprenta de D. Gabriel Ramírez, 1761. (Ed. orig. 1486)

Les dix livres d'architecture de Vitruve. Editado por Perrault, Claude y Tardieu, Eugène Paris: A. Morel, 1859. (Ed. orig

The elements of architecture. Londres: John Bill, 1624. (Ed. orig. 1624).

Wotton, Henry

“En el reino de las ideas” en El futuro de la arquitectura. Barcelona: Poseidón, 1978. (Ed. orig. 1931).

Wright, Frank Lloyd

"El lenguaje de una arquitectura orgánica” en El futuro de la arquitectura. Barcelona: Poseidón, 1978. (Ed. orig. 1953) "The art and craft of the machine" en Frank Lloyd Wright: primers escrits, editado por Quetglas, Josep. Barcelona: Universitat Politècnica de Catalunya, 1994. (Ed. orig. 1901)

"Ausgeführte Bauten und Entwürfe" en Frank Lloyd Wright: primers escrits, editado por Quetglas, Josep. Barcelona: Universitat Politècnica de Catalunya, 1994. (Ed. orig. 1911)

"In the cause of architecture (II)" en Frank Lloyd Wright: primers escrits, editado por Quetglas, Josep. Barcelona: Universitat Politècnica de Catalunya, 1994. (Ed. orig. 1927)

"In the cause of architecture" en On and by Frank Lloyd Wright. A primer of architectural principles, editado por McCarter Robert. Londres: Phaidon, 2005. (Ed. orig. 1908)

"The logic of the plan" en On and by Frank Lloyd Wright. A primer of architectural principles, editado por McCarter, Robert. Londres: Phaidon, 2005. (Ed. orig. 1928)

"In the nature of materials: a philosophy" en On and by Frank Lloyd Wright. A primer of architectural principles, editado por McCarter, Robert. Londres: Phaidon, 2005. (Ed. orig. 1932).

"Máquinas, materiales y hombres" en Arquitectura moderna. The Kahn lectures. Princeton 1930. Barcelona: Paidós 2010. (Ed. orig. 1930).

"La casa de cartóne" en Arquitectura moderna. The Kahn lectures. Princeton 1930. Barcelona: Paidós, 2010. (Ed. orig. 
301 


